\title{
MICHAEL OHMER
}

\section{DIE GRUNDLAGEN DER EINKOMMENSTEUER}

Gerechtigkeit und Effizienz 


\section{MICHAEL OHMER}

\section{DIE GRUNDLAGEN DER EINKOMMENSTEUER}

Das Buch untersucht die Grundlagen der Einkommensteuer. Dabei werden die Grundprinzipien der Besteuerung - Gerechtigkeit und Effizienz - herausgearbeitet. Das Lebenseinkommen wird als geeignete Bemessungsgrundlage für die Besteuerung dargestellt. Es kann durch die Summe der Jahreseinkommen bzw. die Summe des Periodenkonsums und des Lebensendvermögens erfaßt werden. Die Besteuerung des Jahreseinkommens wird abgelehnt, da die Periodisierung zu ungerechten und ineffizienten Ergebnissen führt. Stattdessen wird die Messung des Lebenseinkommens durch den Jahreskonsum und das Lebensendvermögen präferiert. Die Besteuerung des Jahreskonsums wird durch eine Mehrwertsteuer bzw. durch eine Besteuerung der Differenz aus Zuflüssen und Ersparnissen des jeweiligen Jahres sichergestellt, was zu einer gerechteren und effizienteren Besteuerung führt.

Der Autor studierte Betriebswirtschaftslehre an der Universität Mannheim. Nach Abschluß des Studiums erfolgte der Eintritt in eine der führenden internationalen Wirtschaftsprüfungsgesellschaften. 1994 wurde er zum Steuerberater, 1996 zum Wirtschaftsprüfer bestellt. Die Dissertation an der Universität Mannheim aus dem Themengebiet der Volkswirtschaftslehre wurde 1996 abgeschlossen. 
Die Grundlagen der Einkommensteuer 


\section{ALLOKATION IM MARKTWIRTSCHAFTLICHEN SYSTEM}

Herausgegeben von

Heinz König, Hans-Heinrich Nachtkamp, Ulrich Schlieper, Eberhard Wille

\section{Band 37}

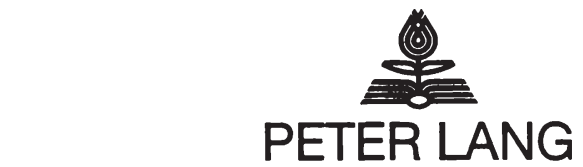

Frankfurt am Main - Berlin · Bern - New York - Paris · Wien

Michael Ohmer - 978-3-631-75563-1 


\section{MICHAEL OHMER}

\section{DIE GRUNDLAGENDER EINKOMMENSTEUER \\ Gerechtigkeit und Effizienz}

\section{$\underbrace{(0)}_{0}$ \\ PETER LANG \\ Europäischer Verlag der Wissenschaften}

Michael Ohmer - 978-3-631-75563-1

Downloaded from PubFactory at 01/11/2019 03:31:45AM

via free access 
Die Deutsche Bibliothek - CIP-Einheitsaufnahme

Ohmer, Michael:

Die Grundlagen der Einkommensteuer : Gerechtıgkeit und Effizienz / Michael Ohmer. - Frankfurt am Maın ; Berlın ; Bern ; New York ; Paris ; Wien : Lang, 1997

(Allokation im marktwirtschaftlichen System ; Bd. 37)

Zugl.: Mannheim, Univ., Diss., 1996

NE: GT

ISBN 3-631-31180-X

Open Access: The online version of this publication is published on www.peterlang.com and www.econstor.eu under the international Creative Commons License CC-BY 4.0. Learn more on how you can use and share this work: http://creativecommons. org/licenses/by/4.0.

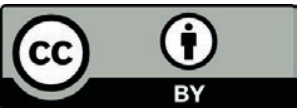

This book is available Open Access thanks to the kind support of ZBW - Leibniz-Informationszentrum Wirtschaft.

\author{
D 180 \\ ISSN 0939-7728 \\ ISBN 3-631-31180-X \\ ISBN 978-3-631-75563-1 (eBook) \\ (C) Peter Lang GmbH \\ Europäischer Verlag der Wissenschaften \\ Frankfurt am Main 1997 \\ Alle Rechte vorbehalten.
}

Das Werk einschließlich aller seiner Teile ist urheberrechtlich geschützt. Jede Verwertung außerhalb der engen Grenzen des

Urheberrechtsgesetzes ist ohne Zustimmung des Verlages

unzulässig und strafbar. Das gilt insbesondere für

Vervielfältigungen, Übersetzungen, Mikroverfilmungen und die Einspeicherung und Verarbeitung in elektronischen Systemen.

Printed in Germany 123457 


\section{Meinen Eltern}

Michael Ohmer - 978-3-631-75563-1

Downloaded from PubFactory at 01/11/2019 03:31:45AM

via free access 
Michael Ohmer - 978-3-631-75563-1

Downloaded from PubFactory at 01/11/2019 03:31:45AM

via free access 


\section{Vorwort}

"The power to tax involves the power to destroy".

Diese Worte eines amerikanischen Richters beschreiben die Gefahren, die durch ein schlechtes Steuersystem drohen, mehr als treffend. Bedauerlicherweise entsteht aber bei der Betrachtung des deutschen Einkommensteuersystems der Eindruck, daß diese Gefahren nicht gesehen werden. Werden Steuern ungerecht auf die Bürger verteilt, steigen die Steuerwiderstände und die Unzufriedenheit über den Staat wächst. Zusätzlich führt eine ineffiziente Steuerhebung neben einer höheren Steuerlast zu weiteren Belastungen der Bürger. Es muß somit das Bestreben aller sein, daß Steuern gerecht und effizient erhoben werden.

Dazu will dieses Buch beitragen, das im Sommersemester 1996 als Dissertation an der Universität Mannheim angenommen wurde.

Ohne die Ermutigung vieler mir nahestehender Menschen wäre dieses Buch nie entstanden.

Danken möchte ich insbesondere meinem Doktorvater Herrn Professor Dr. Hans H. Nachtkamp, der meine Arbeit förderte und mir durch seine Diskussionsbereitschaft sowie seinem Rat wertvolle Hilfe leistete. Dank auch für seine Betreuung während des Promotionsverfahrens. Dank gebührt ebenso Herrn Professor Dr. Eberhard Wille für die Übernahme des Zweitgutachtens.

Mit ihren Anregungen halfen mir Dr. Martin Raab, Karl-Heinz Nöhrbaß, Peter Hudelmaier sowie Dr. Robert Schwager und Thomas Gaube.

Meiner Freundin Martina Sambel, die mich in den letzten Jahren nicht nur bei der Abfassung dieser Arbeit, sondern auch bei der Ablegung des Steuerberaterund Wirtschaftsprüfer-Examens immer wieder ermutigte, möchte ich für ihre Geduld und ihre zeitlichen Opfer danken.

Besonderen Dank schulde ich meinen Eltern Klaus und Elfriede Ohmer, denen ich meine Fähigkeiten und meine Ausbildung zu verdanken habe. Besonders hervorheben möchte ich den Zeitaufwand meines Vaters, der durch das unermüdliche gründliche Durcharbeiten der Manuskripte und Entwürfe viel zum Gelingen des vorliegenden Buchs beigetragen hat. 
Michael Ohmer - 978-3-631-75563-1

Downloaded from PubFactory at 01/11/2019 03:31:45AM

via free access 


\section{Inhaltsübersicht}

Inhaltsübersicht

Inhaltsverzeichnis

Abkürzungsverzeichnis

Problemstellung und Eingrenzung des Themas

1. Teil

Anforderungen an ein "gutes" Steuersystem

\section{Kapitel}

Gerechtigkeitserwägungen als Grundprinzip der Besteuerung

1. Prinzipien zur Steuerlastverteilung

2. Ableitung eines gerechten Besteuerungsprinzips aus verschiedenen philosophischen Denkrichtungen

3. Juristische Ableitung eines gerechten Besteuerungsprinzips

4. Ergebnis: Gerechtigkeitserwägungen als Grundprinzip der Besteuerung

\section{Kapitel}

Effizienz als Grundprinzip der Besteuerung

1. Ökonomische Effizienz als Forderung an ein Steuersystem

2. Praktikabilität als Forderung an ein Steuersystem

\section{Kapitel}

Ableitungen aus den Grundprinzipien der Besteuerung

1. Bezugsobjekte der Leistungsfähigkeit

2. Indikatoren der steuerlichen Leistungsfähigkeit

3. Länge der Besteuerungsperiode

\section{Kapitel}

Zusammenfassung des ersten Teils 


\section{Teil}

Periodeneinkommen als Bemessungsgrundlage der Besteuerung

I. Kapitel

Diskussion verschiedener Einkommensbegriffe

1. Einkommen nach der Konsumtionsfondstheorie 119

2. Einkommen nach der Produktionseinkommenstheorie 120

3. Einkommen nach der Quellentheorie 122

4. Einkommen nach der Reinvermögenszugangstheorie 124

5. Einkommen nach Brandis 126

6. Ergebnis 127

II. Kapitel

$\begin{array}{lr}\text { Sonderprobleme bei der Periodeneinkommensbesteuerung } & 129\end{array}$

1. Die Behandlung von Windfall-Profits und unregelmäßigen Einkünften

2. Das Problem der Zinsbesteuerung 132

3. Steuerliche Erfassung des Wertzuwachses 151

4. Erbschaften und Schenkungen 188

5. Die Besteuerung von Unternehmen 193

6. Glättung der Bemessungsgrundlage 203

\section{Kapitel}

Zusammenfassung des zweiten Teils

\section{Teil}

Periodenkonsum und Lebensendvermögen als steuerliche Bemessungsgrundlage

\section{Kapitel}

Bestimmungsgrößen der individuellen Konsumentscheidung

1. Theoretische Grundlagen der Lebenszyklushypothese 219

2. Empirische Untersuchungen der Lebenszyklushypothese 228 


\section{Kapitel}

Folgerungen für die Ausgestaltung eines Steuersystems

1. Besteuerung nach der individuellen Leistungsfähigkeit 253

2. Neutralität der Besteuerung 266

3. Praktikabilität der Besteuerung 270

4. Ergebnis: Folgerungen für die Ausgestaltung eines Steuersystems 271

\section{Kapitel}

Methoden zur Erfassung des Periodenkonsums

1. Indirekte Ermittlung des Periodenkonsums 275

2. Mehrwertsteuer

3. Erfassung des Periodenkonsums durch eigene Aufzeichnungen des Steuerpflichtigen

IV. Kapitel

Diskussion von Sonderproblemen

1. Langlebige Konsumgüter

2. Besteuerung des Naturalkonsums

3. Besteuerung des Lebensendvermögens

4. Besteuerung von Schenkungen

5. Abgrenzung Investition/Werbungskosten - Konsum

6. Besteuerung von Unternehmen

7. Konsumbesteuerung und Tarifgestaltung

IV. Kapitel

Zusammenfassung des dritten Teils

\section{Teil}

Gesamtergebnis der Arbeit

Literaturverzeichnis 
Michael Ohmer - 978-3-631-75563-1

Downloaded from PubFactory at 01/11/2019 03:31:45AM

via free access 
Inhaltsverzeichnis

Übersicht

Inhaltsverzeichnis

Abkürzungsverzeichnis

Problemstellung und Eingrenzung des Themas

1. Teil

Anforderungen an ein "gutes" Steuersystem

\section{Kapitel}

Gerechtigkeitserwägungen als Grundprinzip der Besteuerung

1. Prinzipien zur Steuerlastverteilung

1.1. Die Kopfsteuer als Maßstab der Lastenverteilung

1.2. Das Äquivalenzprinzip als Maßstab der Lastenverteilung

1.3. Das Leistungsfähigkeitsprinzip als Maßstab der

Lastenverteilung

1.3.1. Nutzentheoretischer Leistungsfähigkeitsbegriff

1.3.2. Verteilungspolitischer Leistungsfähigkeitsbegriff

2. Ableitung eines gerechten Besteuerungsprinzips aus verschiedenen philosophischen Denkrichtungen

2.1. Utilitarismus

2.1.1. Darstellung des Utilitarismus

2.1.2. Besteuerung nach utilitaristischen Regeln

2.1.2.1. Exkurs: Begründung des fallenden Grenznutzens

2.1.2.2. Tauschökonomie

2.1.2.3. Produktionsökonomie

2.2. Neuere Wohlfahrts- und Gerechtigkeitstheorie: Der Ansatz von Rawls

2.2.1. Darstellung des Ansatzes von Rawls

2.2.2. Besteuerung nach Rawls'schen "Maxi-min"-Regel

2.2.2.1. Tauschökonomie

2.2.2.2. Produktionsökonomie 
2.3. Katholische Soziallehre 51

2.3.1. Darstellung der katholischen Soziallehre 52

2.3.1.1. Prinzip der Personalität $\quad 52$

2.3.1.2. Prinzip der Solidarität $\quad 52$

2.3.1.3. Prinzip des Gemeinwohls 53

2.3.2. Besteuerung nach den Prinzipien der katholischen Soziallehre $\quad 54$

2.4. Ergebnis: Philosophische Ableitung eines gerechten 55

Besteuerungsprinzips

3. Juristische Ableitung eines gerechten Besteuerungsprinzips 56

3.1. Das Fundamentalprinzip der gerechten Besteuerung 56

3.2. Das Leistungsfähigkeitsprinzip im Verfassungskontext 59

3.2.1. Das Leistungsfähigkeitsprinzip und die Eigentums-/ Erbrechtsgarantie

3.2.2. Das Leistungsfähigkeitsprinzip und die Sozialstaatlichkeit 62

3.2.3. Das Leistungsfähigkeitsprinzip und die Berufsfreiheit 63

3.2.4. Das Leistungsfähigkeitsprinzip und der Grundsatz der Gesetzesbestimmtheit

3.3. Grenzen des Leistungsfähigkeitsprinzips

4. Ergebnis: Gerechtigkeitserwägungen als Grundprinzip der

Besteuerung

\section{Kapitel}

Effizienz als Grundprinzip der Besteuerung

1. Ökonomische Effizienz als Forderung an ein Steuersystem

1.1. Begriffsklärung und Begründung eines effizienten

Steuersystems

71

1.2. Entscheidungsregeln in einer Laissez-Faire-Ökonomie 76

1.2.1. Konsum-Spar-Entscheidung der Individuen $\quad 76$

1.2.2. Investitionsentscheidung der Unternehmen 78

1.2.3. Exkurs: Einfluß auf das Wirtschaftswachstum 79

1.2.4. Finanzierungsentscheidung der Unternehmen 79

1.2.4.1. Beteiligungsfinanzierung versus Selbstfinanzierung $\quad 80$

1.2.4.2. Fremdfinanzierung versus Beteiligungsfinanzierung 81

1.2.4.3. Fremdfinanzierung versus Selbstfinanzierung $\quad 81$ 
1.2.4.4. Ergebnis

1.2.5. Rechtsformneutralität $\quad 82$

1.3. Grenzen des Modells einer entscheidungsneutralen Besteuerung $\quad 82$

2. Praktikabilität als Forderung an ein Steuersystem 83

\section{Kapitel}

Ableitungen aus den Grundprinzipien der Besteuerung

1. Bezugsobjekte der Leistungsfähigkeit 85

2. Indikatoren der steuerlichen Leistungsfähigkeit $\quad 85$

$\begin{array}{ll}\text { 2.1. Anforderungen an die Meßmethode } & 87\end{array}$

2.2. Indikatoren des nutzentheoretischen Leistungsfähigkeitsbegriffs $\quad 87$

2.3. Indikatoren des verteilungspolitischen Leistungsfähigkeitsbegriffs

2.3.1. Individuelles Potential als Indikator der Leistungsfähigkeit

2.3.1.1. Potentieller Mittelerwerb als Indikator der Leistungsfähigkeit

2.3.1.2. Potentielle Konsumausgaben als Indikator der Leistungsfähigkeit

2.3.1.3. Kritik der Potentialbesteuerung

a) Besteuerung nach der individuellen Leistungsfähigkeit

b) Neutralität der Besteuerung

c) Praktikabilität der Besteuerung

2.3.1.4. Ergebnis

2.3.2. Verwirklichte Größen als Indikatoren der Leistungsfähigkeit

2.3.2.1. Mittelerwerb als Indikator der Leistungsfähigkeit

2.3.2.2. Konsumausgaben als Indikator der Leistungsfähigkeit

2.3.2.3. Kritik der beiden Konzeptionen

a) Besteuerung nach der individuellen

Leistungsfähigkeit

b) Neutralität der Besteuerung 
2.3.3. Ergebnis: Indikatoren des verteilungspolitischen Leistungsfähigkeitsbegriffs

2.4. Ergebnis: Indikatoren der steuerlichen Leistungsfähigkeit

3.1. Empirische Untersuchungen zur Einkommensverteilung

3.2. Theoretische Erwägungen

3.2.1. Besteuerung nach der individuellen Leistungsfähigkeit $\quad 104$

3.2.1.1. Gleiche Lebensdauer der Individuen

3.2.1.2. Unterschiedliche Lebensdauer der Individuen $\quad 107$

3.2.2. Neutralität der Besteuerung

3.2.3. Praktikabilität der Besteuerung

3.3. Ergebnis: Länge der Besteuerungsperiode

IV. Kapitel

Zusammenfassung des ersten Teils

\section{Teil}

Periodeneinkommen als Bemessungsgrundlage der Besteuerung

\section{Kapitel}

Diskussion verschiedener Einkommensbegriffe

1. Einkommen nach der Konsumtionsfondstheorie

2. Einkommen nach der Produktionseinkommenstheorie

3. Einkommen nach der Quellentheorie

4. Einkommen nach der Reinvermögenszugangstheorie

5. Einkommen nach Brandis

6. Ergebnis

\section{Kapitel}

Sonderprobleme bei der Periodeneinkommensbesteuerung

1. Die Behandlung von Windfall-Profits und unregelmäßigen Einkünften

1.1. Besteuerung nach der individuellen Leistungsfähigkeit

1.3. Praktikabilität der Besteuerung 
2. Das Problem der Zinsbesteuerung

2.1. Besteuerung nach der individuellen Leistungsfähigkeit

2.1.1. Einbezug der Zinsen in die steuerliche Bemessungsgrundlage

2.1.2. Freistellung der Zinseinkünfte

2.1.3. Ergebnis

2.2. Neutralität der Besteuerung

2.2.1. Investitionen von Unternehmen

2.2.2. Konsum-Spar-Entscheidung der Individuen

2.2.2.1. Auswirkungen der Zinsbesteuerung

2.2.2.2. Zulässigkeit des Schuldzinsabzugs

a) Exkurs: Laissez-Faire-Ökonomie

b) Besteuerung des Periodeneinkommens

2.2.3. Einfluß auf das Wirtschaftswachstum

2.2.4. Finanzierungsentscheidung der Unternehmen

2.2.5. Intertemporale Arbeitsentscheidung

2.2.6. Ergebnis: Neutralität der Zinsbesteuerung

2.3. Praktikabilität der Besteuerung - dargestellt am Beispiel

Deutschland

2.4. Ergebnis: Besteuerung von Zinseinkünften

3. Steuerliche Erfassung des Wertzuwachses

3.1. Besteuerung nach der individuellen Leistungsfähigkeit

3.1.1. Systematische Betrachtungsweise

3.1.2. Wirtschaftliche Betrachtungsweise

3.1.3. Einbezug des Human Capital

3.1.4. Ergebnis

3.2. Neutralität der Besteuerung

3.2.1. Wahl zwischen verschiedenen Anlageformen

3.2.1.1. Exkurs: Laissez-Faire-Ökonomie

3.2.1.2. Einkommensteuer ohne die Erfassung von Wertänderungen

3.2.1.3. Einkommensteuer mit der Erfassung von realisierten Wertänderungen

3.2.1.4. Einkommensteuer mit der generellen Erfassung von Wertänderungen

3.2.1.5. Ergebnis

3.2.2. Einfluß der Periodeneinkommensbesteuerung auf die Innovationsbereitschaft 
3.2.2.2. Einkommensteuer ohne die Erfassung von Wertänderungen

164

3.2.2.3. Einkommensteuer mit der Erfassung von realisierten Wertänderungen

165

3.2.2.4. Einkommensteuer mit der generellen Erfassung von Wertänderungen

167

3.2.3. Einfluß der Abschreibungshöhe auf die Investitionsentscheidung

168

3.2.4. Exkurs: Folgen der Nichtbesteuerung von Wertänderungen im deutschen Einkommensteuerrecht

3.2.4.1. Besteuerung von Zerobonds 171

3.2.4.2. Möglichkeiten von Steuerarbitrage 172

3.2.5. Ergebnis: Neutralität der Besteuerung 174

3.3. Einwände gegen die steuerliche Erfassung von Wertänderungen 175

3.4. Praktikabilität der Besteuerung 182

3.4.1. Diskussion möglicher Wertansätze 182

3.4.1.1. Historische Marktwerte: Anschaffungskosten 183

3.4.1.2. Liquidationswert einzelner Vermögensgegenstände

183

3.4.1.3. Veräußerungswert des Gesamtvermögens $\quad 183$

3.4.1.4. Ergebnis 184

3.4.2. Bestimmung des Veräußerungswertes des Gesamtvermögens

184

3.5. Ergebnis: Einbezug von Wertänderungen in die steuerliche

Bemessungsgrundlage

187

4. Erbschaften und Schenkungen $\quad 188$

4.1. Besteuerung nach der individuellen Leistungsfähigkeit 188

4.2. Neutralität der Besteuerung $\quad 189$

4.3. Praktikabilität der Besteuerung 191

4.4. Ergebnis 192

5. Die Besteuerung von Unternehmen 193

5.1. Reinvermögenszugangstheorie und Unternehmensbesteuerung 194

5.1.1. Besteuerung nach der individuellen Leistungsfähigkeit $\quad 194$

5.1.2. Neutralität der Besteuerung 194

5.1.2.1. Finanzierungsentscheidung der Unternehmen $\quad 194$

5.1.2.2. Investitionsentscheidung der Unternehmen 195

5.1.2.3. Rechtsformentscheidung der Unternehmen 195

$\begin{array}{ll}\text { 5.1.3. Ergebnis } & 195\end{array}$

5.2. Alternative Gestaltung der Unternehmensbesteuerung 195 
5.2.1. Neutralität der Besteuerung

5.2.1.1. Betriebsteuer ohne Anrechnung beim Gesellschafter 196

a) Rechtsformentscheidung der Unternehmen 196

b) Finanzierungsentscheidung der Unternehmen 197

5.2.1.2. Betriebsteuer mit Anrechnung beim Gesellschafter 198

a) Rechtsformentscheidung der Unternehmen $\quad 198$

b) Finanzierungsentscheidung der Unternehmen 198

5.2.1.3. Teilhabersteuer

a) Rechtsformentscheidung der Unternehmen $\quad 199$

b) Finanzierungsentscheidung der Unternehmen 199

5.2.2. Besteuerung nach der individuellen Leistungsfähigkeit $\quad 199$

5.2.3. Praktikabilität der Besteuerung 200

5.2.4. Ergebnis 201

6. Glättung der Bemessungsgrundlage 203

6.1. Darstellung der Methoden 203

6.2. Beurteilung der Methoden 204

6.3. Ergebnis 208

III. Kapitel

$\begin{array}{ll}\text { Zusammenfassung des zweiten Teils } & 209\end{array}$

3. Teil

Periodenkonsum und Lebensendvermögen als steuerliche Bemessungsgrundlage

\section{Kapitel}

Bestimmungsgrößen der individuellen Konsumentscheidung

1. Theoretische Grundlagen der Lebenszyklushypothese

1.1. Allgemeine Darstellung

1.2. Reaktionen der Individuen auf Einkommensänderungen 225

2. Empirische Untersuchungen der Lebenszyklushypothese 228

2.1. Vorhersagekraft des Konsums 229

2.2. Alter-Vermögens-Relation 230

2.2.1. Untersuchungen mittels Zeitreihendaten 231

2.2.2. Untersuchungen mittels Querschnittsdaten 232

2.2.2.1. Systematische Probleme bei der Verwendung von Querschnittsdaten 
a) Berücksichtigung der unterschiedlichen Lebenserwartung

b) Berücksichtigung des Kohorteneffekts 233

2.2.2.2. Empirische Untersuchungen 235

2.2.2.3. Interpretation der empirischen Untersuchungen $\quad 239$

2.3. Simulation der Ersparnisse $\quad 244$

2.4. Sensitivität des Konsums auf Einkommensänderungen 245

2.4.1. Einzeldaten als Untersuchungsgrundlage 246

2.4.2. Aggregierte Daten als Untersuchungsgrundlage 247

2.4.3. Interpretation der Ergebnisse 248

2.5. Ergebnis: Grundlage der individuellen Konsumentscheidung 250

\section{Kapitel}

Folgerungen für die Ausgestaltung eines Steuersystems

1. Besteuerung nach der individuellen Leistungsfähigkeit 253

1.1. Folgerungen für eine lineare Tarifstruktur 253

1.1.1. In die steuerliche Bemessungsgrundlage einzubeziehende $\quad 254$ Größen

1.1.2. Vergleich der Besteuerung des Periodenkonsums und des -einkommens

1.1.2.1. Die Besteuerung der Zinsen 255

1.1.2.2. Der Einbezug von Vermögenswertänderungen 257

1.1.2.3. Grundgesetzlich gewährte Eigentümergarantie / Eigentümerfreiheit

1.1.3. Ergebnis: Folgerungen für eine lineare Tarifstruktur $\quad 260$

1.2. Folgerungen für eine progressive Tarifstruktur 261

1.2.1. Periode, für die die Leistungsfähigkeit zu bestimmen ist 261

1.2.2. Vergleich der Besteuerung des Periodenkonsums und des Lebensendvermögens mit der Besteuerung des Periodeneinkommens

1.2.3. Ergebnis: Folgerungen für eine progressive Tarifstruktur 265

2. Neutralität der Besteuerung 266

2.1. Konsum-Spar-Entscheidung des Individuums 266

2.2. Investitionsentscheidung der Unternehmen 267

2.3. Einfluß auf das Wirtschaftswachstum 267

2.4. Finanzierungsentscheidung der Unternehmen 267

2.5. Untersuchung weiterer möglicher Entscheidungsbeeinflussungen 268

2.6. Ergebnis: Neutralität der Besteuerung 269 
3. Praktikabilität der Besteuerung $\quad 270$

4. Ergebnis: Folgerungen für die Ausgestaltung eines Steuersystems 271

\section{Kapitel}

Methoden zur Erfassung des Periodenkonsums

1. Indirekte Ermittlung des Periodenkonsums

1.1. Technik der indirekten Konsumermittlung $\quad 276$

1.1.1. Messung der Vermögensänderung 276

1.1.2. Methoden der Einkommensbestimmung 278

1.1.3. Ermittlung des Periodenkonsums 279

1.1.4. Sonderprobleme der indirekten Konsumerfassung 283

1.2. Besteuerung nach der individuellen Leistungsfähigkeit 285

1.3. Neutralität der Besteuerung 285

1.4. Praktikabilität der Besteuerung 286

1.4.1. Erfassung der Zuflüsse 286

1.4.2. Erfassung der Barvermögensänderung 286

1.4.2.1. Grundsätzliche Methode 286

1.4.2.2. Mißbrauchsmöglichkeiten 287

a) Zurechnung des Konsums 287

b) Nichtangabe von investiven Zahlungsabflüssen 288

ba) Vollkommener Kapitalmarkt 288

bb) Unvollkommener Kapitalmarkt 289

1.5. Ergebnis: Beurteilung der indirekten Konsumermittlung 290

2. Mehrwertsteuer 290

2.1. Besteuerung nach der individuellen Leistungsfähigkeit 291

2.2. Neutralität der Besteuerung 291

2.3. Praktikabilität der Besteuerung 291

2.4. Ergebnis: Beurteilung der Mehrwertsteuer 292

3. Erfassung des Periodenkonsums durch eigene Aufzeichnungen des Steuerpflichtigen

3.1. Besteuerung nach der individuellen Leistungsfähigkeit 292

3.2. Neutralität der Besteuerung 293

3.3. Praktikabilität der Besteuerung 293

3.4. Ergebnis: Beurteilung der Erfassung durch eigene
Aufzeichnungen des Steuerpflichtigen 


\section{Kapitel}

Diskussion von Sonderproblemen $\quad 297$

1. Langlebige Konsumgüter $\quad 297$

1.1. Behandlung der langlebigen Konsumgüter im Sinne der 297

"Konsumgutlösung"

1.1.1. Besteuerung nach der individuellen Leistungsfähigkeit 298

1.1.1.1. Laufende Nutzungen 298

1.1.1.2. Behandlung von Veräußerungserlösen 299

1.1.1.3. Weitere Probleme der Konsumgutlösung $\quad 302$

1.1.1.4. Zusammenfassung 303

1.1.2. Neutralität der Besteuerung 304

1.1.3. Praktikabilität der Besteuerung 305

1.1.4. Ergebnis 307

1.2. Behandlung der langlebigen Konsumgüter im Sinne der "Investitionsgutlösung" 307

1.2.1. Besteuerung nach der individuellen Leistungsfähigkeit $\quad 308$

1.2.2. Neutralität der Besteuerung 309

1.2.3. Praktikabilität der Besteuerung $\quad 309$

1.2.4. Ergebnis 311

1.3. Beurteilung der beiden Ansätze 311

2. Besteuerung des Naturalkonsums $\quad 313$

2.1. Besteuerung nach der individuellen Leistungsfähigkeit 313

2.2. Neutralität der Besteuerung $\quad 314$

2.3. Praktikabilität der Besteuerung $\quad 315$

2.4. Ergebnis 318

3. Besteuerung des Lebensendvermögens 318

3.1. Besteuerung nach der individuellen Leistungsfähigkeit 318

3.2. Neutralität der Besteuerung $\quad 319$

3.3. Praktikabilität der Besteuerung 321

3.4. Ergebnis $\quad 322$

4. Besteuerung von Schenkungen $\quad 324$

4.1. Besteuerung nach der individuellen Leistungsfähigkeit 324

4.2. Neutralität der Besteuerung 325

4.3. Praktikabilität der Besteuerung $\quad 325$

$\begin{array}{ll}\text { 4.4. Ergebnis } & 327\end{array}$

5. Abgrenzung Investition/Werbungskosten - Konsum 328

5.1. Besteuerung nach der individuellen Leistungsfähigkeit 328

5.2. Neutralität der Besteuerung 328

5.3. Praktikabilität der Besteuerung $\quad 329$ 
5.4. Ergebnis $\quad 330$

6. Besteuerung von Unternehmen $\quad 330$

6.1. Besteuerung nach der individuellen Leistungsfähigkeit 331

6.2. Neutralität der Besteuerung 331

6.3. Praktikabilität der Besteuerung 331

6.4. Ergebnis $\quad 332$

7. Konsumbesteuerung und Tarifgestaltung 332

7.1. Wohlfahrtsökonomische Überlegungen 333

7.2. Praktikabilität der Besteuerung $\quad 335$

7.2.1. Linearer Tarif 335

7.2.2. Progressiver Tarif $\quad 335$

7.3. Ergebnis 336

IV. Kapitel

Zusammenfassung des dritten Teils 339

4. Teil

Gesamtergebnis der Arbeit 343

Literaturverzeichnis $\quad 353$ 
Michael Ohmer - 978-3-631-75563-1

Downloaded from PubFactory at 01/11/2019 03:31:45AM

via free access 


\section{Abkürzungsverzeichnis}

a.A.

Abschn.

AO

Aufl.

Bd.

BFH

BFHE

BMF

BStBl.

BVerfG

BVerfGE

bzw.

c.p.

d.h.

DB

DStZ A

EStG

FA

FAZ

FR

GG

Hrsg.

KritV

N.F.

Nr.

o.a.

o.ä.

S.

StRK

StuW

u.a.

UK

v.

Vol.

WiSt

WISU andere Auffassung

Abschnitt

Abgabenordnung

Auflage

Band

Bundesfinanzhof

Entscheidungen des Bundesfinanzhofs

Bundesminister der Finanzen

Bundessteuerblatt

Bundesverfassungsgericht

Entscheidungen des Bundesverfassungsgerichts

beziehungsweise

ceteris paribus

das heißt

Der Betrieb (Z)

Deutsche Steuer-Zeitung Ausgabe A (Z)

Einkommensteuergesetz

Finanzarchiv (Z)

Frankfurter Allgemeine Zeitung

Finanz-Rundschau $(\mathrm{Z})$

Grundgesetz

Herausgeber

Kritische Vierteljahresschrift für

Gesetzgebung u. Rechtswissenschaft (Z)

Neue Fassung

Nummer

oben angeführt(e)

oder ähnliches

Seite

Steuerrechtsprechung in Karteiform

Steuer und Wirtschaft $(Z)$

unter anderem, und andere

United Kingdom

von

Volume

Wirtschaftswissenschaftliches Studium (Z)

Das Wirtschaftsstudium (Z) 
Z

z.B.
Zeitschrift

zum Beispiel

Michael Ohmer - 978-3-631-75563-1

Downloaded from PubFactory at 01/11/2019 03:31:45AM

via free access 


\section{Problemstellung und Eingrenzung des Themas}

Das deutsche Steuerrecht ist ein überaus kompliziertes Gebilde, bei dem nahezu gleiche Sachverhalte zu extrem unterschiedlichen steuerlichen Folgen führen. Dies kann an einem einfachen Beispiel verdeutlicht werden. A besitzt in seinem Privatvermögen Anteile an einer Kapitalgesellschaft und veräußert sie einige Monate nach ihrem Erwerb mit Gewinn. Schon bei diesem (anscheinend) einfachen Fall können abhängig von der Beteiligungsquote und der Besitzdauer folgende Konstellationen auftreten ${ }^{l}$ :

\section{Quote Besitzdauer Folgen}

$\begin{array}{lll}24 \% & 5 \text { Monate } & \text { steuerpflichtig; voller Steuersatz (§ 23 EStG) } \\ 24 \% & 7 \text { Monate } & \text { steuerfrei } \\ 26 \% & 5 \text { Monate } & \text { steuerpflichtig, voller Steuersatz (§ 23 EStG) } \\ 26 \% & 7 \text { Monate } & \begin{array}{l}\text { steuerpflichtig, ermäßigter Steuersatz, Freibetrag } \\ (\S \S 17,34 \mathrm{EStG})\end{array}\end{array}$

Angeregt durch die Vielzahl von Regelungen im deutschen Steuerrecht und ihren teilweise gravierend unterschiedlichen Auswirkungen wird versucht, die Grundstrukturen der Besteuerung zu analysieren.

Mit dem Wesen der Besteuerung sind mit unterschiedlichen Ausrichtungen vier Disziplinen, die Betriebs- und die Volkswirtschaftslehre sowie die Wirtschaftsethik und die Rechtswissenschaft beschäftigt.

In der steuerwissenschaftlichen Literatur dominieren disziplinär orientierte Ansätze $^{2}$, die Disziplinen verbindende Ansätze sind selten.

Die betriebswirtschaftliche Steuerlehre ${ }^{3}$ befaßt sich im wesentlichen mit der Bestimmung und dem Vergleich von Steuerbelastungen für Steuersubjekte und der Feststellung von Steuerwirkungen auf unternehmerische Entscheidungen. Sie untersucht die Besteuerung als betrieblichen Einflußfaktor und die mikroökonomischen Auswirkungen der Besteuerung auf das inner- und zwischenbetriebliche Geschehen, wie z.B. auf Rechtsformwahl, Investitionen, Finanzierung und Betriebsverbindungen. Hierbei dient das Kriterium der Entscheidungsneutralität der Besteuerung vielfach als Ausgangspunkt für die Beurteilung von Steuerwir-

\footnotetext{
$1 \quad$ Vgl. Tipke, K. (1993), S. 653.

2 Vgl. Elschen, R. (1991), S. 99.

3 Vgl. Tipke, K./Lang, J. (1991), S. 3 f.
} 
kungen ${ }^{1,2}$. Weiterhin beschäftigt sie sich im Rahmen des Rechnungswesens mit der Technik der Bilanzierung und der Steuerbilanzpolitik. Sie macht überdies -auf den Erkenntnissen der Steuerbelastung und -wirkung beruhend- Vorschläge zur Umgestaltung des Steuersystems ${ }^{3}$. Hierbei ergibt sich für die Betriebswirtschaftslehre das Problem der einzelwirtschaftlichen Orientierung, während das Steuerrecht eine gesamtgesellschaftliche Organisationsregel ist, die zusammen mit anderen Regeln den Handlungsrahmen in einer Volkswirtschaft bildet: was für ein einzelnes Unternehmen sinnvoll ist, muß nicht für die Gesamtwirtschaft/Gesellschaft sinnvoll sein. Daher muß die Betriebswirtschaftslehre bei Gestaltungsvorschlägen entweder ihre einzelwirtschaftliche Orientierung verlassen oder einzelwirtschaftliche Kriterien finden, die mit gesamtwirtschaftlichen oder gesellschaftlichen korrespondieren. Damit kann auch auf rechtswissenschaftliche und volkswirtschaftliche Kriterien zurückgegriffen werden.

Die Volkswirtschaftslehre (Finanzwissenschaft) ${ }^{4}$ beschäftigt sich mit der volkswirtschaftlich optimalen Verteilung der Steuerlasten, Inzidenzfragen sowie den Auswirkungen des Steuersystems auf das Verhalten der Wirtschaftssubjekte.

Sie stellt dabei Kriterien auf, denen ein Steuersystem genügen sollte ${ }^{5}$ :

- Ökonomische Effizienz: die effiziente Ressourcenallokation soll nicht gestört werden;

- Praktikabilität: das Steuersystem soll einfach und die Steuererhebung nicht kostspielig sein;

- Flexibilität: das Steuersystem soll auf Veränderungen der wirtschaftlichen Situation reagieren;

- Transparenz;

- Gerechtigkeit.

Das Kriterium der Effizienz tritt dabei immer mehr in den Vordergrund und drängt das früher in der deutschen finanzpolitischen Literatur dominierende Lei-

1 Vgl. Elschen, R./Hüchtebrock, M. (1983), S. 255 f. Schneider definiert sie wie folgt: "Steuerrechtsetzungen, die keine Ausweichhandlungen bei vernünftigen Steuerpflichtigen verursachen, heißen entscheidungsneutral." (Schneider, D. (1990), S. 169).

2 Durch die Feststellung der Bedingungen der Einflußlosigkeit der Besteuerung (z.B. auf Investitionsentscheidungen) wird somit ein "Nullpunkt" ermittelt, um im nächsten Schritt durch die Veränderung der Bedingungen Steuerwirkungen analysieren zu können (vgl. Elschen, R./Hüchtebrock, M. (1983), S. 255 f.).

3 Vgl. zum folgenden Elschen, R. (1991), S. 99.

4 Vgl. Tipke, K./Lang, J. (1991), S. 3.

$5 \quad$ Vgl. Stiglitz, J.E. (1988), S. 390. 
stungsfähigkeitsprinzip und die daran anknüpfende Frage nach einer "gerechten" Besteuerung zurück ${ }^{l}$. Daher wird im Rahmen dieser Arbeit insbesondere auf Effizienzgesichtspunkte eingegangen, wobei der Begriff "Effizienz" weit gefaßt wird: es wird darunter sowohl Effizienz im ökonomischen Sinne als auch Praktikabilität verstanden.

Die Wirtschaftsethik befaßt sich u.a. mit der Frage, wie ein Steuersystem gestaltet sein muß, um gerechte Ergebnisse zu erzielen.

Die Steuerrechtswissenschaft ${ }^{2}$ beschäftigt sich mit der rechtlichen Ordnung der Besteuerung. Dazu gehört neben verschiedenen anderen Feldern, z.B. internationale Steuerrechtsvergleiche oder der Systematisierung des derzeitigen Steuerrechts, auch die Entwicklung einer Steuergerechtigkeitslehre. Das maßgebliche Beurteilungskriterium der Rechtswissenschaft für ein Steuersystem ist das Kriterium der "Gerechtigkeit"3.

Der Begriff "Gerechtigkeit" kann in zwei Ausgestaltungen differenziert werden: horizontale Gerechtigkeit bedeutet die Gleichbehandlung von Individuen, die (in der relevanten Eigenschaft) gleich sind; vertikale Gerechtigkeit stellt die gerechte Behandlung von ungleichen Individuen dar ${ }^{4}$. Übertragen auf den Themenkomplex der Besteuerung, steht bei der "horizontalen Gerechtigkeit" die Gestaltung der Bemessungsgrundlage der Besteuerung im Mittelpunkt, während die Auseinandersetzung mit dem Tarifverlauf eine Frage der "vertikalen Gerechtigkeit" ist ${ }^{5}$.

In dieser Arbeit wird nur auf Fragen zur Gestaltung einer gerechten Bemessungsgrundlage eingegangen (horizontale Gerechtigkeit), während der Problemkreis der gerechten Tarifgestaltung (vertikale Gerechtigkeit) nicht berührt wird.

Um den Umfang der Arbeit zu begrenzen, erfolgt eine Beschränkung auf die Analyse der Einkommensbesteuerung, d.h. es wird gefragt, ob die Besteuerung des Einkommens gerecht und effizient ist. Weiterhin wird untersucht, wie die Erfassung des Einkommens zu gestalten ist.

I Vgl. Wagner, F.W. (1992), S. 2, 4 f. 6 f.; Elschen, R. (1991), S. 99 f. Einen Überblick über die Entwicklung des Leistungsfähigkeitsprinzips geben Pohmer, D./Jurke, G. (1984).

2 Vgl. Tipke, K./Lang, J. (1991), S. 2.

3 Vgl. z.B. Kruse, H.W. (1990), S. 322 f.

$4 \quad$ Vgl. Birk, D. (1983), S. $165 \mathrm{ff} ., 170 \mathrm{ff}$.

$5 \quad$ Vgl. Kraft, C. (1991), S. 7. 
Dazu wird folgende Vorgehensweise gewählt:

- Zuerst wird untersucht, welchen Kriterien ein gerechtes Steuersystem genügen muß; dazu werden verschiedene Prinzipien zur Steuerlastverteilung dargestellt und mit Hilfe von philosophischen und theologischen Denkrichtungen beurteilt. Anschließend wird geprüft, welches Prinzip zur Lastenverteilung die Jurisprudenz als Fundamentalprinzip der Besteuerung ansieht.

- Es schließt sich der Versuch an, den Begriff "Effizienz" zu konkretisieren und zu analysieren, welche Konsequenzen sich hieraus für ein Steuersystem ergeben.

- Nach dieser Konkretisierung der Grundprinzipien der Besteuerung werden erste Ableitungen für die Gestaltung eines Steuersystems gezogen, z.B. ist die Besteuerung des Einkommens mit der Forderung nach einem gerechten und effizienten Steuersystem zu vereinbaren?

- Im nächsten Schritt wird diskutiert, wie die steuerliche Bemessungsgrundlage aus Gerechtigkeits- und Effizienzüberlegungen zu gestalten ist und welche Größen als steuerliche Bemessungsgrundlagen zu präferieren sind. Dabei wird auch auf die Größen eingegangen, die die Individuen selbst in die steuerliche Bemessungsgrundlage einbeziehen würden. Werden dabei die anhand theoretischer Überlegungen gewonnenen Ergebnisse gestützt, erhalten sie aufgrund des in den westlichen Gesellschaften vorherrschenden Bilds vom eigenverantwortlichen und souveränen Menschen ein stärkeres Gewicht. 


\title{
1. Teil
}

\section{Anforderungen an ein "gutes" Steuersystem}

\author{
I. Kapitel \\ Gerechtigkeitserwägungen als Grundprinzip der \\ Besteuerung
}

"Wertmaßstab des positiven Rechts, Ziel des Gesetzgebers ist die Gerechtigkeit. Die Gerechtigkeit ist ein absoluter Wert gleich dem wahren, dem guten, dem schönen, also auf sich selbst gegründet und nicht von höheren Werten abgeleitet." ${ }^{\prime}$.

Die Gerechtigkeit der Steuerlastverteilung ist in einem Rechtsstaat der höchste Wert in der Gemeinschaft der Steuerpflichtigen ${ }^{2}$. Sie ist ein ethisches Gebot; die Erhebung von Steuern in beliebiger Form und Höhe wäre ein Akt der fiskalischen Willkür ${ }^{3}$.

Aufgabe des Gesetzgebers ist es somit, "gerechte" Gesetze zu machen. Fraglich ist allerdings, was gerecht ist.

Diese Frage löst Radbruch wie folgt:

"Der Kern der Gerechtigkeit ist der Gedanke der Gleichheit"4.

Aus Gerechtigkeitserwägungen sollen somit Gleiche gleich (horizontale Gerechtigkeit) und Ungleiche ungleich (vertikale Gerechtigkeit) behandelt werden. Der Gleichheitssatz kann deshalb als Willkürverbot interpretiert werden ${ }^{5}$. Diese Interpretation erfordert jedoch, Wertaussagen zur Beurteilung zu finden, in welchen Fällen die Gleich- oder Ungleichbehandlung von Menschen als nicht-willkürlich bezeichnet werden kann $^{6,7}$. Zu bestimmen ist der Bezugspunkt, nach

\footnotetext{
Radbruch, G. (1965), S. 24.

2 Vgl. Tipke, K./Lang, J. (1991), S. 47.

3 Tipke, K./Lang, J. (1991, S. 47) sprechen in diesem Zusammenhang von einer "fiskalischen Diktatur" des Gesetzgebers.

4 Radbruch, G. (1965), S. 24.

5 Vgl. BVerfG v. 10.2.1987 -1 BvL 18/81 und 20/82, BVerfGE 74, S. 182-202 (200).

6 Vgl. Lang, J. (1988), S. 124.

7 Durch diese Abhängigkeit von Wertaussagen unterscheidet sich die juristische Gleichheit von der naturwissenschaftlichen (vgl. mit weiteren Nachweisen Lang, J. (1988), S. 124).
} 
dem die verschiedenen Menschen gleich sein sollen, wobei hierbei eine am Gerechtigkeitsgedanken orientierte Betrachtung maßgeblich ist ${ }^{l}$.

Soll Recht auch gerecht sein, sind Prinzipien erforderlich, die zur gerechten Verteilung von Lasten dienen und durch die ein einheitliches $\mathrm{Maß}$-die formale $\mathrm{Ge}$ rechtigkeit- geschaffen wird $^{2}$. Zur Verwirklichung materialer (= inhaltlicher) Gerechtigkeit hat sich das Recht nicht an beliebigen, sondern an sachgerechten Prinzipien zu orientieren ${ }^{3}$. Die Abgrenzung, was sachgerecht ist und was nicht, ist schwierig. Die Sachgerechtigkeit hängt vom Regelungszweck ab, wobei nicht sachgerecht ist, was unvertretbar und unplausibel erscheint. Damit ist die Sachgerechtigkeit die allgemeine Anerkennung des Prinzips durch die Gesellschaft ${ }^{4}$.

$\mathrm{Da}$ es ein "Natur-Steuerrecht" offenbar nicht geben kann, zeigt sich besonders an dem jahrhundertealten Streit über die Steuergerechtigkeit: Steuergerechtigkeit ist nichts Absolutes, sondern abhängig von Ort und Zeit ${ }^{5}$. Es muß daher zuerst ein Konsens darüber gefunden werden, welches Prinzip als das Fundamentalprinzip der Steuergerechtigkeit heranzuziehen ist, da ohne sachgerechte Prinzipien für die Anwendung des Gleichheitssatzes ein Maßstab nicht zur Verfügung steht und damit im Steuerrecht nicht angewendet werden kann ${ }^{6}$. Ist ein Prinzip einmal als Fundamentalprinzip der Besteuerung anerkannt, erfordert der Gleichheitssatz, daß die steuerliche Differenzierung zwischen verschiedenen Individuen grundsätzlich auch nach diesem Prinzip erfolgt ${ }^{7}$.

\section{Prinzipien zur Steuerlastverteilung}

Es wird untersucht, welche finanzwissenschaftlichen Prinzipien zur Anwendung kommen können. Hierbei werden drei grundlegende Prinzipien der Besteuerung, nämlich die Kopfsteuer, das Äquivalenz- sowie das Leistungsfähigkeitsprinzip unterschieden.

Danach wird analysiert, ob diese Prinzipien mit philosophischen bzw. theologischen Denkrichtungen zu vereinbaren sind. Als philosophische Ansätze werden

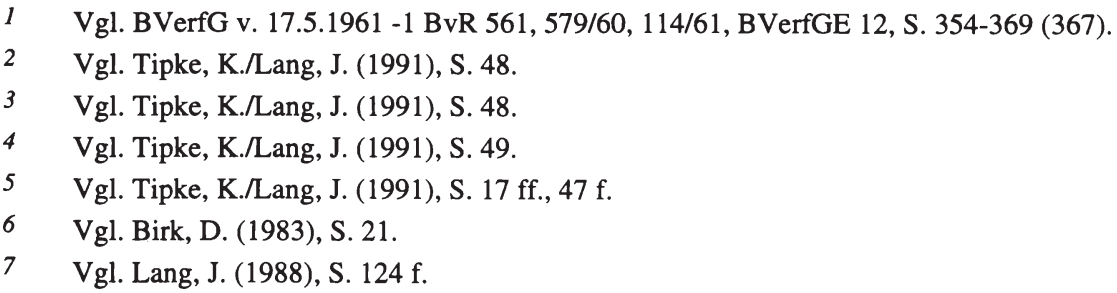


der Utilitarismus sowie der Ansatz von Rawls gewählt, als theologische Denkrichtung die katholische Soziallehre. Für die Einschätzung, ob ein Prinzip gerecht ist, dürfen jedoch nicht nur die Philosophie und Theologie herangezogen werden, da diese die Gerechtigkeitsvorstellungen in der Realität nicht unbedingt widerspiegeln. Um den Bezug zur Realität nicht zu verlieren, wird auch untersucht, welches Prinzip mit der heutigen Rechtsauffassung zu vereinbaren und welches praktikabel ist.

\subsection{Die Kopfsteuer als Maßstab der Lastenverteilung}

Bei einer Kopfsteuer wird der Finanzbedarf des Staates auf die Zahl der Steuerpflichtigen so umgelegt, daß jeder denselben Betrag an Steuern zu entrichten hat. Unerheblich ist dabei, welche wirtschaftliche Kraft der einzelne verkörpert bzw. in welcher Höhe er staatliche Leistungen beansprucht. Da über die Höhe der Staatsausgaben keine Aussage getroffen wird, ist die Kopfsteuer ein reines Steuerlastverteilungsprinzip.

In einem Staat mit funktionierendem Meldewesen ist eine Kopfsteuer ohne weiteres möglich. Da die Höhe der Steuerlast für jeden gleich ist und nicht beeinflußt werden kann, bestehen auch keine Meß-, Bewertungs- sowie Steuerhinterziehungsprobleme: eine Kopfsteuer ist praktikabel durchführbar.

Diese Form der Besteuerung ist allerdings politisch heute nicht mehr durchzusetzen: dies zeigte sich in Großbritannien, wo zum 1.1.1990 auf Gemeindeebene als Ersatz für die Grundsteuer eine Kopfsteuer (poll tax) eingeführt wurde. Sie forderte für jeden gemeindeansässigen Bürger über 18 Jahren einen gleich hohen Betrag; es bestanden allerdings Unterschiede in der Steuerhöhe zwischen den Gemeinden (von $£$ 93,- (Isles of Scilly) bis $£$ 782,- (London, Stadtteil Camden) $)^{l}$. Diese Steuer wurde aufgrund der massiven Bevölkerungsproteste relativ schnell wieder abgeschafft.

\subsection{Das Äquivalenzprinzip als Maßstab der Lastenverteilung ${ }^{2}$}

Das Äquivalenzprinzip (benefit principle) geht historisch zurück auf die Vertragstheorie des Staates, wie sie im 17. Jahrhundert von den Staatstheoretikern

\footnotetext{
$1 \quad$ Vgl. Fischer, H. (1990), S. 567.

2 Vgl. Blankart, C.B. (1991), S. $158 \mathrm{ff}$.
} 
(z.B. Locke, Hobbes) verstanden wurde ${ }^{l}$. Philosophisch ist es den Sophisten zuzurechnen ${ }^{2}$.

Es ist sowohl ein Steuerrechtfertigungs- als auch ein Steuerlastverteilungsprinzip, da sowohl die Einnahmen- als auch die Ausgabenseite des Staates berücksichtigt werden. Das Recht des Staates zur Steuererhebung wird durch sein Angebot an Leistungen an die Bürger begründet.

Bei der Erhebung der Steuern nach dem Äquivalenzprinzip soll die Steuerhöhe des einzelnen Steuerpflichtigen nach dem Wert der von ihm empfangenen staatlichen Leistungen bemessen werden. Die Steuerzahlungen stellen damit das Entgelt für die empfangenen staatlichen Leistungen dar.

Dabei ist zwischen der Finanzierung des Staatsangebots an privaten und öffentlichen Gütern zu unterscheiden. Ist der Staat Anbieter von privaten Gütern (z.B. öffentlicher Nahverkehr, Müllabfuhr), entspricht der nach dem Äquivalenzprinzip vom Staat zu verlangende "Preis" den Grenzkosten der Leistung. Der Staat verhält sich folglich wie ein privater Anbieter auf einem vollkommenen Markt. Die Nachfrager bezahlen genau den Marktwert der beanspruchten Ressourcen, die sie entsprechend ihrer marginalen Zahlungsbereitschaft nachfragen.

Dies kann durch folgende Skizze verdeutlicht werden ${ }^{3}$ :

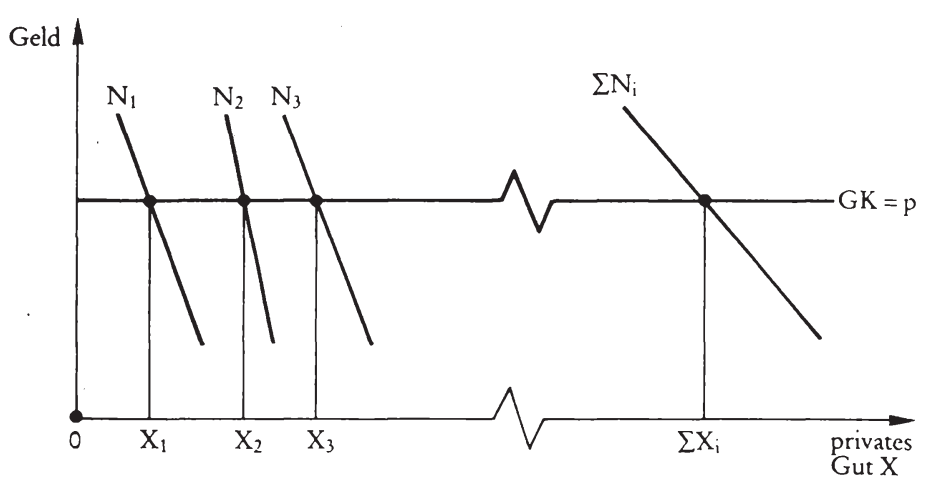

$\mathrm{X}$ ist hierbei ein privates Gut, $\mathrm{X}_{\mathrm{i}}$ bezeichnet die vom Individuum i konsumierte Menge und $\mathrm{N}_{\mathrm{i}}$ bezeichnet die Nachfragekurve des i-ten Individuums; $\mathrm{GK}=\mathrm{p}$ stellt den Grenzkostenpreis dar.

1 Vgl. Musgrave, R.A./Musgrave, P.B./Kullmer, L. (1993), S. 12, Fußnote 1.

2 Vgl. hierzu Neumann, Fr.J. (1880), S. 529 ff.

3 Vgl. Blankart, C.B. (1991), S. 159. 
Die Preisbestimmung von privaten Gütern (die der Staat anbietet) bereitet -zumindest in der Theorie- keine Probleme, da sich die Nachfrager individuell in der Menge anpassen können und die Preisfindung wie bei privaten Anbietern stattfindet.

Bei öffentlichen Gütern (z.B. Landesverteidigung) konsumiert jedes Individuum die gesamte Menge der Güter, da diese definitionsgemäß weder Ausschluß noch Rivalität zulassen; die Individuen können sich mengenmäßig also nicht anpassen.

Es ist davon auszugehen, daß jedes Individuum eine möglichst geringe Steuerlast tragen möchte und deshalb versucht, sich strategisch zu verhalten; d.h. es wird seine Präferenzen verschleiern, um für das bereitgestellte öffentliche Gut nichts zu bezahlen (Freifahrer-Problematik).

Bei der folgenden Analyse wird allerdings davon ausgegangen, daß sich die Individuen nicht strategisch verhalten. Es ist zu klären, auf welche Preis (= Steuer)- Mengenkombination sich die Individuen einigen. Übereinstimmung zwischen den Individuen wird erreicht, wenn jeder entsprechend seiner marginalen Zahlungsbereitschaft für die von ihm bezogenen öffentlichen Güter belastet wird und in der Summe die Kosten hierfür gedeckt werden.

Wird von identischen Individuen (einschließlich Einkommen) ausgegangen, hat jedes der $n$ Individuen eine Steuer von $T=G K / n$ zu entrichten $(\mathrm{GK}=$ Grenzkosten des öffentlichen Gutes). Dieses Ergebnis ist kostendeckend, falls keine Fixkosten entstehen sowie die Grenzkosten konstant sind (da $T * n=G K)$, und paretoeffizient (da die Summe der marginalen Zahlungsbereitschaften den Grenzkosten entspricht). Dies wird durch folgende Graphik verdeutlicht ${ }^{l} . \mathrm{MZB}_{\mathbf{i}}$ bezeichnet dabei die marginale Zahlungsbereitschaft des i- ten Individuums.

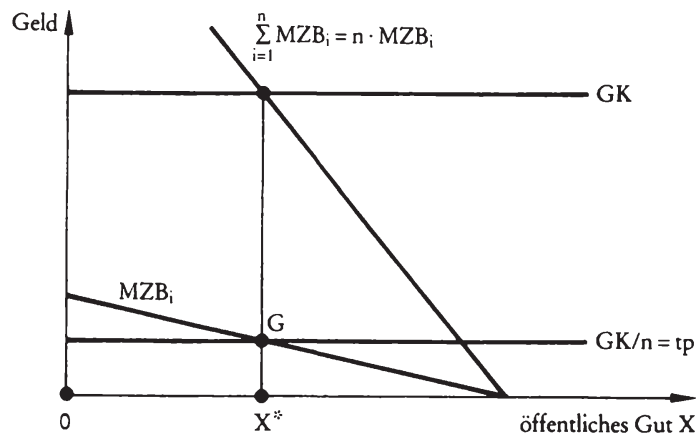

Vgl. Blankart, C.B. (1991), S. 160. 
Die oben verwandte Bedingung der Einkommensgleichheit wird jetzt aufgegeben; es wird somit -mit Ausnahme des Einkommens- von identischen Individuen ausgegangen. Aufgrund der unterschiedlichen Einkommen ist die marginale Zahlungsbereitschaft nicht mehr gleich, die Kurven der marginalen Zahlungsbereitschaft fallen auseinander: bei positiver Einkommenselastizität ist die Nachfrage positiv mit der Einkommenshöhe korreliert. Eine Übereinkunft über die Menge des bereitgestellten öffentlichen Guts zwischen den Individuen wird jedoch erreicht, wenn sich die Steuer an der jeweiligen marginalen Zahlungsbereitschaft orientiert und weiterhin durch die Summe der Steuern eine Kostendeckung erreicht wird.

Zur Verdeutlichung dient folgende Skizze ${ }^{l}$ :

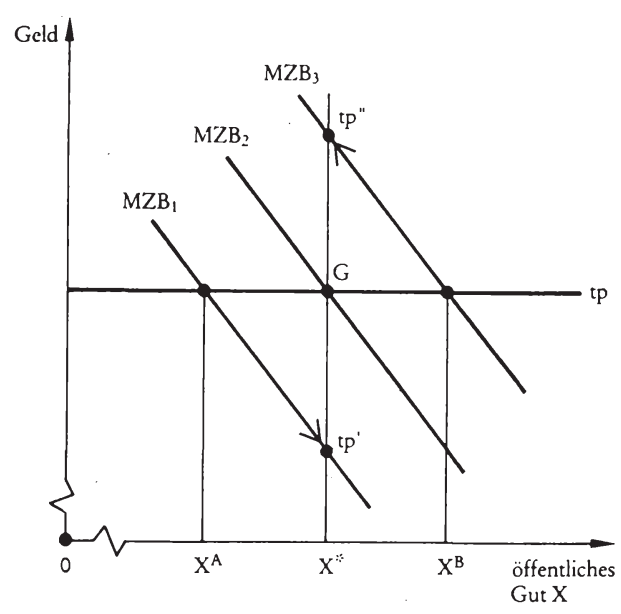

Die beim Steuerpreis von tp angebotene Menge $\mathrm{X}^{*}$ des öffentlichen Gutes befürwortet nur noch Individuum 2, während Individuum 3 aufgrund seines höheren Einkommens (bei positiver Einkommenselastizität) die Menge $\mathrm{X}^{\mathrm{B}}$ und das Individuum 1 aufgrund seines geringeren Einkommens lediglich die Menge $\mathrm{X}^{\mathrm{A}}$ nachfragt. Wird der "Steuerpreis" von 3 auf tp" erhöht, der von 1 auf tp' gesenkt und wird mit dem Gesamtsteueraufkommen Kostendeckung erzielt, wird ein Konsens über die Menge des angebotenen Gutes erreicht. Steigt dabei der Steuerpreis tp" weniger als der Steuerpreis tp' sinkt, muß eine andere als die bisherige Menge $\mathrm{X}^{*}$ angeboten werden. Die Veränderungen der "Steuerpreise" werden also dazu genutzt, die aufgrund der unterschiedlichen Einkommen gewünschten Mengen des öffentlichen Gutes X auszugleichen. Die Höhe der kompen- 
sierenden "Steuerpreisveränderungen" ergibt sich aus dem Verhältnis von Einkommenselastizität

$$
B=\frac{\Delta X / X}{\Delta Y / Y}
$$

und der Steuerpreiselastizität der Nachfrage des Individuums

$$
\partial=\frac{\Delta \mathrm{X} / \mathrm{X}}{\Delta \mathrm{tp} / \mathrm{tp}} .
$$

Der Quotient dieser beiden Größen

$$
\varepsilon=\frac{\Delta \mathrm{tp} / \mathrm{tp}}{\Delta \mathrm{Y} / \mathrm{Y}}
$$

zeigt, wie der "Steuerpreis" für das öffentliche Gut steigen muß, wenn das Einkommen steigt und das Äquivalenzprinzip erfüllt werden soll ${ }^{l}$.

Das Äquivalenzprinzip geht grundsätzlich von der bestehenden Verteilung innerhalb einer Volkswirtschaft aus und bietet keine Handhabe, diese zu verändern. Die Preise für die vom Staat zur Verfügung gestellten Güter sind allerdings nicht gleich, da wohlhabendere Individuen vielfach eine höhere Zahlungsbereitschaft besitzen als ärmere. Die Ärmeren können damit die im wesentlichen von den Reichen finanzierten Güter mitbenutzen, obwohl sie nur zu einem geringen Bruchteil an ihrer Finanzierung mitwirkten. Eine echte Umverteilung -also Transferleistungen des Staates (z.B. Sozialhilfe an Bedürftige)- ist mit dem Äquivalenzprinzip grundsätzlich nicht zu begründen².

Problematisch ist die aufwendige Handhabbarkeit des Äquivalenzprinzips: für jedes öffentliche Gut und für jedes Individuum muß bei konsequenter Anwendung eine eigene Steuer erhoben werden. Eine Lösungsmöglichkeit könnte die Bildung von Güterbündeln sein. Die Wertschätzung der Individuen für einzelne Güter kann möglicherweise anhand von Einkommens- und Steuerpreiselastizitäten abgeschätzt werden, andere Einflußfaktoren müssen jedoch aus praktischen Gründen unberücksichtigt bleiben. Praktikabel durchführbare Lösungen müssen darüberhinaus Typisierungen hinsichtlich der Präferenzen und der Nutzenfunktionen der Individuen vornehmen.

I Empirische Studien dazu wurden durch Bergstrom, T./Goodman, R.P. (1973), Borcherding, T.E./Deacon, R. (1972) sowie Pommerehne, W.W. (1978) angefertigt.

2 Vgl. aber die Ausführungen zu dem Ansatz von Rawls. 
Fraglich ist, ob die Staatsbürger über die Art und den Umfang der wünschenswerten Staatsausgaben befinden können. Dies ist besonders schwierig bei Aufgaben wie der staatlichen Außenpolitik und der Beurteilung des notwendigen Verteidigungsaufwands ${ }^{l}$. Es ist auch offen, ob durch diese unmittelbare Beteiligung der Bürger die Politik nicht in zu hohem Maße tagespolitischer Hektik ausgesetzt wird und langfristige Konzepte keine Chance haben. Weiterhin ist umstritten, ob dieses Konzept mit der Staatsform einer Parlamentarischen Demokratie zu vereinbaren und angesichts der Größe der Staaten überhaupt technisch durchführbar ist ${ }^{2}$.

Ein weiterer Einwand gegen das Äquivalenzprinzip berührt die herrschende Staatsauffassung 3 : eine Äquivalenz setzt die Gleichstellung der Partner voraus (z.B. die Stellung von Käufer und Verkäufer im Markt bei vollkommener Konkurrenz), wie sie z.B. der Auffassung des Staates als Assekuranzanstalt entspricht. Nach den modernen Staatstheorien ist die Steuer eine Zwangsabgabe, die bedingungslos zu entrichten ist; eine Gleichstellung der Partner liegt daher nicht vor. Die Definition der Steuern als quid pro quo ("etwas für etwas") paßt damit nicht mehr zu den modernen Staatsauffassungen.

Ein Problem stellt ebenso das strategische Verhalten der Individuen dar: was -außer ihrer Ehrlichkeit- fordert von ihnen, ihre Präferenzen und Zahlungsbereitschaft für bestimmte Staatsleistungen zu offenbaren, wenn sie auch ohne Kostenbeteiligung am Konsum der öffentlichen Güter, die weder Ausschluß noch Rivalität zulassen, teilnehmen können (Freifahrer-Problematik)? Zur Lösung dieses Problems müssen Abstimmungsregeln über Art und Umfang der Staatsausgaben festgelegt werden. Die Einstimmigkeit dürfte dabei bei der großen Zahl von Individuen aufgrund der hohen Verhandlungskosten ausscheiden. Bei einer Mehrheitsentscheidung besteht allerdings die Gefahr von zyklischen Entscheidungen, d.h. aufgrund der Inhomogenität der Präferenzordnungen der Individuen ist es möglich, daß die zu bevorzugende Alternative von der Abstimmungsreihenfolge über die verschiedenen Möglichkeiten abhängt ${ }^{4}$.

Das Äquivalenzprinzip ist somit als generelle Regel zur Definition der staatlichen Leistungen und zur Aufteilung der Steuerlast praktisch nicht anwendbar ${ }^{5}$. Die Ablehnung beruht hauptsächlich auf praktischen Gründen und nicht auf $\mathrm{Ge}$ -

Vgl. Haller, H. (1981), S. 19 f.

Vgl. Haller, H. (1981), S. 19.

3

Vgl. Neumark, F. (1970), S. 43 f.; Buchanan, J.M. (1960), S. 14 ff.

4 Vgl. hierzu Blankart, C.B. (1991), S. 165.

5 Zur Bestimmung der Höhe von Gebühren bzw. Abgaben kann es jedoch durchaus gute Dienste leisten. 
rechtigkeitserwägungen. Daher wird es hier auch nicht verworfen: später wird untersucht, ob dieses Prinzip aufgrund von Gerechtigkeitserwägungen nicht dennoch zur Steuerlastverteilung herangezogen werden sollte.

\subsection{Das Leistungsfähigkeitsprinzip als Maßstab der Lastenverteilung}

Ausgangspunkt der Besteuerung nach dem Leistungsfähigkeitsprinzip (ability to pay principle) ist, daß der Staat Leistungen im allgemeinen Interesse erbringt. Im Gegensatz zum Äquivalenzprinzip ist das Leistungsfähigkeitsprinzip lediglich ein Steuerlastverteilungsprinzip. Das Angebot an Staatsleistungen wird hierbei als exogene Größe vorausgesetzt. Durch dieses Prinzip soll die Finanzierung des Angebots und somit die Verteilung der Steuerlast auf die einzelnen Bürger geregelt werden. Für die Bemessung der Steuerhöhe des einzelnen ist es mithin im Gegensatz zum Äquivalenzprinzip unerheblich, welche staatlichen Leistungen er beansprucht oder welchen Nutzen aus diesen gezogen werden.

Als Maßstab für die Verteilung der Steuerlast auf die einzelnen Bürger dient vielmehr die Leistungsfähigkeit des einzelnen, d.h. der Leistungsfähigere entrichtet eine höhere Steuerleistung als ein weniger Leistungsfähiger.

Das Leistungsfähigkeitsprinzip kann auf die iustitia distributa (= verteilende Gerechtigkeit) nach Aristoteles zurückgeführt werden ${ }^{1,2}$. Adam Smith betrachtete es ebenfalls als das anzuwendende Prinzip zur Steuerlastverteilung ${ }^{3}$.

Der Begriff der "wirtschaftlichen Leistungsfähigkeit" muß inhaltlich präzisiert werden, um Aussagen über die für die Besteuerung relevanten Fragen der Bemessungsgrundlage machen zu können. Zwei Ausprägungen dieses Begriffes sind zu unterscheiden: die Leistungsfähigkeit wird zum einen als die Opferfähigkeit der Individuen und deren Messung durch die Höhe des individuellen Nutzens (nutzentheoretischer Leistungsfähigkeitsbegriff), zum anderen als die individuelle Fähigkeit der Individuen, zur Deckung des staatlichen Finanzbedarfs beizutragen (verteilungspolitischer Ansatz), definiert ${ }^{4}$.

Die Leistungsfähigkeit eines Individuums ist nicht ohne weiteres meßbar; hierzu sind Indikatoren notwendig. Um befriedigende Aussagen über die praktikable Meßbarkeit der Leistungsfähigkeit treffen zu können, müssen diese Indikatoren zuerst festgelegt und dann beurteilt werden; dies folgt an anderer Stelle. Auf die dortigen Ausführungen zur Praktikabilität wird verwiesen.

\footnotetext{
Vgl. Aristoteles (1956), S. $100 \mathrm{f}$.

Vgl. hierzu Neumann, Fr.J. (1880), S. 511 ff.; Birk, D. (1983), S. 6 f.

Vgl. Smith, A. (1791), Vol. III, S. 255 ff.

Vgl. Ebnet, O. (1978), S. 27.
} 


\subsubsection{Nutzentheoretischer Leistungsfähigkeitsbegriff}

Nach der nutzentheoretischen Definition der wirtschaftlichen Leistungsfähigkeit, ist Bemessungsgrundlage der Besteuerung der durch die individuelle Bedürfnisbefriedigung hervorgerufene Nutzen einer Person: Individuen mit gleicher wirtschaftlichen Leistungsfähigkeit erfahren durch die Besteuerung dieselbe Nutzeneinbuße. Die wirtschaftliche Leistungsfähigkeit wird damit als die Fähigkeit zur individuellen Bedürfnisbefriedigung verstanden ${ }^{l}$; die zu entrichtende Steuer muß so bemessen sein, daß die individuelle Einschränkung der Bedürfnisbefriedigung bei jedem gleich ist ${ }^{2}$. Dies ergibt sich auch aus einer Passage von Mill: "Equality of taxation,..., means equality of sacrifice."3.

Dieser Auffassung des Leistungsfähigkeitsprinzips entsprechen die nachstehend kurz erläuterten Opfertheorien.

Dazu werden zwei Individuen mit gleicher Nutzenfunktion, aber unterschiedlichen Einkommen betrachtet; die Nutzenfunktion ist eine Funktion des Einkommens mit fallendem Grenznutzen. Die insgesamt zu entrichtende Steuer soll so verteilt werden, daß beide Individuen das gleiche Opfer erbringen.

Es ergeben sich folgende Interpretationsmöglichkeiten hinsichtlich des "gleichen Opfers":

- Wird die Opfergleichheit anhand des gleichen Grenzopfers gemessen, bedeutet dies bei jedem Steuerpflichtigen denselben Nutzenverlust durch die zuletzt weggesteuerte Geldeinheit; dies hat bei unterstellten gleichen individuellen Nutzenfunktionen zur Folge, daß ab einem bestimmten Einkommen alles weggesteuert wird; Individuen, die ein geringeres Einkommen haben, entrichten keine Steuern.

- Die Besteuerung nach dem gleichen absoluten Opfer fordert die gleiche Gesamtnutzeneinbuße bei allen Steuerzahlern.

Bei sinkendem Grenznutzen müssen somit Bezieher hoher Einkommen einen höheren Betrag als Steuer entrichten.

- Weiterhin ist noch eine Besteuerung nach dem gleichen proportionalen Opfer möglich; dabei ist der Quotient aus Nutzeneinbuße und Gesamtnutzen bei allen Steuerpflichtigen gleich.

\footnotetext{
Vgl. Haller, H. (1981), S. 42.

Vgl. Haller, H. (1981), S. 42.

Mill, J. S. (1965), S. 804.
} 


\subsubsection{Verteilungspolitischer Leistungsfähigkeitsbegriff}

Nach diesem Konzept drückt sich die wirtschaftliche Leistungsfähigkeit in der individuellen Fähigkeit, zur Finanzierung des staatlichen Finanzbedarfs beizutragen, aus; es wird an der Fähigkeit, Lasten tragen zu können, angeknüpft ${ }^{l}$. Nach dieser (verteilungspolitischen) Definition wird unter der wirtschaftlichen Leistungsfähigkeit der Zuwachs an ökonomischer Verfügungsmacht über knappe Ressourcen der Wirtschaft in einem bestimmten Zeitraum verstanden ${ }^{2,3}$. Der Begriff "Verfügungsmacht" besagt, daß ein Individuum frei zwischen konsumtiver und investiver Verwendung (= Verwendung zugunsten zukünftigen Konsums) der ihm zur Verfügung stehenden Ressourcen entscheiden kann ${ }^{4}$. Zur vollständigen Abbildung der Leistungsfähigkeit sind somit alle (ökonomischen) Elemente zu erfassen, über die ein Individuum verfügen kann (Totalitätsprin$\left.\operatorname{zip}^{5}\right)^{6}$

Mit Hilfe dieser Definition der wirtschaftlichen Leistungsfähigkeit können Aussagen zur Gestaltung der Steuerbemessungsgrundlage getroffen werden. Eine Aussage über die Höhe des Tarifs oder seines Verlaufs kann nicht gemacht werden, was -im Gegensatz zur nutzentheoretischen Definition- auch gar nicht angestrebt wird?

Vgl. Kraft, C. (1991), S. 11.

2 Vgl. Kraft, C. (1991), S. 40; Hackmann, J. (1979), S. 32; Ebnet, O. (1978), S. 55 ff.; Hackmann, J. (1983), S. 666 f.

3 Ist der relevante Zeitraum die Lebensdauer, umfaßt die Leistungsfähigkeit die gesamte ökonomische Verfügungsmacht des Individuums.

$4 \quad$ Vgl. Ebnet, O. (1978), S. 57.

$5 \quad$ Vgl. Lang, J. (1988), S. 171.

6 Vgl. Ebnet, O. (1978), S. 28.

7 Vgl. Kraft, C. (1991), S. 40. 


\section{Ableitung eines gerechten Besteuerungsprinzips aus verschiedenen philosophischen Denkrichtungen}

\subsection{Utilitarismus}

\subsubsection{Darstellung des Utilitarismus}

Als Utilitarismus wird eine philosophische Lehre der Ethik ${ }^{l}$ und der Politik bezeichnet, die im Laufe des 19. Jahrhunderts in England -insbesondere von Jeremy Bentham und John Stuart Mill- entwickelt wurde ${ }^{2}$.

Der Utilitarismus strebt das allgemeine Wohlergehen der Menschheit sowie die Verbesserung der menschlichen Lebensbedingungen mit rein rationalen Mitteln $\mathrm{an}^{3}$. Er zeigt Kriterien auf, nach denen menschliche Entscheidungen, Handlungen, Normen und Institutionen als moralisch richtig oder falsch zu beurteilen sind. Die Handlung bzw. Handlungsregel wird hierbei nicht für sich selbst beurteilt, sondern aufgrund ihrer Folgen. Beurteilungsmaßstab ist der Nutzen/die Glückseligkeit aller der von der Handlung Betroffenen und nicht nur der Nutzen einzelner bzw. einzelner Gruppen ${ }^{4}$.

Eine Handlung ist moralisch richtig bzw. nützlich (Prinzip der Nützlichkeit = Prinzip des größten Glücks/Glückseligkeit ${ }^{5}$ ), wenn sie die Tendenz hat, das Glück zu fördern und moralisch falsch, wenn sie das Gegenteil von Glück för$\operatorname{dert}^{6}$. Unter "Glück" versteht Mill dabei Lust und das Freisein von Unlust, unter "Unglück" Unlust und das Fehlen von Lust ${ }^{7}$. Bentham konkretisiert diese Begriffe wie folgt: unter Glück sind u.a. Sinnesfreuden, Reichtum, Gewinne, Vorteile, Kunstfertigkeit, Freundschaft, Macht, Mildtätigkeit; unter Leiden u.a. Entbehrung, Unbeholfenheit, Feindschaft zu verstehen ${ }^{8}$. Das Nützlichkeitsprinzip beinhaltet aber nicht nur das Streben nach Glück, sondern auch die Verhinderung und Abschwächung von Unglück ${ }^{9}$.

$1 \quad$ Ethik soll hier als "..System von Sollforderungen, von denen sich jede individuelle oder kollektive menschliche Tätigkeit leiten und lenken läßt." verstanden werden (Ludwig, M. (1963), S. 39).

2 Vgl. Ludwig, M. (1963), S. 28.

3 Vgl. Ludwig, M. (1963), S. $36 \mathrm{f}$.

4 Höffe, O. (1975), S. 9.

5 Vgl. Bentham, J. (1975), S. 52 f. (1. Anm. d. Autors).

6 Vgl. Mill, J.S. (1985), S. 13.

7 Vgl. Mill, J.S. (1985), S. 13.

8 Vgl. Bentham, J. (1975), S. $51 \mathrm{f}$.

$9 \quad$ Vgl. Mill, J.S. (1985), S. 22. 
Die Handlung wird demnach nach der Nützlichkeit für die Allgemeinheit beurteilt; sie ist auch dann als gut zu beurteilen, wenn manche eine Einbuße erleiden, andere aber einen Vorteil erhalten, der größer ist als die verursachte Einbuße ${ }^{l}$.

Die Moral des Utilitarismus kann somit definiert werden als ".. die Gesamtheit der Handlungsregeln und Handlungsvorschriften, durch deren Befolgung ein Leben der angegebenen Art [= reich an Glück; Anmerkung des Verfassers] für die gesamte Menschheit im größtmöglichen Umfange erreichbar ist."2.

\subsubsection{Besteuerung nach utilitaristischen Regeln}

Es wird davon ausgegangen, daß die einzelnen Individuen die gleichen Nutzenfunktionen $\mathrm{U}(\mathrm{x})$ mit abnehmendem, aber positivem Grenznutzen haben $\left(\mathrm{u}^{\prime}>0\right.$, $u^{\prime \prime}<0$ ), d.h. je mehr Güter (x) bzw. Einkommen (zum Erwerb von Gütern) dem Individuum zur Verfügung stehen, desto höher ist sein Gesamtnutzen, wobei der Zuwachs einer bestimmten Menge von Gütern bzw. Einkommen zu einem immer geringeren Zuwachs an Nutzengewinn führt.

\subsubsection{Exkurs: Begründung des fallenden Grenznutzens}

Der fallende Grenznutzen kann wie folgt begründet werden ${ }^{3}$ : ist das Einkommen sehr niedrig, wird jede Geldeinheit zur Befriedigung der existentiellen Bedürfnisse benötigt; kann das Einkommen gerade noch die Existenzerhaltung ermöglichen, hat jede Geldeinheit für den Bezieher einen unendlich hohen Nutzen, da jeder Einkommensverlust die weitere Existenz unmöglich macht. Wächst das Einkommen über das zur Existenzerhaltung unbedingt Notwendige hinaus, ist dieser Zuwachs für das Individuum auch noch von sehr großer Bedeutung und bringt einen hohen Grad an Bedürfnisbefriedigung, da eine kultivierte Existenz mehr als nur "Überleben" bedeutet. Ein weiterer Einkommenszuwachs hat die Sättigung dieser in einer kultivierten Gesellschaft vorhandenen Grundbedürfnisse zur Folge; ein weiteres Steigen des Einkommens führt zu einem immer geringeren Zuwachs an Bedürfnisbefriedigung. Dies bedeutet aber nicht, daß es einen Punkt gibt, an dem ein weiterer Zuwachs nicht mehr eintritt. Mit dem Einkommen werden daher zuerst die dringlicheren Bedürfnisse und erst danach die weniger dringlichen Bedürfnisse befriedigt; die Befriedigung der

\footnotetext{
$1 \quad$ Vgl. Mill, J.S. (1985), S. 21.

2 Mill, J.S. (1985), S. 21.

3 Vgl. Haller, H. (1981), S. 76 f.
} 
dringlichen Bedürfnisse trägt aber zur Gesamtbedürfnisbefriedigung mehr bei als die Befriedigung der weniger dringlichen ${ }^{l}$.

Maslow'sche Bedürfnisbefriedigungspyramide ${ }^{2}$

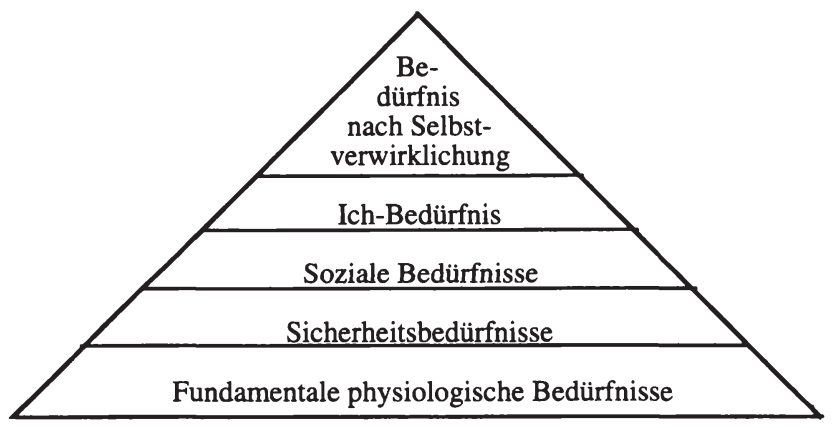

Maslow $^{3}$ verdeutlicht die unterschiedliche Priorität der Bedürfnisse durch den Grundgedanken des Prinzips der relativen Vorrangigkeit: ein höherrangiges Ziel wird erst dann verhaltenswirksam, wenn die Bedürfnisse der vorgelagerten Dringlichkeitsstufen zumindest in einem bestimmten Umfang erfüllt sind.

\subsubsection{Tauschökonomie}

Das Merkmal einer Tauschökonomie ist die gleichbleibende Gütermenge in der Wirtschaft, d.h. unabhängig von der Verteilung auf die einzelnen Individuen än-

Vgl. Haller, H. (1973a), S. 464; Deutscher Bundestag (1974), S. 212.

2 Bedürfnis nach Selbstverwirklichung = Verlangen nach Selbstfindung und Selbstentfaltung

Ich-Bedürfnisse $=$ Verlangen nach Anerkennung, Prestige, Selbstachtung

Soziale Bedürfnisse $=$ Verlangen nach Geselligkeit

Sicherheits-Bedürfnisse = Verlangen nach langfristiger Befriedigung der physiologischen Bedürfnisse

Fundamentale physiologische Bedürfnisse = Verlangen nach Nahrung, Schlaf.

3 Vgl. Maslow, A. H. (1954), S. 83 ff. Auch wenn diese Theorie nicht in ihrer absoluten Form gilt (z.B. können Menschen auch unter extremen Lebensbedingungen (z.B. Mängel in der physiologischen Bedürfnisbefriedigung) aus politischer oder religiöser Überzeugung ein solidarisches Verhalten zeigen und das Ziel der Selbstverwirklichung erreichen (vgl. Keller, J.A. (1981, S. 324), Nieschlag, R./Dichtl, E./Hörschgen, H. (1991, S. $465 \mathrm{f}$.)), so hilft sie hier dennoch, Grundzüge menschlicher Verhaltensweisen zu verdeutlichen. 
dert sich die Gütermenge nicht. Alle Individuen sind anfangs -so die Annahmemit einer unterschiedlichen Menge an Gütern ausgestattet, der Staat kann seine Ausgaben nur aus seinen laufenden Einnahmen bestreiten ${ }^{1}$. Da in einer Tauschökonomie keine Produktion stattfindet, kann es auch zu keinen Anreizverlusten durch die Besteuerung kommen. Einkommen und Vermögen können nicht voneinander getrennt werden, so daß die dem Individuum zur Bedürfnisbefriedigung zur Verfügung stehende Gütermenge seinen Nutzen determiniert.

Ziel des Utilitarismus ist es, mittels Steuer- und Unterstützungszahlungen so umzuverteilen, daß der Gesamtnutzen der Bürger am höchsten ist. Es ist daher die Frage zu beantworten, wie die Steuern und Unterstützungen zu verteilen sind.

Es muß erfüllt sein²:

$$
\begin{array}{ll}
\operatorname{Max} \sum \mathrm{U}\left(\mathrm{X}_{\mathrm{i}}-\mathrm{T}_{\mathrm{i}}+\mathrm{S}_{\mathrm{i}}\right) & \\
\text { unter den Nebenbedingungen: } \quad \mathrm{Y}^{\mathrm{Y}}=\sum \mathrm{X}_{\mathrm{i}} \\
\mathrm{T}_{\mathrm{i}}=\sum \mathrm{S}_{\mathrm{i}} \\
\mathrm{T}_{\mathrm{i}} \geq 0 \\
\mathrm{~S}_{\mathrm{i}} \geq 0
\end{array}
$$

Die Besteuerung und die Umverteilung hat -so das Ergebnis des obigen Maximierungsproblems- nach dem gleichen Grenznutzen zu erfolgen; nach der Umverteilung hat jeder das gleiche Güterbündel zur Verfügung. Die Besteuerung muß somit nach der Leistungsfähigkeit erfolgen: derjenige, der ein größeres Güterbündel hat, zahlt einen höheren Betrag an Steuern und hat eine höhere Nutzeneinbuße.

1 Im folgenden wird lediglich ein Ein-Periodenmodell betrachtet, da in diesem Abschnitt die Betrachtung von intertemporalen Wahlhandlungen keine weiteren Erklärungen bringt und die Argumentation lediglich verkompliziert.

$2 \quad \mathrm{U}=$ kardinale Nutzenfunktion

$\mathrm{T}_{\mathrm{i}}=$ Steuerzahlung von $\mathrm{i}$

$\mathrm{X}_{\mathrm{i}}=$ Güterbündel von $\mathrm{i}$

$\mathrm{Y}=$ Summe der Güterbündel $\left(=\sum \mathrm{X}_{\mathrm{i}}\right)$

$\mathrm{S}_{\mathrm{i}}=$ vom Staat gezahlte Unterstützung an $\mathrm{i}$. 


\subsubsection{Produktionsökonomie}

Es wird davon ausgegangen, daß die Individuen selbst produzieren bzw. arbeiten; die Gütermenge bzw. das Einkommen ist somit nicht mehr wie in der Tauschökonomie konstant ${ }^{l}$.

Für die Bereitschaft mehr zu produzieren bzw. zu arbeiten, ist das verfügbare Einkommen $^{2}$-nach Abzug von Steuern- ausschlaggebend, da nur dieses für Konsumzwecke und damit zur Erzielung eines höheren Nutzens verwendet werden kann. Die Individuen schränken ihre Produktion bzw. ihre Bereitschaft zu arbeiten ein (um sich dann mehr Freizeit zu gönnen), wenn das Einkommen nach Steuern aufgrund des Steuerabzugs sinkt bzw. wenn sie staatliche Unterstützungen erhalten.

Ausgangspunkt soll hier eine Ökonomie mit zwei verschieden leistungsfähigen Gruppen von Individuen sein; der Nutzen von beiden ist abhängig vom Güterkonsum aus dem bezogenen Gesamteinkommen, das sich aus Markteinkommen abzüglich von zu leistenden Steuerzahlungen zuzüglich der vom Staat erhaltenen Transferleistungen zusammensetzt.

Die Umverteilung durch die Besteuerung ist solange im utilitaristischen Sinne als wünschenswert zu beurteilen, solange der Nutzenzuwachs bei denjenigen, die Unterstützungsleistungen erhalten, höher ist als die Nutzeneinbuße bei den Steuerzahlern, da hier die Gesamtsumme aller individuellen Nutzen steigt.

Dies kann an folgender Graphik verdeutlicht werden ${ }^{3}$. Sie zeigt zwei Individuen, deren Nutzen, der vom Güterkonsum aus dem bezogenen Gesamteinkommen abhängig ist, jeweils auf einer Achse abgetragen wird. Die Kurve PT bildet die möglichen Nutzenpositionen bei staatlicher Umverteilung ab. Die Umverteilung ist -geometrisch betrachtet- aus utilitaristischer Sicht solange wünschenswert, bis eine Gerade mit der Steigung von -1 die Kurve berührt. Die erste Ableitung der Funktion hat in diesem Punkt den Wert -1. Dieser Punkt muß nicht auf der 45-Grad-Linie liegen, was einer Gleichverteilung der Nutzen bedeuten würde. Wird solange umverteilt, bis eine Gleichverteilung erreicht ist, wird eventuell ein geringerer Gesamtnutzen der Gesellschaft erzielt, da die, die mehr

1 Die Argumentation erfolgt wiederum im Ein-Periodenmodell.

2 Die Überlegungen werden aufgrund der besseren Anschaulichkeit anhand des Einkommens angestellt; sie gelten in gleicher Weise, wenn statt des Einkommens der verwirklichte Konsum als relevante Variable in das Nutzenkalkül des Individuums einbezogen wird.

Vgl. Atkinson, A.B./Stiglitz, J.E. (1980), S. 338. 
leisten könnten, bei einer solchen steuerlichen Belastung dazu unter Umständen nicht bereit sind.

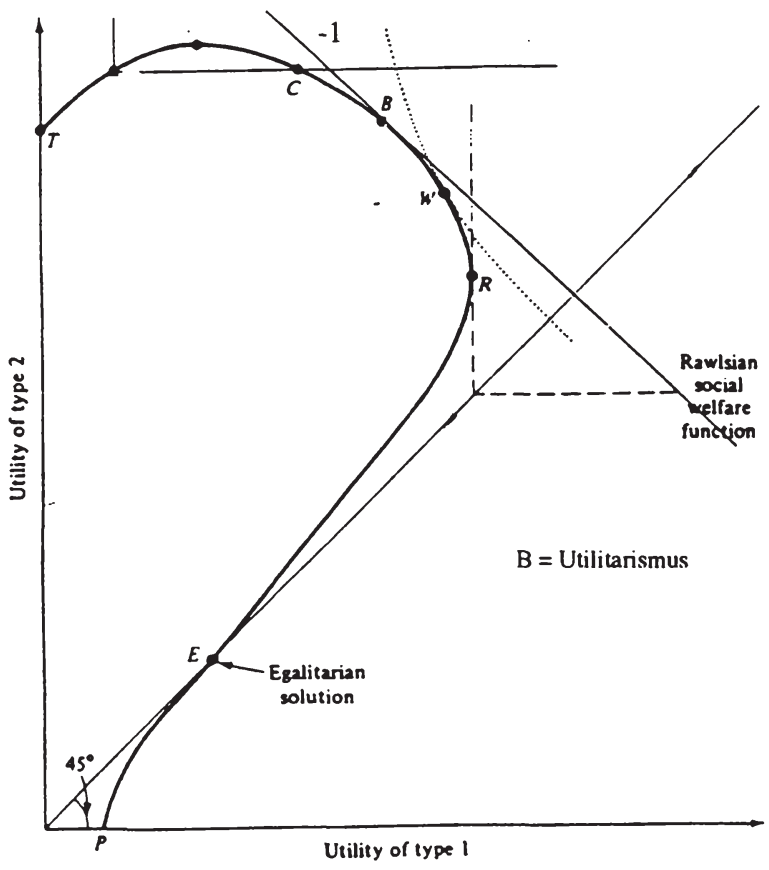

Die Besteuerung erfolgt somit nach dem Leistungsfähigkeitsprinzip, da diejenigen mit einer höheren wirtschaftlichen Leistungsfähigkeit mehr Steuern bezahlen.

\subsection{Neuere Wohlfahrts- und Gerechtigkeitstheorie: Der Ansatz von Rawls}

\subsubsection{Darstellung des Ansatzes von Rawls}

John Rawls wird als Repräsentant der neueren Wohlfahrts- und Gerechtigkeitstheorie gewählt ${ }^{I}$.

I Vgl. zum folgenden Rawls, J. (1979), S. $159 \mathrm{ff}$. 
Rawls geht in seiner Theorie der Gerechtigkeit davon aus, daß sich die Menschen im Urzustand unter einem "Schleier des Nichtwissens" befinden: sie wissen nicht, wie sich verschiedene Alternativen auf ihre Interessen auswirken und müssen deshalb Gerechtigkeitsgrundsätze nach allgemeinen Gesichtspunkten beurteilen. Den Menschen sind Einzeltatsachen über sich unbekannt: sie wissen nichts über ihren Platz in der Gesellschaft, ihre Intelligenz, ihre Körperkraft oder ihre natürlichen Gaben; niemand kann damit die Grundsätze zu seinem Vorteil gestalten. Nach Rawls wissen die Menschen aber, daß "..ihre Gesellschaft die Anwendungsverhältnisse der Gerechtigkeit aufweist und alles, was damit zusammenhängt." ${ }^{I}$. Sie haben einen Gerechtigkeitssinn und halten deshalb die aufgestellten Regeln/Grundsätze ein. Sie verstehen weiterhin politische Fragen, die Grundzüge der Wirtschaftstheorie sowie Grundfragen der gesellschaftlichen Organisation und die Gesetzmäßigkeiten der menschlichen Psychologie. Rawls setzt die Vernunft der Menschen voraus; sie wissen, daß sie einen vernünftigen Lebensplan haben, kennen jedoch nicht seine Einzelheiten; sie möchten lieber mehr als weniger Güter, da ihnen dadurch mehr Mittel zur Erreichung ihrer Ziele zur Verfügung stehen.

Der Mensch "unter dem Schleier des Nichtwissens" kann sich keine besonderen Vorteile durch die Gestaltung der Regeln verschaffen, da er nicht weiß, in welcher Position er sich in späteren Lebensabschnitten befindet. Es gibt aber auch keinen Grund, weshalb er sich mit besonderen Nachteilen zufrieden geben soll. Deshalb ist es für ihn vorerst am vernünftigsten, einen die Gleichverteilung fordernden Gerechtigkeitsgrundsatz anzuerkennen; der anfängliche Grundsatz fordert somit gleiche Grundfreiheiten für alle, eine faire Chancengleichheit sowie die Gleichverteilung von Einkommen und Vermögen. Es gibt aber für die Individuen keinen Grund ${ }^{2}$ (bei Beibehaltung des Vorrangs der Grundfreiheiten sowie der fairen Chancengleichheit), die anfängliche Gleichverteilung beizubehalten, wenn Ungleichheiten des Einkommens, des Vermögens, der Macht sowie der Verantwortung eine Besserstellung eines jeden (auch des am wenigsten Begünstigten) im Vergleich zur Situation der Gleichverteilung zur Folge hat. Dies führt nach Rawls zur "Maxi-min-Regel" der sozialen Gerechtigkeit: es wird diejenige Alternative ausgewählt, bei der das schlechtest mögliche Ergebnis besser ist als das bei anderen Alternativen, d.h. die am schlechtesten gestellte Person den größten Nutzen hat ${ }^{3}$.

Rawls, J. (1979), S. 160.

2 Ein Grund dagegen wäre Neid, wonach die Menschen niedergedrückt sind bei dem Gedanken, daß ein anderer mehr hat als sie selbst. Rawls setzt jedoch voraus, daß die Menschen keine Neidgefühle kennen (vgl. Rawls, J. (1979), S. 175).

3 Das Ziel ist also nicht wie beim Utilitarismus, die Nutzensumme der Gesamtgesellschaft zu maximieren. 
Nach dieser Theorie kann die Umverteilung durch die Besteuerung exante als eine Art "Versicherung" der Individuen angesehen werden ${ }^{1}$ : der später Erfolgreiche verpflichtet sich, mit dem weniger Erfolgreichen zu teilen, indem er höhere Steuern abführt, wodurch der Staat dem einzelnen eine bestimmte Summe zur Bestreitung seines Lebensunterhaltes garantieren kann².

\subsubsection{Besteuerung nach der Rawl'schen "Maxi-min"-Regel}

Das Ziel der Besteuerung ist die Aufbringung der Mittel, die die Gerechtigkeit fordert, so daß der Staat eine Umverteilung im Sinne der "Maxi-min"-Regel vornehmen $\mathrm{kann}^{3}$.

\subsubsection{Tauschökonomie}

Es sollen die oben (unter "Utilitarismus") gemachten Annahmen hinsichtlich der Nutzenfunktionen gelten.

$\mathrm{Da}$ in der betrachteten Tauschökonomie keine Anreizverluste auftreten, kann die Position des am schlechtesten gestellten Individuums durch Umverteilung solange verbessert werden, bis eine Gleichverteilung erreicht ist.

Es ergibt sich das gleiche Ergebnis wie bei der Argumentation über den Utilitarismus.

Der Leistungsfähigere muß mehr Steuern bezahlen als der weniger Leistungsfähige; dies entspricht dem Konzept der Besteuerung nach dem Leistungsfähigkeitsprinzip.

\subsubsection{Produktionsökonomie}

Es sollen die obigen (unter "Utilitarismus") getroffenen Annahmen gelten. 
Nach Rawls wird solange umverteilt, bis die Situation des am schlechtest gestellten Individuums nicht mehr verbessert werden kann. Dies entspricht im Schaubild dem Punkt R; in diesem Zustand wird jede weitere Umverteilung eine Verschlechterung von beiden zur Folge haben, d.h. auch der schlechter Gestellte verliert.

Es kann sich aber eine andere Lösung des Verteilungsproblems als beim Utilitarismus ergeben; eine Gleichverteilung wird ebenfalls nicht verlangt. Das wird an der schon bekannten Graphik deutlich ${ }^{l}$ :

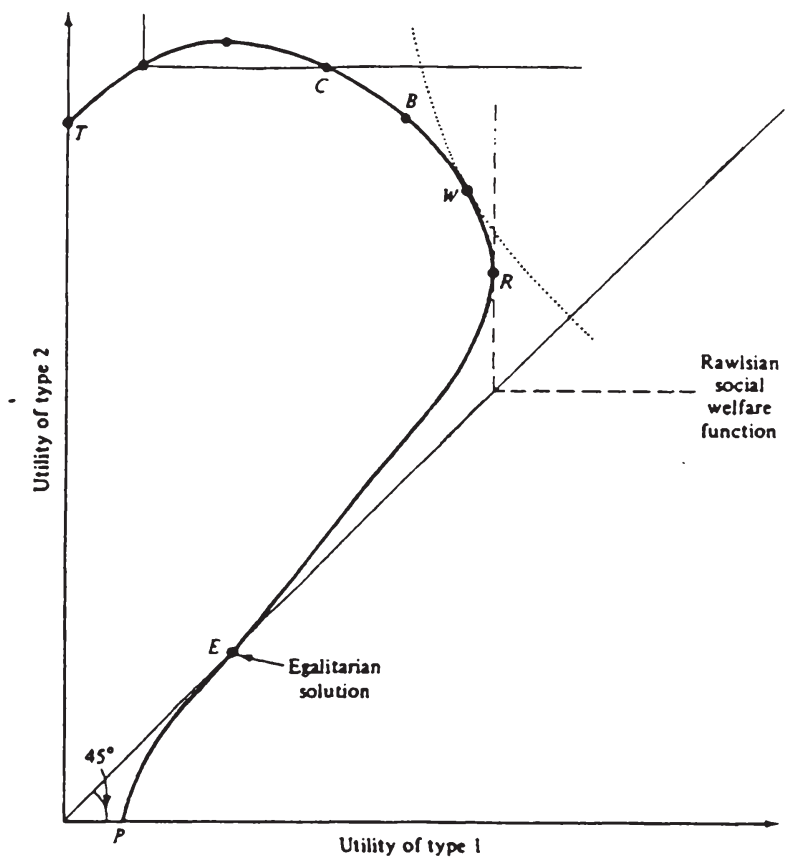

Der Leistungsfähigere muß mehr Steuern bezahlen als der weniger Leistungsfähige. Die Individuen werden also für das Leistungsfähigkeitsprinzip plädieren.

Die Besteuerung kann allerdings auch mit dem Äquivalenzprinzip begründet werden $^{2}$ : die Individuen wollen sich -falls sie risikoavers sind- für zukünftige Notfälle absichern. Manche Notfälle (z.B. Arbeitslosigkeit) sind privatwirtschaftlich nicht versicherbar, da jedem privaten Versicherer dieses Geschäft zu risikoreich ist (wer oder was sollte die Versicherungsnehmer daran hindern,

\footnotetext{
I Vgl. Atkinson, A.B./Stiglitz, J.E. (1980), S. 338.

2 Vgl. Blankart, C.B. (1991), S. 74 f., 164 f.
} 
nach Abschluß der Versicherung einfach aufzuhören zu arbeiten?) ${ }^{I}$. Die Individuen können jedoch auf konstitutioneller Ebene die Organisation dieser Versicherungen durch den Staat vereinbaren. Als Gegenleistung für die Versicherungsleistungen vereinbaren die Individuen, Steuern als (Versicherungs-) Beiträge zu zahlen, sofern sie selbst keiner Unterstützung bedürfen. Ohne diese gegenseitigen Vereinbarungen unter dem Schleier des Nichtwissens ist eine Umverteilung und Unterstützung der Armen nicht möglich: die Armen können nämlich nicht auf die Mildtätigkeit der Bessergestellten rechnen, da die Menschen nach der Auffassung von Rawls aus gegenseitigem Desinteresse handeln ${ }^{2}$.

Die Individuen werden jedoch eine Kopfsteuer ablehnen ${ }^{3}$ : die Steuer ist hier ohne Berücksichtigung existentieller Gesichtspunkte zu entrichten, d.h. die Individuen kommen in große Nöte, wenn sie eine Kopfsteuer entrichten müssen und ihnen nach Entrichtung der Steuer keine Mittel mehr zum Leben verbleiben.

Zusammenfassend ist festzustellen, daß die Individuen im Denkmodell von Rawls die Besteuerung nach der individuellen Leistungsfähigkeit und dem Äquivalenzprinzip als gerecht bezeichnen und präferieren.

\subsection{Katholische Soziallehre}

Die katholische Soziallehre läßt sich definieren als "..das Gesamt der sozialphilosophisch (aus der wesenhaft sozial veranlagten Menschennatur) und sozialtheologisch (aus der christlichen Heilsordnung) gewonnenen Erkenntnisse über Wesen und Ordnung der menschlichen Gesellschaft und über die sich daraus ergebenden und auf die jeweiligen geschichtlichen Verhältnisse anzuwendenden Normen und Ordnungsaufgaben." 4 .

Die katholische Soziallehre hat einige -für das menschliche Zusammenlebenwesentliche Ordnungsprinzipien (Sozialprinzipien) aus der Natur des Menschen abgeleitet. Sie unterscheidet zwischen der Personalität, der Solidarität, dem Gemeinwohl sowie der Subsidiarität.

Im folgenden wird nur auf die für die Verteilung der Steuerlast relevanten Prinzipien eingegangen.

\footnotetext{
I Vgl. Buchanan, J.M./Tullock, G. (1984), S. 192 ff.

2 Vgl. Rawls, J. (1979), S. 168.

3 Vgl. zum folgenden Walzer, K. (1986), S. 205.

4 Höffner, Joseph Kardinal (1983), S. 21.
} 


\subsubsection{Darstellung der katholischen Soziallehre}

\subsubsection{Prinzip der Personalität}

Die Merkmale einer Person, die im Mittelpunkt der Gesellschaftslehre stehen, sind die Ausstattung mit Vernunft, die an das Sittengesetz gebundene Freiheit ${ }^{l}$ sowie die Anlage des Selbstbewußtseins und der Selbstbestimmung ${ }^{2}$. Jeder Mensch ist ein eigenes Individuum, von anderen verschieden ${ }^{3}$ und Träger allgemeingültiger und unveräußerlicher Rechte ${ }^{4}$. Aufgrund seiner Würde muß jeder Mensch Zugang zu den Dingen haben, die er für ein menschliches Leben braucht, z.B. Nahrung, Kleidung und Wohnung 5 .

Die Personalität umfaßt aber mehr als die Individualität des Menschen: er ist von seiner Natur her auf die Gemeinschaft und den Austausch mit anderen Menschen angelegt (Sozialnatur) ${ }^{6}$. Er soll sich im Leben in der Gemeinschaft entfalten $^{7}$; die Personalität ist deshalb Voraussetzung für die physische und geistige Existenz der Person ${ }^{8}$. Die Person ist der Gesellschaft aber nicht untergeordnet, d.h. sie ist nicht für die Gesellschaft da, sondern in der Gesellschaft ${ }^{9}$. Sie ist das Ziel aller gesellschaftlichen Einrichtungen; gesellschaftliche Normen müssen sich am Wohl der Person orientieren ${ }^{10}$.

\subsubsection{Prinzip der Solidarität}

Der Begriff der "Solidarität", der ursprünglich aus dem Rechtswesen stammt, bedeutet Verbundenheit: alle "solidarisch" Verbundenen müssen in der Weise für eine Verpflichtung einstehen, da $\beta$ jeder für die ganze Leistung herangezogen werden kann. Hieraus ergibt sich die Pflicht, sich so zu verhalten, wie es dieser Verbundenheit entspricht ${ }^{H I}$.

$1 \quad$ Vgl. Klüber, F. (1960), S. 109.

2 Vgl. Klüber, F. (1960), S. 106.

3 Vgl. Klüber, F. (1960), S. 106.

4 Vgl. Pastoralkonstitution des 2. Vatikanischen Konzils (Gaudium et spes, 1965), Nr. 26.

5 Vgl. Pastoralkonstitution des 2. Vatikanischen Konzils (Gaudium et spes, 1965), Nr. 26.

$6 \quad$ Nell-Breuning, O. v. (1979), S. 227.

7 Vgl. Klüber, F. (1966), S. 56.

$8 \quad$ Vgl. Klüber, F. (1960), S. 123.

9 Vgl. Nell-Breuning, O.v. (1980), S. 44.

10 Vgl. Pastoralkonstitution des 2. Vatikanischen Konzils (Gaudium et spes, 1965), Nr. 25, 26; Johannes XXIII (Mater et magistra, 1961), Nr. 219.

11 Vgl. Nell-Breuning, O.v. (1987), S. 36. 
Das Prinzip der Solidarität setzt gleichzeitig bei der Individualität und der Sozialität des Menschen an; deshalb werden sowohl der Kollektivismus, der den Menschen nur als Objekt gesellschaftlicher Prozesse sieht und bei dem nur das Interesse der Gemeinschaft zählt, als auch der Individualismus, der die Sozialnatur des Menschen ablehnt, die eigenen Interessen des Individuums in den Vordergrund stellt und in der Gesellschaft nur einen Zweckverband zum Interessenausgleich sieht, abgelehnt ${ }^{l}$.

Als Seinsprinzip sagt das Solidaritätsprinzip aus, daß Mensch und Gesellschaft gegenseitig aufeinander angewiesen sind ${ }^{2}$. Ohne wechselseitige Förderung kann sich weder ein einzelner Mensch, noch die Gesellschaft zufriedenstellend entwikkeln, das Wachstum des Menschen und der Gesellschaft bedingen sich gegenseitig, der einzelne wächst durch den Dialog mit den Mitmenschen und durch den Einsatz, den er für sie leistet ${ }^{3}$. Als sittliches Prinzip besagt das Solidaritätsprinzip, daß Individuum und Gesellschaft wechselseitig füreinander Verantwortung übernommen haben. Das Individuum muß deshalb sich nach seinen Fähigkeiten und Bedürfnissen für die Gemeinschaft einsetzen und die Gemeinschaft muß um das Wohl des einzelnen besorgt sein ${ }^{4}$.

\subsubsection{Prinzip des Gemeinwohls}

Unter "Gemeinwohl" versteht die katholische Soziallehre ".. die Gesamtheit jener Bedingungen des gesellschaftlichen Lebens, die sowohl den Gruppen als auch deren einzelnen Gliedern ein volleres und leichteres Erreichen der eigenen Vollendung ermöglichen,.."5 . Das Gemeinwohlprinzip besitzt somit zwei Bedeutungen ${ }^{6}$ :

- Als "organisatorischer und organisierender Wert" bedeutet Gemeinwohl, daß in der Gemeinschaft die Voraussetzungen und Vorabbedingungen (z.B. Organisation der Gesellschaft) erfüllt sind, die es den Individuen ermöglichen, ihre Kräfte einzusetzen und dadurch ihr eigenes Wohl und ihre eige-

Höffner, Joseph Kardinal (1983), S. 43.

2 Vgl. Pastoralkonstitution des 2. Vatikanischen Konzils (Gaudium et spes, 1965), Nr. 25.

3 Vgl. Pastoralkonstitution des 2. Vatikanischen Konzils (Gaudium et spes, 1965), Nr. 25.

4 Vgl. Pastoralkonstitution des 2. Vatikanischen Konzils (Gaudium et spes, 1965), Nr. 30; Klüber, F. (1966), S. 127.

5 Vgl. Pastoralkonstitution des 2. Vatikanischen Konzils (Gaudium et spes, 1965), Nr. 26.

6 Vgl. Nell-Breuning, O.v. (1987), S. 54. 
ne Vollendung zu verwirklichen ${ }^{I}$. Der Begriff "Gemeinwohl" wird als "Dienstwert" verstanden, die Organisation ist nur dazu da, um eine bestimmte Funktion zu erfüllen².

- Als Selbstwert verstanden, fordert das Gemeinwohlprinzip alle Glieder der Gemeinschaft auf und appelliert an ihr Verantwortungsbewußtsein, diejenigen Handlungen zu unterlassen, die die Verwirklichung des Gemeinwohls vereiteln oder beeinträchtigen könnten und es den anderen Gliedern der Gemeinschaft unmöglich macht bzw. erschwert, ein menschenwürdiges Leben zu führen. Das als Selbstwert verstandene Gemeinwohlprinzip fordert weiterhin, zu tun bzw. zu dulden, was sich nach Lage der Dinge für das Gemeinwohl als notwendig erweist ${ }^{3}$. Die Individuen sollen folglich die eigenen Interessen zugunsten der Bedürfnisse der anderen Menschen zurückstellen ${ }^{4}$.

Das Gemeinwohl verlangt kraft seiner Natur, daß alle an ihm teilhaben, wenn auch in verschiedenen Graden, je nach Aufgaben, Verdiensten und Verhältnissen des einzelnen ${ }^{5}$. Das Gemeinwohlprinzip fordert also vor allem die Wahrung der Rechte der menschlichen Person, die der Ausgangspunkt und das Ziel des Gemeinwohls sind ${ }^{6}$.

\subsubsection{Besteuerung nach den Prinzipien der katholischen Soziallehre}

Die katholische Soziallehre begründet das Steuererhebungsrecht des Staates mit dem Gemeinwohl, das ohne die Opfer der Bürger nicht verwirklicht werden kann? ${ }^{7}$.

Das die Würde des Menschen beinhaltende Prinzip der Personalität fordert den Zugang eines jeden Menschen zu den Dingen, die es ihm ermöglichen, ein menschenwürdiges Leben zu führen. Das Prinzip des Gemeinwohls fordert eine Organisation der Gesellschaft, daß jeder Mensch ein würdiges Leben führen kann und Handlungen, die dieses Ziel gefährden, unterbleiben. Aus diesen Gründen

$1 \quad$ Vgl. Nell-Breuning, O. v. (1979), S. 146; Nell-Breuning, O.v. (1987), S. 54; Pastoralkonstitution des 2. Vatikanischen Konzils (Gaudium et spes, 1965), Nr. 26.

2 Vgl. Nell-Breuning, O.v. (1987), S. 55.

3 Vgl. Nell-Breuning, O.v. (1987), S. 58.

4 Vgl. Johannes XXIII. (Pacem in terris, 1963), Nr. 53.

5 Vgl. Johannes XXIII. (Pacem in terris, 1963), Nr. 56.

6 Vgl. Klüber, F. (1982), S. 30.

7 Höffner, Joseph Kardinal (1983), S. 257. 
muß eine allgemeine Kopfsteuer abgelehnt werden. Diese Steuer würde die Lebensgrundlage der wenig Begüterten gefährden und ihnen die Chance für ein menschenwürdiges Dasein nehmen.

Aus den Prinzipien der katholischen Soziallehre heraus muß die Besteuerung nach dem Äquivalenzprinzip ebenfalls abgelehnt werden, da das Prinzip der Solidarität den Einsatz für das Gemeinwohl (hier: die Verfügungstellung von finanziellen Mitteln für die Erfüllung der staatlichen Aufgaben) unabhängig von dem fordert, was dem einzelnen Steuerpflichtigen davon wieder zugute kommt ${ }^{l}$.

Aus dem Prinzip der Solidarität und des Gemeinwohls kann die Besteuerung nach der Leistungsfähigkeit abgeleitet werden. Aus dem Prinzip der Solidarität resultiert die gegenseitige Verantwortung von Individuum und Gesellschaft. Daraus ergibt sich die Pflicht des einzelnen, sich nach seinen Fähigkeiten für die Gesellschaft einzusetzen, und damit nach seinen Fähigkeiten Steuern zu zahlen. Der Leistungsfähigere hat somit mehr Steuern zu entrichten.

Die Besteuerung nach der individuellen Leistungsfähigkeit kann auch durch das Gemeinwohlprinzip begründet werden, da die Teilhabe am Gemeinwohl die Aufgabe beinhaltet, zu diesem beizutragen. Der Beitrag ist jedoch nicht für jeden gleich, sondern ist -wie die Teilhabe auch- nach den Verhältnissen des einzelnen zu bemessen. Darum erfordert die verteilende Gerechtigkeit, daß Leistungsfähigere einen höheren Beitrag zum Gemeinwohl leisten und eine höhere Steuer zahlen.

Die Besteuerung nach dem Leistungsfähigkeitsprinzip bedeutet aber nicht, da $\beta$ alles, was einen bestimmten Betrag übersteigt, wegzusteuern ist, da dies dem aus dem Prinzip der Personalität abgeleiteten Selbstbestimmungsrecht des Individuums widerspricht, nach dem die Person nicht der Gesellschaft untergeordnet ist, sondern ihr gleichberechtigt gegenübersteht. Dasselbe Ergebnis ergibt sich ebenso aus dem Gemeinwohlprinzip, das nicht gleiche, sondern lediglich menschenwürdige Lebensbedingungen für alle fordert. Hieraus kann die Bejahung eines unterschiedlichen Lebensstandards abgeleitet werden kann.

\subsection{Ergebnis: Philosophische Ableitung eines gerechten Besteuerungs- prinzips}

Im obigen Abschnitt wurde versucht, ein gerechtes Besteuerungsprinzip mit Hilfe von philosophischen bzw. theologischen Denkrichtungen zu finden. Dazu

Gebühren, Beiträge -also Entgelte für Dienstleistungen des Staates an den einzelnen Bürger- sind jedoch auch nach der katholischen Soziallehre nach dem Äquivalenzprinzip zu erheben. 
wurden diese Ansätze zuerst dargestellt und anschließend Aussagen zur Gestaltung eines Steuersystems abgeleitet.

Diese Denkrichtungen sehen die Besteuerung auch als eine Möglichkeit zur Umverteilung. Mit dem Äquivalenzprinzip kann Umverteilung im Sinne von Transferleistungen an Bedürftige bei den hier behandelten Gerechtigkeitsvorstellungen nur begründet werden, wenn von Vereinbarungen auf konstitutioneller Ebene ausgegangen, also der Ansatz von Rawls herangezogen wird. Nach den beiden anderen hier dargestellten Gerechtigkeitsvorstellungen ist das Äquivalenzprinzip zur Bemessung der individuellen Steuerlast abzulehnen. Die Kopfsteuer entspricht nicht den Gerechtigkeitsvorstellungen, da nach diesen die Steuerbelastung nach bestimmten Kriterien zu differenzieren ist ${ }^{l}$.

Das Leistungsfähigkeitsprinzip kann hingegen grundsätzlich aus allen behandelten Ansätzen abgeleitet werden. Im folgenden wird deshalb davon ausgegangen, $\mathrm{da} ß$ das Leistungsfähigkeitsprinzip als Gerechtigkeitsmaßstab für die Steuerlastverteilung zumindest mit den hier behandelten philosophischen bzw. theologischen Denkrichtungen zu vereinbaren ist, während die anderen Prinzipien der Steuerlastverteilung nicht als gerechte Maßstäbe zur Steuerlastverteilung herangezogen werden können.

\section{Juristische Ableitung eines gerechten Besteuerungsprinzips}

\subsection{Das Fundamentalprinzip der gerechten Besteuerung}

Bei der Kopfsteuer muß jedes Individuum denselben Betrag als Steuer entrichten. Dieses Prinzip zur Steuerlastverteilung verstößt damit gegen das Sozialstaatsprinzip, da hier bei den ärmeren Bevölkerungsschichten auch das Existenzminimum besteuert wird. Es richtet sich überdies gegen das demokratische Staats- und egalitäre Menschenbild des Grundgesetzes: das demokratische Prinzip fordert vom Staat, allen seinen Bürgern die gleichmäßige Beteiligung an den Aufgaben der Gemeinschaft zu ermöglichen ${ }^{2}$. Durch die Besteuerung darf niemand gehindert werden, sich am demokratischen Prozeß zu beteiligen. Diese Möglichkeit wird aber durch die Einführung einer absolut gleichen Kopfsteuer für die wirtschaftlich Schwachen eingeschränkt, da diese einen großen Teil ihrer Arbeitskraft dazu aufwenden müssen, um ihre Steuer entrichten zu können. Damit ist die Möglichkeit zur Mitwirkung am Gemeinwesen für die wirtschaftlich

\footnotetext{
$1 \quad$ Vgl. Neumark, F. (1970), S. 26 ff.; Tipke, K./Lang, J. (1991), S. 58 f.

2 Vgl. Isensee, J. (1977), S. 430.
} 
Schwächeren sehr viel schwerer möglich als für die wirtschaftlich Stärkeren ${ }^{I}$. Die Kopfsteuer muß somit aus juristischer Sicht als Steuerlastverteilungsmaßstab abgelehnt werden ${ }^{2}$.

Das Äquivalenzprinzip sieht Steuern als Gegenleistung für staatliche Leistungen an. Nach der deutschen Legaldefinition der Steuern ${ }^{3}$ gemäß § 3 (1) S. 1 AO sind Steuern jedoch Geldleistungen, "...die nicht eine Gegenleistung für eine besondere Leistung darstellen und von einem öffentlich-rechtlichen Gemeinwesen allen auferlegt werden, bei denen der Tatbestand zutrifft, an den das Gesetz die Leistungspflicht knüpft;...". Der Zweck der Steuer ist in der Erzielung von Einnahmen zu sehen, die zur allgemeinen Deckung des öffentlichen Finanzbedarfs dienen sollen. Das Äquivalenzprinzip ist daher im deutschen Recht für die Erhebung von Steuern nicht als Fundamentalprinzip anwendbar ${ }^{4}$.

Zur Beurteilung des Leistungsfähigkeitsprinzips wird zuerst auf die Weimarer Reichsverfassung eingegangen. Sie führte in Art. 134 aus: "Alle Staatsbürger ohne Unterschied tragen im Verhältnis ihrer Mittel zu allen öffentlichen Lasten nach Maßgabe der Gesetze bei.". Das Prinzip der Besteuerung nach der Leistungsfähigkeit wurde ausdrücklich in die Verfassung aufgenommen. Der Artikel sollte das Verbot von Steuerprivilegien bestimmen, hatte allerdings wegen seiner allgemein empfundenen Unbestimmtheit keine großen Auswirkungen ${ }^{5}$. Das heutige Grundgesetz enthält keine vergleichbaren Vorgaben an das Steuersystem $^{6}$. Die verfassungsrechtliche Verpflichtung zur Besteuerung nach der wirtschaftlichen Leistungsfähigkeit kann deshalb lediglich im Wege der Verfassungsauslegung abgeleitet werden. Als Ausgangspunkt dient dabei der Gleichheitssatz (Art. 3 GG); weiterhin sind die Bestimmungen der Finanzverfassung (Art. 104a ff. GG) sowie die Eigentumsgarantie (Art. 14 (1) GG), die Sozialbindung des Eigentums (Art. 14 (2) GG) und die Bestandsgarantie der Erwerbsquelle bei der Auslegung des Gleichheitssatzes heranzuziehen. Hieraus wird das verfassungsmäßige Gebot einer Besteuerung nach der individuellen Leistungsfähigkeit abgeleitet ${ }^{7}$.

\footnotetext{
Vgl. Birk, D. (1983), S. 131.

2 Vgl. Mohr, R. (1992), S. 31.

3 Vgl. Lang, J. (1988), S. $100 \mathrm{f}$.

4 Es wird allerdings im deutschen Recht dann angewandt, wenn die Höhe von Gebühren bzw. Beiträgen bestimmt werden soll, d.h. die Gegenleistung für eine "besondere staatliche Leistung" zu ermitteln ist (vgl. Lang, J. (1988), S. 100 f.).

$5 \quad$ Vgl. Bühler, O. (1930), S. $313 \mathrm{ff}$.

6 Zur Implementierung des Leistungsfähigkeitsprinzips in andere Verfassungen vgl. Tipke, K. (1993), S. 485 ff.

7 Vgl. hierzu (mit weiteren Literaturhinweisen) Kraft, C. (1991), S. 14 f.
} 
Nach der Rechtsprechung des Bundesverfassungsgerichts ${ }^{l}$ steht das Leistungsfähigkeitsprinzip in Zusammenhang mit dem Gleichheitssatz und der Steuergerechtigkeit ${ }^{2}$. Dies zeigt sich z.B. in folgender Urteilsbegründung: "Der Gleichheitssatz hat im Steuerrecht seine besondere Ausprägung in Form des Grundsatzes der Steuergerechtigkeit gefunden, wobei die Besteuerung -insbesondere im Einkommensteuerrecht- grundsätzlich an der wirtschaftlichen Leistungsfähigkeit auszurichten ist." ${ }^{3}$.

Der Bundesfinanzhof ${ }^{4}$ geht in seiner Rechtsprechung ebenfalls davon aus, daß die Steuerlast aufgrund des Leistungsfähigkeitsprinzips auf die Steuerpflichtigen aufzuteilen ist. Folglich betrachtet auch die Rechtsprechung das Leistungsfähigkeitsprinzip als grundsätzliche Wertaussage zum Gleichheitssatz.

Die Absicht, die Besteuerung nach der individuellen Leistungsfähigkeit zu gestalten, ergibt sich weiterhin aus den Materialien zur Gesetzgebung (z.B. Gesetzesbegründungen $)^{5}$.

In der steuerrechtlichen Literatur geht die herrschende Meinung ebenfalls vom Leistungsfähigkeitsprinzip als sachgerechtem Steuerverteilungsmaßstab aus; seine Stellung in der Rechtsordnung ist allerdings umstritten ${ }^{6,7}$.

Es gibt aber auch Gegner dieser Auffassung: Littmann bezeichnet das Leistungsfähigkeitsprinzip als einen im Laufe der Jahrhunderte von einer materiellen zu einer formellen Norm degenerierten Grundsatz, als einen inhaltsleeren Begriff, der in der aktuellen Diskussion den kleinsten gemeinsamen Nenner darstellt und beliebig interpretierbar ist. Die theoretischen Grundlagen, auf denen das Leistungsfähigkeitsprinzip seiner Ansicht nach basiert -nämlich die Opfertheorien- kollidieren -so sein Einwand- mit den neueren wissenschaftlichen Erkenntnissen und sind damit obsolet. Ebenfalls ablehnend ist Leisner ${ }^{8}$, nach dem das Leistungsfähigkeitsprinzip nichts anderes ist als die Legitimation des star-

1 Eine Übersicht über die Entwicklung in der Rechtsprechung des Bundesverfassungsgerichts gibt Martens (1987).

2 Vgl. Kruse, H.W. (1990), S. 327.

3 BVerfG v. 10.2.1987 -1BvL 18/81 und 20/82, BVerfGE 74, S. 182-202 (199 f.); vgl. weiterhin BVerfG v. 14.5.1986 -2 BvL 2/83, BVerfGE 72, S. 200-278 (260); BVerfG v. 3.11.1982 -1BvR 620/78,1335/78, 1104/79 und 363/80, BVerfGE 61, S. 319-357 (343 f.).

$4 \quad$ Vgl. BFH v. 6.7.1973, VI R 253/69, BFHE 110, S. 119-125 (122 f.).

$5 \quad$ Vgl. z.B. Deutscher Bundestag (1988a), S. 6-9.

6 Vgl. Birk, D. (1983), S. 50 ff.; Kruse, H.W. (1990); weitere Literaturquellen bei Kraft, C. (1991), S. 12 ff.

7 Vgl. Littmann, K. (1970), S. $113 \mathrm{ff}$.

8 Vgl. Leisner, W. (1983), S. 97 ff. 
ken Staates, den Bürgern soviel wegzunehmen, wie sie haben ${ }^{l}$. Er stellt die Frage zum Unterschied dieser Vorgehensweise zu den "jahrhundertealten Gewohnheiten der Straßenräuber, die ja auch nur dort nehmen, wo etwas zu finden ist."2. Trotz dieser Gegenmeinungen kann davon ausgegangen werden, daß in der Literatur das Leistungsfähigkeitsprinzip als Maßstab zur Steuerlastverteilung anerkannt wird.

Das Leistungsfähigkeitsprinzip stellt damit als Steuerlastverteilungsmaßstab im Steuerrecht ein anerkanntes Fundamentalprinzip dar. Dieses Prinzip ist durch den Gesetzgebungsproze $\beta$ demokratisch legitimiert und nach der allerdings umstrittenen Meinung von Tipke als Datum hinzunehmen ${ }^{3}$.

\subsection{Das Leistungsfähigkeitsprinzip im Verfassungskontext}

Das Leistungsfähigkeitsprinzip bildet den Ausgangspunkt der Steuergerechtigkeit in Deutschland und ist damit eine erste Konkretisierung des Gleichheitssatzes $^{4}$. Nach dem Gleichheitssatz soll wesentlich Gleiches gleich und Ungleiches ungleich behandelt werden. Fraglich ist dabei, was gleich und was ungleich ist und worin die Gleichbehandlung und die Ungleichbehandlung bestehen ${ }^{5}$. Das Bundesverfassungsgericht hat dem Gesetzgeber einen weiten Spielraum hinsichtlich der Ausgestaltung der Differenzierungskriterien eingeräumt; die gewählte Differenzierung muß allerdings auf sachgerechten Erwägungen (z.B. finanzpolitischen, volkswirtschaftlichen, sozialpolitischen oder steuertechnischen) basieren. Die Grenze liegt in einer willkürlichen Abgrenzung ${ }^{6}$; das Leistungsfähigkeitsprinzip kann somit als Willkürverbot bezeichnet werden ${ }^{7}$. Es ist als abstrakter Begriff auslegungsbedürftig; weitere Wertaussagen und Bezüge zu anderen Rechtsprinzipien sind notwendig, um als Vergleichsmaßstab dienen zu können. Die materielle Konkretisierung des Leistungsfähigkeitsprinzips ist dabei in einem Rechtsstaat an die Verfassung gebunden. Eine Verfassungsbestim-

I Vgl. hierzu auch die Ausführungen von Brennan, G./Buchanan, J.M. (1988) zur Leviathan-Theorie.

2 Leisner, W. (1983), S. 98.

3 Vgl. Tipke, K. (1976), S. 304 f.; A.A. Esser, J. (1964), S. 7, 11.

4 Vgl. Vogel, K. (1975), S. 411.

5 Vgl. Henkel, H. (1977), S. 395.

6 BVerfG v. 10.2.1987-1BvL 18/81 und 20/82, BVerfGE 74, S. 182-202 (200).

7 Die Festlegung von "sachgerechten" Differenzierungsmerkmalen hinsichtlich der gleichen Leistungsfähigkeit ist also innerhalb der oben aufgezeigten Grenzen dem Gesetzgeber und damit der Politik überlassen. 
mung ist danach immer nur im Zusammenhang mit anderen Vorschriften der Verfassung zu sehen ${ }^{l}$. Durch die Verbindung mit anderen Wertaussagen des Grundgesetzes erfährt das Leistungsfähigkeitsprinzip als Vergleichsmaßstab weitere grundsätzliche Konkretisierungen, innerhalb derer eindeutigere Wertaussagen zu einem "gerechten" Steuersystem gemacht werden können ${ }^{2}$. Die nähere Bestimmung des Leistungsfähigkeitsprinzips durch Rechtsgrundsätze, Unterprinzipien u.a. führt dazu, daß eine konkrete, rechtssystematisch folgerichtige Gestaltung des Steuerrechts möglich wird ${ }^{3}$. Dabei wird der Spielraum des Gesetzgebers durch die Konkretisierung immer enger, d.h. der Gesetzgeber ist dazu angehalten, einmal getroffene Wertungen konsequent wieder aufzunehmen und folgerichtig bei seinen weiteren Handlungen/Folgerungen zu verfahren. Damit müssen die weiteren Entscheidungen aus der Grundsatzentscheidung ableitbar $\operatorname{sein}^{4}$. Entschloß sich der Gesetzgeber für eine bestimmte Ausgestaltung des Leistungsfähigkeitsprinzips bei der Besteuerung, darf nicht willkürlich davon abgewichen werden, da sonst ein Systembruch vorliegt, der nur dann gerechtfertigt ist, wenn sachliche Gründe dafür vorliegen ${ }^{5}$. Nach Tipke/Lang muß die Durchbrechung des Prinzips weiterhin von ihrem Zweck her erforderlich, geeignet und verhältnismäßig sein ${ }^{6}$; eine beliebige Durchbrechung des gewählten Prinzips ist nicht zulässig. Die Durchbrechung muß überdies verfassungskonform sein: so können bereits aus Artikel 3 GG

("(2) Männer und Frauen sind gleichberechtigt. ... (3) Niemand darf wegen seines Geschlechtes, seiner Abstammung, seiner Rasse, seiner Sprache, seiner Heimat und Herkunft, seines Glaubens, seiner religiösen oder politischen Anschauungen benachteiligt oder bevorzugt werden.") Aussagen über die Gleichheit vor dem Steuergesetz getroffen werden ${ }^{7}$ : die Zugehörigkeit zu einer der oben genannten Gruppen ist kein Merkmal, das eine unterschiedliche Steuerlast bei gleicher wirtschaftlicher Leistungsfähigkeit rechtfertigt. Die hier genannten Kriterien sind aber keine Kriterien für die Konkretisierung der wirtschaftlichen Leistungsfähigkeit, sondern sind als steuerliche "Diskriminierungsverbote" aufzufassen $^{8}$. Die Art der Betätigung ist für die Höhe der wirtschaftlichen Leistungsfähigkeit ohne Belang; Belastungsunterschiede bei unterschiedlich zu-

Vgl. BVerfG v. 12.10.1951 -BvR 201/51, BVerfGE 1, S. 13-66 (32).

2 Vgl. Lang, J. (1988), S. 127.

3 Vgl. Lang, J. (1988), S. 131.

4 Vgl. hierzu die Ausführungen von Canaris, C.-W. (1983), insbesondere S. 16 ff.; Tipke, K. (1971), S. 6.

5 Vgl. BVerfG v. 7.11.1972, -1 BvR 338/68- BVerfGE 34, S. 103- 118 (115); Tipke, K. (1976), S. 305 f.; Canaris, C.-W. (1983), insbesondere S. 16 ff.

6 Vgl. Tipke, K./Lang, J. (1991), S. 51.

7 Vgl. Lang, J. (1988), S. 127.

8 Vgl. Kirchhof, P. (1992), S. 73. 
sammengesetzter, aber insgesamt doch gleich hohen Leistungsfähigkeit, führen zu einer verfassungsrechtlich bedenklichen Ungleichbehandlung ${ }^{l}$.

Gleichmäßigkeit der Besteuerung bedeutet auch die Allgemeinheit der Besteuerung: es gibt somit keine Privilegien bei der Besteuerung: alle Bürger sind steuerpflichtig ${ }^{2}$; auch sind keine bestimmten Einkünfte von der Besteuerung befreit. Dieses Universalitätsprinzip der Besteuerung ist geschichtlich auf die Abwehr der Steuerprivilegien von Monarchen, Fürsten u.a. zurückzuführen und schließt aus, daß Träger der staatlichen Macht von der Besteuerung befreit sind ${ }^{3}$.

Eine Verletzung dieses Grundsatzes beeinträchtigt die Gleichmäßigkeit der Besteuerung nach dem Leistungsfähigkeitsprinzip.

\subsubsection{Das Leistungsfähigkeitsprinzip und die Eigentums-/Erbrechtsgarantie}

Artikel 14 GG garantiert das Eigentum und das Erbrecht. Der Staat muß aber durch die Besteuerung in die Privatvermögenssphäre der Bürger eindringen, damit er finanziell handlungsfähig ist ${ }^{4}$. Aus Artikel $14 \mathrm{GG}$ kann deshalb nach der herrschenden Meinung kein Schutz des Vermögens gegen die Auferlegung von Steuern generell, sondern lediglich ein Schutz vor konfiskatorischen Steuern abgeleitet werden ${ }^{5}$. Ein Verstoß gegen die Eigentumsgewähr des Grundgesetzes liegt nach Auffassung des Bundesverfassungsgerichts erst dann vor, wenn die Steuerlasten die Steuerpflichtigen übermäßig belasten und ihre Vermögensverhältnisse dadurch grundlegend verändert würden ${ }^{6}$.

In der Literatur gibt es allerdings Meinungen, die eine übermäßige Belastung des Steuerpflichtigen und damit einen Verstoß gegen Artikel 14 GG schon dann annehmen, wenn der Finanzbedarf des Staates nicht erforderlich ist ${ }^{7}$. Die Erforderlichkeit des Finanzbedarfs und somit rechtsstaatlich unzulässige Vermögens-

\footnotetext{
I Vgl. Kirchhof, P. (1992), S. 73.

2 Vgl. Kruse, H.W. (1990), S. 322.

3 Vgl. Tipke, K./Lang, J. (1991), S. 47 f.

4 Vgl. Kirchhof, P. (1980), S. 366.

5 Vgl. BVerfG v. 20.7.1954 -1 BvR 459, 484, 548, 555, 623, 651, 748, 783, 801/52, 5, 9/53, 96, 114/54, BVerfGE 4, S. 7-27 (17); BVerfG v. 14.5.1968 -2 BvR 544/63, BVerfGE 23, S. 288-321 (314); BVerfG v. 17.7.1974, 1 BvR 51, 160, 285/69, 1 BvL $16,18,26 / 72$, BVerfGE 38, S. 61-102 (102).

6 Vgl. BVerfG v. 24.7.1962 - 2Bvl 15, 16/91, BVerfGE 14, S. 221-244 (241); BVerfG v. 9.3.1971, 2 BvR 326, 327,341,342, 343, 344, 345/69, BVerfGE 30, S. 250-272 (272); Lang, J. (1988), S. 156.

7 Vgl. Arnim, H.H.v. (1980), S. 366, Leitsatz 6.
} 
einbußen aufgrund der zu hohen Besteuerung lassen sich jedoch juristisch nur sehr schwer beweisen. Das gilt auch, da der Verfassungsgeber das Ausmaß des Sozialstaates offengelassen hat und für den Sozialstaat je nach konkreter Ausgestaltung ein unterschiedlich hoher Mittelbedarf notwendig ist ${ }^{l}$.

Der Eigentumsschutz des Grundgesetzes konkretisiert -so zumindest Lang- das Leistungsfähigkeitsprinzip somit zwar nicht quantitativ, aber doch qualitativ ${ }^{2}$ : er bietet weniger Schutz gegen die Höhe der Besteuerung als gegen die Kriterien der Steuerlastverteilung auf die Bürger: die Steuerlast ist auf die einzelnen Bürger so zu verteilen, daß "..die gerechte Verteilung der Steuerlasten nach der wirtschaftlichen Leistungsfähigkeit des einzelnen Bürgers der Eigentümerfreiheit möglichst wenig Nachteile zufügt." ${ }^{3}$.

\subsubsection{Das Leistungsfähigkeitsprinzip und die Sozialstaatlichkeit}

Deutschland ist ein sozialer Rechtsstaat; dieses Sozialstaatsprinzip ist in den Artikeln 20 (1) und 28 (1) S. 1 GG verankert. Danach wird der Gesetzgeber zur Schaffung einer gerechten Sozialordnung verpflichtet ${ }^{4}$. Er wird aber nicht zur Schaffung einer bestimmten Wirtschafts- oder Sozialordnung angehalten. Allerdings ist auch nicht jede denkbare Gestaltung der Sozialordnung möglich, da unter Umständen der Gleichheitssatz unzulässigerweise verletzt werden könnte ${ }^{5}$. Eine Verletzung des Gleichheitssatzes liegt nach Auffassung des Bundesverfassungsgerichtes dann nicht vor, "... wenn ein legitimes Unterscheidungskriterium vorhanden ist, so daß die besondere Behandlung der Geförderten einer am Gerechtigkeitsgedanken orientierten Betrachtungsweise entspricht. Dabei muß die verfassungsrechtliche Legitimität der Art und des Ausmaßes der Förderung, ihres Wirkungsbereiches und der dabei angewandten Mittel von Fall zu Fall geprüft werden;.." ${ }^{6}$. Das aus dem Sozialstaatsprinzip abgeleitete Gemeinwohlpostulat bietet darüberhinaus eine Rechtfertigung für eine steuerliche Ungleichbehandlung verschiedener Individuen/Sachverhalte ${ }^{7}$.

\footnotetext{
Vgl. Lang, J. (1988), S. 159.

Vgl. Lang, J. (1988), S. 159.

Vgl. Lang, J. (1988), S. 159.

4 Vgl. BVerfG. v. 18.7.1967 -2 BvF 3,4,5,6,7,8/62; 2 BvR 139, 140, 334, 335/62, BVerfGE 22, S. 180-220 (204); BVerfG v. 19.12.1978 -1 BvR 335, 427, 811/76, BVerfGE 50, S. 57-108 (108).

5 Vgl. BVerfG v. 17.5.1961 -1 BvR 561, 579/60, 114/61 BVerfGE 12, S. 354-369 (367).

6 BVerfG v. 17.5.1961 -1 BvR 561, 579/60, 114/61 BVerfGE 12, S. 354-369 (367).

7 Vgl. Selmer, P. (1972), S. 272 ff.
} 
Aus dem Sozialstaatsprinzip kann aber nicht das Ausmaß der Besteuerung verfassungsrechtlich abgeleitet werden, da der Verfassungsgeber keine Vorgabe hinsichtlich des Ausmaßes des Sozialstaates ${ }^{l}$ und somit auch keine Aussage über den dafür notwendigen Finanzbedarf gemacht hat ${ }^{2}$.

Es kann lediglich abgeleitet werden, daß die Verteilung der Steuerlasten nach der wirtschaftlichen Leistungsfähigkeit ein Prinzip der sozialen Gerechtigkeit ist $^{3}$. Die ausschließliche Ableitung des Leistungsfähigkeitsprinzips aus dem Sozialstaatsprinzip ist jedoch nicht sachgerecht, da das Leistungsfähigkeitsprinzip seine Wurzeln als Gerechtigkeitsmaßstab im Gleichheitssatz hat; das Sozialstaatsprinzip als Maßstab einer sozialen Gerechtigkeit kann aber als Verstärkung der Forderung nach einer Besteuerung gemäß der individuellen Leistungsfähigkeit angesehen werden ${ }^{4}$. Nur durch die Besteuerung kann die -wie auch immer definierte- soziale Gerechtigkeit nicht hergestellt werden, da die Bedürftigsten mit der geringsten wirtschaftlichen Leistungsfähigkeit ohnehin keine Steuern zahlen, stattdessen der Fürsorge durch die Gemeinschaft -z.B. durch Transfersbedürfen.

Es besteht aber auch die Gefahr, daß viele steuerliche Ungleichbehandlungen mit dem Sozialstaatsprinzip legitimiert werden ${ }^{5}$. Um dies zu vermeiden, ist das Zusammenwirken von Leistungsfähigkeits- und Sozialstaatsprinzip erforderlich, um die Dominanz des Sozialstaatsprinzips gegenüber dem Leistungsfähigkeitsprinzip zu vermeiden.

\subsubsection{Das Leistungsfähigkeitsprinzip und die Berufsfreiheit}

Die Besteuerung nach der wirtschaftlichen Leistungsfähigkeit gewährleistet auch eine berufsneutrale Besteuerung, d.h. kein Angehöriger einer bestimmten Berufsgruppe wird einer höheren steuerlichen Belastung unterworfen als die Allgemeinheit ${ }^{6}$.

Es ist allerdings zu berücksichtigen, daß das Grundrecht der freien Berufswahl und -ausübung lediglich als Maßstabsnorm für berufsregelnde Gesetze dient; Artikel 12 GG, der die Berufsfreiheit garantiert, kann deshalb nur gegen solche

I Vgl. BVerfG. v. 18.7.1967 -2 BvF 3,4,5,6,7,8/62; 2 BvR 139, 140, 334, 335/62, BVerfGE 22, S. 180-220 (204).

2 Vgl. Lang, J. (1988), S. 159.

3 Vgl. Ossenbühl, K.H. (1972).

$4 \quad$ Vgl. Lang, J. (1988), S. 165.

5 Die Besteuerung kann deshalb (zumindest in gewissem Umfang) zur Erreichung sozialpolitischer Ziele oder zur Verwirklichung einer sozialen Ideologie eingesetzt werden (vgl. Lang, J. (1988), S. 165).

Vgl. Lang, J. (1988), S. 162 f. 
Vorschriften angewendet werden, die bestimmte Berufe belasten, da dadurch das Steuergesetz mittelbar berufsregelnden Charakter erhält ${ }^{l}$. Nach Auffassung des Bundesverfassungsgerichts kann Artikel 12 (1) GG nur dann als Maßstab für steuerliche Vorschriften genutzt werden, wenn die steuerliche Regelung eine objektive Tendenz zur Regelung des von der Steuer betroffenen Berufs erkennen läßt ${ }^{2}$. Der Schutz von Artikel 12 (1) GG besteht hauptsächlich vor unverhältnismäßig hohen interventionistischen Steuern, die sich auf einen bestimmten Beruf erdrosselnd auswirken können ${ }^{3,4}$.

Gegen die Berufsfreiheit, die in Artikel 12 GG gewährleistet wird und gegen das Leistungsfähigkeitsprinzip verstößt also eine Besteuerung, die Angehörige bestimmter Berufsgruppen unverhältnismäßig höher belastet als andere (und dies nicht mit sehr gewichtigen Argumenten gerechtfertigt werden kann $)^{5}$.

\subsubsection{Das Leistungsfähigkeitsprinzip und der Grundsatz der Gesetzes- bestimmtheit}

Die rechtsstaatliche Konkretisierung einer Besteuerung nach dem Leistungsfähigkeitsprinzip steht unter dem Vorbehalt des Gesetzes (Artikel 2 (1) GG) ${ }^{6}$, da durch das Grundrecht auf freie Persönlichkeitsentfaltung dem Bürger das Grundrecht zugesichert wird, "...nur auf Grund solcher Rechtsvorschriften zu Steuern herangezogen [zu (Anmerkung des Verfassers)] werden, die formell und materiell der Verfassung gemäß sind und deshalb zur verfassungsmäßigen Ordnung gehören."7. Damit ist der Gesetzgeber an die Werte und an die Gerechtigkeitsvorstellungen des Grundgesetzes gebunden, innerhalb derer ein Steuersystem zu entwerfen ist ${ }^{8}$. Daraus kann weiterhin geschlossen werden, daß neben

\footnotetext{
$1 \quad$ Vgl. Lang, J. (1988), S. 162.

2 Vgl. BVerfG v. 30.10.1961 -1 BvR 833/59, BVerfGE 13, S. 181-204 (186); BVerfG v. 12.10.1976 -1 BvR 197/73, BVerfGE 42, S. 374-397 (384 ff.); BVerfG v. 11.10.1977 -1 BvR 343/73, 83/74, 183 und 428/75, BVerfGE 47, S. 1-33 (21).

3 Vgl. Selmer, P. (1972), S. 244 ff., 250 ff.; BVerfG v. 1.4.1971 -1 BvL 22/67, BVerfGE 31, S. 8-32 ( 32); BVerfG v. 15.10.1963 -1 BvL 29/56, BVerfGE 17, S. 135-139 (137).

4 Eine ausführliche Darstellung dieser Problematik und weitere Literaturhinweise finden sich bei Birk, D. (1983), S. 139.

5 Durch diese Form der Besteuerung würde auch die Entscheidung der Steuerpflichtigen hinsichtlich des zu ergreifenden Berufs beeinflußt, so daß ebenso ein Verstoß gegen die Forderung nach einer entscheidungsneutralen Besteuerung entstehen würde (siehe hierzu auch die im weiteren Verlauf der Arbeit aufgestellte Forderung nach einem entscheidungsneutralen Steuersystem).

$6 \quad$ Vgl. Lang, J. (1988), S. 131.

7 BVerfG v. 14.12.1965 - 1 BvR 413, 416/60, BVerfGE 19, S. 206-226 (215 f.).

$8 \quad$ Vgl. hierzu Stern, K. (1984), S. 788; Hesse, K. (1991), S. 78 ff.
} 
der Wahl eines gerechten Maßstabs zur Steuerlastverteilung die Transformation in Gesetze notwendig ist, da erst dies Gerechtigkeit gewährleistet ${ }^{l}$.

Diese Gesetze müssen dem in Artikel 20 (3) GG verankerten Rechtsstaatsprinzip (= rechtsstaatliche Rechtssicherheit) genügen ${ }^{2}$. Der Grundsatz der Rechtssicherheit umfaßt die Begriffe "Vertrauensschutz" und "Gesetzesbestimmtheit".

"Vertrauensschutz" heißt hierbei das Verbot rückwirkender Gesetzgebung, die Bestandskraft von Verwaltungsakten sowie die Rechtskraft gerichtlicher Entscheidungen; im wesentlichen soll dadurch eine verläßliche Anwendung bestehender Gesetze gewährleistet werden ${ }^{3}$. Der Begriff des "Vertrauensschutzes" wird nicht weiter verfolgt, da er für die Frage der Gestaltung der steuerlichen Bemessungsgrundlage ohne Bedeutung ist und überdies von einer im Zeitablauf gleichbleibenden Bemessungsgrundlage ausgegangen wird.

Das Prinzip der "Gesetzesbestimmtheit" zielt mehr auf die Gestaltung der Gesetze $a b$ und fordert, daß Eingriffe des Staates begrenzt und im voraus mit bestehenden Normen berechnet bzw. im nachhinein anhand klarer und eindeutiger Kontrollnormen nachvollzogen werden können (Kriterium der Meßbarkeit) ${ }^{4}$. Weiter müssen die Gesetze hinreichend klar formuliert sein, damit der Bürger sich ein Bild seiner Rechtslage machen kann ${ }^{5}$. Die Gesetzesbestimmtheit macht demnach intersubjektiv überprüfbare, klare und eindeutige Formulierungen von steuerbaren Tatbeständen notwendig ${ }^{6,7}$. Das Kriterium der intersubjektiven Überprüfbarkeit geht aber nicht so weit, eindeutig nachweisbare Tatsachen zu verlangen, vielmehr genügt die intersubjektive Ermittelbarkeit. Diesem rechtsstaatlichen Bestimmtheitserfordernis genügen auch auslegungsbedürftige

I Vgl. Kraft, C. (1991), S. 27; mit weiteren Literaturhinweisen Tipke, K. (1993), S. 150 ff.

2 Vgl. Herzog, R. (1992), RdNr. VII 25 zu Art 20 GG.

3 Vgl. (mit weiteren Nachweisen) Kraft, C. (1991), S. 28; Tipke, K. (1993), S. $177 \mathrm{ff}$.

4 Vgl. Herzog, R. (1992), RdNr. VII 57ff. zu Art 20 GG; BVerfG v. 23.10.1986 -2 BvL 7, 8/84- BVerfGE 73, S. 388-403 (400).

5 Vgl. z.B. BVerfG v. 5.8.1966 -1 BvF 1/61, BVerfGE 20, S. 150-162 (158 f.); BVerfG v. 14.5.1969 -2 BvR 238/68, BVerfGE 26, S. $41-44$ (42).

6 Vgl. Kraft, C. (1991), S. 28. Recht ist -um möglichst viele Konflikte zu vermeidenObjektivierungszwängen ausgesetzt. Das deutsche Steuerrecht knüpft deshalb nach $\$ 3$ AO nicht an die Zielrealisation des Steuerpflichtigen, sondern an die Verwirklichung von steuerrechtlich relevanten Vorgängen an. Besteuert werden hierbei die Einkünfte aus im Gesetz abschließend aufgeführten Einkommensarten. Zur Herstellung von Rechtssicherheit wird vom Steuerrecht in vielfältiger Weise auf Tatbestände des Zivilrechts Bezug genommen, das im Steuerrecht meist erfassungstechnische Aufgaben übernimmt.

7 Der Grundsatz der Gesetzesbestimmtheit wurde auch von Adam Smith in seine Besteuerungsgrundsätze aufgenommen (vgl. Smith, A. (1791), Vol. III, S. 255 ff.). 
Rechtsbegriffe und Generalklauseln, wenn dadurch Ermessensgrenzen abgesteckt und somit gerichtlich überprüfbar werden ${ }^{l}$.

Nachstehend wird dargestellt, in welchem Verhältnis die Prinzipien Leistungsfähig und Gesetzesbestimmtheit zueinander stehen. Dies ist notwendig, da sich Ziele indifferent, komplementär oder konkurrierend zueinander verhalten kön$n^{2}{ }^{2}$. Bei indifferenten Zielbeziehungen beeinflußt die Erfüllung des einen Ziels die des anderen nicht; bei komplementären Zielbeziehungen genügt es, ein Ziel zu verwirklichen, da mit der Verwirklichung des einen das andere ebenfalls erreicht wird. Konkurrierende Zielbeziehungen zeichnen sich dadurch aus, daß die Bessererfüllung des einen Ziels eine Schlechtererfüllung des anderen Ziels nach sich zieht.

Die "wirtschaftliche Leistungsfähigkeit" ist ein unbestimmter, nicht direkt meßbarer Begriff; auch seine möglichen Indikatoren sind -wie sich z.B. an der Vielzahl von Einkommensdefinitionen zeigt- nicht eindeutig bestimmt. A priori erfüllt dieser Begriff die oben aufgestellte Forderung der Gesetzesbestimmtheit nicht, vielmehr ist eine Konkretisierung des Begriffs, seiner Indikatoren sowie deren Ausgestaltung erforderlich. Es besteht hier somit zumindest in weiten Teilen eine konkurrierende Zielbeziehung mit dem Grundsatz der Gesetzesbestimmtheit, so daß beide Ziele bei der Empfehlung einer "gerechten" Steuerbemessungsgrundlage berücksichtigt werden müssen.

Dieser Zielkonflikt ist zu lösen³ dazu muß zuerst eine Rangfolge der konkurrierenden Ziele festgelegt werden.

Das Grundgesetz will nicht eine beliebige Art der Demokratie, sondern eine, in der die materiale Gerechtigkeit verwirklicht ist ${ }^{4}$. Dies zeigt sich z.B. in einem Urteil des Bundesverfassungsgerichts, nach dem gesetzliche Anordnungen nur dann als Recht gelten, wenn "...diese Qualität nicht lediglich dadurch erlangen, $\mathrm{da} ß$ sie von der staatlichen Macht im jeweils vorgesehenen Verfahren gesetzt sind, sondern sie darüber hinaus inhaltlich nicht fundamentalen Prinzipien der Idee der Gerechtigkeit widersprechen dürfen." ${ }^{5}$. Das primäre Ziel ist das der

I Vgl. Herzog, R. (1992), RdNr. VII 63 zu Art 20 GG; Schnapp, F.E. (1985), RdNr. 25 zu Art. 20 GG; BVerfG v. 16.1.1957 -1 BvR 253/56, BVerfGE 6, S.32-45 (42); BVerfG v. 5.8.1966 -1 BvF 1/61, BVerfGE 20, S. 150-162 (158); BVerfG v. 7.7.1971 -1 BvR 775/66, BVerfGE 31, S. 255-270 (264).

2 Vgl. hierzu Bamberg, G./Coenenberg, A. (1992), S. $46 \mathrm{ff}$.

3 Eine ausführliche Darstellung sowie weiterführende Hinweise auf die verschiedenen Lösungsmöglichkeiten von Zielkonflikten finden sich bei Kraft, C. (1991), S. $30 \mathrm{ff}$.

$4 \quad$ Vgl. Tipke, K./Lang, J. (1991), S. 25 ff., 46 ff.

5 BVerfG v. 15.4.1980 -2 BvR 842/77, BVerfGE 54, S. 53-74 (67f). 
Gleichbehandlung; das Prinzip der Gesetzesbestimmtheit ist eine -wenn auch wichtige- Nebenbedingung. Die zu erfüllende Zielfunktion ist deshalb die Verwirklichung der Besteuerung nach der individuellen Leistungsfähigkeit unter der Nebenbedingung der Gesetzesbestimmtheit. Das kann einen geringeren Zielerreichungsgrad des primären Zieles zur Folge haben ${ }^{l}$. Der Zielerreichungsgrad des primären Ziels hängt davon ab, welches Gewicht der Nebenbedingung beizumessen ist. Die Gewichtung der Ziele "Besteuerung nach der Leistungsfähigkeit" und "Gesetzesbestimmtheit" ist eine Wertung, die -in den Grenzen der Verfassung- dem Gesetzgeber obliegt ${ }^{2}$. Zu der reinen Verwirklichung des Leistungsfähigkeitsprinzips ist der Gesetzgeber durch die Verfassung nach Ansicht des Bundesverfassungsgerichts nicht gezwungen ${ }^{3}$.

\subsection{Grenzen des Leistungsfähigkeitsprinzips}

Im bisherigen Verlauf der Arbeit wurde festgestellt, daß aufgrund von Gerechtigkeitsüberlegungen grundlegender Maßstab der Steuerlastverteilung das Leistungsfähigkeitsprinzip ist. Bei der Umsetzung dieses Prinzips in ein Besteuerungssystem sind aufgrund von Gerechtigkeitsüberlegungen weitere Verfassungsgrundsätze sowie die aus dem Rechtsstaatsprinzip abgeleitete Forderung nach der Gesetzesbestimmtheit zu beachten.

Das Leistungsfähigkeitsprinzip stellt daher das Fundamentalprinzip der Besteuerung dar. Damit können aber lediglich Steuernormen legitimiert werden, die zur Verteilung der steuerlichen Lasten dienen; staatliche Lenkungsziele können nicht begründet werden ${ }^{4}$. Bei den Steuern bzw. den steuerlichen Vorschriften, die Lenkungsziele des Gesetzgebers verwirklichen wollen, sind andere Maßstäbe erforderlich ${ }^{5}$. Den Verstoß gegen das Leistungsfähigkeitsprinzip nimmt der Gesetzgeber dabei zur Erreichung seiner Lenkungsziele in Kauf. Die Durchbrechung des Lastenverteilungsmaßstabs bedarf aber einer verfassungsrechtlichen Rechtfertigung; es müssen somit sachgerechte Gründe für die Durchbrechung vorliegen ${ }^{6}$.

\footnotetext{
Vgl. Kraft, C. (1991), S. 34; Schlink, B. (1976), S. 143 ff.

Vgl. Kraft, C. (1991), S. 34; Schlink, B. (1976), S. 143 ff.

3 Vgl. BVerfG v. 2.10.1969-1 BvL 12/68, BVerfGE 27, S. 58-70 (68).

$4 \quad$ Vgl. Birk, D. (1983), S. 53; vgl. zu dieser Problematik auch Tipke, K. (1993), S. 361 ff.

$5 \quad$ Vgl. Vogel, K. (1977), S. 99.

6 Vgl. Birk, D. (1983), S. 164, 236 ff., bei dem sich eine ausführliche Darstellung mit weiterführenden Literaturhinweisen findet.
} 
Ein weiterer Grund für die Durchbrechung des Leistungsfähigkeitsprinzips durch den Gesetzgeber ist die Wahl eines anderen Bezugskriteriums bei der Verteilung der Steuerlasten. Hier wird zwar das Leistungsfähigkeitsprinzip durchbrochen, der die Verteilung der Steuerlast regelnde Gleichheitssatz aber nicht verletzt ${ }^{I}$. Als Beispiel kann die Bevorzugung von Ehepaaren gegenüber wilden Ehen dienen: das verheiratete Paar kommt in den Genuß des Ehegattensplittings, während das ohne Trauschein zusammen lebende Paar jeweils einzeln dem (höheren) Tarif der Grundtabelle unterworfen wird; dadurch ergibt sich eine unterschiedliche Steuerlast, obwohl beide Paare dieselbe wirtschaftliche Leistungsfähigkeit verkörpern ${ }^{2,3}$. Es erfolgen hier also Modifikationen bzw. Relativierungen des Leistungsfähigkeitsprinzips durch andere Verteilungsprinzipien, die durch ein anderes steuerliches Lastengleichheitsverständnis getragen werden (z.B. dem besonderen Schutz der Ehe und Familie).

Ungleichbehandlungen einzelner Steuerpflichtiger können sich auch durch Typisierungen ergeben. Da eine Steuernorm im allgemeinen an Massenvorgänge des Wirtschaftslebens anknüpft, ist es vielfach erforderlich, gewisse Typisierungen der steuerlichen Tatbestände vorzunehmen, um praktikabel zu sein. Der Gesetzgeber hat bei der Typisierung -nach Auffassung des Bundesverfassungsgerichtsweitgehende Gestaltungsfreiheiten ${ }^{4}$. Dabei können nach Auffassung des Bundesverfassungsgerichts in weitem Umfang die Besonderheiten sowohl des Einzelfalles als auch ganzer Fallgruppen vom Gesetzgeber vernachlässigt werden ${ }^{5}$. Artikel 3 GG wird nach der Auffassung des Bundesverfassungsgerichtes nur dann verletzt, wenn tatsächliche Unterschiede nicht berücksichtigt werden, die so gravierend sind, "...daß sie bei einer am Gerechtigkeitsgedanken orientierten Betrachtungsweise beachtet werden müssen." .

\section{Ergebnis: Gerechtigkeitserwägungen als Grundprinzip der Besteuerung}

Von den drei angesprochenen Prinzipien der Steuerlastverteilung (Kopfsteuer, Äquivalenz- und Leistungsfähigkeitsprinzip) kann lediglich das Leistungsfähigkeitsprinzip aus allen hier betrachteten philosophischen und theologischen

Vgl. Birk, D. (1983), S. 164.

2 Die Rechtfertigung dieses Sachverhaltes erfolgt über Artikel 6 GG.

3 Vgl. Birk, D. (1983), S. 164, $172 \mathrm{ff}$.

4 Vgl. BVerfG v. 1.7.1964 - 1 BvR 375/62, BVerfGE 18, S. 121-133 (124).

5 Vgl. BVerfG v. 10.6.1969 -2 BvR 480/61, BVerfGE 26, S. 172-186 (185).

6 BVerfG v. 19.3.1968 -1 BvR 554/65, BVerfGE 23, S. 229-241 (240); vgl. ebenso BVerfG v. 1.7.1964 - 1BvR 375/62, BVerfGE 18, S. 121-133 (124). 
Denkrichtungen abgeleitet werden; die Besteuerung nach dem Äquivalenzprinzip läßt sich lediglich aus dem Ansatz von Rawls ableiten.

Das Leistungsfähigkeitsprinzip wird überdies auch von Gesetzgebung, Rechtsprechung und Literatur als Fundamentalprinzip der Besteuerung angesehen, das hilft, den Gleichheitssatz zu verwirklichen. Es entspricht somit dem gegenwärtigen Gerechtigkeitsverständnis.

Es ist aber zu beachten, daß das Leistungsfähigkeitsprinzip lediglich in Verbindung mit anderen Grundwertungen im Grundgesetz gesehen werden kann, durch die es konkretisiert wird bzw. die dem Gesetzgeber ein Abweichen vom Leistungsfähigkeitsprinzip gestatten oder sogar gebieten.

Eine das Leistungsfähigkeitsprinzip einschränkende Grundwertung ist der besondere Schutz von Ehe und Familie. Es wurde weiterhin festgestellt, daß die Besteuerung nach dem Leistungsfähigkeitsprinzip meist nicht dazu geeignet ist, Lenkungsziele des Gesetzgebers zu verwirklichen; um diese Ziele zu erreichen, muß oft gegen dieses Prinzip verstoßen werden.

Problematisch ist hierbei, ob die Durchbrechung des Leistungsfähigkeitsprinzips gerechtfertigt ist oder nicht.

Der Verfasser kann als Ökonom nicht beurteilen, ob die später zu untersuchenden Steuersysteme dem juristischen Anspruch einer gerechten Besteuerung genügen, ob also ein Abweichen vom Leistungsfähigkeitsprinzip in dem betrachteten Fall dem Gesetzgeber erlaubt oder sogar geboten ist; es soll stattdessen im weiteren Verlauf der Arbeit geprüft werden, ob der durch das Leistungsfähigkeitsprinzip konkretisierte Gleichheitssatz materiell, d.h. ökonomisch verwirklicht wird. Dabei wird auf quantifizierbare Kriterien zurückgegriffen. 
Michael Ohmer - 978-3-631-75563-1

Downloaded from PubFactory at 01/11/2019 03:31:45AM

via free access 


\section{Kapitel}

\section{Effizienz als Grundprinzip der Besteuerung}

Steuern stellen für Individuen eine Belastung dar. Neben der eigentlichen Steuerlast können noch weitere Belastungen der Steuerbürger auftreten. Diese können aus dem Einfluß des Steuersystems auf die Ressourcenallokation in einer Wirtschaft, also der Effizienz im ökonomischen Sinne sowie aus seiner Praktikabilität resultieren.

\section{1. Ökonomische Effizienz als Forderung an ein Steuersystem}

\subsection{Begriffsklärung und Begründung eines effizienten Steuersystems}

Die Individuen beurteilen die Steuerwirkungen als ökonomische Vor- oder Nachteile. Im folgenden wird davon ausgegangen, daß die Individuen als Ziel ihres Wirtschaftens die Maximierung des von ihnen konsumierbaren Betrages nach Steuern anstreben. Dabei werden die Steuern als negative Zielgröße betrachtet.

Werden Handlungsalternativen durch die Besteuerung unterschiedlich belastet, ist es lohnend, eine Steuervermeidungsplanung zu betreiben, um die günstigsten Alternativen herauszufinden. Dies verursacht Planungskosten, da mögliche Alternativen auch auf ihre steuerliche Auswirkung hin untersucht werden müssen ${ }^{l}$. Als Ergebnis dieser Untersuchungen ergibt sich möglicherweise eine andere Rangfolge der Vorteilhaftigkeit von verschiedenen Alternativen.

Beeinflußt nun die andere Rangfolge der Handlungsalternativen die gesamtwirtschaftliche Effizienz der Ressourcenallokation?

Dazu wird als Beispiel zuerst eine Kopfsteuer und anschließend eine Konsumsteuer auf ein Konsumgut betrachtet.

\footnotetext{
1 Durch diese Steuervermeidungsplanung der Individuen können politisch gewünschte Lenkungsabsichten der politischen Entscheidungsinstanzen erreicht werden (ein Beispiel im deutschen Steuerrecht waren hierfür die erhöhten Abschreibungen für dem Umweltschutz dienende Wirtschaftsgüter gemäß §7d EStG). Die Steuervermeidungsplanung der Individuen wird aber auch dann ausgelöst, wenn das Steuerrecht -fern jeder Lenkungsabsicht- Bestimmungen enthält, die verschiedene Handlungsalternativen unterschiedlich behandeln.
} 


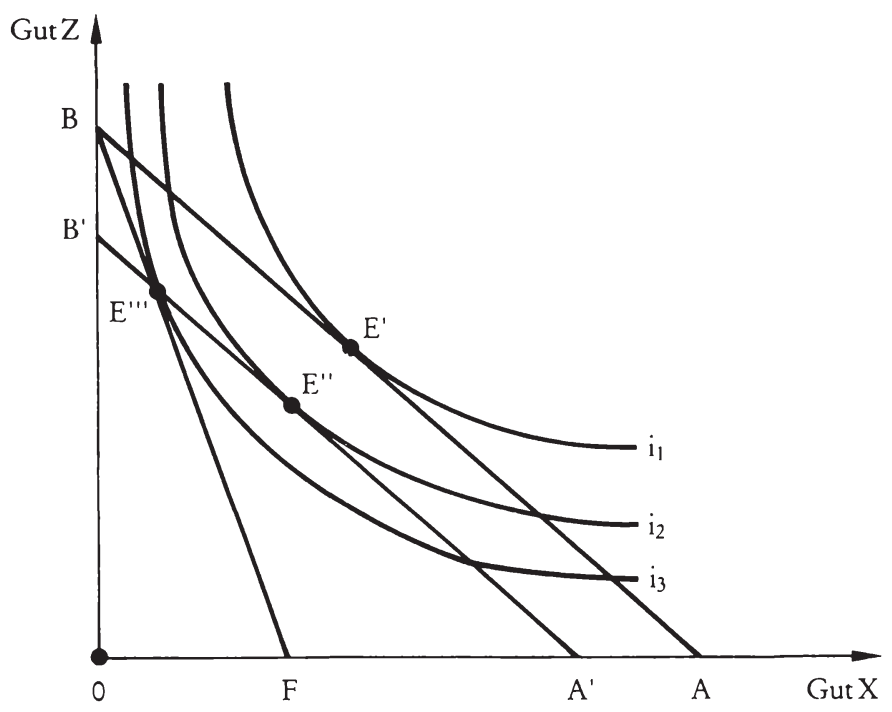

In der Graphik ${ }^{l}$ bezeichnen $\mathrm{X}$ und $\mathrm{Z}$ Konsumgüter.

Wird eine Kopfsteuer erhoben, verschiebt sich die Budgetgerade des Konsumenten nach innen (von $\mathrm{AB}$ nach $\mathrm{A}^{\prime} \mathrm{B}^{\prime}$ ): das Konsumgleichgewicht liegt auf $\mathrm{E}^{\prime \prime}$. Dieser Effekt wird Einkommenseffekt genannt. Durch ihn besteht c.p. eine Nutzeneinbuße bei den Individuen, da sich $E^{\prime}$ auf einer niedrigeren Indifferenzkurve befindet. Entsprach vor der Steuererhebung der Grenzrate der Substitution zwischen $\mathrm{X}$ und $\mathrm{Z}$ der Grenzrate der Transformation und dem Preisverhältnis $\frac{\mathrm{P}_{\mathrm{X}}}{\mathrm{P}_{\mathrm{Z}}}$, gilt diese Gleichheit auch nach der Steuererhebung, d.h. die Ressourcenallokation hat sich -relativ gesehen- nicht geändert.

Wird statt der Kopfsteuer eine Steuer auf Gut X erhoben (Gut Z bleibt unbesteuert), muß -damit das gleiche Steueraufkommen wie bei der Kopfsteuer erzielt wird- die Budgetgerade von Punkt B aus solange nach innen geschwenkt werden, bis ein Tangentialpunkt zwischen der neuen Budgetgerade und einer Indifferenzkurve gefunden wird, der auf A'B' liegt. Dieser Punkt E" liegt aber auf einer tieferen Indifferenzkurve als E'. Die Wohlfahrt des Individuums wird folglich durch diese Steuer mehr gemindert als durch die Kopfsteuer. Es liegt hier sowohl ein Einkommens- als auch ein Substitutionseffekt vor: der Einkommenseffekt verringert das dem Individuum zur Verfügung stehende Budget, während der Substitutionseffekt durch das veränderte Preisverhältnis zwischen $\mathrm{X}$ und Z hervorgerufen wird; das Verhältnis der konsumierten Güter hat sich geändert.

Vgl. Blankart, C.B. (1991), S. 185. 
Die Grenzrate der Substitution, die für die Nachfrager relevant ist, hat sich von $\frac{P_{x}}{P_{z}}$ auf $\frac{(1+\tau) * P_{x}}{P_{z}}$ verändert und entspricht jetzt nicht mehr der für die Anbieter relevanten Grenzrate der Transformation $\left(\frac{P_{x}}{P_{z}}\right)$. Dadurch wird eine geringere Menge von $\mathrm{X}$, aber eine größere Menge von $\mathrm{Z}$ konsumiert; die Konsumentscheidung wird somit durch diese Art der Besteuerung im Vergleich zu einer steuerfreien Ökonomie verzerrt.

Aufgrund dieser Entscheidungsverzerrung entstehen bei den Bürgern zusätzlich zu den abzuführenden Steuern (Einkommenseffekt) weitere Belastungen durch die Besteuerung (Substitutionseffekt), die allokativ unnötig sind, da sie durch eine andere Wahl der Steuerbemessungsgrundlage verhindert werden können.

Bei der nachfolgenden Analyse dient zur Beurteilung eines Steuersystems bzw. einzelner steuerlicher Vorschriften eine Laissez-Faire-Ökonomie ${ }^{l}$. Fraglich ist dann, ob die in einer Laissez-Faire-Ökonomie vorherrschende (effiziente) Ressourcenallokation beeinträchtigt wird und damit die Entscheidungen der Individuen verzerrt werden.

Hierzu werden folgende Annahmen getroffen²:

- In der betrachteten Modellwelt sind sämtliche Märkte vollkommen und keiner der Marktpartner hat Präferenzen für einen anderen Marktteilnehmer; es gibt keine ausbeuterisch einsetzbare Marktmacht und alle Akteure haben vollkommene Voraussicht. Es treten darüberhinaus weder externe Effekte durch die Produktion noch durch den Konsum auf; ebensowenig gibt es institutionelle Schranken für die Marktteilnehmer. Somit herrscht in der betrachteten Modellökonomie eine vollkommene Konkurrenz, die für eine pareto-optimale Ressourcenallokation sorgt und bei der vorausgesetzten optimalen Staatstätigkeit auf der Ausgabenseite auch insgesamt Effizienz sichert.

- Laissez-Faire-Ökonomie bedeutet aber nicht, daß der Vergleich mit einer staats- und steuerfreien Ökonomie erfolgt; es wird hier eine Wirtschaft angenommen, bei der die Bereitstellung von öffentlichen Gütern optimal dimensioniert und strukturiert ist. Die Finanzierung erfolgt durch eine Pauschalsteuer (z.B. eine Kopfsteuer), die unabhängig vom Verhalten der Individuen ist und der sie sich nicht entziehen können. Es tritt somit lediglich der Einkommenseffekt, aber kein Substitutionseffekt auf.

1 Die Wohlfahrtsökonomie geht davon aus, daß bei funktionierenden Märkten das gesamtwirtschaftliche Optimum durch eine Laissez-Faire-Allokation zustande kommt.

2 Vgl. Nachtkamp, H.H. (1988), S. 166 f. 
Unmittelbar vor der Analyse erfolgt eine Steuerreform dahingehend, daß die zu analysierenden Steuern eingeführt werden und dadurch die bisherige Pauschalsteuer aufkommensneutral ersetzt wird. Die Steuerzahllast der Bürger bleibt dadurch insgesamt gleich. Es treten somit keine Einkommenseffekte auf. Weiterhin werden durch die Steuerreform weder Änderungen der Kollektivgutproduktion erzwungen, noch muß die Verschuldungspolitik des Staates geändert werden.

Ein entscheidungsneutrales Steuersystem bedeutet nun, daß steuerliche Vorschriften des analysierten Steuersystems die Entscheidung eines Individuums im Vergleich zu einer Laissez-Faire-Ökonomie nicht verzerren ${ }^{l}$. Die vorteilhafteste Handlungsalternative in einer Laissez-Faire-Ökonomie ist auch in einer Welt mit einem neutralen Steuersystem am vorteilhaftesten. Durch eine neutrale Besteuerung wird die Rangfolge der Alternativen nicht verändert. Damit treten Wohlfahrtsminderungen aufgrund des Substitutionseffekts nicht auf und die Effizienz der Ressourcenallokation wird nicht beeinträchtigt.

Der Forderung nach einem neutralen Steuersystem liegt keine besondere steuerliche Zielvorstellung zugrunde; sie tritt stattdessen akzessorisch zu den Mechanismen der marktwirtschaftlichen Ordnung ${ }^{2}$ und kommt deshalb ohne besondere steuerliche Gerechtigkeitsvorstellungen aus. Ihr Ziel ist, einen durch steuerliche Vorschriften unbeeinflußten Marktmechanismus zu erhalten; sie entspricht damit einer marktwirtschaftlichen Grundüberzeugung.

Es gibt allerdings auch Meinungen, die das Ziel einer neutralen Besteuerung für fragwürdig halten ${ }^{3}$. Als Argument wird beispielsweise angeführt, daß die Laissez-Faire-Allokation zu einem Optimum führt, das nicht unbedingt erhalten werden sollte ${ }^{4}$. Zu Fehlallokationen kann es in einer Laissez-Faire-Welt immer dann kommen, wenn Marktversagen vorliegt. Eine neutrale Besteuerung würde dieses Marktversagen konservieren ${ }^{5}$. Dies ist allerdings kein gewichtiges Argument gegen die Forderung einer neutralen Besteuerung. Finanzpolitische Lenkungsabsichten und Korrekturen von Fehlallokationen, die durch Marktversagen entstanden sind, können in einem neutralen Steuersystem weiterhin verwirklicht werden, da auch hier Lenkungssteuern implementiert werden können. Sie müssen allerdings durch eine politische Willensentscheidung legitimiert werden. Die Folgen dieser Lenkungseingriffe können überdies leichter in ihrer Wirkung dosiert, abgeschätzt und überblickt werden, da keine die gewollte Lenkungsabsicht

\footnotetext{
$1 \quad$ Vgl. Nachtkamp, H.H. (1988), S. 167.

2 Vgl. Wagner, F. W. (1992), S. 4.

3 Vgl. Schneider, D. (1990), S. 171; Faltlhauser, K. (1988), S. 247 f.

$4 \quad$ Vgl. Schneider, D. (1990), S. 171.

5 Vgl. Schwinger, R. (1992), S. 15.
} 
verstärkende oder abschwächende Wirkungen des neutralen "Grund-" Steuersystems vorhanden sind. Bei einem nicht-neutralen-Steuersystem sind überdies vielfach schon Eingriffe notwendig, um unerwünschten Effekten dieser systembedingten Nicht-Neutralität entgegenzusteuern. Die Forderung nach einem neutralen Steuersystem kann ebenfalls als Maßstab dienen, um diese durch einzelne Steuerrechtsbestimmungen hervorgerufenen Substitutionseffekte erkennen und analysieren zu können ${ }^{l}$.

Im weiteren Verlauf der Arbeit wird deshalb ein neutrales Steuersystem gefordert; dies kann -zusammenfassend- sowohl gesamt- als auch einzelwirtschaftlich begründet werden ${ }^{2}$ :

- Gesamtwirtschaftlich betrachtet, verursachen die einzelwirtschaftlichen Anpassungshandlungen zur Steuervermeidung durch die Wahl einer in einer Laissez-Faire-Ökonomie nur suboptimalen Alternative gesellschaftliche Kosten, da die in einer Laissez-Faire-Ökonomie gewährleistete optimale Ressourcenallokation nicht mehr stattfindet und somit gesamtwirtschaftliche Wohlfahrtsverluste entstehen.

- Die gesamtwirtschaftliche Optimalität eines neutralen Steuersystems hat einzelwirtschaftlich zur Folge, daß bei den Individuen keine Aufwendungen für die steuerliche Planung und Beratung anfallen, da steuerliche Entscheidungsvariablen nicht zu ermitteln sind und die übrigen nichtsteuerlichen Entscheidungsvariablen ohnehin im Entscheidungsprozeß ermittelt werden müssen ${ }^{3}$. Somit verringert sich die Summe der durch die Besteuerung verursachten Aufwendungen. Dem Unternehmen steht damit ein höherer Betrag für Ausschüttungen an die Unternehmenseigner zur Verfügung.

Bei den Individuen entstehen bei einem neutralen Steuersystem lediglich Kosten für die Erfüllung ihrer steuerlichen Deklarationspflichten.

Die Verwirklichung der Forderung nach einem neutralen Steuersystem hat -zusammenfassend gesagt- zur Konsequenz, daß für den Entscheidungsträger die Rangfolge (also die Abstufung in der Vorteilhaftigkeit) verschiedener Alternativen in einer Laissez-Faire-Ökonomie und bei der analysierten Besteuerungskonzeption gleich ist.

I Vgl. Nachtkamp, H.H. (1986), S. 188.

2 Vgl. Wagner, F. W. (1989), S. 264 f.; Wagner, F. W. (1992), S. 4.

3 Es ist hierzu allerdings erforderlich, daß die Tatsache des neutralen Steuersystems den Steuerzahlern bekannt ist. 


\subsection{Entscheidungsregeln in einer Laissez-Faire-Ökonomie}

Im Rahmen dieser Arbeit wird auch der Einfluß der Besteuerung auf die Entscheidungen der Individuen und Unternehmen für verschiedene Steuerbemessungsgrundlagen untersucht. Zur Erleichterung der späteren Analyse werden einige Entscheidungsregeln in einer Laissez-Faire-Ökonomie dargestellt.

Dazu wird auf folgende Fragestellungen eingegangen:

- Konsum-Spar-Entscheidung der Individuen

- Investitionsentscheidung der Unternehmen

- Einfluß auf das Wirtschaftswachstum

- Finanzierungsentscheidung der Unternehmen

- Rechtsform der Unternehmen

\subsubsection{Konsum-Spar-Entscheidung der Individuen ${ }^{I}$}

Die Vermögensbildung eines Individuums ist in einer Laissez-Faire-Ökonomie davon abhängig, ob der heutige Konsumverzicht durch einen zukünftigen Mehrkonsum kompensiert wird, d.h. wie sich die Versorgungslage des Individuums aufgrund des momentanen Konsumverzichts zugunsten des zukünftigen Mehrkonsums verändert.

Zur Analyse dieser Überlegung wird eine Marginalbetrachtung durchgeführt:

- $\mathrm{dC}_{\mathrm{G}}\left(\mathrm{dC}_{\mathrm{G}}<0\right)$ bezeichnet den marginalen Rückgang des gegenwärtigen Konsums zugunsten des Sparens,

- $\mathrm{dC}_{\mathrm{z}}\left(\mathrm{dC}_{\mathrm{z}}>0\right)$ ist die marginale Zunahme des zukünftigen Konsums durch die gegenwärtige Ersparnis einschließlich der anfallenden Zinsen.

Die Entscheidung des Individuums ist abhängig vom Marktzinssatz. Ist der Kapitaldienst (Tilgung und Nettoverzinsung) der letzten am Kapitalmarkt eingesetzten Geldeinheit höher, als das, was gebraucht wird, um den gegenwärtigen Konsumverzicht durch zukünftigen Mehrkonsum zu kompensieren, kann die intertemporale Versorgungslage durch gegenwärtigen Konsumverzicht erhöht werden.

Dieser Sachverhalt kann durch den Vergleich der Grenzrate der Substitution mit dem Marktzinssatz r dargestellt werden:

Vgl. Nachtkamp, H.H. (1988), S. 169 f. 
(1) $\frac{-\mathrm{dC}_{2}}{\mathrm{dC}_{\mathrm{G}}}<1+\mathrm{r}$.

Die Konsum-/Sparpläne des Individuums sind optimiert bei

$$
\frac{-\mathrm{dC}_{\mathrm{z}}}{\mathrm{dC}_{\mathrm{G}}}=1+\mathrm{r},
$$

da durch einen weiteren gegenwärtigen Konsumverzicht keine Verbesserung der Versorgungslage erreicht wird.

Dieser Sachverhalt kann auch wie folgt dargestellt werden:

$$
\mathrm{dC}_{\mathrm{z}}=-\mathrm{dC}_{\mathrm{G}}+\Gamma
$$

$\Gamma$ bezeichnet hierbei das Mehr an zukünftigem Konsum, das erforderlich ist, um den gegenwärtigen Konsumverzicht auszugleichen.

Für die Grenzrate der Substitution ergibt sich folgendes:

(2) $\frac{-\mathrm{dC}_{\mathrm{z}}}{\mathrm{dC}_{\mathrm{G}}}=\frac{-\mathrm{dC}_{\mathrm{G}}+\Gamma}{-\mathrm{dC}_{\mathrm{G}}}=1+\gamma$,

wobei $\gamma$ den persönlichen Zinssatz (= Zeitpräferenzrate) darstellt, mit dem der marginale Konsumverzicht zu verzinsen ist, damit das Individuum in seiner Konsum-/Sparfunktion indifferent ist.

Werden die Überlegungen aus (1) und (2) zusammengefaßt, ergibt sich:

$$
\gamma=\mathrm{r} \text {. }
$$

Die individuelle Zeitpräferenzrate des Individuums entspricht folglich dem Marktzinssatz. Bei Gültigkeit dieser Beziehung optimiert das Individuum somit seine intertemporale Konsumentscheidung. 


\subsubsection{Investitionsentscheidung der Unternehmen ${ }^{I}$}

Die Unternehmensleitung ist bestrebt -so der Ausgangspunkt der Überlegung-, den Marktwert des Unternehmens zu maximieren. Der Marktwert des Unternehmens ist die Summe aller künftigen, auf den Gegenwartszeitpunkt abdiskontierten Nettoauszahlungen (Nettoentnahmen bzw. Nettoausschüttungen) an die Anteilseigner. Weiterhin wird davon ausgegangen, daß die letzte Investition der Unternehmung mit Fremdkapital durchgeführt wird. Dies ist zumindest nicht schlechter als die Durchführung der Investition mittels Beteiligungs- oder Eigenfinanzierung, da eine Sachinvestition einen Verzicht auf eine alternative Finanzinvestition am Kapitalmarkt darstellt ${ }^{2}$.

Erhöht die Unternehmung ihren Kapitalstock marginal, hat sie zukünftig höhere Erträge in Höhe der Bruttogrenzproduktivität der Investition. Um den nun allerdings höheren Kapitalstock wertmäßig erhalten zu können, sind im Vergleich zu der Situation ohne Neuinvestition zusätzliche Ersatzinvestitionen in Höhe des Werteverzehrs der Neuinvestition fällig. Damit ist die Nettogrenzproduktivität $\left(f_{k}\right)$ der marginalen Investition die Bruttogrenzproduktivität abzüglich der zur Erhaltung des nun höheren Kapitalstocks notwendigen Ersatzinvestition.

Diesen höheren Erträgen aus der Marginalinvestition stehen die Aufwendungen für die Fremdkapitalaufwendungen in Höhe des Nettozinssatzes gegenüber.

In einer Laissez-Faire-Ökonomie optimiert ein Unternehmen seinen Investitionsplan, wenn für die Grenzinvestition gilt:

$$
f_{k}=r \text {, }
$$

also die Nettogrenzproduktivität dem Marktzinssatz ${ }^{3}$ entspricht.

Der Einfluß der zu analysierenden Besteuerungskonzeption auf die Investitionsentscheidung der Unternehmen wird durch den Vergleich des Entscheidungskriteriums ausgedrückt: bei einem neutralen Steuersystem erfolgt die Entscheidung anhand der gleichen Marginalbedingung wie in einer Laissez-Faire-Ökonomie. Ein Steuersystem ist demzufolge investitionsneutral, wenn die Kosten der Kapitalnutzung nach Einführung des zu analysierenden Besteuerungssystems genauso hoch sind wie in einer Laissez-Faire-Ökonomie.

\footnotetext{
1 Vgl. Sinn, H.-W. (1985), S. 25.

2 Vgl. Sinn, H.-W. (1984), S. 555.

$3 \mathrm{Da}$ in der vorliegenden Untersuchung von Inflationseinflüssen abgesehen wird, entspricht der Marktzinssatz dem Nettomarktzinssatz.
} 


\subsubsection{Exkurs: Einfluß auf das Wirtschaftswachstum}

In einer Laissez-Faire-Ökonomie sorgt der Kapitalmarkt für die Übereinstimmung der subjektiven Zeitpräferenzrate der Individuen $\gamma$ und Nettogrenzproduktivität $f_{k}\left(\gamma=r=f_{k}\right)$. Der marginale Konsumverzicht der Individuen, der gespart und somit als Investition in den Kapitalstock der Unternehmen eingeht, erbringt im investierenden Unternehmen gerade denjenigen Betrag, den die Individuen für ihren Konsumverzicht fordern.

Wachstumsneutralität (= intertemporale Neutralität) des Steuersystems liegt vor, wenn die Anpassung des Kapitalstocks an die intertemporalen Konsumpräferenzen der Individuen in einer Laissez-Faire-Ökonomie und bei der untersuchten Besteuerungskonzeption nach derselben Marginalbedingung vorgenommen wird $^{l}$ :

Ist diese Bedingung nicht erfüllt, ergeben sich bei den üblichen neoklassischen Annahmen über die Produktionsfunktion aufgrund der Besteuerung folgende zwei Verzerrungen im Vergleich zu einer Laissez-Faire-Ökonomie ${ }^{2}$ :

- Das Niveau der Kapitalakkumulation ist nicht optimal.

- Die Grenzproduktivität des Faktors "Arbeit" nimmt einen anderen Wert als im Optimum an; das hat entweder Einfluß auf den Preis der Arbeit (= Lohn) oder den Umfang der Beschäftigung.

\subsubsection{Finanzierungsentscheidung der Unternehmen ${ }^{3}$}

Ein Unternehmen hat zur Finanzierung seiner Nettoinvestitionen drei Möglichkeiten: es kann erstens seine Fremdkapitalaufnahme erhöhen, zweitens einen geringeren Gewinn ausschütten (und den einbehaltenen Gewinn thesaurieren) oder drittens das Beteiligungskapital (= gezeichnetes Kapital bzw. Stammkapital) erhöhen.

Zur Untersuchung der Finanzierungsneutralität wird ein Arbitragemodell herangezogen: die Unternehmung hat einen festgelegten Investitionsplan; sie überlegt

\footnotetext{
1 Vgl. Wenger, E. (1989), S. 183.

2 Vgl. Nachtkamp, H.H. (1988), S. 171.

3 Vgl. Sinn, H.-W.(1984a), S. 232 ff., Nachtkamp, H.H. (1989), S. 117.
} 
nun, ob sie durch eine marginale Änderung der Finanzierungsstruktur einen repräsentativen Eigentümer besser stellen kann $^{l}$.

\subsubsection{Beteiligungsfinanzierung versus Selbstfinanzierung}

Erhöht das Unternehmen die Beteiligungsfinanzierung zu Lasten der Selbstfinanzierung, schüttet es $1 \mathrm{GE}$ mehr an Gewinn an seine Anteilseigner aus, die -um die Kapitalausstattung des Unternehmens unverändert zu lassen- ihre Beteiligung um 1 GE erhöhen.

In einer Laissez-Faire-Ökonomie ist der Wechsel zwischen diesen beiden Finanzierungsformen sowohl für den Anteilseigner als auch für das Unternehmen ohne Auswirkungen.

\subsubsection{Fremdfinanzierung versus Beteiligungsfinanzierung}

Bei dieser Alternative verringert die Unternehmung die Beteiligungsfinanzierung um 1 GE und nimmt stattdessen 1 GE Fremdkapital am Kapitalmarkt auf. Der Anteilseigner kann durch die an ihn ausgeschüttete Verringerung der Beteiligungsfinanzierung $1 \mathrm{GE}$ auf dem Kapitalmarkt anlegen und erhält dort den Marktzinssatz r.

Die Finanzierungsänderung hat beim Anteilseigner folgende Auswirkungen:

Erträge durch Kapitalmarktanlage: $\quad \mathrm{Z}(\mathrm{BF})=\mathrm{r}$

geringere Ausschüttung aufgrund

der zu zahlenden Schuldzinsen : $\quad A(B F)=r$

Der Anteilseigner vergleicht beide Alternativen auf die bei ihm auftretenden Einkommenseffekte.

\footnotetext{
1 Erklärung der Variablen:

$\mathrm{Z}=$ Mittelzufluß beim Anteilseigner

$\mathrm{A}=$ Mittelabfluß vom Anteilseigner

$\mathrm{r}=$ (Netto-) Marktzinssatz

$\mathrm{B}=$ Beteiligungsfinanzierung

$\mathrm{F}=$ Fremdfinanzierung

$\mathrm{S}=$ Selbstfinanzierung.
} 


$$
\begin{aligned}
\text { B } & >\mathrm{F} \Leftrightarrow \mathrm{Z}(\mathrm{BF}) \stackrel{>}{=} \mathrm{A}(\mathrm{BF}) \\
& < \\
& > \\
& >\text { r } \\
& <
\end{aligned}
$$

In einer Laissez-Faire-Ökonomie herrscht folglich Indifferenz zwischen Fremdund Beteiligungsfinanzierung.

\subsubsection{Fremdfinanzierung versus Selbstfinanzierung}

In diesem Fall ersetzt die Unternehmung $1 \mathrm{GE}$ Selbstfinanzierung, die an den Anteilseigner zur Anlage auf dem Kapitalmarkt ausgeschüttet wird, durch eine gleichhohe Kreditaufnahme.

Die Finanzierungsänderung hat beim Anteilseigner folgende Auswirkungen:

Erträge durch Kapitalmarktanlage: $\quad Z(S F)=r$

geringere Ausschüttung aufgrund

der zu zahlenden Schuldzinsen: $\quad A(B F)=r$

Zur Beurteilung der Vorteilhaftigkeit der beiden Finanzierungsmöglichkeiten vergleicht der Anteilseigner die beiden Alternativen:

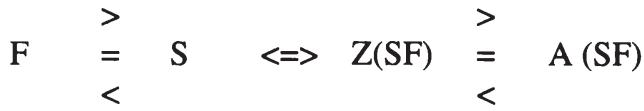

$$
\begin{aligned}
& \begin{aligned}
& > \\
& =
\end{aligned}
\end{aligned}
$$

D.h. in einer Laissez-Faire-Ökonomie herrscht Indifferenz zwischen Fremd- und Selbstfinanzierung. 


\subsubsection{Ergebnis}

In einer Laissez-Faire-Ökonomie mit sicheren Erwartungen und vollkommenem Kapitalmarkt sind die drei Finanzierungsalternativen hinsichtlich der zu erzielenden Erträge gleichwertig ${ }^{I}$.

Ein Steuersystem ist finanzierungsneutral, wenn die Wahl eines Unternehmens zwischen Beteiligungsfinanzierung, Selbstfinanzierung und Fremdfinanzierung nicht beeinflußt wird.

\subsubsection{Rechtsformneutralität}

Ein Unternehmen kann in verschiedenen Rechtsformen (Einzel-, Personen- sowie Kapitalgesellschaft) gegründet werden.

Eine Steuer ist rechtsformneutral, wenn sie die Entscheidung eines Investors für eine bestimmte Rechtsform des Unternehmens nicht beeinflußt, d.h. weder die eine noch die andere Rechtsform steuerlich benachteiligt oder bevorzugt.

\subsection{Grenzen des Modells einer entscheidungsneutralen Besteuerung ${ }^{2}$}

Bei der Untersuchung der Entscheidungsneutralität der Besteuerung sind folgende Grenzen zu beachten.

- Die Konzeption eines neutralen Steuersystems ist nur unter den gemachten Annahmen der jeweiligen ökonomischen Theorie gültig; d.h. sie ist an die jeweiligen Annahmen des Modells gebunden, innerhalb dessen die Neutralität der Besteuerung festgestellt wird.

- Die Definition eines neutralen Steuersystems als Ideal beruht auf der Bejahung einer marktwirtschaftlichen Ordnung und ihrer Effizienz. Ein zusätzlicher sozialer Konsens über ein "gerechtes" Steuersystem ist nicht mehr erforderlich. Die Anforderungen an die Besteuerung lassen sich logisch aus der marktwirtschaftlichen Ordnung ableiten; ohne die Annahme einer marktwirtschaftlichen Ordnung hat oben definiertes Konzept einer neutralen Besteuerung keine Daseinsberechtigung.

Vgl. hierzu auch Modigliani, F./Miller, M.H. (1958).

2 Wagner, F. W. (1992), S. $6 \mathrm{f}$. 


\section{Praktikabilität als Forderung an ein Steuersystem}

"Praktikabilität" der Steuererhebung bedeutet im ersten Schritt, daß die Steuer in der realen Welt auch tatsächlich erhoben werden kann. Vorschläge zur Gestaltung des Steuersystems, die in der realen Welt durchführbar sind, müssen ebenso nach ihrem Aufwand bei der Verwirklichung untersucht werden. Dieser Aufwand muß sowohl beim Fiskus als auch beim Steuerpflichtigen minimiert werden. Diese Forderung wurde bereits von Adam Smith als Besteuerungsgrundsatz erhoben ${ }^{l}$.

In diesen Problemkreis fällt auch die Frage der Möglichkeit der Steuerumgehung: die Umgehung eines steuerbaren Tatbestandes verursacht normalerweise bestimmte Kosten beim Steuerpflichtigen; ebenso fallen auch Kosten beim Fiskus durch den Versuch an, die Steuerumgehung zu verhindern. Eine erfolgreiche Steuerumgehung seitens des Steuerpflichtigen bedeutet überdies immer einen Steuerausfall beim Fiskus. Dies hat für die ehrlichen Steuerpflichtigen zur Folge, daß sie bei gegebenem Ausgabenniveau des Staates eine höhere Steuer zu entrichten haben.

Vgl. Smith, A. (1791), Vol. III, S. 255 ff. 
Michael Ohmer - 978-3-631-75563-1

Downloaded from PubFactory at 01/11/2019 03:31:45AM

via free access 


\section{Kapitel}

\section{Ableitungen aus den Grundprinzipien der Besteuerung}

\section{Bezugsobjekte der Leistungsfähigkeit}

Bezugsobjekte der Besteuerung nach der Leistungsfähigkeit sind im Rahmen dieser Arbeit lediglich natürliche Personen.

Unternehmen besitzen keine eigene Leistungsfähigkeit, sondern nur die die Unternehmen tragenden Individuen, die früher oder später am Erfolg (Gewinn oder Verlust) der Unternehmung durch Ausschüttungen, Liquidation oder durch den Verkauf der Gesellschaftsrechte partizipieren ${ }^{l}$. Dies gilt auch für große Kapitalgesellschaften, die aufgrund ihrer Rechtsform leichteren Zugang zum Kapitalmarkt haben, eine hohe Wirtschaftsmacht und -kraft besitzen und bei denen der einzelne (Klein-) Aktionär kaum Einwirkungsmöglichkeiten auf die Unternehmenspolitik hat. Die Steuererhebung bei den Unternehmen ist also nur eine vereinfachte Erhebungsform für die von natürlichen Personen abzuführende Steu$\mathrm{er}^{2}$.

\section{Indikatoren der steuerlichen Leistungsfähigkeit}

Das Leistungsfähigkeitsprinzip ist -wie jedes andere abstrakte Prinzip- zunächst unbestimmt. Damit muß es aber nicht unbestimmbar sein ${ }^{3}$. Der Gesetzgeber muß dieses Prinzip konkretisieren und zahlenmäßig erfaßbar machen. Dabei ist problematisch, daß die steuerliche Leistungsfähigkeit -unabhängig von ihrer Definition- nicht direkt, sondern nur durch Indikatoren gemessen werden kann. Nachfolgend sollen mögliche Indikatoren für die verschiedenen Definitionen der Leistungsfähigkeit untersucht werden.

Die Systematisierung der möglichen Indikatoren geschieht nach folgenden Kriterien ${ }^{4}$ :

- Der Begriff der "gleichen steuerlichen Leistungsfähigkeit" kann sich sowohl auf die Entstehungs- als auch auf die Verwendungsseite des

\footnotetext{
1 Vgl. Neumark, F. (1970), S. $131 \mathrm{f}$.

2 Vgl. Koniarski, L. (1984), S. 50 f.

3 Vgl. Tipke, K./Lang, J. (1991), S. 59.

$4 \quad$ Vgl. Schneider, D. (1979), S. 27.
} 
Volkseinkommens beziehen, d.h. einzelwirtschaftlich betrachtet auf den Mittelerwerb des Individuums oder auf seinen Verbrauch von Geld oder Gütern zur Bedürfnisbefriedigung.

- Der Begriff der "steuerlichen Leistungsfähigkeit" kann an den Möglichkeiten, also dem Potential des Steuerpflichtigen oder an den durch ihn verwirklichte Tatbestände anknüpfen ("was hätten die Steuerpflichtigen tun können" oder "was haben die Steuerpflichtigen wirklich getan").

Die steuerliche Leistungsfähigkeit kann demnach aus der

- Verwirklichung von Mittelerwerb oder

- Verwirklichung von Bedürfnisbefriedigung bzw. den tatsächlichen Konsumausgaben

$$
\text { oder }
$$

- Möglichkeit zum Mittelerwerb

oder

- Möglichkeit zur Bedürfnisbefriedigung bzw. den möglichen Konsumausgaben

abgeleitet werden.

Dabei hat die Besteuerung nach dem verwirklichten Mittelerwerb oder der verwirklichten Mittelverwendung zum Ziel, alle Individuen gleich zu behandeln, nachdem diese entschieden haben, wieviel sie erwerben oder in welchem Umfang sie ihre Bedürfnisse befriedigen wollen ${ }^{l}$. Es wird auf expost Zustände abgestellt.

Im Gegensatz dazu hat die Anknüpfung der Besteuerung an die potentielle Leistungsfähigkeit zur Folge, daß die Besteuerung exante anknüpft, also vor dem Zeitpunkt, zu dem die Individuen über ihre Handlungen entschieden haben. Daher werden alle Individuen mit denselben Möglichkeiten -unabhängig von ihrem Gebrauch- gleich behandelt, haben also dieselbe Steuerlast zu tragen. Sie können -ohne Auswirkungen auf die Höhe der zu zahlenden Steuern- soviel Mittel erwerben, Konsumausgaben tätigen bzw. Bedürfnisse befriedigen wie sie dazu in der Lage sind oder den Wunsch danach verspüren².

\footnotetext{
Vgl. Schneider, D. (1979), S. 45 f.

Vgl. Schneider, D. (1979), S. 45.
} 


\subsection{Anforderungen an die Meßmethode}

Die Leistungsfähigkeit ist nicht direkt sichtbar bzw. meßbar und muß deshalb über Indikatoren indirekt bestimmt werden.

Um die Besteuerung nach der Leistungsfähigkeit zu vollziehen, müssen die $\mathrm{Me}-$ thoden zur Messung der Leistungsfähigkeit oder ihrer Indikatoren folgende Kriterien erfüllen. Damit ist auch gewährleistet, daß die Indikatoren dem Kriterium der Gesetzesbestimmtheit genügen.

- Das Kriterium der Validität (Gültigkeit) fordert, daß das Meßergebnis ausdrückt, was gemessen werden soll; der Meßindikator muß zweckadäquat $\operatorname{sein}^{l}$.

Die Meßskala ist valide, wenn eine (korrelative) Übereinstimmung zwischen den unbekannten, zu messenden Merkmalswerten und den Meßwerten vorhanden ist. Dieses Kriterium ist von besonderer Relevanz, wenn das Meßobjekt nicht unmittelbar, sondern nur über Indikatoren gemessen werden kann. Eine notwendige Bedingung hierfür ist, daß das Meßinstrument alle Merkmale des zu messenden Objekts isomorph (gleichförmig) abbildet, da ansonsten Verzerrungen auftreten ${ }^{2}$.

- Reliabilität (Zuverlässigkeit) bedeutet, daß die wiederholte Anwendung der Meßvorschrift bei gleichen Meßbedingungen und gleichen Meßmerkmalen zum gleichen Ergebnis führt ${ }^{3}$.

- Das Merkmal der Objektivität verlangt reproduzierbare und intersubjektiv nachprüfbare Ergebnisse ${ }^{4}$, d.h. Messungen von Dritten müssen das gleiche Ergebnis wie die ursprüngliche Messung haben. Subjektive Einflüsse sind bei der Messung auszuschalten.

\subsection{Indikatoren des nutzentheoretischen Leistungsfähigkeitsbegriffs}

Die Indikatoren des nutzentheoretischen Leistungsfähigkeitsbegriffs werden nicht im einzelnen dargestellt, vielmehr wird auf grundsätzliche Unzulänglichkeiten eingegangen. 
Die Besteuerung nach dem nutzentheoretischen Leistungsfähigkeitsbegriff verfolgt das Ziel, Individuen mit gleichem Nutzen gleich zu besteuern. Dafür ist die Unterstellung einer Nutzenfunktion erforderlich, da die Größen des tatsächlichen oder potentiellen Mittelerwerbs bzw. der tatsächlichen oder potentiellen Mittelverwendung andere Maßgrößen als den Nutzen darstellen und der Grad der individuellen Bedürfnisbefriedigung hieraus nicht zwangsläufig abgelesen werden kann ${ }^{l}$. Wird eine allgemeine Nutzenfunktion für alle Individuen mit generell gültigen Unterstellungen angenommen und treffen diese Annahmen nicht für alle Individuen zu, sind die Größen des Mittelerwerbs bzw. der Mittelverwendung keine validen Indikatoren zur Messung des Nutzens der einzelnen Individuen. Das führt zwar dazu, daß Individuen mit den gleichen gemessenen Größen die gleiche Steuer entrichten, die Besteuerung jedoch das tatsächliche Nutzenniveau der Individuen nicht berücksichtigt. In der Realität ist es zumindest fraglich, ob alle Individuen die gleiche Nutzenfunktion haben und diese mit steigendem Lebensalter gleich bleibt ${ }^{2}$.

Damit sind die hier behandelten Größen der Mittelverwendung/-entstehung, also meßbare Einkommens- und Konsumgrößen keine validen Indikatoren für das Nutzenniveau eines Individuums.

Die exakte Bestimmung der individuellen Nutzenfunktionen ist mit den heutigen wissenschaftlichen Methoden nicht möglich. Haller schlägt deshalb ihre Normierung durch Politiker vor, die implizit bei der Festlegung des Tarifverlaufs ohnehin eine Nutzenfunktion zugrunde legen ${ }^{3}$. Dieser Vorschlag ist abzulehnen, da dann die Steuerlast nicht -wie im theoretischen Konzept gefordertauf Nutzenüberlegungen, sondern die Nutzenfunktion aus der politisch gewollten Steuerlastverteilung resultiert ${ }^{4}$.

Aus diesen Gründen wird der nutzentheoretische Leistungsfähigkeitsbegriff als Grundlage der Besteuerung auch von der überwiegenden Meinung abgelehnt und auch im Verlauf dieser Arbeit nicht weiter behandelt.

\subsection{Indikatoren des verteilungspolitischen Leistungsfähigkeitsbegriffs}

Die Definition des Leistungsfähigkeitsbegriffs drückt die wirtschaftliche Leistungsfähigkeit in der individuellen Fähigkeit aus, zur Finanzierung des staatlichen Finanzbedarfs beizutragen. Diese bestimmt sich aus der ökonomischen

\footnotetext{
Vgl. hierzu auch Holzmann, R. (1984), S. $38 \mathrm{ff}$.

Vgl. Littmann, K. (1970), S. 124.

Vgl. Haller, H. (1981), S. 76 ff. (insbesondere S. 79).

Vgl. Ebnet, O. (1978), S. 38.
} 
Verfügungsmacht eines Individuums, über knappe Ressourcen der Wirtschaft frei zwischen konsumtiven und investiven Verwendungen der zur Verfügung stehenden Ressourcen entscheiden zu können ${ }^{l}$.

\subsubsection{Individuelles Potential als Indikator der Leistungsfähigkeit}

\subsubsection{Potentieller Mittelerwerb als Indikator der Leistungsfähigkeit ${ }^{2}$}

Individuen, die dieselben Möglichkeiten (= dasselbe Potential) haben, Mittel zu erwerben, sollen den gleichen Betrag an Steuern zahlen, unabhängig davon, ob die Möglichkeiten zum Mittelerwerb genutzt werden oder nicht.

Bei einer Potentialbesteuerung wird das Potential des Steuerpflichtigen als Bemessungsgrundlage der Besteuerung angesehen. Zugrunde liegt die Idee, daß ein Individuum ebenso über die Ressource "Zeit" verfügen kann: es kann sie investiv zu Ausbildungszwecken, produktiv zur Arbeit oder konsumtiv für Freizeitvergnügungen verwenden. Die Verwendung der Zeit bildet dabei schon eine Disposition des Steuerpflichtigen ab. Durch die Erfassung der "Zeit" des Steuerpflichtigen in der steuerlichen Bemessungsgrundlage wird also die Verfügungsmacht des Individuums über die Ressourcen der Wirtschaft umfassend abgebildet.

Das Potential des Steuerpflichtigen umfaßt (neben Erbschaften und Kapitaleinkünften usw.) auch das potentielle Einkommen aus nichtselbständiger Arbeit; dieses ergibt sich aus der (mit dem relevanten Zinssatz abdiskontierten) Summe seiner maximalen Arbeitszeit pro Periode multipliziert mit dem von ihm in dieser Periode maximal zu erzielenden Lohnsatz. Wahlhandlungen des Individuums (wie z.B. die Arbeit-Freizeit-Entscheidung oder die Berufswahl) beeinflussen die Höhe der steuerlichen Bemessungsgrundlage nicht.

Die individuellen Fähigkeiten eines Individuums, Mittel zu erzielen, sind von der Arbeitszeit sowie von seinen Fähigkeiten (z.B. Belastbarkeit, Sachverstand, Intelligenz, Geschicklichkeit, Verantwortungsbewußtsein) abhängig. Für jedes Individuum müssen damit eine Soll-Arbeitszeit sowie seine Fähigkeiten ermittelt und quantifiziert werden. Die tatsächliche Arbeitszeit bzw. die Verwendung der individuellen Fähigkeiten sind das Ergebnis einer Wahlhandlung. Das dadurch erzielte Einkommen ist steuerlich unerheblich.

\footnotetext{
1 Vgl. Ebnet, O. (1978), S. 57.

2 Vgl. Schneider, D. (1979), S. $41 \mathrm{ff}$.
} 
Fraglich ist, welcher Diskontierungszinssatz in einer Welt mit unvollkommenem Kapitalmarkt zu wählen ist, wenn die Zinssätze individuell differenziert werden. Dabei ist zu klären, ob die individuellen Abweichungen zwischen den Zinssätzen zu berücksichtigen sind oder ob ein einheitlicher Zinssatz für alle Individuen gewählt werden kann. Um beurteilen zu können, ob dies für die Besteuerung überhaupt relevant ist, wird zuerst die Auswirkung der Wahl von verschiedenen Zinssätzen auf den Indikator der Leistungsfähigkeit -also das Potential des Individuums- und das Steueraufkommen untersucht. Dazu wird ein Modell betrachtet, bei dem das für die Potentialbestimmung notwendige maximale Periodeneinkommen von $t_{1}$ und $t_{2}$ auf $t_{0}$ abgezinst wird. Hierbei wird der Einfluß von unterschiedlichen Zinssätzen untersucht. $\mathrm{Y}_{\mathrm{t}}$ bezeichnet das Einkommen der Periode $\mathrm{i}, \mathrm{r}$ den Diskontierungszinssatz und $\tau$ den Steuersatz; $\mathrm{S}$ steht für das gesamte Steueraufkommen und NPV für den Barwert des Potentials nach Steuern.

Der Barwert des Potentials nach Steuern ist

$$
\mathrm{NPV}=\left(\mathrm{y}_{1} * \frac{1}{(1+\mathrm{r})}+\mathrm{y}_{2} * \frac{1}{(1+\mathrm{r})^{2}}\right) *(1-\tau)
$$

Das Steueraufkommen beträgt dann

$$
\mathrm{S}=\left(\mathrm{y}_{1} * \frac{1}{(1+\mathrm{r})}+\mathrm{y}_{2} * \frac{1}{(1+\mathrm{r})^{2}}\right) * \tau \text {. }
$$

Um die Wirkungen von Zinssatzänderungen zu analysieren, wird das totale Differential gebildet. Es ergibt sich dann:

$$
\begin{aligned}
\mathrm{dNPV}= & \frac{1-\tau}{1+\mathrm{r}} d \mathrm{y}_{1}-\left(\mathrm{y}_{1} * \frac{1-\tau}{(1+\mathrm{r})^{2}}\right) \mathrm{dr}+\left(\frac{1-\tau}{(1+\mathrm{r})^{2}}\right) \mathrm{dy}_{2^{-}}\left(2 \mathrm{y}_{2} * \frac{1-\tau}{(1+\mathrm{r})^{3}}\right) \mathrm{dr}- \\
& \left(\frac{\mathrm{y}_{1}}{1+\mathrm{r}}+\frac{\mathrm{y}_{2}}{(1+\mathrm{r})^{2}}\right) \mathrm{d} \tau
\end{aligned}
$$

bzw.

$$
\mathrm{dS}=\frac{\tau}{1+\mathrm{r}} \mathrm{dy}_{1}-\frac{\mathrm{y}_{1} * \tau}{(1+\mathrm{r})^{2}} \mathrm{dr}+\frac{\tau}{(1+\mathrm{r})^{2}} \mathrm{dy}_{2}-\frac{2 \mathrm{y}_{2} * \tau}{(1+\mathrm{r})^{3}} \mathrm{dr}+\left(\frac{\mathrm{y}_{1}}{1+\mathrm{r}}+\frac{\mathrm{y}_{2}}{(1+\mathrm{r})^{2}}\right) \mathrm{d} \tau
$$


Um die Einflüsse von Zinssatzänderungen auf den Barwert des individuellen Potentials zu erhalten, wird die Ableitung $\frac{\mathrm{dNPV}}{\mathrm{dr}}$ gebildet.

$$
\frac{\mathrm{dNPV}}{\mathrm{dr}}=-\frac{1-\tau}{1+\mathrm{r}} *\left(\frac{\mathrm{y}_{1}}{1+\mathrm{r}}+\frac{2 \mathrm{y}_{2}}{(1+\mathrm{r})^{2}}\right)<0
$$

Da der Einfluß des Zinssatzes auf das individuelle Potential vor Steuern geprüft werden soll, werden die Steuern nicht berücksichtigt, der Steuersatz damit auf 0 gesetzt.

$$
\frac{\mathrm{dNPV}}{\mathrm{dr}}=-\frac{1}{1+\mathrm{r}} *\left(\frac{\mathrm{y}_{1}}{1+\mathrm{r}}+\frac{2 \mathrm{y}_{2}}{(1+\mathrm{r})^{2}}\right)<0
$$

Im zweiten Term (in "( )") steht ein Ausdruck, der nicht genau dem Barwert des Potentials des betrachteten Individuums entspricht. Somit ist die Barwertänderung des Potentials von der Verteilung der Periodeneinkommen in den einzelnen Perioden abhängig. Damit kann der Fall entstehen, daß sich die ordinale Reihenfolge in der durch das Potential gemessenen Leistungsfähigkeit zwischen zwei Individuen durch die unterschiedliche Wahl des Diskontierungszinssatzes verändert.

Die Wahl des Diskontierungszinssatzes hat also unmittelbare Auswirkungen auf die ordinale Reihenfolge hinsichtlich der Leistungsfähigkeit der Individuen. Wird von einem unvollkommenen Kapitalmarkt ausgegangen, bei dem Sollund Habenzinssätze voneinander abweichen und zusätzlich noch individuelle Unterschiede in der Zinshöhe festzustellen sind, ist bei der Potentialbestimmung für jedes Individuum der für ihn relevante Zinssatz heranzuziehen, da nur durch die Diskontierung mit einem für das Individuum auch relevanten Zinssatz das individuelle Potential abgebildet werden kann. Die Anwendung eines einheitlichen Zinssatzes führt zu einer Verzerrung der ordinalen Reihenfolge der Individuen hinsichtlich ihrer Leistungsfähigkeit und das so gemessene Potential ist kein valider Indikator. Bei der Wahl des individuell anzuwendenden Zinssatzes darf aber kein Zinssatz angesetzt werden, der bereits durch eine Wahlhandlung des Individuums beeinflußt ist. 


\subsubsection{Potentielle Konsumausgaben als Indikator der Leistungsfähigkeit}

Nach dieser Konzeption wird die Möglichkeit, Konsumausgaben zu tätigen, als Indikator für die individuelle Leistungsfähigkeit verwandt. Es wird hierbei jedoch nicht auf das individuelle Potential zum Mittelerwerb abgestellt. Die Bemessungsgrundlage bilden vielmehr die schon erworbenen finanziellen Mittel. Personen mit den gleichen Möglichkeiten zu Konsumausgaben -unabhängig von den tatsächlichen Konsumausgaben- werden nach dieser Konzeption gleich besteuert. Wer größere Möglichkeiten zur Bestreitung von Konsumausgaben hat, soll mehr Steuern entrichten als derjenige mit nur geringeren Möglichkeiten.

Bei dieser Konzeption stellt das Periodenanfangsvermögen und das durch das Einkommen der Periode neu gebildete Vermögen ${ }^{l}$ das Potential des Steuerpflichtigen für Konsumausgaben dar. Auf diese Größe ist eine einheitliche Steuer anzulegen (keine getrennte Einkommen- und Vermögensteuer) ${ }^{2}$. Wird das Potential für Konsumausgaben nur am Lebensende erfaßt, ergibt sich als Bemessungsgrundlage das Lebenseinkommen. Somit entspricht dieser Indikator dem Indikator des verwirklichten Mittelerwerbs. Erfolgt allerdings eine periodische Erfassung dieses Indikators, entspricht er nur dann dem Indikator des verwirklichten Mittelerwerbs, wenn nichts gespart wird. Es kommt hier also auf den für die Bestimmung der Leistungsfähigkeit relevanten Zeitraum an. Auf diese Frage wird später noch eingegangen.

\subsubsection{Kritik der Potentialbesteuerung}

\section{a) Besteuerung nach der individuellen Leistungsfähigkeit}

Nach dem verteilungspolitischen Leistungsfähigkeitsbegriff bedeutet Leistungsfähigkeit die Verfügungsmacht -also die Möglichkeit zur freien Entscheidung zwischen konsumtiver und investiver Verwendung- über die knappen Ressourcen der Wirtschaft. Die Ressourcen eines Individuums umfassen -wie oben gezeigt- sowohl das Human- als auch das Finanzvermögen. Das Humanvermögen beinhaltet auch die Ressourcen "Zeit" und "Begabung", die ebenfalls zu den knappen Gütern der Wirtschaft gehören und die Leistungsfähigkeit des Individuums beeinflussen. Zur umfassenden Abbildung der individuellen Leistungsfä-

1 Das Einkommen selbst darf nicht als Potential zur Bestreitung der Konsumausgaben betrachtet werden, da es eine Strom- und keine Bestandsgröße ist (ein Potential ist eine Bestandsgröße zu einem bestimmten Zeitpunkt, die Stromgrößen während eines bestimmten Zeitraums erzeugen oder aufnehmen kann (vgl. Schneider, D. (1979), S. 39)).

2

Vgl. Schneider, D. (1979), S. 41. 
higkeit ist daher auch die Zeitausstattung des Individuums und seine Begabung heranzuziehen. Die Entscheidung eines Individuums, seine Ressourcen konsumtiv oder produktiv zu nutzen, ist bereits eine Disposition über die Zeit und damit zur Bestimmung der Leistungsfähigkeit irrelevant.

Die Leistungsfähigkeit wird somit durch die Messung des Potentials zum Mittelerwerb umfassend bestimmt, da hier die Leistungsfähigkeit vor irgendwelchen Wahlhandlungen des Individuums (Arbeit oder Freizeit bzw. der Art von Arbeit) bestimmt wird.

Die Besteuerung der potentiellen Konsumausgaben ist nicht so umfassend wie die Besteuerung des Potentials zum Mittelerwerb: sie umfaßt z.B. nicht die gesamte Zeitausstattung oder die Begabung des Individuums, da sie lediglich auf mögliche Konsumausgaben abstellt, denen eine vorherige Einkommenserzielung vorausgehen muß. Somit wird nur die Zeit erfaßt, die das Individuum zum Erwerb aufgewendet hat, die Freizeit bleibt unberücksichtigt.

Die Frage, in welchen Zeitabschnitten das Potential für Konsumausgaben zu messen ist, wird später behandelt. Hat die Erörterung des relevanten Zeitraums zum Ergebnis, daß der zur Ermittlung der Leistungsfähigkeit heranzuziehende Zeitabschnitt die Lebensdauer des Individuums ist, entspricht dieser Indikator dem des verwirklichten Mittelerwerbs, da dort -wie dann auch hier- auf das Lebenseinkommen des Individuums abgestellt wird.

\section{b) Neutralität der Besteuerung}

Die Konzeption des potentiellen Mittelerwerbs hat die Besteuerung eines SollEinkommens zur Folge. Die Besteuerung kann durch einen geringeren Einsatz der Fähigkeiten (um z.B. mehr Freizeit zu genießen) nicht umgangen werden. Die Höhe der zu entrichtenden Steuer ist unabhängig vom tatsächlichen Einsatz bzw. dem Resultat des Einsatzes der individuellen Fähigkeiten. Es erfolgt keine Verzerrung der Arbeit-Freizeit-, der intertemporalen Konsum- sowie der Konsumentscheidung zwischen verschiedenen Konsumgütern, da die Höhe der steuerlichen Bemessungsgrundlage von den Entscheidungen der Individuen nicht beeinflußt wird und somit auch durch noch so geschickte Planung keine Möglichkeit der Verringerung der steuerlichen Bemessungsgrundlage besteht. Negative Anreizeffekte durch diese Besteuerungskonzeption treten damit im Vergleich zu einer Laissez-Faire-Ökonomie nicht auf ${ }^{l}$; das Steuersystem ist im Rahmen des in dieser Arbeit behandelten Modells entscheidungsneutral.

1 Vgl. Arrow, K.J. (1973), S. 260. 
Werden die potentiellen Konsumausgaben besteuert, erfolgt zumindest eine Verzerrung der Arbeit-Freizeit-Entscheidung, da für die Steuerpflichtigen die Möglichkeit besteht, die steuerliche Bemessungsgrundlage, die nicht ihre Freizeit umfaßt, durch einen geringeren Arbeitseinsatz zu verringern; somit liegt eine selektive Konsumsteuer vor ${ }^{l}$.

$\mathrm{Ob}$ durch die Besteuerung der potentiellen Konsumausgaben (Summe aus Periodenanfangsvermögen und Periodeneinkommen) weitere Entscheidungen verzerrt werden, ist von der Periodendauer abhängig, für die die Bemessungsgrundlage zu bestimmen ist ${ }^{2}$ :

- Umfaßt die Periodenlänge die Lebensdauer des Individuums, entspricht dieser Indikator dem des verwirklichten Mittelerwerbs; auf die dortigen Ausführungen wird verwiesen.

- Ist die Periodenlänge kürzer als die Lebensdauer der Individuen, wird der Vermögensbestand besteuert, damit liegt eine Bestandsteuer vor. Dadurch wird -wie Nachtkamp zeigt ${ }^{3}$ - die intertemporale Konsumentscheidung der Individuen und das Wirtschaftswachstum beeinflußt: es liegt ein Verstoß gegen die Forderung der Neutralität des Steuersystems vor.

\section{c) Praktikabilität der Besteuerung}

Das Potential für Konsumausgaben setzt sich zusammen aus dem Einkommen und dem Vermögen der Periode. Die Probleme der Bestimmung dieser Größen werden später behandelt.

Im folgenden wird nur noch auf den potentiellen Mittelerwerb als Indikator der individuellen Leistungsfähigkeit eingegangen.

Bei der Besteuerung des potentiellen Mittelerwerbs muß das Potential des einzelnen Steuerpflichtigen gemessen werden. In einer vollkommenen Welt mit vollkommener Information gibt es kein Problem bei der Messung des Potentials, da die besteuerungsrelevanten Daten (z.B. Zeit, Lohn, Zins) bekannt sind und damit das Potential des Steuerpflichtigen direkt meßbar ist.

1 Vgl. hierzu Blankart, C.B. (1991), S. 185, sowie die ausführliche Darstellung bei der Diskussion der Besteuerung des verwirklichten Mittelerwerbs bzw. der Konsumausgaben.

2 Diese Frage wird später noch geklärt.

3 Vgl. Nachtkamp, H.H. (1988), S. 170 ff. 
Das Potential eines Individuums kann in der realen Welt aber nicht direkt, sondern nur mit Indikatoren gemessen werden.

Über das Potential einer großen Zahl von Steuerpflichtigen können aufgrund von Erfahrungs- bzw. Vergangenheitswerten statistische Aussagen getroffen werden (ähnlich der Aussagen über die durchschnittliche Lebenserwartung), eine Aussage über das Potential eines einzelnen ist jedoch nicht möglich.

Eine Bestimmung des Potentials nach der Abstammung (das verwirklichte "Potential" der Eltern könnte hier herangezogen werden) ist ebenfalls nicht objektiv, da westliche Gesellschaften eine hohe vertikale Mobilität zwischen den einzelnen Gesellschaftsgruppen aufweisen und somit ein hinreichend strenger $\mathrm{Zu}$ sammenhang zwischen der Abstammung und dem Potential des einzelnen nicht besteht.

Die Bestimmung des Potentials durch die Zugehörigkeit zu einer bestimmten Berufsgruppe oder einem Stand, z.B. Arbeitnehmer, Rentner und Unternehmer ist nicht möglich, da diese Gruppen sehr heterogen zusammengesetzt sind, und die Zugehörigkeit zu einer solchen Gruppe in vielen Fällen bereits die Folge einer Wahlhandlung ist. Die Messung des individuellen Potentials anhand der tatsächlichen, beobachtbaren Leistung stellt eine Abkehr vom Begriff des "Potentials" dar, der gerade nicht an dem verwirklichten, sondern an dem möglichen Ergebnis anknüpfen will. Damit scheidet diese Meßalternative als nicht valide aus.

Ein weiteres Problem bei der Ermittlung des individuellen Potentials stellt die Vorgabe der Zeit dar, in der die individuellen Fähigkeiten zur Einkommenserzielung eingesetzt werden sollen. Hierzu ist eine weitere individuelle Unterscheidung notwendig, da nicht jedes Individuum über dieselbe Konstitution verfügt und auch das Nachlassen der Intensität der Leistung über die Zeit individuell verschieden ist. Dafür fehlt es an geeigneten und hinreichend objektiven, d.h. intersubjektiv nachvollziehbaren Meßmethoden.

Die Welt der unvollkommenen Information birgt bei der Ermittlung der potentiellen Leistungsfähigkeit über den Indikator des potentiell möglichen Einkommens ein weiteres Problem: welches potentielle Einkommen soll für die Ermittlung der steuerlichen Leistungsfähigkeit gewählt werden, wenn ein Individuum mit bestimmten Fähigkeiten ein sicheres Einkommen von 50.000,- DM (darauf zu entrichtende Steuer (ESt-Grundtabelle 1990 einschließlich Zusatztabelle 1993 zur ESt-Grundtabelle 1990) 11.084,- DM) erreicht oder mit jeweils 50\%Wahrscheinlichkeit ein Einkommen von 10.000,- DM (0,-) bzw. 90.000,- DM (26.208,- DM ) erzielen könnte? - Wird das mit Sicherheit zu erreichende Einkommen bzw. der Erwartungswert der verschiedenen Einkommensmöglichkeiten als steuerliche Bemessungsgrundlage gewählt, hat der Steuerpflichtige nur scheinbar die Wahl zwischen verschiedenen Handlungsalternativen: tatsächlich 
kann er aber nur die sichere Alternative wählen, da ihm sonst bei Eintritt der ungünstigen Alternative kein Geld mehr zum Leben bleibt (Einkommen 10.000,-, abzgl. Steuern 11.084,- DM) ${ }^{l}$; die Steuer beeinflußt damit die Wahlhandlung des Individuums hinsichtlich des einzugehenden Risikos.

Bei der Konzeption des potentiellen Mittelerwerbs wird dem vorhandenen Vermögen ein Potential zum Mittelerwerb unterstellt: problematisch ist der Ertrag (= Zinssatz), da dieser bei unvollkommenen Märkten und bei unterschiedlich risikoreichen Anlagen differiert.

Obige Ausführungen zeigen, daß die Messung des individuellen Potentials in der realen Welt nicht objektiv durchführbar ist und somit als Indikator zur Messung der Leistungsfähigkeit ausscheidet.

\subsubsection{Ergebnis}

Die Besteuerung des Potentials zum Mittelerwerb bildet die Dispositionsmöglichkeiten, also die Leistungsfähigkeit, umfassend ab. Die Entscheidungen werden nicht beeinflußt und damit der Forderung nach einem neutralen Steuersystem entsprochen.

Gegen die Verwendung des potentiellen Mittelerwerbs als Indikator der Leistungsfähigkeit sprechen Praktikabilitätsüberlegungen und die fehlende Objektivität der Meßmöglichkeiten des individuellen Potentials.

Der potentielle Mittelerwerb als Indikator zur Messung der individuellen Leistungsfähigkeit scheidet damit aus.

Das Konsumpotential bildet die Dispositionsmöglichkeiten nicht so umfassend ab wie das Potential zum Mittelerwerb, da die Freizeit nicht berücksichtigt wird. Wird das Potential für Konsumausgaben für die gesamte Lebensdauer der Individuen bestimmt und nicht periodisch, entspricht dieser Indikator dem Indikator des verwirklichten Mittelerwerbs ${ }^{2}$. Durch die Besteuerung des Konsumpotentials wird die Arbeit-Freizeit-Entscheidung sowie (bei periodischer Besteuerung) die intertemporale Konsumentscheidung und die Wachstumsneutralität verzerrt.

Vgl. Schneider, D. (1979), S. 44.

2 Auf den relevanten Zeitraum zur Bestimmung der Leistungsfähigkeit wird später eingegangen. 


\subsubsection{Verwirklichte Größen als Indikatoren der Leistungsfähigkeit}

\subsubsection{Mittelerwerb als Indikator der Leistungsfähigkeit}

Nach diesem Indikator sollen alle, die gleich viele Mittel erwerben, auch identische Steuern bezahlen.

Der verwirklichte Mittelerwerb kann durch das Periodeneinkommen gemessen werden.

Das Vermögen spiegelt bei dieser Definition nicht eine besondere steuerliche Leistungsfähigkeit wider und wird daher nicht besteuert ${ }^{l}$.

\subsubsection{Konsumausgaben als Indikator der Leistungsfähigkeit}

Individuen mit gleichen Konsumausgaben entrichten nach dieser Konzeption eine gleich hohe Steuer. Höhere Konsumausgaben signalisieren eine höhere Leistungsfähigkeit und damit eine höhere Steuerzahlung. Hier liegt die Auffassung zugrunde, daß die Ausgaben für eigene Konsumzwecke der beste Indikator für den Beitrag zum Staatshaushalt sind.

Die Bemessungsgrundlage "Konsumausgaben" kann also -entgegen einiger Literaturmeinungen ${ }^{2}$ - auch ohne die Verwendung des nutzentheoretischen Leistungsfähigkeitsbegriffs begründet werden.

\subsubsection{Kritik der beiden Konzeptionen}

Es wird untersucht, ob mit diesen Indikatoren die individuelle Leistungsfähigkeit tatsächlich abgebildet und die Entscheidungen der Individuen beeinflußt werden.

Auf Praktikabilitätserwägungen wird an anderer Stelle eingegangen.

\section{a) Besteuerung nach der individuellen Leistungsfähigkeit}

Bei der Diskussion der Potentialbesteuerung wurde dargelegt, daß die Zeitausstattung des Individuums eine Ressource darstellt. Der verwirklichte Mitteler-

$1 \quad$ Vgl. Schneider, D. (1979), S. 49.

2 Vgl. z.B. Schneider, D. (1984), S. 409 f.; Kraft, C. (1991), S. 41 ff., 47 f. 
werb als Indikator der Leistungsfähigkeit bildet die Leistungsfähigkeit des Individuums nicht in vollem Umfang ab, da nur der Teil der Ressource "Zeit", die das Individuum zum Erwerb (= Arbeitszeit) verwendet, besteuert wird. Die für Freizeitaktivitäten aufgewendete Zeit bleibt unberücksichtigt. Ebenso geht nur der Teil der individuellen Begabung in den Indikator der Leistungsfähigkeit ein, der zum Erwerb genutzt wird; der übrige Teil findet keine Berücksichtigung. Die Bestimmung der individuellen Leistungsfähigkeit erfolgt nach der Disposition des Individuums über seine Ressourcen, d.h. nach der Entscheidung zwischen investiver (= Ausbildungszeit), erwerbender (= Arbeitszeit) und konsumtiver (= Freizeit) Verwendung. Die individuelle Leistungsfähigkeit wird daher nur unvollkommen abgebildet und die Höhe des Indikators der Leistungsfähigkeit -zumindest teilweise- in das Ermessen des Individuums gelegt.

Werden die getätigten Konsumausgaben (ohne das Lebensendvermögen) als Indikator der Leistungsfähigkeit angesehen, geht das am Lebensende vorhandene Vermögen nicht in die Bemessung der Leistungsfähigkeit ein. Die Dispositionsmöglichkeiten des Individuums aus der zum Erwerb verbrachten Zeit werden daher nicht vollständig abgebildet, da die Dispositionsmöglichkeiten über das nicht konsumierte Vermögen unberücksichtigt bleiben. Der Indikator der tatsächlichen Konsumausgaben (ohne Berücksichtigung des Lebensendvermögens) bildet deshalb die Leistungsfähigkeit weniger umfassend ab als der verwirklichte Mittelerwerb.

\section{b) Neutralität der Besteuerung}

Fraglich ist auch, ob die behandelten Indikatoren mit der Forderung nach einem neutralen Steuersystem zu vereinbaren sind. Hierzu wird auf die Arbeit-FreizeitEntscheidung eingegangen ${ }^{l}$.

Der Ausgangspunkt der Überlegung ist ein statisches Modell, in dem das Individuum sein gesamtes monetäres Einkommen konsumiert, also nichts spart ${ }^{2}$.

Vgl. hierzu auch Buchholz, W./Wiegard, W. (1991), S. 22 ff.

2 Vgl. Blankart, C.B. (1991), S. 185, 187. 


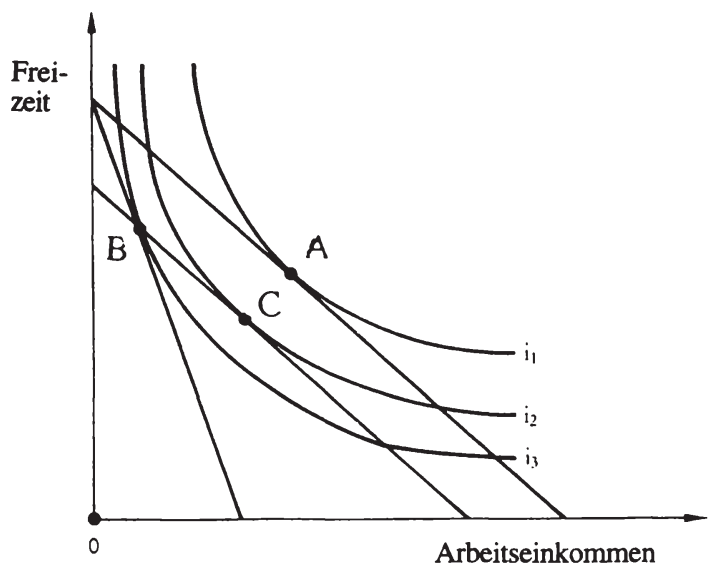

In einer Welt ohne Steuern liegt die optimale Entscheidung des Individuums zwischen Arbeit und Freizeit im Punkt A. Wird eine Pauschalsteuer erhoben, verschiebt sich die Budgetgerade nach innen und die optimale Entscheidung zwischen Arbeit und Freizeit liegt im Punkt C. Die Relation von Arbeit und Freizeit verändert sich nicht. Wird statt der Pauschalsteuer eine aufkommensgleiche Einkommensteuer eingeführt, schwenkt die Budgetgerade nach innen. Der Schnittpunkt mit der Indifferenzkurve liegt nun auf B. In B ist das Verhältnis Arbeit zu Freizeit ein anderes als in A (in A wird, relativ gesehen, mehr gearbeitet), folglich verzerrt die Besteuerung die Arbeit-Freizeit-Entscheidung und ist deshalb nicht neutral. Da das auf der Abzisse abgetragene Einkommen den Konsumausgaben entspricht, kann das Ergebnis auch auf die Besteuerung der Konsumausgaben übertragen werden. Somit wird sowohl durch die Besteuerung des verwirklichten Mittelerwerbs als auch der Konsumausgaben die Arbeit-Freizeit-Entscheidung verzerrt und gegen die Forderung nach einem neutralen Steuersystem verstoßen.

Auf die weiteren möglichen Verzerrungen der Entscheidungen wird an anderer Stelle eingegangen.

\subsubsection{Ergebnis: Indikatoren des verteilungspolitischen Leistungsfähig keitsbegriffs}

Die umfassendste Abbildung der individuellen Leistungsfähigkeit nach dem verteilungspolitischen Leistungsfähigkeitsbegriff erfolgt durch den Indikator des 
potentiellen Mittelerwerbs, der die Entscheidungen der Steuerpflichtigen nicht verzerrt und der Forderung eines effizienten und neutralen Steuersystems genügt. Er ist allerdings aufgrund von Praktikabilitätsüberlegungen abzulehnen, da er nicht objektiv gemessen werden kann und die Anforderungen an ein Meßkonzept nicht erfüllt werden.

Als mögliche Indikatoren der steuerlichen Leistungsfähigkeit verbleiben somit die Größen "Einkommen" und "Konsumausgaben", obwohl diese die Leistungsfähigkeit der Individuen nur eingeschränkt abbilden und die Dispositionsmöglichkeiten des Individuums über seine Zeit -mit Ausnahme der Arbeitszeit- unbesteuert lassen. Der Indikator der getätigten Konsumausgaben umfaßt einen geringeren Teil der Dispositionsmöglichkeiten, wenn unterstellt wird, daß die Individuen Vermögen vererben und dies nicht als Konsumausgabe gewertet wird. Da dieser Indikator nicht die gesamten Dispositionsmöglichkeiten über die aus der Arbeit erzielten Mittel erfaßt, wird er als weniger zweckadäquat zur Messung der Leistungsfähigkeit angesehen als derjenige des verwirklichten Mittelerwerbs. Er wird daher nicht weiter behandelt.

Der Indikator der potentiellen Konsumausgaben entspricht bei der Annahme, $\mathrm{da} ß$ die für die Bestimmung der Leistungsfähigkeit relevante Periode die gesamte Lebensdauer umfa $\mathrm{At}^{1}$, dem Indikator des verwirklichten Mittelerwerbs.

Die Indikatoren beeinflussen zumindest die Arbeit-Freizeit-Entscheidung des Individuums und sind damit nicht völlig entscheidungsneutral. Sie verzerren die optimale Ressourcenallokation.

\subsection{Ergebnis: Indikatoren der steuerlichen Leistungsfähigkeit}

Ein valider Indikator zur Messung der Bedürfnisbefriedigung bzw. des Nutzens konnte nicht gefunden werden, damit ist der nutzentheoretische Leistungsfähigkeitsbegriff aufgrund praktischer Probleme und der fehlenden Validität seiner Indikatoren nicht anwendbar.

Zur Bestimmung der individuellen Leistungsfähigkeit wird deshalb der verteilungspolitische Leistungsfähigkeitsbegriff herangezogen. Er entspricht der vorherrschenden Meinung in der traditionellen Finanzwissenschaft ${ }^{2}$.

Das Potential zum Mittelerwerb als Indikator der Leistungsfähigkeit bietet zwar das beste Abbild der Leistungsfähigkeit und verzerrt die Entscheidungen nicht, aufgrund von Praktikabilitäts- und Objektivitätsgründen ist es jedoch abzulehnen.

1 Ob diese Annahme sachgerecht ist, wird später untersucht.

2 Vgl. Neumark, F. (1970), S. 135 ff.; Schneider, D. (1984); Andel, N. (1980), S. 337. 
Es muß auf eine weniger vollständige Abbildung der individuellen Leistungsfähigkeit zurückgegriffen werden: auf die potentiellen Konsummöglichkeiten bzw. die vom Steuerpflichtigen verwirklichten Größen "Einkommen" und "Konsumausgaben".

Dabei geht es nur um die Verfügungsmöglichkeit von unmittelbar vorhandener bzw. vorhanden gewesener Kaufkraft. Die Dispositionsmöglichkeiten des Individuums werden nicht vollständig abgebildet, da die Ressource "Zeit" nicht vollständig zum Ansatz kommt: es wird nur die Arbeitszeit des Individuums, nicht jedoch die Freizeit berücksichtigt. Die Bemessungsgrundlage wird also erst nach einer Disposition bestimmt.

Das Einkommen und die potentiellen Konsumausgaben bilden die Verfügungsgewalt vollständiger als die Konsumausgaben ab. Daher werden nur noch diese Indikatoren der Leistungsfähigkeit betrachtet.

Die Forderung nach einem neutralen Steuersystem wird durch diese Indikatoren nicht erfüllt, da sie die Arbeit-Freizeit-Entscheidung verzerren.

\section{Länge der Besteuerungsperiode}

Es ist noch zu klären, für welchen Zeitraum die Leistungsfähigkeit zu bestimmen ist. Dies ist vor allem bei einem progressiven Tarif bedeutend, da hier der Grenzsteuersatz mit der Bemessungsgrundlage zunimmt. Bei einer periodischen Ermittlung des Steuersatzes ergibt sich bei schwankenden Bemessungsgrundlagen dadurch eine höhere Steuerschuld als dies bei über die einzelnen Perioden hinweg jeweils gleich hohen Bemessungsgrundlagen der Fall ist.

Weiter ist fraglich, ob in der realen Welt Schwankungen des Periodeneinkommens lediglich bei einigen wenigen Sonderfällen (Tennisprofis oder Fußballstars) in größerem Umfange vorkommen oder häufiger zu beobachten sind und somit ein wirkliches Problem darstellen. Hierzu werden empirische Untersuchungen zur Einkommensverteilung herangezogen: zeigt sich hier als Ergebnis, daß die Verteilung des "Lebenseinkommens" gleichmäßiger ist als die des Periodeneinkommens, ist dies ein Indiz für sich teilweise ausgleichende Schwankungen im Periodeneinkommen.

Ein weiterer Grund zur Klärung dieser Frage ist die Auswahl eines geeigneten Indikators zur Bestimmung der individuellen Leistungsfähigkeit: bisher wurde noch keine Wahl zwischen dem verwirklichten Mittelerwerb und den potentiellen Konsumausgaben getroffen. Ist die zweckadäquate Bemessungsgrundlage die Lebenszeit des Individuums, entsprechen sich beide Indikatoren; somit bestehen keine Auswahlprobleme. 
Zuerst wird auf einige empirische Untersuchungen eingegangen, um zu klären, ob Schwankungen im Periodeneinkommen eine Ausnahmeerscheinung bei einigen wenigen Individuen sind oder sie bei einer Vielzahl von Individuen auftreten.

In einem zweiten Schritt erfolgt die Wahl der "richtigen" Periode anhand der Forderung der Besteuerung nach der individuellen Leistungsfähigkeit, der Forderung nach einem neutralen Steuersystem sowie Praktikabilitätsüberlegungen.

\subsection{Empirische Untersuchungen zur Einkommensverteilung}

Um festzustellen, ob Schwankungen im Periodeneinkommen bei einer Vielzahl von Individuen auftreten, werden empirische Untersuchungen herangezogen. Diese messen die jeweilige Verteilung des Perioden- und Lebenseinkommens. Daraus können Rückschlüsse auf die Schwankungen der Periodeneinkommen gezogen werden. Sind Periodeneinkommen ungleichmäßiger verteilt als Lebenseinkommen, gibt es auch Schwankungen innerhalb der Periodeneinkommen eines Individuums.

Lillard untersucht eine Kohorte von 4.699 Männern ${ }^{l}$, die zwischen 1917 und 1925 geboren wurden und von denen Einkommensdaten zu verschiedenen Zeitpunkten ihres Lebens zwischen 16 und 65 vorliegen $^{2}$. Nach seiner Untersuchung ist das Lebenseinkommen innerhalb der Kohorte wesentlich gleichmäßiger verteilt als das Periodeneinkommen. Die Ungleichheit im Periodeneinkommen ist zu jedem Zeitpunkt bei Männern ab 30 -mit dem Gini-Koeffizienten ${ }^{3}$ gemessen$50 \%$ größer als die Ungleichheit im Lebenseinkommen. Dieser Schluß wird nicht durch Änderungen des Diskontierungszinssatzes beeinflußt. Er vergleicht weiterhin die Einkommensungleichverteilung dieser Kohorte mit den Daten einer zur gleichen Zeit geborenen Gruppe mit mindestens einem High-School-Abschluß aus dem allgemeinen Census 1960 und erhält bei der Vergleichsgruppe keine wesentlich andere Einkommensungleichverteilung. Die obigen Ergebnisse

\footnotetext{
1 Diese Männer waren Freiwillige für Bomberpiloten sowie Navigatoren im Jahre 1943; sie hatten mindestens einen High-School-Abschluß.

2 Vgl. Lillard, L.A. (1977), S. $42 \mathrm{ff}$.

3 Der Gini-Koeffizient entspricht dem Verhältnis der Fläche zwischen Lorenzkurve und der Gleichverteilungslinie zur Dreiecksfläche unter der Gleichverteilungslinie; er nimmt den Wert 0 an, wenn jedes Individuum ein gleich hohes Einkommen erzielt. Er strebt gegen 1, wenn ein Individuum das gesamte Einkommen in der betrachteten Wirtschaft erzielt. Die Lorenzkurve gibt an, wieviel Prozent des Gesamteinkommens der Wirtschaft auf die ärmsten $n$ Prozent der Individuen entfallen. Bezieht jedes Individuum das gleiche Einkommen, wird die Lorenzkurve zur 45-Grad-Linie; je ungleichmäßiger die Verteilung ist, desto stärker weicht sie nach unten von der 45-Grad-Linie ab.
} 
beruhen damit nicht auf der homogeneren Gruppenzusammensetzung im Vergleich zur Gesamtbevölkerung.

Blomquist errechnet beim Übergang von der Betrachtung des Periodeneinkommens auf die Lebenseinkommensbetrachtung in seiner Simulation eine Abnahme des Gini-Koeffizienten um ca. $40-50 \%{ }^{1}$.

Zum tendenziell gleichen Ergebnis -also der Abnahme der Ungleichverteilungkommt auch Creedy ${ }^{2}$.

Das Lebenseinkommen ist -zusammenfassend gesagt- wesentlich gleichmäßiger verteilt als das Periodeneinkommen.

Im folgenden wird noch kurz auf die Unterschiede im Einkommen von jungen Menschen eingegangen: ein geringes Einkommen von Berufsanfängern/jungen Menschen kann sowohl auf einem Investitionskalkül der Berufsanfänger in der Ausbildung -mit einer (erhofften) späteren Kompensation in Form eines höheren Einkommens- als auch auf geringeren permanenten Fähigkeiten zur Mittelerzielung beruhen. Ein höheres Periodeneinkommen muß nicht unbedingt eine höhere Leistungsfähigkeit widerspiegeln; dies zeigt sich insbesondere daran, daß das Lebenseinkommen aus Arbeit eines Hochschülers ca. dem zweifachen, das eines Abiturienten dem 1,3-fachen des eines Hauptschülers entspricht ${ }^{3}$. Die Betrachtung des Periodeneinkommens (in frühen Lebensjahren erzielt der Hochschüler kein oder nur ein geringes Periodeneinkommen) bildet die Leistungsfähigkeit falsch ab, da die Individuen in ihrer Entscheidung frei sind, die intertemporale Allokation der Investitionen in Einkommenspotential zu bestimmen und somit gegenwärtiges Einkommen in zukünftiges tauschen können ${ }^{4}$ : sie können z.B. durch verlängerte Ausbildungszeiten, verstärkte Fortbildungsbemühungen oder durch eine schlechter dotierte Anfangsstellung mit einer besseren Ausbildung momentan niedriges Einkommen gegen später höheres tauschen.

$1 \quad$ Vgl. Blomquist, N.S. (1981), S. 258.

2 Vgl. Creedy, J. (1977), S. $421 \mathrm{ff}$.

3 Vgl. z.B. Helberger, C. (1982). Aus den Tabellen der Seiten S. 141 u. 152 lassen sich o.a. Werte ableiten. Ein Überblick über einzelne Untersuchungen findet sich in Clement, W./Tessaring, M./Weißhuhn, G. (1980), S. $191 \mathrm{ff}$. Sie kommen in ihrer eigenen Untersuchung (S. 204 f.) zu dem Schluß, daß das Periodeneinkommen 1974 aus Arbeit eines Hochschülers 1974 etwa das 2,6-fache, das eines Abiturienten das 1,5-fache und das eines Menschen mit formalem Ausbildungsabschluß das 1,4-fache des Einkommens eines Beschäftigten ohne Ausbildungsabschluß beträgt. Da das Erwerbsleben eines Akademikers aufgrund der längeren Ausbildungszeit naturgemäß später beginnt, kann auch diese Untersuchung als Unterstützung der oben folgenden Argumentation gebraucht werden.

$4 \quad$ Vgl. Zurbrügg, F. (1990), S. 111. 
Es ist festzuhalten, daß das Lebenseinkommen die Einkommenssituation der Individuen über ihr gesamtes Leben abbildet. Das Periodeneinkommen informiert dagegen nur über die momentane Einkommenssituation und ist zur Beurteilung der individuellen Leistungsfähigkeit eine weniger aussagekräftige Größe als das Periodeneinkommen ${ }^{l}$, da es -wie empirische Untersuchungen ergeben- im Lebensverlauf schwankt. Diese Schwankungen sind kein Sonderfall bei einigen wenigen, sondern betreffen die meisten Steuerzahler (z.B. Ausbildungsvergütung - Lohn/Gehalt- Rente) $)^{2}$. Sie werden tendenziell noch verstärkt, wenn -wie bei der deutschen Einkommensteuer- die Kosten der Berufsausbildung im wesentlichen nicht bei der Ermittlung des zu versteuernden Einkommen berücksichtigt werden dürfen ${ }^{3}$. Extrem sind diese Schwankungen bei Personen, deren Erwerbsphase nur sehr kurz, aber sehr einträglich ist (z.B. Berufsfußballer, Tennisstars).

\subsection{Theoretische Erwägungen}

\subsubsection{Besteuerung nach der individuellen Leistungsfähigkeit}

Für die Untersuchung wird zuerst eine gleiche Lebensdauer für alle Individuen unterstellt. Diese Annahme wird später aufgegeben.

\subsubsection{Gleiche Lebensdauer aller Individuen}

In der Literatur ist umstritten, ob die gesamte Lebensdauer zur Bestimmung der Leistungsfähigkeit in einzelne Perioden aufzuteilen ist ${ }^{4}$ oder ob die gesamte Lebensdauer den relevanten Zeitraum zur Bestimmung der Leistungsfähigkeit abbildet ${ }^{5}$.

Das Leistungsfähigkeitsprinzip fordert eine Besteuerung nach der wirtschaftlichen Fähigkeit, Steuern zu tragen. Die Fähigkeit, zum staatlichen Haushalt beitragen zu können, bestimmt sich aus der ökonomischen Verfügungsmacht eines Individuums über knappe Ressourcen der Wirtschaft. Es sind daher alle Elemen-

\footnotetext{
1 Vgl. Lillard, L.A. (1977); Weizsäcker, C.C. von (1978); Holzmann, R. (1984), S. 19 ff.

2 Vgl. Eggesiecker, F. (1971), S. 253.

3 Vgl. Lang, J. (1988), S. 188.

4 Vgl. z.B. Kirchhof, P. (1985), S. 322.

5 Vgl. z.B. Hackmann, J. (1979), S. 55; Tipke, K. (1993), S. 668 ff.
} 
te zu erfassen, die einem Individuum Leistungsfähigkeit vermitteln ${ }^{l}$. Bei gleicher "Gesamtbemessungsgrundlage" über die Lebensdauer hängt die Höhe der insgesamt zu zahlenden Steuern von der Gleichmäßigkeit des Anfalls der steuerlich relevanten Tatbestände $a b$, wenn ein progressiver Tarif zur Anwendung kommt und eine periodische Besteuerung stattfindet. Dabei gilt, daß Zufälligkeiten und Verzerrungen desto mehr an Einfluß auf die Höhe der steuerlichen Bemessungsgrundlage gewinnen, je kürzer die festgelegte Periodendauer ist ${ }^{2}$.

Es ist daher zu untersuchen, ob ein zeitlich unterschiedlicher Anfall der steuerlich relevanten Sachverhalte eine sachgerechte Begründung für eine unterschiedlich hohe Steuer darstellt und damit eine unterschiedliche Leistungsfähigkeit vorliegt.

Zur Analyse wird angenommen, daß der Indikator der Leistungsfähigkeit zu periodisieren ist.

Die Bejahung der Periodisierung bedeutet die Messung der Dispositionsgewalt über die Ressourcen der Wirtschaft zu bestimmten Zeitpunkten. Fraglich ist, welche Periodenlänge aus Gerechtigkeitserwägungen zu wählen ist. Die Festlegung eines größeren als dem eines unendlich kleinen Zeitraums, kann logisch nicht begründet werden und ist somit willkürlich. Es gibt immer noch kürzere Perioden, für die die Dispositionsmöglichkeiten des Individuums bestimmt werden können und dann aus Gerechtigkeitsgründen zu wählen sind. Das führt zu dem Ergebnis, daß die relevante Besteuerungsperiode nicht ein Jahr, sondern lediglich einen "Augenblick" umfaßt, da nur dann auf die Dispositionsgewalt zu jedem Zeitpunkt zurückgegriffen werden kann. Die Zeit ist damit gewissermaßen zu atomisieren. Die gängige Festlegung der Periodenlänge auf ein Jahr ist als willkürlich abzulehnen.

Um die Frage nach der richtigen Periodenlänge (Lebensdauer oder ein unendlich kleiner Zeitabschnitt) zu beantworten, wird zuerst auf den umfassendsten Indikator der Messung der individuellen Leistungsfähigkeit, den potentiellen Mittelerwerb, eingegangen. In einem weiteren Schritt wird untersucht, ob sich Unterschiede ergeben, wenn von der Potentialbesteuerung abgegangen und auf die Besteuerung von tatsächlich erzielten Größen bei vollkommener Information übergegangen wird. Anschließend werden die gewonnenen Ergebnisse auf eine Welt mit unvollkommener Information übertragen.

$1 \quad$ Vgl. Ebnet, O. (1978), S. 28.

2 Vgl. Tipke, K./Lang, J. (1991), S. 189; BFH v. 28.7.1961 -VI 25/61 U, BStBl. III 1961, S. 436-437 (436). 
Die individuelle Leistungsfähigkeit wird bestimmt durch die Verfügungsmacht über Ressourcen, die investiert oder konsumiert werden. Möchte das Individuum seinen gesamten potentiellen Mittelerwerb bereits im ersten Jahr seines Lebens konsumieren, muß es einen Kredit aufnehmen. Für die Höhe des Kredits ist die Einschätzung der Verfügungsgewalt durch einen Dritten bestimmend, der sich unter diesen Modellannahmen am Potential des Kreditnehmers orientiert ${ }^{l}$. Hier kann das Individuum somit durch Verkauf seines Potentials oder durch Kreditaufnahme über sein "Lebenspotential" verfügen.

Auf die Besteuerung übertragen, ergibt sich eine Bemessungsgrundlage, bei der der zeitliche Anfall der steuerlich relevanten Tatbestände, also den Möglichkeiten zum Mittelerwerb, lediglich durch die Höhe des Diskontierungszinssatzes berücksichtigt wird. Ob das "Periodenpotential" des Steuerpflichtigen über die einzelnen Lebensjahre schwankt oder gleichmäßig ist, ist -bei gleichem Barwert des "Lebenspotentials"- für die Höhe der steuerlichen Bemessungsgrundlage unerheblich.

Aus dem Ideal der Potentialbesteuerung kann damit die Lebensdauer des Individuums als "richtige" Periodenlänge abgeleitet werden.

Es wird auf tatsächlich verwirklichte Größen als Indikator der Leistungsfähigkeit übergegangen, wobei die Annahme der vollständigen Information bestehen bleibt.

In einer Welt mit vollständiger exante Information über die in die Bemessungsgrundlage eingehenden Tatbestände ist es möglich, sämtliche Faktoren, die den gewählten Indikator beeinflussen, von vornherein zu bestimmen. Somit kann auch das Lebenseinkommen bestimmt werden ${ }^{2}$. Da aber in dieser Modellwelt ebenfalls die Möglichkeit besteht, durch Kreditaufnahmen bereits am Lebensanfang über den gesamten zukünftigen Mittelerwerb zu disponieren, ist auch hieraus die Ableitung der Lebensdauer als relevanten Zeitraum mit derselben Argumentationslinie wie bei der Potentialbesteuerung möglich.

In diesen Fällen der vollständigen Information ist es unstrittig, die Lebensdauer als relevante Besteuerungsperiode anzusehen und alle Steuerpflichtigen, bei denen der jeweilige Indikator den gleichen Wert annimmt, gleich zu betrachten und gleich zu behandeln. Das gilt unabhängig von zeitlichen Schwankungen der Bemessungsgrundlage. Die zeitliche Verteilung ist daher keine sachgerechte Begründung für unterschiedlich hohe Steuern.

$1 \quad$ Nebenbedingung sind Sanktionsmöglichkeiten des Dritten, um das Individuum zur Ausnutzung seines Potentials zu zwingen.

2

Vgl. Hackmann, J. (1979), S. 55. 
Können diese Ergebnisse auf die reale Welt übertragen werden?

Einziger Unterschied ist der Informationsstand: in der realen Welt gibt es exante nur unvollständige Informationen bzw. Spekulationen über die Zukunft; expost herrscht jedoch in einer Welt mit und ohne vollständige Information der gleiche Wissensstand (der dem exante Wissensstand in einer Welt mit vollkommener Information entspricht). Da es aus Gerechtigkeitserwägungen (nicht jedoch aus Praktikabilitätsüberlegungen) heraus uninteressant ist, wann die Informationen zur Verfügung stehen -sofern das Ziel einer gerechten Besteuerung verwirklicht werden kann- ist es in der realen Welt ein Gebot des Gleichheitssatzes, zur Bestimmung der Leistungsfähigkeit die Lebensdauer heranzuziehen und eine kürzere Periodisierung nicht zuzulassen.

Das Unterscheidungsmerkmal "zeitlicher Anfall" ist als nicht sachgerecht abzulehnen. Die Festlegung eines anderen Zeitraums als der der Lebensdauer ist willkürlich und gleichheitssatzwidrig.

\subsubsection{Unterschiedliche Lebensdauer der Individuen}

Bei der bisherigen Analyse der Indikatoren wurde die gleiche Lebensdauer aller Individuen vorausgesetzt. Diese Annahme wird jetzt aufgegeben. Damit stellt sich die Frage, ob die Lebensdauer bei der Bestimmung der Leistungsfähigkeit von Bedeutung oder unerheblich ist. Es wird untersucht, ob die Definition der Leistungsfähigkeit beibehalten werden kann oder dahingehend zu modifizieren ist, da $\beta$ bei einem progressiven Steuersystem die Höhe des anzuwendenden Steuersatzes lediglich von der Höhe des Lebenseinkommens, nicht aber von der Lebensdauer, abhängt.

Die Konsequenzen aus dieser Frage werden aus folgendem Beispiel ersichtlich. In einer Welt ohne Zinsen wird davon ausgegangen, daß zwei Individuen ein Lebenseinkommen von jeweils 1.000.000,- DM erzielen; A lebt 50 Jahre, B 10 Jahre. Wird die Verfügungsgewalt auf ein Jahr heruntergerechnet, ergibt sich für A ein Betrag von 20.000,- DM und für B 100.000,- DM pro Periode. Sind beide Individuen gleich leistungsfähig, da sie das gleiche Lebenseinkommen erzielen, oder nicht, da sie eine unterschiedliche Lebensdauer haben? Ist also bei einem progressiven Tarif für beide Individuen der gleiche Grenzsteuersatz anzuwenden? Dazu wird auf den Begriff "Leistungsfähigkeit" zurückgegriffen, d.h. auf die Fähigkeit, zur Finanzierung des staatlichen Finanzbedarfs beizutragen. Das Wort "Leistung" hat im allgemeinen einen Zeitbezug (z.B. in der Physik "Arbeit pro Zeiteinheit"). Somit muß auch die Lebensdauer der Individuen in die steuerliche Bemessungsgrundlage eingehen. 
Dasselbe Ergebnis ergibt sich aus folgenden Überlegungen ${ }^{l}$ : die Leistungsfähigkeit eines Individuums bestimmt sich aus der Fähigkeit, zum staatlichen Haushalt beitragen zu können. Diese Fähigkeit setzt jedoch erst ein, wenn das Individuum das Existenzminimum überschritten hat. Wird davon ausgegangen, daß A in jeder Periode gerade das Existenzminimum erzielt und 100 Jahre alt wird, während $\mathrm{B}$, dasselbe -über alle Perioden gleichmäßig verteilte- Lebenseinkommen erzielt, im Alter von 30 Jahren stirbt, ist es unstrittig, da $B$ das Existenzminimum steuerfrei bleibt, A also keine Steuer zu entrichten hat. B muß aber, da er bei kürzerer Lebensdauer das gleiche Einkommen erzielt, in jedem Jahr über dem Existenzminimum liegen; somit besitzt B die Fähigkeit (bei gleichem Lebenseinkommen wie A), zum staatlichen Haushalt beizutragen. Die Lebensdauer der Individuen stellt somit einen die Leistungsfähigkeit beeinflussenden Faktor dar und muß bei der Besteuerung berücksichtigt werden.

Die Individuen sind bei identischem Lebenseinkommen bei gleicher Lebensdauer als gleich leistungsfähig einzuschätzen. Bei gleicher Lebensdauer ist derjenige leistungsfähiger, der ein höheres Lebenseinkommen erzielt. Fraglich ist, wann Individuen als gleich leistungsfähig einzuschätzen sind, wenn sie sowohl ein unterschiedliches Lebenseinkommen als auch eine unterschiedliche Lebensdauer erreichen. Dies wird hier nicht weiter behandelt, da es eine Frage der vertikalen Gerechtigkeit ist und über die Gestaltung des Tarifs gelöst werden muß. Dies ist nicht Gegenstand der vorliegenden Untersuchung.

\subsubsection{Neutralität der Besteuerung}

Ein neutrales Steuersystem fordert, daß Entscheidungen der Steuerpflichtigen durch steuerliche Erwägungen nicht verzerrt werden und somit die relative Vorteilhaftigkeit verschiedener Alternativen im Vergleich zu einer Laissez-FaireÖkonomie nicht beeinflußt wird.

Bei einem progressiven Steuersystem wird die Höhe des Grenzsteuersatzes von der Höhe der Bemessungsgrundlage beeinflußt: je höher die Bemessungsgrundlage, desto höher der Grenzsteuersatz. Wird die Lebenszeit des Individuums in Perioden aufgeteilt und schwankt die steuerliche Bemessungsgrundlage zwischen diesen Perioden, hat der Steuerpflichtige eine höhere Steuer zu entrichten als bei einer gleichmäßigen steuerlichen Bemessungsgrundlage. Er kann durch seine Entscheidungen zumindest teilweise Einfluß auf die Gleichmäßigkeit der steuerlichen Bemessungsgrundlage nehmen. Als Beispiel sind die Entscheidungen zwischen Arbeit und Freizeit bzw. zwischen Arbeit und Ausbildung zu nen-

Vgl. Schneider, D. (1978), S. 51 f. 
nen: bei gleichem "Lebenseinkommen" zahlt derjenige mit einer längeren Ausbildungszeit (z.B. Akademiker) eine höhere Steuer als der früher ins Arbeitsleben Eintretende, da bei diesem sich eine jeweils geringere periodische Bemessungsgrundlage ergibt. Dies gilt auch, wenn ein Individuum in einer Periode mehr und in einer anderen weniger arbeitet im Vergleich zu einem anderen, das in jeder Periode gleich viel arbeitet. Will der Steuerpflichtige seine insgesamt zu entrichtende Steuer verringern, muß er die steuerliche Bemessungsgrundlage über den Zeitablauf glätten. Unter Umständen wird deshalb eine Alternative, die in einer Welt ohne Steuern nur suboptimal ist, aufgrund ihres gleichmäßigen Ertrags in einer Welt mit Besteuerung optimal und deshalb vom Individuum präferiert.

Um dies zu vermeiden, muß die Besteuerungsperiode den ökonomischen Zeithorizont, also die überschaubare Planungsperiode des Entscheidenden umfassen. Damit wird sichergestellt, daß die Entscheidung zugunsten einer bestimmten Alternative nicht durch Progressionseffekte beeinflußt wird, die ihre Ursache einzig im unterschiedlichen zeitlichen Anfall der steuerlich relevanten Tatbestände hat ${ }^{l}$. Als ökonomischer Zeithorizont werden in der Literatur z.B. verschiedene Lebensabschnitte eines Individuums herangezogen. Dies könnte normativ mit dem Argument begründet werden, daß die Individuen in den verschiedenen Lebensabschnitten "andere Personen" sind, da sie sich im Laufe der Zeit verändern und in jedem Abschnitt andere Erfahrungen machen ${ }^{2}$. Diese Vorgehensweise ist abzulehnen, da die verschiedenen Lebensabschnitte nicht eindeutig abgrenzbar sind und die Planungen der Individuen über die Grenzen eines Lebensabschnittes hinausgehen. Der ökonomische Zeithorizont verändert sich im Zeitablauf, da im Laufe der Zeit mehr Informationen verfügbar sind; dadurch verschiebt er sich kontinuierlich in die Zukunft. Ein Zeitpunkt gehört deswegen zu einer Vielzahl von ökonomischen Zeithorizonten ${ }^{3}$; die eindeutige Bestimmung eines ökonomischen Zeithorizonts als Besteuerungsperiode ist nicht möglich.

Daraus folgt, daß ein Steuersystem mit einem progressiven Steuersatz nur bei einer Besteuerungsperiode entscheidungsneutral sein kann. Für die Bestimmung des anzuwendenden Steuersatzes aufgrund von Neutralitätsüberlegungen ist die Größe relevant, die die Leistungsfähigkeit des Individuums über sein ganzes Leben hinweg abbildet. Somit ist die Lebensdauer des Individuums als Besteuerungsperiode heranzuziehen.

\footnotetext{
1 Vgl. Steger, W.A. (1958), S. 223.

2 Vgl. Hackmann, J. (1976), S. 6. Zur Diskussion dieser Vorschläge vgl. Vickrey, W. (1959), S. $124 \mathrm{ff}$.

3 Vgl. Hackmann, J. (1979), S. 49 f.
} 


\subsubsection{Praktikabilität der Besteuerung}

Es wird untersucht, welche Periodenlänge aufgrund von Praktikabilitätsüberlegungen zu präferieren ist.

Der Zeitraum, für den Steuerzahlungen bzw. Vorauszahlungen auf die endgültige Steuerschuld zu leisten sind, sollte aus Praktikabilitätsüberlegungen nicht zu lang sein. Dafür sprechen folgende Gründe:

- Der Staat hat einen stetigen Finanz- und Liquiditätsbedarf für seine laufenden Ausgabenprogramme, braucht also einen stetigen Liquiditätszufluß.

- Die Steuerpflichtigen besitzen noch eher alle besteuerungsrelevanten Unterlagen und können belegbare Auskünfte über steuerlich relevante Tatbestände geben.

- Bei einer kurzen Besteuerungsperiode ist eher gewährleistet, daß die Steuerpflichtigen an ihre Pflicht zur Steuerzahlung denken und die entsprechenden Mittel noch verfügbar sind, d.h. sie wurden somit nicht anderweitig, z.B. zu Konsumzwecken, verwendet.

- Die an den Staat abzuführende Steuer erscheint geringer, wenn sie nicht in einer Summe für einen längeren Zeitraum, sondern in kleineren Beträgen für einen entsprechend kürzeren Zeitraum abzuführen ist; dadurch sind geringere Steuerwiderstände zu erwarten (psychologischer Grund).

\subsection{Ergebnis: Länge der Besteuerungsperiode}

Zur Bestimmung der Leistungsfähigkeit eines Individuums muß die gesamte Lebensdauer herangezogen werden; dies gilt besonders bei Anwendung eines progressiven Tarifs, da -wie empirische Untersuchungen zeigen- das Periodeneinkommen Schwankungen unterworfen ist. Ein anderer Zeitraum als die Lebensdauer ist willkürlich und gleichheitssatzwidrig. Diese Aussage ergibt sich aus der Forderung nach der Besteuerung gemäß der individuellen Leistungsfähigkeit und der Forderung nach einem neutralen Steuersystem. Die Indikatoren des tatsächlichen Mittelerwerbs sowie der des Konsumpotentials sind somit gleich; daher wird nur noch der Indikator des tatsächlichen Mittelerwerbs weiter betrachtet.

Aus der Forderung nach der Besteuerung gemäß der individuellen Leistungsfähigkeit ergibt sich auch, daß die unterschiedliche Lebensdauer bei der Ermittlung der Steuerhöhe zu berücksichtigen ist. Zwei Individuen sind als gleich lei- 
stungsfähig anzusehen, wenn ihr Lebenseinkommen und ihre Lebensdauer gleich sind. Ein Individuum ist leistungsfähiger, wenn bei gleichem Lebenseinkommen die Lebensdauer geringer ist als bei einem anderen. Sind beide Parameter unterschiedlich, ist dies über die Tarifgestaltung (vertikale Gerechtigkeit) zu lösen. Hierauf wird im Rahmen dieser Untersuchung nicht weiter eingegangen.

Aus Praktikabilitätsüberlegungen soll die Besteuerungsperiode kurz sein. Als Lösungsmöglichkeit für diesen Zielkonflikt ist eine den Steuersatz bestimmende, im Zeitablauf möglichst geringen Schwankungen unterworfene, periodische Bemessungsgrundlage heranzuziehen. Dadurch ist sichergestellt, daß die periodisch zu leistenden Steuer(voraus)zahlungen ungefähr den Steuerzahlungen entsprechen, die sich bei Anwendung des durch die Lebensdauer und des Lebenseinkommens bestimmten Steuersatzes auf die periodische Bemessungsgrundlage ergeben. 
Michael Ohmer - 978-3-631-75563-1

Downloaded from PubFactory at 01/11/2019 03:31:45AM

via free access 


\section{Kapitel}

\section{Zusammenfassung des ersten Teils}

In diesem Teil der Arbeit wurde auf die Grundprinzipien der Besteuerung, nämlich Gerechtigkeit und Effizienz eingegangen und hieraus erste Schlüsse für ein Steuersystem gezogen.

Von den drei angesprochenen Möglichkeiten der Steuerlastverteilung (Kopfsteuer, Äquivalenz- und Leistungsfähigkeitsprinzip) kann nur das Leistungsfähigkeitsprinzip aus allen hier behandelten philosophischen und theologischen Denkrichtungen abgeleitet werden. Die Besteuerung nach dem Äquivalenzprinzip ist nur mit dem Ansatz von Rawls zu vereinbaren.

Das Leistungsfähigkeitsprinzip wird auch als Fundamentalprinzip der Besteuerung von Gesetzgebung, Rechtsprechung und Literatur angesehen. Das Leistungsfähigkeitsprinzip darf allerdings nur in Verbindung mit den anderen Grundwertungen im Grundgesetz gesehen werden, durch die es konkretisiert wird bzw. die dem Gesetzgeber ein Abweichen vom Leistungsfähigkeitsprinzip gestatten oder sogar gebieten.

Das Leistungsfähigkeitsprinzip entspricht damit dem gegenwärtigen Gerechtigkeitsverständnis.

Ein weiteres Kriterium zur Beurteilung eines Steuersystems ist die Effizienz. Darunter wird sowohl Effizienz im ökonomischen Sinne als auch Praktikabilität verstanden.

Zuerst wurde auf die Effizienz im ökonomischen Sinne eingegangen. Werden Handlungsalternativen durch die Besteuerung unterschiedlich belastet, ist für das Individuum eine Steuervermeidungsplanung lohnend, um die günstigsten Alternativen zu finden. Es ergibt sich möglicherweise eine andere Rangfolge der Vorteilhaftigkeit von verschiedenen Alternativen. Durch diese Entscheidungsverzerrung entstehen bei den Bürgern zusätzlich zu den abzuführenden Steuern (Einkommenseffekt) weitere Belastungen (excess burden), da sie ihren ursprünglichen Plan ändern (Substitutionseffekt).

Ein entscheidungsneutrales Steuersystem bedeutet nun, daß steuerliche Vorschriften des analysierten Steuersystems die Entscheidungen eines Individuums im Vergleich zu einer Laissez-Faire-Ökonomie mit Ausnahme des Einkommenseffekts nicht verzerren. Dies bedeutet: die vorteilhafteste Handlungsalternative in einer Laissez-Faire-Ökonomie ist auch in einer Welt mit einem entscheidungsneutralen Steuersystem die vorteilhafteste. Wohlfahrtsminderungen aufgrund des Substitutionseffekts treten damit nicht auf, die Effizienz der 
Ressourcenallokation wird nicht beeinträchtigt und beim Steuerpflichtigen fallen überdies keine steuerlichen Planungskosten an.

Der Forderung nach einem neutralen Steuersystem liegt keine besondere steuerliche Zielvorstellung zugrunde; sie tritt stattdessen akzessorisch zu den Mechanismen der marktwirtschaftlichen Ordnung hinzu. Ihr Ziel ist es, einen durch steuerliche Vorschriften unbeeinflußten Marktmechanismus zu erhalten.

Ein effizientes Steuersystem bedeutet neben der Effizienz im ökonomischen Sinne, daß die Steuer in der Realität auch "praktikabel" erhoben werden kann. "Praktikabel" umfaßt dabei aber nicht allein die Möglichkeit der Steuererhebung, sondern ebenso den in der Praxis dafür notwendigen Aufwand, der sowohl beim Fiskus als auch beim Steuerpflichtigen gering sein sollte. In diesen Problemkreis fällt ebenfalls die Frage der Möglichkeit der Steuerumgehung, da auch diese sowohl einen Aufwand beim Steuerpflichtigen als auch beim Fiskus hervorruft.

Erste Ableitungen aus den diskutierten Grundprinzipien der Besteuerung wurden gebildet und auf das Bezugsobjekt der Leistungsfähigkeit, auf mögliche Indikatoren der Leistungsfähigkeit sowie auf den Zeitraum der relevanten Besteuerungsperiode eingegangen.

Bezugsobjekte der Leistungsfähigkeit sind nur natürliche Personen. Unternehmen besitzen keine eigene Leistungsfähigkeit, sondern nur die hinter den Unternehmen stehenden Individuen, die am Erfolg (Gewinn oder Verlust) der Unternehmung durch Ausschüttungen, Liquidation oder Verkauf der Gesellschaftsrechte partizipieren.

Der nutzentheoretisch definierte Leistungsfähigkeitsbegriff wurde aus Praktikabilitätserwägungen ausgeschieden und der verteilungspolitische Leistungsfähigkeitsbegriff herangezogen. Nach diesem ist die wirtschaftliche Leistungsfähigkeit der Zuwachs an ökonomischer Verfügungsmacht über knappe Ressourcen der Wirtschaft in einem bestimmten Zeitraum. "Verfügungsmacht" besagt, daß ein Individuum frei zwischen konsumtiver und investiver Verwendung der ihm zur Verfügung stehenden Ressourcen entscheiden kann.

Der vollständigste Indikator der Leistungsfähigkeit ist dabei das Potential des Individuums zum Mittelerwerb; er ruft keinen Substitutionseffekt hervor und trägt zu einem (im ökonomischen Sinne) effizienten Steuersystem bei. Dieser Indikator ist jedoch aufgrund von Praktikabilitäts- und Objektivitätsgründen abzulehnen.

Es muß daher auf eine unvollständigere Abbildung der individuellen Leistungsfähigkeit zurückgegriffen werden. Hierzu bietet sich der Indikator des verwirk- 
lichten Mittelerwerbs (Einkommen) an, der jedoch die Dispositionsmöglichkeiten nur unvollständig abbildet, da er die Ressource "Zeit" nicht in vollem Umfang umfaßt: es wird nur die Arbeitszeit, nicht aber die Freizeit des Individuums berücksichtigt. Dieser Indikator verstößt auch gegen die Forderung nach einem effizienten und neutralen Steuersystem, da die Arbeit-Freizeit-Entscheidung verzerrt wird.

Trotzdem wird im weiteren Verlauf auf diesen Indikator zurückgegriffen, da er die Leistungsfähigkeit nach dem verteilungspolitischen Leistungsfähigkeitsbegriff vollständiger abbildet als die anderen behandelten, praktikablen Indikatoren.

Der für die Besteuerung relevante Zeitraum ist bei einem progressiven Tarifverlauf von Bedeutung, da -wie empirische Untersuchungen zeigen- das Periodeneinkommen im Zeitablauf Schwankungen unterworfen ist. Als Besteuerungsperiode ist die gesamte Lebensdauer heranzuziehen. Dies ergibt sich aus Gerechtigkeits- und Neutralitätsüberlegungen. Aus Praktikabilitätsüberlegungen müssen jedoch periodische Steuerzahlungen geleistet werden. 
Michael Ohmer - 978-3-631-75563-1

Downloaded from PubFactory at 01/11/2019 03:31:45AM

via free access 


\section{Teil}

\section{Periodeneinkommen als Bemessungsgrundlage der Besteuerung}

Das Ergebnis des 1. Teils der Arbeit war, daß das Lebenseinkommen der geeignete Indikator zur Messung der individuellen Leistungsfähigkeit ist. Aufgrund von Praktikabilitätsüberlegungen (z.B. laufender Finanzbedarf des Staates) muß aber auf periodische Größen zurückgegriffen werden. Eine solche Größe ist das Periodeneinkommen.

Im 2. Teil der Arbeit wird untersucht, ob das Periodeneinkommen eine effiziente, geeignete und gerechte Steuerbemessungsgrundlage ist. Als Maßstab zur Beurteilung dieser Frage dienen die im 1. Teil diskutierten Kriterien: das Leistungsfähigkeitsprinzip, die Forderung nach einem entscheidungsneutralen Steuersystem sowie das Erfordernis der Praktikabilität. Beim dem durch das Leistungsfähigkeitsprinzip konkretisierten Gleichheitssatz wird nur geprüft, ob er materiell, d.h. ökonomisch verwirklicht ist. Ob ein Abweichen des Gesetzgebers von diesem Prinzip möglich oder gar geboten ist, wird nicht untersucht.

In einem ersten Schritt werden verschiedene Einkommensdefinitionen dargestellt und einer ersten Beurteilung unterzogen.

In einem zweiten Schritt werden Sonderprobleme der Periodeneinkommensbesteuerung behandelt. Dabei wird auf Windfall Profits bzw. unregelmäßige Einkünfte, auf die Zins-, Wertänderungs-, die Unternehmensbesteuerung, auf die Behandlung von Erbschaften und Schenkungen sowie auf Verfahren zur Glättung des Steuersatzes eingegangen. 
Michael Ohmer - 978-3-631-75563-1

Downloaded from PubFactory at 01/11/2019 03:31:45AM

via free access 


\section{Kapitel}

\section{Diskussion verschiedener Einkommensbegriffe}

\section{Einkommen nach der Konsumtionsfondstheorie}

Hauptvertreter der Konsumtionsfondstheorie ist Schmoller; weitere Vertreter sind Sax und Held ${ }^{l}$.

Schmoller definiert Einkommen als "... die Summe von Mitteln, welche der Einzelne, ohne in sein Vermögen zurückzukommen, für sich und seine Familie, für seine geistigen und körperlichen Bedürfnisse, für seine Genüsse und Zwecke, kurz für die Steigerung seiner Persönlichkeit in einer Wirtschaftsperiode verwenden kann."2.

Zum Einkommen gehören danach nicht nur der im Tauschverkehr erzielte Reinertrag, sondern weiterhin "..jeder unmittelbare Verbrauch, der in der Benützung eines eigenen Hauses, eigener Pferde, eines eigenen Gartens oder auch nur in dem Genusse der Möglichkeiten einer solchen Benützung liegt." ${ }^{3}$. Die Bewertung erfolgt zum gemeinen Wert, weil "..der Genuss ... dem Betreffenden stets soviel wert sein (muß [Anmerkung des Verfassers]), als der etwaige Ertrag aus der Summe, die durch den Verkauf der Sache erlöst werden könnte"4.

Die Ausgaben für den notwendigen Lebensunterhalt gehören für Schmoller zur Bedürfnisbefriedigung, ein Abzug vom Einkommen ist nicht zugelassen ${ }^{5}$.

Bei dieser Theorie ist Einkommen nicht nach seiner Herkunft, sondern nach seiner Verwendungsfähigkeit zur Bedürfnisbefriedigung definiert ${ }^{6}$; es wird durch die Idee des Konsumtionsfonds begrenzt. Einkommen sind demnach nur die Mittel, die bei wirtschaftlichem, rationalen Verhalten zur Bedürfnisbefriedigung verzehrt werden dürfen, also "..alles was man in rechtlicher und solider Weise verzehren kann."7. Die anderen Einnahmen sind in das Vermögen aufzunehmen $^{8}$. Nicht als Einkommen gelten grundsätzlich einmalige Einnahmen wie Erbschaften, Schenkungen und Lotteriegewinne, da sie bei rationalem, wirt-

\footnotetext{
Vgl. Bauckner, A. (1921), S. 17 f.

2 Schmoller, G. (1863), S. 52.

3 Schmoller, G. (1863), S. 53.

4 Schmoller, G. (1863), S. 76.

5 Vgl. Schmoller, G. (1863), S. 20, 53.

6 Vgl. Sax, E. (1887), S. 364 f.

7 Held, A. (1872), S. 54.

8 Vgl. Moll, B. (1924), S. $122 \mathrm{f}$.
} 
schaftlichen Verhalten nicht für Konsumzwecke verbraucht, sondern dem Vermögen zufließen sollen ${ }^{l}$.

Zur Beantwortung der Frage, was Einkommen ist, muß ein Werturteil darüber abgegeben werden, welche Einnahmen zur Bedürfnisbefriedigung verwendet werden dürfen und welche dem Vermögen zufließen. Die Antwort fällt je nach den individuellen Verhältnissen des Steuerpflichtigen anders aus: ein armer Familienvater mit vielen kleinen Kindern sollte eine auch noch so kleine Erbschaft sparen (es also entsteht kein Einkommen), während ein reicher kinderloser Steuerpflichtiger dieses Geld konsumieren kann und somit Einkommen erzielt ${ }^{2}$.

Die Abgabe eines Werturteils zur Verwendungsfähigkeit von Einnahmen für Konsumzwecke ist intersubjektiv nicht nachvollziehbar. Die Anforderungen, die an ein Meßkonzept sowie an den Grundsatz der Gesetzesbestimmtheit gestellt werden, sind also nicht erfüllt.

Die ökonomische Verfügungsmacht des Steuerpflichtigen steigt auch durch Einnahmen/Zuflüsse, die bei dem in dieser Einkommenstheorie als Leitbild aufgestellten rationalen Verhalten gespart werden sollten. Die die Leistungsfähigkeit repräsentierende ökonomische Verfügungsmacht wird damit durch dieses Meßkonzept nicht vollständig abgebildet.

Dieser Einkommensbegriff ist somit als Indikator der Leistungsfähigkeit nicht geeignet.

\section{Einkommen nach der Produktionseinkommenstheorie}

Sie wird u.a. von Roscher und Lotz vertreten.

Ziel dieser Theorie ist die Besteuerung des Produktionseinkommens. Einkommen kann nach dieser Konzeption nur sein, was neu (originär) in der Volkswirtschaft produziert wurde. Das bestehende Volksvermögen darf nicht einer Einkommensteuer unterworfen werden, da ein Staat seine wiederkehrenden Ausgaben dauerhaft nur aus Steuern entrichten kann, die von den Steuerpflichtigen aus im Laufe der Periode Neuerworbenem bezahlt werden können ${ }^{3}$. Eine Volkswirtschaft liefert nach Lotz nur dann mehr an Mitteln für Steuern, wenn die Produk-

\footnotetext{
$1 \quad$ Vgl. Moll, B. (1924), S. 123.

2 Vgl. Moll, B. (1924), S. 123 f.

3 Vgl. Lotz, W. (1917), S. 446.
} 
tion gesteigert wird und die produzierten Güter und Dienstleistungen einen höheren Wert aufweisen als die Produktionskosten ${ }^{l}$.

Bei Wertsteigerungen, Erbschaften oder Spielgewinnen werden nur geldwerte Güter übertragen; in dem Umfang, in dem jemand reicher wird, wird ein anderer innerhalb der Volkswirtschaft ärmer und weniger steuerkräftig (damit wird kein neuer Reichtum über den schon vorhandenen hinaus gebildet). Somit liegt nach Lotz kein Einkommen vor ${ }^{2}$.

Einkommen sind nur diejenigen Einnahmen, die aus einer wirtschaftlichen Tätigkeit herrühren ${ }^{3}$, wobei hierunter die "..planmäßige Handlung des Menschen, um seinen Bedarf an ä u B e r e n G ü t e r n zu befriedigen"4,5 verstanden wird.

Das Einkommen besteht aus Produkten (Arbeitserfolgen oder Vermögensnutzungen), die der Produzent selbst verbrauchen (so z.B. das vom Bauer zum Eigenverbrauch produzierte Getreide) oder zur Befriedigung anderer Bedürfnisse veräußern kann ${ }^{6}$; ein Marktumsatz ist zur Bestimmung des Einkommens nicht erforderlich.

Das Einkommen ergibt sich bei Lotz nach Abzug der "..unentbehrlichen Bedürfnisse des Produzenten.."7. Bei Personen, die aus ihrer Arbeitskraft Einkommen erzielen, müssen deshalb Haushaltskosten, Abschreibungen auf ihre Arbeitskraft, Ausbildungskosten u.a. bei der Ermittlung des zu versteuernden Einkommens als Produktionskosten ebenso abzugsfähig sein wie die Schuldzinsen für Haushaltskredite, da z.B. ein von einem Arbeitslosen aufgenommener Konsumtivkredit der Erhaltung seiner Arbeitskraft bis zur Erlangung einer neuen Stellung und damit von Verdienst dient ${ }^{8}$.

Nach dieser Einkommensdefinition steigt die steuerliche Bemessungsgrundlage des einzelnen nur, wenn die Zunahme der persönlichen Leistungsfähigkeit durch die Zunahme der volkswirtschaftlichen Produktion hervorgerufen wurde und

I Vgl. Lotz, W. (1917), S. 446.

2 Vgl. Lotz, W. (1917), S. 446.

$3 \quad$ Vgl. Roscher, W. (1918), S. 438.

4 Roscher, W. (1918), S. 5.

5 Ein äußeres Gut stellt ein Mensch durch den Beistand der Außenwelt zur Bedürfnisbefriedigung her oder erhält es, wohingegen ein inneres Gut der Mensch als Gabe besitzt oder in seinem Inneren erzeugt, wie z.B. Gesundheit (vgl. Hermann, F.B.W. von (1870), S. 103 f.).

6 Vgl. Roscher, W. (1918), S. $438 \mathrm{f}$.

7 Roscher, W. (1918), S. 439 f.

$8 \quad$ Vgl. Lotz, W. (1917), S. 449. 
nicht auf der Übertragung von geldwerten Gütern oder auf Wertsteigerungen beruht.

Für die Fähigkeit des einzelnen Steuerpflichtigen, zum Finanzbedarf des Staates beitragen zu können, ist es aber irrelevant, welche Zunahme die Leistungsfähigkeit der gesamten Volkswirtschaft erfuhr. Von Bedeutung ist die individuelle Zunahme der ökonomischen Verfügungsgewalt über die Güter der Volkswirtschaft, unabhängig davon, ob diese durch die Steigerung der volkswirtschaftlichen Produktion oder durch die Übertragung von Gütern (z.B. Spielgewinne) hervorgerufen wurde.

Die Produktionseinkommenstheorie ist somit als Indikator für die Leistungsfähigkeit des Steuerpflichtigen abzulehnen, da sie die Dispositionsmöglichkeiten des Steuerpflichtigen nicht vollständig abbildet.

\section{Einkommen nach der Quellentheorie}

Hauptvertreter der Quellentheorie ist Fuisting ${ }^{1,2}$.

Fuisting definiert Einkommen als "...die Gesammtheit der Sachgüter, welche in einer bestimmten Periode (Jahr) dem Einzelnen als Erträge dauernder Quellen der Gütererzeugung zur Bestreitung der persönlichen Bedürfnisse für sich und für die auf den Bezug ihres Lebensunterhaltes von ihm gesetzlich angewiesenen Personen (Familie) zur Verfügung stehen." ${ }^{3}$.

Unterschieden werden fünf Quellen: Geldkapital, Grundbesitz, Gewerbebetrieb, Arbeitstätigkeit und Hebungsrechte (Rechte auf wiederkehrende Bezüge, die weder aus dem eigenen Vermögen noch aus einer gegenwärtigen Arbeitstätigkeit herrühren) $)^{4}$.

Einkommen und Vermögen sind laut Fuisting wirtschaftliche Gegensätze: Einkommen muß -wenn es als Maßstab der Besteuerung dienen soll- nach wirtschaftlichen Gesichtspunkten von den Vermögensmehrungen/-minderungen abgegrenzt werden, um die zur Bestreitung der persönlichen Lebensbedürfnisse zur Verfügung stehenden Güter von dem auf Dauer zu erhaltenden Vermögensbestand zu trennen. Da dadurch das Einkommen auf die Verfügbarkeit für die persönlichen Lebensbedürfnisse gerichtet ist, kann der Einkommensbegriff nur

\footnotetext{
1 Vgl. Kirchhof, P. (1992a), §2 Anm. A 310.

2 Ähnlich ist die Einkommensdefinition der Periodizitätstheorie (vgl. Wagner, A. (1892), S. 405 f.; Weiß, B. (1878), S. 684 ff.; Cohn, G. (1885), S. 211).

3 Fuisting, B. (1902), S. 110.

4 Zur Darstellung vgl. Fuisting, B. (1902), S. 109 ff.
} 
auf natürliche Personen angewendet werden; juristische Personen können kein Einkommen, sondern nur Ertrag und Vermögen aufweisen.

Als Ertrag bzw. Einkommen kommt ausschließlich der Zugang von Gütern in Betracht, die Gegenstand des wirtschaftlichen Tauschverkehrs sind und einen Geldwert haben. Dabei ist unerheblich, ob es sich um Geld oder geldwerte Güter (bei Naturalbezügen) handelt. Andere Güter fallen, da kein Bewertungsmaßstab vorliegt, aus der Einkommensdefinition heraus.

Der Rohertrag einer Quelle ist alles, "..was sie als solche in ihrer Gesamtheit und in ihren einzelnen Bestandtheilen innerhalb der maßgebenden Jahresfrist infolge ihrer bestimmungsmäßigen Verwendung zur Ertragserzielung an Geld und geldwerthen Gütern thatsächlich hervorgebracht hat."I.

Die Bewertung erfolgt zum gemeinen Wert zum Zeitpunkt des Eingangs bzw. nach der Fälligkeit; somit ist der dem objektiven Kauf- oder Tauschwert entsprechende Wert anzusetzen.

Veräußerungserlöse zählen nur insoweit zum Ertrag als sie im Bereich der Quelle zum Zwecke der Ertragserzielung (z.B. Handel) dienen, ansonsten sind sie dem Vermögensbereich zuzuordnen.

Die Beurteilung, ob Ertrag und damit Einkommen beim Eigenverbrauch entsteht, ist davon abhängig, ob die Quelle bei wirtschaftlicher Betrachtung zu Zwecken der Selbstbeschaffung dient (z.B. selbstgenutztes Wohneigentum) oder ob sie nur gelegentlich zur Ersparnis von Aufwendungen genutzt wird (Gewerbebetrieb). Im ersten Fall liegt ein zum gemeinen Wert zu bewertender Ertrag und damit Einkommen vor, im zweiten Fall nur eine mit den verursachten Kosten zu bewertende Ersparnis von Ausgaben und somit kein Ertrag/Einkommen. Außerordentliche Güterzuwächse (z.B. Lotteriegewinne, Erbschaften), d.h. Erwerbe, die ihren Ursprung nicht in einer bestimmten Ertragsquelle haben, berühren nicht den Ertrags- bzw. Einkommens-, sondern den Vermögensbereich, da eine Quelle einen dauernden Zustand zur Gütererzeugung voraussetzt.

Vom Rohertrag sind die Aufwendungen zu subtrahieren, die zu dessen Erzielung aufgewendet wurden, also die Betriebskosten (z.B. Gehälter, Rohstoffe, Instandhaltung). Nicht abzugsfähig sind die den Vermögensbereich betreffenden Ausgaben (z.B. Einrichtung/Erweiterung der Quelle) sowie die Lebenshaltungskosten zur Erhaltung der Arbeitskraft.

Da nach der Quellentheorie Einkommen und Vermögen streng zu trennen sind und aus verbrauchtem Vermögen kein Einkommen entstehen kann, muß der Rohertrag um den Werteverzehr durch Abnutzung oder Substanzverringerung der dem Vermögensbereich zugeordneten Quelle gekürzt werden. Dadurch flie-

$1 \quad$ Fuisting, B. (1902), S. 135. 
Ben die zur Erzielung des Rohertrags aufgewandten Vermögensverzehre wieder in das Vermögen zurïck und der Vermögensbestand bleibt gleich.

Andere Wertminderungen der Quelle, z.B. aufgrund von Brand oder Veralterung, können bei der Ertrags-/Einkommensermittlung nicht abgesetzt werden, da "...sie nicht durch den laufenden Betrieb selbst, sondern durch fremde, auBerhalb des Betriebes stehende Vorgänge verursacht sind..." ${ }^{I}$ und damit nur den Vermögensbereich betreffen.

Die Bewertung der Abschreibungen erfolgt nach dem Wertverlust -bezogen auf die historischen Anschaffungs-/Herstellungskosten- der Quelle in der Periode.

\section{Einkommen nach der Reinvermögenszugangstheorie}

Die Hauptvertreter der Reinvermögenszugangstheorie sind Schanz, Haig und Simons.

Schanz entwickelt seinen Einkommensbegriff vom zu erfüllenden Zweck her: "Wir wollen wissen, welche selbständige wirtschaftliche Kraft eine Person in einer bestimmten Periode darstellt, wollen wissen, welche Mittel sie in dieser Zeit zu ihrer Disposition hat, ohne daß sie ihr eigenes Vermögen verzehrt oder fremde Mittel (Schulden) hinzunimmt."2

Zum gleichen Ergebnis kommen auch Haig und Simons, die Einkommen definieren als "..the money value of the net accretion to one's economic power between two points of time." ${ }^{3}$ (Haig) bzw. als Reinvermögenszuwachs, der sich aus dem Vergleich des zu Marktpreisen bewerteten Vermögens am Ende der Periode mit dem zu Beginn vorhandenen, zuzüglich dem zu Marktpreisen bewerteten Konsum der Periode (Simons) ${ }^{4}$ ergibt.

Einkommen wird als Zunahme der Fähigkeit zur Befriedigung ökonomischer Bedürfnisse verstanden und auf den Reinvermögenszugang innerhalb eines bestimmten Zeitabschnitts abgestellt ${ }^{5}$.

Dies ist zu konkretisieren:

Zum Einkommen gehört der Zugang von Geld bzw. geldwerten Gütern/Titeln (z.B. die vom Arbeitgeber kostenlos zur Verfügung gestellte Wohnung), da da-

\footnotetext{
1 Fuisting, B. (1902), S. 180.

2 Schanz, G. (1896), S. 5.

3 Haig, R.M. (1921), S. 59 (im Original kursiv).

4 Vgl. Simons, H.C. (1962), S. 49 f.

5 Vgl. Schanz, G. (1896), S. 23.
} 
durch die ökonomische Kraft zum möglichen Erwerb von Gütern oder Diensten einer Person erhöht wird ${ }^{l}$. Dabei ist es -da auf die Zunahme der Fähigkeit zur Befriedigung ökonomischer Bedürfnisse abgestellt wird ${ }^{2}$ - unerheblich, ob diese regelmäßig oder unregelmäßig anfallen, wie sie sich zusammensetzen ${ }^{3}$ und ob die geldwerte Leistung dem Steuerpflichtigen tatsächlich einen Genuß bietet oder nicht ${ }^{4}$. Regelmäßig anfallender Arbeitslohn ist ebenso Einkommen wie Geschenke, Erbschaften oder Lotteriegewinne ${ }^{5}$. Die Zurechnung zum Einkommen erfolgt beim Zugang der wirtschaftlichen Dispositionsfähigkeit und nicht erst bei ihrer Verwendung (zu Konsum- bzw. Investitionszwecken) ${ }^{6}$.

Zum Einkommen gehören auch sämtliche Naturalgenüsse und Nutzungen (z.B. die selbstgenutzte Wohnung) ${ }^{7}$.

Der Genuß von öffentlichen Gütern ist dagegen kein Einkommen ${ }^{8}$.

Wertänderungen des Vermögens beeinflussen die wirtschaftliche Kraft einer Person schon vor Realisierung der Wertänderung durch einen Verkauf und sind deshalb zu berücksichtigen. Wertminderungen stellen einen Verzehr des am Anfang der Periode vorhandenen Vermögens und damit einen Verlust an wirtschaftlicher Kraft der betreffenden Person dar. Dabei ist unerheblich, ob sich die Wertänderungen im Betriebs- oder Privatvermögen niederschlagen?

Erhaltene Zinszahlungen sind als Einkommen zu behandeln, während sämtliche Schuldzinsen (unabhängig davon, ob der Kredit zu Betriebs- oder Privatzwekken dient) bei der Einkommensermittlung abzugsfähig sind, da durch sie die wirtschaftliche Kraft einer Person sinkt.

Aufwendungen, die zur Erlangung dieser Einkommensbestandteile dienen, sind abzugsfähig, da sie die wirtschaftliche Kraft einer Person vermindern. Die Lebenshaltungskosten können vom Arbeitseinkommen nicht abgezogen werden, da sie nach Schanz der Einkommensverwendung zuzurechnen sind ${ }^{10}$.

Vgl. Haig, R.M. (1921), S. 62.

2 D.h. welcher Betrag kann, ohne das Vermögen zu senken oder zu erhöhen, konsumiert werden (vgl. Goode, R. (1977), S. 8 f.).

3 Vgl. Schanz, G. (1896), S. 17.

4 Vgl. Schanz, G. (1896), S. 435.

5 Vgl. Schanz, G. (1896), S. 24.

$6 \quad$ Vgl. Haig, R.M. (1921), S. 59.

7 Vgl. Haig, R.M. (1921), S. 65; Kirchhof, P. (1992a), § 2 Anm. A 326.

8 Vgl. Schanz, G. (1896), S. 437.

9 Vgl. Kirchhof, P. (1992a), § 2 Anm. A 326; Bauckner, A. (1921), S. 74.

10 Vgl. Schanz, G. S. (1922), S. 508 f. 


\section{Einkommen nach Brandis}

Die Einkommensdefinition von Brandis bezieht sich auf das Einkommen, das als Grundlage zur Bestimmung des Tagessatzes bei Strafverfahren herangezogen werden kann. Gleichzeitig will Brandis auch einen Beitrag zur Ausgestaltung eines Einkommensbegriffs im öffentlichen Schuldrecht leisten. Da in sämtlichen Bereichen des öffentlichen Schuldrechts -und somit auch im Steuerrecht- das Einkommen die wirtschaftliche Leistungsfähigkeit abbilden soll, kann es nach Brandis nur einen Einkommensbegriff geben, der aber unter Umständen für die einzelnen Rechtsgebiete zu modifizieren ist.

Da Brandis -unabhängig von irgendwelchen Sekundärwirkungen des Strafrechts- allgemeine Grundsätze des Einkommensbegriffs herausgearbeitet hat ${ }^{2}$, kann sein Einkommensbegriff in die Diskussion der wirtschaftlichen Leistungsfähigkeit einbezogen werden.

Nach Brandis ergibt sich das Einkommen durch den Abzug der Ausgaben von den Bezügen.

Die Bezüge bilden den Ausgangspunkt der Einkommensermittlung, wobei darunter die von dritter Seite zufließenden Gelder sowie der Zufluß anderer geldwerter Güter verstanden wird ${ }^{3}$. Unerheblich ist dabei, woher und in welcher Form (Geld oder Naturalleistungen) der Wertzufluß stammt. Somit sind z.B. Lotteriegewinne, Transferbezüge, Erbschaften, Schenkungen sowie Veräußerungsgewinne ${ }^{4}$ zu erfassen. Dagegen wird der Ansatz von Wertsteigerungen als Einkommen vor ihrer Realisierung am Markt abgelehnt, da noch keine Liquidität zugeflossen ist. Die Möglichkeit der jederzeitigen Realisierung durch Verkauf oder Beleihung stellt nur ein potentielles Einkommen dar, das den für Konsumzwecke tatsächlich zur Verfügung stehenden Betrag nicht erhöht. Einkommen ist auch der Verbrauch von selbsterstellten Gütern.

Zuflüsse aufgrund von Vermögensumschichtungen (z.B. Auszahlung eines Darlehens) werden nicht erfaßt, da die Leistungsfähigkeit dadurch nicht berührt wird.

Abzüge bei der Einkommensermittlung sind jede Minderung der wirtschaftlichen Leistungsfähigkeit mit Ausnahme der Ausgaben, die zur Bedürfnisbefriedigung (z.B. Ausgaben für den Privathaushalt) oder zum Vermögenserwerb die-

Vgl. Brandis, P. (1987); Brandis, P. (1987a), S. $289 \mathrm{ff}$.

2 Vgl. Brandis, P. (1987), S. 11 ff., $43 \mathrm{ff}$.

3 Zur Darstellung vgl. Brandis, P. (1987), S. 90 ff.; Brandis, P. (1987a), S. 289 ff.

4 Sie sollen aus Praktikabilitätsgründen nur Einkommensbestandteil sein, soweit sie sich vorher im Privatvermögen befanden (vgl. Brandis, P. (1987), S. 114). 
nen. Realisierte Wertminderungen im Vermögen, z.B. aufgrund von Abnutzung sind ebenfalls abzugsfähig, nicht jedoch Wertminderungen aufgrund von Preisschwankungen, die erst bei Realisation am Markt berücksichtigt werden dürfen. Die im privaten Bereich anfallenden unabweisbaren Ausgaben, die mit der Erzielung von Bezügen in unmittelbarem Zusammenhang stehen (wie z.B. Pflichtbeiträge zur Sozialversicherung) sind abzugsfähig, da der Steuerpflichtige diesen Betrag nicht zur freien Verfügung hat und somit keine Leistungsfähigkeit vorliegt. Schuldzinsen sind nur dann abzugsfähig, wenn sie betrieblich oder beruflich begründet sind oder die Schuld mit zwangsläufigen privaten Ausgaben im Zusammenhang steht.

Bei den Abzügen sind damit Zweck und Grund der Zahlung entscheidend.

\section{Ergebnis}

Die Einkommensbegriffe der Konsumtionsfonds- und Produktionseinkommenstheorie müssen abgelehnt werden, da sie die Leistungsfähigkeit nur sehr unvollständig abbilden.

Die Einkommensdefinition der Reinvermögenszugangstheorie bzw. die Definition von Brandis bilden die ökonomische Verfügungsmacht eines Individuums in hohem Maße ab, da grundsätzlich sämtliche Zuflüsse von Geld oder geldwerten Gütern erfaßt werden bzw. grundsätzlich jede Minderung der ökonomischen Verfügungsmacht über knappe Güter der Volkswirtschaft mit Ausnahme der Ausgaben der Bedürfnisbefriedigung des Steuerpflichtigen in der steuerlichen Bemessungsgrundlage abgebildet wird.

Die Unterschiede zwischen der Reinvermögenszugangstheorie und der Einkommensdefinition von Brandis liegen hauptsächlich in der unterschiedlichen Behandlung des Einbezugs von unrealisierten Wertänderungen und der Zulässigkeit des Schuldzinsabzugs für Konsumkredite.

Ein wesentlicher Unterschied dieser beiden Einkommensbegriffe zur Quellentheorie ist in der Behandlung von unregelmäßigen Einkünften, Erbschaften und Schenkungen sowie in der Behandlung von Wertänderungen zu sehen.

Die Frage des Einbezugs dieser Sachverhalte in die steuerliche Bemessungsgrundlage wird im nächsten Kapitel behandelt. 
Michael Ohmer - 978-3-631-75563-1

Downloaded from PubFactory at 01/11/2019 03:31:45AM

via free access 


\section{Kapitel}

\section{Sonderprobleme bei der Periodeneinkommensbesteuerung}

In diesem Kapitel werden verschiedene Problemfelder einer periodischen Einkommenserfassung behandelt. Beurteilungsmaßstäbe sind auch hier das Leistungsfähigkeitsprinzip, die Forderung nach einer entscheidungsneutralen Besteuerung sowie Praktikabilitätsüberlegungen.

\section{Die Behandlung von Windfall Profits und unregelmäßigen Einkünften}

Es ist zu klären, ob Windfall Profits (Glücks- oder Zufallseinkünfte ${ }^{l}$ ) bzw. unregelmäßige Einkünfte in die Bemessungsgrundlage einer periodischen Einkommensteuer eingehen sollen.

Diskutiert werden nur Windfall Profits, die nicht an anderer Stelle -wie z.B. in der Analyse der Wertänderungsbesteuerung- behandelt werden.

\subsection{Besteuerung nach der individuellen Leistungsfähigkeit}

Maßstab des verteilungspolitischen Leistungsfähigkeitsbegriffs ist die Verfügungsmacht des Individuums über die knappen Ressourcen der Wirtschaft, d.h. alle Mehrungen der Dispositionsmöglichkeit erhöhen die Leistungsfähigkeit und sind in der steuerlichen Bemessungsgrundlage zu berücksichtigen.

Windfall Profits bzw. unregelmäßig anfallende Einkünfte erhöhen die Dispositionsgewalt über die Ressourcen der Wirtschaft ${ }^{2}$ und sind damit in den Einkommensbegriff einzubeziehen, da hinsichtlich der veränderten Leistungsfähigkeit kein Unterschied zu regelmäßigen Einkünften besteht. Diejenigen Einkommensbegriffe, die o.a. "Einkommensbestandteile" nicht einbeziehen, verstoßen gegen die Forderung einer Besteuerung nach der individuellen Leistungsfähigkeit und sind damit keine validen Indikatoren der steuerlichen Leistungsfähigkeit.

Bei einem progressiven Tarifverlauf ist allerdings problematisch, daß im Zeitablauf schwankende Bemessungsgrundlagen zu einer höheren Steuer führen als gleichmäßige. Es ergibt sich eine höhere Steuer beim Anfall von unregelmäßigen Einkünften bzw. Windfall Profits als bei einer gleichmäßigen Verteilung

$1 \quad$ Vgl. Neumark, F. (1970), S. 136.

2 Ebenso Neumark, F. (1970), S. 136. 
des Lebenseinkommen über die Lebensdauer. Dieser Progressionseffekt ist ein Versto $ß$ gegen die Forderung der Besteuerung nach der individuellen Leistungsfähigkeit. Darauf wurde allerdings schon oben eingegangen. Verfahren zur Vermeidung dieses Nachteils werden später diskutiert.

\subsection{Neutralität der Besteuerung}

Ein neutrales Steuersystem liegt dann vor, wenn die Entscheidungen der Steuerpflichtigen im Vergleich zur Laissez-Faire-Ökonomie nicht verzerrt werden. Es ist zu klären, ob dieses Kriterium eines "guten" Steuersystems Aussagen über den Einbezug oder den Nichteinbezug von Windfall Profits und unregelmäßigen Einkünften zuläßt.

Wesentliches Beurteilungskriterium einer entscheidungsneutralen Besteuerung ist der Einfluß des Steuersystems auf die Entscheidungen und Handlungen des Steuerpflichtigen. Bei Windfall Profits liegt der Anfall jedoch definitionsgemäß aus-serhalb der Einflußsphäre des Steuerpflichtigen. Somit kann keine Verzerrung der Entscheidungen durch das Steuersystem in diesem Bereich auftreten. Dementsprechend ist die Forderung nach der Entscheidungsneutralität der $\mathrm{Be}$ steuerung kein Beurteilungskriterium.

Werden andere unregelmäßig anfallende Einkünfte nicht besteuert, wird die Entscheidung der Steuerpflichtigen zugunsten dieser Einkünfte verzerrt. Neutralitätserwägungen fordern daher die Einbeziehung dieser unregelmäßigen Einkünfte in die steuerliche Bemessungsgrundlage.

\subsection{Praktikabilität der Besteuerung}

Es ist zu klären, ob Windfall Profits bzw. unregelmäßige Einkünfte praktikabel erfaßt bzw. gemessen werden können. Dabei ist das Problem der Steuersicherung ebenfalls zu lösen.

"Windfall Profits" bzw. "unregelmäßige Einkünfte" umfassen eine Vielzahl von "Einkunftsquellen"; eine abschließende Aufzählung ist nicht möglich. Daher können auch keine allgemeingültigen Aussagen über die Praktikabilität der steuerlichen Erfassung getroffen werden. Die Erfassung ist aber grundsätzlich möglich ${ }^{l}$.

1 Vgl. aber die Ausführungen bei der Diskussion des Einbezugs von Wertänderungen in die steuerliche Bemessungsgrundlage. 
Fraglich ist, ob die Steuerpflichtigen dazu angehalten werden können, diese Einkünfte zu deklarieren. Problemlos dürfte das bei Lotteriegewinnen von staatlichen oder privatwirtschaftlichen Lotterien sein, da hier der Fiskus bei der steuerlichen Außenprüfung der Lotteriegesellschaften die Namen der Gewinner und die Höhe der jeweiligen Gewinne erkunden kann.

Problematischer ist allerdings der Fall, wenn diese Informationen dem Fiskus nicht zur Verfügung stehen. Verhält sich der Steuerpflichtige ruhig und werden gewisse Plausibilitäten in seiner Steuererklärung eingehalten (z.B. Zinseinkünfte), hat der Fiskus nur relativ geringe Möglichkeiten, diese Einkünfte zu entdekken und zu erfassen. Somit besteht wegen fehlender Kontrollmöglichkeiten ein Anreiz zur Steuerhinterziehung.

\subsection{Ergebnis}

Der Einbezug von Windfall Profits bzw. unregelmäßig anfallenden Einkünften in die steuerliche Bemessungsgrundlage ist aufgrund des Leistungsfähigkeitsprinzips geboten, da sie die Dispositionsmöglichkeiten erhöhen. Einkommenskonzeptionen, die diese Einkünfte nicht in die steuerliche Bemessungsgrundlage einbeziehen, verstoßen gegen das Leistungsfähigkeitsprinzip. Problematisch hinsichtlich der Besteuerung nach der individuellen Leistungsfähigkeit sind die bei einem progressiven Tarifverlauf auftretenden Verzerrungen.

Die Frage der Entscheidungsneutralität der Besteuerung spielt bei Windfall Profits keine Rolle, da der Anfall definitionsgemäß außerhalb der Entscheidungsgewalt des Individuums liegt. Andere unregelmäßige Einkünfte, deren Anfall im Einflußbereich des Individuums liegt, müssen aufgrund von Neutralitätserwägungen in die steuerliche Bemessungsgrundlage eingehen, da sonst die Entscheidung des Steuerpflichtigen zugunsten dieser Einkünfte beeinflußt wird.

Über die Praktikabilität der Erfassung von Windfall Profits bzw. unregelmäßigen Einkünfte kann eine eindeutige Aussage aufgrund der Vielzahl von verschiedenen "Einkunftsquellen" nicht getroffen werden. 


\section{Das Problem der Zinsbesteuerung}

Die Frage der Zinsbesteuerung ist ein kontrovers diskutiertes Thema der vergangenen Jahre und muß daher gesondert dargestellt werden ${ }^{I}$.

\subsection{Besteuerung nach der individuellen Leistungsfähigkeit}

Ist die Besteuerung von Zinsen mit der Forderung nach der Besteuerung gemäß der Leistungsfähigkeit zu vereinbaren?

Obwohl der Schuldzinsabzug explizit nicht angesprochen wird, wird er ebenso (automatisch) analysiert, da Schuldzinsen -wenn Zinserträge die Leistungsfähigkeit erhöhen- die individuelle steuerliche Leistungsfähigkeit aufgrund der abnehmenden Verfügungsmacht des Individuums über die Ressourcen der Wirtschaft senken. Die Ergebnisse der Analyse des Einbezugs von Zinserträgen gelten deshalb auch spiegelbildlich für die Zulassung des Schuldzinsabzugs. Die gleichartige Behandlung ist auch erforderlich, da es ansonsten zu Steuerarbitrage kommen könnte (z.B. bei der Konstellation ohne Zinsbesteuerung, aber mit Zulassung des Schuldzinsabzugs). Es wäre dann allein aus steuerlichen Gründen lohnend, sich zu verschulden, die Schuldzinsen bei der steuerlichen Bemessungsgrundlage abzusetzen und die Zinserträge steuerfrei zu erlangen.

Bei der Analyse wird angenommen, daß ein vollkommener Kapitalmarkt und vollkommene Informationen vorliegen. Zuerst wird die Steuerpflicht, anschlieBend die Steuerfreiheit von Zinseinkünften diskutiert.

\subsubsection{Einbezug der Zinsen in die steuerliche Bemessungsgrundlage}

Es wird der Fall betrachtet, in dem zwei Individuen A und B denselben Barwert an Arbeitseinkommen vor Steuern erzielen; die Verteilung des Periodeneinkommens allerdings unterschiedlich ist. Beide sind in dieser Modellwelt gleich leistungsfähig, da sie vor Steuern die gleiche Verfügungsgewalt über Ressourcen der Wirtschaft haben.

Der Konsumzeitpunkt wird variiert. Der Untersuchung wird -um Verzerrungen aufgrund eines progressiven Tarifs zu vermeiden- ein linearer Steuertarif zugrunde gelegt ${ }^{2}$.

1 Vgl. hierzu z.B. Wenger, E. (1983); Rose, M. (1991), S. 12, 30 ff.; Kaiser, M. (1992), S. $89 \mathrm{ff}$.

2 Arbeitseinkommen: $\quad \mathrm{y}$ (bzw. $\mathrm{y}(1+\mathrm{r})$ in der zweiten Periode). 
Zuerst wird davon ausgegangen, daß das Einkommen im Entstehungsjahr konsumiert wird:
$\mathbf{A}$
Barwert $^{l}$
$t_{1}$
$t_{2}$
Arbeitseinkommen
$2 y$
$2 y$
0
Steuer
$2 \tau y$
$2 \tau y$
0
Konsum
$2(1-\tau) y$
$2(1-\tau) y$
0
B
Barwert
$\mathrm{t}_{1}$
$t_{2}$

$\begin{array}{llll}\text { Arbeitseinkommen } & 2 \mathrm{y} & \mathrm{y} & (1+\mathrm{r}) \mathrm{y} \\ \text { Steuer } & 2 \tau \mathrm{y} & \tau \mathrm{y} & \tau(1+\mathrm{r}) \mathrm{y} \\ \text { Konsum } & 2(1-\tau) \mathrm{y} & (1-\tau) \mathrm{y} & (1-\tau)(1+\mathrm{r}) \mathrm{y}\end{array}$

Bei sofortigem Konsum des gesamten Periodeneinkommens ist der Barwert der Steuerzahlung gleich; damit ist die Forderung nach einer Besteuerung entsprechend der individuellen Leistungsfähigkeit erfüllt.

Es wird nun folgendes untersucht: A und B streben in der ersten Periode einen Konsum von y bzw. (1- $\tau$ )y (mit Besteuerung) an; A legt die Differenz zu seinem Einkommen in $t_{1}$ zum Zinssatz $r$ auf dem Kapitalmarkt an, während $B$ sein Einkommen weiterhin im Entstehungsjahr konsumiert.

ohne Besteuerung:
$\mathbf{A}$
Barwert
$\mathrm{t}_{1}$
$\mathrm{t}_{2}$

Arbeitseinkommen

$2 y$

$2 y$
$y$
$y$

Anlage

Zinsen

ry

Konsum in $\mathrm{t}_{2}$

$(1+r) y$

Einkommen gesamt

Konsum gesamt

$2 \mathrm{y}$

$2 \mathrm{y}$

Steuersatz: $\quad \tau$

Zinssatz: r.

1 Der Barwert wird auf $t_{1}$ berechnet. 
B Barwert $\quad t_{1} \quad t_{2}$

$\begin{array}{llll}\text { Arbeitseinkommen } & 2 y & y & (1+r) y \\ \text { Konsum } & 2 y & y & (1+r) y\end{array}$

In einer Welt ohne Steuern haben beide gleiche Dispositionsmöglichkeiten über die Ressourcen der Wirtschaft und sind somit gleich leistungsfähig.

mit Besteuerung:
A
Barwert
$\mathrm{t}_{1} \quad \mathrm{t}_{2}$

Arbeitseinkommen 2y

$2 \mathrm{y} \quad 0$

Steuern auf Gehalt $2 \tau y$

$2 \tau y$

Konsum in $\mathrm{t}_{1}$

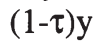

Anlage

$(1-\tau) \mathrm{y}$

Zinsen

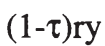

Steuern auf Zinsen

$\tau(1-\tau)$ ry

Konsum in $\mathrm{t}_{2}$

Einkommen gesamt $2 \mathrm{y}$

$(1-\tau)(1-\tau) \mathrm{ry}+(1-\tau) \mathrm{y}$

Konsum gesamt

$\frac{(1-\tau) r y+(1-\tau) y}{1+r}+(1-\tau) y$

Steuern gesamt

$$
\frac{2 \tau y+3 \tau r y-\tau r y}{1+r}
$$

B

Barwert

$t_{1} \quad t_{2}$

Arbeitseinkommen 2y

Steuern auf Gehalt $2 \tau \mathrm{y}$

Konsum

$2(1-\tau) y$

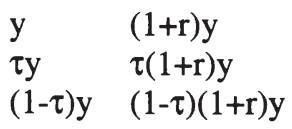

Der Barwert der von A zu entrichtenden Steuer ist um $\frac{r \tau y(1-\tau)}{1+r}$ höher als die von B zu entrichtende Steuer, die möglichen Konsumausgaben von A sind somit um $\frac{r \tau y(1-\tau)}{1+r}$ niedriger als die von B. A hat also bei gleichem Barwert der Zuflüsse vor Steuern einen höheren Barwert an Steuerzahlungen zu entrichten: damit 
steht ihm ein geringerer Betrag (Barwert) für Konsumzwecke (also zur Disposition) zur Verfügung. Da beide vor Steuern gleich leistungsfähig sind und demnach auch den gleichen Steuerbetrag zu entrichten haben, liegt hier durch die Besteuerung ein Verstoß gegen das Leistungsfähigkeitsprinzip vor. Dies führt zu einer Verzerrung in der ordinalen Reihenfolge der Individuen, d.h. wer vor der Besteuerung das leistungsfähigere Individuum war, kann nach der Besteuerung das leistungsschwächere sein.

Es ist damit festzuhalten, daß -bei gleichem Lebenseinkommen in einer Welt ohne Steuern- der Konsumzeitpunkt die Höhe der Steuerzahlungen beeinflußt und somit gegen das Leistungsfähigkeitsprinzip verstoßen wird. Die Ursache dafür liegt in der Zinsbesteuerung.

\subsubsection{Freistellung der Zinseinkünfte}

Der Einbezug der Zinseinkünfte in die steuerliche Bemessungsgrundlage verstößt -wie oben gezeigt- gegen das Leistungsfähigkeitsprinzip. Es wird daher untersucht, inwieweit das System der Zinsbesteuerung zu modifizieren ist, damit es dem Konzept der Besteuerung nach der individuellen Leistungsfähigkeit entspricht. Die Grundkonzeption der Periodeneinkommensbesteuerung bleibt aber ansonsten erhalten.

Es wird der Vorschlag ${ }^{I}$ geprüft, Zinsen nicht als Einkommensbestandteil anzusehen und sie damit nicht zu besteuern ${ }^{2}$. Dazu wird ein Vergleich mit einem Individuum angestellt, das keine Zinseinkünfte, sondern Arbeitseinkünfte in gleicher Höhe erzielt. Es wird angenommen, daß $A$ in $t_{1}$ Arbeitseinkünfte von $2 y$ bezieht und sie zum Zinssatz $r$ anlegt, während $B$ in $t_{1}$ Arbeitseinkünfte in Höhe von y (die es zum Zinssatz $r$ anlegt) und in $t_{2}$ Arbeitseinkünfte in Höhe von $(1+r) y$ bezieht. Beide haben also ein Lebenseinkommen (incl. Zinsen) mit einem Barwert von $2 \mathrm{y}$; zum Zeitpunkt $\mathrm{t}_{2}$ bewertet, beträgt das Lebenseinkommen in beiden Fällen 2(1+r)y. Beide sind vor Steuern gleich leistungsfähig.

So z.B. Braunberger, G. (1991), S. 13.

2 Zur Vermeidung von Steuerarbitrage ist es aber erforderlich, die Abzugsfähigkeit der Schuldzinsen äquivalent zu behandeln. Ansonsten wäre es vorteilhaft, Kredite aufzunehmen, um damit z.B. Rentenpapiere zu kaufen: die Schuldzinsen wären bei der Ermittlung des zu versteuernden Einkommens abzugsfähig, während die Zinserträge steuerfrei blieben. 
In einer Welt mit Steuern ergibt sich folgendes Bild:
A
$t_{1}$
$t_{2}$
stpfl. Arbeitseinkünfte
$2 \mathrm{y}$
Steuern
$2 \tau y$
Anlagebetrag
$(1-\tau) 2 y$
Zinsen
0
$(1-\tau) 2 \mathrm{yr}$
Endkapital (Kapital- und Arbeitsein-
kommen)
Barwert nach Steuern ${ }^{l}$
Barwert Steuerzahlungen
$(1-\tau) 2 y$
$(1+r)(1-\tau) 2 y$
$2 \tau \mathrm{y}$
B
$\mathrm{t}_{1}$
$\mathrm{t}_{2}$
stpfl. Arbeitseinkünfte
y
$\tau y$
$(1-\tau) y$
Steuern
Anlagebetrag
0
Endkapital (Kapital- u. Arbeitsein- kommen)
Barwert Einkünfte
$(1-\tau) 2 y$
Barwert Steuerzahlungen
$2 \tau \mathrm{y}$

Die Freistellung der Kapitaleinkünfte hat zur Folge, daß Individuen mit demselben Barwert an Zuflüssen auch denselben Barwert an Steuern zu entrichten haben und damit die Besteuerung nach der Leistungsfähigkeit verwirklicht ist.

\subsubsection{Ergebnis}

Der Konsumzeitpunkt beeinflußt -bei gleichem Lebenseinkommen vor Steuerndie Höhe der Steuerzahlungen. Somit verstößt die Zinsbesteuerung in einer Welt mit vollkommener Information und vollkommener Sicherheit gegen das Leistungsfähigkeitsprinzip.

Berechnet auf $t_{1}$. 


\subsection{Neutralität der Besteuerung}

Im folgenden Abschnitt wird geprüft, ob die Besteuerung der Zinseinkünfte mit der Forderung nach einem neutralen Steuersystem vereinbart werden kann. Es wird auch untersucht, ob sich aus der Forderung nach einem neutralen Steuersystem Rückschlüsse auf die Abzugsfähigkeit von Schuldzinsen ziehen lassen.

\subsubsection{Investitionen von Unternehmen}

Es wird beurteilt, ob die Frage der Zulässigkeit des Schuldzinsabzugs bei der Ermittlung des zu versteuernden Einkommens Einfluß auf die Investitionsentscheidungen von Unternehmen hat.

Der Schuldzinsabzug für Unternehmen wird bei der folgenden Analyse nicht in voller Höhe zugelassen; $a_{s}$ bezeichnet den prozentualen Anteil der Schuldzinsen, der bei der Ermittlung des zu versteuernden Gewinns des Unternehmens abzugsfähig ist. Sind die Schuldzinsen nicht oder nur teilweise abzugsfähig, ist der Anteil der nichtabzugsfähigen Schuldzinsen aus dem versteuertem Gewinn zu entrichten, der folglich auch nicht ausgeschüttet werden kann; daher ist der Steuersatz auf einbehaltene Gewinne $\left(\tau_{\mathrm{e}}\right)$ bei den nachfolgenden Analysen relevant. Es wird der Fall untersucht, in dem ein Unternehmen zusätzliche Investitionen durchführen möchte und sich die Mittel über den Kapitalmarkt beschafft.

Wie gezeigt, hat die Unternehmung bei einer marginalen Erhöhung ihres Kapitalstocks künftig höhere Nettoerträge in Höhe der Nettogrenzproduktivität der Investition. Diesen höheren Erträgen aus der Marginalinvestition stehen Aufwendungen für Fremdkapitalzinsen zuzüglich eventueller Steuern aufgrund der Nichtabzugsfähigkeit der Schuldzinsen gegenüber. Als Änderung der Nettoausschüttung an die Anteilseigner vor Steuern (aufgrund der durchgeführten Investition) ergibt sich daher die Nettogrenzproduktivität abzüglich des auf das aufgenommene Fremdkapital zu entrichtenden Zinssatzes $r$ abzüglich eventuell höherer Steuerzahlungen aufgrund der teilweisen Nichtabzugsfähigkeit von Schuldzinsen.

Werden für $\mathrm{a}_{\mathrm{s}}$ (= prozentualer Anteil der abzugsfähigen Schuldzinsen) Werte zwischen 0 und 1 angenommen, erfüllt die Grenzinvestition des Unternehmens folgende Bedingung 


$$
f_{k}=\left(a_{s}+\frac{1-a_{s}}{1-\tau_{e}}\right) * r
$$

d.h. das Unternehmen investiert bis zu dem Zeitpunkt, in dem der Nettoertrag der Grenzinvestition gerade noch ausreicht, um die Schuldzinsen und eventuell anfallende Steuern entrichten zu können.

Bei voller Abzugsfähigkeit der Schuldzinsen (as $=1$ ) ergibt sich dann als Marginalbedingung -wie in einer Laissez-Faire-Ökonomie-

$$
\mathrm{f}_{\mathrm{k}}=\mathrm{r} \text {, }
$$

so daß die Investitionsneutralität erhalten bleibt.

Bei nicht vollständiger Abzugsfähigkeit der Schuldzinsen nimmt $a_{s}$ einen Wert $<1$ an, der zweite Faktor in der Gleichung (also $\left.\frac{1-a_{s}}{1-\tau_{e}}\right)$ beeinflußt ebenfalls die Investitionsentscheidung des Unternehmens. Werden einbehaltene oder ausgeschüttete Gewinne mit $100 \%>\tau_{\mathrm{e}}>0 \%$ besteuert, gilt

$$
\frac{1-\mathrm{a}_{\mathrm{s}}}{1-\tau_{\mathrm{e}}}>\left(1-\mathrm{a}_{\mathrm{s}}\right)
$$

Daraus folgt

$$
\left(a_{s}+\frac{1-a_{s}}{1-\tau_{e}}\right)>1
$$

Es ergibt sich also für den gesamten in Klammern stehenden Ausdruck ein Wert $>1$. Die Grenzinvestition muß somit eine höhere Nettogrenzproduktivität als $r$ aufweisen.

Wird die Abzugsfähigkeit von Schuldzinsen völlig ausgeschlossen $\left(a_{\mathrm{s}}=0\right)$, ergibt sich als Marginalbedingung für die Grenzinvestition ${ }^{l}$

$1 \quad$ Diese Beziehung gilt auch, wenn die Grenzinvestition mit Eigenkapital durchgeführt wird, da dieses Eigenkapital auf dem Kapitalmarkt zum Zinssatz $\mathrm{r}$ angelegt werden kann. Die Zinserträge des Unternehmens wären in diesem Fall steuerfrei. Die Unternehmung muß sich also zwischen einer steuerfreien Anlage auf dem Kapitalmarkt und einer nicht-steuerbefreiten Investition entscheiden. Sie ist indifferent, wenn die Investition nach Steuern dieselbe Rendite wie den Kapitalmarktzinssatz aufweist. Dies ist der Fall, wenn

$f_{k}=r /\left(1-\tau_{e}\right)$ gilt. 


$$
f_{k}=\frac{r}{1-\tau_{e}}
$$

Die Grenzinvestition muß eine höhere Nettogrenzproduktivität als $\mathrm{r}$ aufweisen, wenn einbehaltene Gewinne besteuert werden.

Investitionsneutralität liegt somit nicht vor, wenn der Schuldzinsabzug nicht oder nicht in voller Höhe zugelassen wird $^{l}$.

\subsubsection{Konsum-Spar-Entscheidung der Individuen}

\subsubsection{Auswirkungen der Zinsbesteuerung ${ }^{2}$}

Die Vermögensbildung eines Individuums ist davon abhängig, ob der heutige Konsumverzicht durch einen zukünftigen Mehrkonsum kompensiert wird, d.h. wie sich die intertemporale Versorgungslage aufgrund des momentanen Konsumverzichts zugunsten des zukünftigen Mehrkonsums verändert.

Zur Analyse dieser Überlegung wird eine Marginalbetrachtung durchgeführt ${ }^{3}$.

Der momentane Konsumverzicht zugunsten eines späteren Mehrkonsums ist vorteilhaft, wenn die Zahlungszuflüsse (Tilgung und Nettoverzinsung, also der Zinssatz nach Steuern $\left.=\left(1-\tau_{\mathrm{z}}\right) * \mathrm{r}\right)$ aus der letzten am Kapitalmarkt eingesetzten Geldeinheit höher sind, als das, was gebraucht wird, um den gegenwärtigen Konsumverzicht durch zukünftigen Mehrkonsum zu kompensieren. Dadurch kann die intertemporale Gesamtversorgungslage des Individuums verbessert werden.

Die Konsum-/Sparpläne des Individuums sind optimiert bei

$$
\frac{-\mathrm{dC}_{\mathrm{z}}}{\mathrm{dC}_{\mathrm{G}}}=1+\left(1-\tau_{\mathrm{z}}\right) * \mathrm{r},
$$

da durch einen weiteren gegenwärtigen Konsumverzicht eine Verbesserung der Versorgungslage nicht erreicht wird.

1 In einer Laissez-Faire-Ökonomie investiert ein Unternehmen solange, bis die Nettogrenzproduktivität der Investition dem Nettomarktzinssatz entspricht, also die Bedingung $\mathrm{f}_{\mathrm{k}}=\mathrm{r}$ erfüllt ist (s.o.).

2 Vgl. Nachtkamp, H.H. (1988), S. 169 f.

$3 \quad \mathrm{dC}_{\mathrm{G}}\left(\mathrm{dC}_{\mathrm{G}}<0\right)$ bezeichnet den marginalen Rückgang des gegenwärtigen Konsums zugunsten des Sparens; $\mathrm{dC}_{\mathrm{z}}\left(\mathrm{dC}_{\mathrm{z}}>0\right)$ ist die marginale Zunahme des zukünftigen Konsums durch die gegenwärtige Ersparnis einschließlich der anfallenden Zinsen. 
Für die individuelle Zeitpräferenzrate gilt dann folgende Beziehung ${ }^{l}$ :

$$
\gamma=\left(1-\tau_{\mathrm{z}}\right) * \mathrm{r},
$$

d.h. die individuelle Zeitpräferenzrate des Individuums entspricht dem Nettozinssatz nach Steuern. In einer Laissez-Faire-Ökonomie gilt hingegen

$$
\gamma=\mathrm{r}
$$

Die Individuen substituieren somit aufgrund der Zinsbesteuerung teilweise Sparen (= zukünftigen Konsum) durch gegenwärtigen Konsum, da sich die Besteuerung wie ein Keil zwischen Marktzinssatz und Zeitpräferenzrate schiebt. Sie werden veranlaßt, ihre Bruttozinsforderungen soweit anzuheben, daß sich der für die Konsumplanung relevante Nettozinssatz nach Steuern mit ihrer Zeitpräferenzrate deckt ${ }^{2}$. Dadurch geht c.p. die Ersparnis der Individuen zurück. Dies wird auch durch empirische Untersuchungen bestätigt, die einen Anstieg des Sparens bei einer Erhöhung des Zinssatzes zeigen ${ }^{3}$.

Aufgrund des Rückgangs der Ersparnis im Vergleich zu einer Laissez-FaireÖkonomie entsteht eine Zusatzbelastung der Steuerpflichtigen durch die Besteuerung, da sie von dem in einer Laissez-Faire-Ökonomie als optimal betrachteten intertemporalen Konsumplan abgebracht werden.

\subsubsection{Zulässigkeit des Schuldzinsabzugs}

Es soll nun eine Welt betrachtet werden, in der es nur zwei Arten von Individuen gibt: die eine ist bereit, für einen künftigen Mehrkonsum heute weniger zu konsumieren, während die andere zu Lasten des Zukunftskonsums den Gegenwartskonsum erhöht. Der Unternehmenssektor wird hierbei vernachlässigt.

Die Zeitpräferenzrate $\gamma$ der Individuen gibt Aufschluß darüber, für welchen Zinssatz ein Individuum zugunsten eines zukünftigen Mehrkonsums auf gegenwärtigen Konsum verzichtet; im Umkehrschluß sagt die Zeitpräferenzrate aus, welchen Preis (= Zinssatz) die Individuen für einen höheren Gegenwartskonsum zu Lasten des zukünftigen Konsums zu entrichten bereit sind.

\footnotetext{
1 Zur Herleitung siehe oben.

2 Vgl. Wenger, E. (1989), S. 183.

3 Vgl. Wright, C. (1969), S. 293 ff.; Boskin, M. (1978), S. 16.
} 


\section{a) Exkurs: Laissez-Faire-Ökonomie}

Sowohl die Individuen, die Kredite vergeben (Individuen G), als auch die, die Kredite aufnehmen (Individuen N), orientieren sich bei ihrer Entscheidung am herrschenden Marktzinssatz r. Für beide ist demnach

$$
\gamma=\mathrm{r} \text {. }
$$

Im Gleichgewicht, das über den Kapitalmarkt hergestellt wird, gilt damit

$$
\gamma_{\mathrm{G}}=\gamma_{\mathrm{N}}
$$

Der Marktprozeß sorgt dafür, daß die Entschädigung für die letzte Geldeinheit, auf die der Kreditgeber verzichtet, künftig gerade die Verzinsung bringt, die der Kreditnehmer bereit ist, für diesen zusätzlichen Konsum zu zahlen.

\section{b) Besteuerung des Periodeneinkommens}

Es wird angenommen, daß die Zinserträge (wie in den oben dargestellten Einkommensdefinitionen vorgesehen) vollständig zu versteuern sind. Die Abzugsfähigkeit der Schuldzinsen wird durch $a_{s}$ repräsentiert, d.h. $a_{s}$ gibt an, welcher Anteil der Schuldzinsen der Privathaushalte bei der Ermittlung der steuerlichen Bemessungsgrundlage abzugsfähig ist $\left(a_{s}=1\right.$ : voller Schuldzinsabzug; $a_{s}=0$ : kein Schuldzinsabzug).

Wie gezeigt, orientiert sich der zum momentanen Konsumverzicht bereite Haushalt am Zinssatz nach Steuern.

$$
\begin{aligned}
\gamma_{\mathrm{G}} & =\left(1-\tau_{\mathrm{z}}\right) * \mathrm{r} \\
\Leftrightarrow \mathrm{r} & =\frac{\gamma_{\mathrm{G}}}{1-\tau_{\mathrm{z}}} .
\end{aligned}
$$

Aufgrund der Besteuerung verlangen die zum Konsumverzicht bereiten Individuen (Zeitpräferenzrate $=\gamma_{G}$ ) einen höheren Zinssatz als in einer Laissez-FaireÖkonomie. Falls sich c.p. keine Auswirkungen auf den Zinssatz ergeben, wird in dieser Modellwelt das Sparen im Vergleich zu einer Laissez-Faire-Ökonomie diskriminiert. 
Die Individuen, die zugunsten eines gegenwärtigen Mehrkonsums Kredite aufnehmen, orientieren sich bei ihrer Entscheidung nach dem von ihnen zu entrichtenden Zinssatz nach Steuern; dieser Zinssatz muß ihrer persönlichen Zeitpräferenzrate $\gamma_{\mathrm{N}}$ entsprechen.

$$
\begin{aligned}
\gamma_{\mathrm{N}} & =\left(1-\mathrm{a}_{\mathrm{s}} \tau_{\mathrm{z}}\right) * \mathrm{r} \\
<\Rightarrow \mathrm{r} & =\frac{\gamma_{\mathrm{N}}}{1-\mathrm{a}_{\mathrm{s}} \tau_{\mathrm{z}}}
\end{aligned}
$$

Bei Abzugsfähigkeit der Schuldzinsen $\left(a_{s}=1\right)$ akzeptieren die Individuen einen höheren (Soll-) Zinssatz (da $1>\left(1-a_{s} \tau_{z}\right)>0$ und somit $\frac{1}{1-a_{s} \tau_{z}}>1$ wird) als bei Nichtabzugsfähigkeit der Schuldzinsen. Sofern sich der Zinssatz c.p. nicht ändert, wird eine Beeinflussung der intertemporalen Konsum-Spar-Entscheidung in der Weise stattfinden, daß sich der Gegenwartskonsum zu Lasten des $\mathrm{Zu}$ kunftskonsums erhöht.

Im Gleichgewicht, hergestellt über den Kapitalmarkt, gilt:

$$
\frac{\gamma_{G}}{1-\tau_{z}}=\frac{\gamma_{N}}{1-a_{s} \tau_{z}}
$$

Die Marginalbedingung in der Laissez-Faire-Ökonomie lautete

$$
\gamma_{\mathrm{G}}=\gamma_{\mathrm{N}}
$$

Um die Entscheidung der Individuen im Vergleich zu einer Laissez-Faire-Ökonomie nicht zu verzerren, muß diese Bedingung auch hier erfüllt sein. Dies ist der Fall, wenn die Nenner in obiger Gleichung identisch sind:

$$
\begin{aligned}
\left(1-\tau_{\mathrm{z}}\right) & =\left(1-\mathrm{a}_{\mathrm{s}} \tau_{\mathrm{z}}\right) \\
\Leftrightarrow \quad \tau_{\mathrm{z}} & =\mathrm{a}_{\mathrm{s}} \tau_{\mathrm{z}} .
\end{aligned}
$$

Damit die Marginalbedingung aus der Laissez-Faire-Ökonomie gegeben ist, $m u ß a_{s}$ den Wert 1 annehmen. Schuldzinsen müssen somit vollständig abzugsfähig sein. Die Spartätigkeit der kreditgebenden Individuen wird nicht beeinflußt, da der steuerlichen Belastung der kreditgebenden Individuen eine gleich 
hohe Entlastung der kreditaufnehmenden gegenübersteht. Damit heben sich beide Verzerrungseffekte auf und die Kapitalbildung bleibt unverändert ${ }^{l}$.

Daraus ist zu schließen, daß der private Schuldzinsabzug zuzulassen ist, wenn Zinseinkünfte besteuert werden ${ }^{2}$.

Es erfolgt somit keine Verzerrung der intertemporalen Konsum-Spar-Entscheidung, da sich aufgrund der höheren Zahlungsbereitschaft der kreditaufnehmenden Individuen durch die Abzugsfähigkeit der Schuldzinsen das Zinsniveau entsprechend erhöht und die höheren Zinsforderungen der kreditgebenden Individuen befriedigt werden können.

\subsubsection{Einfluß auf das Wirtschaftswachstum}

In einer Laissez-Faire-Ökonomie stimmen die subjektive Zeitpräferenzrate der Individuen $\gamma$ und die Nettogrenzproduktivität $f_{k}\left(\gamma=f_{k}\right)$ überein; d.h. der marginale Konsumverzicht der Individuen erbringt im investierenden Unternehmen gerade denjenigen Betrag, den die Individuen für ihren Konsumverzicht fordern. Wachstumsneutralität (= intertemporale Neutralität) des Steuersystems liegt vor, wenn die Anpassung des Kapitalstocks an die intertemporalen Konsumpräferenzen der Individuen mit und ohne Besteuerung nach derselben Marginalbedingung vorgenommen wird $^{3}$.

Die Individuen richten sich in ihren Planungen nach dem Nettomarktzinssatz nach Steuern; somit gilt:

$$
\gamma=\frac{\mathrm{r}}{1-\tau_{\mathrm{z}}} \quad \Leftrightarrow \mathrm{r}=\gamma *\left(1-\tau_{\mathrm{z}}\right)
$$

$1 \quad$ Vgl. Sinn, H.-W. (1984a), S. $220 \mathrm{ff}$.

2 In Deutschland ist der Abzug privater Schuldzinsen seit dem Steueränderungsgesetz von 1973 (mit Billigung des Bundesverfassungsgerichts vom 13.3.1979 -2 BvR 72/76, DB 1971, S. 872) nicht mehr zulässig; mit der Abschaffung des Schuldzinsabzugs sollte die Gesamtnachfrage nach Verbrauchsgütern begrenzt und notwendige Einnahmeverbesserungen geschaffen werden, um den Anstieg der Verbraucherpreise zu begrenzen. Der Abzug betrieblicher Schuldzinsen blieb erhalten, um ein befriedigendes Wachstum des Bruttosozialprodukts sowie einen hohen Beschäftigungsstand zu gewährleisten.

Vgl. Wenger, E. (1989), S. 183. 
Bei den Unternehmen erfüllt die Grenzinvestition folgende Bedingung:

$$
\mathrm{f}_{\mathrm{k}}=\left(\mathrm{a}_{\mathrm{s}}+\frac{1-\mathrm{a}_{\mathrm{s}}}{1-\tau_{\mathrm{e}}}\right) * \mathrm{r} \quad \Leftrightarrow \mathrm{r} \quad=\frac{\mathrm{f}_{\mathrm{k}}}{\frac{1-\mathrm{a}_{\mathrm{s}} \tau_{\mathrm{e}}}{1-\tau_{\mathrm{e}}},}
$$

$a_{s}$ bezeichnet hierbei den prozentualen Anteil der Schuldzinsen, der bei der Ermittlung des zu versteuernden Gewinns des Unternehmens abzugsfähig ist.

Im über den Kapitalmarkt hergestellten Gleichgewicht gilt

$$
\frac{\gamma}{1-\tau_{z}}=r=\frac{f_{k}}{\frac{1-a_{s} \tau_{e}}{1-\tau_{e}}}
$$

Nachfolgend wird untersucht, ob die Forderung der Wachstumsneutralität erfüllt ist; dabei wird unterschieden, ob die Schuldzinsen abzugsfähig sind oder nicht.

Sind bei den Unternehmen die Schuldzinsen nicht abzugsfähig, ist $a_{\mathrm{s}}=0$. Für obige Gleichung folgt dann

$$
\begin{aligned}
\frac{\gamma}{1-\tau_{\mathrm{z}}} & =\mathrm{r}=\mathrm{f}_{\mathrm{k}} *\left(1-\tau_{\mathrm{e}}\right) \\
\Leftrightarrow \frac{\gamma}{\mathrm{f}_{\mathrm{k}}} & =\left(1-\tau_{\mathrm{e}}\right) *\left(1-\tau_{\mathrm{z}}\right)
\end{aligned}
$$

In einer Laissez-Faire-Ökonomie gilt, daß $\gamma=\mathrm{f}_{\mathrm{k}}$. Daraus folgt $\frac{\gamma}{\mathrm{f}_{\mathrm{k}}}=1$.

Wird diese Bedingung in die obige Gleichung eingesetzt, gilt:

$$
\begin{aligned}
\frac{1}{1-\tau_{\mathrm{z}}} & =1-\tau_{\mathrm{e}} \\
\Leftrightarrow \tau_{\mathrm{z}} & =\frac{\tau_{\mathrm{e}}}{1-\tau_{\mathrm{e}}}
\end{aligned}
$$

Diese Bedingung ist bei $1>\tau_{\mathrm{e}} \geq 0$ und $1>\tau_{\mathrm{z}} \geq 0$ nur erfüllt, wenn

$$
\tau_{\mathrm{z}}=\tau_{\mathrm{e}}=0 \text {. }
$$


Wachstumsneutralität ist bei der Nichtabzugsfähigkeit der Schuldzinsen bei Unternehmen somit nur gewährleistet, wenn weder Zinseinkünfte, noch einbehaltene (= thesaurierte) Gewinne besteuert werden.

Sind bei den Unternehmen sämtliche Schuldzinsen abzugsfähig, nimmt $a_{s}$ den Wert 1 an. Für die zu untersuchende Gleichung gilt dann:

$$
\frac{\gamma}{1-\tau_{\mathrm{z}}}=\mathrm{r} \quad=\quad \mathrm{f}_{\mathrm{k}}
$$

Der sich im Gleichgewicht von den Unternehmen an die Kreditgeber zu entrichtende Zinssatz steigt, da sich die Individuen -wie gezeigt- bei ihrer KonsumSpar-Entscheidung am Zinssatz nach Steuern orientieren. Die in einer LaissezFaire-Ökonomie geltende Bedingung für die Wachstumsneutralität $\left(\gamma=\mathrm{f}_{\mathrm{k}}\right)$ ist damit nicht erfüllt. Daher sinkt aufgrund des im Gleichgewicht gestiegenen Marktzinssatzes das Investitionsvolumen im Vergleich zur Laissez-Faire-Ökonomie, da die Individuen zukünftigen Konsum durch gegenwärtigen ersetzen. Dadurch reduziert sich c.p. das Kapitalangebot; dies hat einen Einfluß auf die Höhe des Kapitalmarktzinssatzes. Im Vergleich zu einer Laissez-Faire-Ökonomie findet somit keine optimale Ressourcenallokation statt.

Bei den üblichen neoklassischen Annahmen über die Produktionsfunktion ergeben sich somit aufgrund der Besteuerung folgende zwei Verzerrungen im Vergleich zu einer Laissez-Faire-Ökonomie ${ }^{l}$ :

- Das Niveau der Kapitalakkumulation ist nicht optimal.

- Die Grenzproduktivität des Faktors "Arbeit" nimmt einen anderen Wert als im Optimum an; dies hat entweder Einfluß auf den Preis der Arbeit (= Lohn) oder den Umfang der Beschäftigung.

\subsubsection{Finanzierungsentscheidung der Unternehmen ${ }^{2}$}

Es wird anschließend untersucht, ob die Zinsbesteuerung bzw. der Schuldzinsabzug notwendig ist, um ein finanzierungsneutrales Steuersystem zu erhalten.

1 Vgl. Nachtkamp, H.H. (1988), S. 171.

2 Die nachfolgende Untersuchungsmethode wurde von Sinn, H.-W.(1984a) übernommen. 
Zur Variation des Einflusses des Schuldzinsabzugs, wird ein Faktor $a_{\mathrm{s}}\left(1 \geq a_{\mathrm{s}} \geq\right.$ 0 ) eingeführt, der den abzugsfähigen Teil der Schuldzinsen bei der steuerlichen Gewinnermittlung angibt ${ }^{l}$.

Wird das oben dargestellte Arbitragekalkül durchgeführt, ergibt sich als Zwischenergebnis $^{2}$ : der Anteilseigner ist indifferent zwischen

- Beteiligungs- und Selbstfinanzierung, wenn der Steuersatz für ausgeschüttete Gewinne $\tau_{\mathrm{a}}$ dem auf einbehaltene $\tau_{\mathrm{e}}$ entspricht.

- Fremd- und Beteiligungsfinanzierung ${ }^{3}$, wenn gilt:

$$
\tau_{\mathrm{z}} \quad=\frac{\tau_{\mathrm{a}}-\left(1-\mathrm{a}_{\mathrm{s}}\right) * \tau \mathrm{e}}{1-\left(1-\mathrm{a}_{\mathrm{s}}\right) * \tau_{\mathrm{e}}}
$$

- Fremd- und Selbstfinanzierung ${ }^{4}$, wenn

$$
\tau_{\mathrm{z}} \quad=\frac{\mathrm{a}_{\mathrm{s}} * \tau_{\mathrm{e}}}{1-\left(1-\mathrm{a}_{\mathrm{s}}\right) * \tau_{\mathrm{e}}}
$$

entspricht.

Bei einem finanzierungsneutralen Steuersystem müssen obige Bedingungen gleichzeitig erfüllt sein.

$1 \quad a_{\mathrm{s}}=0$ bedeutet, da $\beta$ keine Schuldzinsen abzugsfähig sind, $\mathrm{a}_{\mathrm{s}}=1$ hat die volle Abzugsfähigkeit der Schuldzinsen zur Folge.

2 Die verwendeten Variablen bedeuten:

$\tau_{\mathrm{a}}=$ Steuersatz auf ausgeschüttete Gewinne

$\tau_{\mathrm{e}}=$ Steuersatz auf einbehaltene Gewinne

$\tau_{\mathrm{z}}=$ Steuersatz auf Zinseinkünfte.

$3 \quad$ Erträge durch Kapitalmarktanlage: $\quad \mathrm{Z}(\mathrm{BF})=\left(1-\tau_{\mathrm{z}}\right) * \mathrm{r}$

geringere Ausschüttung aufgrund höherer abzugsfähiger Schuldzinsen der Unternehmung:

$$
\mathrm{A}(\mathrm{BF})=\left(1-\tau_{\mathrm{a}}\right) * \frac{\mathrm{r}}{1-\left(1-\mathrm{a}_{\mathrm{s}}\right) * \tau_{\mathrm{e}}}
$$

$4 \quad$ Erträge durch Kapitalmarktanlage: $\quad \mathrm{Z}(\mathrm{SF})=\frac{1-\tau_{\mathrm{a}}}{1-\tau_{\mathrm{e}}} *\left(1-\tau_{\mathrm{z}}\right) * \mathrm{r}$ geringere Ausschüttung aufgrund höherer abzugsfähiger Schuldzinsen der Unternehmung:

$$
\mathrm{A}(\mathrm{BF})=\left(1-\tau_{\mathrm{a}}\right) * \frac{\mathrm{r}}{1-\left(1-\mathrm{a}_{\mathrm{s}}\right) * \tau_{\mathrm{e}}}
$$


Werden für $\mathrm{a}_{\mathrm{s}}$ die beiden Randwerte 0 (= kein Schuldzinsabzug) bzw. 1 (= voller Schuldzinsabzug) eingesetzt, ergibt sich:

$$
\begin{array}{ll}
\mathrm{a}_{\mathrm{s}}=1(=\text { voller Schuldzinsabzug) } & \mathrm{a}_{\mathrm{s}}=0 \text { (= kein Schuldzinsabzug) } \\
\tau_{\mathrm{e}}=\tau_{\mathrm{a}} & \tau_{\mathrm{e}}=\tau_{\mathrm{a}} \\
\tau_{\mathrm{z}}=\tau_{\mathrm{a}} & \tau_{\mathrm{z}}=0 \\
\tau_{\mathrm{z}}=\tau_{\mathrm{e}} &
\end{array}
$$

Das Steuersystem ist bei vollständig erlaubtem Schuldzinsabzug finanzierungsneutral, wenn die Steuersätze für Zinsen sowie für ausgeschüttete und einbehaltene Gewinne identisch sind. Wird ein Schuldzinsabzug nicht zugelassen, besteht Finanzierungsneutralität, wenn die Zinsen nicht besteuert werden und der Steuersatz für ausgeschüttete Gewinne dem für thesaurierte entspricht.

Die Nichtbesteuerung von Zinseinkünften hat also -wenn ein finanzierungsneutrales Steuersystem angestrebt wird- im Umkehrschluß bei einer Einkommensteuer nach den hier behandelten Konzeptionen zur Folge, daß entweder der Schuldzinsabzug unterbunden oder die Steuersätze für einbehaltene und ausgeschüttete Gewinne 0 sind, also Kapitaleinkünfte insgesamt nicht besteuert wer$\operatorname{den}^{l}$.

\subsubsection{Intertemporale Arbeitsentscheidung}

Nöhrbaß/Raab ${ }^{2}$ analysieren, ob die intertemporale Arbeitsentscheidung durch die Zinsbesteuerung verzerrt wird. Sie untersuchen, wie lange ein Arbeitnehmer, der im Jahre 1955 eine Stunde mehr gearbeitet hat als ein Kollege und den zusätzlichen Lohn in Bundesanleihen anlegte, heute weniger arbeiten muß, um das gleiche Vermögen zu besitzen wie der Kollege aus dem Jahre 1955.

Die Untersuchung zeigte, daß der reale Wert einer Arbeitsstunde ohne die Zinsbesteuerung ungefähr gleich geblieben ist, während bei der Besteuerung der Zinseinkünfte mit einem angenommenen Steuersatz von 40\% das in 1955 fleißi-

1 Diese Folgerung gilt nicht bei Besteuerungskonzeptionen, die den Cash-Flow als Bemessungsgrundlage heranziehen (vgl. Brown, E.C. (1948), Kay, J.A./King, M.A. (1978), Meade Committee (1978), Sinn, H.W. (1984a)).

2 Nöhrbaß, K.-H./Raab, M. (1991), S. 75 ff. 
gere Individuum für seine in der Vergangenheit geleistete Mehrarbeit von einer Stunde heute nur noch 26 Minuten zusätzliche Freizeit genießen kann. Die Löhne sind somit schneller gestiegen als die Zinsen (jeweils nach Steuern). Hätte das Individuum statt der Anlage in Bundesanleihen das zusätzliche Kapital zum Spareckzins (= Sparbuch) angelegt, wäre das Ergebnis noch mehr zu seinen Ungunsten ausgefallen.

Die intertemporale Arbeit-Freizeit-Entscheidung wird -expost betrachtet- durch die Besteuerung der Zinsen verzerrt: für die Individuen wäre es günstiger gewesen, in der Vergangenheit möglichst wenig zu arbeiten, da eine zusätzliche Arbeitsstunde in der Vergangenheit lediglich 26 Minuten mehr Freizeit in der Gegenwart ermöglicht bzw. eine zusätzliche Stunde Freizeit in der Vergangenheit heute nur 26 Minuten Mehrarbeit kostet.

\subsubsection{Ergebnis: Neutralität der Zinsbesteuerung}

Werden die Zinseinkünfte in die Bemessungsgrundlage der Besteuerung einbezogen und ein vollständiger Schuldzinsabzug zugelassen, liegt ein neutrales Steuersystem nicht vor: die Individuen sparen weniger als in einer LaissezFaire-Ökonomie, d.h. sie substituieren zukünftigen Konsum durch gegenwärtigen. Dieses Verhalten hat Auswirkungen auf das Wirtschaftswachstum, da der Zinssatz aufgrund des Verhaltens der Individuen c.p. steigt und somit die Grenzinvestition des Unternehmenssektors eine höhere Nettogrenzproduktivität als in einer Laissez-Faire-Ökonomie aufweisen muß. Die Ressourcenallokation ist damit aufgrund der Zinsbesteuerung nur noch suboptimal.

Bei den üblichen neoklassischen Annahmen über die Produktionsfunktion hat dies folgende Konsequenzen im Vergleich zu einer Laissez-Faire-Ökonomie ${ }^{l}$ :

- Das Niveau der Kapitalakkumulation ist nicht optimal.

- Die Grenzproduktivität des Faktors "Arbeit" nimmt einen anderen Wert als im Optimum an; dies hat entweder Einfluß auf den Preis der Arbeit (= Lohn) oder den Umfang der Beschäftigung.

Bei zugelassenem Schuldzinsenabzug ist Finanzierungsneutralität gewährleistet, wenn ausgeschüttete und einbehaltene Gewinne wie Zinseinkünfte besteuert werden.

Vgl. Nachtkamp, H.H. (1988), S. 171. 
Wird der Schuldzinsabzug verweigert und gleichzeitig sämtliche Kapitaleinkünfte (also auch die Zinsen) besteuert, ist die Investitionsneutralität verletzt, da die Grenzinvestition eine höhere Rendite erwirtschaften muß als in der LaissezFaire-Ökonomie. Weiterhin wird gegen die Forderung der Finanzierungsneutralität verstoßen und die intertemporale Konsum-Spar-Entscheidung verletzt.

Bei einem Verbot des Schuldzinsabzugs und -als Folge hieraus- einer Nichtbesteuerung der Zinseinkünfte sowie einem einheitlichen Steuersatz für einbehaltene sowie ausgeschüttete Gewinne, wird gegen die Forderungen der Investitions- und der Wachstumsneutralität verstoßen, da die Grenzinvestition einen höheren Grenzertrag als bei der Abzugsfähigkeit von Schuldzinsen erwirtschaften muß. Die Finanzierungsneutralität ist gewahrt, d.h. die Entscheidung hinsichtlich der Unternehmensfinanzierung wird durch diese steuerlichen Regelungen nicht beeinflußt.

Wird lediglich der private Schuldzinsabzug untersagt (z.B. in Deutschland für nicht-investive Kredite), verteuert dies den kreditfinanzierten Konsum im Vergleich zu einer Laissez-Faire-Ökonomie. Die Individuen ändern wegen des Verbots des Schuldzinsabzugs ihren Konsumplan; die intertemporale Konsumentscheidung der Individuen wird also beeinflußt. Es kommen somit im Vergleich zur Laissez-Faire-Ökonomie nur suboptimale Lösungen zustande.

Wird aus den o.a. Gründen auf die Zinseinkommensbesteuerung verzichtet, ist eine Besteuerung der sonstigen Kapitaleinkünfte abzulehnen, wenn die Schuldzinsen bei den Unternehmen als Betriebsausgabe die steuerliche Bemessungsgrundlage vermindern. Das bedeutet einen Verzicht auf die Kapitaleinkommensbesteuerung. Ansonsten ist die Finanzierungsneutralität verletzt: die Unternehmen werden dann nur noch mit Fremdkapital ausgestattet.

Empirische Daten zur Prüfung der optimalen intertemporalen Arbeitsangebotsplanung zeigen, daß die Zinsbesteuerung -expost in einer wachsenden Wirtschaft mit steigenden Löhnen betrachtet- die intertemporale Arbeitsentscheidung des Individuums verzerrt. Damit liegt ein Verstoß gegen die Forderung nach einem neutralen Steuersystem vor.

\subsection{Praktikabilität der Besteuerung - dargestellt am Beispiel Deutschland}

In Deutschland wurden Zinseinkünfte bisher nur zu einem geringen Anteil im Lohnsteuerjahresausgleich bzw. in der Einkommensteuererklärung angegeben und damit versteuert. Die Angabe der Zinseinkünfte und die darauf zu entrichtende Steuer kommt nach Meinung vieler einer "Dummensteuer" gleich. Dieses Verhalten vieler Bundesbürger ist mit der geringen Entdeckungswahrschein- 
lichkeit dieses Fehlverhaltens zu erklären: das Finanzamt hat gemäß § 30a AO auf das besondere Vertrauensverhältnis zwischen Kreditinstituten und deren Kunden Rücksicht zu nehmen. Kontrollmitteilungen werden deshalb nur in einem sehr geringen Umfang angefordert; somit ist eine wirksame Kontrolle der Zinsen kaum möglich.

Die im Jahre 1989 eingeführte und wieder abgeschaffte "kleine" Kapitalertragsteuer in Höhe von $10 \%$ brachte keine höhere Steuerehrlichkeit, sondern führte zu einem verstärkten Abfluß von Kapital nach Luxemburg oder Österreich. Damit wurden diese Einkünfte der deutschen Einkommensteuer faktisch entzogen. Dieser Weg wird von den Anlegern jetzt wieder beschritten, wie sich nach der Ankündigung der neuen Zinsabschlagssteuer zeigte. Die Möglichkeiten der Steuerhinterziehung durch Verlagerung der Zinseinkünfte ins Ausland stehen aber nur reicheren Individuen offen, da die Geldinstitute im Ausland meist Mindestanlagesummen in der Größenordnung von 100.000,- DM verlangen. Folglich können nur die Reicheren ihre Steuern gefahrlos verkürzen, während die Ärmeren zur Steuer herangezogen werden bzw. ein höheres Entdeckungsrisiko (durch die inländische Kapitalanlage) tragen $^{I}$. Der vorgeschlagene -aber vom Gesetzgeber nicht eingeschlagene- Weg einer Abgeltungssteuer $(=$ mit der Quellensteuer sind alle Steueransprüche des Staates abgegolten) könnte aber auch zu einer Kapitalflucht führen. Zudem hat sie den Nachteil, daß Anleger mit einem höheren Steuersatz als dem Abgeltungssteuersatz bevorzugt werden, da diese im Gegensatz zu einer Erfassung der Einkünfte im Rahmen der Einkommensteuer einen geringeren Steuersatz zu entrichten haben.

\subsection{Ergebnis: Besteuerung von Zinseinkünften}

Bei der Lebenseinkommensbesteuerung durch das Periodeneinkommen ist die Besteuerung von Zinseinkünften mit dem Leistungsfähigkeitsprinzip nicht zu vereinbaren, da -bei gleichem Lebenseinkommen vor Steuern- der Konsumzeitpunkt die Höhe der Steuerzahlungen beeinflußt und durch die Besteuerung sich somit auch die ordinale Reihenfolge der Individuen verschieben kann. Alle oben aufgeführten Einkommenskonzeptionen sowie deren Modifikationen verstoßen deshalb gegen die Forderung nach einem gerechten Steuersystem. Es liegt ein im System der periodischen Erfassung des Einkommens zu suchender Mangel vor.

$1 \quad$ Die Problematik der "vergessenen" Kapitaleinkünfte wird ab dem 1.1.1993 durch die Einführung erhöhter Freibeträge (einzeln zu veranlagende Steuerpflichtige 6.100,- DM, zusammenveranlagte Ehegatten 12.200,- DM) entschärft, da viele Steuerpflichtige Zinseinkünfte in geringerer Höhe erzielen. 
Durch die Zinsbesteuerung wird die optimale Ressourcenallokation gestört: insbesondere verringert sich die Ersparnis der Individuen, da sie durch die Zinsbesteuerung ihren Gegenwartskonsum zu Lasten der Ersparnis erhöhen. Weiterhin ergibt sich ein geringeres Wirtschaftswachstum. Im Vergleich zu einer LaissezFaire-Ökonomie ist daher -bei den üblichen neoklassischen Annahmen über die Produktionsfunktion- das Niveau der Kapitalakkumulation nicht optimal. Die Grenzproduktivität des Faktors "Arbeit" nimmt einen anderen Wert als im Optimum an; dies hat entweder Einfluß auf den Preis der Arbeit (= Lohn) oder den Umfang der Beschäftigung.

Wird -wie in Deutschland- auf Kontrollanfragen bei den Banken weitgehend verzichtet, ist die Erfassung der Zinseinkünfte nicht vollständig gewährleistet. Die Zinseinkünfte können überdies durch Transferierung des Kapitals ins Ausland dem Fiskus vorenthalten werden; somit entstehen Probleme hinsichtlich der Praktikabilität der Zinsbesteuerung.

\section{Steuerliche Erfassung des Wertzuwachses}

Die oben angeführten Einkommensdefinitionen beantworten die Frage des Einbezugs von Wertänderungen in die Bemessungsgrundlage der Einkommensteuer nicht einheitlich: während manche Einkommensdefinitionen lediglich den Einbezug von auf Basis der Anschaffungskosten berechneten Abschreibungen postulieren und von der Erfassung anderer Wertänderungen absehen, fordern andere den Einbezug von realisierten, wieder andere auch den von unrealisierten Wertänderungen.

Es wird nachfolgend untersucht, ob und gegebenenfalls wie der Einbezug von Wertänderungen bei der Ermittlung des zu versteuernden Einkommens vorzunehmen ist. Maßstäbe sind wiederum die Besteuerung nach der individuellen Leistungsfähigkeit und die Neutralität sowie Praktikabilität der Besteuerung.

\subsection{Besteuerung nach der individuellen Leistungsfähigkeit}

\subsubsection{Systematische Betrachtungsweise}

Das Leistungsfähigkeitsprinzip umfaßt auch das Totalitätsprinzip, nachdem jeder Vermögenszufluß und -abfluß in der steuerlichen Bemessungsgrundlage zu 
berücksichtigen ist ${ }^{l}$. Werterhöhungen im Vermögen bedeuten einen Vermögenszufluß beim Steuerpflichtigen, seine Leistungsfähigkeit ist gestiegen. Dies muß seinen Niederschlag in der steuerlichen Bemessungsgrundlage finden. Unerheblich ist dabei, ob das Vermögen erwirtschaftet, zugewendet oder in Form von Windfall Profits entstanden ist; ob es liquide ist oder nicht.

Einkommenskonzeptionen, die Wertänderungen nicht oder erst bei ihrer Realisation in die steuerliche Bemessungsgrundlage einbeziehen, verstoßen gegen das Leistungsfähigkeitsprinzip und somit gegen den Gleichheitssatz.

\subsubsection{Wirtschaftliche Betrachtungsweise}

Wie oben dargestellt, wird die steuerliche Leistungsfähigkeit einer Person durch deren Verfügungsmacht über knappe Ressourcen einer Ökonomie ausgedrückt. Als geeigneter Indikator für die individuelle Leistungsfähigkeit wurde das Lebenseinkommen definiert. Es ist zu klären, ob und gegebenenfalls in welcher Höhe Vermögenswertänderungen das Lebenseinkommen und damit die steuerliche Bemessungsgrundlage beeinflussen.

Dazu sind zunächst die Ursache von Wertänderungen darzustellen. Grundsätzlich können drei Ursachen unterschieden werden:

- Abnutzung

- Verzinsung des eingesetzten Kapitals

- Windfall Profits.

Nachfolgend wird untersucht, wie die verschiedenen Ursachen der Wertänderungen die individuelle Leistungsfähigkeit beeinflussen.

Ein Vermögensgegenstand verliert an Wert, wenn er genutzt wird, da sich sein Nutzenvorrat verringert. Wird der Vermögensgegenstand zur Einkommenserzielung genutzt, sind Wertänderungen bei der Einkommensermittlung abzugsfähig, da Einkommen definitionsgemäß die Veränderung der Verfügungsmacht über die Ressourcen der Wirtschaft darstellt.

$1 \quad$ Vgl. Lang, J. (1988), S. 171. Diese Forderung wurde im Gewinnbegriff des Einkommensteuergesetzes von 1925 berücksichtigt ( $\$ 12$ (1) S.1 i.V.m. §19 (1) S.1 sah vor, daß Wirtschaftsgüter des Anlage- und Umlaufvermögens grundsätzlich mit dem gemeinen Wert anzusetzen sind; dies war allerdings keine Pflicht, da $§ 19$ (2) den Steuerpflichtigen auch das Wahlrecht einräumte, statt des gemeinen Wertes die um Abschreibung verminderten Anschaffungs- oder Herstellungskosten anzusetzen). 
Die Wertminderung des Vermögensgegenstandes muß allerdings genau bestimmt werden, da sonst das Einkommen und somit die individuelle Leistungsfähigkeit nicht exakt bestimmt werden können.

Wertänderungen können auch die Verzinsung des eingesetzten Kapitals repräsentieren. Ein Beispiel für diese Art von Wertänderungen ist die Wertentwicklung von Zerobonds: deren Wert steigt von Jahr zu Jahr aufgrund der laufenden Verzinsung des eingesetzten Kapitals, der Zins wird jedoch nicht periodenweise ausgeschüttet. Zinsen und Wertzuwächse können als äquivalent angesehen werden. Für die Beurteilung der Frage der Verfügungsmacht eines Individuums über die Ressourcen der Wirtschaft ist es unerheblich, in welcher Form die Verzinsung des eingesetzten Kapitals erfolgt. Beide sind gleich zu behandeln, da es sonst zu einer gegen das Leistungsfähigkeitsprinzip verstoßenden Ungleichbehandlung der Individuen kommt. Mit dieser Aussage können daher die Ergebnisse der Untersuchung der Zinseinkommensbesteuerung analog übertragen werden. Dort wurde gezeigt, daß die Zinsbesteuerung gegen das Leistungsfähigkeitsprinzip verstößt. Um aber wenigstens eine Gleichbehandlung zwischen den Steuerpflichtigen mit Zins- und denen mit Wertänderungseinkommen zu gewährleisten, müssen beide hinsichtlich der Klassifizierung als leistungsfähigkeitsbeeinflussend gleich behandelt werden, d.h. entweder werden beide "Einkommensarten" komplett oder überhaupt nicht in die steuerliche Bemessungsgrundlage einbezogen.

Sollen -wie es die Einkommensdefinition von Brandis vorsieht- lediglich realisierte Vermögenswertänderungen in die Bemessungsgrundlage eingehen, Zinsen jedoch jährlich in voller Höhe, führt dies -bei gleichem Lebenseinkommen vor Steuern- zu einer unterschiedlichen Steuerlast, da die Zinseinkünfte jährlich, die Vermögenswertänderungen jedoch erst nach Ablauf einiger Jahre zu versteuern sind. Damit liegt ein Verstoß gegen das Leistungsfähigkeitsprinzip vor; das Konzept ist deshalb abzulehnen.

Wertänderungen können auch als Windfall Profits auftreten, d.h. die Einschätzung des Ertragswertes einer Anlage/Investition hat sich plötzlich geändert. Ein Beispiel für diese Art der Wertänderung ist ein landwirtschaftlich genutztes Grundstück, auf dem unvermutet eine Goldader gefunden wird. War vor dem Fund die Einschätzung der landwirtschaftlichen Erträge der wertbestimmende Faktor, sind jetzt die Erträge aus dem Goldabbau ausschlaggebend. Der Wert ergibt sich aus der abdiskontierten Summe der zukünftigen Erträge aus dem Goldabbau: ein rationaler Käufer wird sein Gebot solange erhöhen, bis der Ertrag aus dem Goldabbau der Verzinsung des eingesetzten Kapitals (also des Kaufpreises) zum Kapitalmarktzinssatz entspricht.

Die Verfügungsmacht des Individuums über die Ressourcen der Wirtschaft nehmen aufgrund der veränderten Werteinschätzungen zu, da höhere ökonomische 
Dispositionsmöglichkeiten (also eine höhere Summe von ökonomischen Rechten) zur Verfügung stehen. Diese Art der Wertänderungen beeinflußt die individuelle Leistungsfähigkeit und ist zur vollständigen Erfassung der individuellen Leistungsfähigkeit in die steuerliche Bemessungsgrundlage einzubeziehen.

Es ist jetzt noch der Zeitpunkt des Einbezugs der Wertänderungen in der steuerlichen Bemessungsgrundlage zu bestimmen. Der verteilungspolitisch definierte Leistungsfähigkeitsbegriff stellt auf die Verfügungsgewalt der Individuen über die Ressourcen der Wirtschaft ab. Wertänderungen im Vermögen des Individuums stellen geänderte Dispositionsmöglichkeiten dar, die Leistungsfähigkeit wird durch diese Vorgänge beeinflußt. Die Realisation von Wertänderungen ist das Ergebnis einer Konsum-Spar-Entscheidung, wenn sich der Steuerpflichtige zwischen weiterem Sparen oder einem höheren Konsum zu entscheiden hat bzw. eine Portfolioentscheidung, wenn die Erlöse aus der erwogenen Veräußerung des Vermögensobjektes in ein anderes Vermögensobjekt reinvestiert wer$\operatorname{den}^{l}$. Wie sich das Individuum letztlich entscheidet (ob konsumtive oder investive Verwendung), spielt für die Bestimmung der Leistungsfähigkeit keine Rolle. Somit sind bei der Ermittlung der steuerlichen Bemessungsgrundlage alle Wertänderungen, die realisierten und die unrealisierten, einzubeziehen.

Ein weiterer Grund gegen den ausschließlichen Einbezug von realisierten Wertänderungen ist ein steuersystematischer: die Höhe der für die Periode abzuführenden Steuer wird in keinem anderen Fall (z.B. der Arbeitslohn wird konsumiert oder gespart) von einer durch das Individuum zu treffenden Konsum-Sparbzw. Portfolio-Entscheidung beeinflußt. Die Ausnahmeregelung in der von Brandis vorgeschlagenen Einkommenskonzeption für die ausschließliche Besteuerung der realisierten Wertänderungen ist also ein Systembruch und aus systematischen Gründen abzulehnen.

Als Schlußfolgerung ergibt sich, daß eine Besteuerungskonzeption, die lediglich die auf Basis der Anschaffungskosten berechneten Wertänderungen (Abschreibungen) berücksichtigt und sonstige Wertänderungen (realisiert oder unrealisiert) generell nicht in die Bemessungsgrundlage der Besteuerung einbezieht, gegen die Forderung nach einer Besteuerung gemäß der individuellen Leistungsfähigkeit verstößt.

$1 \quad$ Vgl. Ebnet, O. (1978), S. 82. 


\subsubsection{Einbezug des Human Capital}

Fraglich ist, ob auch Wertänderungen der menschlichen Arbeitskraft -z.B. aufgrund der Ausbildung oder aufgrund der im Alter nachlassenden körperlichen Leistungsfähigkeit- bei der Einkommensermittlung berücksichtigt werden müssen.

Die Arbeitskraft kann nicht auf Dauer veräußert werden, da es seit der Abschaffung der Sklaverei keinen Markt mehr für sie gibt ${ }^{l}$. Es besteht zwar grundsätzlich der Grundsatz der Vertragsfreiheit gemäß §305 BGB; sie endet aber dort, wo sie durch Gesetz eingeschränkt ist; gesetzliche Schranken ergeben sich aus $\S 138$ BGB (Sittenwidrigkeit) sowie aus dem im Grundgesetz verbrieften Recht der freien Wahl des Arbeitsplatzes (Art. $12 \mathrm{GG})^{2}$; eine dauerhafte Veräußerung der eigenen Arbeitskraft ist nicht möglich. Das Individuum kann sein Humanvermögen im allgemeinen auch nicht als Sicherheit für einen Kredit anbieten, da die Banken dies selbst bei Ärzten, die früher diese Möglichkeit hatten, aufgrund ihrer schlechten Erfahrungen nicht mehr akzeptieren. Der Steuerpflichtige kann damit über seine eigene Arbeitskraft nicht so disponieren, daß er sie auf einem Markt an einen Dritten auf Dauer veräußert oder beleiht. Wertänderungen der menschlichen Arbeitskraft können somit in der Einkommensdefinition nicht berücksichtigt werden ${ }^{3}$.

Der Nichteinbezug der Änderung des Human Capital eines Steuerpflichtigen in sein steuerpflichtiges Einkommen stellt keine Ungleichbehandlung im Vergleich zu der Einbeziehung von Wertänderungen bei anderen Vermögensobjekten dar ${ }^{4}$ : über die Wertänderungen anderer Vermögensobjekte kann er z.B. durch VeräuBerung unmittelbar verfügen, nicht jedoch beim Human Capital.

\subsubsection{Ergebnis}

Es wurden drei Ursachen von Wertänderungen festgestellt: Wertänderungen als Verzinsung des eingesetzten Kapitals, durch Abnutzung sowie als Folge von Windfall Profits.

Wertänderungen durch die Verzinsung des eingesetzten Kapitals (z.B. es erfolgen keine laufenden Ausschüttungen) sind wie Zinseinkünfte zu besteuern; da-

Vgl. z.B. Diamond, P.A. (1975), S. 228.

2 Vgl. Becker-Schaffner, R. (1991), S. 1016.

3 Vgl. Ebnet, O. (1978), S. 57 f.

4 Vgl. hierzu auch Wagner, F.W. (1976), S. 234 ff. 
mit treten dieselben Probleme wie bei der Zinsbesteuerung auf. Um aber der Gleichartigkeit von Wertänderungen und einer (laufenden) Verzinsung gerecht zu werden, müssen die Zinsen und die Wertänderungen in gleichem Umfang in die Bemessungsgrundlage der Besteuerung eingehen.

Wertänderungen aufgrund von Abnutzungen oder Windfall Profits müssen in die steuerliche Bemessungsgrundlage einbezogen werden, da sie einen Einfluß auf die Verfügungsmöglichkeiten des Individuums über die Ressourcen der Wirtschaft haben. Ein Verzicht würde gegen das Konzept der Besteuerung nach der individuellen Leistungsfähigkeit verstoßen.

Die steuerliche Erfassung des Human Capitals ist abzulehnen, da es für dieses seit Abschaffung der Sklaverei keinen Markt gibt; der Steuerpflichtige kann über sein Humankapital somit nicht frei verfügen, seine Dispositionsfähigkeit über die Ressourcen der Wirtschaft hat sich nicht erhöht.

Alle Einkommensdefinitionen, die eine Wertänderung nur dann einbeziehen, wenn sie durch einen Werteverzehr zur Einkommenserzielung entstanden sind (Abschreibungen), bilden somit die individuelle Leistungsfähigkeit nicht umfassend ab. Weiter sind alle Einkommensdefinitionen abzulehnen, die die Abschreibungen anhand pauschalierter Verfahren bzw. anhand der historischen Anschaffungskosten bestimmen. Abzulehnen sind ebenso alle Einkommensdefinitionen, die Wertänderungen erst bei ihrer Realisation in die steuerliche Bemessungsgrundlage einbeziehen.

Problematisch hinsichtlich der Besteuerung nach der individuellen Leistungsfähigkeit ist bei allen Einkommenskonzeptionen aber die Besteuerung der Wertänderungen, die die Verzinsung des eingesetzten Kapitals repräsentieren ${ }^{l}$.

Werden obige Aussagen zusammengefaßt, erfüllt die Einkommensdefinition der Reinvermögenszugangstheorie die Anforderungen am ehesten: hier werden Wertänderungen generell einbezogen; es bleibt lediglich das Problem der Besteuerung der Wertänderungen bestehen, die die Verzinsung des eingesetzten Kapitals repräsentieren.

\subsection{Neutralität der Besteuerung}

Kriterium für die Beurteilung eines Steuersystems ist auch die Frage, wie die Besteuerung die Entscheidungen des Individuums beeinflußt. Es wird deshalb untersucht, ob die Forderung nach der Neutralität der Besteuerung die Erfassung von Wertänderung bei der Ermittlung des zu versteuernden Einkommens nach sich zieht.

l Vgl. hierzu die Darlegungen zur Zinseinkommensbesteuerung. 
Hierzu werden folgende Problemkreise behandelt:

- Wahl zwischen verschiedenen Anlageformen

- Einfluß auf die Innovationsbereitschaft

- Einfluß der Abschreibungshöhe auf die Investitionsentscheidung.

\subsubsection{Wahl zwischen verschiedenen Anlageformen}

Es wird ein Investor betrachtet, der sein Endkapital maximieren möchte und mögliche Alternativen einer Finanzanlage analysiert ${ }^{l}$.

Der Anleger hat die Wahl zwischen einem Papier mit einjähriger und einem mit zweijähriger Laufzeit. Das Papier mit der einjährigen Laufzeit erzielt eine laufende Verzinsung von $r$ und wird am Ende der Laufzeit zuzüglich Zinsen zurückgenommen. Nach einem Jahr besteht die Möglichkeit der Wiederanlage (incl. Zinsen) zu denselben Konditionen. Die Rendite des Papiers mit der zweijährigen Laufzeit beträgt pro Jahr ebenfalls r; sie wird jedoch nicht als laufende Zinszahlung, sondern als Wertänderung aufgefaßt. Das zweijährige Papier wird am Ende der Laufzeit einschließlich Zins und Zinseszins zurückgezahlt, eine zwischenzeitliche Auszahlung der Zinsen ist nicht möglich; wirtschaftlich liegt hier ein Zerobond mit einer zweijährigen Laufzeit vor.

Die Laufzeit ist aus Vereinfachungsgründen vom 1.1.01 bis zum 31.12.01 bzw. 02; die Besteuerungsperiode ist das Kalenderjahr.

Um beide Anlageformen bei unterschiedlichem Anfall von Zahlungsströmen (z.B. Zins-, Steuerzahlungen) vergleichen zu können, werden diese zum Kapitalmarktzinssatz r am Kapitalmarkt angelegt bzw. aufgenommen.

Nach der Analyse der optimalen Entscheidung in einer Laissez-Faire-Ökonomie wird die von einem der Einkommensteuer mit dem Steuersatz $\tau$ besteuerten Anleger zu treffende Entscheidung untersucht. Es wird davon ausgegangen, daß die an den Anleger ausgeschütteten und damit zugeflossenen Zinsen der Einkommensteuer unterliegen.

Der Finanzmarkt wird hier aufgrund der einfachen Darstellungsmöglichkeiten betrachtet; die Ergebnisse gelten aber auch für Investitionen auf anderen Märkten. 


\subsubsection{Exkurs: Laissez-Faire-Ökonomie}

Um einen Vergleichsmaßstab für das Verhalten eines Anlegers zu erhalten, wird zuerst eine Laissez-Faire-Ökonomie betrachtet:

Papier mit einjähriger Laufzeit:

Anlagekapital:

Zinsertrag nach dem ersten Jahr:

Wiederanlagekapital für das zweite Jahr:

Endkapital:

1

$\mathrm{r}$

$1+\mathrm{r}$

$(1+r)^{2}$

Papier mit zweijähriger Laufzeit:

Anlagekapital:

Wertänderung (= fiktiver Zinsertrag) nach dem ersten Jahr: $\quad r$

(Betrag wird dem Kapital zugeschlagen)

"fiktives Wiederanlagekapital" für das zweite Jahr: $\quad 1+r$

Endkapital:

Das Endkapital ist in beiden Fällen gleich. Der Anleger ist somit in einer Laissez-Faire-Ökonomie indifferent zwischen beiden Anlageformen.

\subsubsection{Einkommensteuer ohne Erfassung von Wertänderungen}

Papier mit einjähriger Laufzeit:

Anlagekapital:

Zinsertrag nach dem ersten Jahr:

Steuer auf die Zinserträge:

Wiederanlagekapital für das zweite Jahr:

Zinsertrag nach dem zweiten Jahr:

darauf abzuführende Steuer:

Endkapital:

\section{1}

$\mathrm{r}$

$\mathrm{r} * \tau$

$1+r(1-\tau)$

$(1+\mathrm{r}(1-\tau)) * \mathrm{r}$

$(1+r(1-\tau)) * r * \tau$

$(1+r(1-\tau))^{2}$ 
Papier mit zweijähriger Laufzeit:

Die Wertänderungen des Papiers werden in diesem Fall nicht besteuert; die am Ende der Laufzeit des Papiers ausbezahlte Differenz zwischen Anlage- und Rückzahlungsbetrag soll gemäß den Annahmen nicht unter die Zinsbesteuerung fallen, sondern wird als Wertsteigerung aufgefaßt.

Anlagekapital: $\quad 1$

Wertänderung (= fiktiver Zinsertrag) nach dem ersten Jahr: $\quad r$

(Betrag wird dem Kapital zugeschlagen)

"fiktives Wiederanlagekapital" für das zweite Jahr: $\quad 1+r$

Endkapital:

$(1+r)^{2}$

Wertänderung:

$2 r+r^{2}$

darauf zu entrichtende Steuer:

0

Werden beide Alternativen verglichen, ergibt sich für den Fall der Wahl des zweijährigen Papiers ein um $2 r \tau+2 r^{2} \tau-r^{2} \tau^{2}$ höheres Endkapital ${ }^{l}$. Die Nichtberücksichtigung von Wertänderungen verursacht somit einen Verstoß gegen die Forderung der Neutralität des Steuersystems, da Anlagen mit laufend ausgeschütteten Erträgen im Vergleich zu Anlagen mit Wertänderungen diskriminiert werden.

\subsubsection{Einkommensteuer mit Erfassung von realisierten Wertänderungen}

Papier mit einjähriger Laufzeit:

Nach den Annahmen (konstanter Zinssatz) treten keine Wertänderungen auf, so daß sich das gleiche Ergebnis wie oben ("Einkommensteuer ohne Erfassung von Wertänderungen") ergibt.

\footnotetext{
$1 \quad(1+\mathrm{r})^{2}-(1+\mathrm{r}(1-\tau))^{2}=2 \mathrm{r} \tau+2 \mathrm{r}^{2} \tau-\mathrm{r}^{2} \tau^{2}$

$2 \mathrm{r} \tau+2 \mathrm{r}^{2} \tau-\mathrm{r}^{2} \tau^{2}>0$

$\Rightarrow \mathrm{r}(2-\tau)>-2$
}

Diese Bedingung ist für $r>0$ und $1>\tau>0$ immer erfüllt. 
Papier mit zweijähriger Laufzeit:

Die unrealisierten Wertänderungen des Papiers werden nicht besteuert; zu versteuern ist lediglich die nach Ablauf der beiden Jahre realisierte Wertänderung, die nach den Modellannahmen der Verzinsung des eingesetzten Kapitals entspricht.

Anlagekapital zum Zeitpunkt $\mathrm{t}_{1}$ :

fiktive "Zinserträge" (Wertänderungen) nach dem 1. Jahr: r darauf zu entrichtende Steuer:

"fiktives Anlagekapital" im zweiten Jahr: $\quad 1+r$

Endkapital zum Zeitpunkt $t_{2}$ : $\quad(1+r)^{2}$ realisierte Wertänderung (= End- $t_{2}-$ Anfangskapital $\left.t_{1}\right): 2 r+r^{2}$

darauf zu entrichtende Steuer: $\quad\left(2 r+r^{2}\right) * \tau$

Endkapital nach Steuern (= Endkapital - Steuern): $\quad(1+r)^{2}-\left(2 r+r^{2}\right) * \tau$ $=(1+r)^{2}-r * \tau *(2+r)$

Werden beide Alternativen verglichen, ergibt sich für den Fall der Wahl des zweijährigen Papiers ein um $r^{2} t *(1-\tau)$ höheres Endkapital ${ }^{l}$; das zweijährige Papier ist eine vorteilhaftere Anlage. Der Einbezug von realisierten und die Nichtberücksichtigung von unrealisierten Wertänderungen in die Bemessungsgrundlage der Besteuerung widerspricht der Neutralität des Steuersystems, da Anlagen mit laufend ausgeschütteten Erträgen im Vergleich zu Anlagen mit Wertänderungen diskriminiert werden.

\footnotetext{
$1 \quad \mathrm{r}^{2} \tau *(1-\tau)=(1+\mathrm{r})^{2}-\mathrm{r} * \tau *(2+\mathrm{r})-(1+\mathrm{r}(1-\tau))^{2}$

$\mathrm{r}^{2} \tau(1-\tau)>0, \quad \mathrm{r}, \tau$ sind lt. Definition $>0$

$\Leftrightarrow \quad 1-\tau>0$.
}

Diese Bedingung ist für Steuersätze $100 \%>\tau>0 \%$ immer erfüllt. 


\subsubsection{Einkommensteuer mit genereller Erfassung von Wertänderungen}

Wertänderung werden generell (also sowohl realisierte als auch unrealisierte) als Einkommen aufgefaßt und besteuert; Schuldzinsen sind steuerlich abzugsfähig. Der Anleger hat bei dem zweijährigen Papier nach dem ersten Jahr keine Zahlungsmittelzuflüsse und muß zur Begleichung seiner Steuerschulden am Kapitalmarkt ein Darlehen aufnehmen. Am Ende der Laufzeit des zweijährigen Papiers wird dieses Darlehen mit den aufgelaufenen Zinsen zurückgezahlt.

Papier mit einjähriger Laufzeit:

Hier treten nach den gemachten Annahmen (konstanter Zinssatz) keine Wertänderungen auf; somit ergibt sich das gleiche Ergebnis wie oben.

Papier mit zweijähriger Laufzeit:

Anlagekapital:

Wertänderung (= Wert am Ende des ersten Jahres - Wert zu Beginn): $r$

darauf abzuführende Steuer:

$\mathrm{r} * \tau$

Dieser als Steuern zu entrichtende Betrag wird am Kapitalmarkt zum Zinssatz $r$ aufgenommen (bzw. zum Zinssatz r vom Staat gestundet).

Die für $t_{1} z u$ entrichtende Steuer gehört wirtschaftlich noch zur ersten Periode; sie mindert das in die Berechnung der Vermögenswertänderung eingehende Anfangsvermögen in $t_{2}$. Die Steuerverbindlichkeiten (einschließlich der darauf entfallenden Schuldzinsen) sind vom Endvermögen in $t_{2}$ abzuziehen. Dadurch wird der Tatsache Rechnung getragen, daß ein Teil der Aktiva der Darlehenstilgung dient und somit eine Gleichstellung mit den Individuen erfolgt, die ihre Steuerschuld unmittelbar nach Entstehung beglichen haben.

Das Papier wird am 31.12.02 fällig und mit den aufgelaufenen Zinsen zurückgezahlt. 
Vermögen zu Beginn der Periode $t_{2}$ :

$1+r *(1-\tau)$

Vermögen am Ende der Periode $t_{2}$ :

- Wert des Papiers:

$(1+r)^{2}$

- Darlehensschuld ${ }^{l}$ :

$\Rightarrow$ Vermögensstand am Ende von $t_{2}$ :

$(1+r)^{2}-(1+r) * r * \tau$

Vermögenswertänderung (= Wert am Ende des zweiten Jahres - Wert am Anfang des zweiten Jahres):

$r+r^{2}-r^{2} * \tau$

darauf zu entrichtende Steuer:

$\tau *\left(r+r^{2}-r^{2} * \tau\right)$

Endkapital (nach Steuern):

$(1+r(1-\tau))^{2}$

Bei beiden Alternativen ergibt sich für den Anleger das gleiche Endkapital; er ist also hinsichtlich der Wahl der Alternativen trotz der Besteuerung indifferent. Dies entspricht dem Ergebnis einer Laissez-Faire-Ökonomie. Das Steuersystem ist damit bei der vollständigen Berücksichtigung von Wertänderungen entscheidungsneutral.

\subsubsection{Ergebnis}

Es wurden zwei in einer Laissez-Faire-Ökonomie wirtschaftlich identische Anlagen daraufhin analysiert ${ }^{2}$, wie die Besteuerung hinsichtlich des Einbezugs von Wertänderungen zu gestalten ist, damit beide Anlagen auch in einer Welt mit Steuern wirtschaftlich gleich sind.

Eine Periodeneinkommensbesteuerung (mit Zinsbesteuerung) fordert den Einbezug von realisierten und unrealisierten Wertänderungen, damit die Anlageentscheidungen der Individuen nicht von steuerlichen Gesichtspunkten beeinflußt wird. Bleiben Wertzuwächse im Gegensatz zu anderen Erträgen steuerfrei, bedeutet dies nach Steuern eine Bevorzugung dieser Anlageform, da dann die Rendite nach Steuern der Rendite vor Steuern entspricht. Damit werden Anlagen mit laufend ausgeschütteten Erträgen im Vergleich zu Anlagen mit Wertänderungen diskriminiert.

1 Darlehen: $\mathrm{r} * \tau$, darauf zu entrichtende Zinsen: $r * \mathrm{r} * \tau$; daraus ergibt sich die zurückzuzahlende Schuld in Höhe von $(1+r) * r * \tau$.

2 Die beiden Anlagen unterschieden sich lediglich hinsichtlich der Form des Ertrags, der einmal in Form von Zinsen und zum anderen als Wertänderungen anfiel. 
Werden in einem Steuersystem nur -wie von Brandis vorgeschlagen- die $\mathrm{Zu}$ flüsse aus realisierten Wertänderungen besteuert, ist es für den Anleger günstig, Anlagen ohne laufend ausgeschüttete Erträge, aber mit laufenden Wertsteigerungen zu erwerben, da so der Barwert der Steuerzahlungen verringert wird.

\subsubsection{Einfluß der Wertänderungsbesteuerung auf die Innovations- bereitschaft}

Vor der Diskussion über den Einfluß des Steuersystems auf die Innovationsbereitschaft wird zunächst auf die Bedeutung von Innovationen für die Wirtschaft eingegangen.

Unter "Innovation" wird in Anlehnung an Schumpeter "..die Aufstellung einer neuen Produktionsfunktion" $l$ verstanden, d.h. Produktionsfaktoren werden auf eine neue Art miteinander kombiniert. Innovationen werden von den Unternehmern getätigt, wenn sie einen höheren Gewinn (Pure Profits) versprechen, der aber meist nur temporärer Natur ist, da sich aufgrund des Wettbewerbs Nachahmer -also Konkurrenten- finden und daher dieser "Pioniergewinn" nicht lange erzielt wird.

Ein Steuersystem wird als innovationsneutral bezeichnet, wenn es jeden Investor dazu bringt, von einem Vermögensgegenstand mindestens die Rendite vor Steuern zu verlangen, die einer sicheren Anlage auf dem Kapitalmarkt entspricht und diese Entscheidung nicht von der Höhe der vergangenen Rendite bzw. von der Besitzdauer des Vermögensgegenstandes abhängig ist.

Die Folgen eines nicht-innovationsneutralen Steuersystems bestehen im wesentlichen darin, daß (1) keine optimale Ressourcenallokation stattfindet, da Anlagen unterhalten werden, die lediglich aufgrund steuerlicher Gesichtspunkte "rentabel" sind und (2) der technische Fortschritt verhindert wird, da sich die Einführung neuer Anlagen verzögert. Somit wird die Entwicklung der Wirtschaft, die nach Schumpeter ein fortwährender Prozeß einer schöpferischen Zerstörung, "..der unaufhörlich die Wirtschaftsstruktur von innen heraus revolutioniert, unaufhörlich die alte Struktur zerstört und unaufhörlich eine neue schafft."2 ge- bzw. verhindert.

Die Konsequenzen hieraus zeigen sich darin, daß ein häufiger Grund für den Niedergang von Firmen ihre Unfähigkeit ist, das Tempo der Innovationen in der Wirtschaft mitzuhalten. Der Niedergang wird zwar vielfach dadurch verzögert,

\footnotetext{
1 Schumpeter, J.A. (1961), S. 95.

2 Schumpeter, J.A. (1975), S. 137 f.
} 
daß viele Unternehmen noch einige Jahre von den in früheren Zeiten angesammelten Reserven leben ${ }^{l}$, auf Dauer müssen sich die Unternehmen aber den neuen Gegebenheiten (z.B. einer neuen Produktionstechnologie) anpassen oder sie hören auf zu existieren. Gleiches gilt sinngemäß auch für ganze Volkswirtschaften; das wird besonders deutlich, wenn die Geschichte des wirtschaftlichen Aufstiegs und Falls verschiedener Nationen betrachtet wird.

Zur Analyse der Wirkung der Besteuerung auf die Innovationsbereitschaft wird von einem Zwei-Perioden-Modell bei Sicherheit ausgegangen ${ }^{2}$. Der Investor steht vor der Frage, ob er ein Wirtschaftsgut, z.B. eine Maschine oder einen Anteil an einem Unternehmen, das stille Reserven von g enthält (z.B. aufgrund einer längeren Abschätzung der möglichen Nutzungsdauer) und zukünftig eine Rendite z (auf den aktuellen Gesamtwert des Wirtschaftsgutes) erwirtschaftet ${ }^{3}$, veräußern soll und anschließend eine neue Anlage (z.B. eine Produktionsanlage) erwirbt, die eine Rendite von $\mathrm{R}$ abwirft oder ob er dieses Wirtschaftsgut eine weitere Periode hält.

In der zu untersuchenden Welt mit einer Periodeneinkommensteuer werden $\mathbf{r}, \mathrm{z}$ bzw. eventuell zu besteuernde Wertänderungen mit dem einheitlichen Steuersatz $\tau$ besteuert.

\subsubsection{Exkurs: Laissez-Faire-Ökonomie}

$\mathrm{Zu}$ Vergleichszwecken wird zuerst auf eine Laissez-Faire-Ökonomie eingegangen.

In einer Laissez-Faire-Ökonomie ist ein Anleger indifferent, wenn die zu erzielende Nettorendite $\mathrm{z}$ dem Kapitalmarktzinssatz $\mathrm{r}$ entspricht ${ }^{4}$. Dies gilt unabhängig davon, wie sich die Werte in der Vergangenheit entwickelt haben.

\subsubsection{Einkommensteuer ohne die Erfassung von Wertänderungen}

Es wird untersucht, welche Auswirkung die Steuerfreiheit von Wertänderungen auf die Entscheidung des Investors hat.

Vgl. Schumpeter, J.A. (1961), S. 103.

2 Zur Untersuchungsmethode vgl. Auerbach, A.J. (1991), S. $167 \mathrm{ff}$.

3 Eventuell vorzunehmende Abschreibungen sind hierbei schon abgesetzt.

4 Dies kann aus der Untersuchung der Marginalbedingung für die Grenzinvestition abgeleitet werden (s.o.). 
Wenn das Wirtschaftsgut eine weitere Periode gehalten wird, ergibt sich folgendes Endvermögen:

$$
\mathrm{W}_{\mathrm{H}}=[1+\mathrm{g}] *[1+\mathrm{z} *(1-\tau)] .
$$

Veräußert das Individuum das Wirtschaftsgut, fällt der Veräußerungsgewinn steuerfrei an. Wird der Erlös in eine neue Anlage investiert, ergibt sich am Periodenende folgendes Vermögen:

$$
\mathrm{W}_{\mathrm{V}}=[1+\mathrm{g}] *[1+\mathrm{r} *(1-\tau)] \text {. }
$$

Beim Vergleich beider Alternativen ist der Investor indifferent, wenn $\mathrm{W}_{\mathrm{V}}$ und $\mathrm{W}_{\mathrm{H}}$ gleich sind; dies ist gegeben, wenn folgende -aus der Gleichsetzung von $\mathrm{W}_{\mathrm{H}}$ und $W_{V}$ gewonnene- Beziehung erfüllt ist:

$$
\mathrm{z}=\mathrm{r} \text {. }
$$

Der Anleger ist indifferent bei gleicher Rendite der alten und der neuen Anlage. Dies ist dieselbe Bedingung für Indifferenz wie in einer Laissez-Faire-Ökonomie. Damit liegt bei Nichtbesteuerung von Wertänderungen ein innovationsneutrales Steuersystem vor.

\subsubsection{Einkommensteuer mit Erfassung von realisierten Wertänderungen}

Es werden die Auswirkungen der Besteuerung von realisierten Wertänderungen (unrealisierte Werterhöhungen sollen nicht in die steuerliche Bemessungsgrundlage eingehen) auf die Entscheidung des Investors untersucht. Diese Konzeption hat im deutschen Steuerrecht bei der Unternehmensbesteuerung ihren Niederschlag gefunden: nach dem Niederstwertprinzip in Verbindung mit dem Imparitätsprinzip sind lediglich Wertminderungen bei der Ermittlung des Gewinns einzubeziehen. Werterhöhungen sind erst dann zu berücksichtigen, wenn sie durch eine Markttransaktion realisiert werden ${ }^{l}$.

Dazu wird wiederum von dem o.a. Modell ausgegangen: der Investor steht vor der Frage, ob er das Wirtschaftsgut, dessen Wert um g gestiegen ist, veräußern soll (und dann die realisierten Wertsteigerungen mit dem einheitlichen Steuer-

1 Diese Vorgehensweise (Imparitätsprinzip) wird -da in Deutschland die Handelsbilanz gemäß §5 EStG für die Steuerbilanz maßgeblich ist (Maßgeblichkeitsprinzip)- mit dem Gläubigerschutz und dem daraus abgeleiteten Grundsatz der vorsichtigen Bewertung begründet. 
satz $\tau$ versteuern muß) und eine neue Anlage mit der Rendite $r$ erwirbt oder ob er dieses Wirtschaftsgut eine weitere Periode halten soll.

Veräußert der Investor das Wirtschaftsgut, ergibt sich folgendes Endvermögen:

$$
\mathrm{W}_{\mathrm{V}}=[1+\mathrm{g} *(1-\tau)] *[1+\mathrm{r} *(1-\tau)]
$$

Entscheidet sich der Investor hingegen, das Wirtschaftsgut eine weitere Periode zu halten und es erst nach Ablauf dieser Periode zu veräußern ${ }^{l}$, hat er am Ende der zweiten Periode als Endvermögen²:

$$
\mathrm{W}_{\mathrm{H}}=(1+\mathrm{g}) *(1+\mathrm{z})-\tau *[(1+\mathrm{g}) * \mathrm{z}]-\mathrm{g} * \tau .
$$

Die Steuer auf den in der ersten Periode erzielten Gewinn wird damit zinslos bis zur zweiten Periode gestundet.

Werden beide Alternativen verglichen, ist der Investor indifferent, wenn $\mathrm{W}_{\mathrm{V}}$ und $\mathrm{W}_{\mathrm{H}}$ gleich sind; dies ist erfüllt, wenn folgende -aus der Gleichsetzung von $\mathrm{W}_{\mathrm{H}}$ und $\mathrm{W}_{\mathrm{V}}$ gewonnene- Beziehung erfüllt ist:

$$
\mathrm{z}=\frac{1+\mathrm{g} *(1-\tau)}{1+\mathrm{g}} * \mathrm{r} .
$$

Um indifferent zwischen beiden Anlagen zu sein, ergibt sich bei alternativen Steuersätzen folgendes Bild:

$$
\begin{array}{lll}
\tau=0 \% & \mathrm{z}=\mathrm{r} \\
\tau=100 \% & \mathrm{z}=\frac{\mathrm{r}}{1+\mathrm{g}} .
\end{array}
$$

Der Steuersatz $\tau$ des Investors liegt zwischen $100 \geq \tau>0 \%$; bei Indifferenz gilt dann:

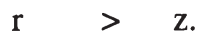

Für einen Anleger kann es aufgrund der Steuerstundung durchaus lohnend sein, ein Wirtschaftsgut mit einer geringeren Rendite als dem Marktzinssatz zu hal-

Aus Vereinfachungsgründen wird angenommen, daß g auch über den Ablauf der zweiten Periode in voller Höhe bestehen bleibt.

$2 \tau *[(1+\mathrm{g}) * \mathrm{r}]$ ist die Steuer, die auf den laufenden Ertrag entfällt; $\mathrm{g} * \tau$ ist die Steuer, die bei der Veräußerung des Vermögensgegenstandes in der zweiten Periode anfällt. 
ten, wenn dadurch die durch die Auflösung der stillen Reserven verursachte Steuerzahlung hinausgeschoben werden kann ${ }^{l}$.

Es kann festgestellt werden, daß die von der bereits vorhandenen Anlage geforderte Rendite desto geringer ist, je höher der Anteil des unrealisierten Gewinnes/ stille Reserve und je höher der anzuwendende Steuersatz $\tau$ ist. Die Besteuerung von lediglich realisierten Wertänderungen ist also nicht innovationsneutral und hindert die Innovationsbereitschaft der Unternehmen.

\subsubsection{Einkommensteuer mit der generellen Erfassung von Wert- änderungen}

Es wird dargestellt, welche Auswirkungen die generelle Besteuerung von Wertänderungen (realisierte und auch unrealisierte) auf die Entscheidung des Investors hat.

Veräußert der Investor das Wirtschaftsgut und legt den Erlös auf dem Kapitalmarkt an, ergibt sich folgendes Endvermögen:

$$
\mathrm{W}_{\mathrm{V}}=[1+\mathrm{g} *(1-\tau)] *[1+\mathrm{r} *(1-\tau)]
$$

Entscheidet sich der Investor, das Wirtschaftsgut eine weitere Periode zu halten, hat er am Ende der zweiten Periode als Endvermögen:

$$
\mathrm{W}_{\mathrm{H}}=[1+\mathrm{g} *(1-\tau)] *[1+\mathrm{z} *(1-\tau)]
$$

Werden beide Alternativen verglichen, ist der Investor indifferent, wenn $\mathrm{W}_{\mathrm{V}}$ und $\mathrm{W}_{\mathrm{H}}$ gleich sind; dies ist der Fall, wenn folgende -aus der Gleichsetzung von $\mathrm{W}_{\mathrm{H}}$ und $\mathrm{W}_{\mathrm{V}}$ gewonnene- Beziehung erfüllt ist:

$1 \quad$ Beispiel:

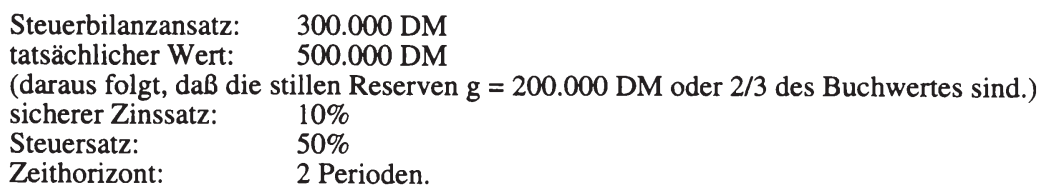

Der Investor ist in diesem Beispiel indifferent, wenn die Rendite der vorhandenen Anlage $8 \%$ beträgt; ist sie höher, ist es für ihn vorteilhaft, die alte Anlage fortzuführen, auch wenn die Rendite vor Steuern geringer als die Rendite einer sicheren Kapitalmarktanlage ist. 


$$
\mathrm{z}=\mathrm{r} \text {. }
$$

Der Investor ist indifferent, wenn die Rendite der alten Anlage gleich der der neuen ist. Die Einkommensbesteuerung nach der Reinvermögenszugangstheorie ist aufgrund der Besteuerung von sowohl realisierten als auch unrealisierten Vermögenswertänderungen innovationsneutral.

Eine Einkommensteuer ist somit innovationsneutral, wenn sie entweder alle Wertänderungen -die realisierten als auch die unrealisierten- besteuert oder von einer Besteuerung von Wertänderungen vollständig absieht. Wertsteigerungen müssen dann im Unternehmensvermögen steuerfrei sein, und zwar auch bei ihrer Realisation. Die Besteuerung von ausschließlich realisierten Wertänderungen ist ein Verstoß gegen die Innovationsneutralität und schwächt die Innovationskraft einer Volkswirtschaft.

\subsubsection{Einfluß der Abschreibungshöhe auf die Investitionsentscheidung}

Es wird untersucht, ob die Forderung nach einem entscheidungsneutralen Steuersystem die Höhe der Abschreibung bestimmt ${ }^{l}$.

Dazu wird die Investition in Sachanlagen mit einer Anlage in gleicher Höhe am Kapitalmarkt verglichen ${ }^{2}$.

Wie gezeigt, gilt für die Grenzinvestition der Unternehmung, daß die Nettogrenzproduktivität dem Nettozinssatz des Kapitalmarktes entspricht:

(1) $\frac{\delta+\mathrm{N}}{\mathrm{A}}=\mathrm{r}$

$1 \quad$ Die folgenden Aussagen gelten, wenn $\tau_{\mathrm{a}}=\tau_{\mathrm{e}}=\tau_{\mathrm{z}}$ ist (vgl. Samuelson, P.A. (1964)). Das Ergebnis verallgemeinert Sinn, H.-W.(1984a, S. 218), so daß die Aussage auch für den Fall von unterschiedlichen Steuersätzen gilt.

2 A $=$ Marktwert der Sachanlage

$\delta=$ Marktwertänderung der Sachanlage (Marktwert der Anlage zu Beginn der Periode Marktwert am Ende der Periode (der Marktwert der Sachanlage ändert sich durch Abnutzung bzw. aufgrund technischer Veralterung))

$\mathrm{N}=$ Erträge aus dem Verkauf der durch die Sachanlage hergestellten Ware

$\mathrm{D}=$ steuerlich zulässige Abschreibung. 


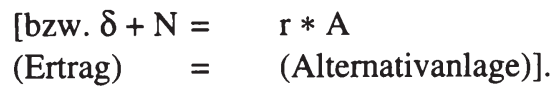

Die Besteuerung ist neutral, wenn sich an obiger Gleichung nach Einbeziehung der Steuer (Steuersatz $\tau$ ) keine Änderung ergibt und folgendes gilt:

$$
\begin{aligned}
\frac{\delta+N}{\mathrm{~A}}-\tau * \frac{\mathrm{N}-\mathrm{D}}{\mathrm{A}} & =\mathrm{r} *(1-\tau) \\
\mathrm{r} & =\left(\frac{\delta+\mathrm{N}}{\mathrm{A}}-\tau * \frac{\mathrm{N}-\mathrm{D}}{\mathrm{A}}\right) * \frac{1}{1-\tau} .
\end{aligned}
$$

(1) und (3) werden nun gleichgesetzt, da der Marktzinssatz in beiden Gleichungen gleich ist.

$$
\begin{array}{rl}
\Leftrightarrow \quad(4) \quad \frac{\delta+N}{A} & =\left(\frac{\delta+N}{A}-\tau * \frac{N-D}{A}\right) * \frac{1}{1-\tau} \\
\Leftrightarrow(5) \quad D & D=-\delta .
\end{array}
$$

Gleichung (2) und damit die Forderung nach einer neutralen Besteuerung ist genau dann erfüllt, wenn $\mathrm{D}=-\delta$ entspricht. Die steuerlich zulässigen Abschreibungen müssen den Ertragswertminderungen des Wirtschaftsgutes entsprechen: das ist der Fall, wenn Ertragswertabschreibungen vorgenommen werden.

Wird ein Abschreibungsverlauf unterstellt, bei dem die anfänglichen Abschreibungen höher sind als die Ertragswertabschreibungen (z.B. aufgrund von Sonderabschreibungen), verringert sich die Steuerbelastung im Jahr der höheren Abschreibung. Die Summe aller Abschreibungen ist allerdings durch die Anschaffungs- bzw. Herstellungskosten begrenzt.

Die Sonderabschreibungen haben zur Folge, daß Investitionen getätigt werden, deren Nettogrenzproduktivität unterhalb des Kapitalmarktzinssatzes liegt; somit besteht keine Investitionsneutralität ${ }^{l}$.

Werden Sonderabschreibungen nur einmalig eingeräumt, sind langlebige Wirtschaftsgüter bevorzugt, da der durch die Sonderabschreibungen gewährte zinslose Steuerkredit eine längere Laufzeit hat und somit die Zinsersparnis größer ist als bei der Investition in kurzlebige Investitionsgüter. Werden sie auf Dauer

l Vgl. Hornbach (1987), S. 131 ff., insbesondere S. 135. 
gewährt, ist die Fristigkeit der Investitionsgüter unerheblich, da die Steuerstundung auch bei kurzlebigen Investitionen durch die immer wieder möglichen Sonderabschreibungen gewährt wird ${ }^{l}$.

Danach bilden nur Ertragswertabschreibungen den Werteverzehr durch die betriebliche Leistungserstellung richtig ab. Entsprechen die steuerlich möglichen Abschreibungen nicht den anzusetzenden Ertragswertabschreibungen, führt dies zu einer Verletzung der Entscheidungsneutralität. Eine andere Abschreibungshöhe als Abschreibungen in Höhe der Verminderung des Ertragswertes ist deshalb abzulehnen.

\subsubsection{Exkurs: Folgen der Nichtbesteuerung von Wertänderungen im deutschen Einkommensteuerrecht}

Im folgenden Teil werden die Folgen einer nicht konsequent durchgeführten Wertänderungsbesteuerung anhand des deutschen Einkommensteuerrechts aufgezeigt. Dazu wird auf die Besteuerung von Zerobonds und die Möglichkeiten von Steuerarbitrage eingegangen.

\subsubsection{Besteuerung von Zerobonds}

Nach §20 (2) Nr. 4 EStG gehören zu den Einkünften aus Kapitalvermögen auch "Kapitalerträge aus der Veräußerung oder Abtretung von abgezinsten oder aufgezinsten Schuldverschreibungen, Schuldbuchforderungen und ähnlichen Kapitalforderungen, soweit die Kapitalerträge rechnerisch auf die Zeit der Innehabung dieser Wertpapiere oder Forderungen entfallen". Mit dieser Vorschrift sollen insbesondere die Gewinne bei der Veräußerung von Zero-Bonds (Nullkupon-Anleihen) und anderen auf- bzw. abgezinsten Papieren erfaßt werden ${ }^{2,3}$.

Steuerpflichtig ist bei diesen Papieren aber nicht die innerhalb der Innehabung tatsächlich erzielte Wertsteigerung, sondern eine rechnerisch ermittelte Wertän-

Vgl. Hornbach (1987), S. 134 ff.

2 Vgl. Deutscher Bundestag (1988), S. 147.

3 Aus Vereinfachungsgründen verzichtet die Finanzverwaltung auf die steuerliche Erfassung, wenn in Abhängigkeit von der Laufzeit bestimmte Prozentsätze des Nennwertes (z.B. Laufzeit bis unter 2 Jahre: $1 \%$ Abschlag; ab 10 Jahren: 6\%) nicht überschritten werden (BMF-Schreiben v. 24.11.1986, IV B4-S 2252-180/86, BStBl. 1986 I, S. 539 f. (539); BFH v. 13.10.1987 VIII R 156/84, BStBI. 1988 II, S. 252-257 (255). 
derung; Wertänderungen aufgrund von Schwankungen des Marktzinssatzes bleiben unberücksichtigt.

Der zur Berechnung notwendige Zinssatz r ergibt sich aus der Formel ${ }^{l}$

$$
\mathrm{r}=\left(\frac{\text { Rückzahlungsbetrag }}{\text { Emissionskurs }}\right)^{1 / n}-1 \text {, }
$$

wobei $\mathrm{n}$ die Gesamtlaufzeit des Papiers in Jahren darstellt.

Der steuerpflichtige Kapitalertrag K errechnet sich aus dem Produkt aus Emissionskurs sowie aus der Differenz der Aufzinsungsfaktoren des Veräußerungs$\left(F_{v}\right)$ und Anschaffungszeitpunkts $\left(F_{a}\right)$. Damit gilt:

$$
\begin{aligned}
& \mathrm{K}=\text { Emissionskurs } *\left(\mathrm{~F}_{\mathrm{v}}-\mathrm{F}_{\mathrm{a}}\right) \quad \text { mit } \\
& \mathrm{F}_{\mathrm{x}}=(1+\mathrm{r})^{\mathrm{m}} *\left(\mathrm{r} * \frac{\mathrm{T}}{360}+1\right), \quad \text { mit } \mathrm{x}=\mathrm{v}, \mathrm{a},
\end{aligned}
$$

wobei m der Laufzeit vom Emissionszeitpunkt bis zur Anschaffung/Veräußerung in vollen Jahren und $\mathrm{T}$ den Jahresbruchteilen in Tagen entspricht.

Erzielt der Veräußerer einen höheren bzw. niedrigeren Preis als den Emissionspreis zuzüglich den rechnerisch ermittelten Kapitalerträgen, ist dieser Mehrbzw. Minderertrag einkommensteuerlich unbeachtlich.

Es ist zu klären, wie sich dies auf die optimale Entscheidung eines Anlegers zwischen Zerobonds und Anleihen mit jährlichem Zinsfluß in Höhe des Zinssatzes $R$ auswirkt. Bei einer Anleihe mit jährlich zu versteuerndem Zinszufluß erhält der Anleger als Rücknahmewert $p_{n}$ der Anteile

$$
p_{n}=(1+R *(1-\tau))^{n}
$$

Dieser Betrag entspricht dem eines Zerobond mit jährlicher Versteuerung der tatsächlichen Wertänderung.

Muß der Anleger den Ertrag aus dem Zerobond entsprechend den Regelungen des $§ 20$ EStG versteuern, erhält er nach Steuern

$$
\mathrm{p}_{\mathrm{n}}=(1-\tau) *(1+\mathrm{R})^{\mathrm{n}}+\tau,
$$

die Rendite nach Steuern beträgt dann

1 Vgl. BMF v. 24.1.1985, IV B4-S 2252-4/85, BStBl 1985 I, S. 77-81. 


$$
\mathrm{r}_{\mathrm{z}}=\mathrm{p}_{\mathrm{n}}^{1 / \mathrm{n}}-1=\left[(1-\tau) *(1+\mathrm{R})^{\mathrm{n}}+\tau\right]^{1 / \mathrm{n}}-1
$$

Bei einer Laufzeit von drei Jahren, einem Steuersatz $\tau$ von $50 \%$ und einem Zinssatz R von $10 \%$ bei der Anlage mit laufenden Zinszahlungen muß der Zerobond nur eine Rendite von 9,56\% vor Steuern aufweisen, damit der Anleger indifferent ist. Liegt die Rendite darüber, ist der Kauf der Zerobonds vorteilhafter.

Um die Vorteilhaftigkeit der Zero-Bond-Anlage gegenüber einer Anlage mit laufenden Zinszahlungen zu verdeutlichen, wird eine Grenzwertbetrachtung durchgeführt.

$$
\lim _{n \rightarrow-\infty} r_{z}=\left\{\left[(1-\tau) *(1+R)^{n}+\tau\right]^{1 / n}-1\right\} .
$$

$\tau$ ist konstant, d.h. der additive Faktor verliert mit größer werdendem $\mathbf{n}$ immer mehr an Gewicht und kann für $\mathrm{n}-->\infty$ schließlich vernachlässigt werden. Als Zwischenergebnis ergibt sich somit:

$$
\lim _{n \rightarrow \infty} r_{z}=\left\{\left[(1-\tau) *(1+R)^{n}\right]^{1 / n}-1\right\}=\lim _{n \rightarrow \infty}\left[(1-\tau)^{1 / n} *(1+R)\right]-1 .
$$

Der Faktor $(1-\tau)^{1 / n}$ strebt für $\mathrm{n}-->\infty$ immer mehr gegen 1 und kann damit bei einer Grenzwertbetrachtung vernachlässigt werden. Es ergibt sich dann folgendes Ergebnis:

$$
\underset{n \rightarrow-\infty}{\lim _{n} r_{z}=R .}
$$

Bei der Besteuerung der Zerobonds nach deutschem Einkommensteuerrecht entspricht der Grenzwert der Rendite nach Steuern der Rendite vor Steuern.

Der Anleger wählt -bei Indifferenz hinsichtlich der Alternativenwahl vor Steuern- bei konstantem Steuersatz den Zerobond als Anlageform, da dieser aufgrund der laufenden Zinsbesteuerung der anderen Alternative eine höhere Rendite nach Steuern sichert. Die Gestaltung der Besteuerung von Zerobonds im deutschen Steuerrecht ist damit nicht entscheidungsneutral.

\subsubsection{Möglichkeiten von Steuerarbitrage}

Unter Arbitrage wird das Ausnutzen von Preisunterschieden auf zwei Märkten durch Kauf und Verkauf verstanden; als Beispiel dafür kann die Kreditaufnahme 
zu einem niedrigen und die Anlage zu einem höheren Zins betrachtet werden; die Differenz zwischen beiden Zinssätzen ist der Gewinn. Werden solche Arbitragegeschäfte durch die Besteuerung rentabel, wird dies als Steuerarbitrage bezeichnet.

Der Steuerpflichtige kann einen Kredit aufnehmen und damit eine niedrig verzinsliche Anlage mit entsprechendem Abschlag erwerben; die Wertänderungen der Anlage, die zu 100\% am Laufzeitende zurückgezahlt wird, sind nicht steuerpflichtig; nur der Saldo aus Soll- und Habenzinsen ist zu versteuern. Wenn der Schuldzinsabzug steuerlich zulässig ist, kann die zu zahlende Einkommensteuer damit reduziert werden. Die Vorteilhaftigkeit ist allerdings abhängig vom Steuersatz des Steuerpflichtigen, da die Schuldzinsen in der realen Welt höher sind als die Habenzinsen.

Durch Steuerarbitrage kann die Zinsbesteuerung legal vermieden werden, sofern -wie hier vorausgesetzt- Wertänderungen nicht besteuert werden und Schuldzinsen bei der Ermittlung des zu versteuernden Einkommens abzugsfähig sind.

Die Anwendbarkeit dieses Modells ist allerdings im deutschen Steuerrecht eingeschränkt: es stellt sich das Problem der fehlenden Gewinnerzielungsabsicht und somit der steuerlichen Liebhaberei. Die Frage, ob die Überschußerzielung oder die Substanzverwertung -also die Erzielung nicht steuerbarer Wertänderungen- bei einer Anlage im Vordergrund steht, kann dabei nur anhand äußerlich erkennbarer Merkmale beurteilt werden. Anhaltspunkte für die Priorität der Substanzverwertung sind gegeben, wenn die Anlage mit Gewinn veräußert wird (Realisation von Wertänderungen), ohne da $\beta$ die Finanzierungskosten für ihre Anschaffung durch die laufenden Erträge abgedeckt werden oder die Anlage lange gehalten wird und die Finanzierungskosten des Erwerbs ständig die laufenden Erträge übersteigen ${ }^{l}$. Werden alle steuerpflichtigen Einnahmen und Ausgaben gegenübergestellt -die steuerfreien Wertänderungen bleiben unberücksichtigt- ergibt sich dann ein negativer Saldo, wenn die Finanzanlage in vollem Umfange fremdfinanziert wird, da die Schuldzinsen die steuerpflichtigen Habenzinsen übersteigen. Damit fehlt die Gewinnerzielungsabsicht; das Finanzamt erkennt den Schuldzinsenabzug nicht an; das gesamte Modell ist nicht mehr rentabel.

Der Steuerpflichtige kann aber nur einen Teil der Anschaffungskosten fremdfinanzieren und für den anderen Teil eigene Mittel verwenden. Bei einer optimalen Gestaltung erzielt er noch positive Erträge (Zinsen aus der Finanzanlage abzüglich den Schuldzinsen); damit liegt eine fehlende Gewinnerzielungsabsicht nicht vor. Davon ist auszugehen "...sofern der Gedanke der -wenn auch nur bescheidenen- Rendite eine Rolle spielt und keine objektiven Anhaltspunkte dafür

I Vgl. BFH v. 23.3.1982 VIII R 132/80, BStBl. 1982 II, S. 463-465 (464); BFH v. 21.7.1981 VIII R 128/76, BStBl. 1982 II, S. 36-37 (37); BFH v. 21.7.1981 VIII $R$ 200/78, BStBl. 1982 II, S. 40-41 (41); Abschn. 153 (1) EStR. 
vorliegen, daß eine solche nicht erwartet wird oder mit ihr nicht zu rechnen ist." ${ }^{l}$. Besteht neben den laufenden Ertragserwartungen noch die Hoffnung auf die Erzielung von Wertsteigerungen, ist dies kein Grund für die Begrenzung des Werbungskostenabzugs bzw. einer Aufteilung dieses Aufwands in eine abzugsfähige und eine nichtabzugsfähige Komponente ${ }^{2}$.

Steuerarbitrage ist daher möglich durch die geschickte Wahl des prozentualen Anteils von Fremdkapital für die Finanzierung der Finanzanlage, bei der auch Wertänderungsgewinne entstehen.

\subsubsection{Ergebnis: Neutralität der Besteuerung}

Wertänderungen sind grundsätzlich auf drei Ursachen zurückzuführen: (1) auf die Verzinsung des eingesetzten Kapitals, (2) die Abnutzung des Vermögensgegenstandes und (3) Windfall Profits.

Wertänderungen, die die Verzinsung des eingesetzten Kapitals repräsentieren und Zinsen, sind prinzipiell gleichartig. Aufgrund der Gleichartigkeit beider "Einkunftsarten" ist es durch die Forderung nach einem entscheidungsneutralen Steuersystem notwendig, beide in der gleichen Weise zu besteuern. Bei einer generellen Besteuerung von Zinsen müssen Wertänderungen, die der Verzinsung des eingesetzten Kapitals entsprechen, besteuert werden. Durch die notwendige gleichartige Vorgehensweise scheidet die Konzeption der ausschließlichen Besteuerung von realisierten Wertänderungen aus, da es bei der Zinsbesteuerung eine äquivalente Verfahrensweise nicht gibt.

Für die Beurteilung der Frage der Neutralität des Steuersystems gelten -aufgrund der Gleichartigkeit von Zins- und Wertänderungen, die die Verzinsung des eingesetzten Kapitals repräsentieren- die bei der Untersuchung der Zinseinkommensbesteuerung festgestellten Mängel: die Individuen verringern aufgrund der Besteuerung ihr Sparen; damit wächst die Wirtschaft langsamer als in einer Laissez-Faire-Ökonomie.

Zur Gewährleistung eines innovationsneutralen Steuersystems ist die Besteuerung von allen oder keinen Wertänderungen notwendig. Die ausschließliche Besteuerung von realisierten Wertänderungen behindert Innovationen, so da $ß$ eine effiziente Ressourcenallokation nicht mehr gegeben ist.

$1 \quad$ Vgl. BFH v. 21.7.1981 VIII R 154/76, BStBl. 1982 II, S. 37-40 (40); bestätigt durch den Großen Senat BFH v. 25.6.1984 GrS 4/82, BStBl. 1984 II, S. $751-770$ (766 f.); BFH v. 8.10.1985 VIII R 234/84 BStBl. 1986 II, S. 596-599 (597).

Vgl. BFH v. 21.7.1981 VIII R 154/76, BStBl. 1982 II, S. 37-40 (39). 
Abschreibungen aufgrund von Abnutzung müssen in Höhe der Änderung des Ertragswertes zwischen Periodenanfang und Periodenende vorgenommen werden, um die Entscheidungsneutralität der Besteuerung zu wahren.

\subsection{Einwände gegen die einkommensteuerliche Erfassung von Wertän- derungen}

An dieser Stelle sind einige Einwände gegen den Einbezug von Wertänderungen in die Bemessungsgrundlage der Besteuerung zu diskutieren ${ }^{l}$.

Gegen die Einbeziehung von Wertzuwächsen in die Bemessungsgrundlage der Einkommensteuer wird angeführt, daß sie kein Einkommen darstellen, sondern als Vorgänge der Vermögenssphäre zu werten und somit für die Einkommensteuer irrelevant sind ${ }^{2}$.

Diesem Argument ist nicht zuzustimmen: das Konzept der Besteuerung nach der Leistungsfähigkeit stellt auf den Zuwachs an ökonomischer Dispositionsfähigkeit ab; somit ist alles, das diese Dispositionsfähigkeit erhöht -also auch Wertzuwächse (realisierte und unrealisierte)- als steuerliches Einkommen anzusehen.

Wertzuwächse treten aufgrund erwarteter höherer Ertragsaussichten auf ${ }^{3}$. So steigt z.B. im allgemeinen der Aktienkurs, wenn ein Unternehmen ein neues Produkt entwickelt, von dem hohe zukünftige Gewinne erwartet werden. Werden nun die Wertzuwächse und die späteren höheren Kapitalzuflüsse besteuert, soll dies eine doppelte Erfassung des gleichen Vorgangs bedeuten.

Dieser Meinung ist entgegenzuhalten, daß der durch erwartete künftige Ertragsteigerungen hervorgerufene Wertzuwachs bei abnutzbaren Vermögensgegenständen durch die über die noch verbleibende Lebensdauer höheren Abschreibungen kompensiert wird und somit keine doppelte Besteuerung erfolgt ${ }^{4}$. Weiterhin liegen zwei unterschiedliche Vorgänge (Wertänderungen bzw. höhere künftige Erträge) mit jeweils selbständigem Einfluß auf die steuerliche Leistungsfähigkeit eines Steuerpflichtigen vor, da beide Vorgänge zeitlich divergieren. Überdies können beide Vorgänge bei zwei verschiedenen Individuen anfal-

1 Eine Übersicht mit weiteren Literaturhinweisen findet sich bei Andel, N. (1980), S. 348 ff.

$2 \quad$ Vgl. Andel, N. (1980), S. 348.

3 Angelehnt an Andel, N. (1980), S. $348 \mathrm{ff}$.

4 Vgl. Goode, R. (1977), S. $11 \mathrm{f}$. 
len, z.B. beim Verkauf des Vermögensgegenstandes vor Zufluß der höheren zu erwartenden laufenden Erträge. Wird nur derjenige besteuert, bei dem die laufenden Erträge anfallen, bleibt die beim Verkäufer entstandene erhöhte Leistungsfähigkeit unberücksichtigt. Werden bei diesem nur die realisierten Wertänderungen besteuert, wird die möglicherweise über mehrere Jahre hinweg entstandene Leistungsfähigkeit in der falschen Periode erfaßt.

Fällt das allgemeine Zinsniveau, steigt der Kurswert von Papieren, die einen höheren Zinssatz aufweisen als der neue Durchschnittszinssatz ${ }^{l}$. Gegen die Erfassung dieser Wertzuwächse wird argumentiert, daß der, der die Papiere weiterhin hält, keinen höheren Zinszufluß als früher erwartet realisiert und somit nur ein scheinbares Einkommen vorliegt ${ }^{2}$.

Diese Auffassung, nach der nur die Marktwertänderungen aus zukünftig höheren Ausschüttungen steuerlich zu erfassen sind, unterstellt, daß die auf einem bestimmten Zeitpunkt berechneten Einzahlungsüberschüsse den Zuwachs an ökonomischer Verfügungsmacht repräsentieren. Wertsteigerungen aufgrund gefallener Zinsen führen nicht zu höheren Zinszahlungen und nicht zu einem Zuwachs an ökonomischer Verfügungsmacht. Dagegen spricht, daß bei Akzeptanz einer abschnittsweisen Besteuerung die Leistungsfähigkeit zu einem bestimmten Zeitpunkt gemessen werden soll. Danach ist das ökonomische Verfügungspotential zu diesem Zeitpunkt als Berechnungsgrundlage für die Bestimmung des Einkommens heranzuziehen. Dies gilt trotz der Tatsache, daß die aufgrund einer Zinssatzänderung hervorgerufene Marktwertänderung nicht das ökonomische Verfügungspotential über die gesamte Investitionsdauer erhöht, da sich der aufgrund einer Zinsänderung gestiegene Wert der Papiere bei näherkommendem Tilgungstermin dem Rückzahlungsbetrag anpaßt und somit ein steuerlich zu berücksichtigender Wertverlust entsteht. Eine doppelte Besteuerung dieser Wertsteigerung findet somit nicht statt. Die aus Zinssatzänderungen resultierende Vermögenswertänderung hat die ökonomische Verfügungsmacht über die knappen Güter der Ökonomie des Individuums zum Zeitpunkt der Zinssatzänderung erhöht; somit steht diesem ein höheres Potential -zum Konsum oder für Investitionen- zur Verfügung ${ }^{3}$. Nach dem Leistungsfähigkeitsprinzip sind daher diese Marktwertänderungen in das zu ermittelnde Einkommen einzubeziehen ${ }^{4}$.

1 Der Einfluß von Risikozuschlägen usw. soll nicht berücksichtigt werden.

2 Vgl. Goode, R. (1977), S. 13; Moxter, A. (1982), S. 56 f., 59 f.; Kaldor, N. (1969), S. 44; Wallich, H.C. (1965), S. $137 \mathrm{f}$.

3 Vgl. Koniarski, L. (1984), S. 92 f.

4 Vgl. Royal Commission of Taxation (1966), Vol. 3, S. 350; Ebnet, O. (1978), S. 84. 
"Wertzuwächse" aufgrund gestiegener Preise sollen keinen realen Zuwachs an wirtschaftlicher Dispositionsfähigkeit repräsentieren und sind damit in die Bemessungsgrundlage der Besteuerung nicht einzubeziehen.

Diesem Argument ist grundsätzlich zuzustimmen: da inflationsbedingte Wertänderungen die Leistungsfähigkeit eines Individuums real nicht erhöhen, ist auch deren Einbezug in die Bemessungsgrundlage der Besteuerung abzulehnen ${ }^{1}$. Dieser Einwand besitzt jedoch nur für inflationsbedingte Wertänderungen Gültigkeit: Wertänderungen aufgrund anderer Einflüsse bleiben hiervon unberührt. Inflationseinflüsse treten nicht nur in Form von Wertänderungen auf; ebenso beinhalten die Zinssätze und die jährlichen Lohnsteigerungen einen "Inflationsausgleich", die die reale Kaufkraft eines Individuums nicht beeinflussen. Würden Inflationseinflüsse lediglich bei Wertänderungen berücksichtigt (und herausgerechnet), könnte dies eine Ungleichbehandlung im Vergleich zu anderen "Einkunftsquellen" darstellen.

Gegen die Besteuerung von Wertänderungen spricht auch das administrative Problem der Durchführung der Bewertung, dessen Umfang davon abhängig ist, welche Wertänderungen steuerlich relevant sind. Sollen lediglich realisierte Wertänderungen erfaßt werden, müssen die Steuerpflichtigen ein Inventar führen, in dem sie unter Berücksichtigung der zugehörigen Belege die Einstandspreise festhalten und ebenso jeder Verkauf dokumentiert wird ${ }^{2}$. Wird diese Argumentation um die Frage der Steuersicherung erweitert, ergibt sich ein zusätzliches und wichtiges Problem: die "Buchführung" der Steuerpflichtigen muß von den Finanzbehörden kontrolliert werden. Dadurch erhöht sich der Verwaltungs- und Erhebungsaufwand sowohl bei den Finanzbehörden als auch bei den Steuerpflichtigen sowie deren Berater. Ohne hinreichende Kontrollen ist die Versuchung für die Steuerpflichtigen groß, die Veräußerungsgewinne nicht zu deklarieren.

Sollen auch unrealisierte Wertänderungen erfaßt werden, ist eine periodische Bewertung des Vermögens der Steuerpflichtigen notwendig. Dies ist schon allein durch die hohe Zahl von Steuerpflichtigen nur mit einem erheblichen Aufwand an Personal und Kosten durchzuführen ${ }^{3}$. Das Problem der praktischen Durchführbarkeit der Wertermittlung wird später erörtert.

\footnotetext{
1 Vgl. zum Vorangegangenen Andel, N. (1980), S. $348 \mathrm{ff}$.

2 Vgl. Andel, N. (1980), S. 348 ff.

3 Deshalb kommen in den alten Bundesländern Deutschlands für bebaute und unbebaute Grundstücke immer noch die Einheitswerte aus dem Jahre 1964 zur Anwendung. In den jungen Bundesländern schreckt man bisher vor der Ermittlung von Einheitswerten zurück.
} 
Das deutsche Steuerrecht wird im Rahmen der Unternehmensbesteuerung über das Maßgeblichkeitsprinzip durch das in der Handelsbilanz vorherrschende Prinzip der vorsichtigen Bewertung beeinflußt, nach dem unrealisierte Wertsteigerungen keinen Ertrag darstellen. Dieses Prinzip der vorsichtigen Bewertung verhindert die Ausschüttung von noch nicht "sicheren" Erträgen an die Anteilseigner bzw. an das Finanzamt, da dadurch die Substanzerhaltung und Liquidität des Unternehmens gefährdet wird.

Eine tendenzielle Unterbewertung von Vermögensgegenständen ist -so ein Einwand gegen diese Argumentation- mit der Besteuerung nach der Leistungsfähigkeit nicht zu vereinbaren ${ }^{I}$. Die Bindung der Wertansätze der Steuerbilanz an die der Handelsbilanz ist nicht zwangsläufig und in anderen Ländern (z.B. Großbritannien, Vereinigte Staaten von Amerika) unbekannt. Da zudem beide Bilanzen andere Zielsetzungen verfolgen (Steuerbilanz: Grundlage der Besteuerung; Handelsbilanz: unter Beachtung der Grundsätze ordnungsmäßiger Buchführung Einblick in die Finanz-, Vermögens- und Ertragslage), ist die Bindung der Steuerbilanz an die Handelsbilanz nicht notwendig und könnte aufgegeben werden: damit verliert auch der handelsrechtliche Grundsatz der vorsichtigen Bewertung seinen Einfluß auf die Einkommensteuer.

Liquiditätsbeschränkungen des Steuerpflichtigen bilden einen weiteren Einwand gegen die Erfassung unrealisierter Wertänderungen. Werden unrealisierte Wertsteigerungen in der Bemessungsgrundlage der Einkommensteuer erfaßt, muß unter Umständen zur Begleichung der Steuerschuld ein Teil des Vermögens veräuBert werden. Problematisch ist dies dann, wenn das Vermögen nicht aus mehreren getrennt veräußerbaren Vermögensgegenständen, sondern aus nur einem Vermögensgegenstand besteht (z.B. ein Eigenheim), der zur Begleichung der Steuerschuld zu veräußern ist. Dieses Problem besteht nicht, wenn nur realisierte Wertänderungen in die steuerliche Bemessungsgrundlage einzubeziehen $\operatorname{sind}^{2}$.

Dieser Argumentation ist entgegenzuhalten, daß die Kreditwürdigkeit des Steuerpflichtigen durch den höheren Vermögenswert ebenfalls eine Steigerung erfahren hat. Somit kann dieser ohne Veräußerung des Vermögensobjektes über den gesamten Wertzuwachs bzw. einen Teil hiervon disponieren und die Steuerzahllast durch Kredite finanzieren ${ }^{3}$; eine Veräußerung ist nicht erforderlich. Die Entscheidung über die Gewinnrealisation ist überdies kein Kriterium für die Frage der Erhöhung der Dispositionsfähigkeit, sondern eine Konsum-Spar- bzw. Portfolioentscheidung des Steuerpflichtigen.

\footnotetext{
1 Vgl. zum Vorangegangenen Andel, N. (1980), S. $348 \mathrm{ff}$.

2 Vgl. Andel, N. (1980), S. 348 ff.

3 Vgl. Schanz, G. (1896), S. 29; Albers, W. (1988), S. 198.
} 
Durch die Berücksichtigung von Wertsteigerungen erhöht sich -dies ein weiterer Einwand- die steuerliche Bemessungsgrundlage und somit steigt bei einem progressiven Tarif der Durchschnittssteuersatz an ${ }^{l}$.

Dies spricht nicht gegen die Besteuerung von Wertzuwächsen, da die progressionsbedingte Erhöhung des Durchschnittsteuersatzes ein gewollter Effekt ist, um den Leistungsfähigeren eine relativ höhere Steuerlast aufzubürden ${ }^{2}$.

Die Erhöhung des Durchschnittsteuersatzes aufgrund periodisch ungleich verteiltem Einkommen ist grundsätzlich kein Problem der Besteuerung von Wertzuwächsen, sondern wird durch die periodenweise progressive Besteuerung hervorgerufen. Es engt die Steuerpflichtigen in ihrer Entscheidung, den Wertzuwachs zu realisieren, ein, falls nur realisierte Wertänderungen besteuert werden. Dies spricht allerdings für die Besteuerung unrealisierter Wertzuwächse, da im Vergleich zur Besteuerung von realisierten Wertänderungen die Wertzuwächse über mehrere Jahre verteilt werden und somit keine "Einkommenspitzen" in den Jahren der Realisation der Wertzuwächse auftreten.

Es wird eingewandt, daß die Besteuerung von Wertänderungen mobilitätshemmend ist, und deswegen die Entscheidung, ein Wirtschaftsgut zu veräußern und in eine andere Anlageform überzugehen, negativ beeinflußt wird.

Dem ist zuzustimmen, wenn lediglich realisierte Wertänderungen besteuert werden. Die Besteuerung hat dann dieselbe Wirkung wie eine Verkehrsteuer bei Vermögensübergängen: sie wirkt mobilitätshemmend, da ein Wechsel in eine andere Anlageform erst vorteilhaft ist, wenn die neue Anlage auch nach Abzug der Steuer eine höhere Rendite bietet als die alte Anlage ${ }^{3}$.

Werden auch unrealisierte Wertänderungen besteuert, fällt die Steuer unabhängig von der Veräußerung des Vermögensgegenstandes an; es besteht keine mobilitätshemmende Wirkung der Besteuerung und negative allokative Wirkungen treten nicht ein.

Gegen die steuerliche Erfassung von Wertänderungen wird angeführt, da $\beta$ die Bewertung aller Vermögen zu Marktpreisen nicht möglich ist, da in einer Volkswirtschaft nicht alle Güter gleichzeitig realisiert werden können ${ }^{4}$.

Die gleichzeitige Realisation aller Vermögen ist jedoch keine Bedingung für eine Besteuerung nach der Leistungsfähigkeit, da es um die Messung der öko-

$1 \quad$ Auf der anderen Seite ergibt sich bei Wertverlusten ein Sinken der Bemessungsgrundlage und des Durchschnittsteuersatzes.

2 Vgl. zum Vorangegangenen Andel, N. (1980), S. 348 ff.

3 Siehe hierzu die Ausführungen im Teil "Innovationsneutralität".

4 Vgl. Wallich, H.C. (1965), S. 138; Haller, H. (1973), S. 265 ff. 
nomischen Verfügungsmacht einer Person im Vergleich zu anderen Personen geht ${ }^{l}$. Die sich in der Kaufkraft ausdrückende ökonomische Macht besteht unabhängig von Kauf oder Verkaufsakten des Individuums; sie besteht vielmehr in der Möglichkeit, über die Ressourcen verfügen zu können².

Einige Autoren -insbesondere rechtswissenschaftliche- hegen verfassungsrechtliche Bedenken gegen diesen umfassenden Einkommensbegriff ${ }^{3}$. Der rechtssystematische Ansatzpunkt zur Beantwortung der Frage des Einbezugs von unrealisierten Wertänderungen liegt -so diese Autoren- im Verfassungsrecht: das rechtsstaatliche Übermaßverbot und die Eigentumsgarantie fordern eine wirtschaftlich maßvolle Besteuerung nach der individuellen Leistungsfähigkeit. Bei der Beurteilung der Frage der maßvollen Besteuerung sind auch tradierte kaufmännische Grundeinsichten -z.B. das Realisationsprinzip- zu berücksichtigen. Somit soll -entgegen der Einkommenskonzeption nach der Reinvermögenszugangstheorie- ein Wesensunterschied zwischen realisierten und unrealisierten Wertänderungen bestehen. Aufgrund der vom Fiskus zu akzeptierenden Eigentümerfreiheit wird die Liquidation des Vermögens als der richtige Zeitpunkt angesehen, zu dem die Gewinnbesteuerung stattfinden soll. Dadurch soll die Besteuerung von Eigentumssubstanz verhindert werden. Weiterhin ist für den Gesetzgeber der verfassungsmäßig relevante Inhalt des Realisationsprinzips, der Besteuerung möglichst sichere Werte zugrunde zu legen und dabei nach dem Verhältnismäßigkeitsgrundsatz bei mehreren möglichen Werten, einen hinreichend sicheren auszuwählen, von Bedeutung. Dazu wird der Vergleich mit kaufmännischen Gepflogenheiten herangezogen: ein Kaufmann, der "unsicheren Gewinn" aus dem Unternehmen abzieht, gefährdet die Vermögenssubstanz seines Unternehmens. Der Staat schöpft durch die Besteuerung einen Teil des Gewinns ab. Dieser staatliche Eingriff wird als übermäßiger Substanzeingriff in das Vermögen des Steuerpflichtigen angesehen, wenn der durch die Wertsteigerung entstandene Gewinn nicht sicher ist. Aufgrund der Verhältnismäßigkeit erscheint es dann -so Lang- sachgerecht, wenn der geeigneteste Zeitpunkt für die Besteuerung gewählt wird und dies soll -der kaufmännischen Grundeinsicht folgend- der Zeitpunkt der Gewinnrealisation sein. Dadurch ist überdies auch eine eigentumsschonende Besteuerung gewährleistet und es wird keine Eigentumssubstanz (sondern lediglich Ertrag) besteuert wird ${ }^{4}$. Die Aufdeckung stiller Reserven ist -so Lang- dem Steuerpflichtigen erst zuzumuten, "..wenn die gleichmäßige Besteuerung nach der wirtschaftlichen Leistungsfähigkeit auf eine an-

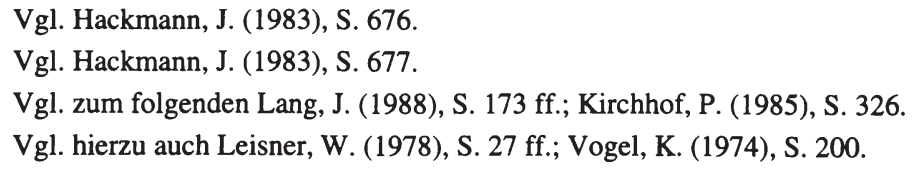


dere Weise nicht mehr verwirklicht werden kann." ${ }^{1}$. Die Meinung von Lang deckt sich mit der Auffassung von Vogel, der in der Besteuerung von unrealisierten Gewinnen ebenfalls einen Eingriff in die Vermögenssubstanz sieht und einen Eingriff in das durch Artikel 14 GG gewährte Eigentumsrecht annimmt ${ }^{2}$. Einen Eingriff in das Eigentumsrecht des Steuerpflichtigen sieht Vogel hingegen nicht in der Besteuerung des Vermögensertrages, der -so Vogel- dem Steuergesetzgeber weitgehend zur Verfügung steht ${ }^{3}$. Leisner ist im Ergebnis derselben Auffassung: "..ruhendes Eigentum wird in seiner Eigentumsgarantie geschützt, nicht Eigentum in Bewegung, der Tauschvorgang gegen andere Güter, der vom Inhaber selbst in Bewegung gesetzt wird."

Diese Autoren verkennen den bestehenden begrifflichen Unterschied zwischen "Ertrag" und "Einnahmen". Soll die Besteuerung nach der individuellen Leistungsfähigkeit stattfinden, muß -soll das Einkommen besteuert werden- auf "Erfolgskategorien" abgestellt werden. Nicht der Zugang an Zahlungsmitteln oder Forderungen, sondern das Entstehen von Aufwendungen oder Erträgen ist bei der Einkommensbesteuerung die entscheidende Größe.

Die Argumentation mit Hilfe des Realisationsprinzips basiert auf der Unsicherheit bei der Wertermittlung und ist damit eher ein praktisches Problem, das in der Unvollkommenheit unserer Welt seinen Ursprung hat. Gegen die grundsätzliche und systematische Notwendigkeit des Einbezugs von unrealisierten Wertänderungen kann es nicht herangezogen werden.

Bei obiger Argumentation ist überdies fraglich, ob eine gleichmäßige Besteuerung ohne die Erfassung von unrealisierten Wertänderungen überhaupt möglich ist. Wird vorerst davon ausgegangen, daß die Vermögenswerte genau ermittelt werden können, besteht grundsätzlich kein Unterschied, woher die Leistungsfähigkeit des Steuerpflichtigen stammt. Ohne die Erfassung unrealisierter Wertänderungen erfolgt ein Verstoß gegen den Gleichheitssatz, da lediglich Vermögensbesitzer temporär von der Besteuerung befreit werden, nicht jedoch Bezieher von Arbeitseinkommen. Die Vermögensbesitzer können überdies noch den Zeitpunkt der Besteuerung bestimmen, da nur sie allein über den Zeitpunkt der Liquidation des Vermögens entscheiden. Der Schutz des Eigentums sollte nicht überbetont werden, da dies zu Verletzungen des Gleichheitssatzes führt. Ein Verstoß gegen Artikel 14 GG (Eigentumsgarantie) liegt nicht vor, da aus der Eigentumsgarantie kein grundsätzlicher Schutz des Vermögens gegen die Auferlegung von Steuern, sondern lediglich ein Schutz vor konfiskatorischen Steuern

\footnotetext{
1 Vgl. Lang, J. (1988), S. 162.

2 Vgl. Vogel, K. (1974), S. 200.

3 Vgl. Vogel, K. (1974), S. 200.

4 Leisner, W. (1978), S. 142.
} 
abgeleitet werden $\operatorname{kann}^{I}$. Er liegt erst vor, wenn die Vermögensverhältnisse des Steuerpflichtigen grundlegend verändert werden ${ }^{2}$.

Ein Großteil der Argumente, die gegen den Einbezug oder die Beschränkung auf die Erfassung von realisierten Wertänderungen vorgebracht wurden, verstoßen gegen die Grundidee der Besteuerung nach der Leistungsfähigkeit bzw. der Forderung nach einem neutralen Steuersystem und wurden widerlegt. Nicht widerlegt werden konnte der Einwand des sehr hohen administrativen Aufwands bei der Ermittlung der Wertänderungen. Dies wird später Gegenstand weiterer Überlegungen $\operatorname{sein}^{3}$.

\subsection{Praktikabilität der Besteuerung}

Bei einer Periodeneinkommensteuer sind Wertänderungen grundsätzlich in die steuerliche Bemessungsgrundlage einzubeziehen. Somit sind für die einzelnen Wirtschaftsgüter des Steuerpflichtigen Werte zu ermitteln. Im folgenden Teil wird untersucht, wie die Werte ermittelt werden sollten und wie praktikabel die Wertermittlung ist.

\subsubsection{Diskussion möglicher Wertansätze}

Der Begriff "Wert" muß aus Objektivierungsgründen intersubjektiv nachvollziehbar sein, persönliche Wertschätzungen des Steuerpflichtigen dürfen bei der Beurteilung des "Wertes" nicht berücksichtigt werden. Aus diesem Grund ist der Marktwert als Wertmaßstab zu wählen, da er unabhängig von subjektiven Einflüssen des Eigentümers ist. Dies bedeutet, daß nur Dinge einen Wert im Sinne der Einkommensdefinition haben können, über die der Steuerpflichtige frei verfügen kann und die auf einem Markt getauscht werden können.

1 Vgl. BVerfG v. 20.7.1954 -1 BvR 459, 484, 548, 555, 623, 651, 748, 783, 801/52, 5,9/53, 96, 114/54, BVerfGE 4, S.7-27 (17); BVerfG v. 14.5.1968 -2 BvR 544/63, BVerfGE 23, S. 288-321 (314); BVerfG v. 17.7.1974 -1 BvR 51, 160, 285/69, 1 BvL $16,18,26 / 72$, BVerfGE 38, S. 61-102 (102).

2 Vgl. BVerfG v. 27.7.1962 -2 BvL 15, 16/61, BVerfGE 14, S. 221-244 (241); BVerfG v. 9.3.1971 -2 BvR 326, 327, 341, 342, 343, 344, 345/69, BVerfGE 30, S. 250-272 (272); Lang, J. (1988), S. 156.

3 Die Probleme durch inflationsbedingte Einflußfaktoren werden im Rahmen dieser Arbeit nicht analysiert. 
Im folgenden wird analysiert, welcher der für die Besteuerung nach der individuellen Leistungsfähigkeit "richtige" Marktwert ist.

\subsubsection{Historische Marktwerte: Anschaffungskosten}

Der Einbezug von Wertänderungen in die steuerliche Bemessungsgrundlage soll die Leistungsfähigkeit des Steuerpflichtigen zu einem aktuellen Stichtag messen.

Die Konzeption der historischen Anschaffungs-/Herstellungskosten bietet damit keine Anhaltspunkte über den aktuellen Wert der Vermögensgegenstände und kann zur Ermittlung der Leistungsfähigkeit nicht herangezogen werden.

\subsubsection{Liquidationswert einzelner Vermögensgegenstände}

Nach dieser Konzeption ist der Wert eines Vermögensgegenstandes der Einzelveräußerungspreis, d.h. das Vermögen wird zerschlagen. Der Wert eines Betriebes würde sich z.B. aus dem Wert des Anlage- und Umlaufvermögens abzüglich der Schulden zusammensetzen. Immaterielle "Vermögensgegenstände" -wie z.B. die Qualifikation des Mitarbeiterstammes oder der Firmenwert- werden bei diesem Verfahren nicht einbezogen, da sie einzeln nicht veräußerbar sind. Ein weiteres Problem liegt darin, daß z.B. Spezialmaschinen, die nur im Anlagenverbund mit anderen sinnvoll nutzbar sind, bei der Einzelveräußerung nur den Schrottwert erzielen, also weniger, als sie im Vermögen des Steuerpflichtigen an Wert darstellen.

Der tatsächliche Vermögensstand des Steuerpflichtigen kann mit Einzelveräußerungswerten nicht gemessen werden, da die Effekte aus dem Zusammenwirken einzelner Vermögensteile nicht berücksichtigt werden.

\subsubsection{Veräußerungswert des Gesamtvermögens}

Es wird von der Veräußerung des Vermögens im Ganzen ausgegangen. Der Wert des Vermögens besteht nicht nur aus der Summe der isoliert betrachteten einzelnen Vermögensgegenstände, sondern es wird das Zusammenwirken bestimmter Vermögensgegenstände -wie z.B. des Firmenwerts mit den Produktionsanlagen eines Unternehmens- werterhöhend berücksichtigt. 
Dieses Konzept kann noch dahingehend modifiziert werden, daß für Wertansätze eines diversifizierten Vermögens die fiktive Veräußerung von geschlossenen Teilen zugelassen wird, wenn dafür potentielle Käufer zu finden sind und sich keine werterhöhenden Faktoren aus der Kombination der verschiedenen Teile ergeben.

Damit werden die Dispositionsmöglichkeiten des Steuerpflichtigen umfassend abgebildet. Die Konzeption ist daher sachgerecht und stellt einen geeigneten Maßstab zur Bestimmung des Vermögenswerts dar.

\subsubsection{Ergebnis}

Die Dispositionsfähigkeit des Steuerpflichtigen wird am besten und umfassendsten durch den Veräußerungswert des Gesamtvermögens abgebildet. Es ist jedoch nichts gegen die Vereinfachung einzuwenden, geschlossene Teile des Vermögens gesondert zu bewerten, wenn sie getrennt veräußerbar sind (z.B. einen Teil bilden die Unternehmensanteile, einen anderen die Grundstücke) und sich keine werterhöhenden Faktoren aus der Kombination der verschiedenen Teile ergeben.

\subsubsection{Bestimmung des Veräußerungswertes des Gesamtvermögens}

Im folgenden Abschnitt werden die Möglichkeiten der Bestimmung des Veräußerungswertes des Gesamtvermögens (bzw. einzelner abgeschlossener Teile davon) unter verschiedenen Annahmen analysiert. Es wird untersucht, ob die Ermittlung eines individuellen Vermögenswerts möglich ist und als steuerliche Bemessungsgrundlage zur Verfügung steht.

In der Realität gibt es meist keinen vollkommenen Markt ${ }^{1}$, da z.B. die Annahme der unendlich schnellen Reaktion der Marktteilnehmer nicht erfüllt ist und diese aufgrund der Informationsvielfalt außerdem keine völlige Marktübersicht haben. Am Beispiel von Unternehmen bzw. nicht-notierten Unternehmensanteilen, gebrauchten Wirtschaftsgütern (z.B. Maschinen) und Grundstücken wird untersucht, ob und wie ein Marktwert ermittelt werden kann.

$1 \quad$ Zur Wertermittlung bei vollkommenen Märkten vgl. Koniarski, L. (1984), S. 86 ff. 
Die Bestimmung des Wertes von Gesellschaftsanteilen ist relativ problemlos, wenn es sich um einige Anteile einer börsennotierten Publikumsaktiengesellschaft handelt.

Für größere Beteiligungsquoten an börsennotierten Gesellschaften, bei denen sich der Wert der Anteile aus dem einfachen Aktienwert sowie (meist) einem Paketzuschlag zusammensetzt sowie für nicht-börsennotierte Anteile an Unternehmen existiert nur ein unvollkommener Markt. Die Unvollkommenheit dieses Marktes ist hauptsächlich durch die fehlende Markttransparenz (die Markttransaktionen werden diskret durchgeführt und über ihre Bedingungen wird Stillschweigen vereinbart) sowie der fehlenden Homogenität des Marktgutes "Unternehmen" (es liegen keine singuläre Wirtschaftsgüter aufgrund der unterschiedlichen Branchen, Größen vor) determiniert. Daher gibt es keinen (wie beim Vorliegen eines vollkommenen Marktes) aus anderen Markttransaktionen ableitbaren Wert für Unternehmen bzw. Anteile. Somit muß für jedes Unternehmen der Wert individuell ermittelt werden.

Dazu wird ein potentieller Erwerber betrachtet, der sich bei seiner Preisentscheidung am Ertragswert orientiert. Die Betriebswirtschaftslehre ${ }^{l}$ entwickelte hierzu verschiedene Verfahren ${ }^{2}$. Diese werden kontrovers diskutiert: z.B. besteht keine Einigkeit darüber, ob der buchhalterische Gewinn, die Unternehmens-NettoZahlungen (= Differenz der zwischen Unternehmen und Umwelt fließenden Einnahmen und Ausgaben) oder die Ausschüttungen als relevante Größen zu wählen sind. Fraglich ist auch die Ermittlung der entscheidungsrelevanten zukünftigen Größen (in der Realität besteht keine vollkommene Voraussicht und die Approximation der Vergangenheit ist fragwürdig) sowie welcher Zeithorizont und welcher zur Diskontierung notwendige Zinssatz zu wählen ist.

Problematisch ist ebenso, wenn von staatlicher Seite eine Methode zur Unternehmenswertermittlung (wie z.B. das von der Finanzverwaltung angewandte "Stuttgarter Verfahren") vorgegeben und als die "richtige" Methode definiert wird. Dies kann nicht die "richtige" Relation zu anderen Vermögenswerten (z.B. Grundstükken oder Sparguthaben) gewährleisten; schon die Herstellung der "richtigen" Wertrelationen innerhalb des Unternehmenssektors ist fragwürdig. So kann es zu einer Diskriminierung/Bevorzugung bestimmter Vermögenswerte kommen; dies widerspricht sowohl dem Prinzip der Besteuerung nach der Leistungsfähigkeit als auch der Forderung nach einem entscheidungsneutralen Steuersystem.

Die Praktikabilität dieser Vorgehensweise ist ein weiteres Problem, da für jedes Unternehmen in jeder Periode eine Wertermittlung stattfinden muß. Eine pauschale Wertfortschreibung kann zu Verzerrungen führen, da sich der Unterneh-

1 Die Betriebswirtschaftslehre ist mit diesem Problem ebenfalls konfrontiert, da bei Unternehmensverkäufen häufig Wirtschaftsprüfungsgesellschaften zur Erstellung einer Unternehmenswertanalyse beauftragt werden.

Vgl. z.B. Buchner, R. (1981), S. 305 ff. 
menswert nicht bei allen Gesellschaften gleichförmig entwickelt. Die praktische Durchführung der Bewertung ist mit einem sehr großem Aufwand verbunden, der die Kosten der Besteuerung in die Höhe treibt ${ }^{1}$. Überdies kann es aufgrund der fehlenden Objektivität zu einer Vielzahl von Rechtsstreitigkeiten kommen, da Bewertungsfragen im allgemeinen umstritten sind.

Ein Anhaltspunkt für den Gesamtunternehmenswert kann die Bewertung der einzelnen Vermögensgegenstände sein. Diese Werte sind aber -wie unten noch gezeigt wird- in der Regel nicht verfügbar. Damit ist überdies das Problem der Bewertung des Firmenwertes nicht gelöst.

In der realen Welt gibt es somit kein Verfahren, das zu genauen Werten führt. Pauschale Verfahren werfen Bedenken hinsichtlich der steuerlichen Gerechtigkeit und der Entscheidungsneutralität auf.

Zur Bestimmung der Ertragswertabschreibungen bei der Einkommensermittlung ist die Bewertung von Maschinen von Bedeutung. Um diese zu ermitteln, muß der Ertragswert eines Vermögensgegenstandes bekannt sein. In der realen Welt besteht keine vollkommene Voraussicht; somit können keine Ertragswerte ermittelt werden. Eine alternative Wertermittlung ist der Ansatz des Marktpreises, in dem sich die Erwartungen der Marktteilnehmer widerspiegeln. In der Realität gibt es allerdings für die meisten Vermögensgegenstände keinen Gebrauchtmarkt; daher ist auch diese Wertermittlungsmethode nicht durchführbar. Die Bestimmung des "richtigen" Marktpreises und damit die Bestimmung der "richtigen" Ertragswertabschreibung ist damit meist nicht möglich. Standardisierte Verfahren sind ungenau und somit aus demselben Grund wie bei der Bestimmung des Unternehmenswertes abzulehnen.

Der Markt für Grundstücke ist ebenso wie derjenige für Unternehmen kein vollkommener Markt, da keine homogenen Güter vorliegen (z.B. durch die unterschiedliche Lage), sondern jedes Grundstück ein singuläres Gut ist. Eine Ableitung des Wertes eines Grundstückes aus anderen Grundstücksverkäufen ist damit grundsätzlich nicht möglich.

Die Ermittlung des Ertragswertes für Grundstücke ist mit ähnlichen Problemen wie bei Unternehmen verbunden. Ein vom Fiskus vorgegebenes, standardisiertes Bewertungsverfahren ist aus den bei der Frage der Unternehmensbewertung angeführten Gründen abzulehnen. Die weiteren Einwände gelten entsprechend.

Dabei ist zu beachten, daß auch Kosten, die beim Fiskus entstehen, letztendlich von den Steuerpflichtigen zu tragen sind. 
Hieraus wird ersichtlich, daß genaue Werte nicht zu ermitteln sind und standardisierte Verfahren zur Wertbestimmung möglicherweise gegen das Leistungsfähigkeitsprinzip und gegen die Forderung nach einem neutralen Steuersystem verstoßen.

\subsection{Ergebnis: Einbezug von Wertänderungen in die steuerliche Bemes- sungsgrundlage}

Es wurde untersucht, ob Wertänderungen in die steuerliche Bemessungsgrundlage einzubeziehen sind.

Wertänderungen sind grundsätzlich auf drei Ursachen, (1) auf die Verzinsung des eingesetzten Kapitals, (2) die Abnutzung des Vermögensgegenstandes oder (3) Windfall Profits, zurückzuführen.

Wertänderungen, die die Verzinsung des eingesetzten Kapitals repräsentieren und Zinsen sind prinzipiell gleichartig. Nach dem Leistungsfähigkeitsprinzip und der Forderung nach einer entscheidungsneutralen Besteuerung ist es somit notwendig, beide gleich zu besteuern. Werden Zinsen generell besteuert, müssen auch Wertänderungen besteuert werden, die der Verzinsung des eingesetzten Kapitals entsprechen. Durch die Notwendigkeit der gleichen Vorgehensweise scheidet die Konzeption der ausschließlichen Besteuerung von realisierten Wertänderungen aus, da es bei der Zinsbesteuerung keine äquivalente Verfahrensweise gibt.

Wertänderungen durch Abnutzung von Vermögensgegenständen zur Einkommenserzielung und Wertänderungen aufgrund von Windfall Profits sind in die steuerliche Bemessungsgrundlage bei ihrer Entstehung einzubeziehen, da sonst gegen das Leistungsfähigkeitsprinzip verstoßen wird. Der Einbezug in die steuerliche Bemessungsgrundlage erst zum Zeitpunkt der Realisation der Wertänderungen ist abzulehnen.

Allgemeine Einwände gegen die Besteuerung von Wertänderungen wurden durch das Leistungsfähigkeitsprinzips und der Forderung nach einem neutralen Steuersystem entkräftet.

Für die Beurteilung der Frage hinsichtlich der Neutralität des Steuersystems gelten aufgrund der Gleichartigkeit von Zins- und Wertänderungen, die die Verzinsung des eingesetzten Kapitals repräsentieren, die bei der Zinseinkommensbesteuerung festgestellten Mängel: die Individuen verringern aufgrund der Besteuerung ihr Sparen und die Wirtschaft wächst langsamer als in einer Laissez- 
Faire-Ökonomie. Es findet eine geringere Kapitalakkumulation als in einer Laissez-Faire-Ökonomie statt; der Faktor "Arbeit" weist damit eine geringere Grenzproduktivität auf; es werden entweder geringere Löhne gezahlt oder es ist eine geringere Beschäftigung zu verzeichnen.

Zur Gewährleistung eines innovationsneutralen Steuersystems müssen entweder alle Wertänderungen erfaßt werden oder sie sind generell freizustellen. Die ausschließliche Besteuerung von realisierten Wertänderungen behindert Innovationen.

Um die Investitionsneutralität zu wahren, sind steuerliche Abschreibungen in Höhe der Änderung des Ertragswertes zwischen Periodenanfang und Periodenende vorzunehmen.

Zur Quantifizierung der Wertänderungen im Vermögen des Steuerpflichtigen muß in jeder Periode die Höhe des individuellen Vermögens ermittelt werden. Der geeignete Wertmaßstab zur Ermittlung des individuellen Vermögens ist der Gesamtveräußerungswert des Vermögens. Er ist aufgrund unvollkommener Märkte für einige Wirtschaftsgüter (z.B. nicht-börsennotierte Unternehmensanteile, Maschinen, Grundstücke) nicht ermittelbar. Die ersatzweise Anwendung von praktikablen standardisierten Hilfsverfahren kann zu systematischen Wertverzerrungen zwischen den einzelnen Arten von Wirtschaftsgütern führen und somit gegen das Leistungsfähigkeitsprinzip und die Forderung nach einem neutralen Steuersystem verstoßen. Diese Verfahren sind überdies bei jährlich durchzuführenden Bewertungen sehr arbeits- und verwaltungsaufwendig.

Zusammengefaßt heißt dies, daß die Einkommensdefinition nach der Reinvermögenszugangstheorie zu präferieren ist, da nur durch sie sowohl realisierte als auch unrealisierte Wertänderungen erfaßt werden; sie ist jedoch nicht praktikabel.

Eine befriedigende Lösung, die der Forderung nach einer Besteuerung gemä $\beta$ der individuellen Leistungsfähigkeit entspricht, entscheidungsneutral und auch praktikabel durchführbar ist, gibt es also nicht.

\section{Erbschaften und Schenkungen}

\subsection{Besteuerung nach der individuellen Leistungsfähigkeit}

Schenkungen und Erbschaften erhöhen die Leistungsfähigkeit des Bedachten, da dessen Verfügungsmacht über knappe Ressourcen der Wirtschaft vergrößert wird. Sie sind deshalb in der steuerlichen Bemessungsgrundlage zu erfassen. 
Beim Schenkenden stellen die Geschenke nach überwiegender Meinung Konsum dar und sind bei der Berechnung des Einkommens nicht abzugsfähig.

Der Einwand, wonach durch die Besteuerung der Erbschaft/Schenkung die vererbten Einkommensteile zweimal (beim Gebenden und beim Bedachten) der Besteuerung unterliegen, ist irrelevant: das Konzept der Besteuerung nach der individuellen Leistungsfähigkeit stellt auf Personen und nicht auf "Einkommensteile" oder "Familien" $a b^{l}$. Diese Aussage wird durch folgende Überlegung unterstützt: in einer Welt mit vollkommener Information verfügt ein Individuum über sein gesamtes Lebenseinkommen bereits in der ersten Periode und verkauft das zukünftige Einkommen an einen Dritten. Dieser zahlt ihm dafür den Barwert des Lebenseinkommens. Erhält der Käufer eine Erbschaft/Schenkung wird diese als Einkommen barwerterhöhend berücksichtigt. Beim Erblasser/Schenker bleibt der Nachlaß bzw. die Schenkung bei der Barwertberechnung seines Lebenseinkommens unberücksichtigt, da diese Sachverhalte eine Disposition des Erblassers/Schenkers über sein Vermögen darstellen.

Die vererbten/verschenkten Beträge erhöhen somit sowohl die Verfügungsgewalt des Gebenden und des Bedachten, allerdings zu verschiedenen Zeitpunkten. Die steuerliche Erfassung der Beträge bei beiden stellt keinen Verstoß gegen das Leistungsfähigkeitsprinzip dar.

\subsection{Neutralität der Besteuerung}

Die Neutralität der Besteuerung fordert, daß Entscheidungen des Individuums im Vergleich zu einer Laissez-Faire-Ökonomie durch die Besteuerung nicht beeinflußt werden.

Schenkungen und Vererbungen stehen generell im Ermessen des Gebenden; daher ist der Einfluß der Besteuerung auf dessen Entscheidungen zu untersuchen. Hierbei sind zwei Problemfelder zu unterscheiden: wird die Form der Gabe -Schenkung oder Erbschaft- durch die Besteuerung beeinflußt oder wird die Entscheidung, etwas zu verschenken oder zu vererben durch die Besteuerung verzerrt?

Schenkungen und Erbschaften stellen unentgeltliche Vermögensübergänge dar. In einem gewissen Umfang können sie als äquivalent angesehen werden. Werden Geschenke nicht in die steuerliche Bemessungsgrundlage einbezogen, das Erbe aber besteuert, kann die Besteuerung durch Schenkung anstatt Vererbung umgangen werden. Die Entscheidung des Steuerpflichtigen zwischen Verschen-

Vgl. Kaldor, N. (1969), S. 204. 
ken und Vererben wird damit verzerrt, wenn Geschenke und Erbschaften nicht gleich behandelt werden.

Um den Einfluß der Besteuerung auf die Entscheidung, etwas zu vererben/verschenken, untersuchen zu können, muß auf die Motivation der Vererbenden/Schenkenden eingegangen werden ${ }^{l}$.

Folgende vier möglichen Motive werden im allgemeinen als Beweggründe der Steuerpflichtigen für Vererbungen/Schenkungen angenommen ${ }^{2}$ :

- Die Vererbung/Schenkung ist altruistisch motiviert, d.h. das Erbe/die Schenkung geht in die Nutzenfunktion des Erblassers ein.

- Es wird vererbt/verschenkt, da sich der Erblasser/Schenkende aufgrund irgendwelcher "moralischer Zwänge" verpflichtet sieht, einen Teil seines Vermögens zu vererben/verschenken, z.B. das von ihm selbst erhaltene Erbe.

- Durch das Erbe/Geschenk sichert sich der Erblasser/Schenkende die Pflege und die Zuwendung des Erben/Beschenkten.

- Die Erbschaften sind lediglich (unbeabsichtigte) Restgrößen, die aufgrund unvollkommener Märkte (z.B. für Leibrenten) entstehen.

Erfolgt die Besteuerung aus Altruismus (geht also die Vererbung/das Geschenk in die Nutzenfunktion des Erblassers ein), ist der Einfluß auf die Entscheidung zwischen Vererbung -also dem Konsum durch zukünftige Generationen- bzw. Schenkung und dem eigenen Konsum des Erblassers zu untersuchen. Als Optimalitätsbedingung ergibt sich in einer Laissez-Faire-Ökonomie, daß der Grenznutzen aus dem eigenen Konsum dem Grenznutzen aus der Vererbung bzw. der Schenkung, also dem Zukunftskonsum der Empfänger aus dem Erhaltenen-, entspricht $^{3}$.

Es gilt ${ }^{4}$

$$
\frac{\partial \mathrm{U}}{\partial \mathrm{C}}=\frac{\partial \mathrm{U}}{\partial \mathrm{E}}
$$

Vgl. zum folgenden Schwinger, R. (1992), S. $81 \mathrm{ff}$.

2 Vgl. Atkinson, A.B. (1980), S. 40-42; Modigliani (1988), S. 36-38; Kotlikoff, L. (1988),

S. 53 f.; Kessler, D./Masson, A. (1989), S. 144 f.

3 Dabei wird davon ausgegangen, daß in die Nutzenfunktion des Vererbenden die Nutzenfunktion der Erben eingeht (vgl. auch Schwinger, R. (1992), S. 82 f.).

4 E bezeichnet hierbei die Vererbung. 
Damit die in der Laissez-Faire-Ökonomie geltende Marginalbedingung auch bei einer Periodeneinkommensteuer erfüllt ist, muß der Konsum des Erblassers und der Zukunftskonsum der Erben aus der Vererbung gleich besteuert werden, d.h. entweder wird das Einkommen beim Gebenden oder beim Empfangenden erfaßt, nicht aber bei beiden. Wird beides besteuert, ist es für den Gebenden nutzenmäßig günstiger, Vererbung/Schenkung durch eigenen Konsum zu substituieren. Dadurch wird die Entscheidung im Vergleich zu einer Laissez-Faire-Ökonomie verzerrt. Das hat eine Verringerung der Ersparnis und somit c.p. ein geringeres Wirtschaftswachstum zur Folge. Somit liegt ein Verstoß gegen die Forderung nach einem neutralen Steuersystem vor.

Erfolgt die Vererbung/Schenkung aufgrund einer "moralischen Verpflichtung", muß sie beim Empfangenden steuerfrei sein, da der Erblasser/Schenker sonst verstärkt sparen muß, um die angestrebte Summe geben zu können.

Wird die Erbschaft/Schenkung als Entgelt für die Sicherung der Pflege durch den Empfangenden aufgefaßt, ist sie als Konsum des Erblassers aufzufassen, da dies wirtschaftlich der Zahlung eines Gehalts an den Pflegenden gleichkommt. Damit diese Entscheidung des Steuerpflichtigen zwischen der Bezahlung des Pflegenden durch ein Gehalt oder einer Erbschaft/ Schenkung nicht beeinflußt wird, muß das Gegebene beim Empfangenden der Besteuerung unterliegen. Ist das Erbe lediglich eine unbeabsichtigte Restgröße, hat die Frage der Besteuerung keinen Einfluß auf die Vererbungsentscheidung des Individuums.

Die Frage der Besteuerung von Erbschaften/Schenkungen kann also nicht eindeutig beantwortet werden, vielmehr ist von der Motivation der Vererbung/ Schenkung auszugehen ${ }^{l}$. Welches Motiv die Entscheidung dominiert ist fraglich; die Untersuchung von Projector/Weiss ${ }^{2}$ ist allerdings ein Indiz dafür, da $B$ die Vererbung nicht aus Altruismus oder aufgrund moralischer Zwänge erfolgt. Wird dies bejaht, hat die Besteuerung des Erbes keinen wesentlichen Einfluß auf die Vererbungsentscheidung; folglich stellt die Besteuerung des Erbes keinen Verstoß gegen die geforderte Neutralität der Besteuerung dar.

\subsection{Praktikabilität der Besteuerung}

Hierbei stellen sich im wesentlichen zwei Fragen: die Bewertbarkeit des Vermögens und die Steuersicherung.

1 Vgl. Schwinger, R. (1992), S. $81 \mathrm{ff}$.

2 Eine von Projector/Weiss (1966) durchgeführte Untersuchung bei über 65-jährigen ergab, daß $47 \%$ für die Altersvorsorge, $34 \%$ zur Notfallvorsorge und $4 \%$ für eine geplante Vererbung sparen. 
Im Teil "Einbezug von Wertänderungen" wurde die Frage der prinzipiellen Bewertbarkeit des Vermögens diskutiert. Auf die dortigen Ausführungen wird verwiesen.

Als zweites Problem ist die Steuersicherung zu sehen, d.h. wird die Schenkung bzw. Erbschaft vollständig erfaßt oder kann der Empfänger die Höhe dieses Einkommens dem Fiskus vorenthalten?

Schenkungen können grundsätzlich nicht überwacht werden. Eine Ausnahme bilden lediglich Immobilien. Bei Immobilien muß der Eigentumsübergang im Grundbuch eingetragen sein, um wirksam zu sein. Bei Personengesellschaften, Kraftfahrzeugen hat hingegen die Eintragung ins Handelsregister bzw. die Zulassung nur deklaratorischen Charakter. Die Selbstdeklaration des Steuerpflichtigen dürfte auch nicht praktikabel sein, da sie -mangels Kontrollmöglichkeiten durch den Fiskus- wohl unterbleibt. Der Schenkende hat grundsätzlich kein Interesse an der Deklaration der Schenkung. Eine Ausnahme bildet die Schenkung einer Einzelgesellschaft bzw. Anteilen an Personengesellschaften, da für die Haftung des Gesellschafters die Eintragung im Handelsregister maßgeblich ist und bei Nichteintragung des Gesellschafterwechsels der Schenkende weiter haftet.

Aus obigen Ausführungen wird ersichtlich, daß in der Realität Schenkungen wohl nur in Ausnahmefällen deklariert und damit versteuert werden.

Erbschaften sind auch als Einkommen zu erfassen, für deren Deklarationspflicht die obigen Ausführungen gelten. Für den Fiskus besteht jedoch die Möglichkeit, "Erbscheine" zu nutzen, auf denen vermerkt sein könnte, welches Vermögen beim Fiskus deklariert wurde. Banken (u.a.) dürfen dem Erben das Erbe nur gegen Vorlage eines solchen Erbscheins aushändigen. Diese Regelung kann allerdings durch die Vererbung von langlebigen Konsumgütern, Gold oder Anlagen und Investitionen im Ausland umgangen werden, wenn es dort eine solche Deklarationsvorschrift nicht gibt.

Die Besteuerung von Erbschaften und Schenkungen kann also relativ leicht umgangen werden.

\subsection{Ergebnis}

Wird das Erbe/Geschenk beim Gebenden und beim Bedachten besteuert, findet eine mehrfache Besteuerung dieser "Einkommensteile" statt. Um aber eine Besteuerung gemäß der individuellen Leistungsfähigkeit zu gewährleisten, ist die Erfassung dieser Einkommensteile bei beiden notwendig, da nur dann das ge- 
samte Lebenseinkommen in die steuerliche Bemessungsgrundlage eingeht. Dies gewährleistet lediglich der Einkommensbegriff von Brandis und der der Reinvermögenszugangstheorie. Aufgrund von Neutralitätserwägungen ist der steuerliche Einbezug allerdings abhängig von den Vererbungs-/Schenkungsmotiven der Individuen. Eine generelle Aussage ist nicht möglich.

Es bestehen jedoch Indizien dafür, da $\beta$ das Vererbungsmotiv im Vergleich zum Vorsorgesparen eine eher untergeordnete Rolle spielt. Somit dürfte die Besteuerung der Erbschaft die Vererbungsentscheidung nur sehr gering beeinflussen und auch keinen großen Verstoß gegen die Forderung eines entscheidungsneutralen Steuersystems darstellen. Um keine Entscheidungsverzerrung zwischen Schenkungen und Vererbung herbeizuführen, sind beide steuerlich gleich zu behandeln.

Ein Problem stellt aber die Bewertung des Erbes/Geschenkes dar; hier gelten die Ausführungen zur "Wertänderungsbesteuerung" analog.

Es besteht weiterhin das Problem der Praktikabilität und das der Steuersicherung, da Geschenke und Erbschaften im allgemeinen nicht deklariert werden und nur geringe Kontrollmöglichkeiten (z.B. bei Immobilien) bestehen. Bei Erbschaften ist die Einführung von "Erbscheinen" eine Kontrollmöglichkeit: auf ihnen steht der von den Erben deklarierte Betrag. Bis zu diesem Betrag dürfen Banken, Versicherungen usw. Geld an die Erben auszahlen. Problematisch sind allerdings Auslandsanlagen, Gold, langlebige Konsumgüter und ähnliches.

Die Erfassung von Geschenken und Erbschaften als Einkommen ist somit nur eingeschränkt möglich.

\section{Die Besteuerung von Unternehmen}

Wie gezeigt, erfordert sowohl das Konzept der Besteuerung nach der Leistungsfähigkeit als auch die Forderung nach einem neutralen Steuersystem den grundsätzlichen Einbezug von realisierten und unrealisierten Wertänderungen, also die Ermittlung des Einkommens nach der Reinvermögenszugangstheorie.

Daher wird im folgenden Abschnitt diese Konzeption hinsichtlich der Durchführung der Unternehmensbesteuerung untersucht.

Im bisherigen Verlauf der Arbeit wurde aber auch festgestellt, da $\beta$ die "richtigen" Vermögenswertänderungen in der realen Welt nicht praktikabel gemessen werden können und durchführbare Meßmethoden nicht unbedingt dem Leistungsfähigkeitsprinzip entsprechen. Daher werden auch Konzeptionen untersucht, bei denen der Unternehmenserfolg direkt besteuert und nicht auf Vermögenswertänderungen abgestellt wird. 


\subsection{Reinvermögenszugangstheorie und Unternehmensbesteuerung}

\subsubsection{Besteuerung nach der individuellen Leistungsfähigkeit}

Für die Beantwortung der Frage, ob und gegebenenfalls wie Unternehmensgewinne zu besteuern sind, ist zwischen den an die Anteilseigner ausgeschütteten und dem vom Unternehmen thesaurierten Gewinnanteil zu unterscheiden:

- Die an den Anteilseigner ausgeschütteten Gewinnanteile werden durch den Vergleich zwischen dem Anfangs- und dem Endvermögen der Besteuerungsperiode erfaßt.

- Die vom Unternehmen thesaurierten Gewinnanteile erhöhen c.p. den Wert der Unternehmensanteile. Diese Marktwertänderung des Unternehmenswertanteils wird ebenfalls durch den Vermögensvergleich beim Individuum erfaßt.

Aus diesen Gründen ist eine gesonderte Einbeziehung von Unternehmensgewinnen in die Bemessungsgrundlage der Steuerpflichtigen oder eine gesonderte Unternehmensbesteuerung bei der Einkommensdefinition nach der Reinvermögenszugangstheorie nicht erforderlich, da die Besteuerung bereits beim Unternehmens-/Anteilseigner erfolgt. Es kann also auch kein Verstoß gegen das Leistungsfähigkeitsprinzip aufgrund der Unternehmensbesteuerung vorliegen.

\subsubsection{Neutralität der Besteuerung}

\subsubsection{Finanzierungsentscheidung der Unternehmen}

Die Analyse der Finanzierungsneutralität wurde bereits vorgenommen; Finanzierungsneutralität ist gegeben bei identischen Steuersätzen für einbehaltene, ausgeschüttete Gewinne sowie für die Zinsbesteuerung.

Wie dargestellt, werden bei der Besteuerung nach der Reinvermögenszugangstheorie die einbehaltenen und die ausgeschütteten Gewinne der Unternehmen aufgrund des Vermögensvergleiches mit dem individuellen Steuersatz des Anteilseigners besteuert. Das gilt auch für die Besteuerung von Zinsen, damit ist die Gleichheit der Steuersätze $\tau_{\mathrm{a}}, \tau_{\mathrm{e}}$ sowie $\tau_{\mathrm{z}}$ und somit die Finanzierungsneutralität gewährleistet. 


\subsubsection{Investitionsentscheidung der Unternehmen}

Bei einem investitionsneutralen Steuersystem muß die Nettogrenzproduktivität dem Marktzinssatz entsprechen. Diese Forderung ist bei einer Besteuerung nach der Reinvermögenszugangstheorie erfüllt; somit liegt eine investitionsneutrale Besteuerung vor.

\subsubsection{Rechtsformentscheidung der Unternehmen}

Wie dargestellt, ist bei der Besteuerung nach der Reinvermögenszugangstheorie eine gesonderte Unternehmensbesteuerung nicht erforderlich, so daß keine Besteuerungsunterschiede zwischen verschiedenen Rechtsformen auftreten können. Die Wahl der Unternehmensrechtsform wird nicht beeinflußt. Die Besteuerung nach der Reinvermögenszugangstheorie ist damit rechtsformneutral.

\subsubsection{Ergebnis}

Eine gesonderte Besteuerung von Unternehmensgewinnen ist weder aufgrund der Konzeption der Besteuerung nach der Leistungsfähigkeit noch aufgrund von Neutralitätsüberlegungen zu befürworten. Die Besteuerung dieser Gewinne erfolgt unmittelbar beim Unternehmens-/Anteilseigner über die Änderung seines Reinvermögens.

\subsection{Alternative Gestaltung der Unternehmensbesteuerung}

Es wird untersucht, wie eine Unternehmensbesteuerung zu gestalten ist, wenn davon ausgegangen werden muß, daß Wertänderungen der Unternehmensanteile in der Realität für die meisten Unternehmen nicht objektiv bestimmt werden können. Die Ergebnisse können dann auch auf die Einkommenskonzeption von Brandis übertragen werden, die bei den natürlichen Personen lediglich die $\mathrm{Zu}$ flüsse der Periode in die steuerliche Bemessungsgrundlage einbezieht. Hierzu werden einige der in der jüngeren Vergangenheit geäußerten Vorschläge zur Unternehmensteuerreform vorgestellt und analysiert. Bei der Analyse werden Ertragswertabschreibungen angenommen; damit wird sichergestellt, da $ß$ die Effekte aus den nicht den Ertragswertabschreibungen entsprechenden Abschrei- 
bungen und den verschiedenen Steuerreformvorschlägen getrennt sichtbar werden.

\subsubsection{Neutralität der Besteuerung}

Bei den hier diskutierten Formen der Unternehmensbesteuerung werden Wertänderungen der Unternehmenswertanteile nicht berücksichtigt. Daher treten die oben bei der Analyse der Besteuerung von Wertänderungen angeführten Verletzungen der Forderung nach einem neutralen Steuersystem bei allen Gestaltungen der Unternehmensbesteuerung auf.

Auch bei den alternativen Formen der Unternehmensbesteuerung werden die Zinsen besteuert; somit treten die o.a. Verzerrungen aufgrund der Zinsbesteuerung auf. Die Investitionsentscheidung der Unternehmen wird durch die Besteuerung nicht beeinflußt, da sich die Unternehmung bei ihrer Investitionsentscheidung weiterhin am Marktzinssatz orientiert; somit ist Investitionsneutralität gegeben.

\subsubsection{Betriebsteuer ohne Anrechnung beim Gesellschafter}

Einen Vorschlag zur Unternehmenssteuerreform stellt die Betriebsteuer dar $^{l}$, bei der das Unternehmen den Anknüpfungspunkt für die Besteuerung bildet; die zivilrechtliche Rechtsform des Unternehmens ist bei diesem Vorschlag genauso unerheblich wie die Gewinnverwendung (Ausschüttung oder Thesaurierung) ${ }^{2}$. Bei der Betriebsteuer ohne Anrechnung beim Gesellschafter wird die vom Unternehmen entrichtete Betriebsteuer nicht auf die Einkommensteuerschuld des Gesellschafters angerechnet. Zinsen und ausgeschüttete Gewinne sind beim Gläubiger bzw. Gesellschafter zu versteuern.

\section{a) Rechtsformentscheidung der Unternehmen}

Bei der Einführung einer allgemeinen Betriebsteuer muß die Ermittlung des Gewinns zwischen Personen- und Kapitalgesellschaften vereinheitlicht werden, um die Gleichheit der Bemessungsgrundlage "Gewinn" bei den unterschiedlichen

\footnotetext{
Vgl. ohne Verfasser (1989).

2 Vgl. Jacobs, O.H./Scheffler, W. (1988), S. 82 f.
} 
Rechtsformen zu gewährleisten. Ist dies erfüllt und werden alle Unternehmensrechtsformen den gleichen Steuerarten und -sätzen unterworfen, sind die Unternehmer hinsichtlich der für ihr Unternehmen zu wählenden Rechtsform indifferent.

\section{b) Finanzierungsentscheidung der Unternehmen}

Wird das oben dargestellte Arbitragekalkül durchgeführt, ergibt sich folgendes Ergebnis $^{l}$. Der Anteilseigner ist indifferent zwischen

- Beteiligungs- und Selbstfinanzierung des Unternehmens, wenn der Steuersatz für ausgeschüttete Gewinne $\tau_{\mathrm{a}}=0$ ist,

- Fremd- und Beteiligungsfinanzierung, wenn $\tau_{\mathrm{z}}=\tau_{\mathrm{a}}+\tau_{\mathrm{b}} *\left(1-\tau_{\mathrm{a}}\right)$ ist,

- Fremd- und Selbstfinanzierung, wenn der Steuersatz für Zinseinkünfte $\tau_{z}$ dem Betriebsteuersatz $\tau_{b}$ entspricht.

Die Betriebsteuer ohne Anrechnung ist somit finanzierungsneutral für:

$$
\tau_{\mathrm{z}}=\tau_{\mathrm{b}} ; \tau_{\mathrm{a}}=0
$$

Um die Finanzierungsentscheidung der Unternehmen nicht zu beeinflussen, muß die nicht anrechenbare Betriebsteuer und die Steuer auf Zinseinkünfte (bzw. das übrige Einkommen) denselben Steuersatz aufweisen und Ausschüttungen müssen unversteuert bleiben; dies widerspricht sowohl dem Einkommensbegriff der Reinvermögenszugangstheorie als auch demjenigen von Brandis, nach denen alle Zuflüsse als Einkommen zu erfassen sind. Weiterhin ist problematisch, daß bei einem unterstellten progressiven Steuertarif obige Bedingung nicht für jeden Anteilseigner erfüllt werden kann; wird für $\tau_{\mathrm{b}}$ ein Wert festgelegt, der unter dem Spitzensteuersatz liegt, gibt es Anleger, für die der Kauf von Gesellschaftsanteilen vorteilhafter ist als die Anlage auf dem Kapitalmarkt. Der marginale Anleger ist jedoch indifferent ${ }^{2}$.

Wird der gesamte Unternehmenssektor betrachtet, wird dessen Finanzierungsstruktur durch das Steuersystem beeinflußt, da den Unternehmen aus steuerlichen Gründen solange Eigenkapital zugeführt wird, solange es Anleger gibt, deren persönlicher Steuersatz über dem der Betriebsteuer liegt und sie Kapital von Steuerpflichtigen ausgeliehen bekommen, die einem geringeren Steuersatz un-

\footnotetext{
$1 \quad \tau_{\mathrm{b}}=$ Betriebsteuersatz.

2 Vgl. Miller (1977), S. $268 \mathrm{ff}$.
} 
terliegen als die Betriebsteuer. Die Betriebsteuer ohne Anrechnung ist also nicht finanzierungsneutral.

\subsubsection{Betriebsteuer mit Anrechnung beim Gesellschafter}

Hier wird die Betriebsteuer auf die vom Unternehmen auf ausgeschüttete Gewinne entrichtete Steuer auf die Einkommensteuerschuld des Anteilseigners angerechnet. Die ausgeschütteten Gewinne werden so mit dem individuellen Steuersatz des Anteilseigners besteuert, während die thesaurierten Gewinne dem Betriebsteuersatz unterliegen.

\section{a) Rechtsformentscheidung der Unternehmen}

Bei der Einführung einer Betriebsteuer mit Anrechnung beim Gesellschafter muß die Ermittlung des Gewinns zwischen Personen- und Kapitalgesellschaften vereinheitlicht und denselben Steuerarten und -sätzen unterworfen sein, um die Wahl der Unternehmensrechtsform nicht durch steuerliche Erwägungen zu verzerren.

\section{b) Finanzierungsentscheidung der Unternehmen}

Bei Durchführung des oben dargestellten Arbitragekalküls ergibt sich als Ergebnis, daß Finanzierungsneutralität bei identischen Steuersätzen für ausgeschüttete Gewinne $\left(\tau_{\mathrm{a}}\right)$, für Zinsen $\left(\tau_{\mathrm{z}}\right)$ und Betriebsteuer $\left(\tau_{\mathrm{b}}\right)$ vorliegt.

Die Gleichheit von $\tau_{\mathrm{a}}$ und $\tau_{\mathrm{z}}$ ist bei gleicher Besteuerung aller Zuflüsse systemimmanent. Der Betriebsteuersatz $\tau_{\mathrm{b}}$ kann jedoch nicht so gestaltet werden, daß er bei einem offen progressiven Tarifverlauf dem Einkommensteuersatz jedes Anteilseigners entspricht.

Die Betriebsteuer mit Anrechnung ist daher bei einem progressiven Tarif nur für den marginalen Anteilseigner finanzierungsneutral, während die Finanzierungsstruktur des Unternehmenssektors wie bei der Betriebsteuer ohne Anrechnung beeinflußt wird (s.o.). 


\subsubsection{Teilhabersteuer}

Bei der Teilhabersteuer richtet sich die Besteuerung der unternehmerischen Betätigung ausschließlich nach den persönlichen Verhältnissen (und somit dem persönlichen Steuersatz $\tau$ ) des Gesellschafters/Einzelunternehmers.

Der Gewinn bzw. Verlust wird unmittelbar beim Gesellschafter erfaßt und unabhängig von der tatsächlichen Ausschüttung des Gewinns -wie zur Zeit bei Personengesellschaften und Einzelunternehmen- besteuert ${ }^{l}$. Ausschüttungen werden nicht noch zusätzlich besteuert.

\section{a) Rechtsformentscheidung der Unternehmen}

Hier kann auf die Ausführungen bei der Diskussion der Betriebsteuer verwiesen werden.

\section{b) Finanzierungsentscheidung der Unternehmen}

Bei der Durchführung des oben dargestellten Arbitragekalküls, ergibt sich folgendes Ergebnis: die $\mathrm{Zu}$ - und Abflüsse beim Anteilseigner, die durch den Übergang von einer Finanzierungsart auf eine andere verursacht werden, sind jeweils gleich hoch, so daß zwischen den Alternativen Indifferenz besteht; die Teilhabersteuer ist damit finanzierungsneutral.

Die Teilhabersteuer verstößt aber gegen die von Brandis vorgeschlagene Systematik, nach der lediglich Zuflüsse als Einkommen zu definieren sind. Hier liegt ein Systembruch vor.

\subsubsection{Besteuerung nach der individuellen Leistungsfähigkeit}

Die individuelle Leistungsfähigkeit wurde als die Verfügungsmacht über die knappen Ressourcen der Wirtschaft definiert. Um diese "richtig" abzubilden, ist die möglichst umfassende Erfassung der Verfügungsmacht notwendig.

Bei allen diskutierten Konzeptionen der Unternehmensbesteuerung ist problematisch, daß nur auf die vom Unternehmen erzielten Gewinne abgestellt wird. Ein

$1 \quad$ Vgl. Jacobs, O.H./Scheffler, W. (1988), S. 84. 
höherer Wert des Unternehmens bzw. der Unternehmenswertanteile aufgrund veränderter Ertragsaussichten wird nicht abgebildet und ist somit steuerlich irrelevant, obwohl sich die Dispositionsmöglichkeiten des Individuums dadurch geändert haben.

Bei der Betriebsteuer werden überdies Verluste der Unternehmen nicht den Anteilseignern zugerechnet. Problematisch ist, da $\beta$ bei der Ermittlung des Unternehmensgewinns Ertragswertabschreibungen für den Werteverzehr des Betriebsvermögens angesetzt werden müssen; die Ermittlung von Ertragswertabschreibungen ist jedoch -wie gezeigt- aufgrund der in der Realität meist fehlenden Second-hand-Märkte für Vermögensgegenstände unmöglich.

Diese Konzeptionen messen somit nicht die Leistungsfähigkeit der Individuen.

\subsubsection{Praktikabilität der Besteuerung}

Bei diesen Vorschlägen ist die Ermittlung des Unternehmensgewinns bzw. -verlusts erforderlich. Es besteht somit das Problem der Bestimmung der Ertragswertabschreibungen (s.o.).

Bei der Betriebsteuer (mit und ohne Anrechnung) ist zur Gewährleistung der Finanzierungsneutralität die Identität von Betriebsteuersatz und dem Steuersatz für Zinseinkünfte erforderlich. Dies ist bei einem linearen Tarif unproblematisch. Bei einem progressiven Tarif hat prinzipiell jeder Anteilseigner einen anderen Steuersatz. Der Betriebsteuersatz kann damit nicht so gestaltet werden, $\mathrm{da} ß$ er dem Steuersatz für Zinseinkünfte entspricht. Die Anwendung eines aus den gewogenen Steuersätzen der Gesellschafter gebildeten Betriebsteuersatzes ist nicht praktikabel: hierbei ist nur an den Aufwand bei größeren Publikumsaktiengesellschaften zu denken; überdies werden die Verzerrungen nicht ausgeräumt.

Bei der Betriebsteuer mit Anrechnung werden die vom Unternehmen auf ausgeschüttete Gewinne entrichteten Steuern auf die Einkommensteuerschuld des Individuums angerechnet. Dafür ist es erforderlich, daß das Finanzamt der Unternehmensbesitzer Kenntnis von der bereits vom Unternehmen entrichteten Steuer erhält. Dies kann -wie es sich bei der deutschen Einkommen-/Körperschaftsteuer bewährt hat- in Form von Steuergutschriften geschehen: die Mitteilung über den ausgeschütteten Gewinn enthält auch eine Mitteilung über die vom Unternehmen bereits abgeführte Steuer.

Daraus wird ersichtlich, daß eine Betriebsteuer mit Anrechnung lediglich bei einem linearen Tarifverlauf praktikabel durchführbar ist. 
Bei der Teilhabersteuer stellt sich ebenfalls die Problematik der Steuererhebung, da den Gesellschaftern ihr jeweiliger Anteil am Unternehmensgewinn zugerechnet werden muß und somit bei einem progressiven Steuertarifverlauf ein einheitlicher Steuersatz auf Unternehmensebene nicht angewendet werden kann. Die Gesellschaft muß den Gesellschaftern ihren zuzurechnenden Gewinn melden bzw. dem Finanzamt die Anteilseigner bekannt geben. Bei Publikumsaktiengesellschaften sind die Aktionäre der Gesellschaft nicht bekannt und die Einführung von Namensaktien erschwert den Anteilshandel. Wird deshalb der Handel mit Aktien nur bei vorheriger Steuerentrichtung gestattet, wird er wiederum behindert und Anteilseigner, die ihre Anteile längere Zeit halten, können auch so nicht periodengerecht zur Steuer herangezogen werden.

Als Lösungsmöglichkeit bietet sich an, daß die Gesellschaft einen bestimmten $\%$-Satz des Gewinns an Steuer für ihre Gesellschafter -unabhängig von deren persönlichem Steuersatz- als Abschlagszahlung für ihre endgültige Steuerschuld abführt. Der Quellensteuersatz muß jedoch dem Spitzensteuersatz der Einkommensteuer (einschließlich Kirchensteuer) angepaßt sein, um jedem Steuerpflichtigen einen Anreiz zur Angabe seiner Einkünfte zu geben (bei geringerem persönlichen Steuersatz wird die Differenz erstattet). Diese Verfahrensweise ist theoretisch durchführbar. Es ergibt sich jedoch ein Mehraufwand im Vergleich zur heutigen Besteuerung von Kapitalgesellschaften, da auch in Jahren ohne Ausschüttung bzw. in Verlustjahren jedem Gesellschafter sein Anteil am Erfolg der Gesellschaft zugerechnet werden muß und sich dadurch der Arbeits- und Verwaltungsaufwand erhöht. Überdies entspricht diese Vorgehensweise nicht dem ursprünglichen Konzept der Teilhabersteuer.

\subsubsection{Ergebnis}

Bei der reinen Form der Reinvermögenszugangstheorie ist eine Unternehmensbesteuerung nicht notwendig, da sich der Unternehmenserfolg entweder im veränderten Anteilswert niederschlägt oder die Ausschüttungen das Vermögen des Gesellschafters erhöhen; in beiden Fällen ist die steuerliche Erfassung und somit eine Besteuerung gemäß der individuellen Leistungsfähigkeit gewährleistet. Bei dieser Meßmethode ist die Finanzierungs- und die Investitionsneutralität der Besteuerung gegeben. Die Verzerrungen aufgrund der Zinsbesteuerung (Vermögensbildung der Individuen und Wachstumsneutralität) bestehen allerdings weiter.

Bei den alternativen Konzepten der Unternehmensbesteuerung bleibt der Wert des Gesellschaftsanteils bei der Ermittlung der steuerlichen Bemessungsgrundlage unberücksichtigt; stattdessen wird der Erfolg des Unternehmens besteuert. 
Die Finanzierungsneutralität der Besteuerung wird nur erreicht, wenn entweder eine Betriebsteuer ohne Anrechnung, bei der allerdings die Ausschüttungen des Unternehmens nicht mehr besteuert werden dürfen und der Betriebsteuersatz dem für Zinsen entspricht (Steuersatz für ausgeschüttete Gewinne 0\%) oder eine Betriebsteuer mit Anrechnung eingeführt wird, bei der der Betriebsteuersatz dem Steuersatz für Zinsen und ausgeschütteten Gewinnen entspricht. Dies ist jedoch bei einem progressiven Steuertarif nur für einen gedachten marginalen Anleger möglich. Grundsätzlich wird also die Finanzierungsstruktur des Unternehmenssektors beeinflußt; es besteht somit keine Finanzierungsneutralität.

Finanzierungsneutralität für alle Anleger ist nur gewährleistet, wenn eine Teilhabersteuer zur Anwendung kommt.

Die Probleme aufgrund der Zinsbesteuerung (die Individuen erhöhen den Gegenwartskonsum zu Lasten des Zukunftskonsums sowie der negative Einfluß auf das Wirtschaftswachstum) werden durch die behandelten Vorschläge zur Unternehmensbesteuerung nicht korrigiert und bleiben bestehen.

Problematisch ist bei allen Konzeptionen, daß Wertänderungen der Unternehmenswertanteile (z.B. aufgrund eines gestiegenen Ertragswertes) bei diesen Vorschlägen nicht in die steuerliche Bemessungsgrundlage eingehen. Aufgrund der Nichterfassung treten die bei der Diskussion des Einbezugs von Wertänderungen aufgezeigten Probleme auf; es wird gegen die Forderung nach einem entscheidungsneutralen Steuersystem und gegen das Leistungsfähigkeitsprinzip verstoßen. Bei der Betriebsteuer liegt ein weiterer Verstoß gegen das Leistungsfähigkeitsprinzip vor, da Verluste des Unternehmens nicht den Anteilseignern zugerechnet werden. Kritisch ist weiter, daß bei allen drei Vorschlägen der Unternehmensgewinn zu berechnen ist und hierfür der Werteverzehr durch Ertragswertabschreibungen abgebildet werden muß. Diese können aber in der realen Welt aufgrund fehlender Second-hand-Märkte für die meisten Wirtschaftsgüter nicht vorgenommen werden. Die Ermittlung des Unternehmensgewinns ist damit hinsichtlich des Leistungsfähigkeitsprinzips problematisch.

Eine befriedigende Lösung und damit einen adäquaten Ersatz für die Wertänderungsbesteuerung im Bereich der Gesellschaftsanteile stellen die vorgeschlagenen Konzeptionen nicht dar. Überdies ist die Handhabung einer reinen Teilhabersteuer nicht praktikabel, da nach dieser Konzeption jedem Gesellschafter sein Gewinnanteil (unabhängig davon, ob ausgeschüttet oder thesauriert) direkt zugerechnet werden muß (wie derzeit bei den Personengesellschaften realisiert). Dazu muß entweder das Finanzamt den Anteil des einzelnen Gesellschafters am Erfolg sowie seinen Namen kennen oder das Unternehmen den Steuersatz jedes Anteilseigners. Dies ist besonders problematisch bei Publikumsaktiengesellschaften. Vereinfachungen der Art, daß Unternehmen einen bestimmten Steuersatz anwenden und die Anteilseigner die Differenz zu ihrem tatsächlichen Steu- 
ersatz wieder vom Finanzamt erstattet bekommen, sind zwar machbar aber relativ aufwendig durchzuführen und entsprechen nicht dem reinen Konzept der Teilhabersteuer.

Es ist aber zu beachten, daß die Betriebsteuer ohne Anrechnung und die Teilhabersteuer gegen die von Brandis verwendete Einkommensdefinition verstoßen, da entweder nicht alle Zuflüsse der Besteuerung unterworfen werden (Betriebsteuer ohne Anrechnung ${ }^{I}$ ) oder auch noch nicht zugeflossene Erträge in die steuerliche Bemessungsgrundlage (Teilhabersteuer) eingehen.

Insgesamt wird festgehalten, da $B$ die Unternehmensbesteuerung in der realen Welt hinsichtlich des Leistungsfähigkeitsprinzips und der Entscheidungsneutralität problematisch ist.

\section{Glättung der Bemessungsgrundlage}

Bei einer abschnittsweisen Besteuerung mit einem progressiven Tarif ergibt sich bei schwankenden Bemessungsgrundlagen grundsätzlich eine andere zu zahlende Steuer als bei einer über die Zeit hinweg konstanten Bemessungsgrundlage. Für identische Lebenseinkommen sind unterschiedlich hohe Steuern zu entrichten ${ }^{2}$. Ziel einer periodenübergreifenden Steuerbemessung in Form einer interperiodischen Durchschnittsbesteuerung ist, das kumulierte Einkommen im Ergebnis mit der Progressionsstufe zu besteuern, die dem durchschnittlichen Periodeneinkommen in der Kumulationsperiode entspricht; Schwankungen in der Bemessungsgrundlage sollen also geglättet werden ${ }^{3}$.

\subsection{Darstellung der Methoden}

Zur Glättung der periodischen Bemessungsgrundlage der Besteuerung werden in der Literatur verschiedene Vorschläge gemacht, die vereinfachend in drei Gruppen eingeteilt werden können:

1 Um die Finanzierungsneutralität zu gewährleisten, dürfen die ausgeschütteten Gewinne auf der Ebene des Anteilseigners nicht besteuert werden.

2 Siehe hierzu auch die oben gemachten Ausführungen über die für die Besteuerung grundsätzlich zu wählende Periodenlänge.

3 Über die Durchschnittsbildung geht die Länge der Kumulationsperiode in die endgültig zu zahlende Steuer ein, d.h. das tatsächlich erreichte Lebensalter wird bei der Lebenseinkommensbesteuerung berücksichtigt; der Vorwurf, daß nur eine von der Lebensdauer unabhängige Einheitssteuer erhoben wird, ist somit hinfällig (vgl. Schneider, D. (1978), S. 51-52). 
- Auf das nicht periodenweise gemittelte kumulierte Einkommen wird ein Steuersatz angewandt, der abhängig ist von der Länge der Kumulationsperiode $^{l}$ oder sich aus nach Alters- und Sozialkohorten differenzierten Steuersatztabellen ${ }^{2}$ ergibt.

- Der auf das Periodeneinkommen anzuwendende Steuersatz ist der sich aufgrund des Einkommensdurchschnitts der Kumulationsperiode ergebende Prozentsatz; die Kumulationsperiode entspricht entweder einem mittelfristigen Zeitraum (3-7 Jahren) ${ }^{3,4}$ oder der Lebensdauer des Individuums ${ }^{5}$.

- Der Steuerpflichtige kann beim Staat ein Konto (= "Einkommensanpassungskonto") führen, auf dem einkommensteuerfrei Beträge "geparkt" werden können ${ }^{6}$; die Einkommensteuer fällt erst bei der Entnahme von diesem Konto an. Durch Ein- und Auszahlungen auf diesem Konto kann der Zeitpunkt der Besteuerung selbst bestimmt und Einfluß auf die periodische Steuerhöhe genommen werden.

\subsection{Beurteilung der Methoden}

Im folgenden Teil werden die einzelnen Verfahren nicht im Detail betrachtet ${ }^{7}$; stattdessen wird auf einige grundsätzliche Probleme dieser Methoden hingewiesen.

Bei den Methoden, die die Steuersätze nach Alters- und Sozialkohorten differenzieren, wird das Einkommen qualitativ differenziert, d.h. ein bestimmtes Einkommen hat nicht eine für alle gleiche (periodische) Steuer zur Folge. Dabei ist fraglich, ob durch diese Verfahren eine Besteuerung nach der individuellen Lei-

I Vgl. Vickrey, W. (1959); Vickrey, W. (1947), S. 175 ff., 417 ff.

2 So z.B. Deutsch, A. (1975).

3 So z.B. Pechman, J.A. (1977), S. 116 ff.; Endriss, H.W. (1966).

4 Diese Art der Besteuerung wurde in Deutschland nach dem preußischen Einkommensteuergesetz von 1891 angewandt; nähere Erläuterungen hierzu finden sich bei Reichsminister der Finanzen (1929).

5 Vgl. Shoup, C.S. (1969), S. 324 ff.; Hackmann, J. (1976), S. 20 ff.; Mitschke, J. (1976), S. 138 ff., 200 ff.; Mitschke, J. (1980), S. 126.

6 So. z.B. die Royal Commission on Taxation (1966), Vol. 3, S. $269 \mathrm{ff}$.

7 Einen gewissen Überblick über die in einzelnen Ländern angewandten Verfahren findet sich in Royal Commission on Taxation (1966), Vol. 3, S. 244 ff. Theoretische Erörterungen zu den einzelnen Verfahren der Durchschnittsbesteuerung sowie weiterführende Literaturhinweise sind bei den o.a. Autoren zu finden. 
stungsfähigkeit möglich ist und die Forderung nach einer gerechten Besteuerung erfüllt werden kann ${ }^{l}$ : es ist der (extreme) Fall vorstellbar, in dem zwei Individuen mit gleichem Lebenseinkommen, gleichem Spar- und Konsumverhalten sowie gleichem intertemporalen Einkommensverlauf aufgrund ihrer unterschiedlichen Gruppenzugehörigkeit eine unterschiedliche Steuer entrichten. Deutsch schlägt z.B. als Einflußgröße für die gruppenspezifische Steuerbemessung vor: "One of the logical considerations in setting the tax rates for each cohort is the amount of life benefit each group will receive from the stream of public goods made available." ${ }^{2}$. Hier kommt also wieder der oben schon abgelehnte Äquivalenzgedanke zum Tragen; mit dem verteilungspolitischen Leistungsfähigkeitsbegriff ist dieses Vorgehen nicht zu begründen. Diese Methode ist weiterhin unpraktikabel, da vom Parlament ein jeweiliger Tarifverlauf für eine Unzahl von Gruppen festgelegt werden muß. Ein Erfordernis, das aufgrund der nur schwierigen Vergleichbarkeit der verschiedenen Gruppen und der erforderlichen Festlegung von Gruppenmerkmalen zu langwierigem politischen Streit und -aller Voraussicht nach- zu einer Welle von Prozessen führt ${ }^{3}$. In einem demokratischen Staat droht weiterhin die Gefahr, daß diejenigen Gruppen mit der besten (lautesten) Interessenvertretung die geringste Steuer zu entrichten haben; dies entspricht nicht dem Prinzip der Gerechtigkeit der Besteuerung und dem Leistungsfähigkeitsprinzip.

Deutsch will darüberhinaus die aufgrund der Ausbildung bzw. der Berufszugehörigkeit in der Restlebenszeit voraussichtlich noch zu erzielenden Einkommen bei der Ermittlung des anzuwendenden Steuersatzes miteinbeziehen ${ }^{4}$. Dadurch soll die Abschätzung des auf das Lebenseinkommen anzuwendenden Steuersatzes verbessert und Steuerüberzahlungen bzw. Steuerunterzahlungen -jeweils bezogen auf die letztendlich zu entrichtende Steuer- vermieden werden. Problematisch ist dabei, daß eine dritte Stelle das voraussichtlich noch zu erwartende Einkommen prognostiziert. Sie zieht dafür Indikatoren heran, die bei objektiver Betrachtung zwar nicht völlig unerheblich für die Höhe des zukünftig zu erzielenden Einkommens sind, jedoch nur einen Teil der Wirklichkeit abbilden und allenfalls (bei optimistischer Einschätzung) den durchschnittlichen Durchschnittseinkommensbezieher abbilden ${ }^{5}$. Da die Gruppenzugehörigkeit vom Steuerpflichtigen durch seine Entscheidungen beeinflußt wird, beeinflußt dieses

\footnotetext{
$1 \quad$ Vgl. auch Mitschke, J. (1980), S. 129.

2 Deutsch, A. (1975), S. 311.

3 Vgl. auch Mitschke, J. (1980), S. 129.

4 Vgl. Deutsch, A. (1975), S. 311.

5 Ein Diplom-Kaufmann kann sowohl als Einkommensmillionär als auch als Sachbearbeiter sein Berufsleben beenden. Was er tatsächlich erreicht, ist in der realen Welt im voraus durch Dritte nicht abzuschätzen.
} 
Verfahren auch das Verhalten der Individuen. Somit ist es nicht entscheidungsneutral.

Verfahren, die an der Gruppenzugehörigkeit des Individuums ansetzen sind, so das Fazit, aus Gerechtigkeits- und Praktikabilitätsüberlegungen abzulehnen.

Die Verfahren, die einen mittelfristigen Zeitraum der Einkommenskumulation vorschlagen, vermindern zwar die Probleme, die sich aus schwankenden Einkommen ergeben, beseitigen sie aber konzeptionsbedingt nicht vollständig, da auch die während der Lebensdauer des Individuums zu ermittelnden verschiedenen Durchschnittseinkommen schwanken können. Sie weisen auch fast dieselben Probleme wie die auf die Gesamtlebensdauer des Individuums abstellenden Verfahren (s.u.) auf. Sie sind deshalb unbefriedigend und werden nicht weiter untersucht.

Im folgenden werden einige strittige Punkte der Verfahren behandelt, die die gesamte Lebensdauer des Individuums bei der Durchschnittsbesteuerung berücksichtigen.

- Problematisch ist, ob die Einkommen- und Steuerbeträge früherer Jahre bei der Ermittlung der Steuerschuld des laufenden Jahres aufgezinst oder ob die Periodeneinkommen einfach -also ohne Gewichtung- addiert werden. Es ist weiter der anzuwendende Zinssatz umstritten ${ }^{l}$. Dies hat Auswirkungen bei einem progressiven Steuersystem, da sich für das aufgezinste Einkommen einer Vorperiode eine höhere Steuer als die aufgezinste in der Vergangenheit entrichtete Steuer ergibt. Die Befürworter einer Aufzinsung argumentieren, da $\beta$ aufgrund der individuellen Zeitpräferenz dem früher bezogenen Einkommen eine höhere Wertschätzung beigelegt wird als dem später bezogenem; dagegen wird eingewandt, daß auf das früher bezogene Einkommen auch früher die entsprechenden Steuern gezahlt wurden und somit eine Symmetrie zwischen Einkommenserzielung und Steuerzahlung besteht.

- Kontrovers ist bei den verschiedenen Vorschlägen zur Durchschnittsbesteuerung auch die Verwirklichung des grundgesetzlich verankerten Schutzes der Familie, der im deutschen Steuerrecht (u.a.) durch das Ehegattensplitting verwirklicht wird. Strittig ist, ob beide Ehepartner als einheitliches Steuersubjekt gesehen werden oder nicht; wird von einem einheitlichen Steuersubjekt ausgegangen, beginnt mit der Heirat eine neue Durch-

I Vgl. mit weiteren Nachweisen Mitschke, J. (1980), S. 127 f.; Hackmann, J. (1979). 
schnittsbesteuerungsperiode, die bis zur Eheauflösung andauert. Diese Verfahrensweise kann in manchen Fällen aufgrund des Wegfalls der Perioden vor der Eheschließung eine höhere Steuerbelastung bedeuten als ohne bzw. vor der Ehe. Wird von zwei Steuersubjekten ausgegangen, besteht obiges Problem nicht. Stattdessen bedarf es einiger weiterer Regelungen, da die einfache Zurechnung der Hälfte des gemeinsamen Jahreseinkommens auf jeden Ehepartner (wie es jetzt geschieht) bei einer Durchschnittsbesteuerung zu einer Schlechterstellung im Vergleich vor der Ehe führen kann ${ }^{I}$. Eine weitere Möglichkeit ist ein Wahlrecht zwischen beiden o.a. Besteuerungsmethoden ${ }^{2}$.

- In der realen Welt ist über eine längere Dauer nicht mit gleichbleibenden Steuersätzen zu rechnen. Aufgrund von rechtspolitischen Überlegungen ist aber eine Rückwirkung von Steuertarifänderungen nicht zulässig ${ }^{3}$. Von einer Rückwirkung ist auszugehen, wenn ein Verfahren bei Tarifänderungen dazu führt, daß die in bestimmten Vorperioden bezogenen Einkommen den Steuersätzen anderer Jahre unterworfen werden ${ }^{4}$. Hier herrscht ebenfalls Uneinigkeit hinsichtlich des anzuwendenden Verfahrens ${ }^{5}$.

- Weitere Probleme hinsichtlich der Länge der Kumulationsperiode und des Einbezugs ausländischer Einkommen in die Durchschnittsbetrachtung ergeben sich, wenn Personen vorübergehend ins Ausland ziehen oder Ausländer vorübergehend in Deutschland Einkommen beziehen.

- Kein Problem ist hingegen die Speicherung der Daten der Steuerpflichtigen, da leistungsfähige magnetische oder optische Speichermedien und die dazugehörige Datenverwaltungssoftware vorhanden sind.

Aus dieser kurzen Aufzählung einiger umstrittener Punkte wird ersichtlich, daß die Verfahren zur Durchschnittsbesteuerung viele nicht einfach zu lösende Probleme aufweisen.

1 Dies ist der Fall, wenn der Ehepartner mit dem höheren momentanen Jahreseinkommen ein geringeres Durchschnittseinkommen hat als sein Ehepartner (vgl. Vickrey, W. (1947), S. 286).

2 Weitere Vorschläge (und Gegenvorschläge) siehe in der o.a. Literatur.

3 Vgl. Tipke, K./Lang, J. (1991), S. 34 ff.

$4 \quad$ Vgl. Hackmann, J. (1980), S. 320.

5 Ein gutes Beispiel hierfür ist die Diskussion zwischen Mitschke, J. (1980) und Hackmann, J. (1980). 
Bei den Vorschlägen, die sich für die Einrichtung eines "Einkommensanpassungskontos" aussprechen, muß davon ausgegangen werden, daß der Staat lediglich die Führung von Konten gestattet, die einen positiven Saldo aufweisen. Der Steuerpflichtige zahlt hierauf Einkommensbestandteile ein, die er erst bei der Entnahme in späteren Jahren versteuern will. Somit können nur momentane Einkommensspitzen mit geringeren Einkommen in der Zukunft ausgeglichen werden, eine Rückrechnung auf die Vergangenheit ist nicht möglich. Die meisten Steuerpflichtigen haben jedoch in jungen Jahren im Vergleich zu später ein geringeres Einkommen, z.B. aufgrund der Ausbildung, Karriere. Mit der Einzahlung von gegenwärtigem Einkommen auf ein Steuerkonto können diese Menschen ihr Periodeneinkommen nicht glätten. Somit kann nur eine kleine Minderheit von Steuerpflichtigen von diesem Konzept profitieren. Die Methode ist deshalb nur als bedingt tauglich einzustufen.

\subsection{Ergebnis}

Die Besteuerung nach der individuellen Leistungsfähigkeit erfordert ein Besteuerungsverfahren, das auf die gesamte Lebensdauer des Individuums abstellt und die geeigneten Indikatoren als Basis hat. Diese Forderung erfüllen nur die Verfahren, die bei der Errechnung des Durchschnittsteuersatzes die gesamte Lebensdauer berücksichtigen und nicht nur einige Teilabschnitte.

Abzulehnen sind diejenigen Verfahren, die auf Indikatoren wie Berufsgruppenzugehörigkeit o.ä. abstellen. Gegen die Einrichtung von Steuerkonten ist einzuwenden, daß aufgrund von Praktikabilitätsüberlegungen lediglich ein vorwärtsgerichteter Periodeneinkommensausgleich möglich ist; dies ist ebenfalls unbefriedigend.

Die Frage des anzuwendenden Durchschnittbesteuerungsverfahrens bei der Einkommensbesteuerung auf Lebensbasis ist in der Wissenschaft umstritten; hinsichtlich vieler Probleme (s.o.) bestehen unterschiedliche Auffassungen. Es deutet sich aber an, daß ein "gerechtes" Verfahren nicht auch gleichzeitig ein einfaches Verfahren ist, so daß eine Vielzahl von Unterscheidungen zu treffen sind, die wiederum einen hohen Beratungsbedarf der Steuerpflichtigen erfordern. 


\section{Kapitel}

\section{Zusammenfassung des zweiten Teils}

Es wurde die Besteuerung des Lebenseinkommens durch eine Periodeneinkommensteuer untersucht; dazu wurden einige Einkommenskonzeptionen vorgestellt und Sonderprobleme der Periodeneinkommensbesteuerung diskutiert.

Wesentliches Unterscheidungsmerkmal der dargestellten Einkommenskonzeptionen ist die Behandlung von unregelmäßig anfallenden "Einkünften" sowie von Wertänderungen.

Bei der Behandlung von Sonderproblemen wurde auf die Behandlung von Windfall Profits bzw. unregelmäßigen Einkünften, die Zins- und Wertänderungsbesteuerung, Schenkungen und Erbschaften, Unternehmensbesteuerung sowie Verfahren zur Glättung der periodischen Bemessungsgrundlage eingegangen.

Windfall Profits bzw. unregelmäßige Einkünfte müssen aufgrund des Leistungsfähigkeitsprinzips in die steuerliche Bemessungsgrundlage einbezogen werden, da sie die Dispositionsmöglichkeiten der Individuen erhöhen. Die Frage der Entscheidungsneutralität der Besteuerung ist bei Windfall Profits irrelevant, da deren Anfall definitionsgemäß außerhalb der Entscheidungsgewalt der Individuen liegt.

Unregelmäßig anfallende Einkünfte, deren Anfall im Entscheidungsbereich der Steuerpflichtigen liegt, müssen aufgrund von Neutralitätserwägungen in die steuerliche Bemessungsgrundlage einbezogen werden. Über die Praktikabilität der Erfassung dieser Einkünfte kann keine eindeutige Aussage getroffen werden, da hierunter eine Vielzahl von verschiedenen "Einkunftsquellen" fallen.

Problematisch ist die Frage der Zinsbesteuerung. Die Besteuerung der Zinseinkünfte ist mit dem Leistungsfähigkeitsprinzip nicht zu vereinbaren. Die Verstöße gegen das Leistungsfähigkeitsprinzip haben zur Folge, daß -bei gleichem Lebenseinkommen in einer Laissez-Faire-Ökonomie- der Konsumzeitpunkt die Höhe der Steuerzahlungen beeinflußt. Alle oben aufgeführten Einkommenskonzeptionen und deren Modifikationen verstoßen deshalb gegen die Forderung nach einem gerechten Steuersystem. Damit liegt ein im System der periodischen Erfassung des Einkommens zu suchender Mangel vor.

Weiterhin stört die Zinsbesteuerung die optimale Ressourcenallokation: insbesondere verringert sich die Ersparnis der Individuen, da sie aufgrund der Zinsbesteuerung ihren Gegenwartskonsum zu Lasten der Ersparnis erhöhen. Es ergibt sich c.p. ein geringeres Wirtschaftswachstum. Daraus folgt bei den üblichen 
neoklassischen Annahmen über die Produktionsfunktion, daß im Vergleich zu einer Laissez-Faire-Ökonomie das Niveau der Kapitalakkumulation nicht optimal ist und die Grenzproduktivität des Faktors "Arbeit" einen anderen Wert als im Optimum annimmt. Dies hat Einfluß auf den Preis der Arbeit (= Lohn) oder den Umfang der Beschäftigung.

Anhand des Beispiels Deutschlands wurde aufgezeigt, daß die Zinseinkünfte relativ einfach durch die Transferierung des Kapitals in das Ausland dem Fiskus vorenthalten werden können; somit bestehen auch Praktikabilitätsprobleme.

Als weiteres Problemfeld wurde auf die Besteuerung von Wertänderungen eingegangen. Wertänderungen, die durch die Abnutzung von Vermögensgegenständen zur Einkommenserzielung verursacht werden und Wertänderungen aufgrund von Windfall Profits sind in die steuerliche Bemessungsgrundlage zum Zeitpunkt ihrer Entstehung einzubeziehen, da ansonsten gegen das Leistungsfähigkeitsprinzip verstoßen wird. Ihr Einbezug in die steuerliche Bemessungsgrundlage erst zum Realisationszeitpunkt der Wertänderungen ist abzulehnen. Generelle Einwände gegen die Besteuerung von Wertänderungen konnten mit Hilfe des Leistungsfähigkeitsprinzips sowie der Forderung nach einem neutralen Steuersystem entkräftet werden.

Beim Einbezugs von Wertänderungen, die die Verzinsung des eingesetzten Kapitals repräsentieren, treten hinsichtlich der Besteuerung nach der individuellen Leistungsfähigkeit dieselben Probleme wie bei der Zinsbesteuerung auf. Um der Gleichartigkeit von Wertänderungen und einer laufenden Verzinsung gerecht zu werden, müssen Zinsen und Wertänderungen in gleichem Umfang in die Bemessungsgrundlage der Besteuerung eingehen.

Somit ist auf die Einkommensdefinition der Reinvermögenszugangstheorie zurückzugreifen, wenn die Besteuerung nach der individuellen Leistungsfähigkeit in diesem Punkt verwirklicht werden soll, da die anderen Einkommenskonzeptionen diese Einkünfte nicht erfassen.

Für die Beurteilung der Frage hinsichtlich der Neutralität des Steuersystems gelten aufgrund der Gleichartigkeit von Zins- und Wertänderungen, die die Verzinsung des eingesetzten Kapitals repräsentieren, die bei der Untersuchung der Zinseinkommensbesteuerung festgestellten Mängel: die Individuen verringern aufgrund der Besteuerung ihr Sparen und die Wirtschaft wächst langsamer als in einer Laissez-Faire-Ökonomie.

Zur Gewährleistung eines innovationsneutralen Steuersystems ist die Besteuerung entweder von allen oder keinen Wertänderungen notwendig. Die ausschließliche Besteuerung von realisierten Wertänderungen behindert Innovationen, so daß keine effiziente Ressourcenallokation gegeben ist.

Ferner wurde festgestellt, daß steuerliche Abschreibungen in Höhe der Änderung des Ertragswertes zwischen Periodenanfang und Periodenende vorgenom- 
men werden müssen, um die Entscheidungsneutralität der Besteuerung zu wahren.

Um die Wertänderungen im Vermögen des Steuerpflichtigen zu quantifizieren, muß in jeder Periode die Höhe des individuellen Vermögens ermittelt werden. Der geeignete Wertmaßstab zur Ermittlung des individuellen Vermögens ist der Gesamtveräußerungswert des Vermögens. Dieser Wert ist jedoch aufgrund unvollkommener Märkte für einige Wirtschaftsgüter (z.B. nicht-börsennotierte Unternehmensanteile, Grundstücke) nicht in allen Fällen ermittelbar. Die ersatzweise Anwendung von standardisierten Hilfsverfahren kann zu systematischen Verzerrungen zwischen den einzelnen Wirtschaftsgütern führen. Überdies sind diese Verfahren bei jährlich durchzuführenden Bewertungen sehr arbeits- und verwaltungsaufwendig.

Die periodische Ermittlung von Wertänderungen im Vermögen der Steuerpflichtigen ist also praktisch nicht durchführbar, wenn aufgrund des Leistungsfähigkeitsprinzips und der Forderung nach einem entscheidungsneutralen Steuersystem auf genaue Werte abgestellt werden soll. Eine befriedigende Lösung, die sowohl der Forderung nach einer gerechten und effizienten Besteuerung genügt als auch praktikabel durchführbar ist, gibt es nicht.

Es wurde weiter auf Schenkungen und Erbschaften eingegangen, die aufgrund des Leistungsfähigkeitsprinzips in die steuerliche Bemessungsgrundlage einzubeziehen sind. Ob damit allerdings noch der Forderung nach einem neutralen Steuersystem Genüge getan wird, ist von der Motivation der Schenkung bzw. Vererbung abhängig. Es gibt jedoch Indizien dafür, daß die Entscheidungen nicht oder nur unwesentlich beeinflußt werden. Die Erfassung dieser Einkommensteile gestaltet sich aufgrund von Praktikabilitätserwägungen äußerst schwierig, wenn nicht sogar unmöglich.

Die Unternehmensbesteuerung war ein weiteres Thema dieses Teils. Bei der reinen Form der Reinvermögenszuwachstheorie ist eine Unternehmensbesteuerung nicht notwendig, da sich der Unternehmenserfolg entweder im veränderten Anteilswert niederschlägt oder die Ausschüttungen das Vermögen des Gesellschafters erhöhen; in beiden Fällen ist die steuerliche Erfassung und somit eine Besteuerung gemäß der individuellen Leistungsfähigkeit gewährleistet. Bei dieser Meßmethode ist weiterhin die Finanzierungs- und die Investitionsneutralität der Besteuerung gegeben. Die Verzerrungen aufgrund der Zinsbesteuerung (Vermögensbildung der Individuen und Wachstumsneutralität) bestehen allerdings weiterhin.

Da die Besteuerung nach der Reinvermögenszugangstheorie aufgrund der Wertänderungsbesteuerung nicht durchführbar ist, wurden auch alternative Konzepte 
zur Unternehmensbesteuerung (Betriebsteuer mit und ohne Anrechnung, Teilhabersteuer) diskutiert. Sie konnten aber die an sie gestellten Anforderungen nicht erfüllen und verstoßen in unterschiedlichem Maße gegen das Leistungsfähigkeitsprinzip, gegen die Neutralität der Besteuerung sowie gegen das Praktikabilitätserfordernis.

Ein weiteres Problem waren die Schwankungen im Periodeneinkommen. Die Besteuerung nach der individuellen Leistungsfähigkeit erfordert bei einer progressiven Tarifstruktur ein Besteuerungsverfahren, das auf die gesamte Lebensdauer des Individuums abstellt.

Bei der Diskussion dieser Fragestellung wurde nicht im Detail auf einzelne Verfahren eingegangen, sondern nur grundsätzliche Probleme angesprochen. Die Frage des anzuwendenden Durchschnittbesteuerungsverfahrens ist in der Wissenschaft umstritten; bei vielen Problemen bestehen unterschiedliche Auffassungen. Es deutet sich aber an, daß ein gerechtes und entscheidungsneutrales Verfahren nicht auch ein einfaches Verfahren ist, so daß eine Vielzahl von Unterscheidungen zu treffen sind und Praktikabilitätsprobleme auftreten können.

Als Ergebnis kann festgestellt werden, daß zur umfassendsten Abbildung der Leistungsfähigkeit somit die Einkommenskonzeption der Reinvermögenszugangstheorie heranzuziehen ist. Diese verstößt jedoch aufgrund der Zinsbesteuerung gegen das Leistungsfähigkeitsprinzip und gegen die Forderung nach einem neutralen Steuersystem. Somit führt die Besteuerung des Periodeneinkommens nicht zu einem gerechten und effizienten Steuersystem und ist überdies aufgrund der praktischen Probleme der Vermögenswertermittlung nicht durchführbar. 


\section{Teil}

\section{Periodenkonsum und Lebensendvermögen als steuerliche Bemes- sungsgrundlage}

Die Leistungsfähigkeit drückt sich nach dem verteilungspolitischen Leistungsfähigkeitsbegriff in der individuellen Fähigkeit aus, zur Finanzierung des staatlichen Finanzbedarfs beizutragen. Diese Fähigkeit bestimmt sich aus der ökonomischen Verfügungsmacht eines Individuums über knappe Ressourcen der Wirtschaft. Der Begriff "Verfügungsmacht" stellt auf die individuellen Möglichkeiten $a b$, frei zwischen konsumtiver und investiver Verwendung über die individuellen ökonomischen Ressourcen zu entscheiden ${ }^{l}$. Die investive Verwendung kann dabei als Verwendung zugunsten künftigen Konsums gedeutet werden.

Im weiteren Verlauf wird untersucht, ob der Periodenkonsum und das Lebensendvermögen eines Individuums, also die Verwendungsseite des Einkommens, eine "bessere" steuerliche Bemessungsgrundlage als das Periodeneinkommen ist. In diesem Zusammenhang wird auch auf die Selbsteinschätzung der individuellen Leistungsfähigkeit durch die Individuen eingegangen.

Zuerst wird der arithmetische Zusammenhang zwischen Einkommen, Konsum und Ersparnis aufgezeigt. Unter "Konsum" wird dabei "... der tatsächlich oder verkehrsüblich in Geld bewertete Güter- und Dienstleistungsverzehr einer Person... für Zwecke nicht mit Erwerbszielen verbundener Bedürfnisbefriedigung..." verstanden ${ }^{2}$. Wird der Konsum eines Individuums und sein Lebensendvermögen addiert, ergibt sich das Lebenseinkommen, das sowohl aus Gerechtigkeits- als auch aus Neutralitätserwägungen als steuerliche Bemessungsgrundlage heranzuziehen ist.

Dieser einfache arithmetische Zusammenhang ergibt sich durch die Betrachtung des Einkommens y in der Periode t; es gilt die Beziehung zwischen Einkommen, Konsum und Ersparnis (E)

[1] $\mathrm{y}_{\mathrm{t}}=\mathrm{C}_{\mathrm{t}}+\mathrm{E}_{\mathrm{t}}$.

$1 \quad$ Vgl. Ebnet, O. (1978), S. 57.

2 Vgl. Mitschke, J. (1980), S. 282. 
Das Lebenseinkommen $\mathrm{Y}_{\mathrm{L}}$ stellt die Addition sämtlicher T Periodeneinkommen eines Individuums dar ${ }^{l}$ :

[2] $\mathrm{Y}_{\mathrm{L}}=\sum_{\mathrm{t}=1}^{\mathrm{T}}(1+\mathrm{r})^{\mathrm{T}-\mathrm{t}} * \mathrm{y}_{\mathrm{t}}$

Aus [1] und [2] entsteht

$$
\begin{aligned}
\mathrm{Y}_{\mathrm{L}} & =\sum_{\mathrm{t}=1}^{\mathrm{T}}(1+\mathrm{r})^{\mathrm{T}-\mathrm{t}} * \mathrm{C}_{\mathrm{t}}+\sum_{\mathrm{t}=1}^{\mathrm{T}}(1+\mathrm{r})^{\mathrm{T}-\mathrm{t}} * \mathrm{E}_{\mathrm{t}} \\
& =\sum_{\mathrm{t}=1}^{\mathrm{T}}(1+\mathrm{r})^{\mathrm{T}-\mathrm{t}} * \mathrm{C}_{\mathrm{t}}+\mathrm{V}_{\mathrm{T}}
\end{aligned}
$$

wobei $\mathrm{T}$ die Lebensdauer und $\mathrm{V}_{\mathrm{T}}$ das zu Marktpreisen vererbbare Vermögen (Nachlaß) darstellt.

Das Lebenseinkommen ergibt sich somit aus der Summe des Periodenkonsums zuzüglich des zu Marktpreisen bewerteten Nachlasses. Werden diese Größen als Bemessungsgrundlage für die Besteuerung herangezogen, wird damit das Lebenseinkommen besteuert.

Nachdem die arithmetische Beziehung zwischen Lebenseinkommen, Konsum und Ersparnis geklärt ist, wird auf das Hauptanliegen dieses Teils eingegangen. Hierbei ergeben sich folgende Fragen:

- Die Besteuerung nach der Leistungsfähigkeit ist bei einer Einkommensbesteuerung nach der Reinvermögenszugangstheorie aufgrund praktischer Probleme (Bewertungsfragen) nicht durchführbar; überdies widerspricht die Zinsbesteuerung dem Leistungsfähigkeitsprinzip und verzerrt Entscheidungen der Steuerpflichtigen. Eine durchführbare Einkommensbesteuerung ohne die Erfassung unrealisierter Wertänderungen (= Einkommenskonzeption von Brandis) ist mit dem Prinzip einer Besteuerung nach der Leistungsfähigkeit nicht vereinbar und verstößt gegen die Forderung nach einem entscheidungsneutralen Steuersystem.

Vgl. Mitschke, J. (1975), S. 70. 
Es ist daher zu prüfen, ob die Besteuerung des Konsums und des Lebensendvermögens dem Prinzip der Besteuerung nach der individuellen Leistungsfähigkeit eher entspricht und darüberhinaus die Forderung nach einem effizienten und praktikablen Steuersystem erfüllt wird.

- Das Periodeneinkommen schwankt bei vielen Individuen. Die Bemessungsgrundlage sollte jedoch bei einem progressiven Tarifverlauf möglichst keinen großen Schwankungen im Zeitablauf unterliegen. Sonst kommt es je nach zeitlichem Anfall der steuerlich relevanten Sachverhalte zu unterschiedlich hohen Steuerzahlungen, wenn keine (problematische) Durchschnittsbildung durchgeführt wird ${ }^{l}$. Es ist zu klären, ob die Bemessungsgrundlage "Periodenkonsum und Lebensendvermögen" geringere Schwankungen aufweist.

Ob der Periodenkonsum und das Lebensendvermögen eine bessere steuerliche Bemessungsgrundlage darstellen als das Periodeneinkommen, hängt von den Größen, die die Individuen ihrer Konsum-Spar-Entscheidung zugrundelegen, ab. Dabei sind folgende drei Möglichkeiten zu unterscheiden:

- Die Individuen richten ihren Periodenkonsum an den (Zahlungsmittel-) Zuflüssen der Periode aus. Unrealisierten Wertänderungen billigen sie keinen Einfluß auf ihre Leistungsfähigkeit zu. Aus Praktikabilitätsgründen wäre die Besteuerung des Konsums und des Lebensendvermögens gegenüber einer Einkommensbesteuerung nach der Reinvermögenszugangstheorie zu präferieren, da die periodische Vermögensermittlung entfällt.

- Die Individuen richten ihren Periodenkonsum am Periodeneinkommen nach der Reinvermögenszugangstheorie (also einschließlich der unrealisierten Wertänderungen) aus. Die Individuen schätzen dann die Wertveränderungen ihres Vermögens selbst ab und beziehen sie in ihre Konsumentscheidung (also der Abschätzung ihrer Leistungsfähigkeit) ein. Hierbei ergeben sich Vorteile für die Konsumbesteuerung gegenüber einer Einkommenskonzeption, die unrealisierte Wertsteigerungen unberücksichtigt läßt, da die Leistungsfähigkeit durch die Erfassung der unrealisierten Wertänderungen besser abgebildet wird. Gegenüber einer Besteuerung nach der Reinvermögenszugangstheorie ergibt sich weiterhin der praktische Vorteil, da $\beta$ die Bewertung des Vermögens nur einmal -nämlich am Lebensende des Individuums- durchgeführt werden muß. Es bestehen jedoch die bei der Rein-

1 Eine gleichmäßige Bemessungsgrundlage trägt auch dazu bei, daß die aus praktischen Gründen (laufender Finanzbedarf des Staates usw.) erforderlichen periodenweisen Steuerzahlungen der Individuen denen aufgrund ihrer (Lebens-) Leistungsfähigkeit zu leistenden Zahlungen nahekommen. 
vermögenszugangstheorie diskutierten Probleme der Vermögensbewertung weiter.

Das Problem der ungleichmäßigen Besteuerung bei einem progressiven Tarifverlauf aufgrund des unterschiedlichen zeitlichen Anfalls des Konsums (Progressionseffekt) besteht unverändert; die Besteuerung nach der Leistungsfähigkeit ist damit nicht vollkommen erfüllt.

- Die Individuen richten ihren Periodenkonsum an einem langfristigen Konsumplan aus, der von ihrem durch sie selbst abgeschätzten Lebenseinkommen (einschließlich Wertänderungen) bestimmt wird. Sie versuchen, durch Sparen und Aufnahme von Krediten ihren Konsum zu glätten ${ }^{I}$. Bei dieser Verhaltensweise werden die theoretisch aus dem Begriff der "Leistungsfähigkeit" abgeleiteten Forderungen an ein Steuersystem erfüllt, da sowohl Wertänderungen implizit erfaßt werden als auch aufgrund des geglätteten Konsums ein geglätteter Steuersatz zur Anwendung kommt. Das Problem der Ermittlung eines auf die Lebensperiode des Steuerpflichtigen anzuwendenden Steuersatzes wird dadurch entschärft.

Gegenüber einer Besteuerung nach der Reinvermögenszugangstheorie ergibt sich der praktische Vorteil, das Vermögens nur einmal -nämlich am Lebensende des Individuums- bewerten zu müssen. Hierbei ergeben sich jedoch wieder die bei der Reinvermögenszugangstheorie diskutierten Probleme der Vermögensbewertung.

Durch die Bestimmung der Größen, die in die Konsum-Spar-Entscheidung eingehen, kann auf die Größen geschlossen werden, über die die Individuen nach ihrer eigenen Auffassung die Verfügungsmacht haben und über die sie disponieren können, wie sie also ihre eigene Leistungsfähigkeit einschätzen. Interessant ist hierbei die Frage, welchen Zeithorizont sie ihrer Konsum-Spar-Entscheidung zugrunde legen. Hierdurch können Antworten auf die Frage nach dem "richtigen" Leistungsfähigkeitsbegriff gefunden werden. Fraglich und umstritten ist dabei -wie oben dargelegt- das Zeitintervall, für das die Leistungsfähigkeit zu bestimmen ist sowie die sie bestimmenden ökonomischen Größen. Dies zeigt sich besonders deutlich an dem Streit über die "richtige" Besteuerungsperiode und an der Vielzahl von Einkommensbegriffen.

Der Bezug auf die Selbsteinschätzung der Individuen wird gewählt, um Hinweise zu erhalten, wie ein Steuersystem, das die Individuen nach ihrer Leistungsfähigkeit besteuern will, aus ihrer Sicht aufgebaut sein muß. Damit wird die Forderung von Slitor "Ability to pay should be measured by the income con-

Dahinter steht der Gedanke, daß die Individuen eine gleichmäßige Konsumhöhe im Zeitablauf präferieren. 
cept on which individuals generally base their behavior." 1 erfüllt. Sollten die theoretischen und systematischen Überlegungen des 1 . und 2. Teils bestätigt werden, ist dies auch für die Beantwortung politisch und wissenschaftlich umstrittener Fragen, wie z.B. der Einbezug von Wertänderungen und Erbschaften in die steuerliche Bemessungsgrundlage, von Bedeutung. Die theoretisch gewonnenen Ergebnisse können dann nach dem in den westlichen Gesellschaften vorherrschenden Bild vom eigenverantwortlichen und souveränen Menschen nicht einfach übergangen werden, da die Steuerpflichtigen selbst bei der Einschätzung ihrer eigenen Leistungsfähigkeit diese Größen einbeziehen. Um jedoch eine Verschleierung der individuellen Leistungsfähigkeit zu vermeiden, ist eine Größe zu wählen, die einem wichtigen Ziel des individuellen Handelns entspricht und die Leistungsfähigkeit widerspiegelt. Die Befragung der Steuerpflichtigen wird nicht zu den gewünschten Ergebnissen führen, da die Antworten und das tatsächliche Handeln bzw. die tatsächliche Leistungsfähigkeit differieren werden. Daher wird auf das durch Konsumausgaben dokumentierte Verhalten abgestellt. Dies beruht auf der Vermutung, daß die Individuen bei ihrer Konsumentscheidung die eigene Leistungsfähigkeit berücksichtigen. Der Konsum -so der Gedanke- bringt den Individuen Nutzen und diesen wird niemand verringern, nur um seine Leistungsfähigkeit zu verschleiern.

Es ist deshalb nach einem Modell zu suchen, das die Konsum-Spar-Entscheidung erklärt. Hierzu wird -da damit andere Konzepte obsolet werden- der aufgrund theoretischer Überlegungen für die Besteuerung ideale Fall untersucht, da $ß$ die Individuen ihren Konsum tatsächlich an ihrer individuellen Leistungsfähigkeit über das Leben hinweg ausrichten. Dies wird anhand der von Modigliani/Brumberg ${ }^{2}$ entwickelten Lebenszyklushypothese durchgeführt ${ }^{3}$.

Die Lebenszyklushypothese geht davon aus, daß die Individuen einen größtmöglichen Lebensnutzen erzielen wollen und deshalb einen langfristigen Konsumplan aufstellen. Die Theorie versucht, die Konsum-Spar-Entscheidung der Individuen $\mathrm{zu}$ beschreiben und deren Ursachen zu erklären. Sie trifft sowohl Aussagen über die Größen, die in die Entscheidung eingehen, als auch über den Zeitraum, den die Individuen bei ihrer Konsum-Spar-Entscheidung als entscheidungsrelevant ansehen. Sie beschreibt somit, wie die Individuen ihre Verfügungsmacht über die Ressourcen der Wirtschaft -also ihre eigene Leistungsfähigkeit- selbst einschätzen. Aus diesem Grunde können ihre -durch empirische

Vgl. Slitor, R.E. (1946), S. 268.

2 Vgl. Modigliani, F./Brumberg, R. (1954).

3 Eine andere -zwar im Detail differierende aber sonst ähnliche- Erklärung ist die "Permanente Einkommenshypothese" von Friedman, M. (1957) (vgl. Dornbusch, R./Fischer, S. (1989), S. 250, 261, 267). 
Untersuchungen untermauerten- Implikationen auch zu Aussagen über Anforderungen an ein nach dem Leistungsfähigkeitsprinzip ausgestalteten Steuersystem genutzt werden.

Dazu wird zuerst die Lebenszyklushypothese dargestellt. In einem zweiten Schritt werden Ergebnisse von verschiedenen empirischen Untersuchungen diskutiert. Danach wird untersucht, ob und gegebenenfalls wie aus den Aussagen der Lebenszyklushypothese Schlüsse für die Besteuerung gezogen werden können. 


\section{Kapitel}

\section{Bestimmungsgrößen der individuellen Konsum- entscheidung}

\section{Theoretische Grundlagen der Lebenszyklushypothese}

\subsection{Allgemeine Darstellung ${ }^{1}$}

Die Lebenszyklushypothese geht davon aus, daß das Individuum sein Konsumund Sparverhalten über seine (angenommene) Lebensdauer plant und versucht, seinen auf Konsumausgaben beruhenden Nutzen während seines Lebens zu maximieren. Sie versucht zu erklären, wie das Individuum seinen Konsumplan gestaltet und wie es die Konsum-Spar-Entscheidung in den einzelnen Perioden trifft. Die bestimmenden Größen dieses Plans sind die individuellen Präferenzen sowie das (geplante) Budget.

Im Modell wird angenommen, das Individuum zieht Nutzen nur aus seinem gegenwärtigen und zukünftigen Konsum sowie aus der Höhe des Vermögens, das es an seine Nachkommen vererbt ${ }^{2}$. Der Konsum des Individuums wird im Modell durch die Ausgaben für kurzlebige Konsumgüter und Dienstleistungen sowie den Wertverlust langlebiger Konsumgüter abgebildet.

Die Nutzenfunktion des Individuums wird definiert als ${ }^{3}$

$1 \quad$ Vgl. Modigliani, F./Brumberg, R. (1954).

2 Das Wissen des Erblassers um die Vererbung stiftet ihm somit Nutzen.

3 Definition der im Modell verwandten Variablen:

t : bezeichnet die Zeit, die seit Beginn des ökonomisch relevanten Zeitraums $(\mathrm{L})$ vergangen ist

$c_{t} \quad$ : individueller Konsum während der Periode $t$

$y_{t}$ : Einkommen (ohne Zinseinkünfte) während der Periode $t$ ( $y_{k}$ und $c_{k}$ mit $k>t$ stellt das erwartete Einkommen bzw. den geplanten Konsum des k-ten Jahres dar).

$\mathrm{s}_{\mathrm{t}} \quad$ : Ersparnis der Periode $\mathrm{t}$

$\mathrm{v}_{\mathrm{t}}$ : Vermögen zu Beginn der Periode $\mathrm{t}$

$\mathrm{r} \quad$ : Zinssatz

$\mathrm{N}$ : Erwerbstätigkeitszeitraum

M : Zeitspanne der Pension

L : Lebensspanne $(\mathrm{L}=\mathrm{N}+\mathrm{M})$

- : bezeichnet das Maximum der betreffenden Variablen. 


$$
\mathrm{U}=\mathrm{U}\left(\mathrm{c}_{\mathrm{t}}, \mathrm{c}_{\mathrm{t}+1}, \ldots, \mathrm{c}_{\mathrm{L}}, \mathrm{v}_{\mathrm{L}+1}\right)
$$

Diese Funktion muß unter der Budgetbeschränkung (der Zinssatz r wird über die Zeit hinweg als konstant angenommen) maximiert werden.

Die Budgetbeschränkung kann wie folgt ausgedrückt werden:

$$
\text { [2] } v_{t}+\sum_{k=1}^{N} \frac{y_{k}}{(1+r)^{k+1-t}}=\frac{v_{L+1}}{(1+r)^{L+1-t}}+\sum_{k=1}^{N} \frac{c_{k}}{(1+r)^{k+1-t}}
$$

Um die Nutzenfunktion [1] zu maximieren, müssen die Werte für $c_{k}$ und $v_{L+1}$ folgende Bedingungen der ersten Ordnung erfüllen:

$$
\frac{\partial \mathrm{U}}{\partial c_{\mathrm{k}}}=\frac{\lambda}{(1+\mathrm{r})^{\mathrm{k}+1-\mathrm{t}}} ; \mathrm{k}=\mathrm{t}, \mathrm{t}+1, \ldots, \mathrm{L}
$$

$$
\frac{\partial U}{\partial v_{L+1}}=\frac{\lambda}{(1+r)^{L+1-t}}
$$

wobei $\lambda$ einen Lagrange-Multiplikator abbildet. Aus den Gleichungen [2] und [3] ergeben sich L-t+3 Gleichungen, aus denen sich die (L-t+1) $\overline{c_{k}}$ 's (= optimaler Periodenkonsum), $\bar{v}_{L+1}$ sowie $\bar{\lambda}$ bestimmen lassen.

Falls das laufende Einkommen $y_{t}+r * v_{t}$ nicht gleich $c_{t}$ ist, spart oder entspart das Individuum. Das gilt auch, sofern $y+r * v_{k}$ nicht $\overline{c_{k}}$ entspricht, so daß das Individuum plant, im Alter $\mathrm{k}$ zu sparen oder zu entsparen (sparen bzw. entsparen wird hier definiert als die positive oder negative Änderung im Vermögen während einer bestimmten Zeit). Dies gilt insbesondere angesichts der Modellannahme, daß das Individuum im Alter kein Arbeitseinkommen mehr bezieht und deshalb Vorsorge betreiben muß. Diese Vorsorge kann auch im Erwerb von Ansprüchen gegen eine Rentenversicherung bestehen. Das Individuum spart also, um seinen optimalen Konsumplan (einschließlich des Vererbungsziels) verwirklichen zu können. In einer Welt mit Unsicherheit wird überdies gespart, um eine Reserve für Notfälle (z.B. außergewöhnlich hohe Ausgaben wegen Krankheit) zu bilden.

Nachstehend werden verschiedene Annahmen getroffen, um einige Beziehungen zwischen Sparen, Einkommen und anderen Variablen zu erhalten. Sie dienen -mit Ausnahme der Annahme II- der Vereinfachung und könnten entfallen. 


\section{Annahme I:}

Es wird weder etwas geerbt, noch etwas vererbt, also $v_{1}=0$ und $\overline{v_{L+1}}=0$. Damit kann das Individuum Vermögen nur durch eigenes Sparen bilden.

Der laufende und der geplante Konsum sind daher vom Periodeneinkommen, dem erwarteten (diskontierten) Zukunftseinkommen sowie dem zu Beginn der Periode vorhandenen Vermögen abhängig. Es gilt also:

$$
\overline{c_{k}}=f\left(w_{t}, t, k\right), \quad k=t, t+1, \ldots, L
$$

mit $\quad w_{t}=\sum_{k=t}^{N} \frac{y_{k}}{(1+r)^{k+1-t}}+v_{t}$.

Annahme II:

Die Nutzenfunktion hat die Eigenschaft, daß der proportionale Anteil seiner Gesamtressourcen, den ein Individuum in einem beliebigen Jahr $\mathrm{k}$ seines verbleibenden Lebens zu konsumieren plant, nur von seinen Präferenzen und nicht von der Höhe seiner Ressourcen abhängig ist.

Dies kann ausgedrückt werden als

$$
\overline{c_{k}}=a_{k}^{t} * w_{t}, \quad \text { mit } k=t, t+1, \ldots, L,
$$

wobei für ein gegebenes $t$ und $k$ die Größe von $a^{t}{ }_{k}$ von der spezifischen Form der Nutzenfunktion $U$ und dem Zinssatz $r$, aber nicht von den Gesamtressourcen $\mathrm{w}_{\mathrm{t}}$ abhängt.

Diese Annahme ist erfüllt bei einer in $c_{t}, c_{t-1}, \ldots, c_{L}$ homogenen Nutzenfunktion (eines beliebigen positiven Grades). Unerwartete Zuflüsse werden nicht in irgendeiner Periode als Ganzes verbraucht, sondern über die noch verbleibende Lebensdauer des Individuums verteilt.

Annahme III:

Der Zinssatz ist Null, also $\mathrm{r}=0$. 
Daraus folgt für die Gesamtressourcen $w_{t}$ eines Individuums, daß der bisherige Ausdruck

$$
w_{t}=\sum_{k=t}^{N} \frac{y_{k}}{(1+r)^{k+1-t}}+v_{t}
$$

vereinfacht wird zu

$$
w_{t}=y_{t}+(N-t) * y_{t}^{e}+v_{t},
$$

wobei $\mathrm{y}_{\mathrm{t}}^{\mathrm{e}}=\stackrel{\mathrm{N}}{\left(\Sigma \mathrm{y}_{\mathrm{k}}\right)} * \frac{1}{\mathrm{~N}-\mathrm{t}}$

$$
k=t+1
$$

den Durchschnitt des erwarteten Einkommens über die Erwerbszeit darstellt ${ }^{l}$.

Die Gleichung [4] reduziert sich deshalb auf

[4'] $\overline{c_{k}}=a_{k}^{t} *\left\{y_{t}+(N-t) * y_{t}^{e}+v_{t}\right\}$.

Für den Lebenskonsum des Individuums ergibt sich

$$
\sum_{\mathrm{k}=\mathrm{t}}^{\mathrm{L}} \overline{\mathrm{c}_{\mathrm{k}}}=\left\{\mathrm{y}_{\mathrm{t}}+(\mathrm{N}-\mathrm{t}) * \mathrm{y}_{\mathrm{t}}^{\mathrm{e}}+\mathrm{v}_{\mathrm{t}}\right\} * \sum_{\mathrm{k}=\mathrm{t}}^{\mathrm{L}} \mathrm{a}_{\mathrm{k}}^{\mathrm{t}} \text {. }
$$

Wird hierbei Annahme I -es wird nichts vererbt $\left(\overline{v_{L+1}}=0\right.$; der Lebenskonsum des Individuums entspricht seinem Einkommen)- berücksichtigt, ergibt sich

$$
\text { [5] } \sum_{\mathrm{k}=\mathrm{t}}^{\mathrm{L}} \overline{\mathrm{c}_{\mathrm{k}}}=\mathrm{y}_{\mathrm{t}}+(\mathrm{N}-\mathrm{t}) * \mathrm{y}_{\mathrm{t}}^{\mathrm{e}}+\mathrm{v}_{\mathrm{t}} \text {. }
$$

Dieses Einkommen entspricht dem permanenten Einkommen (= langfristig erzielbares durchschnittliches Einkommen) der permanenten Einkommenshypothese, nach der sich sich das Einkommen aus einem permanenten und einem transitorischen Bestandteil zusammensetzt (vgl. hierzu Friedman, M. (1957)). 
Aus [4'] und [5] folgt

[6] $\sum_{\mathrm{k}=\mathrm{t}}^{\mathrm{L}} \mathrm{a}_{\mathrm{k}}^{\mathrm{t}}=1$.

Annahme IV:

Alle $\mathrm{a}_{\mathrm{k}}^{\mathrm{t}}$ sind gleich, d.h. das betrachtete Individuum plant einen gleichmäßigen Konsum. Diese Annahme kann mit dem Konzept des fallenden Grenznutzens des Konsums begründet werden ${ }^{1}$ und deckt sich mit der empirischen Beobachtung, nach der die meisten Individuen einen "gleichmäßigen" Lebensstil wählen und nicht in einem Jahr übermäßig sparen, um sich dann in der nächsten Periode einen übermäßigen Konsum erlauben zu können.

Wird $a_{t}$ als der Wert von $a_{k}^{t}$ eines Individuums im (ökonomischen) Alter $t$ bezeichnet, ergibt sich aus [6] mit der Verwendung der Annahme IV

L

[7]

$\sum a_{k}^{t}=(L+1-t) a_{t}=1$

$\mathrm{k}=\mathrm{t}$

oder

$$
a_{k}^{t}=a_{t}=\frac{1}{L+1-t}=\frac{1}{L_{t}},
$$

wobei $\mathrm{L}_{\mathrm{t}}=\mathrm{L}+1-\mathrm{t}$ die verbleibende Lebensspanne im (ökonomischen) Alter $\mathrm{t}$ bezeichnet.

Wird in [4'] für $\mathrm{a}_{k}{ }_{k}$ der sich aus [7] ergebende Wert eingesetzt, folgt daraus die individuelle Funktion für den gegenwärtigen Konsum:

1 Es sollen zwei alternative Konsumpläne für zwei Perioden betrachtet werden; der erste sieht einen gleichmäßigen Konsum in beiden Perioden vor, während der zweite den gesamten Konsum in einer und keinen Konsum in der anderen Periode vorsieht. Aufgrund des fallenden Grenznutzens des Konsums kann sich das Individuum im zweiten Fall besser stellen, wenn es Teile seines Konsums in die Periode transferiert, in der nach dem ursprünglichen Plan nichts konsumiert wird, da aufgrund des fallenden Grenznutzens die Nutzeneinbuße durch den Konsumverzicht geringer ist als der Nutzengewinn durch den zusätzlichen Konsum in der anderen Periode (vgl. hierzu auch die Begründung für die Annahme eines fallenden Grenznutzens bei der philosophischen Begründung des Leistungsfähigkeitsprinzips). 
[8] $\quad c=c\left(y, y^{e}, v, t\right)=\frac{1}{L_{t}} * y+\frac{N-t}{L_{t}} * y^{e}+\frac{1}{L_{t}} * v$,

wobei die nicht mit einem Datumsindex versehenen Variablen die laufende Periode betreffen.

Das Individuum macht seine Abschätzungen für den Konsum der Folgeperiode $\mathrm{t}$ mit dem ihm zur Verfügung stehenden Wissen der laufenden Periode t-1. Für den Konsum der Folgeperiode ergibt sich dann als Abschätzung:

$$
(\mathrm{t}-1) \mathrm{c}_{\mathrm{t}}=\frac{1}{\mathrm{~L}_{\mathrm{t}}} *(\mathrm{t}-1) \mathrm{y}+\frac{\mathrm{N}-\mathrm{t}}{\mathrm{L}_{\mathrm{t}}} *(\mathrm{t}-1) \mathrm{y}^{\mathrm{e}}+\frac{1}{\mathrm{~L}_{\mathrm{t}}} *(\mathrm{t}-1) \mathrm{v}_{\mathrm{t}}
$$

Aus der Definition des Modells folgt, daß das Individuum zum Zeitpunkt t-1 keine Änderung seines Konsums (da es ihn als konstanten Strom über seinen Planungshorizont hinweg betrachtet) annimmt. Es gilt somit

[8b] $\quad(\mathrm{t}-1) \mathrm{c}_{\mathrm{t}}=\mathrm{c}_{(\mathrm{t}-1)}$.

Um die Abweichung zwischen dem tatsächlichen Konsum in der laufenden Periode und dem für die laufende in der vorherigen Periode geplanten Konsum abzuschätzen, wird [8b] in [8a] eingesetzt und von [8a] subtrahiert. Es ergibt sich

$$
c_{t}-c_{(t-1)}=\frac{1}{L_{t}} *[y-(t-1) y]+\frac{1}{L_{t}} *\left[v_{t}-(t-1) v_{t}\right]+\frac{N-t}{L_{t}} *\left[y^{e}-(t-1) y^{e}\right]=u_{t}
$$

Jeder Term auf der rechten Seite der Gleichung ist ein Fehler, der ausschließlich auf das Fehlen der vollkommenen Voraussicht zurückzuführen ist. Die beiden ersten Terme bilden z.B. die Differenz zwischen den tatsächlichen Größen und den dafür eine Periode früher erwarteten Werte ab. Der letzte Term ist die aufgrund neuer Informationen durchgeführte Korrektur der Erwartungen über das zukünftige Einkommen. $u_{t}$ ist hierbei eine Zufallsvariable, die den Fehler der früheren Abschätzung des Konsums angibt; $u_{t}$ ist unkorreliert zu den anderen Größen und hat den Wert 0 zum Zeitpunkt $t-1\left(={ }_{(t-1)} u_{t}^{e_{t}}\right)$, da alle anderen Werte implizieren, daß die Erwartungen zum Zeitpunkt t-1 systematisch und bekanntermaßen falsch sind. Daraus folgt

$$
c_{t}=c_{t-1}+u_{t} \quad \operatorname{mit}_{(t-1)} u_{t}^{e}=0 .
$$


Das Individuum nimmt keine Veränderung seines Konsums an. Ändern sich die Erwartungen, beeinflußt dies auch den Konsum. Liegen rationale Erwartungen des Individuums vor, kann eine Änderung des Konsums nicht eine Periode zuvor vorausgesagt werden.

Die beste Voraussage über das Konsumniveau der Folgeperiode stellt somit das der laufenden Periode dar, da dieses auf den zuletzt getroffenen Einschätzungen des Individuums beruht und alle momentan zur Verfügung stehenden Informationen -z.B. auch Erwartungen hinsichtlich des Zukunftseinkommens oder der Politik- enthält. Das laufende Einkommen oder das der Vergangenheit bzw. das momentane Vermögen hat keine zusätzliche Vorhersagekraft für den zukünftigen Konsum, da diese Größen bereits in der Selbstabschätzung des Individuums enthalten sind. Nach der Lebenszyklushypothese hat das laufende Einkommen somit nicht den bestimmenden Einfluß auf den Periodenkonsum wie in einem keynesianischen Modell.

Zu [8] korrespondiert die Sparfunktion

[9] $\mathrm{s}=\mathrm{y}-\mathrm{c}=\frac{\mathrm{L}-\mathrm{t}}{\mathrm{L}_{\mathrm{t}}} * \mathrm{y}-\frac{\mathrm{N}-\mathrm{t}}{\mathrm{L}_{\mathrm{t}}} * \mathrm{y}^{\mathrm{e}}-\frac{1}{\mathrm{~L}_{\mathrm{t}}} * \mathrm{v}$.

Das Individuum spart, wenn es ein höheres Periodeneinkommen erzielt als es für den geplanten (Perioden-) Konsum aufwenden muß. Im umgekehrten Fall wird entspart. Wird davon ausgegangen, da $\beta$ junge Menschen mit zunehmendem Alter ein höheres Einkommen erwarten, wird in jungen Jahren ein geringerer Teil des Einkommens gespart bzw. Kredite aufgenommen, die später -bei höherem Einkommen- wieder zurückgezahlt werden. Weiterhin sparen die erwerbstätigen Menschen für ihre Altersversorgung.

\subsection{Reaktion des Individuums auf Einkommensänderungen}

Nachfolgend wird die Veränderung des Konsums bei einer unerwarteten transitorischen Einkommensänderung untersucht. Erwartete Einkommensänderungen sind nicht gesondert zu untersuchen, da sie bereits vom Individuum antizipiert und in die Selbsteinschätzung der Leistungsfähigkeit und damit in den Konsumplan einbezogen sind. 
Um die Reaktion des Konsums auf eine Einkommensänderung analysieren zu können, wird die erste Ableitung der Konsumfunktion [8] nach dem Periodeneinkommen y gebildet.

[10] $\frac{\mathrm{dc}}{\mathrm{dy}}=\frac{1}{\mathrm{~L}_{\mathrm{t}}}<1$.

Der Mehrkonsum ist somit unabhängig von der Höhe des zusätzlichen Periodeneinkommens, hängt jedoch vom Alter bzw. der noch verbleibenden Lebensdauer ab. Je höher das Lebensalter, desto höher ist der vom Zusatzeinkommen konsumierte Teil. Wird zur Kontrolle die Sparfunktion [9] nach dem zusätzlichen Einkommen abgeleitet, ergibt sich

[11] $\frac{\mathrm{ds}}{\mathrm{dy}}=\frac{\mathrm{L}-\mathrm{t}}{\mathrm{L}_{\mathrm{t}}}=\frac{\mathrm{L}-\mathrm{t}}{\mathrm{L}+1-\mathrm{t}^{\prime}}$

d.h. je höher das Alter, umso weniger wird vom zusätzlichen Einkommen gespart, was konsistent mit [10] ist.

Es wird jetzt angenommen, ein Teil der Veränderung des gegenwärtigen Periodeneinkommens ist permanent. Dieser Teil geht in die Erwartungen des Individuums hinsichtlich seines zukünftigen Periodeneinkommens $\mathrm{y}^{\mathrm{e}}$ ein; $\mathrm{y}^{\mathrm{e}}$ ist hier eine Funktion des gegenwärtigen Einkommens y. dy $/$ dy liegt im allgemeinen zwischen 0 und 1, d.h. ein Teil der unerwarteten Einkommensänderung ist dauerhaft. Das zu Beginn der Periode vorhandene Vermögen v wird durch die Einkommensänderung nicht berührt.

Für die Ableitung des Konsums c ([8]) nach y folgt dann

$$
\frac{\mathrm{dc}}{\mathrm{dy}}=\frac{1}{\mathrm{~L}_{\mathrm{t}}}+\left(\frac{\mathrm{N}-\mathrm{t}}{\mathrm{L}_{\mathrm{t}}} * \frac{\mathrm{dy}}{\mathrm{dy}}\right)<1
$$

Der Konsum verändert sich hier stärker als bei einer nur transitorischen Einkommensänderung. Das liegt daran, daß das Individuum seine Erwartungen bezüglich seines zukünftig höheren (laufenden) Einkommens ebenfalls in die Bestimmung seines Konsumplans einbezieht. Der Konsum ändert sich aber nicht in Höhe der gesamten Einkommensänderung, wenn $\mathrm{dy} / \mathrm{dy}$ zwischen 0 und 1 liegt ${ }^{l}$.

$$
\begin{array}{ll}
1 \quad \frac{1}{\mathrm{~L}_{\mathrm{t}}}+\frac{\mathrm{N}-\mathrm{t}}{\mathrm{L}_{\mathrm{t}}} * \frac{d \mathrm{dy}^{\mathrm{e}}}{\mathrm{dy}}<1 \\
<=>(\mathrm{N}-\mathrm{t}) * \frac{d y^{\mathrm{e}}}{\mathrm{dy}}<\mathrm{N}-\mathrm{t}+\mathrm{M}
\end{array}
$$


Zum Verständnis dieses Verhaltens wird das Vermögen des Individuums in die Betrachtung einbezogen.

Zuerst wird unterstellt, das Individuum erwarte beim Eintritt in die Erwerbsphase für die Zukunft ein konstantes Einkommen y $\left(y_{t}=y^{e}\right)$ und diese Erwartungen werden auch in jedem Zeitpunkt seines Lebens erfüllt (stationärer Zustand).

Daraus ergibt sich folgender Sparplan

$$
s_{k}= \begin{cases}\frac{M}{L} * y & \text { für } k=1,2, \ldots, N \\ -\frac{N}{L} * y & \text { für } k=N+1, N+2, \ldots, L\end{cases}
$$

und folgendes Vermögen zum Zeitpunkt t:

[14] $\mathrm{v}_{\mathrm{t}}(\mathrm{y}, \mathrm{t})= \begin{cases}(\mathrm{t}-1) * \frac{\mathrm{M}}{\mathrm{L}} * \mathrm{y} & \text { für } \mathrm{t}=1,2, \ldots, \mathrm{N} \\ \frac{\mathrm{N} *(\mathrm{~L}+1-\mathrm{t})}{\mathrm{L}} * \mathrm{y} & \text { für } \mathrm{t}=\mathrm{N}+1, \mathrm{~N}+2, \ldots, \mathrm{L}\end{cases}$

Im nächsten Schritt wird diese Annahme aufgegeben und unerwartete Einkommensänderungen zugelassen. Hierzu wird in der Sparfunktion [9] bzw. der Konsumfunktion [8] die Definition des Vermögens $v_{t}$ aus [14] verwendet. Für die Ersparnis und den Konsum ergeben sich dann folgende Beziehungen

$$
\mathrm{s}=\frac{\mathrm{M}}{\mathrm{L}} * \mathrm{y}^{\mathrm{e}}+\frac{\mathrm{L}-\mathrm{t}}{\mathrm{L}_{\mathrm{t}}} *\left(\mathrm{y}-\mathrm{y}^{\mathrm{e}}\right)-\frac{1}{\mathrm{~L}_{\mathrm{t}}} *\left[\mathrm{v}-\mathrm{v}\left(\mathrm{y}^{\mathrm{e}}, \mathrm{t}\right)\right]
$$

$$
\mathrm{c}=\frac{\mathrm{N}}{\mathrm{L}} * \mathrm{y}^{\mathrm{e}}+\frac{1}{\mathrm{~L}_{\mathrm{t}}} *\left(\mathrm{y}-\mathrm{y}^{\mathrm{e}}\right)+\frac{1}{\mathrm{~L}_{\mathrm{t}}} *\left[\mathrm{v}-\mathrm{v}\left(\mathrm{y}^{\mathrm{e}}, \mathrm{t}\right)\right]
$$

wobei $\left[y-y^{e}\right]$ die gegenwärtige Abweichung des laufenden Einkommens vom durchschnittlich erwarteten Einkommen während der Erwerbsphase (= transitorische Einkommenskomponente) bzw. [ $\left.\mathrm{v}-\mathrm{v}\left(\mathrm{y}^{\mathrm{e}}, \mathrm{t}\right)\right]$ die Abweichung des momentanen tatsächlichen Vermögens vom Vermögen mit einer vollständigen Anpassung an $\mathrm{y}^{\mathrm{e}}$ abbildet.

Diese Beziehung ist immer erfüllt, wenn $\frac{d y^{e}}{d y}<1$, was annahmegemäß der Fall ist. 
Das Individuum spart/konsumiert also

- einen -vom Alter und der Höhe des Einkommens unabhängigen- Teil des erwarteten Einkommens; einen Teil des transitorischen Einkommens, der unabhängig von der Höhe des Einkommens, aber abhängig vom Alter ist

sowie

- einen -vom Alter abhängigen- Teil des vom Idealfall abweichenden Vermögens.

Ist z.B. die gesamte Einkommensänderung nur transitorisch, entspricht $\mathrm{v}_{\mathrm{t}}=\mathrm{v}\left(\mathrm{y}^{\mathrm{e}}, \mathrm{t}\right)$, d.h. der letzte Term ist gleich Null ${ }^{l}$. Die Spartätigkeit bzw. der Konsum aufgrund der transitorischen Einkommensänderung wird dann lediglich durch den zweiten Term beeinflußt. Von der transitorischen Einkommensänderung wird dabei umso weniger gespart (also umso mehr konsumiert), je älter das Individuum ist.

Ist die unerwartete Erhöhung des Einkommens hingegen permanent, ist das am Periodenanfang vorhandene Vermögen $\mathrm{v}$, das auf das bisherige durchschnittlich erwartete Einkommen $y^{\mathrm{e}}$ zugeschnitten war, aufgrund der erwarteten permanenten Einkommensänderung zur Nutzenoptimierung zu gering, um auch im Alter den optimalen Konsumplan verwirklichen zu können. Das Individuum spart daher mehr als vorher.

Das Modell impliziert somit, daß ein Individuum, dessen Einkommen sich unerwartet ändert, einen höheren Anteil seines Einkommens spart als zuvor. Weiterhin spart es bei einer dauernden Erhöhung des Einkommens einen höheren Anteil als diejenigen Individuen, die schon zuvor ein höheres durchschnittliches Einkommen erwarten ${ }^{2}$.

\section{Empirische Untersuchungen der Lebenszyklushypothese}

In diesem Abschnitt wird auf einige empirische Untersuchungen der Aussagen der Lebenszyklushypothese eingegangen und geprüft, ob ihre Aussagen durch die Realität verworfen oder unterstrichen werden. Es können Schlüsse gezogen werden, inwiefern sich die Individuen in der Realität als vorausschauende, nut-

1 Das zu Beginn der Periode vorhandene Vermögen entspricht dem Vermögen, das aufgrund des erwarteten Einkommens vorhanden ist. Die Erhöhung der Ersparnis in der Periode resultiert aus dem zweiten Term.

2 Bei diesen Individuen ist der letzte Term in Gleichung [15] 0, da sie bei ihrer bisherigen Konsumplanung schon von diesem durchschnittlich erwarteten Einkommen ausgingen. 
zenmaximierende und rationale Subjekte verhalten. Ebenso ergeben sich Aussagen darüber, welchen Größen die Individuen zur Abschätzung ihrer eigenen Leistungsfähigkeit einen Einfluß zubilligen. Die Ansatzpunkte der Untersuchungen sind die verschiedenen Aussagen der Lebenszyklushypothese, wie

- die beste Voraussage für die Höhe des gegenwärtigen Konsums ist der Konsum der Vorperiode

- die Sensitivität des Konsums auf Einkommensänderungen

- die Alter-Vermögens-Relation

- die gesamtwirtschaftliche Akkumulation der Ersparnisse.

\subsection{Vorhersagekraft des Konsums}

Dieser Test untersucht die Aussage der Lebenszyklushypothese, nach der lediglich der Konsum der vergangenen Periode Auskunft über die Höhe des Konsums der laufenden Periode gibt, da das Individuum aufgrund seines vorausschauenden und intelligenten Verhaltens in diesem alle ihm zur Verfügung stehenden Informationen hinsichtlich seiner Zukunft berücksichtigt hat. Der Konsum früherer Perioden, das Einkommen und das Vermögen besitzen dann bezüglich der Höhe des gegenwärtigen Konsums keinen weiteren Erklärungscharakter.

Hall $^{l}$ testet die Aussagen der Lebenszyklushypothese anhand quartalsweise aggregierter Daten des U.S. National Income and Product accounts über den Konsum von kurzlebigen Konsumgütern und Dienstleistungen und des disponiblen Einkommens. Zur Abbildung von Vermögenseinflüssen werden die -im Gegensatz zum Wert der meisten anderen Vermögensgegenstände- zu jeder Zeit verfügbaren Marktwerte von Aktien verwendet ${ }^{2}$.

Er kommt dabei zu dem Ergebnis, daß im wesentlichen nur der Konsum der vorausgegangenen Periode zur Abschätzung des gegenwärtigen Konsums dient, während der Konsum der vorausgegangenen 2-4 Perioden keinen signifikanten Einfluß hat: er hilft lediglich die Genauigkeit der Voraussage für den gegenwärtigen Konsum um ca. $10 \%$ pro Person und Jahr zu verbessern.

1 Vgl. Hall, R.E. (1978).

2 Der Test erfordert keinen umfassenden Vermögensbegriff, so daB ein auf den Aktienpreisen basierender Test ausreichend ist; dies gilt insbesondere, wenn in der gewünschten Gleichung lediglich die strukturelle Beziehung zwischen Vermögen und Konsum beschrieben werden soll. 
Weiterhin prüft Hall, ob der Konsum aus dem disponiblen Einkommen vorhergesagt werden kann. Der Einbezug des Einkommens der Vorperiode besitzt -so sein Ergebnis- praktisch keine Voraussagekraft für den gegenwärtigen Konsum. Der Einbezug des Einkommens der vier Vorperioden bringt wiederum keine wesentliche Verbesserung der Voraussagequalität. Das gleiche gilt auch für das Einkommen der vergangenen 12 Perioden.

Zusammenfassend kann gesagt werden: es besteht eine statistisch marginale und wertmäßig geringe Relation zwischen dem gegenwärtigen Konsum und den Einkommen der Vorperioden. Dieses Ergebnis wirft allerdings keinen großen Zweifel auf die Lebenszyklushypothese.

Hall testet ferner, ob die Höhe des Vermögens -abgebildet durch einen Aktienindex- die Höhe des Konsums beeinflußt.

Er kommt zum Ergebnis, daß der Einbezug des Vermögens in Form des Aktienindexes eine statistisch signifikante, quantitativ aber zu vernachlässigende Ergänzung bei der Voraussage des gegenwärtigen Konsums ist. Den größten Teil der Voraussagekraft hat dabei die Änderung des Aktienindexes der Vorperiode.

Die reine Aussage der Lebenszyklushypothese -der gegenwärtige Konsum $\left(c_{t}\right)$ kann nicht durch andere Variablen als dem Konsum der Vorperiode $\left(\mathrm{c}_{\mathrm{t}-1}\right)$ vorausgesagt werden- hat Hall widerlegt; es ergeben sich bessere Voraussagen bei Einbezug eines Aktienindexes als Indikator des Vermögens. Dieses Ergebnis ist nach Hall vereinbar mit einer Modifikation der Lebenszyklushypothese, die aber deren Kernaussagen unberührt läßt: der Konsum ist vom permanenten Einkommen $^{l}$ abhängig; ein Teil des Konsums braucht jedoch eine kurze Zeit, um sich Änderungen im nicht-beobachtbaren permanenten Einkommen anzupassen. Somit hilft jede Variable (also auch Vermögenswertänderungen), die in der Vergangenheit mit dem permanenten Einkommen korreliert ist, den gegenwärtigen Konsum abzuschätzen, da ein Teil der Konsumänderung die verzögerte Antwort auf die vorausgegangene Änderung im permanenten Einkommen ist.

\subsection{Alter-Vermögens-Relation}

Nach der Lebenszyklushypothese ist das Individuum bestrebt, über seine Lebensdauer hinweg ein möglichst gleichmäßiges Konsumniveau zu verwirklichen. Das Individuum spart deshalb in Zeiten mit hohem laufenden Einkommen, in Zeiten mit geringerem Einkommen zehrt es von seinen Ersparnisse bzw. nimmt Kredite auf.

$1=$ langfristig erzielbares durchschnittliches Einkommen (vgl. hierzu Friedman, M. (1957)). 
In der Realität ist ein typischer Verlauf des Periodeneinkommens festzustellen: während der Ausbildung verdient das Individuum wenig; nach Abschluß der Ausbildung ist ein Ansteigen des Einkommens zu beobachten, das längstens bis zur Pensionierung anhält.

Aufgrund dieses Einkommensverlaufs müßte das Individuum nach den Implikationen der Lebenszyklushypothese in frühen Jahren wenig sparen oder Kredite aufnehmen, in Zeiten mit höherem Einkommen müßte das Vermögen ansteigen, um dann ab der Pensionierung wieder abzunehmen.

Diese These wurde schon mehrfach empirisch und für verschiedene Länder untersucht. Nachfolgend soll auf einige Studien eingegangen und deren Aussagewert geklärt werden. Hierbei wird zwischen Studien mit Zeitreihen- und Querschnittsdaten unterschieden.

\subsubsection{Untersuchungen mittels Zeitreihendaten}

Diamond/Hausman ${ }^{l}$ testen die Lebenszyklushypothese mit Hilfe des Sparverhaltens der Individuen. Als Datenbasis nutzen sie Zeitreihendaten (zwischen 1966 - 1976) von Männern im Alter (1966) zwischen 45 und 59 Jahren. Im Jahre 1966 haben 7,6\% der Männer in der Stichprobe ein negatives Vermögen; weitere $12,1 \%$ besitzen ein Vermögen zwischen 0 und US-\$1000. Ein beachtlicher Teil der Bevölkerung hat somit mangels Vermögen nicht die Möglichkeit, im Alter dieses Vermögen aufzuzehren. Die Anwendbarkeit der Lebenszyklushypothese auf diesen Teil der Bevölkerung ist deshalb begrenzt. In der durchgeführten Regressionsanalyse werden daher nur diejenigen mit einem Vermögen von mindestens US- $\$ 4000$ im Jahre 1966 berücksichtigt. Als Ergebnis der Regressionsanalyse ist nach der Pensionierung ein Entsparen in Höhe von 5,1\% pro Jahr zu beobachten ${ }^{2,3}$; diese Rate sinkt bei steigenden Renten- bzw. Pensionszahlungen. Überdies läßt eine höhere Altersversorgung und bessere soziale Absicherung die private Ersparnis sinken.

Die Lebenszyklushypothese wird also nicht widerlegt.

1 Diamond, P.A./Hausman, J.A. (1984).

2 Umfang der Stichprobe: 1096 Beobachtungen (Individuen mit einem Vermögen > $\$ 4.000$ ).

3 Diese Raten entsprechen ungefähr den bei einer Simulation von Davies (1980) mit Unsicherheit über den Todeszeitpunkt durchgeführten Simulation. 


\subsubsection{Untersuchungen mittels Querschnittsdaten}

Idealerweise sollten zum Test der Lebenszyklushypothese Zeitreihendaten (dieselben Individuen werden über einen Zeitraum hinweg beobachtet) genutzt werden. Da diese in den meisten Fällen nicht vorliegen, wird auf Querschnittsdaten zurückgegriffen, d.h. Individuen verschiedenen Alters werden zu einem bestimmten Zeitpunkt beobachtet. Mit Hilfe von Annahmen wird aus diesen Daten auf das Verhalten der Individuen zu unterschiedlichen Zeitpunkten ihres Lebens geschlossen. Vor der Darstellung verschiedener Untersuchungen werden systematische Probleme bei der Verwendung von Querschnittsdaten aufgezeigt.

\subsubsection{Systematische Probleme bei der Verwendung von Querschnitts- daten}

\section{a) Berücksichtigung der unterschiedlichen Lebenserwartung}

In der Realität ist ein Zusammenhang zwischen Vermögen und Lebenserwartung festzustellen; beide Größen sind negativ korreliert ${ }^{l}$. Mit zunehmendem Alter nimmt deshalb der Anteil der wohlhabenderen Individuen in der Altersgruppe zu. Die Nichtberücksichtigung dieser Korrelation hat eine Verzerrung des Aussagegehalts der gefundenen Beziehung zur Folge; dies zeigt folgendes Beispiel:

Individuum Vermögen

$\begin{array}{llll} & \mathrm{t}_{1} & \mathrm{t}_{2} & \mathrm{t}_{2} \\ & & \text { Fall I } & \text { Fall II } \\ \text { A } & 10 & 8 & -- \\ \text { B } & 30 & 24 & 24 \\ \text { C } & 60 & 48 & 48 \\ \text { D } & 80 & 64 & 64\end{array}$

$\begin{array}{llcl}\text { Summe } & 180 & 144 & 120 \\ \text { Durchschnittsvermögen } & 45 & 36 & 45,3\end{array}$

Vgl. Shorrocks, A.F. (1975), S. 156. 
$\mathrm{t}_{1}$ soll den Ausgangszeitpunkt der Betrachtung darstellen. A, B, C und D sind Individuen einer Altersklasse mit unterschiedlichen Ersparnissen. Aus Vereinfachungsgründen verbrauchen die Individuen von ihren Ersparnissen 20\% für Konsumzwecke; das Durchschnittsvermögen der Individuen nimmt somit im Fall I ebenfalls um $20 \%$ ab. Im Fall II stirbt A, die anderen Individuen verbrauchen wiederum $20 \%$ ihres Vermögens zu Konsumzwecken. Als Durchschnittsvermögen ergibt sich dann -obwohl die überlebenden Individuen ihre Ersparnisse um 20\% abbauten- ein höherer Wert als zum Ausgangszeitpunkt $t_{1}$. Bei der Interpretation der Daten liegt der Schluß nahe, daß die Ersparnisse weiter ausgebaut werden und das Vermögen mit zunehmendem Alter steigt. Zur richtigen Interpretation der Daten ist es somit notwendig, die Korrelation zwischen Vermögensstand und Lebensdauer einzubeziehen, sowie die geänderte Gruppenzusammensetzung im Zeitablauf aufgrund unterschiedlicher Mortalitätsraten zu berücksichtigen.

\section{b) Berücksichtigung des Kohorteneffekts}

Der nach den Aussagen der Lebenszyklushypothese vermutete Knick im Sparverhalten ist eine Aussage über die Vermögenshaltung eines Individuums oder einer Kohorte über ihre gesamte Lebensdauer. Eine aus Querschnittsdaten -also den Daten verschiedener Altersgruppen zu einem Zeitpunkt- künstlich erzeugte Kohorte muß nicht zwangsläufig ein Abbild der Vermögenshaltung einer Gruppe über ihre Lebensperiode ergeben. Wird von einer wachsenden Wirtschaft mit steigenden Reallöhnen und einer über den Zeitablauf konstanten Sparquote ausgegangen, ist die Höhe der Ersparnis vom Lebensalter und vom Geburtsjahr abhängig. Die Höhe der Ersparnis Gleichaltriger wächst von Generation zu Generation, d.h. die Ersparnis eines $x$-jährigen zum Zeitpunkt $t_{1}$ ist höher als die eines x-jährigen zum Zeitpunkt $t_{0}$. Bei der Analyse ist deshalb bei der Verwendung von Querschnittsdaten zu beachten, daß ohne entsprechende Korrekturen verschiedene Generationen verglichen werden und dadurch das Alter-Vermögen-Profil beeinflußt werden kann.

Dazu kann ein einfaches Beispiel konstruiert werden, das zeigt, daß das Anwachsen und anschließende Sinken der Ersparnis in einem Querschnittsprofil nicht das tatsächliche Alter-Vermögen-Profil eines Individuums zeigt ${ }^{1,2}$. Im Beispiel wird -obwohl ein stetiges Wachstum des individuellen Vermögens model-

$1 \quad$ Vgl. Shorrocks, A.F. (1975), S. 157 f.

2 Eine analytische Darstellung über das Weglassen relevanter Daten bei einer Regression findet sich beispielsweise bei Maddala, G.S. (1988), S. $121 \mathrm{ff}$. 
liert wird- durch die Querschnittsbetrachtung ein zuerst steigender, dann aber fallender Verlauf der Ersparnis in Abhängigkeit zum Lebensalter beobachtet.

Das Vermögen $v$ des einzelnen Individuums ist im Beispiel linear zu seinem Alter h korreliert. Das Geburtsjahr j beeinflußt die Höhe des Vermögens in der Weise, daß die Ersparnis bei einem späteren Geburtsjahr höher ist als im gleichen Alter bei einem früheren Geburtsjahr; $k$ repräsentiert die -aus Vereinfachungsgründen lineare- "Generationen-Wachstumsrate", die den steigenden Wohlstand der Generationen im Zeitablauf abbilden soll. Es wird von einer Vermögensbildung ab dem 25. Lebensjahr ausgegangen.

$$
\mathrm{v}(\mathrm{j}, \mathrm{h})= \begin{cases}0 & \text { für } 0 \leq \mathrm{h} \leq 25 \\ \alpha *(\mathrm{~h}-25) * \mathrm{e}^{\mathrm{kj}} & \text { für } \mathrm{h}>25\end{cases}
$$

Wird aufgrund dieser Funktion das Querschnittsprofil gebildet, zeigt sich folgender funktionaler Zusammenhang:

$$
\begin{aligned}
D(t, h) & =v(t-h, h) \\
& = \begin{cases}0 & \text { für } 0 \leq h<25 \\
\alpha *(h-25) * e^{k(t-h)} & \text { für } h \geq 25\end{cases}
\end{aligned}
$$

Bei der Ableitung der Funktion D nach dem Alter ergibt sich

$$
\frac{\mathrm{dD}(\mathrm{t}, \mathrm{h})}{\mathrm{dh}}=\alpha * \mathrm{e}^{\mathrm{k}(\mathrm{t}-\mathrm{h})} *(1-\mathrm{k} *(\mathrm{~h}-25))
$$

Wird die Wachstumsrate $\mathrm{k}=2,5 \%$ gesetzt, hat die Funktion ihr Maximum bei einem Alter von 65 Jahren. Das Vermögen der Individuen steigt somit bis zu einem Alter von 65 Jahren an und fällt anschließend, wie es nach der Lebenszyklushypothese erwartet wird.

Ohne die Berücksichtigung des Kohorteneffekts ergibt sich -wie die nachfolgende Graphik ${ }^{l}$ zeigt- ein von den tatsächlichen Verhältnissen abweichender Vermögensverlauf: das Vermögen steigt gemäß den hier gemachten Modellannahmen mit steigendem Alter ständig an, während die aus Querschnittsdaten gewonnene Kohorte ab einem bestimmten Alter eine Vermögensabnahme zeigt. Das Vermögen im Alter wird als Folge zu gering geschätzt; deshalb ist allein aufgrund dieses Effekts eine Abnahme des Vermögens im Alter zu beobachten.

\footnotetext{
Vgl. Shorrocks, A.F. (1975), S. 158.
} 


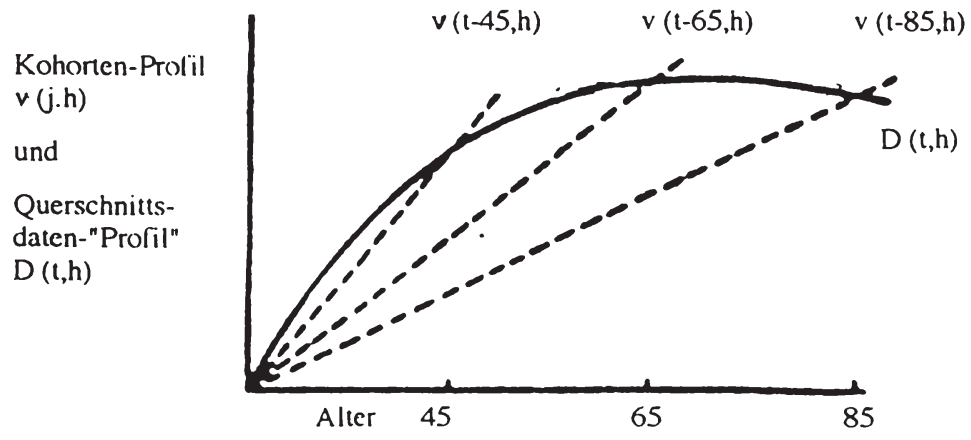

\subsubsection{Empirische Untersuchungen}

Mirer ${ }^{1}$ untersucht die Relation zwischen Lebensalter und Vermögen; er verwendet hierzu Querschnittsdaten des Jahres 1968 von 2.713 Ehepaaren zwischen 65 und 99, darunter einige, die noch Arbeitseinkünfte erzielen ${ }^{2}$. Als Mittelwert des Vermögens (in 1967-US-\$) ergab sich ca. 19 T\$, als Median 12 T\$, das untere und obere Quartil beträgt ca. 4 T\$ und $24 \mathrm{~T} \$$. Nicht im Vermögensbegriff der Untersuchung enthalten sind u.a. Geschäftsanteile, Pensionen, Rentenversicherungen sowie lebenslange Nutzungen. Weiterhin wird die positive Korrelation zwischen Vermögen und Lebenserwartung nicht berücksichtigt. Als Ergebnis erhält Mirer unter Zugrundelegung der nicht um den Kohorten-Effekt korrigierten Daten, daß die Ersparnis leicht fällt; wird der Kohorten-Effekt berücksichtigt, ist mit steigendem Alter eine Zunahme des Vermögens zu beobachten, wobei sich die Alter-Vermögens-Relation sensitiv gegenüber Variationen des Kohorten-Effekts verhält.

Weiterhin untersucht Mirer, inwiefern sich die Relation Hauseigentum ${ }^{3} \mathrm{zu}$ Gesamtvermögen im zunehmendem Lebensalter verändert. Würde entspart werden, müßte mit zunehmendem Alter das Verhältnis Hauseigentum/Gesamtvermögen

1 Vgl. Mirer, T.W. (1979).

2 Die ursprüngliche Stichprobe umfaßte 8.248 alte Ehepaare, die alle alten Altersschichten der USA im Jahre 1968 repräsentieren. Es wurden jedoch alle Ehepaare aus der Stichprobe herausgenommen, bei denen ein Vermögensbestandteil oder der Bildungsstand unklar oder der Ehemann jünger als 65 war.

3 Die Bewertung des Hauseigentums basiert auf Schätzungen der Eigentümer (Marktpreise), abzügl. den ausstehenden Hypotheken und anderen Schulden auf den Besitz. 
anwachsen, da im allgemeinen das Hauseigentum zuletzt veräußert wird. Mirer stellt jedoch keine Zunahme fest.

Shorrocks ${ }^{l}$ untersucht die Lebenszyklushypothese mit Hilfe von Daten, die auf der erhobenen Erbschaftsteuer der Jahre 1912, 1921, 1931, 1939, 1951, 1961 sowie 1971 in England und Wales basieren. Er betrachtet die Höhe des Vermögens der wohlhabendsten 1, 5 oder 10\% der Bevölkerung sowie dessen Veränderungen im Zeitablauf.

Bei diesen Tests wird angenommen, die Verstorbenen einer Altersgruppe seien ein repräsentatives Abbild der jeweiligen Altersgruppe. Mit Hilfe von Sterbewahrscheinlichkeiten wird dann auf das Vermögen in der jeweiligen Altersgruppe geschlossen.

Als Ergebnis erhält Shorrocks -nach Modifikation der Mortalitätsfaktoren um die positive Vermögen-Lebenserwartung-Korrelation ${ }^{2}$ - ein Ansteigen des Vermögens mit zunehmendem Alter.

Wird allerdings die sich im Zeitablauf verändernde Gruppenzusammensetzung (zur Berücksichtigung der positiven Vermögen-Lebenserwartung-Relation) in die Überlegung miteinbezogen, ergibt sich ein Vermögensanstieg bis zur Altersgruppe der 65-74-jährigen (oberste 1\%) bzw. bis zu Gruppe der 55-64-jährigen bei den wohlhabendsten 10\% der Bevölkerung (die Gruppe der wohlhabendsten 5\% liegt dazwischen). Danach fällt die Ersparnis wieder ab; dabei ist der "Knick" bei den weniger wohlhabenden Gruppen stärker ausgeprägt.

Für einen weiteren Test nutzt Shorrocks Daten aus verschiedenen Jahren und konstruiert damit ein Abbild des Vermögens einer Kohorte im Zeitablauf (der Kohorten-Effekt wird damit vermieden $)^{3}$. Hierbei ergab sich ein Vermögensanstieg bei den wohlhabendsten 1, 5 und 10\% der Bevölkerung.

Wird die sich im Zeitablauf aufgrund der positiven Vermögen-Lebenserwartung-Relation ändernde Gruppenzusammensetzung als Modifikation miteinbezogen, wächst das Nominalvermögen der oberen 1 und 5\% weiter. Ein Sinken ist lediglich bei den wohlhabendsten 10\% der Bevölkerung ab einem Alter von 80 Jahren zu beobachten. Wird das Vermögen allerdings in den Wertverhältnissen von 1960 ausgedrückt, wächst das Vermögen bis zur Gruppe der 65-70-jährigen an und sinkt anschließend. Dabei ist die Vermögensabnahme bei der Gruppe der oberen $10 \%$ ausgeprägter als bei den oberen $1 \%$.

Vgl. Shorrocks, A.F. (1975).

2 Die Faktoren resultieren aus einer Untersuchung von Revell, J.R.S. (1967).

3 Z.B. entspricht die Altersgruppe der 35-44-jährigen 1921 fast der Altersgruppe der 4554-jährigen im Jahre 1931. 
Atkinson $^{1}$ und Atkinson/Harrison ${ }^{2}$ untersuchen die Vermögensverteilung der wohlhabendsten 1\%, 5\% und 10\% der Bevölkerung in Großbritannien mit Daten der "Estate duty statistics" (Erbschaftsteuer) der Jahre 1963 bis 1968.

Als Ergebnis stellt Atkinson fest, daß das Vermögen mit dem Alter zunimmt, also ein Entsparen nicht festzustellen ist.

Atkinson/Harrison ${ }^{3}$ kommen beim Test der Vermögensverteilung zu einem bestimmten Zeitpunkt ebenfalls zu dem Schluß, daß das Vermögen mit steigendem Lebensalter zunimmt. Auch mit der Konstruktion einer Reihe aus den Daten verschiedener Jahrgängen zu verschiedenen Zeitpunkten ${ }^{4}$ ergibt sich eine $\mathrm{Zu}$ nahme des Vermögens mit zunehmendem Alter.

Diese Ergebnisse stehen im Widerspruch zu den Aussagen der Lebenszyklushypothese. Die Untersuchung von Atkinson berücksichtigt aber nicht die sich im Zeitablauf (aufgrund der positiven Vermögen-Lebenserwartung-Relation) verändernde Gruppenzusammensetzung.

King/Dicks-Mireaux ${ }^{5}$ schätzen die Relation Vermögen - Alter mit Querschnittsdaten kanadischer Haushalte aus dem Jahre 1976/77. Bei der Erfassung des zum Marktwert 1977 bewerteten Vermögens (einschl. des Wohneigentums) bleiben langlebige Konsumgüter mit Ausnahme von Fahrzeugen unberücksichtigt. "Vermögensgegenstände", wie erwartete Erbschaften oder Unterstützungsleistungen von Kindern bzw. Verwandten, werden nicht erfaßt. Die Abschätzung wird zuerst ohne den Einbezug von Pensions- bzw. Rentenansprüchen in das Vermögen durchgeführt, später werden diese einbezogen.

Danach können die Haushalte in drei Gruppen eingeteilt werden:

- Haushalte mit einem negativen Gesamtvermögen (ca. 10\% der Stichprobe): in dieser Gruppe befinden sich viele junge Menschen, die sich in einem frühen Stadium ihres Lebenszyklusses befinden. Die beobachteten negativen Vermögen rühren daher, daß nicht alle positiven Vermögensbestandteile (z.B. langlebige Konsumgüter wie Wohnungseinrichtungen) berücksichtigt werden, die dafür aufgenommenen Schulden aber das Gesamtvermögen mindern.

Vgl. Atkinson, A.B. (1971).

2 Vgl. Atkinson, A.B./Harrison, A.J. (1978).

3 Vgl. Atkinson, A.B./Harrison, A.J. (1978), S. $250 \mathrm{ff}$.

4 Vgl. hierzu auch das Vorgehen von Shorrocks, A.F. (1975).

5 Vgl. King, M.A./Dicks-Mireaux, L.-D.-L. (1982); Folgestudie King, M.A./Dicks-Mireaux, L.-D.-L. (1984). 
- Die zweite Gruppe (ca. 13\% der Stichprobe) besitzt ein sehr kleines $(0<$ Vermögen $<$ Can-\$ 2.500) Vermögen ${ }^{l}$. Hauptmerkmale dieser Gruppe sind das geringe Einkommen, die geringe Quote von Lebensversicherungen bzw. privaten Pensionsansprüchen sowie ein geringeres Bildungsniveau als im Durchschnitt der Stichprobe. Diese Gruppe ist damit wirtschaftlich weniger erfolgreich als die mit einem negativen Vermögenswert. Die Zugehörigkeit zu dieser Gruppe ist wahrscheinlich dauerhaft. Möglicherweise erzielen diese Individuen ein so geringes Einkommen, das Sparen unmöglich macht und nach dem optimalen Lebenszykluskonsumplan der Konsum im Ruhestand kleiner oder gleich dem Konsum aus der gesetzlichen Rentenzahlung ist.

- Die dritte Gruppe besteht aus den Individuen, die nicht den beiden ersten Gruppen zuzurechnen sind; sie umfaßt über $75 \%$ der Stichprobe.

Das permanente Einkommen wird von King/Dicks-Mireaux anhand von beobachtbaren Größen wie Schulbildung, Beschäftigung sowie des Periodeneinkommens (zur Berücksichtigung von Einflußfaktoren wie Glück oder Geschick) abgeschätzt.

Das Ergebnis ihrer Untersuchungen wird nachfolgend graphisch dargestellt. V bezeichnet dabei das Vermögen der Individuen (einschließlich Wohneigentum). $V^{\prime}$ steht für die entsprechenden Vermögenswerte ohne das Wohneigentum. Y repräsentiert das permanente Einkommen.

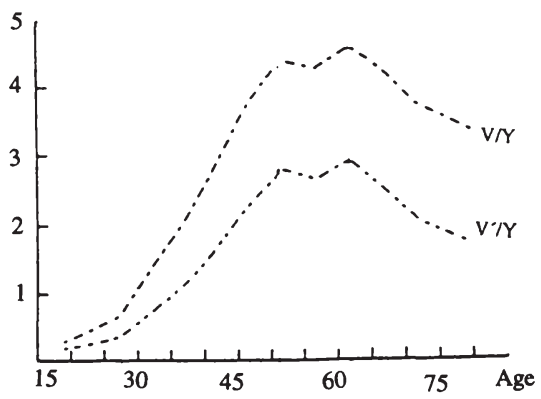

Ratio of wealth to permanent income/ age profile

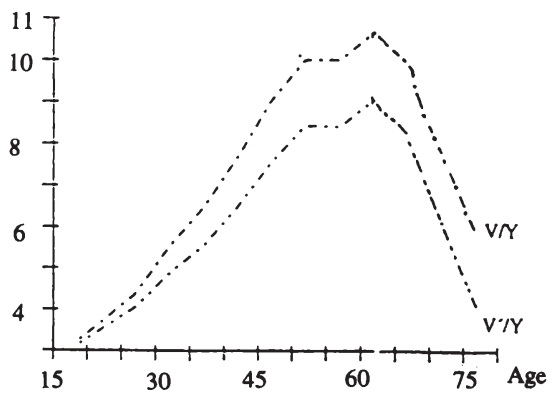

Age profile of the ratio of wealth to permanent income

Schaubild 2

Schaubild 1

Diese Wertgrenze entspricht ungefähr den US-\$1000 im Jahre 1966, die Diamond / Hausman (1984) als Grenze wählten. 
Wie aus dem Schaubild $1^{l}$ ersichtlich, erreicht das Verhältnis

\author{
Vermögen \\ permanentes Einkommen
}

das Maximum in der Altersgruppe 60-64, also vor der Pensionierung ${ }^{2}$. Die prozentuale Abnahme der durchschnittlichen Relation Vermögen - permanentes Einkommen zwischen der Altersstufe 60-64 und über 75 Jahre beträgt bei Einbezug des selbstgenutzten Wohneigentums $26,3 \%$ für die gesamte Stichprobe bzw. 20,9\% für Haushalte mit einem Vermögen von mehr als $\$ 2.500$. Wird das selbstgenutzte Wohneigentum nicht berücksichtigt, beträgt die prozentuale $\mathrm{Ab}$ nahme 39,4\% bzw. 35,3\%. Wird der Wert der gesetzlichen Rentenversicherung (Mittelwert (je Anspruchsberechtigten) Can-\$ 74.363) und anderer privater Pensionspläne (Mittelwert (je Anspruchsberechtigten) Can-\$61.349) einbezogen (Schaubild $\left.2^{3}\right)^{4}$, ergibt sich eine wesentlich stärkere Abnahme dieser Relation mit zunehmendem Alter 5 .

\title{
2.2.2.3. Interpretation der empirischen Untersuchungen
}

Die größte Fehlerquelle bei den Untersuchungen von Shorrocks (1975), Atkinson (1971) und Atkinson/Harrison (1978) ist die unterschiedliche Abschätzung der Sterbewahrscheinlichkeit, die sowohl die Abschätzung des Vermögens der überlebenden Bevölkerung als auch die quantitativ bedeutenden Korrekturfaktoren zur Veränderung der Gesellschaftszusammensetzung beeinflußt ${ }^{6}$. Diese Überlebensrelationen sind besonders sensitiv gegenüber Änderungen der Sterbewahrscheinlichkeit. Somit ist ihre Genauigkeit fraglich, solange die Beziehung zwischen Vermögen und Sterberate nicht zuverlässig erforscht ist. Dabei ist zu beachten, daß sich der durch die Lebenszyklushypothese vorausgesagte

\footnotetext{
$1 \quad$ Entnommen aus: King, M.A./Dicks-Mireaux, L.-D.-L. (1982), S. 258.

2 Das Absinken der Relation für die Altersgruppe der 55-59-jährigen kann dadurch begründet sein, daß diese Altersgruppe ihr Arbeitsleben mit Beginn des 2 . Weltkriegs begann und sie durch die Unterbrechung ihrer ersten Arbeitserfahrung negativ beeinflußt wurde.

3 Entnommen aus: Dicks-Mireaux, L.-D.-L. /King, M.A. (1984), S. 119.

4 Zum Vergleich: der Mittelwert des anderen in die Untersuchung einbezogenen Vermögens beträgt Can-\$65.821.

5 Hierbei wurde die Stichprobe noch um die Haushalte vermindert, die ein geringeres Nettovermögen als Can-\$2500 haben, da hier ein anderes Sparverhalten festgestellt wurde (vgl. Dicks-Mireaux, L.-D.-L./King, M.A. (1984)).

Vgl. Shorrocks, A.F. (1975), S. 163.
} 
Vermögensverlauf bei den jeweiligen Untersuchungen lediglich aufgrund der durchgeführten Modifikationen ergibt. Weiterhin berücksichtigen nicht alle Studien die veränderte Gruppenzusammensetzung im Zeitablauf aufgrund der positiven Vermögen-Lebenserwartung-Relation.

Es ist überdies fraglich, ob die Verstorbenen einer Altersgruppe -insbesondere bei jüngeren Altersgruppen- repräsentativ für die Altersgruppe sind: sie haben meist eine unterdurchschnittliche Gesundheit, was die Höhe ihres Vermögens beeinflussen könnte (frühere Pensionierung, geringere Einkunftsmöglichkeiten, höhere Ausgaben für Krankenpflege, Medikamente). Es ist wahrscheinlich, daß diejenigen mit einer geringen Lebenserwartung -z.B. die SchwerkrankenSchritte unternehmen (z.B. Schenkungen, geschickte steuerliche Gestaltungen), um Erbschaftsteuer zu vermeiden ${ }^{l}$.

Darüberhinaus wird das Vermögen der Individuen nur unvollständig abgebildet: so bleiben z.B. Vermögensbestandteile, die an die Person des Erblassers gebunden sind -z.B. Renten-/Pensionsansprüche- ebenso unberücksichtigt wie Lebensversicherungen oder Teile des Eigentums, das auf den überlebenden Ehepartner übertragen wird. Wird davon ausgegangen, daß Verstorbene aus jüngeren Altersgruppen häufiger verheiratet sind als ältere, deren Ehepartner möglicherweise schon vorher verstarb, wird das Vermögen der jüngeren tendenziell zu niedrig ausgewiesen.

Diese Generation mußte auch zwei Weltkriege miterleben. Die Kriege hatten gravierende Auswirkungen auf das Vermögen und die Lebensplanung der Menschen; aufgrund dieser Sondereinflüssen ist die Repräsentativität der Stichprobe zur Untersuchung der Lebenszyklushypothese fraglich.

Daher ist sowohl die Unterstützung als auch die Ablehnung der Lebenszyklushypothese durch diese Untersuchungsmethode nicht stichhaltig.

Bei der Untersuchung von Mirer ist die starke Reduktion des Stichprobenumfangs um diejenigen Haushalte problematisch, bei denen irgendein Vermögensbestandteil zweifelhaft ist. Möglicherweise besteht eine Korrelation zwischen dieser "Haushaltseigenschaft" und dem Vermögen; somit geht die Repräsentativität der Stichprobe verloren. Fraglich ist auch, inwieweit die Korrekturen für den Kohorten-Effekt angemessen sind: ein großer Anteil der Stichprobe dürfte aufgrund des Bildungsniveaus (30\% hatten eine Schulausbildung von 0-6 Jahren und 34\% eine von 7-8 Jahren) von der Weltwirtschaftskrise (ab 1929, 30 Millionen Arbeitslose in den USA) betroffen gewesen sein. Da wiedereingestellte Arbeitslose unabhängig vom Alter ungefähr gleich viel verdienen, ist die Annahme eines Kohorten-Effekts fraglich. Für die Annahme einer Art "KohortenEffekt" spricht allerdings die Abnahme des individuellen Vermögens während

Vgl. Atkinson, A.B./Harrison, A.J. (1978), S. 32 f. 
der Weltwirtschaftskrise; wird vom Extremfall des Totalverlusts ausgegangen, hatten die Jüngeren in der Stichprobe aufgrund ihrer längeren noch verbleibenden Arbeitszeit die Möglichkeit, ein höheres Vermögen aufzubauen. Welcher der beiden Effekte überwiegt und sich quantitativ auswirkt, wurde von Mirer nicht untersucht. Die ausgewählte Stichprobe ist somit nicht repräsentativ; das Ergebnis kann damit nicht als stichhaltiges Argument für die Ablehnung der Lebenszyklushypothese gedeutet werden.

Die beobachtete Abnahme des Vermögens nach der Pensionierung ist bei King/ Dicks-Mireaux geringer als es die Lebenszyklushypothese voraussagt, wenn weder Unsicherheit bezüglich des Todeszeitpunkts noch der Wunsch nach Vererbung eines Teils des Vermögens auf die Nachfahren besteht.

Ihre Ergebnisse stehen jedoch mit den Aussagen der Lebenszyklushypothese in Einklang, wenn entweder ein starkes Vererbungsmotiv oder Unsicherheit hinsichtlich des Todeszeitpunkts besteht ${ }^{l}$, also -zumindest in Bezug auf den Todeszeitpunkt- realitätsnähere Annahmen getroffen werden. Ein Vorteil der Verhältnisbildung zwischen Vermögen und permanentem Einkommen ist, daß die Relation Sterblichkeit-Vermögen sowie die unterschiedliche Gruppenzusammensetzung hinsichtlich der -das Einkommen und somit das Vermögen beeinflussenden- Ausbildung nicht gesondert berücksichtigt werden muß. Das senkt die Fehleranfälligkeit, wenn das Verhältnis von Vermögen zu permanentem Einkommen nicht durch die Höhe des permanenten Einkommens beeinflußt wird. In ihrer Abschätzung ist aber der Einfluß des permanenten Einkommens signifikant auf das Verhältnis von Vermögen zu permanentem Einkommen (es sinkt mit steigendem permanenten Einkommen ${ }^{2}$ ), wenn Renten- und Pensionsansprüche nicht in die Abschätzung einbezogen werden ${ }^{3}$. Der Einfluß ist jedoch nicht mehr signifikant, wenn Pensions- und Rentenansprüche in die Abschätzung einbezogen werden. Die Aussagen des Tests mit Einbezug der Pensions- und Rentenan-

$1 \quad$ King, M.A./Dicks-Mireaux, L.-D.-L. (1982), S. 265.

2 Diamond/Hausman (1984) kommen allerdings zum Ergebnis, daß das Verhältnis Ersparnis zu permanentem Einkommen mit steigendem permanenten Einkommen zunimmt. Dies kann aber auch an der unterschiedlichen Konstruktion des permanenten Einkommens liegen.

3 Wird davon ausgegangen, daß aufgrund der durchschnittlich besseren Ausbildung, das Einkommen der jüngeren Altersgruppen höher ist, wird das Verhältnis Vermögen/permanentes Einkommen der jüngeren Gruppen im Vergleich zu den älteren als zu niedrig ausgewiesen, so daß die Aussage -im Alter ist eine Abnahme des Vermögens zu beobachten- nicht beeinflußt wird. Die Qualität der Aussage könnte jedoch dadurch beeinflußt werden, daß der Anteil der wohlhabenderen Individuen -die wahrscheinlich auch ein höheres permanentes Einkommen haben- aufgrund der höheren Lebenserwartung in den höheren Altersgruppen zunimmt, so daß ein Sinken der Verhältniszahl -zumindest in geringem Umfang- auch aufgrund der unterschiedlichen Gruppenzusammensetzung zustandekommen kann. Welcher der beiden Einflüsse überwiegt, kann hier nicht abgeschätzt werden. 
sprüche können somit zur Unterstützung der Lebenszyklushypothese verwendet werden.

Ein Problem bei der Vermögensermittlung stellt bei einigen Untersuchungen der Nichteinbezug langlebiger Konsumgütern dar: diese Konsumgüter sind als Ersparnis für die Zukunft zu werten, da sie ihre Nutzungen im Zeitablauf abgeben und ihre Eigentümer dafür dann keine Ausgaben mehr aufbringen müssen. Werden diese Güter mit Krediten finanziert, mindern diese das individuelle Vermögen in voller Höhe; die davon angeschafften langlebigen Konsumgüter bleiben jedoch unberücksichtigt. Langlebige Konsumgüter (z.B. Einrichtungsgegenstände) werden verstärkt von jüngeren Altersgruppen (z.B. bei der Haushaltsgründung) angeschafft; das Vermögen dieser jüngeren Altersgruppen wird somit tendenziell zu gering ausgewiesen.

Eine weitere Ursache für das beobachtete Anwachsen des Vermögens mit zunehmendem Alter dürfte in den Vermögensdefinitionen liegen, die das tatsächliche Vermögen des Individuums nur unvollkommen abbilden. Die Lebenszyklushypothese unterstellt, daß das Individuum für die Planung seiner Konsumausgaben sämtliche ihm zur Verfügung stehenden Informationen nutzt. Ein rationales Individuum wird in seine Abschätzung alle zukünftigen Zuflüsse einbeziehen und nicht nur Vermögensteile, die auf Dritte übertragen werden können. Ein Indiz dafür ist, da $B$-wie verschiedene Untersuchungen zeigen- die (sonstige) Ersparnis mit einer steigenden Absicherung des Alters durch gesetzliche Rentenversicherungen oder sonstige Vorsorgen (z.B. Betriebsrenten, Lebensversicherungen) abnimmt ${ }^{I}$. Somit beziehen die Individuen diese Ansprüche in ihre Vorsorgeplanung ein: Ansprüche auf Renten bzw. Pensionen müssen daher im Vermögensbegriff berücksichtigt werden.

Das Weglassen dieser "Vermögensbestandteile" wäre -ohne die Ergebnisse der Untersuchungen zu verfälschen- nur möglich, wenn ihr Wert geringfügig oder im Laufe der Zeit konstant wäre. Wie die Abschätzungen der Renten- und Pensionsansprüche durch Dicks-Mireaux, L./King, A. zeigen, liegt der Wert von gesetzlichen und privaten Renten-/Pensionszusagen ungefähr in der Größenordnung des sonstigen Vermögens ${ }^{2}$. Die Außerachtlassung wegen Geringfügigkeit scheidet somit aus. Die Ansprüche sind auch nicht über die Zeit konstant, da ihr Wert aufgrund von Auszahlungen oder aufgrund der sich im Zeitablauf ergebenden geringeren Lebenserwartung des Begünstigten abnimmt; sie müssen also berücksichtigt werden. Das gilt auch für Kapitallebensversicherungen: sie werden meist kurz nach der Pensionierung fällig und erhöhen dann das (gemessene)

Vgl. Diamond, P.A./Hausman, J.A. (1984) und King, M.A./Dicks-Mireaux, L.-D.-L. (1982).

2 Vgl. King, M.A./Dicks-Mireaux, L.-D.-L. (1982), S. 264. 
Vermögen, während die Ansprüche gegen den Lebensversicherer vorher nicht einbezogen wurden.

Ein weiterer Grund für die Erfordernis des Einbezug von Lebensversicherungen, Ansprüche auf Rente/Pension usw. liegt in der Konsistenz der Daten: das Vermögen kann lediglich durch Zuflüsse oder Wertänderungen wachsen:

- Erhöht es sich durch Zuflüsse, müssen diese aus irgendwelchen Quellen stammen. Im Alter sind diese Quellen meist Kapitallebensversicherungen, Renten oder Pensionen, deren Wert abnimmt. Wird nun aus diesen Zuflüssen gespart, steigt das gemessene "Vermögen" des Sparenden, da der Wertverlust der Quelle in der Vermögensdefinition unberücksichtigt bleibt. Da das Individuum aber gleichzeitig Konsumausgaben hat, also im allgemeinen wesentlich weniger gespart werden kann als zufließt, nimmt das wirkliche Vermögen des Individuums tatsächlich ab, während es bei Nichteinbezug des Wertverlusts der Quelle zunimmt ${ }^{l}$. Es ist weiterhin aufgrund der beobachteten Vermögensstände unwahrscheinlich, daß die Zuflüsse aus anderen Vermögensteilen (z.B. Zinsen, Dividenden) so hoch sind, daß sie sowohl zur Bestreitung des Konsums und als auch zur weiteren Bildung von Ersparnissen ausreichen.

- Bei der betrachteten Höhe der Vermögen ist es unwahrscheinlich, daß die Werterhöhungen im Vermögen (z.B. des Wohneigentums) so groß sind, daß davon der Konsum bestritten und gleichzeitig die (gemessene) Ersparnis erhöht werden kann.

Untersuchungen, bei denen die Ansprüche aus Renten, Pensionen, Kapitallebensversicherungen o.ä. nicht in die Höhe des individuellen Vermögens einbezogen werden, verfälschen infolgedessen die Alter-Vermögens-Relation: das Vermögen der Individuen wird generell zu niedrig abgeschätzt; der Fehler steigt dabei bis zur Pensionierung stetig an, während er sich danach wieder verringert. Hieraus lassen sich also keine stichhaltigen Gründe gegen die Lebenszyklushypothese ableiten.

$1 \quad$ Bei laufenden Rentenzahlungen o.ä. fließt aufgrund versicherungsmathematischer Gegebenheiten (die Lebenserwartung eines $x$-jährigen ist um weniger als ein Jahr höher als die eines $x+1$-jährigen) ein höherer Betrag zu als der Vermögenstamm an Wert verliert; wird von den Zuflüssen nichts konsumiert, wird auch bei Einbezug des Wertverlusts des Stamms das Vermögen zunehmen. 


\subsection{Simulation der Ersparnisse}

Eine andere Methode des Tests der Aussagen der Lebenszyklushypothese ist die Abschätzung der Ersparnisse der Individuen. Damit kann untersucht werden, welchen Umfang intergenerationelle Transfers besitzen und welcher Teil der Ersparnis mit der Lebenszyklushypothese zu erklären ist. Es wird unterstellt, die Individuen verhalten sich nach den Implikationen der Lebenszyklushypothese und vererben nichts. Werden die Ergebnisse der Simulation mit den tatsächlichen Ersparnissen verglichen, kann der Stellenwert von intergenerationellen Transfers und des Lebenszyklussparens abgeschätzt werden.

Kotlikoff/Summers ${ }^{l}$ verwenden als Datenbasis das aggregierte Einkommen und den aggregierten Konsum in den USA, die Verzinsung verschiedener Anlagen im Zeitablauf sowie demographische Bevölkerungsdaten zur Bildung von AlterEinkommen- und Alter-Konsum-Profilen. Das über den Konsum hinausgehende Einkommen nach Steuern und die staatlichen Transfers werden jedes Jahr ermittelt und bis 1974 unter Verwendung von Zinssätzen verschiedener Anlageformen akkumuliert.

Im günstigsten Falle ergibt sich ein akkumuliertes Lebenszyklus-Vermögen von US-\$ 733 Milliarden (= 19\% des amerikanischen Gesamtvermögens von US-\$ 3.884 Milliarden $^{2}$ ). Werden die Annahmen (Zinssätze, Einbezug der Ehegattenvererbung ins Lebenszyklusvermögen des überlebenden Partners) verändert, ist das Ergebnis vielfach ein negatives akkumuliertes Lebenszyklus-Vermögen. Wird das Konsumprofil modifiziert ${ }^{3}$, ergibt sich als akkumuliertes Lebenszyklus-Vermögen max. US-\$2.178 Mrd.

Kotlikoff/Summers folgern daraus, daß nur ein Teil der momentanen Ersparnis mit der Lebenszyklushypothese erklärt werden kann und ein hohes Gewicht auf intergenerationale Transfers zu legen ist.

White ${ }^{4}$ variiert bei seiner Simulation verschiedene Annahmen hinsichtlich des individuellen Einkommens (z.B. Steigerungen, Kohorten-Effekte). Das Einkommen wird zu Kontrollzwecken für jede Altersgruppe in der Simulation so berechnet, daß die Summe dem beobachteten aggregierten Einkommen des betref-

\footnotetext{
$1 \quad$ Kotlikoff, L.J./Summers, L.H. (1981).

2 = Gesamtvermögen (US-\$ 4.154 Mrd.) abzgl. \$ 270 Mrd. für Vermögen, das von gemeinnützigen Organisationen gehalten wird.

3 Der Konsum für das akkumulierte Lebenszyklus-Vermögen wird auf Basis des Konsumprofils von 1960 berechnet; diese Werte werden dahingehend modifiziert, daß der relative Konsum vor dem 40 . Lebensjahr um 10\% reduziert, der sich daran anschließende um $10 \%$ erhöht wird.
}

4 Vgl. White, B.B. (1978). 
fenden Jahres (gewählt wurden die Jahre 1953, 1959, 1964) entspricht; weiterhin wurde die jeweilige Altersverteilung in der Bevölkerung berücksichtigt.

Im günstigsten Fall können lediglich -so White- $60 \%$ der aggregierten tatsächlichen Ersparnis mit der Lebenszyklushypothese erklärt werden.

Die Ersparnisse der Individuen sind also höher, als sie aufgrund der reinen Lebenszyklushypothese vorausgesagt werden. Es ist den möglichen Gründen für dieses Ergebnis nachzugehen und die Frage zu stellen, ob obige Ergebnisse die Kernaussagen der Lebenszyklushypothese falsifizieren.

Die für den intergenerationellen Transfer ermittelten Werte enthalten nicht nur den von den Individuen gewünschten Transfer an ihre Erben. Dieser Betrag beinhaltet in einer Welt mit nur unvollkommener Voraussicht weiterhin die Notfallrücklagen der Individuen, die sie aufgrund des Ausbleibens von Notfällen nicht verbrauchten. Weiterhin umfaßt dieser Wert noch die weiteren Altersrücklagen der Individuen, die diese zu einem späteren Zeitpunkt ihres Lebens verbrauchen wollten, aber durch ihr vorzeitiges Ableben verhindert wurden. Dies wird gestützt durch die von Projector/ Weiss ${ }^{I}$ durchgeführte Untersuchung bei über 65-jährigen, nach der $47 \%$ für die Altersvorsorge, $34 \%$ zur Notfallvorsorge und $4 \%$ für eine geplante Vererbung sparen.

Diese Simulationen bringen somit keine stichhaltigen Einwände gegen die Kernaussagen der Lebenszyklushypothese vor. Als Ergebnis ist allerdings ein umfangreiches Lebensendvermögen festzustellen.

\subsection{Sensitivität des Konsums auf Einkommensänderungen}

Im folgenden Teil werden Tests vorgestellt, die die Sensitivität des Konsums auf Einkommensänderungen untersuchen. Nach der Lebenszyklushypothese werden diese nicht in voller Höhe konsumiert, sondern auf die erwartete Lebensdauer verteilt.

Zuerst werden Untersuchungen diskutiert, die als Grundlage Panel- oder Einzeldaten nutzen. Anschließend folgen dann Tests, die aggregierte Daten als Grundlage haben.

Vgl. Projector, D./Weiss, G. (1966). 


\subsubsection{Einzeldaten als Untersuchungsgrundlage}

Der Ansatz von Landsberger ${ }^{l}$ geht von der Idee des sich aus der Lebenszyklushypothese ergebenden Sparzyklusses aus, nach dem mit zunehmendem Alter die Neigung steigt, aus dem Vermögen zu konsumieren. Er unterstellt, daß Windfall Profits in voller Höhe als Vermögenszuwächse angesehen werden können. Somit ist die marginale Neigung, sie zu konsumieren, eine Abschätzung der marginalen Neigung zum Konsum aus dem Gesamtvermögen.

Als Datenbasis dienen zwei Statistiken über das Sparen in Israel in den Jahren 1957-58 und 1963-64, die auch Informationen über das Vorliegen von Windfall Profits ${ }^{2}$ enthalten.

Als Ergebnis stellt Landsberger -nach Berücksichtigung der unterschiedlichen Familiengrößen- fest, daß die Beziehung zwischen marginaler Neigung, die Windfall Profits zu konsumieren und dem Lebensalter in 6 von 18 Fällen statistisch signifikant ist, wobei in diesen Fällen immer eine Zunahme zu beobachten ist. In weiteren 5 Fällen ist ebenfalls eine -wenn auch nicht signifikante- Zunahme mit steigendem Lebensalter zu verzeichnen.

Landsberger betrachtet seine Ergebnisse als Unterstützung der Lebenszyklushypothese.

Bernanke $^{3}$ untersucht die Sensitivität der Reaktion der Ausgaben für den Kauf von Automobilen auf transitorische Einkommensschwankungen und dem Bestand an flüssigen Mitteln (einschließlich Bankguthaben, Aktien sowie kurzfristigen Bonds) mit Hilfe von über vier Jahren vorliegenden Panel-Daten von 1.434 Familien. Die Ausgaben für den Autokauf der Familie sind -so sein Ergebnis- entsprechend der Lebenszyklushypothese nicht von transitorischen Einkommensschwankungen, sondern von der Abschätzung des langfristigen Einkommens abhängig. Bei den Haushalten mit geringeren flüssigen Mitteln ist keine höhere, sondern sogar eine geringere Sensitivität festzustellen. Diese (ärmeren) Haushalte reagieren damit nicht stärker auf transitorische Einkommensschwankungen. Dies legt den Schluß nahe, daß Liquiditätsbeschränkungen oder der unvollständige Kapitalmarkt den Zeitpunkt des Autokaufs ebenfalls nicht beeinflussen.

$1 \quad$ Vgl. Landsberger, M. (1970).

2 Meist Entschädigungen der Deutschen Regierung in der Größenordnung eines Jahreseinkommens der Empfänger.

3 Vgl. Bernanke, B.S. (1984). 
Grundlage der von Hall/Mishkin ${ }^{I}$ durchgeführten Studie sind Panel-Daten von über 2000 Haushalten in der Zeit zwischen 1969 und 1975. Sie untersuchen den Zusammenhang zwischen Einkommen und Ausgaben für Lebensmittel; sie berücksichtigen auch den mit steigendem Einkommen abnehmenden Einkommensanteil, der für Nahrungsmittel aufgewendet wird. Das Ergebnis ihrer Untersuchung ist, daß der Konsum wesentlich stärker auf permanente Einkommensänderungen als auf transitorische reagiert. Weiterhin wird die reine Lebenszyklushypothese durch den Test der Unabhängigkeit des Konsums widerlegt: die beobachtete Korrelation von Konsum und Einkommen ist mit reinem Lebenszyklushypothese-Verhalten zu 80\% des Konsums kompatibel, zu $20 \%$ besteht eine einfache Proportionalität zwischen Konsum und Einkommen.

\subsubsection{Aggregierte Daten als Untersuchungsgrundlage}

Darby $^{2}$ testet die Lebenszyklushypothese anhand der Nachfrage nach langlebigen Konsumgütern sowie der Geldnachfrage; als Datenbasis dienen quartalsweise aggregierte Daten zwischen 1947-I und 1966-IV.

Er zeigt, daß das transitorische Einkommen -wie von der Lebenszyklustheorie beschrieben- keinen Einfluß auf den laufenden Konsum hat und im allgemeinen gespart wird: ein Teil des transitorischen Einkommens fließt in das Geldvermögen, der andere Teil wird in Form von langlebigen Konsumgütern -deren Nutzungen über einen längeren Zeitraum konsumiert werden können- gespart. Dabei hat die marginale Neigung, Ausgaben für langlebige Konsumgüter zu tätigen, ihr Minimum nahe bei den Wellenbergen und -tälern des Konjunkturzyklusses.

Flavin $^{3}$ verwendet US-Quartalsdaten von 1949-III - 1979-I über den Konsum kurzlebiger Konsumgüter. Sie beobachtet eine stärkere Sensitivität des Konsums zum laufenden Einkommen als durch die Lebenszyklushypothese vorhergesagt wird. Dies gilt auch bei der Annahme, daß Änderungen im laufenden Einkommen auch Änderungen des permanenten Einkommens nach sich ziehen können.

Bernanke $e^{4}$ untersucht sowohl die Konsumausgaben für langlebige als auch die für kurzlebige Konsumgüter und Dienstleistungen. Er unterstellt dabei, daß der Wechsel im Bestand der langlebigen Konsumgüter Kosten der Anpassung nach

\footnotetext{
$1 \quad$ Vgl. Hall, R.E./Mishkin, F.S. (1982).

2 Vgl. Darby, M.R. (1972).

3 Vgl. Flavin, M.A. (1981).

4 Vgl. Bernanke, B. (1985).
} 
sich zieht. Als Daten verwendet er -um Trends und Saisoneinflüsse korrigierteaggregierte Zeitreihen der Quartale 1947 I - 1980 II mit Wertbasis 1972. Er stellt fest, daß sowohl die Ausgaben für kurzlebige als auch die für langlebige Konsumgüter -entgegen den Aussagen der Lebenszyklushypothese- signifikant sensitiv gegenüber Einkommenssteigerungen $\operatorname{sind}^{l}$.

West $^{2}$ verwendet auf die Wertbasis 1972 korrigierte und um saisonale Einflüsse bereinigte US-Quartalsdaten 1953 II - 1984 II für das Einkommen und Ausgaben für kurzlebige Konsumgüter (ohne Kleidung und Schuhe) und Dienstleistungen. Nach seinen Untersuchungen ist der Konsum nicht sensitiv gegen Einkommensänderungen; somit wird die Lebenszyklushypothese nicht widerlegt.

Hayashi $^{3}$ testet die Lebenszyklushypothese mit Hilfe aggregierter Daten. Zur Untersuchung werden zwei verschiedene Datensätze benutzt:

1. Daten, in denen Konsumausgaben für Dienstleistungen und kurzlebige Konsumgüter zuzüglich dem Wert der aus den langlebigen Konsumgütern bezogenen Nutzungen definiert sind.

2. Konsumausgaben für die USA in der Periode 1948-1978, die auch die Ausgaben für langlebige Konsumgüter beinhalten.

Als Ergebnis erhält Hayashi die Unterstützung der Lebenszyklushypothese, wenn die Konsumreihen auch die Nutzungen von langlebigen Konsumgütern -also Datensatz (1)- enthalten; sie ist abzulehnen, wenn die Konsumdaten stattdessen die Ausgaben für den Erwerb der langlebigen Konsumgüter beinhalten.

\subsubsection{Interpretation der Ergebnisse}

Die Tests, denen Panel-Daten zugrunde liegen, unterstützen die Aussagen der Lebenszyklushypothese hinsichtlich der langfristigen Konsumplanung in hohem Maße. Dies zeigt sich insbesondere daran, daß der Periodenkonsum im wesentlichen nicht übermäßig stark von transitorischen Einkommensschwankungen abhängt. Die Ergebnisse zeigen auch eine wesentlich stärkere Beeinflussung des Konsums durch Änderungen des permanenten Einkommens als durch transitorische Einkommensschwankungen. Ein weiteres Indiz für die Annahme der langfristigen Planung des Konsums ist, daß die Neigung der Individuen, transitorische Einkommen zu konsumieren, mit steigendem Alter zunimmt. Dies ist ein

1 Die Lebenszyklushypothese wird bei einem in der Realität nicht beobachtbaren realen Zinssatz von ca. $14 \%$ nicht widerlegt, da dann von einer Einkommenserhöhung mehr gespart wird.

2 Vgl. West, K.D. (1988).

3 Vgl. Hayashi, F. (1982). 
Zeichen dafür, daß die Individuen ihre voraussichtliche Lebensdauer abschätzen und bestrebt sind, ihren Konsum zu glätten.

Die Verwendung von aggregierten Daten führt zu unterschiedlichen Ergebnissen. Es ist daher zu untersuchen, welche Einflüsse dazu führen.

Ein verzerrender Einflußfaktor ist möglicherweise die Aggregation ${ }^{l}$.

Eine andere Erklärung ${ }^{2}$ ist, daß die hauptsächliche Quelle für Einkommens-Variationen auf der mikroökonomischen eine andere als die der makroökonomischen Ebene ist: auf Ebene der Haushalte sind die wichtigsten Einflüsse auf das Einkommen unsystematische Faktoren wie Fähigkeiten, Bildung, Vererbung, Erbschaften; im aggregierten Zustand verwischen diese unsystematischen Einflüsse und die Einkommens-Variationen werden vom Konjunkturzyklus dominiert. Die schlechtere Anwendbarkeit der Lebenszyklushypothese auf zyklisch induzierte bedingte Einkommenswechsel ist plausibel: der Einfluß der Rezession ist ungleichmäßig. Größere Verluste aufgrund fallender Einkommen erleiden meist die, die arbeitslos werden. Falls diese Haushalte geringere Ersparnisse besitzen und Schwierigkeiten haben, sich Geld zu borgen, müssen sie als Reaktion auf den Einkommensrückgang ihren laufenden Konsum stark einschränken. Diese These wird auch durch die Studie von King/Dicks-Mireaux ${ }^{3}$ gestützt, nach der ein Teil der Haushalte (in ihrer Stichprobe 13\%) sowohl ein geringes Einkommen und Vermögen besitzt als auch ein geringeres Bildungsniveau als der Durchschnittshaushalt aufweist. Diese Haushalte, die aufgrund ihres geringen Bildungsniveaus wohl am ehesten von Arbeitslosigkeit betroffen werden, sind aufgrund ihres geringen Vermögens nicht in der Lage, bei Arbeitslosigkeit ihre Konsumausgaben beizubehalten ${ }^{4}$. Somit unterliegt -obwohl sich die Mehrheit der Konsumenten nach den Implikationen der Lebenszyklushypothese verhält- der "marginale" Konsument Liquiditätsbeschränkungen und als Folge davon reagiert der Konsum übermäßig sensitiv auf Einkommensänderungen ${ }^{5}$. Um obige Einflüsse auszuschalten, sollten diese Untersuchungen besser mittels Einzeldaten durchgeführt werden ${ }^{6}$.

Ein ähnliches Problem stellen die (relativ hohen) Ausgaben für langlebige Konsumgüter dar. Dadurch sind auch die unterschiedlichen Ergebnisse von Hayashi ${ }^{7}$ zu erklären, der eine hohe Sensitivität der Ausgaben für langlebige Konsumgüter bezüglich Einkommensänderungen, nicht jedoch eine hohe Sensitivität der

\footnotetext{
1 Vgl. hierzu Blinder, A.S. (1986).

2 Vgl. Bernanke, B. (1985), S. 63 f.

3 Vgl. King, M.A./Dicks-Mireaux, L.-D.-L. (1982).

4 Vgl. hierzu auch Hall, R.E. (1989), S. 172 f.

5 Vgl. Bernanke, B. (1985), S. 64.

6 Vgl. Mankiw, N.G./Shapiro, M.D. (1985), S. 173.

7 Vgl. Hayashi, F. (1982).
} 
aus langlebigen Konsumgütern gezogenen Nutzungen festgestellt hat. Als mögliche Erklärung führt Hayashi ${ }^{l}$ an, daß sich die Mehrheit der Haushalte in der Bevölkerung als vorausschauende Konsumenten verhält, die versucht, ihren Konsumpfad vor kurzfristigen Veränderungen im verwendbaren Einkommen zu schützen. Bei perfekten Mietmärkten für langlebige Konsumgüter, wäre der Zeitpunkt des Kaufs dieser langlebigen Güter unwichtig. In der Realität gibt es diese nur selten Mietmärkte (Ausnahme: Immobilien, Kfz-Leasing), so daß jeder Haushalt den gewünschten Nutzen aus seinen eigenen Beständen ziehen muß. Ferner sind die Kapitalmärkte unvollkommen, da für Kredite ein höherer Zins als für Guthaben gezahlt wird. Unter diesen Umständen ist es für einen vorausschauenden Haushalt das beste, massive Käufe dieser Gütern zu tätigen, wenn kurzfristige Einkommenssteigerungen auftreten, um die Kreditaufnahme zu minimieren. Dies gilt insbesondere für die Haushalte, die kaum Ersparnisse bzw. (Geld- / Forderungs-) Vermögen haben, da es aufgrund von Budgetrestriktionen bzw. Kreditbeschränkungen und zur Vermeidung von Kreditzinsen am vorteilhaftesten ist, langlebige Konsumgüter beim Anfall von transitorischen Einkommenserhöhungen zu kaufen. Diese Aussage steht auch nicht in Widerspruch zu der Untersuchung von Bernanke, der keine übermäßige Sensitivität der Ausgaben für Kraftfahrzeuge auf transitorische Einkommensänderungen feststellt: dieses Verhalten ist plausibel, da transitorische Einkommensänderungen sicherlich selten so groß sind, um zum Erwerb eines Kraftfahrzeuges auszureichen. Es ist hier also für ein Individuum trotz des transitorischen Einkommensanfalls zur Vermeidung von Kreditzinsen günstiger, bei einem transitorischen Einkommensanfall nicht sofort ein neues Auto zu kaufen. Somit liegt keine übermäßige Sensitivität der Kfz-Ausgaben in Bezug auf transitorische Einkommensänderungen vor.

Um die Aussagen der Lebenszyklushypothese zu prüfen, dürfen daher nur die aus den langlebigen Konsumgütern gezogenen Leistungen herangezogen werden und nicht die Ausgaben für ihren Erwerb, da das verbleibende Nutzenpotential des dauerhaften Konsumguts eine Ersparnis darstellt. Aus diesem Grund kann sich der aggregierte Konsumstrom, der die Nutzungen der langlebigen Konsumgüter enthält (und nicht die Ausgaben für ihren Erwerb), anders verhalten als die individuellen Konsumausgaben.

\subsection{Ergebnis: Grundlage der individuellen Konsumentscheidung}

Die oben diskutierten Tests ergeben unterschiedliche Ergebnisse hinsichtlich der Frage, ob sich die Individuen rational und nutzenmaximierend nach einem über

$1 \quad$ Vgl. Hayashi, F. (1982), S. 912. 
die Gesamtlebensdauer abgeschätzten Konsumplan verhalten oder nicht. Dabei ist generell zu beachten, daß die Bestätigung bzw. die Ablehnung der Lebenszyklushypothese durch einen Test nur für das getestete Modell mit seinen Annahmen -die aufgrund der Unmöglichkeit der Messung bestimmter Größen oder der unzureichenden Daten notwendig sind- gilt, nicht jedoch für die Lebenszyklushypothese generell.

Gegen die Untersuchungen, die die Ablehnung der Aussagen der Lebenszyklushypothese zur Folge haben, konnten allerdings stichhaltige Einwände hinsichtlich ihrer Aussagefähigkeit vorgebracht werden: meist wurde bei diesen Untersuchungen das Vermögen nur sehr unvollständig abgebildet oder es wurden aggregierte Daten verwendet.

Unterstützung für die Aussagen der Lebenszyklushypothese brachten in der Hauptsache Untersuchungen, die Einzeldaten als Datenbasis nutzten. Die Verwendung aggregierter Daten führte zu unterschiedlichen Ergebnissen: diese konnten teilweise auf den Einbezug der Konsumausgaben für langlebige Konsumgüter -statt des Werts der daraus bezogenen Nutzungen- zurückgeführt werden.

Die Unterstützung der Implikationen der Lebenszyklushypothese zeigte sich insbesondere daran, daß die beste Vorhersage des zukünftigen Konsums der gegenwärtige (unter Einbezug von Vermögensänderungen der Vorperiode) ist, der Konsum von unerwarteten Einkommensänderungen nicht vollständig in der laufenden Periode erfolgt (sondern über einen längeren Zeitraum verteilt wird) sowie ein Entsparen nach der Pensionierung festzustellen ist. Die festgestellte höhere Ersparnis in der Volkswirtschaft spricht nicht gegen die Lebenszyklushypothese, da die Annahme, daß nichts vererbt wird, nicht zwingend ist und somit die Kernaussagen der Lebenszyklushypothese nicht falsifiziert werden. Gründe für höhere Ersparnisse können darin zu finden sein, daß die Individuen in der Realität nicht ihren Todeszeitpunkt (wie in der Lebenszyklustheorie vielfach angenommen) kennen, die intergenerationelle Vererbung eine Rolle spielt und die Individuen für Notfälle sparen. Ein weiteres Indiz für die Annahme einer langfristigen Konsum-Spar-Entscheidung ist das Sinken der "sonstigen" Ersparnis, wenn Pensions- bzw. Rentenansprüche bestehen. Ein Grund für die Bejahung der Aussagen der Lebenszyklushypothese ist auch darin zu sehen, daß die Individuen unerwartete Einkommenszuflüsse nicht in irgendeiner Periode in voller Höhe verbrauchen, sondern sie über ihre abgeschätzte Lebensdauer verteilen.

Um für die Gültigkeit der Lebenszyklushypothese zu abschließenden Ergebnissen zu kommen, sind noch weitere Untersuchungen notwendig. Es sprechen allerdings gute Gründe dafür, daß die Individuen ihren aus dem Konsum empfangenen Nutzen optimieren wollen und deshalb ihr Konsumniveau langfristig planen. Ob diese Planung die gesamte Lebensspanne oder lediglich einen längeren 
Zeitraum umfaßt, ist für die Tendenz der Aussagen von nicht allzu großer Bedeutung.

Die größte Zahl der Individuen ist also -zusammenfassend gesagt- bestrebt, ihren Nutzen aus dem Konsum über ihre Lebensdauer zu maximieren. Um dieses Ziel zu erreichen, richten sie ihren Periodenkonsum an einem langfristigen Konsumplan aus. Sie schätzen zu diesem Zweck ihre -mittels des Indikators "Lebenseinkommen" gemessene (oder als abgeschwächte Version an ihrem über einen längeren Zeitraum abgeschätzten zukünftigen Einkommen)- Leistungsfähigkeit selbst ab. Dabei berïcksichtigen sie dauerhafte Einkommensänderungen und einmalige Einkommensanfälle (z.B. Windfall Profits wie Erbschaften, Lottogewinne usw.) sowie Wertänderungen in ihrem Vermögen; die Reaktion des Konsums auf die Vermögenswertänderungen erfolgt aber -entgegen den Implikationen der Lebenszyklushypothese- mit einer geringen zeitlichen Verzögerung.

Weiterhin berücksichtigen sie nach der Lebenszyklushypothese das erwartete zukünftige Einkommen in ihrer langfristigen Konsumplanung. Es geht somit auch in die Entscheidung für die Höhe des gegenwärtigen Periodenkonsums ein. Unerwartete Einkommenszuwächse werden als Folge der geplanten Nutzenmaximierung und der dadurch ausgelösten langfristigen Konsumplanung nicht in der Periode ihres Anfalls konsumiert, da die Individuen einen gleichmäßigen Konsum im Vergleich zu einem schwankenden präferieren. Der Konsum dieser unerwarteten Einkommenszuwächse erfolgt vielmehr über den gesamten Planungshorizont der Individuen. Einkommensschwankungen führen damit nicht zu Konsumschwankungen gleichen Ausmaßes.

Der Konsum ist daher weder eine Funktion des Periodeneinkommens im Sinne der Reinvermögenszugangstheorie noch eine der Zuflüsse der Periode. Die Höhe des gegenwärtigen Periodeneinkommens ist somit nicht der bestimmende Einflußfaktor, sondern lediglich ein Einflußfaktor bei der Entscheidung hinsichtlich der Höhe des gegenwärtigen Periodenkonsums. Der Periodenkonsum ist stattdessen abhängig von der durch die Individuen exante selbst abgeschätzten Leistungsfähigkeit.

Weiterhin ergibt sich als Ergebnis der obigen Untersuchungen, daß die Individuen teilweise ein beachtliches Vermögen an ihre Nachfahren vererben.

Eine Minderheit der Haushalte scheint sich allerdings nicht nach den Implikationen der Lebenszyklushypothese zu verhalten: die Ursache hierfür ist vermutlich ihr zu geringes Einkommensniveau, um für die Zukunft sparen zu können. 


\section{Kapitel}

\section{Folgerungen für die Ausgestaltung eines Steuersystems}

Die Implikationen der Lebenszyklushypothese gelten -so das Ergebnis des vorherigen Kapitels- zumindest für die Mehrheit der Individuen. Die Individuen schätzen somit bei ihrer Konsum-Spar-Entscheidung ihre Leistungsfähigkeit selbst ab.

Fraglich ist, welche Konsequenzen sich aus diesen Ergebnissen für die Besteuerung ergeben. Es wird deshalb versucht, Rückschlüsse auf die in die steuerliche Bemessungsgrundlage einzubeziehenden Größen zu ziehen. Werden dabei die im zweiten Teil anhand theoretischer und systematischer Überlegungen gewonnenen Ergebnisse bestätigt, erhalten sie in der politischen und wissenschaftlichen Diskussion ein höheres Gewicht. Sie können nach dem in den westlichen Gesellschaften vorherrschenden Bild vom eigenverantwortlichen und souveränen Menschen nicht einfach übergangen werden, da die Steuerpflichtigen selbst ihre Leistungsfähigkeit so einschätzen. Darüberhinaus werden die gefundenen Ergebnisse genutzt, um eine Periodeneinkommen- und Periodenkonsumsteuer hinsichtlich ihrer Vorteilhaftigkeit zu untersuchen. Die Kriterien sind hierbei die Besteuerung nach der individuellen Leistungsfähigkeit, die Entscheidungsneutralität der Besteuerung und die Praktikabilität der Steuererhebung. Um die einzelnen Auswirkungen unterscheiden zu können, wird zwischen einem Steuersystem mit linearem und einem mit progressiven Steuertarif differenziert.

Zur Erleichterung der Untersuchungen, wird vorerst postuliert, daß der Konsum praktikabel meßbar ist. Diese Annahme wird später noch auf ihre Realitätsnähe geprüft.

\section{Besteuerung nach der individuellen Leistungsfähigkeit}

\subsection{Folgerungen für eine lineare Tarifstruktur}

Im folgenden Teil wird zuerst untersucht, welche Größen in ein Steuersystem, das die Steuerlast nach der individuellen Leistungsfähigkeit verteilt, eingehen müssen. In einem weiteren Schritt wird geprüft, ob die Besteuerung des Periodenkonsums vorteilhafter ist als die des Periodeneinkommens. 


\subsubsection{In die steuerliche Bemessungsgrundlage einzubeziehende Größen}

Umstritten ist -wie an der Vielzahl von Einkommensbegriffen leicht ersichtlich wird- welches die für die individuelle Leistungsfähigkeit bestimmenden Elemente sind. Diese Fragen wurden anhand theoretischer und systematischer Überlegungen beantwortet. Es soll nun geklärt werden, ob die Implikationen der Lebenszyklushypothese helfen, dieses Problem aus der Sicht der Individuen zu lösen. Dahinter steht die Idee, daß die Individuen bei ihrer Konsum-Spar-Entscheidung ihre Leistungsfähigkeit selbst abschätzen und sich daraus Hinweise auf die einzubeziehenden Größen ergeben.

Interessant ist die Frage, ob die Individuen den Vermögenswertänderungen grundsätzlich einen Einfluß auf ihre individuelle Leistungsfähigkeit beimessen. Die empirischen Untersuchungen zum Konsumverhalten der Individuen zeigen, $\mathrm{da} ß$ bei der langfristigen Konsumplanung und der daraus abgeleiteten Bestimmung des gegenwärtigen Konsums Vermögenswertänderungen miteinbezogen werden und ihnen somit einen Einfluß auf die Leistungsfähigkeit eingeräumt wird. Dies ergibt sich insbesondere aus der Untersuchung von Hall (1978), der eine Beeinflussung des Konsums durch Vermögenswertänderungen, die ihrerseits die Höhe des permanenten Einkommens beeinflussen, feststellt.

Die empirischen Untersuchungen ergeben weiterhin, daß die Mehrheit der Individuen bei ihrer Konsumplanung auch unregelmäßige Einkünfte einbezieht. Sie schreiben diesem "Einkommensbestandteil" einen eigenständigen Einfluß auf ihre individuelle Leistungsfähigkeit zu.

Die Individuen sehen damit in den Vermögenswertänderungen und in den Windfall Profits einen Zuwachs an ökonomischer Verfügungsmacht über die knappen Ressourcen der Wirtschaft und damit eine Erhöhung ihrer Leistungsfähigkeit. Dies wird durch die Konsum-Spar-Entscheidung der Individuen nach außen dokumentiert. Die aus den empirischen Tests der Lebenszyklushypothese gewonnen Ergebnisse unterstützen demnach die oben anhand theoretischer Überlegungen gewonnene Auffassung, nach der sowohl (realisierte und unrealisierte) Wertänderungen als auch Windfall Profits und unregelmäßige Einkünfte in die steuerliche Bemessungsgrundlage eingehen müssen, wenn eine Einkommensbesteuerung nach der individuellen Leistungsfähigkeit erfolgen und das Einkommen als valider und zweckadäquater Indikator der Leistungsfähigkeit angesehen werden soll.

Der Nichteinbezug von Wertänderungen, Windfall Profits und unregelmäßigen Einkünften bei einer Periodeneinkommensteuer führt somit zu einer nur unvollständigen Abbildung der Leistungsfähigkeit und damit -da nicht alle Individuen 
in gleichem Umfang diese "Einkommensbestandteile" erzielen- zu Ungerechtigkeiten, da das gleiche Lebenseinkommen unterschiedlich besteuert wird.

Es ist zu prüfen, ob der Einbezug des Lebensendvermögens in die steuerliche Bemessungsgrundlage entfallen kann. Der Einbezug ist zwar prinzipiell notwendig, da sich das Lebenseinkommen aus der Summe des Periodenkonsums und des Lebensendvermögens zusammensetzt. Der Fehler, der durch die Vernachlässigung des Lebensendvermögens entsteht, wäre aber bei einem betragsmäßig nur unwesentlichen Lebensendvermögen vernachlässigbar. Die Möglichkeit der Vernachlässigung wäre von Vorteil, da die Bewertung des Vermögens -wie oben gezeigt- nicht objektiv und praktikabel durchführbar ist. Aus theoretischer Sicht wäre das Lebensendvermögen sehr klein, wenn die Individuen kein Vererbungsziel haben, sie mit ausreichender Sicherheit ihre Lebenszeit abschätzen oder sie keine bzw. nur eine geringe Vorsorge für einen unverhofften Geldbedarf, z.B. Pflegebedürftigkeit im Alter, Krankheiten, treffen, der dann doch nicht eintritt.

Die empirischen Untersuchungen ergaben jedoch, daß die meisten Individuen einen nicht geringen Betrag ihren Nachkommen hinterlassen. Wird der verwirklichte Mittelerwerb -also das Lebenseinkommen- als der geeignete Indikator zur Messung der individuellen Leistungsfähigkeit angesehen, muß der Nachlaß in die Bemessungsgrundlage der Besteuerung eingehen. Eine Steuerbefreiung des Lebensendvermögens wegen Geringfügigkeit ist nicht gerechtfertigt und stellt einen Verstoß gegen die Besteuerung nach der individuellen Leistungsfähigkeit dar.

\subsubsection{Vergleich der Besteuerung des Periodenkonsums und des -ein- kommens}

\subsubsection{Die Besteuerung der Zinsen}

Bei der Diskussion der Periodeneinkommensteuer wurde nachgewiesen, daß die Behandlung der Zinseinkünfte sowie der Wertänderungen, die einer Verzinsung des eingesetzten Kapitals entsprechen, problematisch ist. Individuen mit gleichem Lebenseinkommen (vor Steuern) haben daher bei einer Periodeneinkommensbesteuerung aufgrund der Zinsbesteuerung einen unterschiedlichen Steuerbetrag (Barwert) zu entrichten, wenn die Einkünfte bei ihnen zeitlich ungleich anfallen oder bei gleichem zeitlichen Anfall der Konsumzeitpunkt differiert. Um zu klären, ob dieser Verstoß gegen das Leistungsfähigkeitsprinzip auch bei der Besteuerung des Konsums auftritt, werden drei in einer Welt ohne Steuern 
gleich leistungsfähige Individuen (A, B, C) mit gleichem Lebenseinkommen betrachtet, die zu unterschiedlichen Zeitpunkten Zuflüsse bzw. Konsumausgaben haben.

In einer Laissez-Faire-Ökonomie sind die Individuen gleich leistungsfähig.

$\mathbf{A}$

$\begin{array}{llll} & \text { Barwert } & \mathrm{t}_{1} & \mathrm{t}_{2} \\ & & & \\ \text { Zuflüsse } & 2 \mathrm{y} & 2 \mathrm{y} & 0 \\ \text { Konsum (netto) } & 2(1-\tau) \mathrm{y} & 2(1-\tau) \mathrm{y} & 0 \\ \text { Steuer } & 2 \tau \mathrm{y} & 2 \tau \mathrm{y} & 0\end{array}$

B

$\begin{array}{llll}\text { Zuflüsse } & 2 \mathrm{y} & \mathrm{y} & (1+\mathrm{r}) \mathrm{y} \\ \text { Konsum (netto) } & 2(1-\tau) \mathrm{y} & (1-\tau) \mathrm{y} & (1-\tau)(1+\mathrm{r}) \mathrm{y} \\ \text { Steuer } & 2 \tau \mathrm{y} & \tau \mathrm{y} & \tau(1+\mathrm{r}) \mathrm{y}\end{array}$

C

$\begin{array}{llll}\text { Zu- - Abflüsse } & 2 y & 2 y & (1+r) y \\ \text { Konsum (netto) } & 2(1-\tau) \mathrm{y} & (1-\tau) \mathrm{y} & (1-\tau)(1+\mathrm{r}) \mathrm{y} \\ \text { Steuer } & 2 \tau \mathrm{y} & 2 \tau \mathrm{y} & \tau(1+\mathrm{r}) \mathrm{y} \\ \text { Anlage (Abfluß) } & & \mathrm{y} & \end{array}$

In allen drei Fällen sind die Individuen auch nach der Besteuerung des Periodenkonsums gleich leistungsfähig, ihre ordinale Rangfolge ändert sich nicht.

Bei der Besteuerung des Periodenkonsums ist durch den Wegfall der Zinsbesteuerung gewährleistet, daß die Steuerbemessungsgrundlage das Lebenseinkommen (vor Steuern) ist und der Zeitpunkt des Konsums bzw. des Einkommensanfalls -im Gegensatz zu einer periodischen Einkommensbesteuerung- keinen Einfluß auf die Steuerhöhe hat. Steuerpflichtige mit gleichem Lebenseinkommen entrichten daher auch die gleiche Steuer. Ein Verstoß gegen das Leistungsfähigkeitsprinzip erfolgt nicht. 
Zu klären ist nun, ob Zinseinkünfte (bzw. Schuldzinsen), die die Leistungsfähigkeit beeinflussen (z.B. eine höhere als die übliche Rendite), tatsächlich in die steuerliche Bemessungsgrundlage eingehen.

Bei der Besteuerung des Periodenkonsums (und des Lebensendvermögens) werden die Zinsen und die Vermögenswertänderungen, die der Verzinsung des eingesetzten Kapitals entsprechen, durch die Individuen in ihrem Konsumplan und damit in ihrem Periodenkonsum berücksichtigt. Sie sind also in der Bemessungsgrundlage der Besteuerung -nämlich im Konsum- enthalten; eine gesonderte Erfassung und Besteuerung der Zinseinkünfte kann daher entfallen.

Obwohl die Zinseinkünfte bei ihrem Konsum in der steuerlich erfaßt werden, treten die oben bei der Periodeneinkommensteuer dargelegten Probleme der Zinsbesteuerung bei der Besteuerung des Periodenkonsums nicht auf.

\subsubsection{Der Einbezug von Vermögenswertänderungen}

Die Wertermittlung ist bei vielen Vermögensgegenständen (z.B. Grundstücke, Anteile an nicht börsennotierten Unternehmen) äußerst problematisch, wenn nicht sogar unmöglich. Aus diesem Grund müßten bei der Wertermittlung standardisierte Verfahren zur Anwendung kommen. Dabei besteht aber die Gefahr, daß bestimmte Vermögensgegenstände systematisch falsch bewertet werden und damit nicht für alle Arten von Vermögensgegenständen ein einheitlicher Wertmaßstab zur Anwendung gelangt. Damit kommt es zu systematischen Verzerrungen zwischen einzelnen Arten von Vermögensgegenständen und daraus folgend zu einer verzerrten Einkommensermittlung. Das Lebenseinkommen -gemessen nach den "tatsächlichen" Werten- kann dann nicht mehr ermittelt werden. Dies wäre unproblematisch, wenn die Verzerrung bei allen Individuen gleich wäre. Davon kann aber nicht ausgegangen werden, da sie sicherlich nicht bei allen Arten von Vermögensgegenständen in gleichem Umfang auftritt. Individuen mit gleichem Lebenseinkommen hätten dann je nach Vermögensstruktur eine unterschiedlich hohe Steuer zu entrichten. Eine Besteuerung nach der individuellen Leistungsfähigkeit ist so nicht mehr gewährleistet.

Erfolgt die Besteuerung über den Periodenkonsum und das Lebensendvermögen, ist die Erfassung des Vermögens lediglich beim Ableben des Individuums notwendig. Beeinträchtigungen der Besteuerung nach der individuellen Leistungsfähigkeit aufgrund der Bewertung können deshalb nur einmal auftreten. Zudem ist der Umfang des zu bewertenden Vermögens kleiner (die im Laufe der Lebensdauer erworbenen und wieder veräußerten bzw. untergegangenen Vermögensgegenstände brauchen am Lebensende nicht bewertet werden), so daß es daher wiederum zu geringeren Beeinträchtigungen des Leistungsfähigkeitsprin- 
zips durch die ungenaue Bewertung bei der Erfassung des Lebensendvermögens kommt als bei einer Periodeneinkommensteuer nach der Reinvermögenszugangstheorie ${ }^{l}$.

Es treten somit durch die Besteuerung des Periodenkonsums geringere Beeinträchtigungen des Leistungsfähigkeitsprinzips auf als bei einer periodischen Einkommensbesteuerung.

Wird aus Praktikabilitätsüberlegungen nicht der Reinvermögenszugangstheorie gefolgt, sondern die Einkommensdefinition von Brandis, nach der nur realisierte Wertänderungen der Besteuerung unterworfen werden, präferiert, ergeben sich durch die Besteuerung des Periodenkonsums folgende zusätzlichen Überlegungen. Bei einer Einkommensdefinition, nach der lediglich realisierte Wertänderungen erfaßt werden, beeinflußt der Realisationszeitpunkt der Wertänderungen die Steuerhöhe (s.o.): bei gleichem Lebenseinkommen (vor Steuern) ist je nach Realisationszeitpunkt der Wertänderungen eine unterschiedlich hohe Steuer zu entrichten. Die Individuen können demnach durch die "richtige" Wahl des Veräußerungszeitpunktes die Steuerhöhe beeinflussen.

Dieses Problem besteht bei der Besteuerung des Periodenkonsums nicht, da hier erstens Wertänderungen nicht erfaßt werden und zweitens die Individuen bei ihrer Konsumplanung nicht nur realisierte Wertänderungen, sondern generell Wertänderungen berücksichtigen, da sie sich zur Erreichung eines größtmöglichen Nutzenniveaus nicht an ihren Periodenzuflüssen, sondern an der geschätzten Leistungsfähigkeit orientieren.

Somit ist sichergestellt, da $\beta$ der Realisationszeitpunkt nicht -wie bei der Einkommensdefinition nach Brandis- die Steuerhöhe beeinflußt. Damit ist durch die Konsumbesteuerung eine Besteuerung nach der individuellen Leistungsfähigkeit besser gewährleistet als bei dem von Brandis vorgeschlagenen Konzept.

Die Besteuerung des Periodenkonsums und des Lebensendvermögens entspricht also eher der Forderung einer gerechten Besteuerung als die Besteuerung des Periodeneinkommens.

\subsubsection{Grundgesetzlich gewährte Eigentumsgarantie / Eigentümerfreiheit}

In der rechtswissenschaftlichen Literatur gibt es Meinungen, die in der Eigentumsgarantie des Grundgesetzes auch die Aufgabe des Staates sehen, die Steuer-

Bei einer Periodeneinkommensteuer nach der Reinvermögenszugangstheorie ist eine periodische Bewertung des Vermögens erforderlich. 
last nach der wirtschaftlichen Leistungsfähigkeit so zu verteilen, daß in die Eigentümerfreiheit möglichst wenig eingegriffen wird ${ }^{I}$.

Um diese Nebenbedingung bei der Besteuerung nach der individuellen Leistungsfähigkeit zu erfüllen, muß auf die Anknüpfungspunkte der Besteuerung eingegangen werden ${ }^{2}$. Die Anknüpfung an der Vermögenssubstanz sollte möglichst vermieden werden, da hier die Steuer aus der Vermögenssubstanz bestritten werden muß. Bei der Besteuerung des Einkommens findet hingegen lediglich eine Besteuerung der im Laufe der Periode hinzuerworbenen Eigentümerfreiheit statt, was laut Kirchhof keinen Eingriff in die Vermögenssubstanz darstellt $^{3}$. Die Eigentümerfreiheit wird von einer Konsumsteuer am wenigsten beeinflußt, da dem Eigentümer nur ein Konsumverzicht auferlegt wird, aber sein Vermögensspielraum im wesentlichen erhalten bleibt ${ }^{4}$. Weiterhin wird weniger stark in die Eigentümerfreiheit eingegriffen als bei der generellen Besteuerung von unrealisierten Wertzuwächsen bei einer Periodeneinkommensteuer, da sich die steuerliche Abschöpfung unrealisierter Wertänderungen an der Konsumentscheidung des Eigentümers ausrichtet. Dieser hat sich bereits vor der Besteuerung entschlossen, unrealisierte Wertänderungen konsumtiv zu verwenden. Nach Kirchhof kann die Besteuerung des Konsums überdies auch mit der Sozialbindung des Eigentums begründet werden ${ }^{5}$. Die Konsumbesteuerung hat gegenüber einer Einkommensbesteuerung nach der Reinvermögenszugangstheorie auch den Vorteil, daß der Steuerpflichtige nicht zur Veräußerung eines Vermögensgegenstandes gezwungen ist, um die Einkommensteuer auf den Vermögenszuwachs aufgrund von Wertsteigerungen bezahlen zu können. Diese bei einer Einkommensteuer unter Umständen notwendige Handlung ist nach der Ansicht von Lang verfassungsrechtlich bedenklich ${ }^{6}$. Durch die Besteuerung des Konsums wird auch auf die Erkenntnisse des Steuerpflichtigen hinsichtlich des Wertes seines Vermögens zurückgegriffen. Somit wird der verfassungsrechtlich relevante Teil des Realisationsprinzips, auf möglichst sichere Werte bei der Besteuerung abzustellen, bei der Besteuerung des Periodenkonsums berücksichtigt $^{7}$.

Die Besteuerung des Periodenkonsums ist deshalb aus der Sicht der aus Artikel 14 GG abgeleiteten Eigentümerfreiheit als vorteilhaft gegenüber einer Besteuerung des Periodeneinkommens nach der Reinvermögenszugangstheorie zu beurteilen.

\footnotetext{
1 Vgl. hierzu auch die Ausführungen im ersten Teil.

2 Vgl. Lang, J. (1988), S. $160 \mathrm{f}$.

3 Vgl. Kirchhof, P. (1980), S. 362.

4 Vgl. Lang, J. (1988), S. $160 \mathrm{f}$.

5 Vgl. Kirchhof, P. (1980), S. 362.

6 Vgl. Lang, J. (1988), S. 160 ff., $171 \mathrm{ff}$.

7 Vgl. Lang, J. (1988), S. 174.
} 


\subsubsection{Ergebnis: Folgerungen für eine lineare Tarifstruktur}

Die hier behandelten empirischen Untersuchungen zum Konsumverhalten der Individuen zeigen, daß diese bei ihrer langfristigen Konsumplanung und der daraus abgeleiteten Bestimmung des gegenwärtigen Konsums, Vermögenswertänderungen sowie unregelmäßige Einkünfte bzw. Windfall Profits einbeziehen und somit diesen "Einkommensbestandteilen" einen Einfluß auf ihre individuelle Leistungsfähigkeit zumessen. Damit werden die im ersten und zweiten Teil angestellten theoretischen Überlegungen hinsichtlich des Einflusses dieser GröBen auf die Leistungsfähigkeit durch das Verhalten der Individuen bestätigt. Unregelmäßige Einkünfte und auch Wertänderungen sind damit unabhängig von ihrer Realisation in die Bemessungsgrundlage einer Steuer, die nach der individuellen Leistungsfähigkeit erhoben wird, einzubeziehen.

Es bestätigt sich das Ergebnis des zweiten Teils: die Reinvermögenszugangstheorie erfaßt grundsätzlich -das Problem der Zinsbesteuerung soll vernachlässigt werden- die Faktoren, die die individuelle Leistungsfähigkeit bestimmen und denen die Individuen selbst einen Einfluß auf ihre Leistungsfähigkeit zumessen. Die anderen Einkommenskonzeptionen bilden die Leistungsfähigkeit durch die Vernachlässigung der unrealisierten Wertänderungen und der unregelmäßigen Einkünfte nicht vollständig ab.

$\mathrm{Da}$ diese Größen in die Konsumplanung der Individuen eingehen, werden sie über die Konsumausgaben automatisch in der steuerlichen Bemessungsgrundlage berücksichtigt. Somit bestehen keine Probleme hinsichtlich ihrer Erfassung. Wird der verwirklichte Mittelerwerb als zweckadäquater Indikator der Leistungsfähigkeit angesehen, ist die Erfassung der Vermögenswerte lediglich einmal, nämlich zum Zeitpunkt des Ablebens, notwendig, was aus Gerechtigkeitserwägungen vorteilhaft ist. Die Erfassung kann nicht unterbleiben, da die Individuen einen nicht zu vernachlässigenden Teil ihres Vermögens weitervererben. Ein weiterer Vorteil einer Konsumsteuer im Vergleich zu einer Besteuerung des Periodeneinkommens besteht durch die weggefallene Zins- bzw. Wertänderungsbesteuerung; somit beeinflußt der Konsumzeitpunkt die Höhe der abzuführenden Steuer nicht. Das hat zur Konsequenz, daß Individuen mit identischem Lebenseinkommen auch die gleiche Steuer abführen. Die durch die Zins- bzw. Wertänderungsbesteuerung hervorgerufene systematische Durchbrechung der Besteuerung nach der individuellen Leistungsfähigkeit findet daher nicht statt. Ebenso werden die Individuen bei einer Konsumbesteuerung weniger stark in ihren Eigentümerfreiheiten eingeschränkt als bei einer periodischen Einkommensbesteuerung.

Die Besteuerung des Lebenseinkommens über die Summe aus Periodenkonsum und Lebensendvermögen führt damit zu gerechteren, dem Leistungsfähigkeitsprinzip eher entsprechenden Ergebnissen als die Besteuerung des Periodenein- 
kommens. Die Besteuerung des Periodenkonsums und des Lebensendvermögens ist deshalb unter dem hier behandelten Aspekt als vorteilhafter im Vergleich zu einer periodischen Einkommensteuer zu beurteilen.

\subsection{Folgerungen für eine progressive Tarifstruktur}

\subsubsection{Periode, für die die Leistungsfähigkeit zu bestimmen ist}

Bei einem progressiven Tarif wird die Steuerhöhe von Schwankungen in der periodischen Bemessungsgrundlage beeinflußt. Die zu entrichtende Steuer ist dabei bei gleichem Lebenseinkommen umso höher, je ungleichmäßiger die Höhe der Periodeneinkommen im Zeitablauf verteilt ist. Individuen mit der gleichen -mit Hilfe des Indikators "Lebenseinkommen" gemessenen- Leistungsfähigkeit haben somit eine unterschiedlich hohe Steuer zu entrichten. Über den Zeitablauf schwankende Einkommen sind kein Phänomen, das auf einige wenige Individuen (z.B. Spitzensportler) beschränkt ist, sondern betrifft fast alle Personen ${ }^{I}$. Die Schwankungen in der Bemessungsgrundlage können durch die Wahl der Länge der Periode, für die der Steuersatz bestimmt wird, beeinflußt werden, da sich bei einer längeren Periode kurzfristige Schwankungen ausgleichen. Die Wahl der relevanten Periodenlänge ist bei einem progressiven Tarif ein die Steuerhöhe der einzelnen Individuen wesentlich beeinflussender Faktor.

Bei den oben durchgeführten theoretischen Überlegungen für die Bestimmung des für die Leistungsfähigkeit relevanten Zeitraums ergab sich, daß aufgrund von Gerechtigkeits- und Neutralitätsüberlegungen die Lebensdauer der Individuen zur Bestimmung ihrer Leistungsfähigkeit heranzuziehen ist.

Im folgenden wird untersucht, ob aufgrund der Implikationen der Lebenszyklushypothese Aussagen zu der für die Bestimmung der Leistungsfähigkeit relevanten Periode getroffen werden können. Dazu wird analysiert, welche Periodenlänge die Individuen bei der eigenen Abschätzung ihrer Leistungsfähigkeit zugrunde legen, d.h. über welchen Zeitraum sie ihre Konsum-Spar-Entscheidung treffen.

Die Lebenszyklushypothese nimmt an, daß die Individuen ihre Leistungsfähigkeit über ihre Lebensdauer abschätzen. Diese Behauptung wurde durch empirische Untersuchungen nicht falsifiziert ${ }^{2}$. Es kann mithin davon ausgegangen werden, daß die Mehrheit der Individuen bei ihrer Konsumplanung -bei der geplan-

\footnotetext{
$1 \quad$ Vgl. hierzu oben.

2 Gegen die ablehnenden empirischen Untersuchungen wurden plausible Gegenargumente vorgebracht.
} 
ten Verfügung über ihre Ressourcen und damit der Abschätzung ihrer individuellen Leistungsfähigkeit- ihre abgeschätzte Lebensdauer bzw. (in einer etwas schwächeren Form) zumindest einen längeren Zeitraum berücksichtigen. Der Zeitraum, für den die Leistungsfähigkeit zu bestimmen ist, ist somit aus der Sicht der Individuen nicht ein Jahr, sondern umfaßt ihre Lebensdauer. Die isoliert betrachteten Verhältnisse während eines Jahres sind deshalb nicht die maßgeblichen Bestimmungsgrößen für die Konsum-Spar-Entscheidung der Individuen in der laufenden Periode.

Die im ersten Teil angestellten theoretischen Überlegungen hinsichtlich der Periode, für die die individuelle Leistungsfähigkeit zu ermitteln ist, werden demnach durch die aus der Lebenszyklushypothese gewonnenen und durch die Empirie unterstrichenen Ergebnisse bestätigt. Das Periodeneinkommen ist nur eine Bestimmungsgröße unter vielen für die Höhe des Periodenkonsums und ein weniger guter Indikator zur Abschätzung der Leistungsfähigkeit.

\subsubsection{Vergleich der Besteuerung des Periodenkonsums und des Lebens- endvermögens mit der Besteuerung des Periodeneinkommens}

Es wird geprüft, ob die Messung des Lebenseinkommens als Indikator der Leistungsfähigkeit durch den Periodenkonsum und das Lebensendvermögen vorteilhafter zu beurteilen ist als die Messung über das Periodeneinkommen. Dabei wird lediglich auf die durch ein progressives Steuersystem hervorgerufenen Probleme eingegangen ${ }^{I}$.

Zur Bestimmung der Leistungsfähigkeit ist die gesamte Lebensdauer heranzuziehen. Aufgrund von Praktikabilitätsüberlegungen sollte jedoch eine periodenweise Besteuerung durchgeführt werden. Im Rahmen der Untersuchung der Periodeneinkommensteuer wurde gezeigt, da $\beta$ das Periodeneinkommen stärkeren Schwankungen unterworfen ist als das Lebenseinkommen. Aus diesem Grund wurde auch auf Verfahren eingegangen, die versuchen, einen geglätteten Steuersatz zu ermitteln. Diese Verfahren sind in der Wissenschaft umstritten und meist auch nicht einfach zu handhaben. Es muß daher geklärt werden, ob die Besteuerung des Periodenkonsums zu einer weniger schwankenden Bemessungsgrundlage führt und damit eine geringere Notwendigkeit zur Implementierung von Glättungsverfahren im Vergleich zu einer Periodeneinkommensteuer besteht.

Die Probleme, die auch bei einem linearen Steuertarif auftreten, wurden bereits behandelt. 
Die behandelten empirischen Untersuchungen zur Lebenszyklushypothese implizieren, daß die Mehrheit der Individuen ihre Leistungsfähigkeit selbst abschätzt. Dazu werden alle zur Verfügung stehenden Informationen -einschließlich der Erwartungen hinsichtlich ihres zukünftigen Einkommensgenutzt, um den Konsum zu planen. In diese Abschätzung beziehen die Individuen auch Daten ein, die nur ihnen bekannt sind, z.B. bis zu welchem Lebensalter und mit welcher Intensität sie planen zu arbeiten, wie sie ihr eigenes Potential abschätzen und welche Umweltbedingungen (z.B. Beförderungsmöglichkeiten, Chancen auf dem Arbeitsmarkt) sie vorfinden. Diese Daten, die sich nicht unbedingt im aktuellen Periodeneinkommen widerspiegeln, beeinflussen in sehr hohem Maße die Höhe des Lebenseinkommens und die Verteilung auf die verschiedenen Jahre. Sie werden von den Individuen zur Planung ihrer KonsumSpar-Entscheidung genutzt, durch den Konsum nach außen dokumentiert und somit auch dem Fiskus als Besteuerungsgrundlage zugänglich gemacht. Da die Individuen einen geglätteten Periodenkonsum einem stark schwankenden vorziehen, führt die langfristige Konsumplanung dazu, daß der Periodenkonsum geringeren Schwankungen unterworfen ist als das Periodeneinkommen. Für umstrittene Glättungsverfahren, die ohnehin meist nur vergangenheitsorientierte Daten oder sehr pauschale Annahmen (z.B. Abschätzung des zukünftigen Einkommens nach der Berufsgruppenzugehörigkeit) nutzen, besteht eine geringere Notwendigkeit ${ }^{l}$. Die Probleme von schwankenden Bemessungsgrundlagen werden also gemindert.

Damit wird auch ein weiterer Nachteil der progressiven Periodeneinkommensbesteuerung beseitigt bzw. abgemildert: bei der Periodeneinkommensteuer wurde die Ungleichbehandlung von Individuen mit gleichem Lebenseinkommen, aber einer unterschiedlichen intertemporalen Arbeit-Freizeit- bzw. Arbeit-Ausbildungs-Entscheidung angeführt. Bei einer Einkommensbesteuerung ist es günstiger, ein Arbeitnehmer erzielt über die gesamte mögliche Lebensarbeitszeit hinweg ein gleichmäßiges (Perioden-) Arbeitseinkommen als ein unregelmäßiges. Diese Verzerrung findet bei einer (Perioden-) Konsumbesteuerung nicht in dem Maße statt, da die Individuen bei ihrer langfristigen Konsumplanung ihr intertemporales Arbeitsangebot einbeziehen. Dadurch ist der Periodenkonsum geringeren Schwankungen unterworfen als das Periodeneinkommen.

Die empirischen Untersuchungen zur Lebenszyklushypothese zeigen auch, da $\beta$ transitorische Einkommensänderungen (z.B. Windfall Profits, unregelmäßige Einkünfte) in die langfristige Konsumplanung einbezogen werden, d.h. die Individuen schreiben ihnen eine leistungsfähigkeitssteigernde Funktion zu. Dies spricht für einen Einbezug in die steuerliche Bemessungsgrundlage. Bei einer

1 Die Daten, die die Individuen zur Konsumplanung nutzen, sind für Dritte -auch den Fiskus- exante nicht vorhersehbar, d.h. sie könnten auch für die Verfahren zur Glättung der einzelnen Perioden nicht genutzt werden. 
jährlichen Einkommensteuer werden daher durch die Berücksichtigung dieser unregelmäßig anfallenden Einkommensbestandteile die Schwankungen in der steuerlichen Bemessungsgrundlage und damit die des Steuersatzes verstärkt. Wie obige empirische Untersuchungen jedoch auch zeigen, werden Windfall Profits bzw. unregelmäßige Einkünfte nicht im Zugangsjahr konsumiert, sondern beeinflussen die Konsumhöhe über einen längeren Zeitraum hinweg. Der Periodenkonsum weist damit einen gleichmäßigeren Verlauf auf als das Periodeneinkommen. Dies bedeutet bei der Besteuerung des Periodenkonsums -ohne die Anwendung von umstrittenen Glättungsverfahren- eine glättere Bemessungsgrundlage im Vergleich zu einer periodisch durchgeführten Einkommensbesteuerung.

Wird aus Praktikabilitätsüberlegungen heraus als Vergleichsmaßstab zu einer Periodenkonsumsteuer eine Periodeneinkommensteuer gewählt, bei der lediglich die realisierten Wertänderungen berücksichtigt werden (Einkommensdefinition nach Brandis), besteht bei der Besteuerung des Periodenkonsums der zusätzliche Vorteil, daß die Individuen Vermögenswertänderungen zeitnah zu ihrer Entstehung -und nicht erst bei ihrer Realisation- in ihren Konsumplan einbeziehen. Sie gehen sofort in die Bemessungsgrundlage ein; es entstehen deshalb keine negativen Progressionseffekte. Treten die Vermögenswertänderungen nicht langsam ein (z.B. als Verzinsung des eingesetzten Kapitals), sondern schlagartig, werden sie gespart und gehen erst im Laufe der Zeit über den Konsum in die steuerliche Bemessungsgrundlage ein. Infolgedessen ergibt sich ohne die Anwendung umstrittener Glättungsverfahren bei der Konsumbesteuerung eine glättere Bemessungsgrundlage als bei der Einkommensdefinition nach Brandis.

Das Lebensendvermögen ist bei der Besteuerung des Lebenseinkommens über die Verwendungsseite ebenfalls zu erfassen. Es wird jedoch unter Umständen -bei einer progressiven Tarifstruktur- mit einem Steuersatz besteuert, der wesentlich vom "durchschnittlichen" Steuersatz auf den Periodenkonsum abweicht, wenn dieselbe Tarifstruktur wie bei der Besteuerung des Periodenkonsums zur Anwendung kommt. Aufgrund von Gerechtigkeitserwägungen sollte aber ein durchschnittlicher Steuersatz angewendet werden. Dessen Bestimmung ist allerdings weniger problematisch als bei der Besteuerung des Periodeneinkommens, da die Durchschnittsbildung nur einmal stattfindet und zu diesem Zeitpunkt das Lebenseinkommen sowie das erreichte Lebensalter des Steuerpflichtigen feststehen.

Zusammenfassend kann festgestellt werden: das Periodeneinkommen genügt als Indikator der Leistungsfähigkeit aufgrund der fehlenden Validität nicht den An- 
forderungen an ein Meßkonzept, da der relevante Zeitraum für die Besteuerung der Leistungsfähigkeit nicht abgebildet wird. Es ist damit als Indikator zur Messung der Leistungsfähigkeit abzulehnen.

Die Besteuerung des Periodenkonsums führt im Vergleich zu einer Periodeneinkommensteuer zu einer glätteren Bemessungsgrundlage; damit ist auch der periodische Steuersatz geringeren Schwankungen unterworfen. Die Besteuerung nach der individuellen Leistungsfähigkeit wird somit durch eine Konsum- und Lebensendvermögensbesteuerung eher gewährleistet.

\subsubsection{Ergebnis: Folgerungen für eine progressive Tarifstruktur}

Die Individuen planen ihren Konsum längerfristig und schätzen damit ihre Leistungsfähigkeit über einen längeren Zeitraum ab. Dies bestätigt die im ersten Teil gewonnenen Ergebnisse, nach denen der Zeitraum, für den die Leistungsfähigkeit zu bestimmen ist, nicht ein Jahr, sondern die Lebensdauer der Individuen umfaßt.

Die Bemessungsgrundlage "Periodenkonsum" ist weniger starken Schwankungen unterworfen als das Periodeneinkommen. Somit wird auch ohne komplizierte und umstrittene Glättungsverfahren ein Steuersatz auf die Bemessungsgrundlage "Periodenkonsum" angewendet, der weniger schwankt als der, der sich bei der periodischen Einkommensbesteuerung ergeben würde. Darüberhinaus werden hierbei auch die Erwartungen des Individuums über sein eigenes $\mathrm{Zu}$ kunftseinkommen berücksichtigt - auf diese Daten könnte bei einem Glättungsverfahren nicht zurückgegriffen werden.

Durch die langfristige Konsumplanung der Individuen wird ebenfalls ein Zielkonflikt des ersten Teils gelöst. Aus Gerechtigkeits- und Neutralitätserwägungen heraus sollte die Besteuerungsperiode die Lebensdauer umfassen; aus Praktikabilitätserwägungen jedoch nur eine kurze Zeitspanne. Durch die Besteuerung des Periodenkonsums können aufgrund der langfristigen Konsumplanung beide Forderungen erfüllt werden. Die Besteuerungsperiode umfaßt faktisch einen sehr langen Zeitraum, für den das Individuum seine eigene Leistungsfähigkeit abschätzt; dies ist aus Gerechtigkeits- und Neutralitätserwägungen zu begrüßen. Dagegen umschließt die tatsächliche Besteuerungsperiode einen wesentlich kürzeren Zeitraum, z.B. ein Jahr bei einer jährlich erhobenen Konsumsteuer. Dadurch werden Gerechtigkeits- und Neutralitätserfordernisse erfüllt, ohne die praktischen Nachteile einer langen Besteuerungsperiode.

Problematisch ist allerdings, daß die Individuen unter Umständen ein Lebensendvermögen hinterlassen, das aufgrund der progressiven Tarifstruktur zu einem nicht dem "durchschnittlichen" Steuersatz entsprechenden Tarif führt. Hier 
ist eventuell eine Glättung durchzuführen, die allerdings weniger problematisch ist als bei einer periodischen Einkommensbesteuerung, da mit dem Ableben des Individuums alle besteuerungsrelevanten Daten, wie das Lebenseinkommen und das erreichte Lebensalter, feststehen.

Durch die Besteuerung des Periodenkonsums und des Lebensendvermögens wird dem Gerechtigkeitsideal "gleiches Lebenseinkommen, gleiche zu zahlende Steuer" und somit dem Leistungsfähigkeitsprinzip auch bei einem progressiven Tarif eher entsprochen als bei einer Periodeneinkommensteuer.

\section{Neutralität der Besteuerung}

Nachfolgend werden einige Neutralitätsüberlegungen zur Konsum- und Lebensendvermögensbesteuerung angestellt. Es wird untersucht, ob bei der Konsumbesteuerung ebenso Probleme hinsichtlich der Neutralität der Besteuerung bestehen wie bei der periodischen Einkommensbesteuerung ${ }^{l}$.

Im Rahmen der Analyse wird u.a. auf die Konsum-Spar-Entscheidung der Individuen, die Investitionsentscheidung der Unternehmen sowie das Wirtschaftswachstum eingegangen. Weiterhin wird der Einfluß auf die Wahl der Unternehmensrechtsform und die Art der Unternehmensfinanzierung betrachtet. Die Probleme der Besteuerung des Lebensendvermögens wird an anderer Stelle diskutiert.

\subsection{Konsum-Spar-Entscheidung des Individuums ${ }^{2}$}

Die Vermögensbildung eines Individuums ist davon abhängig, ob der heutige Konsumverzicht durch einen zukünftigen Mehrkonsum kompensiert wird, d.h. wie sich die Versorgungslage aufgrund des momentanen Konsumverzichts zugunsten eines zukünftigen Mehrkonsums verändert. Die Entscheidung ist abhängig von dem zu erzielenden Nettomarktzinssatz. Das Individuum ist in einer

1 Bei der periodischen Einkommensbesteuerung verzerrt die Zinsbesteuerung die intertemporale Konsumentscheidung der Individuen: sie ersetzen Sparen (= zukünftigen Konsum) durch gegenwärtigen Konsum. Weiterhin vermindert das durch die Zinsbesteuerung erhöhte Zinsniveau im Kapitalmarktgleichgewicht das Wirtschaftswachstum im Vergleich zu einer Laissez-Faire-Ökonomie. Es findet somit keine optimale Ressourcenallokation statt.

2 Methodisch angelehnt an Nachtkamp, H.H. (1988), S. 169 f. 
Laissez-Faire-Ökonomie dann indifferent, wenn die individuelle Zeitpräferenzrate dem Kapitalmarktzinssatz entspricht $(\gamma=r)$.

Bei einer Konsumbesteuerung sind die Zinsen im Gegensatz zu einer Einkommensbesteuerung nach der Reinvermögenszugangstheorie steuerfrei; das Individuum orientiert sich bei seiner intertemporalen Konsumentscheidung weiter am Kapitalmarktzinssatz. Die intertemporale Konsumentscheidung und damit die Vermögensbildung wird nicht beeinflußt.

\subsection{Investitionsentscheidung der Unternehmen}

In einer Laissez-Faire-Ökonomie entspricht die Nettogrenzproduktivität dem Kapitalmarktzinssatz $\left(f_{k}=r\right)$.

Die Unternehmen werden bei einer reinen Konsumbesteuerung nicht besteuert, d.h. die obige Beziehung wird nicht durch steuerliche Effekte beeinflußt. Somit werden die Investitionsentscheidungen der Unternehmen durch die Konsumbesteuerung nicht verzerrt.

\subsection{Einfluß auf das Wirtschaftswachstum}

Die Verbindungsstelle zwischen den Unternehmen und den Individuen ist der Kapitalmarkt, so daß wie in einer Laissez-Faire-Ökonomie gilt:

$$
\gamma=\mathrm{r}=\mathrm{f}_{\mathrm{k}}
$$

Das Wirtschaftswachstum wird durch die Besteuerung des Konsums nicht beeinflußt; die Ressourcenallokation findet insoweit analog zur Laissez-FaireÖkonomie statt.

\subsection{Finanzierungsentscheidung der Unternehmen}

Ein Unternehmen hat zur Finanzierung seiner Nettoinvestitionen drei Möglichkeiten: es kann erstens seine Fremdkapitalaufnahme erhöhen, zweitens einen geringeren Gewinn ausschütten und den einbehaltenen Gewinn thesaurieren oder drittens das Beteiligungskapital erhöhen. 
Die Analyse der Finanzierungsneutralität wurde bereits vorgenommen: Finanzierungsneutralität ist gegeben bei identischen Steuersätzen für einbehaltene bzw. ausgeschüttete Gewinne sowie für die Zinsbesteuerung.

Bei der Konsumbesteuerung werden ausgeschüttete bzw. thesaurierte Gewinne sowie Zinsen nicht besteuert (wenn die entsprechenden Größen nicht vom Individuum konsumiert werden). Die Gleichheit der Steuersätze $\tau_{\mathrm{a}}, \tau_{\mathrm{e}}$ sowie $\tau_{\mathrm{z}}$ (jeweils $=0 \%$ ) und somit die Finanzierungsneutralität ist daher gewährleistet.

\subsection{Untersuchung weiterer möglicher Entscheidungsbeeinflussungen}

Bei der Periodeneinkommensbesteuerung ist auch die Beeinflussung der intertemporalen Arbeitsentscheidung problematisch. Sie wurde -expost betrachtetdurch die Besteuerung der Zinsen dahingehend verzerrt, daß es für die Individuen günstiger gewesen wäre, in der Vergangenheit möglichst wenig zu arbeiten, da eine zusätzliche Arbeitsstunde in der Vergangenheit lediglich 26 Minuten mehr Freizeit in der Gegenwart ermöglicht bzw. eine zusätzliche Stunde Freizeit in der Vergangenheit heute nur 26 Minuten Mehrarbeit kostet. Der Arbeitnehmer ist mithin aufgrund der Zinsbesteuerung nicht mehr indifferent bezüglich des Arbeitszeitpunktes.

Es wurde auch gezeigt, daß eine Einkommensdefinition, die ausschließlich realisierte Wertänderungen in ihrer Bemessungsgrundlage berücksichtigt, die Innovationsbereitschaft der Unternehmen negativ beeinflußt und somit langfristig die Leistungskraft der Volkswirtschaft abnimmt.

Ein Problem, das allerdings nur besteht, wenn bei der Periodeneinkommensbesteuerung lediglich die realisierten Wertänderungen besteuert werden ${ }^{l}$, ist die steuerliche Diskriminierung von Anlagen, die laufende Zinszahlungen aufweisen, im Vergleich zu Anlagen mit Wertsteigerungen, die der Verzinsung des eingesetzten Kapitals entsprechen. Weiterhin wird -wenn nur die realisierten Wertänderungen besteuert werden- die Entscheidung zwischen kurz- und langfristigen Anlagen verzerrt: für einen Anleger mit längerfristiger Anlageabsicht ist es unvorteilhaft, kurzfristige Anlagen zu erwerben, da bei jeder Realisation von Wertsteigerungen hierauf Steuern anfallen.

Hinsichtlich der Entscheidungsneutralität ist bei einem progressiven Periodeneinkommensteuertarif die Ungleichbehandlung von Individuen mit gleichem Lebenseinkommen, aber einer unterschiedlichen intertemporalen Arbeit-Freizeitbzw. Arbeit-Ausbildung-Entscheidung zu nennen. Bei einer Einkommensbe-

I Wie z.B. bei der von Brandis vorgeschlagenen Einkommenskonzeption. 
steuerung ist es günstiger über die gesamte mögliche Lebensarbeitszeit ein gleichmäßiges (Perioden-) Arbeitseinkommen zu beziehen, da bei schwankendem Periodeneinkommen vor Steuern ein höherer Barwert an Steuern zu entrichten ist als bei einem gleichbleibenden periodischen Einkommensniveau.

Ist der Periodenkonsum Bemessungsgrundlage der Besteuerung, entfallen alle o.a. Verstöße gegen die Entscheidungsneutralität der Besteuerung, die ihre Ursache in der Zins- und Wertänderungsbesteuerung bzw. in den stärkeren Schwankungen des Periodeneinkommens im Vergleich zum Periodenkonsum haben. Weiterhin wird die Arbeit-Freizeit- bzw. Arbeit-Ausbildung-Entscheidung bei einer (Perioden-) Konsumbesteuerung nicht durch einen progressiven Steuertarif beeinflußt, wie dies bei der Besteuerung des Periodeneinkommens geschieht.

Die grundsätzliche Verzerrung der Arbeit-Freizeit-Entscheidung im Vergleich zu einer Laissez-Faire-Ökonomie bleibt allerdings -wie oben gezeigt- auch durch die Besteuerung des Konsums bestehen.

\subsection{Ergebnis: Neutralität der Besteuerung}

Die Besteuerung des Periodenkonsums beeinflußt weder die intertemporale Konsumentscheidung der Individuen, noch die Investitionsentscheidung der Unternehmen; dadurch ist Wachstumsneutralität und somit eine optimale Ressourcenallokation gewährleistet. Weiterhin wird durch die Konsumbesteuerung weder die Art der Unternehmensfinanzierung noch die Wahl der Rechtsform beeinflußt.

Problematisch war bei der Besteuerung des Periodeneinkommens auch die Beeinflussung der intertemporalen Arbeitsentscheidung sowie die Verzerrung der Anlageentscheidung der Individuen hinsichtlich der Auswahl von Anlagen mit Wertsteigerungen im Vergleich zu solchen mit laufenden Zinszahlungen. Bei einem progressiven Steuertarif wurde darüberhinaus die intertemporale ArbeitFreizeit- bzw. Arbeit-Ausbildung-Entscheidung zusätzlich beeinflußt. Diese Entscheidungen werden bei der Besteuerung des Periodenkonsums nicht beeinflußt. Die grundsätzliche Verzerrung der Arbeit-Freizeit-Entscheidung bleibt hingegen -ebenso wie bei einer Periodeneinkommensteuer- auch bei der Konsumbesteuerung bestehen.

Die Verstöße gegen die Forderung nach einem neutralen Steuersystems, die bei der Periodeneinkommensbesteuerung aufgrund der Zinsbesteuerung bzw. des schwankenden Periodeneinkommens auftreten, sind somit bei der Besteuerung 
des Lebenseinkommens über die Verwendungsseite, also der Besteuerung des Periodenkonsums und des Lebensendvermögens, nicht vorhanden.

\section{Praktikabilität der Besteuerung}

Im folgenden Teil wird nur auf die bei einer Einkommensteuer auftretenden Probleme und deren Lösbarkeit durch die Besteuerung des Konsums eingegangen. Dabei wird vorerst die praktikable Meßbarkeit des Konsums unterstellt. Diese Annahme wird später gesondert behandelt.

Die Untersuchungen der Lebenszyklushypothese über das Konsumverhalten der Individuen zeigen, daß diese bei ihrer langfristigen Konsumplanung und der daraus abgeleiteten Bestimmung des gegenwärtigen Konsums Vermögenswertänderungen miteinbeziehen. Wertänderungen im Vermögen gehen somit über die Konsumausgaben automatisch in die steuerliche Bemessungsgrundlage ein; deshalb bestehen keine Probleme hinsichtlich ihrer Erfassung ${ }^{l}$. Eine weitere Erleichterung ergibt sich dadurch, daß bei den Vermögensgegenständen keine Ertragswertabschreibungen vorzunehmen sind. Somit ist auch keine periodische Wertermittlung zur Bestimmung der Leistungsfähigkeit des Steuerpflichtigen durchzuführen. Die Erfassung der Vermögenswerte ist lediglich einmal, nämlich zum Zeitpunkt des Ablebens des Individuums notwendig. Sie kann nicht wegen Geringfügigkeit des vererbten Vermögens unterbleiben, da die Individuen -wie obige Untersuchungen zeigen- einen nicht unbeachtlichen Betrag vererben. Es ist aber ein wesentlich geringerer Umfang an Vermögen zu bewerten, da die Vermögensgegenstände, die ein Steuerpflichtiger während seines Lebens erwirbt und wieder veräußert oder die im Laufe seines Lebens vollständig verbraucht werden, nicht mehr im Lebensendvermögen vorhanden sind und daher nicht bewertet werden müssen. Das Problem des Messens von Vermögenswertänderungen wird damit -mit Ausnahme des Lebensendvermögens- auf die Messung des Konsums verlagert. Bei der Bestimmung des Lebensendvermögens bestehen jedoch grundsätzlich dieselben Probleme wie bei einer periodisch durchzuführenden Einkommensbesteuerung. Diese Problematik wird allerdings dadurch abgemildert, daß aufgrund des geringeren Umfangs des zu bewertenden Vermögens ein höherer Aufwand zur Bestimmung des Vermögenswertes betrieben werden $\mathrm{kann}^{2}$ bzw. der Einsatz von pauschalierten Verfahren zu geringeren Verzerrungen führt.

1 Die Einkommensbesteuerung nach der Reinvermögenszugangstheorie wurde oben als nicht praktikabel beurteilt. Ursache hierfür war die praktische Unmöglichkeit der jährlich durchzuführenden Gesamtbewertung des Vermögens.

Es kann z.B. vom Fiskus mehr Zeit auf den einzelnen Sachverhalt verwendet werden. 
Ein Problem der Periodeneinkommensbesteuerung besteht bei einer progressiven Tarifstruktur: es wurde aufgrund des aus dem Gleichheitssatz abgeleiteten Leistungsfähigkeitsprinzips gefordert, daß die Höhe des Steuersatzes aus einer Bemessungsgrundlage abzuleiten ist, die zeitlich die gesamte Lebensdauer des Individuums umfaßt. Auf der anderen Seite muß der Steuerpflichtige aus Praktikabilitätsgründen (z.B. laufender Finanzbedarf des Staates, Zahlungsfähigkeit der Steuerpflichtigen) Steuerzahlungen für kürzere Zeiträume entrichten. Diese ("Abschlags-") Zahlungen sollten denjenigen Beträgen nahekommen, die zu entrichten sind, wenn auf die periodische Bemessungsgrundlage der Steuersatz angelegt wird, der aufgrund der Höhe des Lebenseinkommens anzuwenden ist; somit besteht die Notwendigkeit, Glättungsverfahren anzuwenden.

Durch die -auch empirisch- nicht widerlegten Implikationen der Lebenszyklushypothese wurde festgestellt, daß der Periodenkonsum geringere Schwankungen aufweist als das Periodeneinkommen. Es besteht folglich eine geringere Notwendigkeit, Glättungsverfahren anzuwenden. Die Besteuerung des Periodenkonsums ist daher im Vergleich zur Periodeneinkommensteuer vorteilhafter zu beurteilen.

Problematisch ist jedoch, daß das Lebensendvermögen unter Umständen einem Steuersatz unterworfen wird, der erheblich von dem "durchschnittlichen" Steuersatz abweicht. Hier müßte aus Gerechtigkeitsüberlegungen eine Durchschnittsbildung stattfinden, die aber weniger problematisch als bei einer Periodeneinkommensteuer ist, da sie nur einmal durchgeführt werden muß und überdies alle relevanten Daten (z.B. das Lebenseinkommen und das erreichte Lebensalter) mit dem Ableben des Individuums feststehen. Somit sind viele Probleme einer ansonsten periodisch durchzuführenden Glättung weggefallen.

Aus Praktikabilitätsgründen ist die Besteuerung des Periodenkonsums und des Lebensendvermögens somit der periodischen Einkommensbesteuerung nach dem Konzept der Reinvermögenszugangstheorie überlegen.

\section{Ergebnis: Folgerungen für die Ausgestaltung eines Steuersystems}

Empirische Untersuchungen zum Konsumverhalten bestätigen eine langfristige Konsumplanung der Individuen. Die Individuen streben weiterhin einen geglätteten Periodenkonsum an. In die Planung und dem daraus abgeleiteten Periodenkonsum werden Vermögenswertänderungen, unregelmäßige Einkünfte (einschließlich Windfall Profits) sowie das zukünftig erwartete Einkommen einbezogen. Diesen Faktoren rechnen die Individuen infolgedessen einen Einfluß auf ihre Leistungsfähigkeit zu. 
Die im ersten und zweiten Teil angestellten theoretischen Überlegungen hinsichtlich des Einflusses von unregelmäßigen Einkünften und Vermögenswertänderungen auf die Leistungsfähigkeit werden also durch das Verhalten der Individuen bestätigt. Dementsprechend sind sowohl unregelmäßige Einkünfte als auch Wertänderungen -unabhängig von ihrer Realisation- in die Bemessungsgrundlage einer gerechten Steuer einzubeziehen.

Bei der Besteuerung des Periodenkonsums gehen diese Größen -so das Ergebnis der obigen Untersuchungen- in die steuerliche Bemessungsgrundlage ein, da sie die Höhe der periodischen Konsumausgaben beeinflussen. Damit bestehen auch keine Probleme hinsichtlich ihrer Erfassung. Ein weiterer Vorteil einer Konsumsteuer im Vergleich zu einer Besteuerung des Periodeneinkommens besteht in der weggefallenen Zinsbesteuerung: der Konsumzeitpunkt beeinflußt mithin die Höhe der abzuführenden Steuer nicht, so daß Individuen mit gleichem Lebenseinkommen auch die gleiche Steuer abführen. Die durch die Zinsbesteuerung hervorgerufene systematische Durchbrechung der Besteuerung nach der individuellen Leistungsfähigkeit findet deshalb nicht statt. Die Individuen werden überdies bei einer Konsumbesteuerung weniger stark in ihren Eigentümerfreiheiten eingeschränkt als bei einer Einkommensbesteuerung.

Die Erfassung von Vermögenswerten muß lediglich beim Ableben des Individuums vorgenommen werden; Ungerechtigkeiten, die durch die Vermögensbewertung verursacht werden könnten, treten nur einmal auf. Die Erfassung des Lebensendvermögens kann aber aus Gerechtigkeitsgründen nicht entfallen, da die Individuen einen nicht zu vernachlässigenden Teil ihres Vermögens vererben.

Bei einem progressiven Steuertarif führen im Zeitablauf schwankende Bemessungsgrundlagen zu einer höheren zu zahlenden Steuer als eine gleichmäßige. Es ist deshalb fraglich, für welchen Zeitraum die Leistungsfähigkeit zu ermitteln ist. Effizienz- und Gerechtigkeitsüberlegungen im ersten Teil führen zu dem Schluß, daß die Lebensdauer des Individuums als Besteuerungsperiode herangezogen werden sollte. Die hier behandelten empirischen Untersuchungen zeigen, daß die Individuen zur Bestimmung ihres Periodenkonsums eine langfristige Konsumplanung betreiben, der sie ihre selbst abgeschätzte Leistungsfähigkeit zugrunde legen. Dies bestätigt die im ersten Teil gewonnenen Ergebnisse, nach denen der Zeitraum, für den die Leistungsfähigkeit zu bestimmen ist, nicht ein Jahr, sondern die Lebensdauer der Individuums umfassen soll.

Die Individuen streben überdies einen geglätteten Periodenkonsum an und präferieren ihn gegenüber einem stark schwankenden. Somit entsprechen die periodisch zu leistenden Steuerzahlungen eher als bei einer Periodeneinkommensteuer den Steuerzahlungen, die sich bei der Anwendung des auf die Lebensdauer und das Lebenseinkommen des Steuerpflichtigen bezogenen Steuersatzes auf eine periodische Bemessungsgrundlage ergeben. 
Durch die langfristige Konsumplanung der Individuen wird auch ein Zielkonflikt des ersten Teils gelöst: obwohl die Besteuerungsperiode faktisch einen sehr langen Zeitraum umfaßt (nämlich den, für den das Individuum seine eigene Leistungsfähigkeit abschätzt), was aus Gerechtigkeits- und Neutralitätserwägungen $\mathrm{zu}$ begrüssen ist, kann die tatsächliche Besteuerungsperiode einen wesentlich kürzeren Zeitraum umfassen. Damit werden Gerechtigkeits- und Neutralitätserfordernisse erfüllt, ohne daß die praktischen Nachteile einer langen Besteuerungsperiode auftreten.

Angesichts des geglätteten Konsums wird auch ohne komplizierte und umstrittene Glättungsverfahren ein Steuersatz auf die Bemessungsgrundlage "Periodenkonsum" angewendet, der weniger schwankt als bei der periodischen Einkommensbesteuerung. Darüberhinaus werden hierbei auch die Erwartungen der Individuen über ihr eigenes Zukunftseinkommen berücksichtigt - auf diese Daten könnte bei einem Glättungsverfahren nicht zurückgegriffen werden.

Problematisch ist allerdings, daß die Individuen unter Umständen ein Lebensendvermögen hinterlassen, das aufgrund der progressiven Tarifstruktur zu einem nicht dem "durchschnittlichen" Steuersatz entsprechenden Tarif führt. Hier ist eventuell eine Glättung durchzuführen; zu diesem Zeitpunkt stehen jedoch alle besteuerungsrelevanten Daten (z.B. das Lebenseinkommen und das erreichte Lebensalter), die für ein Glättungsverfahren benötigt werden, fest.

Die Messung und Besteuerung des Lebenseinkommens mit Hilfe des Periodenkonsums und des Lebensendvermögens (auch bei einem progressiv gestalteten Steuertarif) führt damit zu gerechteren, dem Prinzip der Besteuerung nach der individuellen Leistungsfähigkeit eher entsprechenden Ergebnissen als eine Periodeneinkommensteuer.

Die Besteuerung der Konsumausgaben stellt auf die Verwendungsseite des Einkommens ab. Somit können auch keine Verstöße gegen die Entscheidungsneutralität der Besteuerung wie durch die Zinsbesteuerung entstehen. Bei einem progressiven Tarifverlauf wird die intertemporale Arbeitsentscheidung des Individuums bei der Besteuerung des Periodenkonsums nicht zusätzlich durch den progressiven Tarifverlauf verzerrt. Die grundsätzliche Verzerrung der ArbeitFreizeit-Entscheidung besteht jedoch weiter.

Die Besteuerung des Periodenkonsums und des Lebensendvermögens ist auch aus praktischen Gründen zu präferieren: die Bewertung des Vermögens muß nur einmal durchgeführt werden. Somit entsteht ein wesentlich geringerer Erhebungs- und Verwaltungsaufwand. Weiterhin ist ein bedeutend geringerer Umfang an Vermögen zu bewerten als bei einer periodischen Vermögensbewertung, 
die bei einer Einkommensteuer nach der Reinvermögenszugangstheorie zur Erfassung des Periodeneinkommens notwendig ist. 


\section{Kapitel}

\section{Methoden zur Erfassung des Periodenkonsums}

In diesem Teil der Arbeit werden verschiedene Möglichkeiten zur Erfassung des Periodenkonsums eines Steuerpflichtigen untersucht. Zuerst werden folgende Methoden zur Erfassung und Besteuerung des Periodenkonsums dargestellt und diskutiert:

- Indirekte Ermittlung des Periodenkonsums

- Mehrwertsteuer

- Eigene Aufzeichnungen des Steuerpflichtigen

Danach wird auf verschiedene Sonderprobleme eingegangen ${ }^{l}$. Beurteilungskriterien sind wiederum das Leistungsfähigkeitsprinzip sowie die Neutralität und Praktikabilität der Besteuerung.

\section{Indirekte Ermittlung des Periodenkonsums}

Als repräsentativer Vorschlag für die indirekte Ermittlung des Periodenkonsums wird der Vorschlag von Mitschke ${ }^{2}$ diskutiert, der prinzipiell auf der Konzeption der "Expenditure Tax" von Nicholas Kaldor ${ }^{3}$ beruht. Der Unterschied zwischen den Vorschlägen von Kaldor und Mitschke zeigt sich im wesentlichen in der unterschiedlichen Behandlung von langlebigen Konsumgütern ${ }^{4}$ und der Tarifgestaltung. Beide lehnen eine selbständige Unternehmensbesteuerung als Ergänzung zur Konsumbesteuerung auf der Ebene der privaten Haushalte $a b^{5}$. Eine

1 Diese Vorgehensweise wird wegen der besseren Übersichtlichkeit gewählt.

2 Vgl. Mitschke, J. (1985).

3 Vgl. Kaldor, N. (1969), S. $191 \mathrm{ff}$.

4 Kaldor, N. (1969, S. 195 ff.) bevorzugt grundsätzlich die Konsumgutlösung; die höheren Ausgaben für langlebige Konsumgüter will er den Steuerpflichtigen grundsätzlich über einen bestimmten Zeitraum verteilen lassen (bei selbstgenutzten Immobilien will er einen Wohnwert ansetzen). Mitschke, J. (1985, S. 113 f.) präferiert ebenfalls grundsätzlich die Konsumgutlösung, für betraglich bedeutende Anschaffung schlägt er aber die Investitionsgutlösung vor. Zur näheren Erläuterungen dieses beiden Methoden siehe unten.

$5 \quad$ Vgl. Kaldor, N. (1969), S. 169 ff.; Mitschke, J. (1985), S. 76. 
(anrechenbare) Quellenbesteuerung der Kapitaleinkünfte wird hingegen als Hilfe zur Erhebung der Konsumsteuer von Mitschke befürwortet ${ }^{l}$.

Bei der Konzeption von Mitschke wird der Periodenkonsum indirekt ermittelt, d.h. Aufzeichnungen des Steuerpflichtigen über seinen Konsum sind nicht erforderlich; stattdessen werden Hilfsgrößen herangezogen.

Ausgangspunkt ist die Überlegung, daß sich das Einkommen der Periode -von der Verwendungsseite her betrachtet- aus dem Periodenkonsum und der Änderung des Vermögens (= End- - Anfangsvermögen) der Periode zusammensetzt. Es gilt

$$
\begin{aligned}
Y_{t} & =C_{t}+\Delta V_{t} \\
\Leftrightarrow \quad C_{t} & =Y_{t}-\Delta V_{t} .
\end{aligned}
$$

Es wird nun untersucht, wie die zur indirekten Konsumermittlung notwendigen periodischen Größen (Einkommen und Vermögensänderung) bestimmt werden können.

\subsection{Technik der indirekten Konsumermittlung}

\subsubsection{Messung der Vermögensänderung ${ }^{2}$}

Zur Vereinfachung der Messung der Vermögensänderung einer Periode wird das Vermögen eines Individuums in drei Gruppen von Vermögensgegenständen bzw. Schulden unterteilt, nämlich dem Bestand an Zahlungsmitteln, den Forderungen (ohne Zahlungsmittel) bzw. Verbindlichkeiten gegen Dritte sowie das sonstige Vermögen (z.B. Sach- und immaterielles Vermögen) ${ }^{3}$.

Die Vermögensänderung einer Periode kann dann grundsätzlich nach zwei unterschiedlichen Methoden bestimmt werden:

- durch den Vergleich der Vermögensbestände zu Beginn und am Ende der Periode. Die Ersparnisbildung der Periode setzt sich aus der Veränderung des Bestands an Zahlungsmittel $\left(\Delta \mathrm{Z}_{\mathrm{t}}\right)$, Forderungen $\left(\Delta \mathrm{SG}_{\mathrm{t}}\right)$ sowie des übrigen Vermögens $\left(\Delta S V_{t}\right)$ zusammen.

\footnotetext{
1 Vgl. Mitschke, J. (1985), S. 75 f.

2 Vgl. Mitschke, J. (1980), S. 284 f.

3 Hier ist die Aufstellung bei Mitschke (1980, S. 284 f.) unvollständig, da er das immaterielle Vermögen -wie z.B. Patente, Rechte- nicht berücksichtigt; dies hat aber keine Auswirkungen auf die weiteren Ergebnisse von Mitschke.
} 
Es gilt somit ${ }^{1}$

$\Delta \mathrm{V}_{\mathrm{t}}=\Delta \mathrm{Z}_{\mathrm{t}}+\Delta \mathrm{SG}_{\mathrm{t}}+\Delta \mathrm{SV}_{\mathrm{t}}$

- durch Kumulation und Saldierung aller Bruttoveränderungen des Vermögens (z.B Auszahlungen $\left(\mathrm{A}_{\mathrm{t}}^{\mathrm{Z}}\right)$ und Einzahlungen $\left(\mathrm{E}_{\mathrm{t}}^{\mathrm{Z}}\right)$ ) während der Periode. Daraus folgt

$$
\Delta V t=\left(E_{t}^{Z}-A_{t}^{Z}\right)+\left(S G_{t}^{+}-S G_{t}^{-}\right)+\left(S V_{t}^{+}-S V_{t}^{-}\right)
$$

oder

$$
\Delta \mathrm{Vt}=\left(\mathrm{E}_{\mathrm{t}}^{\mathrm{G}}-\mathrm{A}_{\mathrm{t}}^{\mathrm{G}}\right)+\left(\mathrm{SV}_{\mathrm{t}}^{+}-\mathrm{SV}_{\mathrm{t}}^{-}\right),
$$

wobei $\left(E_{t}{ }^{G}-A_{t}{ }^{G}\right)$ den Einnahmeüberschuß bezeichnet und "+" für die $\mathrm{Zu}$ bzw. "-" für die Abnahme der entsprechenden Größe steht.

Beide Methoden führen zum gleichen Ergebnis, wenn alle Veränderungsvorgänge erfaßt werden. Werden beide Methoden zusammengefaßt, kann die Veränderung des Vermögens der Periode auch dargestellt werden als

$$
\Delta \mathrm{V}_{\mathrm{t}}=\Delta \mathrm{Z}_{\mathrm{t}}+\left(\mathrm{SG}_{\mathrm{t}}^{+}-\mathrm{SG}_{\mathrm{t}}^{-}\right)+\left(\mathrm{SV}_{\mathrm{t}}^{+}-\mathrm{SV}_{\mathrm{t}}^{-}\right)
$$

Die Veränderung des Vermögens kann somit in verschiedene Kategorien aufgeteilt werden:

- Die Veränderung des individuellen Vermögens auf der Zahlungsmittelebene (= Veränderung des Barvermögens) wird durch die Veränderung des Zahlungsmittelbestandes in der laufenden Periode repräsentiert.

- Wird zu der periodischen Veränderung des Zahlungsmittelbestandes die Differenz aus der Forderungs- und Schuldenerhöhung hinzugerechnet, ergibt sich die Veränderung auf der Geldvermögensebene.

1 SG steht für das sonstige Geldvermögen, d.h. ohne Zahlungsmittel

$\mathrm{Z}$ bezeichnet die Zahlungsmittelebene (z.B. Kassenbestand)

G steht für die Geldvermögensebene (ohne Zahlungsmittelebene (also z.B. Forderungen)). 
- Durch die Addition der Differenz aus der Sachvermögenserhöhung und -minderung und der Veränderung des Bestandes an immateriellen Vermögensgegenständen zum Geldvermögen ergibt sich die gesamte Veränderung des individuellen Reinvermögens.

\subsubsection{Methoden der Einkommensbestimmung ${ }^{l}$}

Das Einkommen nach der umfassenden Reinvermögenszugangstheorie kann -wie gezeigt- durch einen Vermögensvergleich zwischen Beginn und Ende der Periode unter Hinzufügung des Periodenkonsums ermittelt werden (Bestandskonzept). Es gilt

$$
\mathrm{Y}_{\mathrm{t}}=\mathrm{C}_{\mathrm{t}}+\Delta \mathrm{V}_{\mathrm{t}}
$$

Soll der Periodenkonsum als Differenz von Einkommen und der Änderung des Vermögens bestimmt werden, liegt nur dann keine Tautologie vor, wenn das Einkommen nicht einfach durch Addition von Periodenkonsum und Periodenvermögensänderung ermittelt wird.

Eine andere Möglichkeit der Einkommensermittlung (Stromkonzept) besteht in der Saldierung von den in Geldeinheiten ausgedrückten Zuflüssen an Gütern und Dienstleistungen -also den Erträgen der Periode ("Erwerbs-Ertrag" EE $_{t}$ )mit den nicht-konsumtiven Aufwendungen ("Erwerbsbedingter Aufwand" EA ${ }_{t}$ ), also den in Geldeinheiten bewerteten Abflüssen an Gütern und Dienstleistungen (einschließlich den Wertverlusten im Vermögen, wie z.B. den Güterverbrauch zur Einkommenserzielung). Es gilt somit:

$$
\Delta \mathrm{Y}_{\mathrm{t}}=\mathrm{EE}_{\mathrm{t}}-\mathrm{EA}_{\mathrm{t}}
$$

Erfolgt eine vollständige Erfassung aller Erträge und Aufwendungen und werden in beiden Verfahren dieselben Bewertungsmaßstäbe angewandt, führen beide zum gleichen Ergebnis. Damit gilt

$$
Y_{t}=E E_{t}-E A_{t}=\Delta V t+C_{t}=V_{t}-V_{t-1}+C_{t}
$$

Das auf der Vermögensebene definierte Einkommen kann ebenso wie der Periodenkonsum durch die Addition von Bareinkommen (Zahlungsmittelebene), Forderungseinkommen (Einnahmeebene) und Naturaleinkommen (Veränderun-

Vgl. hierzu Mitschke (1980), S. 286 ff. 
gen des Sach- und immateriellen Vermögens, Naturallohn usw.) ermittelt werden; somit gilt:

$$
Y_{t}=\left(E E_{t}^{Z}-E A_{t}^{Z}\right)+\left(E E^{S G}-E A^{S G}\right)+\left(E E^{S V_{t}}-E A^{S V_{t}}\right)=E E_{t}-E A_{t}
$$

Das Einkommen kann deshalb in folgende "Einkommenskategorien" aufgeteilt werden:

- Das Bareinkommen $\left(E^{Z_{t}}-E{ }_{t}\right)$ umfaßt alle nicht vermögensneutralen Zahlungseingänge abzüglich der nicht-konsumtiven und vermögensneutralen Auszahlungen.

- Das Geldeinkommen ist die Differenz aus allen nicht vermögensneutralen Einnahmen und nicht-konsumtiven, vermögensneutralen Ausgaben. Es setzt sich also aus dem Bareinkommen sowie der Änderung des Forderungs-/ Verbindlichkeitenbestandes $\left(\mathrm{EE}_{\mathrm{t}}^{\mathrm{SG}}-\mathrm{EA}_{\mathrm{t}}^{\mathrm{SG}_{\mathrm{t}}}\right)$ des Individuums $\mathrm{zu}$ sammen.

- Das (Gesamt-) Einkommen setzt sich aus der Differenz aus allen Erträgen abzüglich aller Aufwendungen zusammen, d.h. es resultiert aus der Summe des Geldeinkommens zuzüglich des Naturaleinkommens $\left(\mathrm{EE}^{\mathrm{SV}}{ }_{\mathrm{t}}-\mathrm{EA}_{\mathrm{t}} \mathrm{SV}_{\mathrm{t}}\right.$.

\subsubsection{Ermittlung des Periodenkonsums ${ }^{1}$}

Es wird nun dargestellt, wie der Periodenkonsum ermittelt werden kann. Dazu werden zuerst die einzelnen Konsumkategorien aufgezeigt.

Ein mögliches Differenzierungsmerkmal für die Einteilung des Konsums in verschiedene Kategorien ist die Art und Weise, wie die konsumierten Sachgüter und Dienstleistungen in den Verfügungsbereich des Konsumenten gekommen sind:

- Entgeltlicher Erwerb durch Hingabe von Zahlungsmitteln (= Barkonsum). Hierunter fällt auch der Konsum, der aus Barmitteln bestritten wird, die aus einer Kreditaufnahme stammen.

1 Vgl. hierzu Mitschke (1980), S. 290 ff. 
- Entgeltlicher Erwerb durch die Erhöhung der Verbindlichkeiten des Konsumenten (= Kreditkonsum), ohne daß der Kredit ausgezahlt wird (z.B. Lieferungen auf Ziel). Diese Konsumkategorie umfaßt auch die Aufnahme eines Sachkredits, dessen Tilgung in Naturalien erfolgt.

- Entgeltlicher Erwerb durch Hingabe von Sachgütern oder Dienstleistungen (Naturaltausch) sowie der unentgeltliche Erwerb (z.B. geschenkte, geerbte Konsumgüter, Entnahmen aus dem eigenen Betrieb). In diese Kategorie fallen auch die Nutzungen, die aus dauerhaften Konsumgütern gezogen werden, wenn die dauerhaften Konsumgüter entsprechend der Investitionsgutlösung behandelt werden (siehe hierzu unten). Diese Kategorie wird im folgenden "Naturalkonsum" genannt.

Der Konsum auf der Geldvermögensebene setzt sich damit aus der Summe von Bar- und Kreditkonsum zusammen. Der gesamte Konsum des Individuums besteht aus der Summe von Bar-, Kredit- und Naturalkonsum.

Nachfolgend wird auf die Ermittlung der Höhe des Periodenkonsums eingegangen.

Der Periodenkonsum wird bei der indirekten Methode ermittelt, indem vom Periodeneinkommen die Änderung des Vermögens abgezogen wird. Es können somit die verschiedenen (jeweils gleichartigen) Kategorien des Einkommens und der Vermögensänderung zur Ermittlung des Periodenkonsums herangezogen werden. Je nachdem, welche Größen gewählt werden, ergibt sich eine mehr oder weniger vollständige Abbildung des Periodenkonsums. Fraglich ist deshalb, welche Größen zur Ermittlung des Periodenkonsums heranzuziehen sind. Es kommen folgende Größen in Betracht:

- Der Barkonsum der Periode ergibt sich aus der Differenz des Bareinkommens abzüglich den Vermögenswertänderungen der Periode, die aus Zahlungsvorgängen, also den Barvermögensänderungen, resultieren (z.B. der Barkauf einer Aktie).

- Der Geldkonsum (= Barkonsum zuzüglich dem kreditfinanzierten Konsum) entspricht dem Geldeinkommen abzüglich den Geldvermögensänderungen der Periode, die aus dem Saldo von Einnahmen und Ausgaben -also der Änderung des Geldvermögens- stammen.

- Der Gesamtkonsum entspricht dem Einkommen abzüglich sämtlichen Vermögensänderungen der Periode. 
Aus der Einteilung wird ersichtlich, daß lediglich bei der Erfassung des (Gesamt-) Einkommens und der gesamten Vermögenswertänderung der Periodenkonsum vollständig und umfassend abgebildet wird. Wird lediglich die Geldvermögensebene betrachtet, bleibt der Naturalkonsum unberücksichtigt. Eine Konsumsteuer auf dieser Basis könnte damit durch Naturaltausch umgangen werden. Wird der Konsum auf der Basis von den auf Zahlungsmittelebene ermittelten Größen Bareinkommen und Barvermögensänderung errechnet, bleibt der Naturalkonsum ebenso unberücksichtigt wie der Erwerb von Konsumgütern bzw. Dienstleistungen auf Ziel, der erst bei Rückzahlung des Kredits erfaßt wird. Eine auf dieser Basis beruhende Steuer kann durch Tauschvorgänge sowie durch besondere Formen der Tilgung des Kredits (Aufrechnung, Abtretung von Forderungen usw.) umgangen werden.

Die Wahl der relevanten Konsumgröße wird auch von Praktikabilitätsüberlegungen beeinflußt ${ }^{l}$.

Die Ermittlung des Gesamtkonsums mit Hilfe einer umfassenden Einkommenskategorie erfordert nicht, das Sachvermögen in jeder Periode mit den tatsächlichen Werten zu bewerten. Es ist infolge von Saldierungen nur erforderlich, bei der Bestimmung der Ersparnis und des Einkommens den gleichen Bewertungsmaßstab anzuwenden ${ }^{2}$, so daß nicht wie bei der Einkommensbesteuerung nach der Reinvermögenszugangstheorie Probleme aufgrund der praktisch undurchführbaren periodischen Bewertung des Vermögens des Steuerpflichtigen auftreten.

Zur Erfassung des Naturalkonsums zu Marktpreisen ist aber erforderlich, daß dieser vorher als Naturaleinkommen gezählt und zu Marktpreisen bewertet wurde. Überdies ist die Aufstellung von Vermögensbilanzen Bedingung, in denen sämtliche $\mathrm{Zu}$ - und Abgänge (auch die aufgrund buchtechnischer $\mathrm{Zu}$ - und $\mathrm{Ab}$ schreibungen) verzeichnet werden. Diese Verfahrensweise umgeht zwar die Schwierigkeit der periodischen Vermögensbewertung, ist aber aufgrund des Erfordernisses von Vermögensbilanzen sehr aufwendig zu handhaben und relativ unpraktikabel.

Soll der Konsum auf Basis des Geldkonsums und somit mit Hilfe der Größen "Geldeinkommen" und "Geldvermögensänderung" ermittelt werden, ist die Erfassung sämtlicher Vorgänge notwendig, die nicht sofort mit Zahlungsvorgängen verbunden sind (z.B. Eingang einer Lieferantenforderung). Somit müßten zum Stichtag Bilanzen aller Forderungen und Schulden erstellt (Bestandskonzept) bzw. Aufzeichnungen über alle zahlungsabhängigen und

1 Vgl. Mitschke, J. (1985), S. 125.

2 Vgl. Mitschke, J. (1975), S. 73. 
zahlungsunabhängigen Forderungs- und Verbindlichkeitenzu- bzw. -abgänge mit den dazugehörigen Einkommensdaten angefertigt werden. Diese Vorgehensweise ist sehr aufwendig und von der Finanzbehörde auch nur mit hohem Arbeitsaufwand nachzuvollziehen.

Wird der Barkonsum ermittelt -die dazu notwendigen Größen basieren auf Zahlungsströmen- besteht nicht die Notwendigkeit, umfassende Vermögensbilanzen aufzustellen, da bei dieser Konzeption sowohl das Bareinkommen als auch die Änderung des Barvermögens der Periode auf der Grundlage von einfach zu ermittelnden Zahlungsströmen beruhen. Um die Erfassung des gesamten Konsums zu gewährleisten und Umgehungen zu vermeiden, sind außer diesen Angaben weiterhin Angaben zum Naturalkonsum, zu dem durch den Verkäufer finanzierten Abzahlungskonsum sowie zur nicht durch Zahlungsströme dokumentierten Tilgung von Krediten (Forderungsabtretung, Aufrechnung usw.) erforderlich. Die auf Zahlungsströmen basierenden Größen sind relativ leicht zu ermitteln. Auf die daneben noch zusätzlich zu ermittelnden Größen "Natural-" und "Kreditkonsum" wird später eingegangen. Vorerst wird die praktikable Meßbarkeit dieser Größen unterstellt.

Aus Praktikabilitätsüberlegungen sollte somit die Größe "Barkonsum" gewählt werden.

Der Barkonsum einer Periode wird ermittelt,

indem

- von allen Zahlungszuflüssen (ZZ) der Periode (aus Erwerbstätigkeit, Vermögen, Versicherungen, Erbschaften, Gewinnen ${ }^{l}$ u.a.) einschließlich sämtlicher Kreditaufnahmen -sowohl für konsumtive als auch für investive Zwecke- und die erhaltenen Rückzahlungen eigener Ausleihungen (z.B. die Tilgung von Bundesobligationen durch den Schuldner)

nachfolgende Größen abgezogen werden:

- die nicht-konsumtiven Zahlungsabflüsse (ZA) der Periode, d.h. Zahlungsabflüsse, die dem Erwerb von Erträgen dienen (einschließlich der Zahlungsabflüsse zur Erhöhung des Forderungsbestandes des Individuums, wie z.B. der Kauf von Industrie- oder Bundesobligationen) sowie vom

1 Der im deutschen Steuerrecht überwiegend quellentheoretisch ausgerichtete Einkommensbegriff müßte deshalb um private Veräußerungserlöse, Lottogewinne, Erbschaften usw. erweitert werden. 
Steuerpflichtigen geleistete Rückzahlungen von Krediten jeglicher Art, also auch die Rückzahlung von Konsumentenkrediten

sowie

- die Erhöhung des Zahlungsmittelbestandes $\Delta \mathrm{ZM}$, also der Differenz zwischen dem Bar- und Giralgeldbestand am Ende und Anfang der Periode.

Der Barkonsum der Periode läßt sich somit über die Beziehung

$$
\mathrm{C}_{\mathrm{ZM}}=\mathrm{ZZ}-\mathrm{ZA}-\Delta \mathrm{ZM}
$$

errechnen.

\subsubsection{Sonderprobleme der indirekten Konsumerfassung}

Konsumvorgänge, die sich nicht auf der Zahlungsmittelebene niederschlagen (z.B. durch den Verkäufer finanzierte Abzahlungsgeschäfte), werden steuerlich nicht erfaßt. Zum Zeitpunkt des Kaufs fließen keine Zahlungsmittel, die spätere Kredittilgung geht ebenfalls nicht in die Ermittlung des Konsums ein, da der Abzug sämtlicher Kredittilgungen bei der Konsumermittlung zugelassen wurde. Fraglich ist, wie der kreditfinanzierte Konsum steuerlich erfaßt werden kann. Dazu bieten sich prinzipiell zwei Möglichkeiten an:

- Der Steuerpflichtige gibt diese Art von Konsumfinanzierung im Jahr des Erwerbs in seiner Steuererklärung an. Sie unterliegt dann in diesem Jahr der Besteuerung. Die späteren Tilgungszahlungen werden als nicht-konsumtive Zahlungsabflüsse (ZA) aufgefaßt ${ }^{l}$.

- Kredittilgungen, die auf ein vom Verkäufer finanziertes Abzahlungsgeschäft zurückgehen, sind bei der Ermittlung der nicht-konsumtiven Zahlungsabflüsse (ZA) nicht abzugsfähig. Diese Zahlungen gehen im Jahr der Kredittilgung in die Bemessungsgrundlage ein. Im Jahr der Anschaffung werden die Ausgaben für die Kredittilgung des laufenden Jahres berücksichtigt.

Die Erfassung der Beträge für die Kredittilgung als Konsum hat bei einem progressiven Tarif den Vorteil, daß bei Fremdfinanzierung keine Progressionsef-

Diese Möglichkeit wird von Mitschke, J. (1985, S. 128) vorgeschlagen. 
fekte auftreten und systemgerecht lediglich auf Zahlungsvorgänge abgestellt wird. Nachteilig ist, daß eine Tilgung des Kredits auf andere Art (z.B. Aufrechnung, Naturaltilgung, Forderungsabtretung) nicht erfaßt wird ${ }^{l}$. Für die Bestimmung des Konsums über die Deklaration des Abzahlungsgeschäftes gilt die umgekehrte Argumentation. Durch die Erfassung des Konsums über die Angabe des Abzahlungsgeschäftes wird aber eine Gleichbehandlung mit dem auf andere Weise kreditfinanzierten Konsum geschaffen.

Offen ist, welche Erfassungsmethode aufgrund der Forderung einer leistungsfähigkeitsgerechten und neutralen Besteuerung zu präferieren ist.

In einer vollkommenen Welt mit vollkommenem Kapitalmarkt besteht kein Unterschied zwischen Schuld- und Guthabenzinssatz. Somit sind beide Alternativen der steuerlichen Erfassung gleich.

In der realen Welt sind die Schuldzinsen höher als die Guthabenzinsen, d.h. derjenige, der die Mittel hat, um das Konsumgut aus eigenen Mitteln zu kaufen, wird dieses tun.

Schuldzinsen mindern die steuerliche Leistungsfähigkeit eines Individuums; der betreffende Indikator muß dies abbilden. Bei der Deklaration des Abzahlungsgeschäfts im Jahr des Geschäfts gehen die Schuldzinsen insgesamt nicht in die steuerliche Bemessungsgrundlage ein, da sie als nicht-konsumtive Zahlungsabflüsse zu interpretieren sind. Sie mindern somit den Indikator der Leistungsfähigkeit; das gilt unabhängig von der Höhe der Schuldzinsen. Dadurch werden alle Kredittilgungen und -zinsen bei der Ermittlung der steuerlichen Bemessungsgrundlage systematisch gleich behandelt; dies ist aufgrund von Praktikabilitäts- und Neutralitätsüberlegungen von Vorteil. Ansonsten wäre es bei unterschiedlichen Soll- und Habenzinssätzen günstiger, einen Barkredit aufzunehmen und damit das Gewünschte zu erwerben, anstatt ein Abzahlungsgeschäft direkt mit dem Verkäufer abzuschließen.

Aus den angeführten Praktikabilitäts- und Neutralitätsüberlegungen sowie aufgrund des Leistungsfähigkeitsprinzips ist somit der Einbezug des vom Verkäufer finanzierten Konsums als Barkonsum in die steuerliche Bemessungsgrundlage im Jahr des Erwerbs zu präferieren.

Im folgenden wird wie bei Mitschke von der Deklaration des Konsums im Jahr des Kaufs ausgegangen; spätere Tilgungen werden somit als nicht-konsumtive Zahlungsabflüsse aufgefaßt ${ }^{2}$. Somit können die "ungewöhnlicheren" Tilgungs-

Vgl. Mitschke (1980), S. 291.

2 Hier irrt Mohr, R. (1992, S. 288, 383), indem er den Befürwortern der Konsumbesteuerung unterstellt, daß sie Kreditzinsen für Konsumentenkredite der Besteuerung unterwerfen wollen. 
verfahren (Aufrechnung, Naturaltilgung, Forderungsabtretung) nicht die Einbeziehung des Konsums in die steuerliche Bemessungsgrundlage verhindern.

Zur umfassenden Erfassung des Konsums sind allerdings noch Modifikationen vorzunehmen: wie oben gezeigt, umfaßt der Barkonsum nicht den Naturalkonsum. Um den Periodenkonsum jedoch umfassend abzubilden, ist neben dem Bar- auch der Naturalkonsum zu erfassen. Auf dieses Problem wird später in einem eigenen Abschnitt noch detaillierter eingegangen.

\subsection{Besteuerung nach der individuellen Leistungsfähigkeit}

Die Konzeption der Besteuerung gemäß der individuellen Leistungsfähigkeit erfordert die umfassende Abbildung des Periodenkonsums. Die Ermittlung des Periodenkonsums durch die indirekte Methode erfaßt -falls auf den Barkonsum abgestellt wird- nur den Konsum, der aus Vorgängen auf der Zahlungsmittelebene herrührt. Ohne weitere Modifikationen wird daher gegen das Leistungsfähigkeitsprinzip verstoßen. Der Periodenkonsum wird vollständig erfaßt, wenn die Konsumermittlung noch um den Naturalkonsum sowie den kreditfinanzierten Konsum erweitert wird!

Da der Periodenkonsum umfassend abgebildet wird, wenn die vorgeschlagenen Modifikationen implementiert werden, bestehen keine grundsätzlichen Einwände hinsichtlich der Besteuerung gemäß der individuellen Leistungsfähigkeit, die in der Systematik der indirekten Erfassung des Periodenkonsums begründet sind.

\subsection{Neutralität der Besteuerung}

Die Methode der indirekten Erfassung des Periodenkonsums auf der Zahlungsmittelebene verzerrt die Entscheidung zugunsten des kreditfinanzierten Konsums, da dieser ohne weitere Modifikationen steuerlich nicht erfaßt wird. Das gleiche gilt für den Naturalkonsum. Kann allerdings durch entsprechende Modifikationen sichergestellt werden, daß auch diese "Konsumarten" erfaßt werden, wird der Periodenkonsum vollständig durch die steuerliche Bemessungsgrundla-

1 Auf die Problematik des Einbezugs des Naturalkonsums sowie auf weitere Sonderprobleme wird im weiteren Verlauf der Arbeit noch näher eingegangen. 
ge abgebildet (Sonderprobleme werden später noch diskutiert). Die grundsätzlichen Ausführungen zur Neutralität der Periodenkonsumbesteuerung gelten daher weiterhin.

\subsection{Praktikabilität der Besteuerung}

\subsubsection{Erfassung der Zuflüsse}

Bei der heutigen (deutschen) Einkommensteuer müssen Lohn- und Kapitaleinkünfte als Zuflüsse erfaßt werden. Zur Steuersicherung kann eine Quellensteuer erhoben werden. Daneben ist die Rubrik "Sonstige Einkünfte" wesentlich zu erweitern. Hierunter müssen zukünftig Rentenzahlungen (die Beiträge zu den Versicherungen sind als Vermögensbildung bei der Konsumermittlung abzugsfähig), Gewinne, Erbschaften sowie alle anderen einmaligen und laufenden $\mathrm{Zu}$ wendungen erfaßt werden; weiterhin sind hier alle Erlöse aus dem Verkauf von Wertpapieren, Immobilien usw. aufzuführen. Der Umfang der zu erfassenden Veräußerungserlöse von langlebigen Konsumgütern kommt auf die generelle Behandlung dieser Güter an (siehe hierzu die Diskussion dieser Problematik im Rahmen dieser Arbeit). Es ist jedoch keine periodische Vermögensbewertung notwendig. Die Erfassung sämtlicher Zuflüsse ist im Vergleich zu einer periodisch durchzuführenden Vermögensbewertung (Einkommensdefinition nach der Reinvermögenszugangstheorie) ein wesentlich geringeres Problem.

\subsubsection{Erfassung der Barvermögensänderung}

\subsubsection{Grundsätzliche Methode}

Die nicht-konsumtiven Zahlungsabflüsse der Periode, also Zahlungsabflüsse, die dem Erwerb von "Erträgen" dienen, sind bei der Ermittlung des Periodenkonsums abzuziehen; ihre Erfassung ist zu klären.

Die nicht-konsumtiven Zahlungsabflüsse können durch Bestätigungen der Institutionen (z.B. Banken) nachgewiesen werden, bei denen die Investition/Anlage erfolgt. Wird von der betreffenden Stelle jährlich eine Bestätigung gegeben (unabhängig davon, ob in dieser Periode tatsächlich etwas investiert wurde), kön- 
nen im Rahmen der Bestätigung auch die Höhe der Abflüsse aus dieser Investition/Anlage vermerkt werden ${ }^{I}$.

\subsubsection{Mißbrauchsmöglichkeiten}

Um eine Steuererhebungsmethode beurteilen zu können, muß auf die Gefahr der Steuerhinterziehung eingegangen werden. Ansonsten kann eine in der Theorie sehr praktikable Erfassungsmethode völlig unbrauchbar sein, da die steuerlich relevanten Tatbestände leicht verschleier- oder umgehbar sind.

Die Beantwortung dieser Frage steht im Mittelpunkt dieses Abschnitts.

\section{a) Zurechnung des Konsums}

Es ist fraglich, ob durch diese Methode tatsächlich der Konsum eines bestimmten Individuums gemessen wird oder ob hier Umgehungsmöglichkeiten der Art bestehen, daß ein Individuum anstelle eines Dritten den Konsum des Dritten zugerechnet bekommt. Diese Vorgehensweise ist dann profitabel, wenn ein progressiver Tarifverlauf gegeben ist. Bei einem linearen Tarifverlauf ist die Höhe des Grenzsteuersatzes gleich und die Verlagerung der Konsumausgaben auf andere Personen nicht von Vorteil.

Eine Möglichkeit ist die Verlagerung von Zuflüssen auf Dritte, die aus diesen Zuflüssen Konsumgüter kaufen und sie rückübertragen, ohne die Rückübertragung als (steuerpflichtiges) Geschenk zu deklarieren. Diese Möglichkeit der Steuerumgehung besteht jedoch auch bei einer Einkommensbesteuerung (z.B. Anstellung der Lebensgefährtin); somit taucht kein neues Problem im Vergleich zu einer Periodeneinkommensbesteuerung auf. Keine Umgehungsmöglichkeit besteht, wenn ein Individuum mit einem hohen Grenzsteuersatz einem Individuum mit einem niedrigen Grenzsteuersatz Vermögen "schenkt", womit dieses Konsumgüter kaufen und wieder rückübertragen soll, da die Schenkung beim Schenkenden als Konsum der Besteuerung unterliegt ${ }^{2}$. Die Erfassung erfolgt automatisch, weil die wie auch immer konsumierten Mittel nicht noch zusätzlich gespart werden können.

Aus diesen kurzen Ausführungen wird ersichtlich, daß hier auch kein höheres Mißbrauchspotential als bei einer periodischen Einkommensteuer vorliegt.

1 Die Behandlung von "Werbungskosten" wird später gesondert diskutiert.

2 Vgl. Mitschke (1985), S. 134. 


\section{b) Nichtangabe von investiven Zahlungsabflüssen}

Es werden jetzt die Folgen der Nichtangabe von investiven Zahlungsabflüssen geprüft. Dabei wird angenommen, daß auch spätere Zuflüsse aus dieser Anlage/ Investition nicht deklariert werden.

Durch die Nichtangabe von investiven Zahlungsabflüssen steigt in dieser Periode die Bemessungsgrundlage an; damit ist der nicht angegebene Betrag so zu versteuern, als ob er konsumiert wurde.

Zur weiteren Analyse wird zwischen verschiedenen Tarifstrukturen und verschiedenen Annahmen hinsichtlich der Vollkommenheit des Kapitalmarktes unterschieden.

\section{ba) Vollkommener Kapitalmarkt}

Bei einem linearen Tarif ist der Zeitpunkt der Besteuerung bei vollkommenem Kapitalmarkt (Soll- und Habenzinssatze sind identisch) dann unerheblich, wenn die Investition/Anlage keine Pure-Profits abwirft: der Barwert des möglichen Konsums aus dieser nicht deklarierten Anlage entspricht dann immer dem als Konsum versteuerten Betrag. Das Individuum hat dadurch keinen Vorteil. Wirft die Anlage hingegen Pure-Profits ab, ist der Barwert des möglichen Konsums höher als der als Konsum versteuerte Betrag. Hier ist die Nichtangabe der Anlage/Investition und die sofortige Besteuerung als Konsum für das Individuum vorteilhaft, da das Individuum eine höhere Leistungsfähigkeit, als die durch den versteuerten Konsum erfaßte, hat.

Bei einem progressiven Tarif gelten grundsätzlich die gleichen Überlegungen wie bei einem linearen Tarif. Der Vorteil der Nichtangabe von investiven Zahlungsabflüssen hängt weiterhin von der Erwartung der Höhe der zukünftigen Bemessungsgrundlage (= Konsum) ab: wird eine steigende Bemessungsgrundlage z.B aufgrund von Familienzuwachs bzw. höherem zukünftig geplanten Konsum erwartet, ist es für das Individuum vorteilhaft, die Bemessungsgrundlage zu glätten, indem die Erhöhung der Ersparnis in einer Periode mit niedrigerer Bemessungsgrundlage als zum (geplanten) Konsumzeitpunkt nicht angegeben und somit als Konsum versteuert wird. Der spätere Konsum daraus ist dann steuerfrei. 


\section{bb) Unvollkommener Kapitalmarkt}

In der Realität weichen Soll- und Habenzinssätze voneinander ab.

Wird angenommen, daß der Steuerpflichtige keinen Kredit aufnehmen muß, um Steuern zu bezahlen und den für die Bezahlung der Steuern notwendigen Betrag auch nur zum marktüblichen Habenzinssatz anlegen kann, gelten bei einem linearen Tarif die gleichen Überlegungen wie in einer Welt mit vollkommenem Kapitalmarkt, da der für das Individuum entscheidungsrelevante Zinssatz dem Habenzinssatz (= Opportunitätskosten der Anlage/Investition des als Steuer zu zahlenden Betrages) entspricht.

Ist hingegen eine Kreditaufnahme zur Begleichung der Steuerschuld notwendig, ist bei einem linearen Tarif die zutreffende Deklarierung der investiven Zahlungsabflüsse als Ersparnis steuerlich günstiger, wenn die Rendite der Anlage/ Investition unter dem für die Begleichung der Steuerschuld relevanten Sollzinssatz liegt.

Bei einem progressiven Tarif gelten -falls das Individuum keinen Kredit aufnehmen muß- die gleichen Überlegungen wie bei einem vollkommenen Kapitalmarkt, es ist also keine allgemeingültige Aussage möglich.

Muß zur Begleichung der Steuerschuld ein Kredit aufgenommen werden, kann ebenfalls keine eindeutige Aussage über die Vorteilhaftigkeit der Nichtangabe der investiven Zahlungsabflüsse gemacht werden: die entscheidungsrelevanten Parameter sind die zukünftige Entwicklung der steuerlichen Bemessungsgrundlage sowie die Rendite der Anlage/Investition.

Ein besonderes Problem stellen nicht deklarierte Ersparnisse beim Ableben des Individuums dar. Sie wurden zwar in der Vergangenheit als Konsumausgaben versteuert und damit prinzipiell auf der Ebene des Erblassers der Besteuerung unterworfen. Werden diese Beträge beim Erbenden jedoch nicht als Zufluß erfaßt (ihre Existenz ist ja gar nicht bekannt), sind bei diesem der Konsum dieser Beträge steuerfrei. Die Erben profitieren somit durch die Falschangaben des Erblassers, wenn sie diese "schwarzen Kassen" nicht nachträglich deklarieren. Die Nichtangabe von investiven Zahlungsabflüssen (und damit die Bildung von "schwarzen Kassen") ist somit für den Steuerpflichtigen sowie seine Erben vorteilhaft.

Soll die Besteuerung nach der individuellen Leistungsfähigkeit erfolgen, sind diese Mißbrauchsmöglichkeiten einzuschränken. Die investiven Zahlungsabflüsse müssen daher auch als solche deklariert und nicht als Konsumausgaben versteuert werden. Eine Möglichkeit zur Prüfung der Angaben des Steuerpflichtigen sind Kontrollmitteilungen: dadurch kann überprüft werden, ob die bei einer (Anlage-) Institution vorhandenen Mittel aus deklarierten investiven Zah- 
lungsabflüssen gebildet wurden oder ob es bereits als Konsum versteuerte Mittel sind. Für die Schwarzgelder von ängstlichen Naturen bliebe dann nur noch der Sparstrumpf oder das Ausland als Anlageform übrig. Eine weitere Möglichkeit zur Steuersicherung ist die Quellenbesteuerung der Zuflüsse aus Finanzinvestitionen mit einem relativ hohen Steuersatz. Dadurch ist gewährleistet, daß die Steuerpflichtigen ihre Zuflüsse und damit ihre investiven Ersparnisse deklarieren, da sie dann ein Interesse an der Rückerstattung zuviel bezahlter Steuer haben. Die Höhe der investiven Abflüsse der Vorperioden könnte durch den Vergleich mit den deklarierten (Zins-) Zuflüssen verprobt werden.

\subsection{Ergebnis: Beurteilung der indirekten Konsumermittlung}

In diesem Abschnitt wurde die Methode der indirekten Erfassung des Periodenkonsums vorgestellt und diskutiert. Am einfachsten in der Handhabung erschien die Erfassung des Barkonsums, da lediglich auf relativ einfach meßbare Zahlungsstöme zurückgegriffen werden muß. Der Barkonsum ergibt sich, indem von allen Zahlungszuflüssen der Periode die nicht-konsumtiven Zahlungsmittelabflüsse sowie die Erhöhung des Zahlungsmittelbestandes abgezogen werden. Diese Erfassungsform kann sehr leicht durch kreditfinanzierten oder Naturalkonsum umgangen werden. Zur Vermeidung dieser Steuerumgehung muß somit auch der Natural- sowie der kreditfinanzierte Konsum erfaßt werden. Damit wird grundsätzlich der gesamte Konsum erfaßt ${ }^{l}$ und die Besteuerung erfolgt nach dem Leistungsfähigkeitsprinzip. Wird der Natural- sowie der kreditfinanzierte Konsum erfaßt, werden die Entscheidungen der Individuen c.p. durch diese Erfassungsmethode des Periodenkonsums nicht beeinflußt, so daß c.p. Entscheidungsneutralität vorliegt ${ }^{2}$.

Der Barkonsum ist ebenfalls relativ einfach zu bestimmen und Steuerumgehungsmöglichkeiten können leicht eingeschränkt werden. Damit treten auch keine grundsätzlichen Einwendungen aufgrund von Praktikabilitäts- und Steuersicherungserwägungen auf.

\section{Mehrwertsteuer}

Durch die Mehrwertsteuer wird der Konsum beim Kauf der Konsumgüter bzw: Dienstleistungen besteuert: es wird ein bestimmter Prozentsatz des Warenwertes

Auf Sonderprobleme wird noch eingegangen.

2 Die grundsätzlichen Verzerrungen der Konsumbesteuerung wurden bereits behandelt. 
bzw. des Wertes der Leistung dem Nettopreis als Steuer zugeschlagen und vom Händler/Dienstleistenden an den Fiskus abgeführt.

\subsection{Besteuerung nach der individuellen Leistungsfähigkeit}

Die Konzeption der Besteuerung gemäß der individuellen Leistungsfähigkeit erfordert die umfassende Abbildung des Periodenkonsum. Die Mehrwertsteuer er$\mathrm{fa} \mathrm{Bt}$ in ihrer reinen Form lediglich den Konsum, der gegen Hingabe von Geld bzw. Eingehens von Verbindlichkeiten abgewickelt wird. Der Naturalkonsum wird ohne entsprechende Modifikationen nicht erfaßt ${ }^{l}$. Wird der Naturalkonsum jedoch aufgrund von Modifikationen berücksichtigt, bestehen keine grundsätzliche Einwände hinsichtlich der Besteuerung gemäß der individuellen Leistungsfähigkeit, die in der Systematik der Mehrwertsteuer begründet sind.

\subsection{Neutralität der Besteuerung}

Bei der Mehrwertsteuer ergeben sich grundsätzlich dieselben Probleme wie bei der indirekten Ermittlung des Periodenkonsums; damit kann auf die dortigen Ausführungen verwiesen werden.

\subsection{Praktikabilität der Besteuerung}

In Deutschland gibt es bereits eine Mehrwertsteuer, die relativ problemlos angewendet wird. Eine gesonderte Ermittlung des Konsums über den Umweg des Periodeneinkommens und der Periodenersparnis ist bei der Besteuerung des Periodenkonsums mittels einer Mehrwertsteuer ebensowenig erforderlich wie gesonderte und detaillierte Aufzeichnungen des Steuerpflichtigen über seine Ausgaben. Somit fallen keine Erfassungsarbeiten beim Steuerpflichtigen an, die vom Fiskus zu kontrollieren sind. Steuerumgehungen werden erschwert, da hierzu immer der Verkäufer miteinbezogen werden muß, der jedoch im Rahmen von steuerlichen Außenprüfungen überprüft werden kann. Eine Mehrwertsteuer mit einem linearen Tarif ist relativ unproblematisch. Zur Herbeiführung eines progressiven Tarifs sind differenzierte Steuersätze einzuführen. Dies sowie das

$1 \quad$ Auf die Ausgestaltung dieser Modifikation wird später eingegangen. 
Problem von Steuerermäßigungen bzw. -befreiungen werden noch ausführlich erläutert ${ }^{l}$.

\subsection{Ergebnis: Beurteilung der Mehrwertsteuer}

Die Besteuerung des Lebenseinkommens durch eine Mehrwertsteuer und einer Lebensendvermögensbesteuerung weisen grundsätzlich dieselben Vor- und Nachteile wie eine Besteuerung des Konsums mit Hilfe der oben dargestellten indirekten Konsumerfassung auf. Ein Vorteil der Mehrwertsteuer gegenüber der indirekten Konsumerfassung ist die einfachere Erhebungsart, da der Steuerpflichtige keine Aufzeichnungen seiner Zahlungsmittelzuflüsse oder Ersparnisse anzufertigen hat. Nachteilig ist die nicht getrennte Ermittlung der Bemessungsgrundlage, wodurch ein progressiver Tarif mit steigendem Grenzsteuersatz nur über den Weg der verschieden hohen Steuersätze für verschiedene Güter beschritten werden kann.

\section{Erfassung des Periodenkonsums durch eigene Aufzeichnungen des Steuerpflichtigen}

Die Erfassung des Periodenkonsums durch eigene Aufzeichnungen des Steuerpflichtigen erfordert eine genaue und detaillierte Buchführung über alle Konsumausgaben und den Naturalkonsum. Die Aufzeichnungen müssen dabei zumindest -wenn der Steuerpflichtige die Ausgaben als nicht-konsumtiv veranlaßt (= Werbungskosten bei der Einkommenserzielung) absetzen will- die Bezeichnung der erworbenen Waren/Dienstleistungen enthalten.

\subsection{Besteuerung nach der individuellen Leistungsfähigkeit}

Bei der Besteuerung nach der individuellen Leistungsfähigkeit besteht die Notwendigkeit, die Dispositionsmöglichkeiten des Steuerpflichtigen umfassend abzubilden.

Werden bei dieser Erfassungsmethode sämtliche Konsumausgaben erfaßt, bestehen die Probleme der langlebigen Konsumgüter sowie der Erfassung und Bewertung des Naturalkonsums. Auf diese Fragen wird später noch eingegangen.

Siehe Gliederungspunkt 7. "Konsumbesteuerung und Tarifgestaltung". 
Können diese Fragen zufriedenstellend beantwortet werden, wird der Periodenkonsum zutreffend erfaßt und es liegen keine Verstöße gegen die Besteuerung gemäß der individuellen Leistungsfähigkeit vor.

\subsection{Neutralität der Besteuerung}

Die Erfassung des Periodenkonsums durch eigenen Aufzeichnungen ist im Sinne der Neutralität der Besteuerung grundsätzlich gleichwertig mit der Methode der indirekten Ermittlung des Periodenkonsums; die oben erhaltenen Ergebnisse gelten auch hier.

\subsection{Praktikabilität der Besteuerung}

Die gesamten Konsumausgaben sind vollständig zu erfassen. Diese Aufzeichnungen sind für den Steuerpflichtigen umständlich, aufwendig und fehleranfällig, da jeder Kauf zu dokumentieren ist.

Die Aufzeichnungen können überdies von der Finanzbehörde nicht nachvollzogen und auf Vollständigkeit geprüft werden. Der Steuerpflichtige ist bestrebt, die als Bemessungsgrundlage der zu zahlenden Steuer dienenden Konsumausgaben, tendenziell zu niedrig anzugeben. Die Vorlage von Belegen stellt keine Kontrollmöglichkeit dar, da niemand ihre Vollständigkeit prüfen kann. Eine Kontrolle über Plausibilitätsanalysen ist zwar grundsätzlich möglich (es erscheint z.B. sehr unglaubwürdig, wenn ein Steuerpflichtiger keine Aufwendungen für Nahrungsmittel deklariert). Durch sie kann aber nur ein Wertebereich angegeben werden, in dem die Angaben des Steuerpflichtigen liegen sollten; eine genaue Kontrolle ist dadurch auch nicht möglich. Keine Hilfe bei diesen Analysen ist die Schaffung bestimmter Kennzahlen (z.B. der durchschnittliche Konsum), da fraglich ist, mit welcher Bezugsgröße die Plausibilität geprüft werden soll ${ }^{l}$. Kontrollen könnten bei einer Prüfung des Verkäufers stichprobenweise durch Querprüfungen gemacht werden ${ }^{2}$. Diese Vorgehensweise ist jedoch sehr unpraktikabel, da bei jedem Kauf des Steuerpflichtigen ein Beleg mit dessen Namen oder einer Kennummer ausgestellt (mit Prüfung der Identität des Käufers) und vom Fiskus eine Vielzahl von Kontrollmitteilungen versandt und

\footnotetext{
I Wie sich aus der Diskussion der Implikationen der Lebenszyklushypothese ergeben hat, ist das Periodeneinkommen keine geeignete Bezugsgröße zur Ermittlung des Konsums, da die Konsumplanung der Individuen wesentlich von anderen Größen beeinflußt wird.

2 Kontrolliert werden könnte, ob die Käufer die in der Stichprobe enthaltenen Käufe auch deklariert haben.
} 
überprüft werden müßte. Es ist weiterhin fraglich, ob hierdurch die Belange des Datenschutzes berücksichtigt werden können, da aus Kontrollzwecken der Steuerpflichtige über intimste Daten -z.B. bei wem und was er einkauft- der Finanzbehörde Auskunft erteilen müßte.

Selbst wenn davon ausgegangen wird, daß eine Kontrolle auf Vollständigkeit möglich ist, muß das Finanzamt die Belege des Steuerpflichtigen in Stichproben sichten und addieren. Der Aufwand hierfür ist leicht vorstellbar.

Ein Problem bei der Erfassung des Konsums durch eigene Aufzeichnungen des Steuerpflichtigen ist -wie bei allen Methoden der Konsumermittlung- die Erfassung des Naturalkonsums und der langlebigen Konsumgüter.

Problematisch und unabhängig von der Tarifstruktur sowie der verwendeten Aufzeichnungsmethode ist die Möglichkeit eines an der Erfassung der Käufe vorbeigehenden Konsums. Dieses Problem besteht aber grundsätzlich bereits bei einer Einkommensteuer, bei der der Verkäufer kein Interesse an einer offiziellen Rechnungserstellung hat. Bei der Ermittlung des Konsums durch eigene Aufzeichnungen haben aber u.U. (je nach der Form der Unternehmensbesteuerung) weder Käufer noch Verkäufer ein Interesse an der steuerlichen Erfassung der Umsätze; es besteht also ein Anreiz zur Steuerverkürzung sowohl auf der Käufer- als auch auf Verkäuferseite.

Eine andere -modernere- Erfassungsmöglichkeit ist eine Chip-/Magnet-Karte, auf der die Einkäufe automatisch gespeichert werden und die der Konsument bei jedem Einkauf vorlegen muß. Diese Lösung ist technisch sicherlich durchführbar, ist aber mit einem immensen Aufwand bei den Händlern/Dienstleistern verbunden, da jeder diese technischen Einrichtungen (Erfassungsgeräte) vorhalten muß. Die von den Händlern/Dienstleistern (und damit letztendlich von den Kunden) zu tragenden Kosten wären sehr hoch. Weiterhin ist bei dieser Lösung fraglich -falls ein progressiver Tarif zur Anwendung kommt-, wie der Einkauf mit fremden Karten, der nicht in jedem Falle einen Mißbrauch darstellt (z.B. eine Frau kauft für eine bettlägrige Nachbarin ein), kontrolliert werden kann.

\subsection{Ergebnis: Beurteilung der Erfassung durch eigene Aufzeichnungen des Steuerpflichtigen}

Wenn gewährleistet wird, daß die Aufzeichnung des Konsums vollständig und zutreffend erfolgt, wird das Lebenseinkommen als Indikator der Leistungsfähigkeit im gleichen Umfang erfaßt wie bei den anderen beiden Erfassungsmethoden. Unter dieser Annahme besteht auch kein Unterschied in der Beurteilung 
hinsichtlich der Entscheidungsneutralität des Steuersystems; um Wiederholungen zu vermeiden, wird auf die dortigen Ausführungen verwiesen.

Negativ bei dieser Erfassungsmethode ist dagegen die Praktikabilität. Die direkte Erfassung des Periodenkonsums durch eigene Aufzeichnungen des Steuerpflichtigen bzw. über elektronische Aufzeichnungen ist entweder unpraktikabel und unkontrollierbar oder technisch nur sehr aufwendig durchzuführen. Ein weiteres Problem besteht bei einem progressiven Tarifverlauf: es ist bei dieser Erfassungsmethode nicht ohne zusätzlichen Aufwand kontrollierbar, ob der Käufer auch der Konsument ist. Somit ist es für Steuerpflichtige mit hohem Grenzsteuersatz interessant, die Konsumartikel von Dritten auf deren Namen kaufen zu lassen und sie dann von ihnen (steuerfrei) zu erwerben.

Weiter besteht das Problem der Besteuerung der langlebigen Konsumgüter und des Naturalkonsums; dies wird später gesondert diskutiert. 
Michael Ohmer - 978-3-631-75563-1

Downloaded from PubFactory at 01/11/2019 03:31:45AM

via free access 


\section{Kapitel}

\section{Diskussion von Sonderproblemen}

Bei der Vorstellung der Erfassungsmethoden wurden Sonderprobleme ausgespart. In diesem Kapitel wird geklärt, ob und gegebenenfalls wie die zu behandelnden Sachverhalte in die steuerliche Bemessungsgrundlage einzubeziehen sind.

Kriterien sind auch hier die Besteuerung nach der individuellen Leistungsfähigkeit sowie die Entscheidungsneutralität. In einem weiteren Schritt wird die aufgrund von Praktikabilitätsüberlegungen zu präferierende Erfassungsmethode untersucht.

\section{Langlebige Konsumgiiter}

Unter langlebigen Konsumgütern werden Konsumgüter verstanden, die mehr als eine Periode (Jahr) genutzt werden können. Sie werden gesondert behandelt, da zwei verschiedene Einbeziehungsmöglichkeiten denkbar sind: sie können (1) wie kurzlebige Konsumgüter und (2) wie Investitionsgüter betrachtet werden. Beide Möglichkeiten werden untersucht und beurteilt. Dabei ist insbesondere zu beachten, daß bei manchen dieser langlebigen Konsumgütern in der Vergangenheit erhebliche Wertsteigerungen zu beobachten waren (z.B. beim Wohneigentum) und sie in vielen Fällen einen erheblichen Wert besitzen.

\subsection{Behandlung der langlebigen Konsumgüter im Sinne der "Konsumgutlösung"}

Werden die langlebigen Konsumgütern im Sinne der "Konsumgutlösung" behandelt, gehen die Ausgaben für den Erwerb der langlebigen Konsumgüter im Jahr des Erwerbs in die Bemessungsgrundlage "Periodenkonsum" ein und sind voll zu versteuern. Die aus ihnen in künftigen Perioden gezogenen Nutzungen sind steuerlich irrelevant. 


\subsubsection{Besteuerung nach der individuellen Leistungsfähigkeit}

Wertänderungen beeinflussen die durch das Lebenseinkommen ausgedrückte Leistungsfähigkeit eines Individuums. Es ist daher zu untersuchen, ob die Besteuerung der Konsumausgaben und des Lebensendvermögens tatsächlich das Lebenseinkommen umfaßt, wenn langlebige Konsumgüter im Sinne der Konsumgutlösung behandelt werden.

\subsubsection{Laufende Nutzungen}

Bei der reinen Konsumgutlösung werden die laufenden Nutzungen nicht der Besteuerung unterworfen; das gilt unabhängig davon, wie sich der Preis für die Nutzung auf dem entsprechenden (Miet-) Markt verhält. Fraglich ist, ob dadurch nicht gegen das Leistungsfähigkeitsprinzip verstoßen wird.

Mietet das Individuum ein Konsumgut, werden die Mietzahlungen in der Bemessungsgrundlage der periodisch $\mathrm{zu}$ entrichtenden Konsumsteuer erfaßt. Die Zahlungen als Entgelt für die Nutzungen steigen aufgrund der Wertsteigerungen bei funktionierenden Märkten; damit wird der höhere Wert der Nutzung bei der Besteuerung berücksichtigt.

Um eine steuerliche Gleichheit zwischen dem Kauf des langlebigen Konsumguts und dem Kauf der aus ihm zu ziehenden Nutzungen (Miete) und damit die Gleichbehandlung der Individuen mit gleicher Leistungsfähigkeit zu erhalten, ist es notwendig, daß die aus dem langlebigen Konsumgut gezogenen Nutzungen -zu Marktpreisen bewertet- berücksichtigt werden. Die Nichtberücksichtigung dieses höheren Wertes der Nutzungen hat die unvollständige Abbildung des Lebenseinkommens und somit einen Verstoß gegen das Leistungsfähigkeitsprinzip zur Konsequenz. Um auch Windfall Profits bei den Konsumgütern zu erfassen, muß zusätzlich noch eine teilweise Erfassung des Naturalkonsums aus diesen Gütern stattfinden. Dies kann durch den Einbezug der am Markt zu beobachtenden Mietpreisänderungen aufgrund von Wertänderungen für gleiche oder ähnliche Konsumgüter geschehen. Dieses ist aber bei der Konsumgutlösung ein systematischer Fremdkörper.

Damit erfaßt die reine Konsumgutlösung beim Vorliegen von Windfall Profits nicht das gesamte Lebenseinkommen und ist daher abzulehnen. 


\subsubsection{Behandlung von Veräußerungserlösen}

Bei der reinen Konsumgutlösung ist lediglich der Erwerb eines langlebigen Konsumguts steuerlich von Interesse. $\mathrm{Da}$ in der Realität aber auch ein reger Handel mit langlebigen Konsumguitern (z.B. Autos, Immobilien) stattfindet, ist die Behandlung der Veräußerungserlöse zu klären, die die Besteuerung nach der Leistungsfähigkeit gewährleistet.

Werden diese Güter verkauft, sind diese Beträge nach Vorschlägen von Mitsch$\mathrm{ke}^{l}$ und Kaldor ${ }^{2}$ weder als Zuflüsse noch als Ersparnisse aufzufassen. Der Konsum aus ihnen ist steuerfrei. Ansonsten wird das Einkommen, aus dem das langlebige Konsumgut ursprünglich angeschafft wurde, mehrfach besteuert. VeräuBerungsgewinne bzw. -verluste gehen nach diesem Vorschlag nicht in die Bemessungsgrundlage der Besteuerung ein ${ }^{3}$.

Es ist zu entscheiden, ob dieser Vorschlag der Konzeption der durch das Lebenseinkommen gemessenen Leistungsfähigkeit entspricht. Hierzu wird zuerst die Verfahrensweise in einer Modellwelt mit vollkommener Information und vollkommenen Märkten betrachtet; anschließend werden Windfall Profits zugelassen.

In einer Welt mit vollkommener Information setzt sich der Preis für die Nutzungen aus einem langlebigen Konsumgut aus der durch die Nutzenabgabe hervorgerufenen Wertänderung des Konsumguts sowie der Verzinsung des gebundenen Kapitals zusammen.

Wird das Konsumgut vom Individuum selbst gekauft, genutzt und in einer Folgeperiode verkauft, bezahlt der Käufer den Marktpreis der aus diesem langlebigen Konsumgut noch zu ziehenden Nutzungen. Der Preis, der vom Käufer entrichtet wird, repräsentiert damit den im Konsumgut noch enthaltenen "Nutzenvorrat", der vom Verkäufer nicht "verbraucht", jedoch beim Ersterwerb versteuert wurde. Der Verkäufer zahlt -ohne die Berücksichtigung der Steuer- für die von ihm bezogenen Nutzungen die Wertminderung zuzüglich der Zinsen auf das gebundene Kapital, also den der Miete entsprechenden Betrag.

Bei einem linearen Tarifverlauf ergeben sich durch die Veräußerung keine steuerlichen Auswirkungen, wenn im Falle der indirekten Konsumermittlung beim

l Vgl. Mitschke, J. (1985), S. 106, 113. Er präferiert ebenfalls grundsätzlich die Konsumgutlösung, für betraglich bedeutende Anschaffung schlägt er aber die Investitionsgutlösung vor.

2 Vgl. Kaldor, N. (1969), S. 197 f.

3 Vgl. Mitschke, J. (1985), S. 106. 
Verkäufer die Veräußerungserlöse als Ersparnis und Zufluß erfaßt werden. Wird später aus den Veräußerungserlösen konsumiert, unterliegen sie nochmals der Besteuerung, so daß eine doppelte Besteuerung stattfindet. Damit wird gegen das Leistungsfähigkeitsprinzip verstoßen. Wird dagegen die Deklaration der Zuflüsse vom Fiskus nicht gefordert, erhöhen sich durch den Veräußerungserlös c.p. nur die Ersparnisse des Verkäufers: der von ihm zu versteuernde Konsum und die Steuerschuld verringern sich. Im Ergebnis hat der Verkäufer nur die von ihm gezogenen Nutzungen versteuert; das Leistungsfähigkeitsprinzip ist gewahrt. Dies ergibt sich auch beim Vorschlag von Mitschke, nachdem die VeräuBerungserlöse insgesamt steuerfrei sind.

Beim Käufer verringern sich durch den Erwerb c.p. die Ersparnisse und damit erhöht sich der steuerpflichtige Konsum. Somit ist die Besteuerung gemäß der individuellen Leistungsfähigkeit erfüllt.

Bei der Erhebung einer Mehrwertsteuer und der Methode der eigenen Aufzeichnungen ergibt sich das gleiche Ergebnis, wenn der Erwerb beim Käufer der Besteuerung unterliegt und der Veräußerer die zuviel entrichtete Steuer wieder vom Finanzamt erstattet bekommt oder aber der Konsum der Veräußerungserlöse steuerfrei ist.

Ist der Erwerb beim Käufer hingegen steuerfrei, ist dieser bereit, einen höheren Preis zu zahlen: die Alternative ist bei ihm die Miete; hier muß er als Miete den Preis der Nutzung und die darauf entfallende Steuer entrichten. Infolgedessen ist für ihn die eingesparte Miete (einschließlich Steuern) der Kaufpreis.

Der Verkäufer hat beim Kauf den gesamten Nutzenvorrat versteuert, ihn aber nicht vollständig verbraucht. Beim Verkauf erhält er vom Käufer als Preis den Wert der Nutzung zuzüglich der Steuer, die bei der Miete anfallen würde. Er bekommt somit die zuviel bezahlte Steuer vom Käufer erstattet. Der Konsum des Verkäufers aus diesem Betrag unterliegt wie jeder andere Konsum wieder der Besteuerung, eine Befreiung ist nicht gerechtfertigt.

Eine doppelte Besteuerung findet somit bei den hier behandelten Methoden nicht statt. Da überdies sowohl der Käufer als auch der Verkäufer die Steuer auf die von ihnen bezogenen Nutzungen entrichten, wird nicht gegen das Leistungsfähigkeitsprinzip verstoßen.

Wird die reine Konsumgutlösung angewendet, ist die steuerliche Bemessungsgrundlage und damit der Tarif unter Umständen größeren Schwankungen unterworfen. Wird ein langlebiges Konsumgut verkauft und soll die Steuer vom Fiskus zurückerstattet werden, stellt sich bei einem progressiven Steuersystem die Frage des anzuwendenden Steuersatzes, da der beim Kauf angewandte vom heute anzuwendenden abweichen dürfte. 
Bei Implementierung des oben gemachten Vorschlags zur Modifikation der indirekten Konsumerfassung (keine Erfassung der Zuflüsse beim Verkäufer), wird der Verkäufer praktisch mit seinem derzeitigen Steuersatz entlastet ${ }^{l}$. Wird dem Vorschlag von Mitschke gefolgt (der Verkaufsvorgang wird nicht erfaßt und der Konsum daraus ist steuerfrei), wird faktisch der beim Kauf gültige Steuersatz angewandt.

Werden -wie oben vorgeschlagen- dem Verkäufer keine Steuern erstattet und ist dafür der Kauf von Gebrauchtgütern steuerfrei, ergeben sich folgende Auswirkungen: bei der Konsumerfassung durch eigene Aufzeichnungen des Steuerpflichtigen weichen in der Regel die Steuersätze von Käufer und Verkäufer voneinander ab. Hier wird sich über den Markt ein mittlerer Steuersatz bei der Preisfindung einstellen, so daß nicht jedes Individuum die von ihm bezogenen Nutzungen mit seinem Steuersatz versteuert und gegen das Leistungsfähigkeitsprinzip verstoßen wird.

Keine Probleme entstehen bei einer Mehrwertsteuer, bei der die Progression durch gespaltene Steuersätze für verschiedene Güter hergestellt wird, da hier sowohl der Käufer als auch der Verkäufer dem gleichen Steuersatz für das jeweilige Gut unterliegen.

Zusammenfassend kann gesagt werden, daß die Besteuerung bei einem linearen Steuertarif bei alle drei Methoden nach dem Leistungsfähigkeitsprinzip erfolgt. Bei einem progressiven Steuersystem ist hingegen die Höhe des anzuwendenden Steuersatzes (historischer oder aktueller) zur Korrektur der ehemals zuviel bezahlten Steuer bei der indirekten Konsumerfassung und der Erfassung durch eigene Aufzeichnungen fraglich. Beide Methoden sind zur Anwendung beider Steuersätze geeignet. Bei einer Mehrwertsteuer besteht dieses Problem nicht, da jeder dem gleichen Steuersatz für das jeweilige Gut unterliegt.

Bisher wurde davon ausgegangen, daß eine Welt mit vollkommener Information besteht. Diese Annahme wird jetzt aufgegeben und Windfall Profits zugelassen. Windfall Profits erhöhen die Leistungsfähigkeit der Individuen und sind zu erfassen, da sonst gegen das Leistungsfähigkeitsprinzip verstoßen wird. Somit ist der Vorschlag von Mitschke (der Konsum der Veräußerungserlöse ist steuerfrei) abzulehnen.

1 Dies kann zu folgender Situation führen: der Kaufpreis beträgt ursprünglich 100 , der Verkaufspreis zu Beginn der zweiten Periode 50. Die Nutzungsdauer des Konsumguts ist zwei Jahre, von Zinsen wird abstrahiert. Ist der relevante Steuersatz in der Erwerbsperiode 10\%, entrichtet das Individuum 10 an Steuern. Steigt der Steuersatz in der Veräußerungsperiode auf $50 \%$, so erhält es 25 erstattet. Somit erhält das Individuum für seine Nutzung eine Steuererstattung (!) von 15. 
Die laufenden Nutzungen des Verkäufers werden durch die oben vorgeschlagenen Modifikationen zutreffend besteuert. Somit ist hier lediglich die Behandlungsweise der Veräußerungserlöse von Interesse.

Im Fall von Windfall Profits erhält der Veräußerer einen höheren Preis für die im Konsumgut noch enthaltenen Nutzungen als er selbst dafür zahlte. Um die Windfall Profits zu erfassen, kann z.B. der Konsum aus den Veräußerungserlösen der Besteuerung unterworfen werden. Die ursprünglich beim Kauf des veräußerten Gegenstandes entrichtete Steuer muß dann aber insoweit erstattet werden, als sie auf die noch nicht gezogenen Nutzungen entfällt (dazu sind die noch nicht verbrauchten Nutzungen mit dem Wert beim Kauf zuzüglich Zinsen anzusetzen).

Die reine Konsumgutlösung verstößt daher auch hier gegen das Leistungsfähigkeitsprinzip und ist abzulehnen. Vorzunehmende Modifikationen müssen dafür sorgen, daß die noch nicht versteuerten Windfall Profits bei der Veräußerung der Besteuerung zugänglich gemacht werden. Die von Mitschke vorgeschlagene Nichterfassung ist also nicht sachgerecht.

\subsubsection{Weitere Probleme der Konsumgutlösung}

Sind die Konsumgüter am Lebensende des Steuerpflichtigen noch vorhanden, bleibt ihr Wert bei der Ermittlung des Lebensendvermögens unberücksichtigt. Bei Anwendung der reinen Konsumgutlösung bleiben somit auch Windfall Profits außer Ansatz. Es liegt daher ein Verstoß gegen das Leistungsfähigkeitsprinzip vor.

Ein weiteres Problem sind bei einem progressiven Tarif die Progressionseinflüsse. Aus der Konsumgutlösung folgt, daß sich beim Erwerb eines teueren Konsumguts (Immobilien, Kraftfahrzeuge, Wohnungseinrichtungen) die steuerliche Bemessungsgrundlage schlagartig stark erhöht. Bei einem progressiven Tarif treten dann dieselben Probleme hinsichtlich der insgesamt zu zahlenden Steuer wie bei einer periodischen Einkommensteuer bei schwankendem Einkommen auf; der Vorteil der Konsumbesteuerung -die glättere Bemessungsgrundlage- wird hierdurch zumindest teilweise wieder aufgehoben. Dies stellt einen Verstoß gegen das Leistungsfähigkeitsprinzip dar, da bei gleichem Lebenseinkommen derjenige, der teuere langlebige Konsumgüter kauft, eine höhere Steuer zu entrichten hat als derjenige, der diese Güter mietet.

Ein anderes Problem bei der Konsumgutlösung dürfte für viele Steuerpflichtigen auch die Fähigkeit zur Zahlung der Steuerlast sein: langlebige Konsumgüter (wie z.B. Wohnungen) werden aufgrund ihres hohen Preises zu einem hohen 
Anteil fremdfinanziert und gleichzeitig als Sicherheit gestellt. Die Steuer müßte in diesen Fällen auch zu einem hohen Prozentsatz über Kredite finanziert werden. $\mathrm{Da}$ in der Realität die Beleihungsgrenze eines Vermögensgegenstandes unter seinem Veräußerungserlös liegt, reicht der dem Steuerpflichtigen zur Verfügung stehende Kreditrahmen vielfach nicht für die Finanzierung des Vermögensgegenstandes und der Steuer aus; somit kommen Liquiditätsbeschränkungen zum Tragen ${ }^{l}$.

\subsubsection{Zusammenfassung}

Die Konsumgutlösung bildet in ihrer reinen Form die mit Hilfe des Indikators "Lebenseinkommen" gemessene Leistungsfähigkeit in der realen Welt nicht ab, da Windfall Profits in Form von Wertsteigerungen bei langlebigen Konsumgütern nicht erfaßt werden. Damit das Lebenseinkommen in voller Höhe abgebildet und somit dem Gleichheitsgrundsatz entsprochen wird, müssen die aus dem selbstgenutzten langlebigen Konsumgut gezogenen Nutzungen mit dem tatsächlichen Wert in der Verbrauchsperiode bewertet und die ursprünglich beim Kauf des langlebigen Konsumguts entrichtete Steuer gegebenenfalls korrigiert werden. Dies kann durch den Einbezug der am Markt zu beobachtenden Mietpreissteigerungen aufgrund von Wertänderungen für gleiche oder ähnliche Konsumgüter geschehen. Ebenso müssen diese Wertänderung beim Verkauf des Wirtschaftsgutes bzw. bei der Erfassung des Lebensendvermögens berücksichtigt werden. Problematisch ist weiterhin, daß die als notwendig erachteten Modifikationen die Konsumgutlösung soweit verfremden, da $ß$ im Ergebnis die Investitionsgutlösung durchgeführt wird und somit die Vorzüge der Konsumgutlösung verloren gehen.

Bei der Anwendung eines progressiven Tarifs geht der gesamte "Nutzenvorrat" des langlebigen Konsumguts in der Periode des Kaufs in die Bemessungsgrundlage ein; somit schwankt sie im Zeitablauf erheblich. Dadurch ergeben sich die bei der Untersuchung der Periodeneinkommensteuer dargestellten Probleme der schwankenden Bemessungsgrundlagen: diejenigen Individuen, die sich langlebige Konsumgüter kaufen, müssen aufgrund des progressiven Tarifs eine höhere Steuer entrichten als diejenigen, die diese Güter mieten. Ein anderes Problem stellen Liquiditätsbeschränkungen dar, da der Steuerpflichtige in der Erwerbspe-

1 Im Fall der Einkommensbesteuerung nach der Reinvermögenszugangstheorie sind -wie oben gezeigt- unrealisierte Wertzuwächse zu versteuern; da die Steuer auf diese Wertzuwächse im allgemeinen betragsmäßig nur einen Bruchteil der hier behandelten Steuer darstellt, ergibt sich dort das Problem der Kreditbesicherung nicht in diesem Ausmaß. 
riode die Steuer auf den gesamten Kaufpreis und nicht nur auf die von ihm in der Periode konsumierten Nutzungen entrichten muß.

\subsubsection{Neutralität der Besteuerung}

Ist die Konsumgutlösung in ihrer reinen Form -also ohne die oben vorgeschlagenen Modifikationen- mit der Forderung nach einem entscheidungsneutralen Steuersystem zu vereinbaren?

Ein Gesichtspunkt ist hierbei die Entscheidung zwischen Kauf und Miete von langlebigen Konsumgütern.

Als Vergleichsmaßstab dient wiederum eine Laissez-Faire-Ökonomie. Hier besteht Indifferenz zwischen Kauf oder Miete eines Wirtschaftsguts, wenn die Kosten der Nutzung in beiden Fällen gleich sind; steuerliche Einflüsse spielen -da die Steuern unabhängig von der Wahl anfallen- keine Rolle. Daran ändert auch die Besteuerung des Periodenkonsums -wenn keine Wertsteigerungen auftretennichts, da bei beiden Alternativen die zu entrichtende Steuer gleich ist. Ein Verstoß gegen die Neutralität der Besteuerung gibt es nicht.

Werden bei einem langlebigen Konsumgut Wertsteigerungen (z.B. aufgrund besonderer Knappheiten) erwartet, ist es in einer Laissez-Faire-Ökonomie günstiger, diese Güter zu kaufen, statt zu mieten. Diese Entscheidung wird bei der reinen Konsumgutlösung noch durch steuerliche Erwägungen gefördert, da beim Kauf die erwarteten Wertsteigerungen nicht zu versteuern sind. Bei der Alternative "Miete" rufen die Wertsteigerungen vielfach Mietpreiserhöhungen hervor, die in die steuerliche Bemessungsgrundlage eingehen. Durch den Kauf kann das Individuum also noch zusätzlich Steuern sparen.

Fraglich ist überdies, ob die Veräußerungsentscheidung beeinflußt wird.

Ohne die oben vorgeschlagenen Modifikationen werden Veräußerungsgewinne und ihr Konsum steuerlich nicht erfaßt. Damit wird die Entscheidung, ein Konsumgut zu verkaufen, die Veräußerungsgewinne zu realisieren und die Erlöse zu konsumieren durch steuerliche Erwägungen nicht beeinflußt und die Entscheidungsneutralität nicht verletzt.

Durch die Besteuerung könnte beim Kauf eine Beeinflussung der Entscheidung hinsichtlich der möglichen Nutzungsdauer der langlebigen Konsumgüter ausgeübt werden: erwerben die Individuen z.B. ein langlebiges Konsumgut mit einer möglichen Nutzungsdauer von drei oder von zehn Jahren? Wird angenommen, der Preis ist für beide proportional zu ihrem Nutzenvorrat, besteht in einer Lais- 
sez-Faire-Ökonomie Indifferenz zwischen beiden Alternativen. Bei einem linearen Steuersystem ändert sich daran nichts, da der Barwert der Steuerzahlung -unter Berücksichtigung des unterschiedlichen Nutzenvorrats der Güter- gleich ist.

Die Vernachlässigung von Progressionseffekten ist in der Realität eine fehlerhafte Annahme, da für den Gesetzgeber die Progression eine viel zu starke Anziehungskraft ausübt ( sei es zur "Schließung einer Gerechtigkeitslücke" oder "nur" zur Einnahmenverbesserung). Wird diese Annahme aufgegeben, ergeben sich durch den ungleichmäßigen Anfall von Ausgaben für langlebige Konsumgüter periodisch schwankende Bemessungsgrundlagen mit den bereits erwähnten negativen Auswirkungen ${ }^{l}$. Im Ergebnis ist es c.p. zur Glättung der Bemessungsgrundlage und somit zur Minimierung der Steuerzahlungen am günstigsten, langlebige Konsumgüter zu mieten statt zu kaufen bzw. beim Kauf weniger langlebige gegenüber extrem langlebigen Konsumgütern zu präferieren. Somit werden die Entscheidungen durch die Besteuerung verzerrt.

\subsubsection{Praktikabilität der Besteuerung}

Bei der Beurteilung der Praktikabilität muß zwischen der reinen Konsumgutlösung und ihren Modifikationen unterschieden werden.

Die reine Konsumgutlösung ist praktikabel, da jede Bewertung der aus dem Gut gezogenen Nutzungen entfällt. In die Bemessungsgrundlage der Besteuerung geht lediglich der Kaufpreis zum Zeitpunkt des Erwerbs des betreffenden Gutes ein.

Werden die oben als notwendig erachteten Modifikationen zur Berücksichtigung von Nutzwertänderungen implementiert, geht die Praktikabilität der Konsumgutlösung verloren. Für jedes langlebige Konsumgut ist dann zu prüfen, ob sich der Wert der (Eigen-) Nutzung nicht im Vergleich zum Zeitpunkt der Anschaffung verändert hat (z.B. durch Windfall Profits). Diese Veränderung ist der Besteuerung zu unterwerfen.

$\mathrm{Zu}$ analysieren ist auch die Praktikabilität der verschiedenen Möglichkeiten zur Behandlung der Veräußerungserlöse.

Werden sie bei der indirekten Methode nicht als Zufluß erfaßt bzw. ist bei den anderen beiden Erfassungsmethoden der Kauf von gebrauchten Gütern steuerfrei, muß -wie oben gezeigt- dem Verkäufer vom Fiskus keine Steuer zurücker-

1 Vgl. hierzu die Ausführungen im ersten und im zweiten Teil der vorliegenden Arbeit. 
stattet werden. Der spätere Konsum aus diesen Gütern unterliegt der normalen Besteuerung. Es sind keine gesonderten Regelungen und Aufzeichnungen zur Erfassung der Veräußerungserlöse notwendig. Diese Verfahrensweise ist deshalb als praktikabel anzusehen.

Soll der spätere Konsum aus den Veräußerungserlösen steuerfrei sein, müssen die Steuerpflichtigen gesonderte Aufzeichnungen über diese Erlöse führen; weiterhin ist eine Erfassung des Käufers notwendig, da dieser den Kauf der Besteuerung zu unterwerfen hat. Diese Verfahrensweise ist sehr aufwendig. Beide Methoden können allerdings nur angewandt werden, wenn keine Windfall Profits auftreten, da sonst gegen das Leistungsfähigkeitsprinzip verstoßen wird.

Soll hingegen die ursprünglich zu hoch entrichtete Steuer vom Fiskus erstattet werden, muß der Käufer den Kauf des gebrauchten Guts als Konsum versteuern. Damit muß jeder Verkauf dem Finanzamt gemeldet werden, was unpraktikabel ist. Diese Methode kann aber auch beim Vorliegen von Windfall Profits angewandt werden.

Es wird nun noch auf das Problem der Steuersicherung eingegangen. Es ist zu klären, ob und welche Möglichkeiten der Steuerpflichtige hat, seine Steuerschuld zu verkürzen. Bei der reinen Konsumgutlösung ist die Erfassung der Ausgaben für den Kauf des Konsumguts notwendig. Ist das gewährleistet, bestehen für den Steuerpflichtigen keine Möglichkeiten, die Steuerschuld zu verkürzen ${ }^{l}$. Werden allerdings die oben als notwendig erachteten Modifikationen zur Erfassung der Windfall Profits implementiert, ergibt sich ein anderes Bild: zur Steuersicherung muß der Fiskus wissen, welche langlebigen Konsumgüter ein Steuerpflichtiger in seinem Eigentum hat; diese Kenntnis hat der Fiskus nur bei der Erfassung des Periodenkonsums durch eigene Aufzeichnungen des Steuerpflichtigen. Bei den anderen Erfassungsmethoden hat der Fiskus keine Kenntnis davon, ob der Steuerpflichtige seine Ausgaben für den Erwerb von Dienstleistungen, für kurzlebige oder für langlebige Konsumgüter tätigte. Dieser Mangel ist nur durch weitere (aufwendige) Kontrollmechanismen zu beheben.

Die als notwendig erachteten Korrekturen müssen jedoch nur erfolgen, um Windfall Profits zu erfassen. Das einzige langlebigen Konsumgut, bei dem in der Vergangenheit in nennenswertem Umfang Windfall Profits aufgetreten sind, ist selbstgenutztes Wohneigentum. Somit dürften die Modifikationen nur bei diesem Gut notwendig sein. Die Eigentumsdaten sind über die Grundbuchämter verfügbar; der Fiskus kann darauf zugreifen. Diese Modifikation bedeutet aber eine starke Abkehr von der reinen Konsumgutlösung.

Da dies ein grundsätzliches Problem der jeweiligen Erfassungsmethode ist, wird auf die dortigen Ausführungen verwiesen. 


\subsubsection{Ergebnis}

Die reine Konsumgutlösung verstößt in einer Welt, in der es Windfall Profits gibt, gegen die Forderung der Besteuerung nach der individuellen Leistungsfähigkeit. Um dies zu vermeiden, muß der tatsächlich aus den langlebigen Konsumgütern gezogene Nutzen mit dem zum Anschaffungszeitpunkt versteuerten verglichen werden und gegebenenfalls die Nutzwerterhöhung, die durch Windfall Profits entstanden ist, versteuert werden. Diese Windfall Profits sind auch bei den Veräußerungserlösen sowie der Lebensendvermögensbesteuerung zu berücksichtigen. Dadurch wird die einfache Handhabung der Konsumgutlösung erheblich eingeschränkt. Dieses Problem dürfte allerdings lediglich bei Wohneigentum auftreten, so daß es relativ entschärft ist. Für die Steuersicherung entstehen bei der reinen Konsumgutlösung keine zusätzlichen Probleme.

Problematisch ist bei einem progressiven Tarifverlauf, daß die Anschaffung von teueren langlebigen Konsumgütern zu stark schwankenden periodischen Bemessungsgrundlagen führt. Damit führt die ungleichmäßige Verteilung der Konsumausgaben zu einer insgesamt höheren abzuführenden Steuer als beim gleichmäBigen Anfall der Konsumausgaben. Dadurch treten Verstöße gegen das Leistungsfähigkeitsprinzip sowie gegen die Forderung nach einem neutralen Steuersystem auf. Die Bemühungen der Individuen, ihren Periodenkonsum zu glätten, können durch die Anknüpfung an die Konsumausgaben, statt an den tatsächlichen Konsum, nicht vollständig genutzt werden.

Die reine Konsumgutlösung ist als sehr praktikabel einzustufen; wird der Kauf von gebrauchten Gütern bei einer Mehrwertsteuer bzw. der Methode der eigenen Aufzeichnungen nicht der Besteuerung beim Käufer unterworfen bzw. unterbleibt bei der indirekten Konsumerfassung die Erfassung als Zufluß, muß der Fiskus keine Steuer dem Verkäufer zurückerstatten. Somit ist die reine Konsumgutlösung auch aus Sicht der Steuerverwaltung vorteilhaft.

Die drei behandelten Erfassungsmethoden sind dabei insgesamt als gleichwertig einzuordnen.

\subsection{Behandlung der langlebigen Konsumgüter im Sinne der "Investitionsgutlösung"}

Werden langlebige Konsumgüter analog zu den Investitionsgüter behandelt, die ihre Nutzungen nach und nach abgeben, sind die Ausgaben für den Erwerb des Wirtschaftsgutes sowie die eventuell anfallenden Finanzierungskosten (Zinsen usw.) als erwerbswirtschaftliche Investition und damit als Ersparnis aufzufassen. 
Die Anschaffungskosten gehen in der Anschaffungsperiode somit nicht als Konsum in die Steuerbemessungsgrundlage ein. Die laufende private Nutzung des Gutes wird als Naturalkonsum mit den entsprechenden Werten erfaßt und besteuert. Der aus dem Verkaufserlös bestrittene Konsum unterliegt der normalen Besteuerung.

\subsubsection{Besteuerung nach der individuellen Leistungsfähigkeit}

Werden die langlebigen Konsumgüter wie Investitionsgüter behandelt, geht in die periodische Bemessungsgrundlage der Wert der aus diesen Gütern gezogenen Nutzungen ein, der damit zu ermitteln ist. Dieser Wert kann zu den Verhältnissen zum Zeitpunkt des Kaufs und zum Zeitpunkt der Nutzung angesetzt werden. Um Windfall Profits bei selbstgenutzten dauerhaften Konsumgütern in der steuerlichen Bemessungsgrundlage erfassen zu können, ist der Wert der Nutzung im Zeitpunkt der Nutzung zu berücksichtigen. Dadurch gehen die erhöhten Dispositionsmöglichkeiten des Steuerpflichtigen -das langlebige Konsumgut könnte statt der Eigennutzung auch verkauft oder vermietet werden- in die steuerliche Bemessungsgrundlage ein. Würde der Wert der Nutzung aufgrund der historischen Anschaffungs- oder Herstellungskosten angesetzt, blieben die Windfall Profits unberücksichtigt und die individuelle Leistungsfähigkeit würde nur unvollkommen abgebildet.

Ein weiterer Grund für den Einbezug des aktuellen Wertes der Nutzung in die steuerliche Bemessungsgrundlage liegt in der Gleichbehandlung von Individuen, die bei identischer Leistungsfähigkeit vor Steuern, das langlebige Konsumgut kaufen im Vergleich zu denen, die es mieten ${ }^{l}$. Die eigene Nutzung des Gutes stellt denselben wirtschaftlichen Sachverhalt wie die Miete dar; beide Tatbestände sind daher auch gleich zu besteuern.

Wird das selbstgenutzte langlebige Wirtschaftsgut veräußert, unterliegt der spätere Konsum aus dem Verkaufserlös der Besteuerung. Der erzielte Veräußerungserlös ist als Zufluß des betreffenden Jahres anzusehen. Angefallene Windfall Profits gehen somit entweder über den zukünftig höheren Konsum oder durch das höhere Lebensendvermögen in die steuerliche Bemessungsgrundlage ein. Der Wert des Konsumgutes beim Ableben des Individuums unterliegt der Lebensendvermögensbesteuerung, da der Teil des Lebenseinkommens, aus dem die Anschaffung des langlebigen Konsumguts finanziert wurde, wie jede andere Ersparnis des Individuums, noch nicht der Besteuerung unterworfen wurde.

Treten diese Windfall Profits bei gemieteten Wirtschaftsgütern auf, steigt die vom Vermieter verlangte Miete entsprechend, da der Vermieter nur so eine angemessene Verzinsung des eingesetzten Kapitals erzielt. 
Die Besteuerung des Lebenseinkommens ist durch die Investitionsgutlösung dann gewährleistet, wenn der Naturalkonsum zu Marktpreisen bewertet wird ${ }^{I}$; gegen das Leistungsfähigkeitsprinzip wird nicht verstoßen.

\subsubsection{Neutralität der Besteuerung}

Durch die Besteuerung kann die Entscheidung des Steuerpflichtigen, zu kaufen oder zu mieten sowie die Veräußerungsentscheidung beeinflußt werden; weiterhin kann die (Kauf-) Entscheidung des Steuerpflichtigen zwischen einem relativ langlebigen und einem weniger langlebigen Vermögensgegenstand verzerrt werden.

Bei der Investitionsgutlösung ist die Bewertung des Naturalkonsums problematisch. Erfolgt sie mit realistischen Wertansätzen, d.h. mit dem Wert, den der Naturalkonsum beim Erwerb von einem Dritten kosten würde, wird die Entscheidung des Steuerpflichtigen zwischen Kauf und Miete sowie der Wahl der Lebensdauer des langlebigen Konsumguts nicht beeinflußt. Das gilt auch für die Entscheidung des Steuerpflichtigen hinsichtlich der Fristigkeit des zu kaufenden langlebigen Konsumguts. Im umgekehrten Fall wird die Entscheidung des Steuerpflichtigen zwischen Kauf und Miete des langlebigen Konsumguts verzerrt.

Die Entscheidung zum Verkauf des langlebigen Konsumguts wird durch die Besteuerung dann nicht beeinflußt, wenn die aus dem langlebigen Konsumgut gezogenen Nutzungen zutreffend bewertet werden. Der Verkäufer hat aus steuerlichen Gründen keinen Anreiz, das betreffende Gut weiterhin zu halten oder zu veräußern, da in jedem Fall der Wert des tatsächlichen Konsums zu versteuern ist. Da die Veräußerungsentscheidung nicht beeinflußt wird, ist die Entscheidungsneutralität der Besteuerung gewährleistet.

\subsubsection{Praktikabilität der Besteuerung}

Wird die Investitionsgutlösung konsequent verwirklicht, muß jeder Steuerpflichtige ein vom Fiskus zu kontrollierendes Verzeichnis der in seinem Eigentum stehenden langlebigen Konsumgüter führen. Weiterhin muß für jedes langlebige Konsumgut der Wert der daraus gezogenen Nutzungen zur Erfassung des Natu-

1 Das Problem der Bewertung des Naturalkonsums wird an anderer Stelle behandelt. 
ralkonsums bestimmt werden. Die konsequente Anwendung der Investitionsgutlösung ist recht aufwendig.

Es wird nun geprüft, ob die Investitionsgutlösung in die drei hier behandelten Methoden zur Erfassung des Periodenkonsums einbezogen werden kann und ob eine Methode zu präferieren ist.

Bei der Mehrwertsteuer werden die Güter/Leistungen direkt beim Kauf der Besteuerung unterworfen; es bestehen keine Aufzeichnungen über den Erwerb dieser Güter. Weiterhin gibt es keine "eingebaute" Möglichkeiten zur Kontrolle des Güterbestandes eines Steuerpflichtigen. Die Behandlung der langlebigen Konsumgüter im Sinne der Investitionsgutlösung kann jedoch eingeführt werden, wenn der Steuerpflichtige auf entsprechenden Nachweis die auf dem langlebigen Konsumgut liegende Mehrwertsteuer wieder erstattet bekommt. Der Naturalkonsum aus dem Konsumgut unterliegt dann solange der Besteuerung, bis der Steuerpflichtige den Abgang des langlebigen Konsumgutes meldet.

Die Erfassung des Periodenkonsums durch eigene Aufzeichnungen des Steuerpflichtigen zeigt auch -die Vollständigkeit der Aufzeichnungen vorausgesetztdie Ausgaben für langlebige Konsumgüter, so daß hier Informationen über den Güterbestand des Individuums bestehen. Der Abgang dieser Güter wird jedoch nicht automatisch aufgezeichnet. Dieses Problem kann allerdings durch eine relativ einfache Modifikation gelöst werden: der Steuerpflichtige muß solange den Naturalkonsum aus diesen Gütern versteuern, bis er den Abgang durch geeignete Belege nachweist (z.B. Verkaufsrechnung); dadurch besteht ein Interesse seitens des Steuerpflichtigen, den Abgang anzuzeigen.

Bei der indirekten Ermittlung des Periodenkonsums werden die Ausgaben für den Erwerb der langlebigen Konsumgüter als investive Abflüsse aufgefaßt, d.h. der Steuerpflichtige muß geeignete Nachweise (z.B. Rechnungen) vorlegen. Ansonsten werden die Ausgaben für den Erwerb der langlebigen Konsumgüter als "normale" Konsumausgaben angesehen und im Jahr des Erwerbs versteuert. Dadurch besteht eine Kontrolle über den zu versteuernden Naturalkonsum. Die Deklaration der Abgänge muß wie bei der Erfassung des Periodenkonsums durch eigene Aufzeichnungen des Steuerpflichtigen erfolgen, da sonst kein Interesse besteht, den Abgang der Güter und somit die Erhöhung der Zuflüsse durch die Verkaufserlöse zu deklarieren.

Der Steuerpflichtige ist jedoch bei der Investitionsgutlösung eventuell bestrebt, die Ausgaben für das langlebige Konsumgut nicht als investiven Zahlungsabfluß anzugeben, sondern sie sofort als Konsumausgaben zu versteuern. Diese Vorge- 
hensweise wäre dann faktisch die Wiedereinführung der Konsumgutlösung mit den aufgezeigten Schwächen. Bezüglich dieses Problems gelten die gleichen Überlegungen wie bei der generellen Frage der Deklaration von investiven Zahlungsabflüssen bzw. der vorgezogenen Versteuerung von zukünftigem Konsum ${ }^{l}$.

Grundsätzlich sind also alle hier behandelten Methoden zur Erfassung des Periodenkonsums geeignet, langlebige Konsumgüter im Sinne der Investitionsgutlösung zu behandeln.

\subsubsection{Ergebnis}

Die Behandlung der langlebigen Konsumgüter analog zu den Investitionsgütern genügt dem Konzept der Besteuerung nach der individuellen Leistungsfähigkeit und der Forderung nach einem neutralen Steuersystem. Zu bemängeln ist bei der Investitionsgutlösung allerdings ihre Aufwendigkeit durch das Führen von Verzeichnissen über die langlebigen Konsumgüter sowie die Notwendigkeit, die Nutzungen aus diesen Gütern als Naturalkonsum zu bewerten. Die im Rahmen der Arbeit behandelten Erfassungsmethoden zur Bestimmung des Periodenkonsums können -nach Modifikationen- im Hinblick auf die Durchführbarkeit der Investitionsgutlösung als gleichwertig beurteilt werden.

\subsection{Beurteilung der beiden Ansätze}

Aus den bei der Diskussion der Konsumgutlösung angeführten Gründen, die gegen die reine Konsumgutlösung sprechen (Verstoß gegen das Leistungsfähigkeitsprinzip, mögliche Verletzung der Entscheidungsneutralität, mögliche Progressionseffekte durch schwankende Bemessungsgrundlagen sowie Liquiditätseffekte), ist die Behandlung der langlebigen Konsumgüter im Sinne der Investitionsgutlösung zu präferieren. Dafür spricht, daß die Bewertung der aus den langlebigen Konsumgütern gezogenen Nutzungen auch bei der Konsumgutlösung notwendig ist, um Wertsteigerungen von langlebigen Konsumgütern zu erfassen. Somit wird die Entscheidung zwischen beiden Konzeptionen durch diesen Problemkreis nicht beeinflußt. Die anderen Probleme der Konsumgutlösung (Liquiditäts- und Progressionseffekte) bleiben aber erhalten, ohne daß Vorteile gegenüber der Investitionsgutlösung entstehen. Aus diesen Gründen ist die $\mathrm{Be}-$ handlung von langlebigen Konsumgütern analog zu den erwerbswirtschaftlichen

\footnotetext{
I Vgl. hierzu die entsprechenden Ausführungen.
} 
Investitionsgütern zu präferieren. Somit muß zwischen den Ausgaben für Konsumgüter sowie dem Verbrauch von Konsumgütern in der jeweiligen Periode unterschieden werden.

In der Praxis ist jedoch die reine Investitionsgutlösung nicht praktikabel. Es sollte darum ein Verfahren gefunden werden, das die Vorteile der beiden Möglichkeiten bietet, deren Nachteile aber möglichst minimiert.

Um dies zu erreichen, wird nochmals auf die Probleme der Konsumgutlösung eingegangen. Hier war kritisch, daß Windfall Profits steuerlich unberücksichtigt bleiben und unter Umständen Liquiditätseffekte bei hochpreisigen Gütern auftreten. Bei einer progressiven Tarifstruktur besteht weiterhin das Problem des Progressionseffektes beim Kauf von relativ teueren langlebigen Konsumgütern. Langlebige Konsumgüter, bei denen aller Voraussicht nach keine Windfall Profits auftreten ${ }^{l}$ und die einen nicht allzu hohen Wert besitzen, können somit ohne größere Schwierigkeiten hinsichtlich der Besteuerung nach der individuellen Leistungsfähigkeit bzw. der Forderung nach einem neutralen Steuersystem im Sinne der Konsumgutlösung behandelt werden.

Windfall Profits sind bei langlebigen Konsumgütern in der Vergangenheit im wesentlichen bei Wohneigentum aufgetreten. Langlebige Konsumgüter mit einem Wert, der eventuell größere Liquiditätsprobleme und Progressionseffekte hervorrufen könnte, sind im wesentlichen Wohneigentum, Wohnungseinrichtungen sowie Kraftfahrzeuge.

Bei anderen (gebräuchlichen) langlebigen Konsumgütern treten in der Regel weder Windfall Profits auf, noch hat ihre Anschaffung wesentliche Liquiditätsund Progressionseffekte zur Folge ${ }^{2}$. Aus Vereinfachungsgründen können diese Güter im Sinne der Konsumgutlösung behandelt werden. Größere Einschränkungen bei der Besteuerung gemäß der individuellen Leistungsfähigkeit oder der Forderung nach einem neutralen Steuersystem sind nicht zu erwarten.

Wohneigentum, Wohnungseinrichtungen und Kraftfahrzeuge sind allerdings im Sinne der Investitionsgutlösung zu behandeln.

Aufgrund dieser Vereinfachung muß nur ein Verzeichnis über wenige langlebige Konsumgüter geführt werden. Dessen Umfang kann weiter verringert werden, wenn auf die Daten der Grundbuchämter (Wohneigentum) bzw. auf die der Kfz-Zulassungsstellen (Kraftfahrzeuge) zugegriffen werden darf. Damit fällt ein wesentlich geringerer Erfassungs- und Überwachungsaufwand an. Durch diese

\footnotetext{
1 Ein Anhaltspunkt hierfür kann die Vergangenheit sein.

2 Relativ hohe Wertsteigerungen haben auch manche Kunstgegenstände erfahren; weiterhin gibt es auch sehr teuren Schmuck. Da die Anschaffung dieser Gegenstände lédiglich eine Minderheit der Haushalte betrifft, wird nicht weiter darauf eingegangen. Überdies ist fraglich, ob es sich hierbei um Investitions- oder Konsumgüter handelt (vgl. hierzu auch die Ausführungen zur Abgrenzung Investition - Konsum).
} 
differenzierte Behandlung der dauerhaften Konsumgüter ist überdies ein geringerer Umfang an Naturalkonsum zu bewerten.

Durch diese differenzierte Behandlungsweise ist es möglich, die Vorteile der Konsumgutlösung -nämlich Praktikabilität- in einem hohen Umfang zu wahren und gleichzeitig ein Steuersystem, das dem Leistungsfähigkeitsprinzip und der Neutralität der Besteuerung entspricht, zu gestalten. Somit kommen administrative Vorteile gegenüber einer Periodeneinkommensteuer gemäß der Reinvermögenszugangstheorie zum Tragen, da dort das ganze Vermögen und nicht nur einige wenige Nutzungen periodisch zu ermitteln ist ${ }^{l, 2}$.

\section{Besteuerung des Naturalkonsums}

Unter "Naturalkonsum" werden z.B. Naturaldeputate, die private Nutzung von betrieblichen Sachgütern oder deren Entnahme aus dem eigenen Betrieb verstanden. Unter dem Naturalkonsum werden -falls langlebige Konsumgüter analog den Investitionsgütern behandelt werden- auch die Nutzungen aus langlebigen Konsumgütern erfaßt.

\subsection{Besteuerung nach der individuellen Leistungsfähigkeit}

Es wird untersucht, ob der Naturalkonsum die Leistungsfähigkeit erhöht und wie er gegebenenfalls zu bewerten ist. Bei der Bestimmung des Lebenseinkommens über den Periodenkonsum und des Lebensendvermögens ist notwendig, den Periodenkonsum vollständig abzubilden. Deshalb ist auch der Naturalkonsum in die steuerliche Bemessungsgrundlage einzubeziehen. Dafür spricht, daß das Leistungsfähigkeitsprinzip für gleich Leistungsfähige die Entrichtung von gleich viel Steuern fordert. Die Höhe der Leistungsfähigkeit wird nicht dadurch beeinflußt, daß ein Individuum z.B. von seinem Arbeitgeber Sachleistungen, ein

I Der Ansicht von Seidl, C. (1990, S. 422-427), daß die Behandlung von langlebigen Konsumgütern bei einer Besteuerung des Periodenkonsums größere Probleme aufwirft als bei einer Einkommensbesteuerung, ist zumindest bei der Einkommensdefinition nach der Reinvermögenszugangstheorie nicht zu folgen (der gleichen Auffassung Schwinger, R. (1992), S. 232).

2 Mitschke (1985, S. 113 f.) kommt -allerdings mit einer anderen Begründung- zu einem ähnlichen Ergebnis. Kaldor (1969, S. 195ff.) möchte bei größeren Ausgaben auch die Konsumgutlösung anwenden, d.h. die aus dem Konsumgut gezogenen Nutzungen sind ohne Bedeutung. Er möchte stattdessen Kredittilgungen, Abzahlungsraten, lineare Abschreibungsraten u.ä. als Bemessungsgrundlage nutzen. 
anderes hingegen einen entsprechenden Betrag mehr an Lohn erhält und daraus konsumiert. Beide sind gleich leistungsfähig und müssen die gleiche Steuer entrichten. An diesem Beispiel wird die Bewertung des Naturalkonsums ersichtlich. Die Forderung der steuerlichen Gleichbehandlung der Individuen impliziert die Bewertung des Naturalkonsums zu aktuellen Marktpreisen.

Dies gilt auch -bei Anwendung der Investitionsgutlösung- für Nutzungen aus langlebigen Konsumgütern. Die aus ihnen gezogenen Nutzungen sind zu versteuern, da ihr Kaufpreis beim Erwerb nicht der Besteuerung unterworfen wurde. Aufgrund von Gerechtigkeitserwägungen muß die Bewertung zum Marktpreis der Nutzung erfolgen, da nur so Windfall Profits bei den langlebigen Konsumgütern erfaßt werden und eine Gleichbehandlung mit den Mietern dieser Güter erfolgt. Zum gleichen Ergebnis führt das Leistungsfähigkeitsprinzip als Ausdruck der Verfügungsgewalt über Ressourcen, da das Individuum im Zeitpunkt der Eigennutzung die Nutzungsentscheidung -Eigennutzung oder Vermietung- über die ihm zur Verfügung stehenden Ressourcen getroffen hat. Das Individuum hat damit über den Betrag disponiert, den eine Vermietung eingebracht hätte; somit ist der Naturalkonsum mit dem Marktwert anzusetzen.

Als Resümee ergibt sich damit, daß der Naturalkonsum zu Marktwerten in die steuerliche Bemessungsgrundlage eingehen muß, um einen Verstoß gegen das Leistungsfähigkeitsprinzip zu vermeiden.

Der Naturalkonsum wird von keiner der hier behandelten Methoden automatisch erfaßt. Sie sind damit aufgrund von Leistungsfähigkeitserwägungen als gleichwertig einzustufen; zur Erfassung des Naturalkonsums sind also bei allen Erfassungsmethoden Modifikationen notwendig.

\subsection{Neutralität der Besteuerung}

Durch die Besteuerung könnte die Entscheidung zwischen Kauf oder Miete eines langlebigen Konsumguts beeinflußt werden. Weiterhin könnte die Entscheidung des Steuerpflichtigen zwischen Geld- oder Naturallohn für seine Arbeitsleistung verzerrt werden.

In einer Laissez-Faire-Ökonomie besteht bei obigen Entscheidungen Indifferenz, wenn die Aufwendungen für die Selbstnutzung eines Wirtschaftsguts der zu zahlenden Miete entsprechen. Hinsichtlich der Form der Entlohnung liegt dann Indifferenz vor, wenn der Marktwert des Naturallohns dem Verzicht an Geldeinkommen gleichkommt. Ein Individuum ist somit in einer Welt ohne Be- 
steuerung immer dann indifferent, wenn der Marktwert des Naturalkonsums dem Wert der Alternative entspricht. Erfolgt nun die steuerliche Bewertung des Naturalkonsums zu (aktuellen) Marktpreisen, werden z.B. Miete und Eigennutzung eines langlebigen Konsumguts in gleicher Höhe besteuert. Der Konsum kostet infolgedessen auch nach Steuern bei beiden Alternativen gleich viel; eine Beeinflussung der Entscheidung tritt nicht auf. Bei einer anderen steuerlichen Bewertung des Naturalkonsums erfolgt eine Verzerrung der Entscheidungen der Steuerpflichtigen aufgrund von steuerlichen Erwägungen. Somit liegt ein Verstoß gegen die Forderung eines entscheidungsneutralen Steuersystems vor.

Damit muß auch aus Neutralitätserwägungen die steuerliche Bewertung des $\mathrm{Na}$ turalkonsums zu aktuellen Marktpreisen erfolgen.

\subsection{Praktikabilität der Besteuerung}

Bei der Beurteilung der Praktikabilität der Bewertung des Naturalkonsums ist zwischen der prinzipiellen Durchführbarkeit und der Möglichkeit der Implementierung in die verschiedenen Erfassungsmethoden zu unterscheiden, wobei auch auf Aspekte der Steuersicherung eingegangen wird.

Zuerst wird die prinzipielle Möglichkeit der Bewertung des Naturalkonsums behandelt.

Der Umfang des zu bewertenden Naturalkonsums wird im wesentlichen davon beeinflußt, ob langlebige Konsumgüter im Sinne der (reinen ${ }^{l}$ ) Konsumgut- oder der Investitionsgutlösung behandelt werden. Bei Behandlung dieser Güter im Sinne der (reinen) Konsumgutlösung sind die aus den langlebigen Konsumgütern gezogenen Nutzungen steuerlich irrelevant, da der gesamte Nutzenvorrat dieser Güter bei ihrem Erwerb der Besteuerung unterliegt. Damit verringert sich der Umfang des zu bewertenden Naturalkonsums erheblich. Der Naturalkonsum umfaßt dann im wesentlichen Naturaldeputate, Naturallohn sowie die private Nutzung von betrieblichen Sachgütern. Für diese Nutzungen muß ein Marktwert festgestellt werden, der sich am Entgelt eines Dritten für diese Nutzungen/Leistungen orientiert. Für den hier behandelten Naturalkonsum kann in der Regel ein Marktwert bestimmt werden, da diese Güter auch am Markt gehandelt werden bzw. es im Fall des Naturallohns Individuen gibt, die für die gleiche Arbeitsleistung eine Geldentlohnung erhalten. In diesem Fall ist der gleiche Um-

1 Die oben als notwendig erachteten Korrekturen bleiben unberücksichtigt, um die Konsumgutlösung in ihrer reinen Form zu beurteilen. Sollen die Korrekturen einbezogen werden, ergibt sich -wie oben gezeigt- faktisch die Investitionsgutlösung, so da $\beta$ auf diese Ausführungen zurückgegriffen werden kann. 
fang an Naturalleistungen zu erfassen und zu bewerten wie bei einer Einkommensbesteuerung.

Werden hingegen die langlebigen Konsumgüter im Sinne der Investitionsgutlösung behandelt, müssen zusätzlich die aus ihnen gezogenen Nutzungen als Naturalkonsum bewertet werden. Dabei ist zu klären, ob es für diese Nutzungen einen Marktwert gibt. Eine generelle Antwort ist nicht möglich: so besteht z.B. ein Mietmarkt für Wohnungen, nicht jedoch für Wohnungseinrichtungen. Muß der Wert der Nutzungen für alle langlebigen Konsumgüter bestimmt werden, ist dies mit einem hohen Aufwand verbunden.

Es sind aber Vereinfachungen möglich. Wird dem Vorschlag der differenzierten Behandlung der langlebigen Konsumgüter gefolgt ${ }^{l}$, sind nur Wohneigentum und (bei einem progressiven Tarif sowie aufgrund möglicher Liquiditätsbeschränkungen) Kraftfahrzeuge sowie Wohnungseinrichtungen im Sinne der Investitionsgutlösung zu behandeln; somit ist nur für diese Güter ein Marktwert für die Nutzung zu ermitteln. Für Wohneigentum kann die Ermittlung des Nutzwert anhand der ortsüblichen Miete vorgenommen werden; zur Kontrolle des Eigentums können die Daten des Grundbuchs dienen. Bei Kraftfahrzeugen kann die durch die Nutzung hervorgerufene Wertänderung anhand des Gebrauchtwagenmarktes (Schwacke-Liste) bestimmt werden. Problematisch ist die Bewertung des aus der Wohnungseinrichtungen gezogenen Konsums, da weder ein Mietmarkt noch ein Second-Hand-Markt besteht. Der pauschale Ansatz eines bestimmten Anteils der Anschaffungskosten als Nutzwert ist aber möglich, da im allgemeinen Windfall Profits nicht auftreten.

Mit diesen Vereinfachungen kann damit für die meisten langlebigen Konsumgüter die Konzeption der Konsumgutlösung durchgeführt werden. Der zu bewertende Naturalkonsum verringert sich beträchtlich.

Fraglich ist, ob sich die im Rahmen dieser Arbeit diskutierten Erfassungsmethoden des Periodenkonsums auch für den Einbezug des Naturalkonsums eignen. Die Methoden stellen in ihrer reinen Form alle auf den Konsum ab, der auf Zahlungsvorgängen beruht. Soll der Naturalkonsum ebenfalls erfaßt werden, müssen die drei Erfassungsmethoden modifiziert werden. Der Steuerpflichtige ist allerdings nicht daran interessiert, diesen Konsum dem Fiskus zu offenbaren, da hierauf Steuern zu entrichten sind. Damit stellt sich das Problem der Steuersicherung. Bei Naturalentlohnung oder -deputaten, die von den Unternehmen gewährt werden sowie bei Entnahmen aus dem eigenen Betrieb, könnte das Unternehmen diese Sachverhalte mitteilen. Sowohl bei der Mehrwertsteuer als auch bei der Erfassung des Periodenkonsums durch eigene Aufzeichnungen des Steuerpflichtigen, müssen die Unternehmen grundsätzlich keine Auskunft über die

Vgl. hierzu die Ausführungen zu der steuerlichen Behandlung der langlebigen Konsumgüter. 
Bezüge ihrer Mitarbeiter geben. Die Deklaration dieser Sachbezüge durch die Unternehmen ist deshalb ein systemfremdes Element. Wird die Mehrwertsteuer allerdings nach dem deutschen Modell ausgestaltet, führt das Unternehmen die Steuer auf den Naturalkonsum direkt ab; Überprüfungsmöglichkeiten ergeben sich durch die ohnehin notwendigen Mehrwertsteuerprüfungen. Erfolgt die Erfassung des Konsums durch eigene Aufzeichnungen des Steuerpflichtigen, muß sich das Finanzamt auf die Angaben des Steuerpflichtigen verlassen und gegebenenfalls Prüfungen beim gewährenden Unternehmen durchführen.

Bei der indirekten Erfassung des Periodenkonsums erhält jeder Arbeitnehmer eine Bescheinigung über die ihm vom Arbeitgeber gewährten Bezüge und unterliegt somit automatisch der Besteuerung. Zusätzliche Kontrollen sind nicht notwendig.

Erfolgt die Besteuerung der langlebigen Konsumgüter im Sinne der Investitionsgutlösung, muß der Naturalkonsum aus jedem langlebigen Konsumgut bestimmt werden, wenn nicht der obigen Vereinfachungsregel gefolgt wird. Bei der Mehrwertbesteuerung bzw. bei der indirekten Ermittlung des Periodenkonsums muß der Steuerpflichtige über den Erwerb eines langlebigen Konsumguts einen Nachweis erbringen, da sonst der Kaufpreis in voller Höhe als Konsum zu versteuern ist. Dies könnte allerdings im Interesse des Steuerpflichtigen liegen, wenn hohe Wertsteigerungen erwartet werden, da er dann -mangels Kenntnis des Fiskus- keinen Naturalkonsum (dessen Wert auch entsprechend steigt) versteuern und somit insgesamt weniger Steuern entrichten muß. Die Kontrollmöglichkeiten des Fiskus sind damit gering. Bei Erfassung des Periodenkonsums durch eigene Aufzeichnungen des Steuerpflichtigen -die grundsätzliche Anwendbarkeit dieser Methode vorausgesetzt- kann der Gesetzgeber die aufzuzeichnenden Erwerbe festlegen. Ist auch der Erwerb der langlebigen Konsumgüter angabepflichtig, kann der Fiskus bei der Bewertung des Naturalkonsums auf diese Daten zurückgreifen. Wird dies nicht gefordert, muß der Steuerpflichtige nur den jährlichen Gegenwert der Nutzungen in seinen Aufzeichnungen angeben. Kontrollmöglichkeiten bestehen keine; deshalb wird diese Alternative auch nicht mehr weiter verfolgt.

Beim Fiskus sind somit Aufzeichnungen über die langlebigen Konsumgüter eines Steuerpflichtigen vorhanden, wenn dieser seiner Deklarationspflicht Folge leistet. Hat der Steuerpflichtige bei der Mehrwertsteuer bzw. bei der indirekten Methode kein Interesse an der Deklaration, werden die langlebigen Konsumgüter im Sinne der Konsumgutlösung behandelt.

Wird die oben vorgeschlagene Vereinfachungsregelung angewandt, verringert sich der zu erfassende Naturalkonsum, da im wesentlichen nur noch das Wohneigentum, die Wohnungseinrichtung sowie die Kraftfahrzeuge zu erfassen sind. Kann auf die Daten der Grundbücher und der Zulassungsstellen zurückgegriffen werden, stellt sich das Problem der Steuersicherung lediglich bei der Erfassung 
der Wohnungseinrichtung; hier besteht c.p. für keine der hier genannten Erfassungsmethoden ein Vorteil.

Die indirekte Ermittlung des Periodenkonsums und die Mehrwertsteuer sind somit als gleichwertig zu bezeichnen; bei der Erfassung über eigene Aufzeichnungen des Steuerpflichtigen wären zusätzliche Kontrollen bei den Unternehmen einzuführen.

\subsection{Ergebnis}

Das Leistungsfähigkeitsprinzip und die Entscheidungsneutralität des Steuersystems erfordern die Erfassung des Naturalkonsums zu Marktpreisen. Bei Anwendung der Investitionsgutlösung für langlebige Konsumgüter sind somit sämtliche aus ihnen gezogenen Nutzungen zu bewerten. Da für viele dieser Güter keine Mietmärkte bestehen, kann der Marktpreis der Nutzung (= Miete) vielfach nicht ermittelt werden. Die Steuerpflichtigen müssen überdies ein vom Fiskus zu kontrollierendes Inventar führen. Der Umfang des zu bewertenden Naturalkonsums kann allerdings -ohne große Einbußen hinsichtlich des Leistungsfähigkeitsprinzips bzw. der Forderung eines neutralen Steuersystems- verringert werden, wenn lediglich die langlebigen Konsumgüter Wohneigentum, Wohnungseinrichtungen und Kraftfahrzeuge im Sinne der Investitionsgutlösung und die anderen langlebigen Konsumgüter im Sinne der Konsumgutlösung behandelt werden. Bei der Diskussion der Frage, welche der vorgeschlagenen Erfassungsmethoden des Periodenkonsums zur Erfassung des Naturalkonsums am geeignesten sind, bestehen leichte Vorteile für die indirekte Konsumermittlung sowie für die Mehrwertsteuer.

\section{$\underline{\text { 3. Besteuerung des Lebensendvermögens }}$}

\subsection{Besteuerung nach der individuellen Leistungsfähigkeit}

Das Lebenseinkommen ist der geeignete Indikator zur Messung der individuellen Leistungsfähigkeit. Wird das Lebenseinkommen über den Periodenkonsum gemessen, wird nur dann das Lebenseinkommen zutreffend ermittelt, wenn auch das Lebensendvermögen erfaßt wird. Wie bei der Behandlung der empirischen Tests der Lebenszyklushypothese dargestellt, hinterlassen die Individuen einen nicht unwesentlichen Betrag; somit kann aufgrund des Leistungsfähigkeitsprinzips der Einbezug des Lebensendvermögens nicht vernachlässigt werden. Der 
Einwand, durch die Besteuerung des Lebensendvermögens unterliegen die vererbten Einkommensteile zweimal (beim Erblasser und beim Erben) der Besteuerung, ist irrelevant: das Konzept der Besteuerung nach der individuellen Leistungsfähigkeit stellt auf Personen und nicht auf "Einkommensteile" $a b^{I}$. Die vererbten Beträge erhöhen sowohl die Verfügungsgewalt des Erblassers als auch die des Erben, allerdings zu verschiedenen Zeitpunkten. Die steuerliche Erfassung der Erbschaft beim Erblasser und beim Erben stellt somit keinen Verstoß gegen das Leistungsfähigkeitsprinzip dar ${ }^{2,3}$.

Die Lebensendvermögenbesteuerung muß bei allen hier behandelten Konsumerfassungsmethoden gesondert implementiert werden; sie sind daher aus Sicht des Leistungsfähigkeitsprinzips als gleichwertig zu beurteilen.

\subsection{Neutralität der Besteuerung}

Um den Einfluß der Besteuerung auf die Entscheidung des Steuerpflichtigen untersuchen zu können, muß auf die Motivation des Vererbenden eingegangen werden ${ }^{4}$. Mögliche Motive, etwas zu vererben, wurden bereits bei der Diskussion der Periodeneinkommensteuer analysiert. Deshalb werden nur die Konsequenzen für die Besteuerung des Periodenkonsums und des Lebensendvermögens betrachtet.

Erfolgt die Vererbung aus Altruismus (geht also die Vererbung in die Nutzenfunktion des Erblassers ein), gilt es, den Einfluß auf die Entscheidung zwischen Vererbung -also dem Konsum durch zukünftige Generationen- und dem eigenen Konsum des Erblassers zu untersuchen. Als Optimalitätsbedingung ergibt sich in einer Laissez-Faire-Ökonomie, daß der Grenznutzen aus dem eigenen Konsum dem Grenznutzen aus der Vererbung, also dem Zukunftskonsum der Erben aus der Erbschaft, entspricht. Damit die in der Laissez-Faire-Ökonomie geltende Marginalbedingung auch bei einer Konsumbesteuerung erfüllt ist, muß der Konsum des Erblassers und der Zukunftskonsum der Erben aus der Vererbung gleich besteuert werden, d.h. entweder darf das Lebensendvermögen der Steuer

1 Vgl. Kaldor, N. (1969), S. 204.

2 Siehe hierzu auch die Ausführungen im 2. Teil zu "Erbschaften und Schenkungen".

3 Vgl. hierzu auch die Ausführungen zum Vergleich der Periodeneinkommensteuer mit der Besteuerung des Periodenkonsums und des Lebensendvermögens, wo auf das Problem eventuell notwendiger Glättungsverfahren bei einer progressiven Tarifstruktur aufgrund des hohen Lebensendvermögens eingegangen wurde.

4 Vgl. zum folgenden Schwinger, R. (1992), S. 81 ff. 
unterworfen werden oder der Konsum aus dem Erbe, nicht aber beides. Wird beides besteuert, ist es für den Erblasser nutzenmäßig günstiger, Vererbung durch eigenen Konsum zu substituieren. Dadurch wäre seine Vererbungsentscheidung im Vergleich zu einer Laissez-Faire-Ökonomie verzerrt. Das hat eine Verringerung der Ersparnis und somit c.p. ein geringeres Wirtschaftswachstum zur Folge. Somit liegt ein -übrigens auch bei der Einkommensbesteuerung nach der Reinvermögenszugangstheorie bestehender- Verstoß gegen die Forderung nach einem neutralen Steuersystem vor.

Erfolgt die Vererbung aufgrund einer "moralischen Verpflichtung", muß die Erbschaft -also das Lebensendvermögen- beim Erblasser steuerfrei sein, da dieser sonst zu einer verstärkten Ersparnisbildung gezwungen ist, um die angestrebte Summe vererben zu können. Die Besteuerung beim Erben ist dann davon abhängig, ob er das Erbe weitervererben, dann müßte auch bei ihm die Besteuerung am Lebensende unterbleiben, oder ob er es konsumieren will, was die Besteuerung im Konsumzeitpunkt rechtfertigt.

Wird die Erbschaft als Entgelt für die Sicherung der Pflege durch den Erbenden aufgefaßt, ist sie als Konsum des Erblassers anzusehen, da dies wirtschaftlich der Zahlung eines Gehalts an den Pflegenden gleichkommt. Um die Entscheidung des Steuerpflichtigen zwischen Bezahlung des Pflegenden durch ein Gehalt oder einer Erbschaft nicht zu beeinflussen, muß das Lebensendvermögen beim Erblasser der Besteuerung unterliegen; beim Erbenden stellt die Erbschaft dann einen normalen Zufluß dar, der beim Konsum in die steuerliche Bemessungsgrundlage eingeht.

Ist das Erbe lediglich eine unbeabsichtigte Restgröße, hat die Frage der Besteuerung keinen Einfluß auf die Vererbungsentscheidung des Individuums.

Die Frage der Besteuerung des Lebensendvermögens kann also nicht eindeutig beantwortet werden, vielmehr ist die Motivation der Vererbung ausschlaggebend ${ }^{I}$. Das die Entscheidung dominierende Motiv ist fraglich; die Untersuchung von Projector/Weiss ${ }^{2}$ ist allerdings ein Indiz dafür, daß die Vererbung nicht aus Altruismus oder aufgrund moralischer Zwänge erfolgt. Wird dieser Untersuchung gefolgt, hat die Besteuerung des Lebensendvermögens keinen großen Einfluß auf die Vererbungsentscheidung der Individuen und stellt damit keinen Verstoß gegen die geforderte Neutralität der Besteuerung dar.

I Vgl. Schwinger, R. (1992), S. 81 ff.

2 Eine von Projector/Weiss (1966) durchgeführte Untersuchung bei über 65-jährigen ergab, daß 47\% für die Altersvorsorge, $34 \%$ zur Notfallvorsorge und $4 \%$ für eine geplante Vererbung sparen. 
Das Problem der Verletzung der intergenerationellen Vererbungsneutralität besteht im übrigen auch bei einer Einkommensbesteuerung, da das schon vom Erblasser versteuerte Einkommen bei der Vererbung als Zufluß vom Erben erneut zu versteuern ist. Es besteht also kein Problem, das lediglich bei der Besteuerung von Periodenkonsum und Lebensendvermögen auftritt.

\subsection{Praktikabilität der Besteuerung}

Bei der Diskussion der Praktikabilität stellen sich im wesentlichen zwei Fragen: die Bewertbarkeit des Vermögens und die Steuersicherung.

Bei der Lebensendvermögensbewertung müssen alle Vermögensbestandteile erfaßt werden, die noch nicht der Besteuerung unterlagen. Die langlebigen Konsumgüter, die im Sinne der Konsumgutlösung behandelt wurden, dürfen nicht nochmals beim Erblasser erfaßt werden. Durch die oben vorgeschlagene vereinfachte Behandlung der langlebigen Konsumgüter verringert sich der Umfang des zu bewertenden Vermögens beim Erblasser; beim Erben ist jedoch die gesamte Erbschaft zu erfassen. Im übrigen bestehen grundsätzlich qualitativ die gleichen Bewertungsprobleme wie bei einer periodischen Einkommensbesteuerung.

Das zweite Problem ist die Steuersicherung, d.h. wird das Lebensendvermögen vollständig erfaßt oder kann der Steuerpflichtige bzw. seine Erben dem Fiskus die Höhe des Lebensendvermögens vorenthalten bzw. falsch angeben?

Bei der Erfassung des Periodenkonsums über eine Mehrwertsteuer bzw. durch eigenen Aufzeichnungen des Steuerpflichtigen bestehen keine Aufzeichnungen des Steuerpflichtigen über die von ihm getätigten Investitionen/Ersparnisse, da er sie zur Bestimmung der periodischen Bemessungsgrundlage nicht angeben muß. Bei der indirekten Ermittlung des Periodenkonsums bestehen hingegen Aufzeichnungen des Steuerpflichtigen über die von ihm getätigten Anlagen/Investitionen, da die Deklaration Bedingung für die Steuerfreiheit dieser Zahlungsabflüsse ist. Eine weitere Plausibilitätsprüfung kann bei der Methode der indirekten Konsumermittlung durch Gegenüberstellung der deklarierten investiven Abflüsse und Zuflüsse stattfinden. Erfolgte für einen früher deklarierten investiven Abfluß noch kein Zufluß aus der Auflösung der Anlage, muß die Anlage noch im Eigentum des Individuums stehen (oder aber wertlos geworden sein). Somit bestehen bei dieser Methode bessere Kontrollmöglichkeiten über die Vollständigkeit des deklarierten Lebensendvermögens. Gelingt es dem Erb- 
lasser aber dennoch, seine versteuerten Ersparnisse zu verheimlichen ${ }^{l}$, wird der Erbe die Erbschaft wohl auch nicht als Zufluß deklarieren. Dieser Einkommensteil unterliegt dann beim Konsum des Erben nicht der Besteuerung.

Anders hingegen bei der Mehrwertsteuer und bei den eigenen Aufzeichnungen des Steuerpflichtigen: hier entgeht zwar das Lebensendvermögen der Besteuerung, wenn es der Erblasser verheimlichen will, nicht hingegen der Konsum des Erben.

Eine Möglichkeit zur Kontrolle stellt bei allen drei Erfassungsmethoden die Einführung von "Erbscheinen" durch den Fiskus dar. Hierauf könnte vermerkt sein, welches Vermögen beim Fiskus deklariert wurde. Die Banken (u.a.) dürfen dem Erben das Erbe nur gegen Vorlage eines solchen Erbscheines aushändigen. Diese Regelung kann durch Anlagen und Investitionen im Ausland umgangen werden, sofern es dort eine solche Deklarationsvorschrift nicht gibt.

Ein Problem sind jedoch die im Sinne der Konsumgutlösung behandelten langlebigen Konsumgüter, da über deren Bestand keine Aufzeichnungen vorliegen und der Erbe kein Interesse an deren Deklaration hat. Wird jedoch die oben vorgeschlagene Methode zur Behandlung der langlebigen Konsumgüter implementiert (werden also die wertvolleren langlebigen Konsumgüter, z.B. Immobilien, im Sinne der Investitionsgutlösung behandelt), werden lediglich die geringwertigeren langlebigen Konsumgüter im Sinne der Konsumgutlösung erfaßt. Daher dürfte dieser nur schwer erfaßbare Teil des Vermögens keinen zu großen Umfang annehmen.

Die indirekte Erfassung des Periodenkonsums gewährleistet somit unter dem Aspekt der Steuersicherung eher die vollständige Erfassung des Lebensendvermögens als die beiden anderen Methoden, da hier grundsätzlich bessere Kontrollmöglichkeiten über das Vermögen des Steuerpflichtigen bestehen.

\subsection{Ergebnis}

Wird das Lebensendvermögen beim Erblasser und beim späteren Konsum durch den Erben besteuert, findet eine mehrfache Besteuerung dieser "Einkommensteile" statt. Um aber eine Besteuerung nach der individuellen Leistungsfähigkeit zu gewährleisten, ist die Erfassung des Lebensendvermögens des Steuerpflichtigen notwendig, da nur dann das gesamte Lebenseinkommen in die steuerliche

\footnotetext{
1 Der Erblasser gab also seine Ersparnisse nicht an und versteuerte damit diese Beträge als Konsum.
} 
Bemessungsgrundlage eingeht. Aufgrund von Neutralitätserwägungen ist auf die Vererbungsmotive einzugehen: es bestehen jedoch Indizien dafür, daß das Vererbungsmotiv im Vergleich zum Vorsorgesparen eine eher untergeordnete Rolle spielt. Da die Besteuerung des Lebensendvermögens die Vererbungsentscheidung nur gering beeinflußt, liegt nur ein minimaler Verstoß gegen die Forderung eines entscheidungsneutralen Steuersystems vor. Überdies besteht dieses Problem auch bei der Periodeneinkommensbesteuerung. Somit besteht kein Nachteil der Periodenkonsum- gegenüber der Periodeneinkommensbesteuerung nach der Reinvermögenzugangstheorie.

Aufgrund von Praktikabilitätsüberlegungen sollten beim Erblasser möglichst viele langlebige Konsumgüter im Sinne der Konsumgutlösung behandelt werden, da sich hierdurch der Umfang des zu bewertenden Lebensendvermögens verringert. Wird die oben vorgeschlagene differenzierte Behandlung der langlebigen Konsumgüter implementiert, sind lediglich die Konsumgüter "selbstgenutztes Wohneigentum", "Wohnungseinrichtungen" und "Kraftfahrzeuge" als Bestandteil des steuerpflichtigen Lebensendvermögens des Steuerpflichtigen zu erfassen; die anderen Konsumgüter wurden bereits bei ihrem Kauf besteuert. Beim Erben sind sie allerdings zu erfassen; die Mißbrauchsmöglichkeiten (also die Nichtdeklaration durch den Erben) dürften nicht zu groß sein, wenn die vorgeschlagene differenzierte Behandlung der langlebigen Konsumgüter durchgeführt wird, da danach die wesentlichen werthaltigen Konsumgüter im Sinne der Investitionsgutlösung behandelt werden, über deren Bestand der Fiskus Informationen besitzt. Weiterhin sollten "Erbscheine" ausgegeben werden, auf denen der beim Finanzamt als Erbschaft deklarierte Betrag angegeben ist. Nur diesen Betrag dürfen die Banken usw. dem Erben ausbezahlen.

Aus Gründen der Steuersicherung bestehen leichte Vorteile für die indirekte Erfassung des Periodenkonsums. Hier existieren grundsätzlich Aufzeichnungen über das angelegte Kapital, da die Steuerpflichtigen die investiven Abflüsse in der Vergangenheit deklarieren mußten, um sie von der Besteuerung auszunehmen. Bei den anderen Methoden können Vermögen einfacher verschwiegen werden.

Das Problem der Erfassung des Lebensendvermögens besteht aber auch bei einer Periodeneinkommensteuer nach der Reinvermögenszugangstheorie, da hier die Erbschaft als Einkommen des Erben zu qualifizieren ist. Damit wird durch die Besteuerung des Periodenkonsums und des Lebensendvermögens kein neues Problem geschaffen. 


\section{Besteuerung von Schenkungen}

\subsection{Besteuerung nach der individuellen Leistungsfähigkeit}

Schenkungen erhöhen die Leistungsfähigkeit des Beschenkten, da seine Verfügungsmacht über knappe Ressourcen der Wirtschaft vergrößert wird. Sie sind deshalb in der steuerlichen Bemessungsgrundlage zu erfassen. Da die Geschenke nach überwiegender Meinung beim Schenker Konsum darstellen, sind sie bei der Berechnung der steuerlichen Bemessungsgrundlage nicht abzugsfähig.

Es ist zu prüfen, ob die behandelten Erfassungsmethoden den Einbezug der Geschenke in die steuerliche Bemessungsgrundlage sowohl beim Schenkenden als auch beim Beschenkten prinzipiell gewährleisten und dem Leistungsfähigkeitsprinzip entsprechen. Hierzu ist zwischen Geld- und Sachgeschenken zu unterscheiden.

Geldgeschenke gehen beim Beschenkten in die steuerliche Bemessungsgrundlage ein, wenn er daraus konsumiert bzw. beim Ableben durch die Erhöhung des Lebensendvermögens. Das gilt unabhängig von der Erfassungsmethode des Periodenkonsums, wenn eine ordnungsgemäße Deklaration erfolgt. Die Behandlung beim Schenkenden ist abhängig von der Erfassungsmethode. Bei der indirekten Ermittlung des Periodenkonsums unterliegt die Schenkung als nicht-investiver Abfluß der Besteuerung. Bei der Erfassung über eigene Aufzeichnungen des Steuerpflichtigen geht die Schenkung (Deklaration vorausgesetzt) ebenfalls in die steuerliche Bemessungsgrundlage ein. Erfolgt die Besteuerung des Periodenkonsums durch eine Mehrwertsteuer, wird die geschenkte Geldsumme beim Schenkenden nicht als Konsum erfaßt, da der Erwerb eines Gutes oder einer Dienstleistung nicht stattfand. Die Besteuerung durch eine Mehrwertsteuer verstößt damit gegen das Leistungsfähigkeitsprinzip.

Bei Sachgeschenken wird das Geschenk beim Schenkenden im Rahmen der Ermittlung seines Periodenkonsums erfaßt. Beim Beschenkten erfolgt bei keiner Methode eine Erfassung, da weder ein Zufluß (indirekte Erfassung des Konsums) noch ein Kaufakt (Erfassung des Konsums über eigene Aufzeichnungen des Steuerpflichtigen bzw. Mehrwertsteuer) vorliegt. Sachgeschenke müssen beim Beschenkten als Naturalkonsum behandelt werden, um eine Besteuerung zu ermöglichen; erfolgt diese Korrektur nicht, wird -da nicht das gesamte Lebenseinkommen erfaßt wird- das Leistungsfähigkeitsprinzip nicht erfüllt. 


\subsection{Neutralität der Besteuerung}

Werden Geschenke nicht in die steuerliche Bemessungsgrundlage einbezogen, unterliegt aber das Lebensendvermögen der Besteuerung, kann die Besteuerung durch Schenkung statt Vererbung umgangen werden. Die Entscheidung zwischen Schenken und Vererben wird verzerrt, wenn Geschenke beim Beschenkten und beim Schenkenden nicht analog der Vererbung behandelt werden. Werden Schenkungen besteuert, werden Schenkungen sowohl beim Beschenkten als auch beim Schenkenden der Besteuerung unterworfen (Schenkungen sollen als Konsumausgaben gesehen werden); somit findet eine doppelte Besteuerung statt. $\mathrm{Ob}$ dadurch eine Entscheidungsverzerrung entsteht, ist von der Motivation der Schenkung abhängig. Eine Schenkung wird grundsätzlich durch die gleichen Überlegungen wie die Vererbungsentscheidung beeinflußt ${ }^{1}$. Daher wird auf die dortigen Ausführungen verwiesen.

Eine generelle Aussage über die Einbeziehung von Geschenken in die steuerliche Bemessungsgrundlage aufgrund von Neutralitätsüberlegungen ist also nicht möglich. Das gleiche Problem besteht auch bei der Besteuerung des Periodeneinkommens. Es wird nicht erst durch die Konsumbesteuerung geschaffen.

\subsection{Praktikabilität der Besteuerung}

Die Erfassung von Geldgeschenken beim Schenkenden ist bei der indirekten Ermittlung des Periodenkonsums praktikabel, da verschenktes Geld nicht nochmals gespart werden kann und somit die investiven Zahlungsabflüsse entsprechend sinken. Bei der Methode der eigenen Aufzeichnungen ist zweifelhaft, ob eine Deklaration erfolgt; Kontrollmöglichkeiten über Schenkungen bestehen keine. Bei der Mehrwertsteuer erfolgt keine Erfassung der Schenkung auf Seiten des Schenkenden.

Erfolgt die Besteuerung des Periodenkonsums über eine Mehrwertsteuer oder durch eigene Aufzeichnungen des Steuerpflichtigen, gehen beim Beschenkten Geldgeschenke zwangsläufig in die steuerliche Bemessungsgrundlage ein. Bei der indirekten Erfassung des Periodenkonsums muß das Geldgeschenk als $\mathrm{Zu}-$ fluß behandelt werden, um einen steuerlichen Einbezug zu ermöglichen. Da dies praktisch nicht nachzuprüfen ist, wird die Deklaration deshalb wohl auch unterbleiben ${ }^{2}$.

$1 \quad$ Der Fall der "unbeabsichtigten" Restgröße ist allerdings nicht möglich.

2 Das gleiche Problem besteht aber auch bei der Besteuerung des Periodeneinkommens nach der Einkommensdefinition der Reinvermögenszugangstheorie. 
Bei Geldgeschenken ist die indirekte Ermittlung des Periodenkonsums beim Schenkenden eine praktikable Erfassungsmethode, nicht jedoch beim Beschenkten. Die Mehrwertsteuer sowie die Methode der eigenen Aufzeichnungen dagegen sind beim Beschenkten praktikabel.

Sachgeschenke gehen grundsätzlich bei allen drei Erfassungsmethoden beim Schenkenden in die steuerliche Bemessungsgrundlage ein. Diese Aussage gilt aber nur dann, wenn alle langlebigen Konsumgüter im Sinne der Konsumgutlösung behandelt werden. Problematisch sind diejenigen langlebigen Konsumgüter, die im Sinne der Investitionsgutlösung behandelt werden, da diese noch nicht der Besteuerung unterworfen worden sind. Die Schenkung dieser Güter muß daher gesondert erfaßt werden. Das ist relativ problemlos möglich, wenn -wie beim Wohneigentum- zum Vollzug des Eigentumsübergangs eine öffentliche Eintragung notwendig ist oder wie bei den Kraftfahrzeugen eine Ummeldung bei der Zulassungsstelle erfolgen muß. Bei anderen Gütern ist eine Kontrolle nicht möglich.

Fraglich ist jedoch, ob der Schenkende an einer Deklaration interessiert ist.

Der Schenkende hat aus Haftungsgründen ein Interesse an der Deklaration, wenn eine Einzelgesellschaft oder Anteile an einer Personengesellschaft verschenkt werden. Bei langlebigen, im Sinne der Investitionsgutlösung behandelten Konsumgütern erhält der Schenkende keinen Naturalkonsum mehr zugerechnet, wenn die Schenkung deklariert wird. Andererseits muß er den Wert dieser Güter in der Periode der Schenkung insgesamt versteuern; damit muß er -falls keine Windfall Profits aufgrund von Wertsteigerungen auftreten- die gleiche Steuer entrichten. Durch die Verschleierung der Schenkung bleiben die Nutzungen beim Beschenkten aber steuerfrei. Es besteht daher kein Anreiz zur Deklaration. Werden zukünftige Wertsteigerungen "erwartet", ist es für den Schenkenden allerdings vorteilhaft, die Schenkung zu deklarieren. Ansonsten hätte er aufgrund der Windfall Profits eine höhere Konsumsteuer für die fiktiven "Nutzungen" als für die Schenkung zu zahlen.

Konsumgüter, die im Sinne der Konsumgutlösung behandelt werden, unterlagen bei der Anschaffung der Besteuerung, die Schenkung löst also beim Schenkenden nicht nochmals eine Steuerpflicht aus. Diese Geschenke müssen vom Beschenkten allerdings als Geschenk deklariert und versteuert werden; in der Realität dürfte die Deklaration dieser Geschenke wohl nur durch besonders ehrliche oder ängstliche Naturen stattfinden. Dieser Vorschlag ist mithin wenig praktikabel und nur in einem Überwachungsstaat durchführbar.

Beim Beschenkten erfolgt grundsätzlich keine automatische Erfassung der Sachgeschenke. Diese Argumentation gilt für alle drei behandelten Erfassungsmethoden. 
Die Besteuerung von Geschenken weist Probleme hinsichtlich der Steuersicherung auf. Eine eindeutige Beurteilung der Frage, welche Erfassungsmethode vorteilhafter gegenüber den anderen ist, kann nicht getroffen werden. Die indirekte Messung des Periodenkonsums bietet ein höheres Maß an Steuersicherung bei der Erfassung von Geldgeschenken beim Schenkenden, die Mehrwertsteuer und die eigenen Aufzeichnungen beim Beschenkten. Bei Sachgeschenken sind die Methoden gleichwertig.

\subsection{Ergebnis}

Aufgrund des hier verwendeten Leistungsfähigkeitsbegriffs sind Geschenke in die steuerliche Bemessungsgrundlage einzubeziehen. Dies kann -ordnungsgemäße Deklaration vorausgesetzt- mit der indirekten Erfassung des Periodenkonsums sowie durch die Methode der eigenen Aufzeichnungen erfolgen. Die Mehrwertsteuer verstößt bei Geldgeschenken gegen das Leistungsfähigkeitsprinzip.

Problematisch ist allerdings die Frage des Einbezugs hinsichtlich der Forderung nach einem neutralen Steuersystem. Dabei muß zwischen den verschiedenen Motivationen für eine Schenkung unterschieden werden. Eine generelle Aussage ist -analog zur Lebensendvermögensbesteuerung- nicht möglich. Falls jedoch nur eine einmalige Erfassung der Geschenke (entweder beim Schenkenden oder beim Beschenkten) stattfindet, Erbschaften jedoch beim Erblasser (Lebensendvermögen) und beim Erben (Konsum) besteuert werden, wird die Entscheidung der Individuen zwischen Schenkung und Vererbung beeinflußt.

Es besteht ferner das Problem der Praktikabilität und das der Steuersicherung, da Geschenke im allgemeinen nicht deklariert werden und nur geringe Kontrollmöglichkeiten bestehen. Werden Geldgeschenke isoliert betrachtet, bietet die indirekte Erfassung des Periodenkonsums ein höheres $\mathrm{Ma} ß$ an Steuersicherheit bei der Besteuerung des Schenkenden, die eigenen Aufzeichnungen und die Mehrwertsteuer bei der des Beschenkten.

$\mathrm{Da}$ aber sowohl bei der Methode der indirekten Erfassung als auch bei den eigenen Aufzeichnungen die Hinterziehungsmöglichkeiten sehr verlockend sind, sollte dieser Verstoß der Mehrwertsteuer gegen das Leistungsfähigkeitsprinzip nicht zu sehr gewichtet werden. Bei Sachgeschenken sind die hier behandelten Erfassungsmethoden als gleichwertig zu beurteilen; die Erfassung beim Beschenkten ist jedoch kritisch. Welche Erfassungsmethode präferiert werden sollte, ist also offen.

Das Problem der Erfassung von Schenkungen und die Frage der Neutralität der Besteuerung besteht allerdings auch bei einer Einkommensbesteuerung; damit entsteht kein spezifisches Problem der Konsumbesteuerung. 


\section{Abgrenzung Investition/Werbungskosten - Konsum}

Ist die Abgrenzung zwischen Konsum und Investitionen bzw. Werbungskosten, also Aufwendungen, die zur Schaffung, Erhaltung oder Sicherung einer Einkommensquelle dienen, notwendig? Die Beantwortung dieser Frage ist von Bedeutung, da eine Differenzierung nicht immer zweifelsfrei möglich ist und überdies der Wegfall dieses Problems die Besteuerung erleichtern würde.

\subsection{Besteuerung nach der individuellen Leistungsfähigkeit}

Wird das Lebenseinkommen über den Periodenkonsum und das Lebensendvermögen gemessen, müssen die Werbungskosten bzw. investiven Ausgaben steuerlich irrelevant sein, da sie keinen Konsum darstellen. Falls sie der Besteuerung unterworfen werden, wird nicht mehr das Lebenseinkommen erfaßt; es liegt ein Verstoß gegen das Leistungsfähigkeitsprinzip vor. Aufgrund dieses Prinzips ist somit eine exakte Abgrenzung zwischen Konsumausgaben und Werbungskosten bzw. Investitionen notwendig.

Diese Abgrenzung wird bei der indirekten Konsumerfassung erreicht, in dem die Ausgaben als investive Abflüsse deklariert werden; bei der Methode der eigenen Aufzeichnungen werden sie einfach nicht erfaßt.

Bei der Mehrwertsteuer muß der Steuerpflichtige keine Aufzeichnungen über seine Ausgaben anfertigen. Da manche Güter/Dienstleistungen sowohl einer konsumtiven als auch investiven Verwendung zugerechnet werden können, führt die generelle Besteuerung oder Nichtbesteuerung dieser Güter und Dienstleistungen zu einer falschen (zu hohen bzw. zu niedrigen) Abbildung des Lebenseinkommens und damit zu einer Verzerrung der Besteuerung nach der individuellen Leistungsfähigkeit. Die Mehrwertsteuer kann folglich ohne zusätzliche Aufzeichnungen nicht als Besteuerungsform des Periodenkonsums gewählt werden; diese Modifikationen sind jedoch -wie noch gezeigt wird- ohne weiteres möglich.

Alle drei Methoden erfüllen daher das Leistungsfähigkeitsprinzip.

\subsection{Neutralität der Besteuerung}

Verlangt die Forderung nach einem neutralen Steuersystem die genaue Abgrenzung zwischen Konsumausgaben und Ausgaben für Investitionen bzw. Werbungskosten? 
Bei der Konsum-Spar-Entscheidung orientiert sich das Individuum in einer Laissez-Faire-Ökonomie an der Rendite der Investition. Es stellt dem eingesetzten Kapital den Gewinn gegenüber, der sich durch die Saldierung von Aufwendungen und Erträgen ergibt. Sind nun die Aufwendungen für eine Anlage analog dem Periodenkonsum der Besteuerung zu unterwerfen, werden bei gleichem Gewinn vor Steuern die Anlagen diskriminiert, die höhere Aufwendungen verursachen. Nach dieser Argumentation muß die genaue Trennung zwischen Konsumausgaben und Investitionen bzw. Werbungskosten gefordert werden, da sonst kein entscheidungsneutrales Steuersystem besteht.

\subsection{Praktikabilität der Besteuerung}

Der gesamte Güter- und Dienstleistungsverbrauch einer Person ist in einen investiven Aufwand zur Einkommenserzielung sowie einen konsumtiven Aufwand zur Bedürfnisbefriedigung aufzuteilen. Dieses Abgrenzungskriterium bildet in den Fällen, in denen der Aufwand nicht zweifelsfrei einer Kategorie zugeordnet werden kann oder bei nicht eindeutiger Zweckbestimmung von langlebigen Gütern (z.B. Kunstgegenstände, Teppiche - Geldanlage oder Konsumgut?), eine verschwommene Grenze zwischen Konsum und Investition ${ }^{I}$. Es besteht darüberhinaus die Gefahr der Steuerverkürzung durch Falschangaben des Steuerpflichtigen.

Diese Problematik ist bei allen drei behandelten Konsumerfassungsmethoden und auch bei der Periodeneinkommensteuer vorhanden.

Es soll kurz analysiert werden, welche der im Rahmen dieser Arbeit behandelten Methoden zur Konsumerfassung zu präferieren ist.

Bei der indirekten Ermittlung des Periodenkonsums hat der Steuerpflichtige seine nicht-konsumtiven Zahlungsabflüsse dem Fiskus nachzuweisen, um sie nicht der Besteuerung zu unterwerfen; zusätzliche Aufzeichnungen zur Abgrenzung sind nicht notwendig.

Bei der Mehrwertsteuer werden -da ein Gut in vielen Fällen sowohl zu Konsumals auch zur Einkommenserzielung verwendet werden kann- generell alle Güter besteuert. Damit das Finanzamt dem Steuerpflichtigen die Steuer zurückerstatten kann, die er für zur Einkommenserzielung genutzte Güter entrichtet hat, müssen diese Ausgaben dem Finanzamt belegt werden.

Bei der Erfassung des Konsums durch eigene Aufzeichnungen braucht der Steuerpflichtige diese Käufe nicht anzugeben. Um jedoch Mißbrauchsmöglichkeiten zu verringern, sollten sie vom Steuerpflichtigen dennoch geführt werden, da es

Vgl. Mitschke, J. (1980), S. 282. 
bei der Qualifikation dieser Güter naturgemäß Abgrenzungsprobleme gibt und dem Fiskus Kontrollmöglichkeiten eingeräumt werden sollten.

Somit sind bei den drei hier behandelten Methoden zur Erfassung des Periodenkonsums Aufzeichnungen und Nachweise des Steuerpflichtigen notwendig, um eine Abgrenzung zwischen Konsum und Investition bzw. Werbungskosten zu ermöglichen.

Die Methoden zur Erfassung des Periodenkonsums sind deshalb als gleichwertig zu beurteilen.

\subsection{Ergebnis}

Aufgrund von Leistungsfähigkeits- und Neutralitätserwägungen müssen investive Ausgaben bzw. Werbungskosten bei der Ermittlung des Periodenkonsums abzugsfähig sein. Die behandelten Erfassungsmethoden sind hinsichtlich ihrer Praktikabilität als gleichwertig zu beurteilen. Bei allen drei Erfassungsmethoden sind Aufzeichnungen über die investiven Ausgaben bzw. die Werbungskosten anzufertigen. Dies ist erforderlich, da viele Güter/Dienstleistungen sowohl zu konsumtiven als auch zu investiven Zwecken genutzt werden können und somit eine eindeutige Abgrenzung nach Güter-/Dienstleistungsgruppen, die Konsumzwecken dienen, nicht möglich ist.

Das Problem der Abgrenzung zwischen konsumtiven und investiven Ausgaben bzw. Werbungskosten besteht auch bei einer Periodeneinkommensteuer ${ }^{l}$. Damit ergibt sich kein zusätzliches Problem, das lediglich bei der Messung des Lebenseinkommens über den Konsum und das Lebensendvermögen auftritt.

\section{Besteuerung von Unternehmen}

Bei der Messung der Leistungsfähigkeit über die Konsumausgaben schlagen Kaldor und Mitschke vor, die Unternehmen nicht gesondert zu besteuern.

Es ist daher zu prüfen, ob dies mit dem Leistungsfähigkeitsprinzip, der Forderung nach einer neutralen Besteuerung sowie dem Praktikabilitätserfordernis harmonisiert.

Vgl. zu dieser Problematik auch die umfangreiche Literatur und Rechtsprechung zum Problem der "steuerlichen Liebhaberei" in der deutschen Einkommensteuer. 


\subsection{Besteuerung nach der individuellen Leistungsfähigkeit}

Die Besteuerung nach der individuellen Leistungsfähigkeit verlangt die Besteuerung der Dispositionsgewalt des Steuerpflichtigen über die Ressourcen der Wirtschaft. Dazu gehört auch die Verfügungsgewalt über Unternehmenswertanteile. Die Besteuerung dieser Dispositionsgewalt erfolgt bei der Konsum- bzw. Lebensendvermögensbesteuerung zum Konsumzeitpunkt oder beim Ableben des Steuerpflichtigen. Die über das Lebenseinkommen gemessene individuelle Leistungsfähigkeit wird damit auch ohne eine gesonderte Unternehmensbesteuerung abgebildet.

\subsection{Neutralität der Besteuerung}

Durch ein neutrales Steuersystem werden die Entscheidungen des Steuerpflichtigen im Vergleich zu einer Laissez-Faire-Ökonomie nicht beeinflußt. Entfällt die Unternehmensbesteuerung insgesamt und werden andere Kapitaleinkünfte ebenfalls nicht besteuert, kann auch keine Verzerrung durch die Unternehmensbesteuerung hervorgerufen werden. Bei der indirekten Ermittlung des Periodenkonsums muß aber zur Gewährleistung der Rechtsformneutralität die Behandlung der Personengesellschaften geändert werden. Im derzeitig gültigen deutschen Einkommensteuerrecht werden die Einkünfte dieser Gesellschaften den Gesellschaftern sofort zugerechnet. Bei der indirekten Erfassung darf jedoch lediglich die Ausschüttung den Gesellschaftern als Zufluß zugerechnet (analog zu den Kapitalgesellschaften) werden, da sonst eine ungleiche Behandlung verschiedener Rechtsformen und somit ein Verstoß gegen die Rechtsformneutralität vorliegt.

Wird dies befolgt, ist die Forderung nach einem neutralen Steuersystem aufgrund der fehlenden Unternehmens- und Kapitaleinkommensbesteuerung hier erfüllt.

\subsection{Praktikabilität der Besteuerung}

Der Wegfall der Unternehmensbesteuerung steht mit dem Leistungsfähigkeitsprinzip sowie mit der Forderung nach einem neutralen Steuersystem in Einklang. Die Frage der Praktikabilität der Unternehmensbesteuerung entfällt auf der Ebene des Unternehmens. Somit besteht ein Vorteil gegenüber den Einkommenskonzeptionen, bei denen die Ermittlung des Unternehmensgewinns erforderlich ist. Um bei der indirekten Erfassung des Periodenkonsums die Registrie- 
rung der Zuflüsse auf der Ebene des Unternehmenseigentümers sicherzustellen, kann eine Quellenbesteuerung der Ausschüttungen des Unternehmens (Geld oder Naturalien) implementiert werden ${ }^{l}$. Bei den anderen Methoden zur Erfassung des Periodenkonsums müssen die Zuflüsse von den Steuerpflichtigen nicht deklariert werden. Die indirekte Erfassung des Periodenkonsums bedeutet hier einen etwas höheren Aufwand, da die Zuflüsse aus den Unternehmenswertanteilen erfaßt werden müssen ${ }^{2}$.

\subsection{Ergebnis}

Die Besteuerung der Unternehmen kann entfallen, wenn Periodenkonsum und Lebensendvermögen der Individuen erfaßt werden ${ }^{3}$. Das Steuersystem ist dann praktikabel, entscheidungsneutral und genügt dem Leistungsfähigkeitsprinzip. Erfolgt die Erfassung des Periodenkonsums nach der indirekten Methode, kann eine auf die individuelle Steuerschuld anrechenbare Quellensteuer auf die Ausschüttung eingeführt werden; dies trägt zur Steuersicherung bei. Die indirekte Erfassung des Periodenkonsums ist somit etwas aufwendiger durchzuführen als die beiden anderen Methoden.

\section{Konsumbesteuerung und Tarifgestaltung}

Die Entscheidung über die zu präferierende Erfassungsmethode wird ebenfalls durch die gewünschte Tarifstruktur beeinflußt, wenn Unterschiede bei den einzelnen Erfassungsalternativen bestehen.

$\mathrm{Zu}$ klären ist deshalb, ob die behandelten Erfassungsmethoden des Periodenkonsums für verschiedene Tarifstrukturen geeignet sind. Zuerst wird analysiert, ob die Individuen eine bestimmte Art der Konsumerfassung und der Tarifgestaltung aus wohlfahrtsökonomischen ${ }^{4}$ Überlegungen präferieren bzw. ablehnen. In einem zweiten Schritt wird auf die prinzipielle Eignung und die Praktikabilität eingegangen.

$1 \quad$ Vgl. Mitschke, J. (1985), S. 76.

2 Dieses Problem besteht auch bei der Besteuerung des Periodeneinkommens, wenn die alternativen Konzeptionen zur Unternehmensbesteuerung angewandt werden.

3 Mit der Frage, welche Form der Unternehmensbesteuerung mit der Konsumbesteuerung auf Haushaltsebene zu vereinbaren ist, beschäftigt sich Kaiser, M. (1992).

4 Zur Darstellung der Leviathanischen Besteuerungstheorie vgl. Brennan, G./Buchanan, J.M. (1988), S. 70 ff. 


\subsection{Wohlfahrtsökonomische Überlegungen}

Bei der wohlfahrtsökonomischen Betrachtungsweise ${ }^{l}$ wird vom Staat als wohlwollenden Diktator ausgegangen, der lediglich im Interesse der Bürger und nicht aus Eigeninteresse handelt. Der Steuerbelastung durch den Staat steht hier stets eine entsprechende Gegenleistung gegenüber. Die Überschußbelastung (= Mehrbelastung, excess burden), die aufgrund der Besteuerung auftritt, soll minimiert werden ${ }^{2}$. In der wohlfahrtsökonomischen Theorie wird ein Steuersystem somit gegenüber einem anderen als vorteilhaft beurteilt, wenn es eine geringere Überschußbelastung der Steuerzahler verursacht.

Bei der folgenden Analyse muß unterschieden werden, ob der Staat alle Güter (also auch die Freizeit) besteuern kann oder nur einige.

Hat der Staat das Recht, alle Güter (einschließlich der Freizeit) zu besteuern, kann das Individuum der Besteuerung nicht ausweichen; die Besteuerung der Güter mit einem einheitlichen Satz wirkt dann wie eine Pauschalsteuer (s.o.).

In der Realität kann der Staat nicht alle Güter besteuern (der Wert der Freizeit ist in der realen Welt nicht meßbar). Es stellt sich deshalb die Frage, ob aufgrund von wohlfahrtsökonomischen Überlegungen möglichst viele Güter zu belasten sind und ob für alle besteuerten Güter ein einheitlicher Tarif anzuwenden ist.

Es kann gezeigt werden, daß im 2-Güter-Fall (mit verschwindend kleiner Kreuzpreiselastizität) die Überschußbelastung durch die Besteuerung minimiert wird, wenn sich die Steuersätze auf die zu besteuernden Güter umgekehrt proportional zu den Preiselastizitäten der Nachfrage $(\varepsilon)$ verhalten. Die Besteuerung wird hier hauptsächlich auf die Güter verlagert, bei denen die Preiselastizität der Nachfrage nur relativ gering ist und somit nur geringe Substitutionseffekte auftreten.

Es gilt also ${ }^{3}$

$$
\frac{\tau_{\mathrm{x}}}{\tau_{\mathrm{z}}}=\frac{\varepsilon_{\mathrm{z}}}{\varepsilon_{\mathrm{x}}}
$$

Zur Darstellung der wohlfahrtsökonomischen Besteuerungstheorie vgl. z.B. Blankart, C.B. (1991), S. $179 \mathrm{ff}$.

2 Die Ursachen für die Entstehung der Mehrbelastungen aufgrund der Besteuerung wurde oben dargelegt; um Wiederholungen zu vermeiden, wird auf die dortigen Ausführungen verwiesen.

$3 \quad \mathrm{X}$ und $\mathrm{Z}$ stellen die betrachteten Güter dar, $\tau_{\mathrm{x}}$ und $\tau_{\mathrm{z}}$ die Steuersätze auf die jeweiligen Güter; $\varepsilon_{\mathrm{z}}$ und $\varepsilon_{\mathrm{x}}$ repräsentieren die Preiselastizität der Nachfrage. 
Werden anstelle der Steuersätze die durch die Besteuerung ausgelösten Preiserhöhungen geschrieben und wird die Preiselastizität in endlich kleinen Änderungen ausgedrückt, kann obige Gleichung umgeformt werden in:

$$
\frac{\Delta \mathrm{X}}{\mathrm{X}}=\frac{\Delta \mathrm{Z}}{\mathrm{Z}}
$$

Die durch die Besteuerung hervorgerufene Überschußbelastung wird minimiert, wenn die Menge bei allen Gütern aufgrund der Besteuerung um den gleichen Prozentsatz zurückgeht (Ramsey-Regel) ${ }^{1,2}$. Falls es neben den beiden betrachteten Gütern X und Z ein weiteres Gut Y gibt, sollte dieses auch besteuert werden, da ansonsten die Ramsey-Regel im Verhältnis zu anderen Gütern nicht mehr erfüllt ist.

Aus wohlfahrtsökonomischen Gründen ist deshalb eine möglichst breite Bemessungsgrundlage zu wählen und jene Güter stärker zu besteuern, bei denen die Preiselastizität möglichst gering ist. Hier sind die Ausweichmöglichkeiten der Individuen weniger zahlreich; damit entsteht eine geringere Überschußbelastung durch die Besteuerung. Aufgrund dieser Regel müssen insbesondere die Güter des Grundbedarfs (z.B. Grundnahrungsmittel) einem höheren Steuersatz unterliegen als die Güter des sogenannten gehobenen Bedarfs, da bei den Gütern des Grundbedarfs geringere Preiselastizitäten zu beobachten sind ${ }^{3}$. Wird davon ausgegangen, daß bestimmte Grundnahrungsmittel eine Preiselastizität von (fast) 0 aufweisen, muß aus Effizienzgesichtspunkten fast die gesamte Steuerlast auf diesen Gütern liegen. Ein linearer Tarif, der auf den Periodenkonsum der Individuen angelegt wird, wird also von den Individuen aus wohlfahrtsökonomischen Erwägungen nicht präferiert. Es ergibt sich dadurch -da der Bedarf an Grundnahrungsmitteln nicht sehr variiert bzw. mit steigendem Einkommen eher abnimmt ("Brot kann schließlich auch durch Kaviar ersetzt werden!")- im Verhältnis zum Lebenseinkommen ein regressiver Steuersatz: der Durchschnittssteuersatz sinkt mit steigendem Lebenseinkommen.

Um das Ziel der Minimierung der Überschußbelastung zu erreichen, eignet sich die Erfassung des Periodenkonsums durch eigene (die Art der Güter/Dienstleistungen nennende) Aufzeichnungen des Steuerpflichtigen und eine Mehrwertsteuer, da bei beiden Erfassungsmethoden differenzierte Steuersätze anwendbar sind. Die Ermittlung des Periodenkonsums durch die indirekte Erfassungsme-

1 Diese Regel gilt auch bei Gütern, deren Kreuzpreiseffekte nicht verschwindend klein sind.

2 Sie wurde zum erstenmal von Ramsey (1927) formuliert. Eine gute Übersicht findet sich in Atkinson, A.B./Stiglitz, J.E. (1980), S. $366 \mathrm{ff}$.

3 Eine Auswahl von Preiselastizitäten findet sich bei Mansfield, E. (1988), S. 142. 
thode ist hierfür ungeeignet, da expost nicht ersichtlich ist, welche Güter in welcher Quantität konsumiert wurden; damit können keine differenzierte Steuersätze für einzelne Güter eingeführt werden.

Für die Politik und wichtige gesellschaftliche Gruppen (z.B. Gewerkschaften) ist ein progressives Steuersystem eine unabdingbare Voraussetzung zur Herstellung der Steuergerechtigkeit. Ohne die höhere Besteuerung der sogenannten Besserverdienenden bestehe eine "Gerechtigkeitslücke". Zur Herstellung der Steuerprogression wird vorgeschlagen, z.B. Grundnahrungsmittel sehr niedrig oder gar nicht, "Luxusgüter" (wie auch immer diese definiert werden) dafür einem relativ hohen Steuersatz zu unterwerfen'.

Die Beurteilung dieses Vorschlags aus wohlfahrtsökonomischer Sicht führt zu vernichtenden Ergebnissen! Seine Verwirklichung führt geradezu zu einer Umkehrung der Tarifstruktur, die nach der Ramsey-Regel als optimal angesehen wird. Er führt deshalb zu einer Vergrößerung der Mehrbelastung der Steuerpflichtigen im Vergleich zu einer Besteuerung mit dem gleichen Steuersatz für alle Güter.

Aus wohlfahrtsökonomischen Überlegungen ist die Einführung eines progressiven Tarifs bei einer Mehrwertsteuer und der Methode von eigenen Aufzeichnungen des Steuerpflichtigen nach diesem Vorschlag abzulehnen.

\subsection{Praktikabilität der Besteuerung}

\subsubsection{Linearer Tarif}

Um einen linearen Tarif zu verwirklichen, kann jede der drei genannten Erfassungsmethoden des Periodenkonsums gewählt werden.

\subsubsection{Progressiver Tarif}

Wird der Konsum indirekt ermittelt oder existieren Aufzeichnungen des Steuerpflichtigen über die Höhe seines Konsums, ist die Höhe der Konsumausgaben und somit die steuerliche Bemessungsgrundlage bekannt. Somit kann ein progressiver Tarif angewandt werden.

Bei der Besteuerung des Konsums durch eine Mehrwertsteuer ist die Höhe der Bemessungsgrundlage nicht bekannt, da weder Aufzeichnungen des Steuer-

1 Vgl. Janssen, B. (1991). 
pflichtigen existieren noch die Daten für eine Ermittlung des Konsums auf indirektem Wege bekannt sind.

Es ist daher nach einer Möglichkeit zu suchen, um leistungsfähigere Individuen mit einem höheren Grenzsteuersatz zu belasten als ärmere. Eine Möglichkeit besteht in der Einführung von unterschiedlichen Steuersätzen für verschiedene Güter. Aufgrund von Gerechtigkeitsüberlegungen sind die Güter mit einem höheren Steuersatz zu besteuern, die von den leistungsfähigeren Individuen in größerem Umfang gekauft werden. Substitute müssen in dieselbe Steuerkategorie fallen, da es ansonsten zu Ausweichreaktionen kommen würde.

Janssen $^{l}$ schlägt vor, differenzierte Steuersätze derart einzuführen, daß Grundnahrungsmittel umsatzsteuerbefreit sind, Luxusgüter (entweder müssen sie definiert oder es muß eine Preisgrenze eingeführt werden) sollen mit bis zu $100 \%$ besteuert werden. Es müssen dann sämtliche zu besteuernden Güter in verschiedene Güterklassen eingeteilt werden, die mit einem differenzierten Steuersatz besteuert werden. Fraglich ist, ob eine solche Differenzierung für einzelne Güter und Gütergruppen vollzogen werden kann. Dies macht umfangreiche -auch vom Handel nachzuvollziehende- Katalogisierungsmaßnahmen erforderlich und führt zu einem hohen Verwaltungsaufwand. Wahrscheinlich ist auch die Gütereinteilung (auch politisch) strittig und somit sicherlich ein Fall für die Gerichte. Durch diese Vorgehensweise entsteht im Vergleich zur Einkommensbesteuerung und zur indirekten Konsumerfassung sowie zur Erfassung des Konsums durch eigene Aufzeichnungen des Steuerpflichtigen ein neues, sehr verwaltungsintensives Problem.

Die drei im Rahmen dieser Arbeit diskutierten Methoden zur Erfassung des Periodenkonsums sind somit im Hinblick auf die Tarifstruktur grundsätzlich geeignet, eine progressive Tarifstruktur zu verwirklichen. Wird diese präferiert, sollte aber (trotz der prinzipiellen Eignung) von einer Mehrwertsteuer Abstand genommen werden, da hier für verschiedene Gütergruppen unterschiedliche Steuersätze festgelegt werden müssen und dadurch Praktikabilitätsprobleme entstehen ${ }^{2}$.

\subsection{Ergebnis}

Werden als Kriterium der Beurteilung wohlfahrtsökonomische Erwägungen herangezogen, schneidet die Mehrwertsteuer sowie die Erfassung des Periodenkonsums über die eigenen Aufzeichnungen (mit genauer Bezeichnung der einzelnen

Vgl. Janssen, B. (1991).

2 Zur Inzidenz von Verbrauchsteuern vgl. Folkers, C. (1987), S. 143 ff. 
Güter) am besten ab, da hier die Steuersätze auf die einzelnen Güter so festgelegt werden können, daß Güter mit einer geringeren Preiselastizität höher besteuert werden. Diese Steuersatzdifferenzierung ist bei der indirekten Erfassung des Periodenkonsums nicht möglich. Da aber die wohlfahrtsökonomisch optimale Gestaltung der Tarifstruktur politisch ohnehin nicht durchsetzbar ist, liegt hier kein tatsächlicher Nachteil dieser Methode vor.

Die hier behandelten Erfassungsmethoden sind als gleichwertig einzustufen, wenn ein linearer Tarifverlauf zur Anwendung kommen soll. Bei einem progressiven Tarifverlauf ist die Erfassung des Periodenkonsums über die eigenen Aufzeichnungen der Steuerpflichtigen bzw. der indirekten Ermittlung zu präferieren, da diese beiden Methoden zur Implementierung eines steigenden Grenzsteuersatzes eher geeignet sind. 
Michael Ohmer - 978-3-631-75563-1

Downloaded from PubFactory at 01/11/2019 03:31:45AM

via free access 


\section{Kapitel}

\section{Zusammenfassung des dritten Teils}

Im dritten Teil der Arbeit wurde die Besteuerung des Lebenseinkommens mit Hilfe des Periodenkonsums und des Lebensendvermögens untersucht. Weiterhin wurde analysiert, ob die Individuen ihre Leistungsfähigkeit selbst abschätzen, welche Einflußgrößen sie gegebenenfalls bestimmend für ihre eigene Leistungsfähigkeit ansehen und welchen Zeitraum sie dabei als relevant betrachten. Diese Vorgehensweise wurde gewählt, da dann die Ergebnisse der theoretischen Überlegungen des 1 . und 2 . Teils -falls sie unterstützt werden- nach dem in den westlichen Gesellschaften vorherrschenden Bild vom eigenverantwortlichen und souveränen Menschen bei der Gestaltung des Steuersystems nicht übergangen werden dürfen.

Zur Beantwortung dieser Fragen wurde auf die individuelle Konsum-Spar-Entscheidung eingegangen, da die Individuen beim Konsum ihre eigene Leistungsfähigkeit berücksichtigen. Es wurde die Lebenszyklushypothese, die die Konsum-Spar-Entscheidung zu erklären versucht, herangezogen; schließlich wurde geprüft, ob ihre Aussagen auf die Realität übertragen werden können. Hierbei zeigte sich, daß die empirischen Untersuchungen differenzierte Ergebnisse hinsichtlich der Unterstützung oder Ablehnung der geprüften Hypothese aufweisen. Es konnten allerdings stichhaltige Argumente gegen die Untersuchungen vorgebracht werden, die die Lebenszyklushypothese ablehnen.

Insgesamt sprechen viele Gründe dafür, daß sich die Individuen nach den Aussagen der Lebenszyklushypothese verhalten.

Die meisten Individuen sind somit bestrebt, den Nutzen aus dem Konsum zu maximieren; sie präferieren daher einen im Zeitablauf gleichmäßigeren Periodenkonsum als den, der sich ergeben würde, wenn der Periodenkonsum eine Funktion des Periodeneinkommens wäre. Zur Optimierung wird der Periodenkonsum an einem langfristigen Konsumplan ausgerichtet, der sich an der selbst abgeschätzten Leistungsfähigkeit orientiert. Der für die Abschätzung der Leistungsfähigkeit relevante Zeitabschnitt umfaßt daher einen wesentlich längeren Zeitraum als ein Jahr. Bei der Abschätzung der Leistungsfähigkeit werden dauerhafte Einkommensänderungen und einmalige Einkommensanfälle sowie Wertänderungen im Vermögen berücksichtigt. Außerdem wird das erwartete zukünftige Einkommen in die langfristigen Konsumplanung einbezogen. Die empirischen Untersuchungen unterstützen somit die im Verlauf der Arbeit angestellten theoretischen Überlegungen hinsichtlich der die individuelle Leistungsfähigkeit beeinflussenden Größen und des relevanten Zeitraums. 
Werden der Periodenkonsum und das Lebensendvermögen als Bemessungsgrundlage der Besteuerung genutzt, werden sowohl Vermögenswertänderungen als auch Windfall Profits erfaßt, da sie in die langfristige Konsumplanung einbezogen werden. Damit wird die durch den Indikator Lebenseinkommen abgebildete Leistungsfähigkeit besteuert.

Der Periodenkonsum ist geringeren Schwankungen unterworfen als das Periodeneinkommen. Somit bestehen geringere Probleme bei einer progressiven Tarifgestaltung für die Besteuerung nach der individuellen Leistungsfähigkeit als bei einer Periodeneinkommensteuer. Ist aufgrund des hohen Lebensendvermögens ein Steuerglättungsverfahren notwendig, ist es einfacher anzuwenden als ein jährlich erforderliches bei einer Periodeneinkommensteuer, da mit dem Ableben des Individuums alle besteuerungsrelevanten Daten feststehen. Durch die langfristige Konsumplanung wird auch ein Zielkonflikt bei der Bestimmung der relevanten Besteuerungsperiode gelöst: obwohl die Besteuerungsperiode faktisch den langen Zeitraum umfaßt, für den das Individuum seine eigene Leistungsfähigkeit abschätzt, kann die tatsächliche Besteuerungsperiode einen wesentlich kürzeren Zeitraum umfassen. Folglich werden Gerechtigkeits- und Neutralitätserfordernisse ohne die praktischen Nachteile einer langen Besteuerungsperiode erfüllt.

Da diese Konzeption auf die Verwendungsseite des Einkommens abstellt, entstehen keine Verstöße gegen die Neutralität der Besteuerung durch die Zinsbesteuerung.

Bei einem progressiven Tarifverlauf wird die intertemporale Arbeitsentscheidung des Individuums bei der Besteuerung des Periodenkonsums nicht zusätzlich durch den Tarifverlauf verzerrt. Die grundsätzliche Verzerrung der ArbeitFreizeit-Entscheidung besteht aber weiter.

Die Besteuerung des Periodenkonsums und des Lebensendvermögens ist auch aus praktischen Gründen gegenüber einer Periodeneinkommensteuer zu präferieren: die Bewertung des Vermögens muß nur einmal durchgeführt werden. Die Bewertung des Lebensendvermögens kann aber aus Gerechtigkeitserwägungen nicht entfallen, da die Individuen -wie empirische Untersuchungen zeigen- teilweise ein beachtliches Vermögen vererben. Es entsteht ein geringerer Verwaltungsaufwand, mögliche Verzerrungen und Ungerechtigkeiten bei der Vermögensbewertung treten nur einmal auf. Der Umfang des zu bewertenden Vermögens ist weitaus geringer als bei einer periodischen Vermögensbewertung, die bei einer Einkommensteuer nach der Reinvermögenzugangstheorie neben der Bewertung des Lebensendvermögens zur Erfassung der Erbschaft beim Erben zusätzlich notwendig ist. 
Im nächsten Schritt wurden Methoden zur Erfassung des Periodenkonsums grundsätzlich analysiert; dabei wurde auf die Erfassung des Periodenkonsums durch eigene Aufzeichnungen, auf die indirekte Konsumerfassung sowie auf die Mehrwertsteuer eingegangen; anschließend wurden Sonderprobleme diskutiert.

Die Erfassung des Konsums der Steuerpflichtigen durch eigene Aufzeichnungen ist als nicht praktikabel abzulehnen.

Ein Problem stellt die steuerliche Behandlung der langlebigen Konsumgüter dar: aus systematischen Gründen und aus Praktikabilitätsüberlegungen sollte die Konsumgutlösung zur Anwendung kommen. Sie verstößt aber unter Umständen gegen das Leistungsfähigkeitsprinzip und der Forderung nach einem neutralen Steuersystem. Diese Gefahr besteht bei der Investitionsgutlösung nicht. Sie hat aber den Nachteil, daß sie sowohl für den Steuerpflichtigen als auch für den Fiskus aufwendiger durchzuführen ist. Eine Lösungsmöglichkeit ist, langlebige Konsumgüter, bei denen unter Umständen Windfall Profits auftreten (ein Hinweis könnte die Vergangenheit sein) oder die einen höheren Wert haben (Liquiditätsprobleme sowie Progressionseffekte bei einem progressiven Tarif) im Sinne der Investitionsgutlösung und die anderen Güter im Sinne der Konsumgutlösung zu behandeln.

Veräußerungserlöse der im Sinne der Konsumgutlösung behandelten Güter werden nicht doppelt besteuert, wenn bei der indirekten Ermittlung des Periodenkonsums auf die Deklaration der Zuflüsse bzw. bei der Mehrwertsteuer auf die Besteuerung des Gebrauchtgüterkaufs verzichtet wird.

Problematisch ist die Bewertung des Vermögens am Lebensende. Bei der Methode der indirekten Ermittlung des Periodenkonsums besteht für das Finanzamt die Möglichkeit, auf die frühere Deklaration der investiven $\mathrm{Ab}$ - und Zuflüsse Bezug zu nehmen: hieraus wird ersichtlich, wo der Steuerpflichtige investiert hat. Das Problem kann allerdings gemildert werden, wenn z.B. die Banken (wie bereits heute) Geld von einem Konto eines Verstorbenen erst auszahlen, wenn ein Erbschein vorliegt. Dieses System kann über die Anlage im Ausland umgangen werden; dies ist bei der indirekten Ermittlung des Periodenkonsums nicht so leicht möglich wie bei den anderen Erfassungsmethoden, da dem Finanzamt die investiven Abflüsse bekannt sind.

Keine der Konzeptionen bietet die Möglichkeit, den Bestand an langlebigen Konsumgütern, die im Sinne der Konsumgutlösung behandelt werden, bei der Lebensendvermögenbesteuerung zu kontrollieren.

Ein Manko der Mehrwertsteuer ist die Behandlung von Geschenken, die entweder nur beim Schenkenden (Sachgeschenke) oder beim Beschenkten (beim Konsum aus Geldgeschenken) steuerlich erfaßt werden. Diese Unzulänglichkeit be- 
steht bei der indirekten Ermittlung des Periodenkonsums theoretisch nicht, da Schenkungen sowohl vom Schenkenden als auch vom Beschenkten zu deklarieren sind. Ob diese Vorschrift jedoch befolgt wird und vom Fiskus wirksam kontrolliert werden kann, ist zweifelhaft.

Eine gesonderte Unternehmensbesteuerung ist bei allen Erfassungsmethoden nicht erforderlich.

Problematisch ist die Trennung zwischen Konsumausgaben und Werbungskosten sowie die Bewertung des Naturalkonsums; das Problem der Bewertung des Naturalkonsums wird entschärft, wenn möglichst viele langlebige Konsumgüter im Sinne der Konsumgutlösung behandelt werden. Dies sind allerdings grundsätzliche Probleme, die auch bei einer Einkommensbesteuerung nach der Reinvermögenszugangstheorie bestehen, so daß keine spezifischen Probleme der Konsumbesteuerung vorliegen.

Damit bestehen leichte Vorteile für die indirekte Ermittlung des Periodenkonsums, da durch die Deklaration der investiven Zahlungsabflüsse dem Fiskus Anhaltspunkte gegeben werden, in welcher Höhe sich das Lebensendvermögen bewegt und damit Steuerhinterziehungen erschwert werden. Wird diesem Problem, das im übrigen auch bei der Besteuerung des Periodeneinkommens nach der Reinvermögenszugangstheorie besteht, weniger Bedeutung beigemessen, hängt die Entscheidung, ob die Erfassung des Periodenkonsums über eine Mehrwertsteuer oder ob eine indirekte Erfassung durchzuführen ist, wesentlich von der gewünschten Tarifstruktur ab: wird ein progressiver Tarif als der geeignete angesehen, scheidet die Mehrwertsteuer als steuerliche Bemessungsgrundlage aus; es muß auf die indirekte Ermittlung des Periodenkonsums zurückgegriffen werden. Wird ein linearer Tarif präferiert, ist die indirekte Ermittlung und die Mehrwertsteuer denkbar. Die Mehrwertsteuer ist im Vergleich zur indirekten Ermittlung des Periodenkonsums leichter zu handhaben, da weder die Zuflüsse noch die Erhöhung der Ersparnisse zu erfassen sind. Dazu kommt, daß das in Deutschland hervorragend funktionierende System der Umsatzbesteuerung nur mit einem anderen Steuersatz auszustatten wäre. 


\section{Teil}

\section{Gesamtergebnis der Arbeit}

In dieser Arbeit wurde analysiert, ob die Einkommensteuer eine gerechte und effiziente Steuer ist und wie sie nach diesen Kriterien ausgestaltet werden muß. Die Ergebnisse der Arbeit werden zusammenfassend in Kurzform dargestellt; die wichtigsten Aussagen werden thesenartig hervorgehoben.

\section{"Das Leistungsfähigkeitsprinzip entspricht dem gegenwärtigen Gerechtig- keitsverständnis"}

Von den drei angesprochenen Prinzipien der Steuerlastverteilung (Kopfsteuer, Äquivalenz- und Leistungsfähigkeitsprinzip) entspricht nur das Leistungsfähigkeitsprinzip dem gegenwärtigen Gerechtigkeitsverständnis. Das Leistungsfähigkeitsprinzip wird von Gesetzgebung, Rechtsprechung und Literatur als Fundamentalprinzip der Besteuerung angesehen.

\section{"Eine effiziente Besteuerung ist eine entscheidungsneutrale und praktikable Besteuerung"}

Unter Effizienz wird sowohl Effizienz im ökonomischen Sinne als auch Praktikabilität verstanden.

Belastet die Besteuerung Handlungsalternativen unterschiedlich, verzerrt sie die Entscheidungen des Individuums. Dadurch entstehen zusätzlich zu den abzuführenden Steuern weitere Belastungen; das Steuersystem ist im ökonomischen Sinne ineffizient. Aus Effizienzgründen ist ein entscheidungsneutrales Steuersystem zu fordern. Ein entscheidungsneutrales Steuersystem verzerrt nicht die Entscheidungen eines Individuums im Vergleich zu einer Laissez-Faire-Ökonomie mit Ausnahme der Budgetverengung (Einkommenseffekt). Dieser Forderung liegt keine besondere steuerliche Zielvorstellung zugrunde; sie tritt akzessorisch zu den Mechanismen der marktwirtschaftlichen Ordnung hinzu. Ihr Ziel ist es, einen durch steuerliche Vorschriften unbeeinflußten Marktmechanismus zu erhalten.

Ein effizientes Steuersystem bedeutet auch, daß die Steuer in der Realität "praktikabel" erhoben werden kann. "Praktikabel" beinhaltet dabei die Möglichkeit der Steuererhebung, wobei auch der auftretende Aufwand und die Möglichkeit der Steuerumgehung zu berücksichtigen ist. 


\section{"Ein praktikabler und gerechter Indikator der Leistungsfähigkeit ist das Le- benseinkommen"}

Bezugsobjekte der Leistungsfähigkeit sind natürliche Personen. Unternehmen besitzen keine eigene Leistungsfähigkeit, diese ist ihren Eigentümern zuzurechnen.

"Leistungsfähigkeit" ist ein abstrakter Begriff, der zu konkretisieren ist. Zur Bestimmung der individuellen Leistungsfähigkeit wird der verteilungspolitische Leistungsfähigkeitsbegriff herangezogen. Danach ist wirtschaftliche Leistungsfähigkeit der Zuwachs an ökonomischer Verfügungsmacht -also der freien Entscheidung zwischen investiver und konsumtiver Verwendung- über knappe Ressourcen der Wirtschaft in einem bestimmten Zeitraum.

Die Leistungsfähigkeit eines Individuums kann nicht direkt, sondern nur mit Indikatoren gemessen werden. Der umfassendste Indikator der Leistungsfähigkeit ist das Potential des Individuums zum Mittelerwerb. Dieser Indikator ruft keinen Substitutionseffekt hervor und trägt deshalb zu einem (im ökonomischen Sinne) effizienten Steuersystem bei. Diese Konzeption ist aber aufgrund von Praktikabilitäts- und Objektivitätsgründen abzulehnen.

Somit muß auf eine unvollständigere Abbildung der individuellen Leistungsfähigkeit zurückgegriffen werden. Dafür eignet sich der Indikator des verwirklichten Mittelerwerbs (Einkommen), obwohl er die Dispositionsmöglichkeiten des Individuums nicht vollständig abbildet, da von der Ressource "Zeit" lediglich die Arbeitszeit des Individuums, nicht jedoch die Freizeit berücksichtigt wird. Er bildet die Leistungsfähigkeit jedoch umfassender ab als die Konsumausgaben. Durch die nur unvollständige Erfassung der Ressource "Zeit" verstößt dieser Indikator gegen die Forderung nach einem effizienten und neutralen Steuersystem, da er die Arbeit-Freizeit-Entscheidung des Individuums verzerrt.

\section{"Die Besteuerungsperiode ist die Lebensdauer des Individuums"}

Der für die Bestimmung der Leistungsfähigkeit relevante Zeitraum ist -so die angestellten Gerechtigkeits- und Neutralitätserwägungen- die Lebensdauer des Individuums. Die Besteuerungsperiode bekommt bei einem progressiven Tarifverlauf besondere Bedeutung, da -wie empirische Untersuchungen zeigen- das Periodeneinkommen im Zeitablauf Schwankungen unterworfen ist. Somit wäre bei einer periodischen Besteuerung je nach Intensität der Schwankungen bei gleichem Lebenseinkommen eine Steuer in unterschiedlicher Höhe zu entrichten. Aus Gründen der Praktikabilität müssen jedoch periodische Steuerzahlungen geleistet werden. 
"Das Lebenseinkommen ergibt sich aus der Summe der Periodeneinkommen"

Zur Messung des Lebenseinkommens gibt es verschiedene Möglichkeiten: es kann sowohl das Periodeneinkommen als auch der Periodenkonsum und das Lebensendvermögen erfaßt werden.

Wesentliches Unterscheidungsmerkmal der Periodeneinkommenskonzeptionen ist die Behandlung von unregelmäßig anfallenden Einkünften und von Wertänderungen.

Aufgrund von Gerechtigkeits- und Neutralitätserwägungen sind sowohl regelmäßig als auch unregelmäßig anfallende Einkünfte in die steuerliche Bemessungsgrundlage einzubeziehen.

\section{"Die Zinsbesteuerung ist ungerecht und ineffizient"}

Bei der Besteuerung des Periodeneinkommens ist die Zinsbesteuerung problematisch: mit dem Leistungsfähigkeitsprinzip ist die Beteuerung der Zinseinkünfte nicht zu vereinbaren. Die Zinsbesteuerung stört die optimale Ressourcenallokation: insbesondere verringern sich die Ersparnisse der Individuen und das Wirtschaftswachstum. Somit ist -bei den üblichen neoklassischen Annahmen über die Produktionsfunktion das Niveau der Kapitalakkumulation nicht optimal. Die Grenzproduktivität des Faktors "Arbeit" nimmt einen anderen Wert als im Optimum an. Dies hat entweder Einfluß auf den Preis der Arbeit (= Lohn) oder den Umfang der Beschäftigung.

Es bestehen auch Praktikabilitätsprobleme: anhand des Beispiels Deutschlands zeigt sich, daß Zinseinkünfte relativ einfach durch Transferierung von Kapital in das Ausland dem Fiskus vorenthalten werden können.

"Wertänderungen sind als Einkommen zu berücksichtigen; sie können aber nicht (genau und praktikabel) erfaßt werden; die Einkommensbesteuerung ist damit nicht effizient und gerecht"

Problematisch ist die Besteuerung von Wertänderungen.

Wertänderungen, die durch Abnutzung von Vermögensgegenständen zur Einkommenserzielung und durch Windfall Profits entstehen, sind aus Gerechtigkeits- und Neutralitätserwägungen zum Zeitpunkt ihrer Entstehung in die steuerliche Bemessungsgrundlage einzubeziehen. Somit ist -da die anderen Einkommenskonzeptionen diese Einkünfte nicht berücksichtigen- auf die Einkommensdefinition der Reinvermögenszugangstheorie zurückzugreifen. Beim Einbezug 
von Wertänderungen, die die Verzinsung des eingesetzten Kapitals repräsentieren, treten dieselben Probleme wie bei der Zinsbesteuerung auf. Um aber zumindest der Gleichartigkeit dieser Wertänderungen und einer laufenden Verzinsung gerecht zu werden, müssen Zinsen und Wertänderungen in gleichem Umfang in die Bemessungsgrundlage der Besteuerung eingehen.

Die ausschließliche Besteuerung von realisierten Wertänderungen behindert Innovationen; eine effiziente Ressourcenallokation ist nicht gegeben.

Um die Wertänderungen im Vermögen des Steuerpflichtigen zu quantifizieren, ist in jeder Periode die Höhe des individuellen Vermögens zu ermitteln. Geeigneter Wertmaßstab hierzu ist der Gesamtveräußerungswert des Vermögens. Die periodische Ermittlung von Wertänderungen ist in der Realität nicht durchführbar, da ein objektiver Marktpreis nicht für alle Vermögensgegenstände bestimmt werden kann. Standardisierte Wertermittlungsverfahren sind aus Gerechtigkeitsund Neutralitätserwägungen abzulehnen. Somit können Wertänderungen nicht (genau) erfaßt werden; daraus folgen Verstöße gegen das Leistungsfähigkeitsprinzip und gegen die Forderung nach einem neutralen Steuersystem.

\section{"Schenkungen und Erbschaften sind Einkommen"}

Schenkungen und Erbschaften sind nach dem Leistungsfähigkeitsprinzips in die steuerliche Bemessungsgrundlage einzubeziehen. Die Erfassung dieser Einkommensteile gestaltet sich aufgrund von Praktikabilitätserwägungen äußerst schwierig, teilweise ist sie sogar unmöglich. Es bestehen Anhaltspunkte, daß die Besteuerung dieser Größen nicht gegen die Neutralität der Besteuerung verstößt.

\section{"Bei einem umfassenden Einkommensbegriff bedarf es keiner gesonderten Unternehmensbesteuerung"}

Bei der reinen Form der Reinvermögenszugangstheorie ist eine gesonderte Unternehmensbesteuerung nicht notwendig. Alternative Konzepte zur Unternehmensbesteuerung (Betriebsteuer mit und ohne Anrechnung, Teilhabersteuer) können die an sie gestellten Anforderungen nicht erfüllen: sie verstoßen in unterschiedlichem Maße gegen das Leistungsfähigkeitsprinzip, die Neutralität der Besteuerung und das Praktikabilitätserfordernis.

\section{"Durchschnittsbesteuerungsverfahren sind umstritten und unpraktikabel"}

Ein Problem sind die Schwankungen im Periodeneinkommen. Die Besteuerung nach der individuellen Leistungsfähigkeit sowie das Kriterium der Neutralität 
der Besteuerung erfordern bei einer progressiven Tarifstruktur ein Besteuerungsverfahren, das auf die gesamte Lebensdauer des Individuums abstellt. Bei einer Periodeneinkommensteuer sind somit Durchschnittsbesteuerungsverfahren anzuwenden, die in der Wissenschaft allerdings umstritten sind. Es deutet sich aber an, daß ein gerechtes und entscheidungsneutrales Verfahren nicht auch ein einfaches Verfahren ist und Praktikabilitätsprobleme auftreten können.

\section{"Die Besteuerung des Periodeneinkommens verstößt gegen das Leistungsfä- higkeitsprinzip, ist ineffizient und unpraktikabel"}

Zur umfassendsten Abbildung der Leistungsfähigkeit ist der Einkommensbegriff der Reinvermögenszugangstheorie heranzuziehen. Er verstößt aber aufgrund der Zinsbesteuerung gegen das Leistungsfähigkeitsprinzip sowie gegen die Forderung nach einem neutralen Steuersystem und führt nicht zu einem gerechten und effizienten Steuersystem.

Aufgrund der praktischen Probleme der Vermögenswertermittlung ist dieser Einkommensbegriff überdies nicht anwendbar.

\section{"Das Lebenseinkommen ergibt sich aus Periodenkonsum und Lebensendver- mögen"}

Das Lebenseinkommen ergibt sich auch durch die Erfassung des Periodenkonsums und des Lebensendvermögens.

Welche Größen und welcher Zeitraum gehen in die Konsum-Spar-Entscheidung der Individuen ein? Hierdurch können Antworten auf die Frage nach dem "richtigen" Leistungsfähigkeitsbegriff gefunden werden, da die Individuen beim Konsum ihre Leistungsfähigkeit berücksichtigen. Damit ist sichergestellt, daß die Leistungsfähigkeit nicht nur durch theoretische Überlegungen zu den einzubeziehenden Größen und dem relevanten Zeitraum konkretisiert wird, sondern auch die Größen berücksichtigt werden, denen die Individuen selbst einen Einfluß auf ihre Leistungsfähigkeit zumessen; es wird dadurch ersichtlich, wie ein Steuersystem, das die Individuen nach ihrer selbst abgeschätzten Leistungsfähigkeit besteuert, aufgebaut sein muß. Die theoretischen Überlegungen erhalten dadurch aufgrund des in den westlichen Gesellschaften vorherrschenden Bilds vom eigenverantwortlichen und souveränen Menschen ein höheres Gewicht. Zur Beleuchtung dieser Fragestellung kann die Lebenszyklushypothese, die die Konsum-Spar-Entscheidung der Individuen beschreibt, herangezogen werden. 


\section{"Die Individuen betreiben eine langfristige Konsumplanung und schätzen dazu ihre Leistungsfähigkeit langfristig selbst ab"}

Die empirischen Untersuchungen ergeben unterschiedliche Ergebnisse hinsichtlich der Unterstützung oder Ablehnung der Lebenszyklushypothese. Es sprechen viele Gründe dafür, daß sich die Mehrzahl der Individuen nach den Annahmen der Lebenszyklushypothese verhält und bestrebt ist, den Nutzen aus dem Konsum zu maximieren.

Zur Optimierung ihres Nutzens richten sie ihren Periodenkonsum an einem langfristigen Konsumplan aus, der sich an der selbst geschätzten Leistungsfähigkeit orientiert. Daher ist die für die Bestimmung der Leistungsfähigkeit relevante Periode wesentlich länger als ein Jahr.

\section{"Der Periodenkonsum ist geringeren Schwankungen unterworfen als das Pe- riodeneinkommen"}

Die Individuen präferieren einen im Zeitablauf gleichmäßigeren Periodenkonsum als den, der sich ergeben würde, wenn der Konsum eine Funktion des Periodeneinkommens wäre. Somit wird bei einem progressiven Tarifverlauf dem Leistungsfähigkeitsprinzip eher entsprochen.

Die langfristige Konsumplanung und der geringer schwankende Periodenkonsum lösen den Konflikt zwischen Gerechtigkeits- und Neutralitätsüberlegungen einerseits sowie der Praktikabilität andererseits: obwohl die Besteuerungsperiode faktisch einen langen Zeitraum umfaßt (für den das Individuum seine eigene Leistungsfähigkeit abschätzt), kann die tatsächliche Besteuerungsperiode einen wesentlich kürzeren Zeitraum umfassen. Gerechtigkeits- und Neutralitätserfordernisse werden erfüllt ohne das Auftreten der praktischen Nachteile einer langen Besteuerungsperiode.

\section{"Im Konsum werden Wertänderungen und einmalige Einkommensanfälle be- rücksichtigt"}

Bei der Abschätzung der Leistungsfähigkeit berücksichtigen die Individuen dauerhafte Einkommensänderungen und einmalige Einkommensanfälle sowie Wertänderungen in ihrem Vermögen. Weiterhin beziehen sie das erwartete zukünftige Einkommen in ihre langfristige Konsumplanung ein. Empirischen Untersuchungen unterstützen somit die im Verlauf der Arbeit angestellten theoretischen Überlegungen hinsichtlich der die individuelle Leistungsfähigkeit beeinflussenden Größen und des relevanten Zeitraums. 
Bei der Besteuerung des Periodenkonsums gehen diese Größen in die steuerliche Bemessungsgrundlage ein, da sie die Höhe der periodischen Konsumausgaben beeinflussen. Es bestehen auch keine Probleme bei ihrer Erfassung. Eine systematische Durchbrechung der Besteuerung nach der individuellen Leistungsfähigkeit durch die Zinsbesteuerung findet -da die Besteuerung an der Verwendungsseite anknüpft- nicht statt.

\section{"Das Vermögen muß nur einmal bewertet werden"}

Die Erfassung des Lebensendvermögens kann aus Gerechtigkeitsgründen nicht entfallen, da die Individuen einen nicht zu vernachlässigenden Teil ihres Vermögens weitervererben.

Die Besteuerung des Periodenkonsums und des Lebensendvermögens ist aus praktischen Gründen gegenüber einer Periodeneinkommensteuer zu präferieren: die Bewertung des Vermögens muß nur einmal (und damit nicht am Ende jeder Periode) durchgeführt werden. Damit ist ein wesentlich geringerer Umfang an Vermögen zu bewerten und somit entsteht weniger Verwaltungsaufwand. Mögliche Verzerrungen und Ungerechtigkeiten bei der Vermögensbewertung können nur einmal auftreten.

Ist bei einem progressiven Tarifverlauf ein Glättungsverfahren aufgrund des hohen Lebensendvermögens notwendig, kann es einfacher als bei einer Periodeneinkommensteuer implementiert werden, da mit dem Ableben eines Individuums alle besteuerungsrelevanten Daten feststehen.

\section{"Eine Unternehmensbesteuerung braucht nicht implementiert zu werden"}

Bei der Besteuerung des Periodenkonsums und des Lebensendvermögens ist eine gesonderte Unternehmensbesteuerung nicht erforderlich.

\section{"Es entstehen keine Effizienzverluste durch eine Zinsbesteuerung"}

Bei dieser Konzeption wird auf die Verwendungsseite des Einkommens abgestellt, daher entstehen keine Verstöße gegen die Neutralität der Besteuerung durch die Zinsbesteuerung. Die Besteuerung des Periodenkonsums durch einen progressiven Tarif verzerrt die intertemporale Arbeitsentscheidung des Individuums nicht zusätzlich. Die grundsätzliche Verzerrung der Arbeit-Freizeit-Entscheidung besteht allerdings weiterhin. 


\section{"Bei einem progressiven Tarif ist die indirekte Erfassung des Periodenkon- sums heranzuziehen"}

Der Periodenkonsum kann durch eigene Aufzeichnungen des Steuerpflichtigen, durch die indirekte Konsumerfassung sowie durch eine Mehrwertsteuer erfaßt werden.

Die Erfassung des Konsums der einzelnen Steuerpflichtigen durch eigene Aufzeichnungen ist nicht praktikabel. Die Entscheidung, ob die Erfassung des Periodenkonsums über eine Mehrwertsteuer oder über eine indirekte Erfassung nach dem Vorschlag von Mitschke durchzuführen ist, hängt wesentlich von der gewünschten Tarifstruktur ab: wird ein progressiver Tarif als der geeignete angesehen, scheidet die Mehrwertsteuer als steuerliche Bemessungsgrundlage aus und es muß auf die indirekte Ermittlung des Periodenkonsums zurückgegriffen werden.

\section{"Bei einem linearen Tarif ist eine Mehrwertsteuer zu präferieren"}

Kommt ein linearer Tarif zur Anwendung, ist sowohl die indirekte Ermittlung als auch die Mehrwertsteuer denkbar. Die indirekte Erfassung des Periodenkonsums bietet zwar leichte Vorteile gegenüber einer Mehrwertsteuer, da Geschenke theoretisch sowohl beim Schenker als auch beim Beschenkten besteuert werden. $\mathrm{Ob}$ in der Praxis der Beschenkte zur Deklaration veranlaßt werden kann, ist allerdings fraglich. Überdies bestehen bei der indirekten Erfassung des Periodenkonsums bessere (automatische) Kontrollmöglichkeiten über das Lebensendvermögen; dieses Problem kann aber durch geeignete Kontrollmechanismen entschärft werden. Wird diesen Problemen, die im übrigen auch bei der Besteuerung des Periodeneinkommens nach der Reinvermögenszugangstheorie bestehen, nicht zu großes Gewicht beigemessen, muß wegen ihrer Einfachheit bei einem linearen Tarif die Mehrwertsteuer präferiert werden.

Zudem wäre das in Deutschland hervorragend funktionierende System der Umsatzbesteuerung nur mit einem anderen Steuersatz auszustatten.

\section{"Langlebige Konsumgüter sind grundsätzlich im Sinne der Konsumgutlösung zu behandeln"}

Ein Problem stellt die steuerliche Behandlung der langlebigen Konsumgüter dar. Aufgrund von Gerechtigkeits- und Neutralitätserwägungen sollten sie im Sinne 
der Investitionsgut- ${ }^{I}$, aus Gründen der Praktikabilität im Sinne der Konsumgutlösung ${ }^{2}$ behandelt werden. Dieser Konflikt ist zu lösen, wenn langlebige Konsumgüter, bei denen unter Umständen Windfall Profits auftreten können (ein Hinweis kann die Vergangenheit sein) oder die einen höheren Wert aufweisen (Liquiditätsprobleme sowie Progressionseffekte bei einem progressiven Tarif) im Sinne der Investitionsgutlösung und die anderen Güter im Sinne der Konsumgutlösung behandelt werden. Veräußerungserlöse dieser Güter werden dann nicht doppelt besteuert, wenn bei der indirekten Ermittlung des Periodenkonsums auf die Deklaration der Zuflüsse bzw. bei der Mehrwertsteuer auf die Besteuerung des Gebrauchtgüterkaufs verzichtet wird.

\section{"Problematisch ist die Differenzierung zwischen Konsumausgaben und Wer- bungskosten sowie die Bewertung des Naturalkonsums"}

Der Umfang der Bewertung des Naturalkonsums kann dann verringert werden, wenn möglichst viele langlebige Konsumgüter im Sinne der Konsumgutlösung behandelt werden. Dies sind allerdings grundsätzliche Probleme, die auch bei einer Einkommensbesteuerung nach der Reinvermögenszugangstheorie bestehen, so daß keine spezifischen Probleme der Konsumbesteuerung vorliegen.

\section{"Die Besteuerung des Periodenkonsums und des Lebensendvermögens sollte die Periodeneinkommensteuer ablösen"}

Die Besteuerung des Periodeneinkonsums und des Lebensendvermögens führt also auch nicht in allen Beziehungen zu optimalen Ergebnissen. Neue, bei einer Periodeneinkommensbesteuerung nicht auftretende Probleme, werden aber im wesentlichen nicht geschaffen, bei der Periodeneinkommensteuer bestehende jedoch beseitigt.

Als Fazit ist daher abschließend festzuhalten, daß die Besteuerung des Konsums und des Lebensendvermögens zu einer gerechteren und praktikableren Besteuerung führt als eine periodische Einkommensteuer. Durch sie werden die bei einer Einkommensteuer auftretenden Ressourcenfehlallokationen durch die Zinsbesteuerung vermieden. Sie sollte deshalb die bestehende Periodeneinkommensbesteuerung ablösen. Ein kleiner Wermutstropfen bleibt aber: die Verzerrung der Arbeit-Freizeit-Entscheidung kann auch durch sie nicht beseitigt werden.

1 Der Erwerb der Güter ist steuerfrei; stattdessen unterliegen die laufenden Nutzungen der Besteuerung.

2 Der Erwerb der Güter ist steuerpflichtig; die laufenden Nutzungen sind hingegen steuerfrei. 
Michael Ohmer - 978-3-631-75563-1

Downloaded from PubFactory at 01/11/2019 03:31:45AM

via free access 


\section{Literaturverzeichnis}

Albers, W. (1988): Einkommensbesteuerung I: Einkommensteuer, in: Albers, W./Born, K.E./Dürr, E./..., (1980): Handwörterbuch der Wirtschaftswissenschaften (HdWW) - Zugleich Neuauflage des Handwörterbuchs der Sozialwissenschaften Bd. 2, Stuttgart/New York/Tübingen/...1980, S. 189-218.

Andel, N. (1980): Einkommensteuer, in: Neumark, F. (Hrsg., 1980): Handbuch der Finanzwissenschaft, Bd. II, 3. Aufl., Tübingen 1980, S. 331-404.

Aristoteles (1956): Nikomanische Ethik, übersetzt von Dirlmeier, F., Berlin 1956.

Arnim, H.H.v. (1980): Referat, in: Birk, D. (1980): Besteuerung und Eigentumsgarantie - Bericht über die Tagung der Vereinigung der deutschen Staatsrechtslehrer in Innsbruck 1980, in: StuW 1980, S. 361-369.

Arrow, K.J. (1970): Uncertainty and the Welfare Economics of Medical Care, in: Essays in the Theory of Risk-Bearing, Amsterdam/London 1970, S. 177-211.

Arrow, K.J. (1973): Some Ordinalist-Utilitarian Notes on Rawls's Theory of Justice, in: Journal of Philosophy, Vol. 70 (1973), S. 245-263.

Atkinson, A.B. (1971): The Distribution of Wealth and the Individual Life-Cycle, in: Oxford Economic Papers, Vol. 23 (1971), S. 239-254.

Atkinson, A.B. (1980): Inheritance and the Redistribution of Wealth, in: Hughes, G./Heal, G. (Hrsg., 1980): Public Policy and the Tax System, London etc. 1980, S. 36-66.

Atkinson, A.B./Harrison, A.J. (1978): Distribution of personal wealth in Britain, Cambridge/London/New York/Melbourne 1978.

Atkinson, A.B./Stiglitz, J.E. (1980): Lectures of Public Economics, Maidenhead /Berkshire (UK) 1980.

Auerbach, A.J. (1991): Retrospective Capital Gains Taxation, in: American Economic Review, Vol. 81 (1991), S. 167-178.

Baetge, J. (1970): Möglichkeiten der Objektivierung des Jahreserfolges, Düsseldorf 1970.

Bamberg, G./Coenenberg, A. (1992): Betriebswirtschaftliche Entscheidungslehre, 7. Aufl., München 1992.

Bauckner, A. (1921): Der privatwirtschaftliche Einkommensbegriff, München 1921.

Becker-Schaffner, R. (1991): Die Rechtsprechung zur Rückerstattung von Ausbildungskosten, DB 1991, S. 1016 - 1020. 
Bentham, J. (1975): Einführung in die utilitaristische Ethik - Klassische und zeitgenössische Texte, herausgegeben von Höffe O, München 1975, S. 3558 (Original: An Introduction to the Principles of Morals and Legislation, London 1789).

Bergstrom, T./Goodman, R.P. (1973): Private Demand for Public Goods, in: American Economic Review, Vol. 63 (1973), S. 280-296.

Bernanke, B. (1985): Adjustment Costs, Durables, and Aggregate Consumption, in: Journal of Monetary Economics, Vol. 15 (1985), S. 41-68.

Bernanke, B.S. (1984): Permanent Income, Liquidity, and Expenditure on Automobiles: Evidence from Panel Data, in: The Quarterly Journal of Economics, Vol. 99 (1984), S. 587-614.

Birk, D. (1983): Das Leistungsfähigkeitsprinzip als Maßstab der Steuernormen - Ein Beitrag zu den Grundfragen des Verhältnisses Steuerrecht und Verfassungsrecht, Köln 1983.

Blankart, C.B. (1991): Öffentliche Finanzen in der Demokratie - Eine Einführung in die Finanzwissenschaft, München 1991.

Blinder, A.S. (1986): A Sceptical Note on the New Econometrics, in: Peston, M.H./Quandt, R.E. (Hrsg., 1986): Prices, Competition and Equilibrium, Oxford 1986, S. 73-83.

Blomquist, N.S. (1981): A Comparison of Distributions of Annual and Lifetime Income: Sweden around 1970, in: The Review of Income and Wealth, Vol. 27 (1981), S. 243-264.

Borcherding, T.E./Deacon, R. (1972): The Demand for Services of Non-Federal Governments, in: American Economic Review, Vol. 62 (1972), S. 891-901.

Boskin, M. (1978): Taxation, Saving, and the Rate of Interest, in: Journal of Political Economy, Vol. 86 (1978), S. S3-S27.

Brandis, P. (1987): Geldstrafe und Nettoeinkommen - Zugleich ein Beitrag zur Ausgestaltung eines Einkommensbegriffs im Öffentlichen Schuldrecht, Köln 1987.

Brandis, P. (1987a): Einkommen als Rechtsbegriff, in: StuW 1987, S. 289 - 301. Braunberger, G. (1991): Angriff auf die Einkommensteuer - Bietet sich die Konsumbesteuerung als Alternative an?, in: FAZ v. 1.6.1991.

Brennan, G./Buchanan, J.M. (1988): Besteuerung und Staatsgewalt - Analytische Grundlagen einer Finanzverfassung, Hamburg 1988.

Brown, E.C. (1948): Business-Income Taxation and Investment Incentives, in: Metzler, L.A./Domar, E.D./... (Hrsg., 1948): Income, Employment and Public Policy - Essays in Honor of A.H. Hansen, New York 1948. 
Buchanan, J.M. (1960): The Pure Theory of Government Finance: A suggested Approach, in: Fiscal Theory and Political Economy - Selected Essays, Chapel Hill 1960, S. 8-23, (leicht modifizierter Wiederabdruck des Artikels in: Journal of Political Economy, Vol. 57 (1949): S. 496-505).

Buchanan, J.M./Tullock, G. (1984): The Calculus of Consent - Logical Foundations of Constitutional Democrazy, 8. Aufl., Ann Arbor 1984

Buchholz, W./Wiegard, W. (1991): Einfache Wahrheiten über intertemporal neutrale Besteuerung, in: Wahl, J.(Hrsg., 1991): Steuerpolitik vor neuen Aufgaben: Tagungen des Arbeitskreises Politische Ökonomie 1990 in Passau, Regensburg 1991, S. 11-47.

Buchner, R. (1981): Grundzüge der Finanzanalyse, München 1981.

Bühler, O. (1930): Gleichheit in der Lastenverteilung, in: Nipperdey H.C. (Hrsg., 1930): Die Grundrechte und Grundpflichten der Reichsverfassung - Kommentar zum zweiten Teil der Reichsverfassung, 2. Bd., S. 313-318, Berlin 1930 (Nachdruck Scriptor Verlag, Kronberg 1975).

Canaris, C.-W. (1983): Systemdenken und Systembegriff in der Jurisprudenz entwickelt am Beispiel des deutschen Privatrechts, 2. Aufl. Berlin 1983.

Clement, W./Tessaring, M./Weißhuhn, G. (1980): Zur Entwicklung der qualifikationsspezifischen Einkommensrelationen in der Bundesrepublik Deutschland, in: Mitteilungen aus der Arbeitsmarkt- und Berufsforschung, 13. Jahrgang (1980), S. 184-212.

Cohn, G. (1885): Grundlegung der Nationalökonomie - Ein Lesebuch für Studierende, Stuttgart 1885.

Creedy, J. (1977): The Distribution of Lifetime Earnings, in: Oxford Economic Papers, Vol. 29 (1977), S. 412-429.

Darby, M.R. (1972): The Allocation of Transitory Income Among Consumers' Assets, in: American Economic Review, Vol. 62 (1972), S. 928-941.

Davies, J.B. (1980): Uncertain Lifetime, Consumption, and Dissaving in Retirement, in: Journal of Political Economy, Vol. 89 (1980), S. 561-578.

Deutsch, A. (1975): On the Taxation of Life Income, in: Public Finance Quarterly, Vol. 3 (1975), S. 299-319.

Deutscher Bundestag (1974): Entwurf eines Dritten Steuerreformgesetzes vom 8.1.1974, Bundestagsdrucksache 7/1470.

Deutscher Bundestag (1988): Entwurf eines Steuerreformgesetzes 1990 vom 19.4.1988, Bundestagsdrucksache 11/2157.

Deutscher Bundestag (1988a): Entwurf eines Steuerreformgesetzes 1990 vom 2.5.1988, Bundestagsdrucksache 11/2226. 
Diamond, P.A. (1975): Inflation and the Comprehensive Tax Base, in: Journal of Public Economics, Vol. 4 (1975), S. 227-244.

Diamond, P.A./Hausman, J.A. (1984): Individual Retirement and Savings Behavior, in: Journal of Public Economics, Vol. 23 (1984), S. 81-114.

Dichtl. E./Kaiser, A. (1978): Zur Verläßlichkeit der Ergebnisse empirischer Untersuchungen, in: WiSt 1978, S. 490-492.

Dicks-Mireaux, L.-D.-L./King, M.A. (1984): Pension Wealth and Household Savings: Tests of Robustness, in: Journal of Public Economics, Vol. 23 (1984), S. 115-139.

Dornbusch, R./Fischer, S. (1989): Makroökonomik, München/Wien 1989.

Ebnet, O. (1978): Die Besteuerung des Wertzuwachses - Ein theoretischer Ansatz im Rahmen der Einkommensbesteuerung, Baden-Baden 1978.

Eggesiecker, F. (1971): Zur Quantifizierung des Ausbildungsprogressionseffektes der Einkommensteuer, in: StuW 1971, S. 253-260.

Elschen, R. (1991): Entscheidungsneutralität, Allokationseffizienz und Besteuerung nach der Leistungsfähigkeit - Gibt es ein gemeinsames Fundament der Steuerwissenschaften?, in: StuW 1991, S. 99-115.

Elschen, R./Hüchtebrock, M. (1983): Steuerneutralität in Finanzwissenschaft und Betriebswirtschaftslehre - Diskrepanzen und Konsequenzen, in: FA, Bd. 41 (1983), S. 253-280.

Endriss, H.W. (1966): Zur Notwendigkeit eines Progressionsausgleichs, in: FR 1966, S. 17-20.

Esser, J. (1964): Grundsatz und Norm der richterlichen Fortbildung des Privatrechts, 2. Aufl., Tübingen 1964.

Faltlhauser, K. (1988): Unternehmensbesteuerung: Überkommene Steuerprinzipien überprüfen, in: Falthauser, K. (Hrsg., 1988): Steuerstrategie, Köln 1988.

Fischer, H. (1990): Die Kopfsteuer - Eine gute Gemeindesteuer?, in: WiSt 1990, S. 567-569.

Flavin, M.A. (1981): The Adjustment of Consumption to Changing Expectations about Future Income, in: Journal of Political Economy, Vol. 89 (1981), S. 974-1009.

Folkers, C. (1987): Wandlungen der Verbrauchsbesteuerung, in: Häuser, K. (Hrsg., 1987): Wandlungen der Besteuerung, Berlin 1987, S. 89-212.

Friedman, M. (1957): A Theory of the Consumption Function, Princeton 1957.

Fuisting, B. (1902): Die preußischen direkten Steuern, 4. Bd. Grundzüge der Steuerlehre, Berlin 1902. 
Goode, R. (1977): The Economic Definition of Income, in: Pechman, J.A. (Hrsg., 1977): Comprehensive Income Taxation, Washington D.C. 1977, S. 1-30.

Hackmann, J. (1976): Interperiodische Durchschnittsbesteuerung des Einkommens, in: FA, Bd. 34 (1976), S. 1-38.

Hackmann, J. (1979): Die Besteuerung des Lebenseinkommens - Ein Vergleich von Besteuerungsverfahren, Tübingen 1979.

Hackmann, J. (1980): Lebenseinkommensbesteuerung durch interperiodischen Progressionsausgleich - Eine Stellungnahme zum jüngsten Vorschlag von Mitschke, in: StuW 1980, S. 318-324.

Hackmann, J. (1983): Die Bestimmung des steuerrechtlichen Einkommensbegriffs aus finanzwissenschaftlicher Sicht, in: Hansmeyer, K.-H. (Hrsg., 1983): Staatsfinanzierung im Wandel - Verhandlungen auf der Jahrestagung der Gesellschaft für Wirtschafts- und Sozialwissenschaften, Verein für Socialpolitik in Köln 1982; Schriften des Vereins für Socialpolitik, Gesellschaft für Wirtschafts- und Sozialwissenschaften, N.F. Bd. 134, Berlin 1983, S. 661-702.

Haig, R.M. (1921): The Concept of Income - Economic and Legal Aspects, in: Musgrave R.A./Shoup, C.S. (Hrsg., 1959): Readings in the Economics of Taxation, London 1959, S. 54-76; (Original: The Federal Income Tax, New York 1921).

Hall, R.E. (1978): Stochastic Implications of the Life Cycle - Permanent Income Hypothesis: Theory and Evidence, in: Journal of Political, Vol. 86 (1978), S. 971-987.

Hall, R.E. (1989): Consumption, in: Barro, R.J. (1989): Modern Business Cycle Theory, Oxford (UK) 1989, S. 153-177.

Hall, R.E./Mishkin, F.S. (1982): The Sensitivity of Consumption to Transitory Income: Estimates from Panel Data on Households, in: Econometrica, Vol. 50 (1982), S. 461-481.

Haller, H. (1973): Grundsätzliches zur Besteuerung von Grundstücksgewinnen, in: Kredit und Kapital, Bd. 6 (1973), S. 255-294.

Haller, H. (1973a): Zur Diskussion über das Leistungsfähigkeitsprinzip, in: FA, Bd. 31 (1973), S. 461 - 494.

Haller, H. (1981): Die Steuern - Grundlinien eines rationalen Systems öffentlicher Abgaben, 3. Aufl., Tübingen 1981.

Hayashi, F. (1982): The Permanent Income Hypothesis: Estimation and Testing by Instrumental Variables, in: Journal of Political Economy, Vol. 90 (1982), S. 895-916. 
Helberger, C. (1982): Auswirkungen öffentlicher Bildungsausgaben in der Bundesrepublik Deutschland auf die Einkommensverteilung der Ausbildungsgeneration, Stuttgart/Berlin/Köln/Mainz 1982.

Held, A. (1872): Die Einkommensteuer - Finanzwissenschaftliche Studien zur Reform der directen Steuern in Deutschland, Bonn 1872.

Henkel, H. (1977): Einführung in die Rechtsphilosophie: Grundlagen des Rechts, 2. Aufl., München 1977.

Hermann, F.B.W. von (1870): Staatswirtschaftliche Untersuchungen, 2. Aufl., München 1870.

Herzog, R. (1992) in: Maunz, T./Dürig, G. u.a. (Hrsg., 1991): Maunz/Dürig Grundgesetz-Kommentar, München 1991, Stand 30. Erg.lief. Dezember 1992.

Hesse, K. (1991): Grundzüge des Verfassungsrechts der Bundesrepublik Deutschland, 18. Aufl., Heidelberg 1991.

Höffe, O. (1975): Einführung in die utilitaristische Ethik - Klassische und zeitgenössische Texte, München 1975.

Höffner, Joseph Kardinal (1983): Christliche Gesellschaftslehre - Studienausgabe, 4. Aufl., Kevelaer 1983.

Holzmann, R. (1984): Lebenseinkommen und Verteilungsanalyse. Ein methodischer Rahmen für eine Neuorientierung der Verteilungspolitik, Berlin etc. 1984.

Hornbach, H. (1987): Besteuerung, Inflation und Kapitalallokation - Intersektorale und internationale Aspekte, Frankfurt am Main/Bern/New York/.. 1987.

Ijiri, Y. (1967): The Foundations of Accounting Measurement, London/Sydney/ Toronto/... 1967.

Isensee, J. (1977): Steuerstaat als Staatsform, in: Stödter, R./Thieme, W. (Hrsg., 1977): Festschrift für Hans Peter Ipsen zum 70. Geburtstag, Tübingen 1977, S. 409-436.

Jacobs, O. H./Scheffler, W. (1988): Unternehmensbesteuerung und Rechtsform - Handbuch und EDV-gestützter Belastungsvergleich der Besteuerung von Unternehmen unterschiedlicher Rechtsform.

Janssen, B. (1991): Totalreform des Steuersystems?, in: StuW 1991, S. 593-596.

Johannes XXIII (Mater et magistra, 1961): in: Bundesverband der Katholischen Arbeitnehmer-Bewegung Deutschlands - KAB (1985): Texte zur katholischen Soziallehre - Die sozialen Rundschreiben der Päpste und andere kirchliche Dokumente mit einer Einführung von Oswald von NellBreuning SJ, 6. Auflage, Kevelaer 1985, S. 201-270. 
Johannes XXIII. (Pacem in terris, 1963): in: Bundesverband der Katholischen Arbeitnehmer-Bewegung Deutschlands - KAB (1985): Texte zur katholischen Soziallehre - Die sozialen Rundschreiben der Päpste und andere kirchliche Dokumente mit einer Einführung von Oswald von NellBreuning SJ, 6. Auflage, Kevelaer 1985, S. 271-320.

Kaiser, M. (1992): Konsumorientierte Reform der Unternehmensbesteuerung, Heidelberg 1992.

Kaldor, N. (1969): An Expenditure Tax, 5. Aufl., London 1969.

Kay, J.A./King, M.A. (1978): The British Tax System, Oxford 1978.

Keller, J.A. (1981): Grundlagen der Motivation, München 1981.

Kessler, D./Masson, A. (1989): Bequest and Wealth Accumulation: Are Some Pieces of the Puzzles Missing, in: Journal of Economic Perspectives, Vol. 3 (1989), S. 141-152.

King, M.A./Dicks-Mireaux, L.-D.-L. (1982): Asset Holdings and the Life-Cycle, in: Economic Journal, Vol. 92 (1982), S. 247-267.

Kirchhof, P. (1980): Referat, in: Birk, D. (1980), Besteuerung und Eigentumsgarantie - Bericht über die Tagung der Vereinigung der deutschen Staatsrechtslehrer in Innsbruck 1980, in: StuW 1980, S. 361-369.

Kirchhof, P. (1985): Der verfassungsrechtliche Auftrag zur Besteuerung nach der finanziellen Leistungsfähigkeit, in: StuW 1985, S. 319-329.

Kirchhof, P. (1992): Der Sachverstand ist da - Verfassungsrichter Paul Kirchhof über ein gerechtes Steuersystem und Ungereimtheiten der geltenden Regeln, in: Der Spiegel, 30.11.1992, S. 68-74.

Kirchhof, P. (1992a): in: Kirchhof, P./Söhn, H. (Hrsg. 1992): Einkommensteuergesetz - Kommentar, Stand 50. Ergänzungslieferung vom Januar 1994, Heidelberg 1992.

Klüber, F. (1966): Naturrecht als Ordnungsnorm der Gesellschaft - Der Weg der katholischen Gesellschaftslehre, Köln 1966.

Koniarski, L. (1984): Einkommen als Maßstab steuerlicher Leistungsfähigkeit Ein betriebswirtschaftlicher Beitrag zum Problem einer leistungsäquivalenten Einkommensermittlung, München 1984.

Kotlikoff, L. (1988): Intergenerational Transfers and Savings, in: Journal of Economic Perspectives, Vol. 2, Nr. 2 (1988), S. 41-58.

Kotlikoff, L.J./Summers, L.H. (1981): The Role of Intergenerational Transfers in Aggregate Capital Accumulation, in: Journal of Political Economy, Vol. 89 (1981), S. 706-732. 
Kraft, C. (1991): Steuergerechtigkeit und Gewinnermittlung - Eine vergleichende Analyse des deutschen und US-amerikanischen Steuerrechts, Wiesbaden 1991.

Kruse, H.W. (1990): Über die Gleichmäßigkeit der Besteuerung, in: StuW 1990, S. 322-330.

Landsberger, M. (1970): The Life-Cycle Hypothesis: A Reinterpretation and Empirical Test, in: American Economic Review, Vol. 60 (1970), S. 175183.

Lang, J. (1988): Die Bemessungsgrundlage der Einkommensteuer - Rechtssystematische Grundlagen steuerlicher Leistungsfähigkeit im deutschen Einkommensteuerrecht - Kölner Habilitationsschrift 1981, Köln 1988.

Leisner, W. (1978): Wertzuwachsbesteuerung und Eigentum, Berlin 1978.

Leisner, W. (1983): Von der Leistung zur Leistungsfähigkeit - die soziale Nivellierung - Ein Beitrag wider das Leistungsfähigkeitsprinzip, in: StuW 1983, S. 97-102.

Lillard, L.A. (1977): Inequality: Earnings vs. Human Wealth, in: American Economic Review, Vol. 67 (1977), S. 42-53.

Littmann, K. (1970): Ein Valet dem Leistungsfähigkeitsprinzip, in: Theorie und Praxis des finanzpolitischen Interventionismus, Festschrift für Fritz Neumark zum 70. Geburtstag, Haller, H./Kullmer, L./Shoup, C./Timm, H. (Hrsg.), Tübingen 1970, S. 113-134.

Lotz, W. (1917): Finanzwissenschaft, 1. Aufl., Tübingen 1917.

Ludwig, M. (1963): Die Sozialethik des John Stuart Mill - Utilitarismus, Zürich 1963.

Maddala, G.S. (1988): Introduction to Econometrics, New York/London 1988.

Mankiw, N.G./Shapiro, M.D. (1985): Trends, Random Walks, and Tests of the permanent Income Hypothesis, in: Journal of Monetary Economics, Vol. 16 (1985), S. 165-174.

Mansfield, E. (1988): Microeconomics, Theory and Applications, New York/ London, 6. Aufl. 1988.

Martens (1987): Grundrecht auf Steuergerechtigkeit? Die Rechtsprechung des Bundesverfassungsgerichts zum Leistungsfähigkeitsprinzip, in: KritV 1987, S. 39-60.

Maslow, A. H. (1954): Motivation and Personality, New York/ Evanston/ London 1954.

Meade Committee (1978): The Structure and Reform of Direct Taxation. - Report of a Committee Chaired by Professor J.E. Meade (The Institute for Fiscal Studies), London/Boston/Sydney 1978. 
Mill, J. S. (1965): Principles of Political Economy with some of their applications to social philosophy, New York 1965 (Wiederabdruck der Aufl. von 1909; Erstauflage 1848).

Mill, J.S. (1985): Der Utilitarismus, Stuttgart 1985 (durchgesehene Aufl., Übersetzungsgrundlage: Ausgabe von 1871).

Miller, M. H. (1977): Debt and Taxes, in: Journal of Finance, Vol. 32 (1977), S. 261-275.

Mirer, T.W. (1979): The Wealth-Age Relation among Aged, in: American Economic Review, Vol. 69 (1979), S. 435-443.

Mitschke, J. (1975): Trivialarithmetik der Staatsbürgersteuer - Eine Replik auf Dieter Schneiders Rezension 'Staatsbürgersteuer - ein Schildbürgerstreich' in StuW 1974, 369ff., in: StuW 1975, S. 69-77.

Mitschke, J. (1976): Über die Eignung von Einkommen, Konsum und Vermögen als Bemessungsgrundlagen der direkten Besteuerung. Eine meßtechnische Analyse, Berlin 1976.

Mitschke, J. (1980): Lebenseinkommensbesteuerung durch interperiodischen Progressionsausgleich, in: StuW 1980, S. 122-134.

Mitschke, J. (1980): Methoden der indirekten Konsummessung für Zwecke einer persönlichen allgemeinen Ausgabensteuer, in: FA, Bd. 38 (1980), S. 274-301.

Mitschke, J. (1985): Steuer- und Transferordnung aus einem Guß - Entwurf einer Neugestaltung der direkten Steuern und Sozialtransfers in der Bundesrepublik Deutschland, Baden-Baden 1985.

Modigliani (1988): The Role of Intergenerational Transfers and Life Cycle Saving in the Accumulation of Wealth, in: Journal of Economic Perspectives, Vol. 2, Nr. 2 (1988), S. 15-40.

Modigliani, F./Brumberg, R. (1954): Utility Analysis and the Consumption Function: An Interpretation of Cross-Section Data, in: Kurihara, K.K. (1954): Post Keynesian Economics, London 1954, S. 388-436.

Modigliani, F./Miller, M.H. (1958): The Cost of Capital, Corporation Finance and the Theory of Investment, in: American Economic Review, Vol. 48 (1958), S. 261-297.

Mohr, R. (1992): Konsum- versus Vermögenszuwachsbesteuerung - Eine kritische Analyse der Übereinstimmung alternativer Unternehmensbesteuerungssysteme mit den Grundsätzen der Besteuerung, Stuttgart 1992.

Moll, B. (1924): Probleme der Finanzwissenschaft - methodologische und finanztheoretische Untersuchungen, Leipzig 1924.

Moxter, A. (1982): Betriebswirtschaftliche Gewinnermittlung, Tübingen 1982. 
Musgrave, R.A./Musgrave, P.B./Kullmer, L. (1993): Die öffentlichen Finanzen in Theorie und Praxis, 2 Bd., 5. Aufl, Tübingen 1993.

Nachtkamp, H.H. (1986): Allokationswirkungen der Bestandsbesteuerung (unter besonderer Berücksichtigung der Vermögensteuer, der Gewerbekapitalsteuer und der Grundsteuer in der Bundesrepublik Deutschland), in: FA, Bd. 44 (1986), S. 185-223.

Nachtkamp, H.H. (1988): Analyse von Bestandsteuerwirkungen: Eine Einführung unter allokationstheoretischem Aspekt, in: WISU 1988, S. 166-172.

Nachtkamp, H.H. (1989): Analyse von Bestandsteuerwirkungen: Der Einfluß der Bestandsbesteuerung auf die Wirtschaftsstruktur, in: WISU 1989, S. 117-123.

Nell-Breuning, O.v. (1979): Soziale Sicherheit? - Zu Grundfragen der Sozialordnung aus christlicher Verantwortung, Freiburg/Basel/Wien 1979.

Nell-Breuning, O.v. (1980): Gerechtigkeit und Freiheit - Grundzüge katholischer Soziallehre, Wien/München/Zürich 1980.

Nell-Breuning, O.v. (1987): Unsere Verantwortung - Für eine solidarische Gesellschaft, Freiburg/Basel/Wien 1987.

Neumann, Fr.J. (1880): Die Steuer nach der Steuerfähigkeit - Ein Beitrag zur Kritik und Geschichte der Lehren von der Besteuerung., in: Jahrbücher der Nationalökonomie und Statistik, 1. Bd., Jena 1880, S. 511-578.

Neumark, F. (1970): Grundzüge gerechter und ökonomisch rationaler Steuerpolitik, Tübingen 1970.

Nieschlag, R./Dichtl, E./Hörschgen, H. (1991): Marketing, 16. Aufl., Berlin 1991.

Nöhrbaß, K.-H./Raab, M. (1991): Zinsurteil: Wie kommt Waigel aus der Zwickmühle - Aberwitzige Resultate, in: Wirtschaftswoche, Nr. 37, 1991 (45. Jahrgang), S. 75-79.

ohne Verfasser (1989): Handelsblatt vom 10.10.1989.

Ossenbühl, K.H. (1972): Die gerechte Steuerlast - Prinzipien der Steuerverteilung unter staatsphilosophischem Aspekt, Heidelberg/Löwen 1972.

Pastoralkonstitution des 2. Vatikanischen Konzils (Gaudium et spes, 1965), in: Bundesverband der Katholischen Arbeitnehmer-Bewegung Deutschlands KAB (1985): Texte zur katholischen Soziallehre - Die sozialen Rundschreiben der Päpste und andere kirchliche Dokumente mit einer Einführung von Oswald von Nell-Breuning SJ, 6. Auflage, Kevelaer 1985,S. 321425.

Pechman, J.A. (1977): Federal Tax Policy, 3. Aufl., Washington 1977. 
Pohmer, D./Jurke, G. (1984): Zu Geschichte und Bedeutung des Leistungsfähigkeitsprinzips - unter besonderer Berücksichtigung der Beiträge im Finanzarchiv und der Entwicklung der deutschen Einkommensbesteuerung, in: FA, Bd. 42 (1984), S. 445-489.

Pommerehne, W.W. (1978): Institutional Approaches to Public Expenditure, in: Journal of Public Economics, Vol. 9 (1978), S. 255-280.

Popitz, J. (1926): Einkommensteuer, in: Handwörterbuch der Staatswissenschaften, hrsg. v. Elster, L./Weber, A./Wieser, F., 3. Bd., 4. Aufl. Jena 1926, S. $400-491$.

Projector, D./Weiss, G. (1966): Survey of Financial Characteristics of Consumers, Washington 1966.

Radbruch, G. (1965): Vorschule der Rechtsphilosophie (bearb. von Kaufmann, A.), 3. Aufl., Göttingen 1965.

Ramsey, F.P. (1927): A contribution to the theory of taxation, in: Economic Journal, Vol. 37 (1927), S. 47-61.

Rawls, J. (1979): Eine Theorie der Gerechtigkeit, Frankfurt/Main 1979.

Revell, J.R.S. (1967): The Wealth of the Nation, Cambridge/New York/New Rochelle/... 1967, S. 121-129.

Reichsminister der Finanzen (Hrsg., 1929): Denkschrift über die Besteuerung nach dem dreijährigen Durchschnitt und die Abzugsfähigkeit des Verlustvortrags bei der Einkommensteuer und Körperschaftsteuer, Berlin 1929.

Roscher, W. (1918): Grundlagen der Nationalökonomie - Ein Hand- und Lesebuch für Geschäftsmänner und Studierende. Ergänzt durch Robert Pöhlmann, 25. Aufl., Stuttgart/Berlin 1918.

Rose, M. (1991): Plädoyer für ein konsumbasiertes Steuersystem, in: Rose, M. (Hrsg. (1991): Konsumorientierte Neuordnung des Steuersystems, Berlin/Heidelberg/New York/...1991, S. 7-34.

Royal Commission of Taxation (1966): Report of Royal Commission on Taxation, Vol. 3, Ottawa 1966.

Samuelson, P.A. (1964): Tax Deductibility of Economic Depreciation to Insure Invariant Valuations, in: Journal of Political Economy Vol. 72 (1964), S. 604-606.

Sax, E. (1887): Grundlegung der theoretischen Staatswissenschaften, Wien 1887.

Schanz, G. (1896): Der Einkommensbegriff und die Einkommensteuergesetze, FA, Bd. 13 (1896), S. 1-87.

Schanz, G. (1896): ohne Titel (Erwiderung zu J. Kleinwächter das Einkommen und seine Verteilung, Leipzig 1896), FA, Bd. 13 (1896), S. 434-437. 
Schanz, G. S. (1922): Der privatwirtschaftliche Einkommensbegriff, in: FA, Bd. 39 (1922), S. 505-523.

Schlink, B. (1976): Abwägungen im Verfassungsrecht, 1. Aufl., Berlin 1976.

Schmoller, G. (1863): Die Lehre vom Einkommen in ihrem Zusammenhang mit den Grundprincipien der Steuerlehre, in: Zeitschrift für die gesamte Staatswissenschaft, 1863, S. 1-86.

Schnapp, F.E. (1985), in: Münch, I. von (Hrsg., 1985): Grundgesetzkommentar, Band 1 (Präambel bis Art. 20), München 1985.

Schneider, D. (1978): Steuerbilanzen - Rechnungslegung als Messung steuerlicher Leistungsfähigkeit, Wiesbaden 1978.

Schneider, D. (1979): Bezugsgrößen steuerlicher Leistungsfähigkeit und Vermögensbesteuerung, FA, Bd. 37 (1979), S. 26-49.

Schneider, D. (1984): Der Einkommensbegriff und die Einkommensteuerrechtsprechung, in: FA, Bd. 42 (1984), S. 407-432.

Schneider, D. (1990): Investition, Finanzierung und Besteuerung, 6. Aufl., Wiesbaden 1990.

Schumpeter, J.A. (1961): Konjunkturzyklen - Eine theoretische, historische und statistische Analyse des kapitalistischen Prozesses, Erster Band, Göttingen 1961.

Schumpeter, J.A. (1975): Kapitalismus, Sozialismus und Demokratie, 4. Aufl., München 1975.

Schwinger, R. (1992): Einkommens- und konsumorientierte Steuersysteme Wirkungen auf Investition, Finanzierung und Rechnungslegung, Heidelberg 1992.

Seidl, C. (1990): Administration Problems of an Expenditure Tax, in: Rose, M. (Hrsg., 1990): Heidelberg Congress on Taxing Consumption - Proceedings of the International Congress on Taxing Consumption, Held at Heidelberg, June 28 - 30, 1989, Berlin/Heidelberg/New York/... 1990, S. 407 - 449.

Selmer, P. (1972): Steuerinterventionismus und Verfassungsrecht, Frankfurt/M. 1972.

Shorrocks, A.F. (1975): The Age-Wealth Relationship: A Cross-Section and Cohort Analysis, in: Review of Economics and Statistics, Vol. 57 (1975), S. 155-163.

Shoup, C.S. (1969): Public Finance, Chicago 1969.

Simons, H.C. (1962): Personal Income Taxation - The Definition of Income as a Problem of Fiscal Policy, 4. Aufl., Chicago 1962 (1. Aufl. Chicago 1938). 
Sinn, H.-W. (1984): Die Bedeutung des Accelerated Cost Recovery System für den internationalen Kapitalverkehr, in: Kyklos, Bd. 37 (1984), S. 542-576.

Sinn, H.-W. (1984a): Systeme der Kapitaleinkommensbesteuerung - Ein allokationstheoretischer Vergleich, in: Bös, D./Rosen, M./Seidl, C. (Hrsg., 1984), Berlin/Heidelberg/New York 1984, S. 209-238.

Sinn, H.-W. (1985): Kapitaleinkommensbesteuerung - Eine Analyse der intertemporalen, internationalen und intersektoralen Allokationswirkungen, Tübingen 1985.

Slitor, R.E. (1946): The Flexibility of Income Tax Yield Under Averaging, in: Journal of Political Economics, Vol. 54, S. 266-268.

Smith, A. (1791): An Inquiry into the Nature and Causes of the Wealth of Nations, 3 Volumes, 6. Aufl., London 1791 (1. Aufl. 1776).

Steger, W.A. (1958): On the Theoretical Equity of an Averaging Concept for Income Tax Purpose, in: Tax Law Review, Vol. 13 (1958), S. 211-227.

Stern, K. (1984): Das Staatsrecht der Bundesrepublik Deutschland, Bd. I, Grundbegriffe und Grundlagen des Staatsrechts, Strukturprinzipien der Verfassung, 2. Aufl., München 1984.

Stiglitz, J.E. (1988): Economics of the Public Sector, 2. Aufl., New York/London 1988.

Tipke, K. (1971): Steuerrecht - Chaos, Konglomerat oder System, in: StuW 1971, S. 2-17.

Tipke, K. (1976): Die Steuergesetzgebung in der Bundesrepublik Deutschland aus der Sicht des Steuerrechtswissenschaftlers - Kritik und Verbesserungsvorschläge, in: StuW 1976, S. 293-310.

Tipke, K. (1993): Die Steuerrechtsordnung, Band 1-3, Köln 1993.

Tipke, K./Lang, J. (1991): Steuerrecht - Ein systematischer Grundriß, 13. Aufl., Köln 1991.

Vickrey, W. (1947): Agenda for Progressive Taxation, New York 1947.

Vickrey, W. (1959): Averaging of Income for Tax Purposes, in: Musgrave, R.A. /Shoup, C.S. (Hrsg., 1959): Readings in the Economics of Taxation, London 1959, S. 77-92; (Original: Journal of Political Economy Vol. 47, Nr. 3 (1939)).

Vogel, K. (1977): Die Abschichtung von Rechtsfolgen im Steuerrecht - Lastenausteilungs-, Lenkungs- und Vereinfachungsnormen und die ihnen zuzurechnenden Steuerfolgen: ein Beitrag zur Methodenlehre des Steuerrechts, in: StuW 1977, S. 97-121.

Vogel, K. (1974): Bemerkungen zur Gewinnverwirklichung und Gewinnberichtigung im deutschen Außensteuerrecht, in: StuW 1974, S. 193-203. 
Vogel, K. (1975): Steuergerechtigkeit und soziale Gestaltung, in: DStZ A 1975, S. 409-415.

Wagner, A. (1892): Grundlegung der politischen Oekonomie Erster Theil. Grundlagen der Volkswirthschaft. 1 Halbband, 3. Aufl., Leipzig 1892.

Wagner, F.W. (1976): Einkommensbesteuerung und Inflation - Ein betriebswirtschaftlicher Beitrag zum steuerlichen Einkommensbegriff, in: StuW 1976, S. 228-239.

Wagner, F. W. (1989): Die zeitliche Erfassung steuerlicher Leistungsfähigkeit, in: Hax, H./Kern, W./Schröder, H.H. (Hrsg., 1989): Zeitaspekte in betriebswirtschaftlicher Theorie und Praxis - 50. Wissenschaftliche Jahrestagung des Verbandes der Hochschullehrer für Betriebswirtschaft e.V. Köln, 24.28. Mai 1988, Stuttgart 1989.

Wagner, F.W. (1992): Neutralität und Gleichmäßigkeit als ökonomische und rechtliche Kriterien steuerlicher Normkritik, in: StuW 1992, S. 2-13.

Wallich, H.C. (1965): Taxation of Capital Gains in the Light of Recent Economic Developments, in: National Tax Journal, Bd. 18 (1965), S. 133-150.

Walzer, K. (1986): Hauptgründe für die Wahl einer Besteuerung nach dem Leistungsfähigkeitsprinzip, in: StuW 1986, S. 201 - 209.

Weiß, B. (1878): Die Lehre vom Einkommen, in: Zeitschrift für die gesamte Staatswissenschaft, 1878, S. 684-725.

Weizsäcker, C.C. von (1978): Annual income, lifetime income and other concepts in measuring income distribution, in: Krelle, W./Shorrocks, A.F. (Hrsg., 1978): Personal income distribution - Proceedings of a Conference held by the International Economic Association Noordwijk aan Zee, Netherlands April 18-23, 1977, Amsterdam/New York/Oxford 1978, S. 101105.

Wenger, E. (1983): Gleichmäßigkeit der Besteuerung von Arbeits- und Vermögenseinkünften, in: FA, Bd. 41 (1983), S. 207-252.

Wenger, E. (1989): Wirtschaftswachstum, Unternehmensfinanzierung und internationaler Kapitalverkehr unter dem Einfluß der Besteuerung von Vermögenseinkünften, in: FA, Bd. 47 (1989), S. 181-249.

West, K.D. (1988): The Insensitivity of Consumption to News about Income, in: Journal of Monetary Economics, Vol. 21 (1988), S. 17-33.

White, B.B. (1978): Empirical Tests of the Life Cycle Hypothesis, in: American Economic Review, Vol. 68 (1978), S. 547-560.

Wright, C. (1969): Saving and the Rate of Interest, in: Harberger, A.C./Bailey, M.J. (Hrsg., 1969): The Taxation of Income from Capital, Washington, D.C. 1969 , S. 275-299. 
Zurbrügg, F. (1990): Einkommensentwicklung im Lebenszyklus - Eine Längsschnittuntersuchung mit Daten der staatlichen Rentenversicherung der Schweiz, Bern/Stuttgart 1990.

\section{Urteile des Bundesfinanzhofs}

BFH v. 28.7.1961 -VI 25/61 U, BStB1. 1961 III, S. 436-437.

BFH v. 6.7.1973, VI R 253/69, BFHE 110, S. 119-125.

BFH v. 21.7.1981 VIII R 128/76, BStBl. 1982 II, S. 36-37.

BFH v. 21.7.1981 VIII R 154/76, BStBl. 1982 II, S. 37-40.

BFH v. 21.7.1981 VIII R 200/78, BStBl. 1982 II, S. 40-41.

BFH v. 23.3.1982 VIII R 132/80, BStBI. 1982 II, S. 463-465.

BFH v. 25.6.1984 GrS 4/82, BStBl. 1984 II, S. 751- 770.

BFH v. 8.10.1985 VIII R 234/84, BStBl. 1986 II, S. 596-599.

BFH v. 13.10.1987 VIII R 156/84, BStB1. 1988 II, S. 252-257.

\section{Urteile des Bundesverfassungsgerichts}

BVerfG v. 12.10.1951 -BvR 201/51, BVerfGE 1, S. 13-66.

BVerfG v. 20.7.1954 -1 BvR 459, 484, 548, 555, 623, 651, 748, 783, 801/52, 5,9/53, 96, 114/54-, BVerfGE 4, S. 7-27.

BVerfG v. 16.1.1957 -1 BvR 253/56, BVerfGE 6, S. 32-45.

BVerfG v. 17.5.1961 -1 BvR 561, 579/60, 114/61, BVerfGE 12, S. 354-369.

BVerfG v. 30.10.1961 -1 BvR 833/59, BVerfGE 13, S. 181-204.

BVerfG v. 24.7.1962 - 2 Bvl 15, 16/91, BVerfGE 14, S. 221-244.

BVerFG v. 27.7.1962 -2 BvL 15, 16/61, BVerfGE 14, S. 221-244.

BVerfG v. 15.10.1963 -1 BvL 29/56, BVerfGE 17, S. 135-139.

BVerfG v. 1.7.1964 - 1 BvR 375/62, BVerfGE 18, S. 121-133.

BVerfG v. 14.12.1965 -1 BvR 413, 416/60, BVerfGE 19, S. 206-226.

BVerfG v. 5.8.1966 -1 BvF 1/61, BVerfGE 20, S. 150-162.

BVerfG v. 19.3.1968 -1 BvR 554/65, BVerfGE 23, S. 229-241.

BVerfG v. 14.5.1968 -2 BvR 544/63, BVerfGE 23, S. 288-321. 
BVerfG v. 14.5.1969 -2 BvR 238/68, BVerfGE 26, S. 41-44.

BVerfG v. 10.6.1969 -2 BvR 480/61, BVerfGE 26, S. 172-186.

BVerfG v. 2.10.1969 -1 BvL 12/68, BVerfGE 27, S. 58-70.

BVerfG v. 9.3.1971 -2 BvR 326, 327, 341, 342, 343, 344, 345/69, BVerfGE 30, S. 250-272.

BVerfG v. 1.4.1971 -1 BvL 22/67, BVerfGE 31, S. 8-32.

BVerfG v. 7.7.1971 -1 BvR 775/66, BVerfGE 31, S. 255-270.

BVerfG v. 7.11.1972, -1 BvR 338/68, BVerfGE 34, S. 103- 118.

BVerfG v. 17.7.1974 -1 BvR 51, 160, 285/69, 1 BvL 16, 18, 26/72,

BVerfGE 38, S. 61-102.

BVerfG v. 12.10.1976 -1 BvR 197/73, BVerfGE 42, S. 374-397.

BVerfG v. 11.10.1977 -1 BvR 343/73, 83/74, 183 und 428/75, BVerfGE 47, S. 1-33.

BVerfG v. 19.12.1978 -1 BvR 335, 427, 811/76, BVerfGE 50, S. 57-108.

BVerFG v. 13.3.1979 -2 BvR 72/76, DB 1971, S. 872.

BVerfG v. 15.4.1980 -2 BvR 842/77, BVerfGE 54, S. 53-74.

BVerfG v. 3.11.1982 -1 BvR 620/78,1335/78, 1104/79 und 363/80, BVerfGE 61, S. 319-357.

BVerfG v. 14.5.1986 -2 BvL 2/83, BVerfGE 72, S. 200-278.

BVerfG v. 23.10.1986 -2 BvL 7, 8/84, BVerfGE 73, S. 388-403.

BVerfG v. 10.2.1987 -1 BvL 18/81 und 20/82, BVerfGE 74, S. 182-202.

BVerfG. v. 18.7.1967 -2 BvF 3,4,5,6,7,8/62; 2 BvR 139, 140, 334, 335/62, BVerfGE 22, S. 180-220.

\section{Schreiben des Bundesministers für Finanzen}

BMF v. 24.1.1985. IV B4-S 2252-4/85, BStB1. 1985 I, S. 77-81.

BMF-Schreiben v. 24.11.1986, IV B4-S 2252-180/86, BStBl. 1986 I, S. 539 f. 


\section{STAATLICHE ALLOKATIONSPOLITIK IM MARKTWIRTSCHAFTLICHEN SYSTEM}

Band

Band

Band

Band

Band

Band

Band

Band

Band

Band

Band

Band

Band

Band

Band

Band

Band

17 Christine Pfitzer: Integrierte Entwicklungsplanung als Allokationsinstrument auf Landesebene. Eine Analyse der öffentlichen Planung der Länder Hessen, Bayern und Niedersachsen. 1985.

Band 18 Heinz König (Hrsg.): Kontrolltheoretische Ansätze in makroökonometrischen Modellen. 1985.

Band 19 Theo Kempt: Theorie und Empirie betrieblicher Ausbildungsplatzangebote. 1985.

Band 20 Eberhard Wille (Hrsg.): Konkrete Probleme öffentlicher Planung. Grundlegende Aspekte der Zielbildung, Effizienz und Kontrolle. 1986.

Band 21 Eberhard Wille (Hrsg.): Informations- und Planungsprobleme in öffentlichen Aufgabenbereichen. Aspekte der Zielbildung und Outputmessung unter besonderer Berücksichtigung des Gesundheitswesens. 1986.

Band 22 Bernd Gutting: Der Einfluß der Besteuerung auf die Entwicklung der Wohnungs- und Baulandmärkte. Eine intertemporale Analyse der bundesdeutschen Steuergesetze. 1986.

Band 23 Heiner Kuhl: Umweltressourcen als Gegenstand internationaler Verhandlungen. Eine theoretische Transaktionskostenanalyse. 1987. 
Band 24 Hubert Hornbach: Besteuerung, Inflation und Kapitalallokation. Intersektorale und internationale Aspekte. 1987.

Band 25 Peter Müller: Intertemporale Wirkungen der Staatsverschuldung. 1987.

Band 26 Stefan Kronenberger: Die Investitionen im Rahmen der Staatsausgaben. 1988.

Band 27 Armin-Detlef Rieß: Optimale Auslandsverschuldung bei potentiellen Schuldendienstproblemen. 1988.

Band 28 Volker Ulrich: Preis- und Mengeneffekte im Gesundheitswesen. Eine Ausgabenanalyse von GKV-Behandlungsarten. 1988.

Band 29 Hans-Michael Geiger: Informational Efficiency in Speculative Markets. A Theoretical Investigation. Edited by Ehrentraud Graw. 1989.

Band 30 Karl Sputek: Zielgerichtete Ressourcenallokation. Ein Modellentwurf zur Effektivitätsanalyse praktischer Budgetplanung am Beispiel von Berlin (West). 1989.

\section{ALLOKATION IM MARKTWIRTSCHAFTLICHEN SYSTEM}

Band 31 Wolfgang Krader: Neuere Entwicklungen linearer latenter Kovarianzstrukturmodelle mit quantitativen und qualitativen Indikatorvariablen. Theorie und Anwendung auf ein mikroempirisches Modell des Preis-, Produktions- und Lageranpassungsverhaltens von deutschen und französischen Unternehmen des verarbeitenden Gewerbes. 1991.

Band 32 Manfred Erbsland: Die öffentlichen Personalausgaben. Eine empirische Analyse für die Bundesrepublik Deutschland. 1991.

Band 33 Walter Ried: Information und Nutzen der medizinischen Diagnostik. 1992.

Band 34 Anselm U. Römer: Was ist den Bürgern die Verminderung eines Risikos wert? Eine Anwendung des kontingenten Bewertungsansatzes auf das Giftmüllrisiko. 1993.

Band 35 Eberhard Wille, Angelika Mehnert, Jan Philipp Rohweder: Zum gesellschaftlichen Nutzen pharmazeutischer Innovationen. 1994.

Band 36 Peter Schmidt: Die Wahl des Rentenalters. Theoretische und empirische Analyse des Rentenzugangsverhaltens in West- und Ostdeutschland. 1995.

Band 37 Michael Ohmer: Die Grundlagen der Einkommensteuer. Gerechtigkeit und Effizienz. 1997. 


\section{Bernd Halfar}

\section{Der Gegenstand der Besteuerung im Rahmen der Einkünfte aus Kapitalvermögen}

Frankfurt/M., Berlin, Bern, New York, Paris, Wien, 1995. 173 S., 1 Tab. Europäische Hochschulschriften: Reihe 5, Volks- und Betriebswirtschaft. Bd. 1704 ISBN 3-631-48565-4 br. DM 65..-*

Die Unterscheidung von Einkommen und Vermögen ist weder ökonomisch noch rechtlich gelöst. Die Einkommensbesteuerung setzt eine solche Trennbarkeit aber voraus. Die Arbeit zeigt, wie die Vorstellungen von Nutzungsüberlassung, Erwerbstätigkeit und Rechtsverhältnis an den empirischen Erscheinungsformen der Kapitaleinkünfte scheitern. Demgegenüber erweist sich die Agiotheorie als ein einfacher und umfassender Ansatz zur Anpassung des Einkommensteuergesetzes an die Wirklichkeit der modernen Finanzmärkte.

Aus dem Inhalt: Voraussetzungen und Zustand der Kapitaleinkommensbesteuerung . Ökonomische Aspekte der Tatbestände des § 20 EStG . Mögliche Steuergegenstände · Vorschlag: Besteuerung eines Aufgelds

\section{Peter Lang Europäischer Verlag der Wissenschaften}

Frankfurt a.M. - Berlin - Bern - New York - Paris - Wien

Auslieferung: Verlag Peter Lang AG, Jupiterstr. 15, CH-3000 Bern 15 Telefon (004131) 9402121, Telefax (004131) 9402131

- Preisänderungen vorbehalten - *inklusive Mehrwertsteuer 
Michael Ohmer - 978-3-631-75563-1

Downloaded from PubFactory at 01/11/2019 03:31:45AM

via free access 